\title{
Late Neogene Radiolaria \\ from the East Coast Deformed Belt, New Zealand
}

by

Jeffrey Noel Ashby

A thesis submitted for the degree of
Doctor of Philosophy
Research School of Earth Sciences
Victoria University of Wellington

April 1986 


\begin{abstract}
Within the East Coast Deformed Belt there are a number of Late Neogene sedimentary basins with relatively deep-water sediments which, at places, contain abundant radiolarian skeletons. The region was subject to relatively open ocean circulation patterns during the Neogene which, combined with the input of rhyolitic glass shards, has enhanced the siliceous microfossil preservation. A short review of the silica budget is presented and discussed in relation to the preservation of siliceous microfossils in the New Zealand sequences.
\end{abstract}

Techniques were developed to extract and quantitatively study fossil Radiolaria from some of the relatively barren shelf/slope sediments. One hundred and thirty-eight radiolarian taxa are described, most of which can be assigned at the generic level, but thirty-one of which can not be assigned specific names and may eventually prove to be new species.

The radiolarian zonation presented is based on detailed analysis of 155 samples from 26 sections and sites ranging in age from basal Tongaporutuan (early Late Miocene) to middle Nukumaruan (early Pleistocene). Sediments of the Kapitean (uppermost Miocene) were generally deposited in shallow water environments or are missing in unconformities in the East Coast Deformed Belt, consequently the radiolarian zonation is based on very poor data in this time segment. Also upper Opoitian and Waipipian (middle Pliocene) sediments, although at places deposited in relatively deep water, generally lack siliceous tuffs, and radiolarian preservation is poor. Five major radiolarian zones can be recognised: Diartus hughesi Zone, Didymocyrtis sp. A Zone, Didymocyrtis tetrathalmus tetrathalmus Zone, Lamprocyrtis heteroporos Zone, and Lamprocyclas gamphonycha Zone. In samples with good radiolarian preservation six subzones can be identified. The Diartus hughesi Zone can be divided into the Heliodiscus umbonatum Subzone, Didymocyrtis laticonus Subzone, Heliodiscus asteriscus forma large pores Subzone, and Anthocyrtidium ehrenbergi pliocenica Subzone. Additionally the Didymocyrtis tetrathalmus tetrathalmus Zone can be divided into the Lychnocanium sp. aff. grande Subzone and Lamprocyrtis hannai Subzone. The bioevents that define the zonal boundaries are discussed along with other biostratigraphically useful radiolarian datums.

These zones and subzones are correlated to the foraminiferal zonation which in turn 
has been related, in part, to the paleomagnetic time scale. Correlations are then made with other radiolarian zonations in the north Pacific, tropics, and southern ocean. Points to emerge from these correlations include the apparent provincialism in the transition from Stichocorys delmontense to Stichocorys peregrina in the tropical Pacific. This transition has been reported to occur during approximately $1.5 \mathrm{Ma}$ but in New Zealand occurs over a time segment of at least 5.5Ma. The first appearance of Lamprocyclas gamphonycha appears to be an isochronous datum level in temperate radiolarian faunas of the northern and southern Pacific. The last appearance datum of Diartus hughesi at about $7.5 \mathrm{Ma}$ is in good agreement with its level in the tropics. The presence of this taxon in lower Gilbert Antarctic cores suggests either a grossly diachronous event between tropical/temperate areas and the southern ocean or, more probably, a misinterpretation of the paleomagnetic signature from key southern ocean piston cores. If the latter situation is the case then the real age estimates on the "pre middle Gilbert" southern ocean diatom and silicoflagellate stratigraphies are questionable because they are based on the same key cores.

Statistical faunal analysis shows that during the Miocene there was not much change in the radiolarian faunas with time and a major change, probably climatically controlled, took place across the Miocene/Pliocene boundary. Variability in preservation has probably affected the faunas to obscure more precise time variation although post-Miocene faunas indicate that some is present.

In conclusion, the Radiolaria, although not as common in the fossil record as the foraminifera, definitely contribute to New Zealand Late Neogene integrated stratigraphy and suggest that our knowledge could be greatly enhanced by the study of other siliceous microfossil groups. 


\section{ACKNOWLEDGEMENTS}

Firstly, I wish to thank Dr. N. de B. Hornibrook of the Geological Survey and my supervisor Prof. P. Vella for initiating the project and record my appreciation of their patience in awaiting completion of this dissertation.

Additionally, Dr. Bob Hoskins, George Scott, Hugh Morgans, Tony Edwards and Guyon Warren of the Geological Survey; Dr. Peter Barrett and Dr. Rodney Grapes of Victoria University; and Dr. W.R. Riedel of Scripps Institution of Oceanography have all contributed either in the field or by critically reviewing or discussing parts of this dissertation.

Valuable technical assistance has been gained from Adrian Trask of the Geological Survey and Stephen Eagar of Victoria University in obtaining samples from their respective institutional collections. The technical help from Merv Loper (retired), Kenny Goldie and Bob Thomson of the Electron Microscope Facility, John Casey and co-workers of the Photographic Facility, and members of the Computer Services Centre; all of Victoria University, is appreciated.

Financial support was provided by DSIR Research Contract UV 6/28 and the Internal Research Grant Committee of Victoria University.

Fellow students and ex-students of the Geology Department, especially Dr. Barry Roser, Dr. Paul Morris, Dr. Bill Hackett, Dr. Barbara Ward, Greg Gosson, Ian Wright, Alex Pyne, Martin Crundwell and Annette George, have collectively contributed a great deal to this thesis. Paul Hoverd and Jenny Askwith draughted some of the diagrams.

Finally appreciation must go to my parents and my wife, Christine, whose encouragement and financial support allowed for this dissertation to be completed. It is to Christine and our two sons, David and Michael, that this thesis is dedicated. 
ABSTRACT

ACKNOWLEDGEMENTS i

TABLE OF CONTENTS

LIST OF FIGURES

LIST OF TABLES

LIST OF PLATES

iii

iv

$\mathrm{x}$

xii

xiii

CHAPTER 1 INTRODUCTION

1.1 PREAMBLE

1.2 AIM AND SCOPE

1.3 RADIOLARIAN BIOLOGY

1.3.1 Introduction

1.3.2 Cytoplasmic structure . . . . . . . . . . . . . 4

1.3.2.1 Preamble

1.3.2.2 Ectoplasm

1.3.2.3 Endoplasm

1.3.2.4 Central capsular membrane

1.3.3 Reproduction

1.3.4 Skeleton

1.3.5 Nutrition

1.3.6 Radiolarian mobility

1.4 HISTORY OF STUDY

1.5 PREVIOUS WORK

1.5.1 Land based sections

1.5.1.1 Europe

1.5.1.2 Asia

1.5.1.3 America

1.5.2 Deep sea cores

1.5.2.1 Deep Sea Drilling Project sites . . . . . . . 12

1.5.2.2 Eltanin cores . . . . . . . . . . . 14

1.5.2.3 Vema core . . . . . . . . . . . . . 14

1.5.2.4 Swedish Deep Sea Expedition cores . . . . . . 14

1.5.3 New Zealand . . . . . . . . . . . . . 15

1.6 NOMENCLATURE . . . . . . . . . . . . . . . . . . 15

1.6.1 Size classification of sediments . . . . . . . . . 15

1.6.2 Lithologic symbols and abbreviations . . . . . . . 15

1.6.3 New Zealand Cenozoic time scale . . . . . . . . 16

1.6.4 Definition of type sections . . . . . . . . . . 16

1.6.5 Nomenclature pertaining to type specimens . . . . . . 16

1.6.6 Ecologic zones . . . . . . . . . . . . . 16

1.6.7 Biostratigraphic zones . . . . . . . . . . . . 16

1.6.8 Paleomagnetic zones . . . . . . . . . . . . . 16 
CHAPTER 2 TECHNIQUES

2.1 PREAMBLE

2.2 DISAGGREGATION

2.2.1 Initial disaggregation

2.2.3 Freeze-thaw disaggregation . . . . . . . . . . 19

2.2.4 Initial washing . . . . . . . . . . . . . 20

2.3 WET SIEVING . . . . . . . . . . . . . . . 20

2.4 DENSITY SEPARATION . . . . . . . . . . . . . 21

2.5 MOUNTING METHOD . . . . . . . . . . . . . 23

2.6 STATISTICAL COUNTING . . . . . . . . . . . . . 24

2.7 QUALITATIVE STUDIES . . . . . . . . . . . . . . 25

2.8 PHOTOGRAPHY OF RADIOLARIAN SPECIMENS . . . . . . . 25

2.9 NUMBER OF RADIOLARIANS PER GRAM OF SEDIMENT * . . 26

CHAPTER 3 RADIOLARIAN PRESERVATION . . . . . . . . . 27

3.1 SILICA DISTRIBUTION PATTERNS . . . . . . . . . 27

3.2 SILICA BUDGET * . . . . . . . . . . . . . . . 29

3.2.1 River input . . . . . . . . . . . . . . 30

3.2.2 Submarine volcanic sources . . . . . . . . . . 30

3.2.3 Low temperature reactions at the sea floor . . . . . 30

3.2.4 Release of interstitial waters . . . . . . . . . 31

3.2.5 Oxidative dissolution . . . . . . . . . . . . . . 31

3.2.6 Non-oxidative dissolution . . . . . . . . . . 31

3.2.7 Biologic fixation . . . . . . . . . . . . 32

3.2.8 Inorganic absorption . . . . . . . . . . . . 32

3.2.9 Deposition . . . . . . . . . . . . . . . 32

3.3 SILICA DISSOLUTION IN THE WATER COLUMN . . . . . 32

3.4 FAECEL PELLET DEPOSITION . . . . . . . . . . . . 33

3.5 SILICA DISSOLUTION IN SEDIMENTS . . . . . . . . . 34

3.6 MECHANICAL PROCESSES AFFECTING SILICA PRESERVATION • • 35

3.6.1 Bottom currents . . . . . . . . . . . . . 35

3.6.2 Bioturbation . . . . . . . . . . . . . . 36

3.7 SELECTIVE SPECIES DISSOLUTION . . . . . . . . . 36

3.8 SILICA DIAGENESIS . . . . . . . . . . . . . 37

3.9 VOLCANIC ASSOCIATION . . . . . . . . . . . . 38

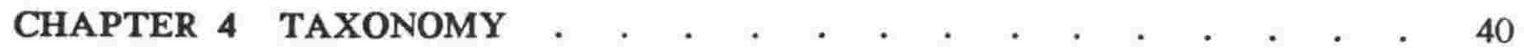

4.1 INTRODUCTION . . . . . . . . . . . . . . . . . 40

4.2 SYSTEMATIC SECTION FORMAT . . . . . . . . . . . 41

4.3 CHECKLIST OF SPECIES . . . . . . . . . . . . . . . 43

4.4 SYSTEMATICS . . . . . . . . . . . . . . . . 50 
5.1 PALEONTOLOGICAL CRITERIA FOR DEFINING NEW ZEALAND LATE NEOGENE STAGES

5.1.1 Introduction . . . . . . . . . . . . . . . . . 149

5.1.2 Waiauan Stage . . . . . . . . . . . . . 149

5.1.3 Tongaporutan Stage . . . . . . . . . . . . 150

5.1.4 Kapitean Stage . . . . . . . . . . . . . 151

5.1.5 Opoitian Stage . . . . . . . . . . . . . 152

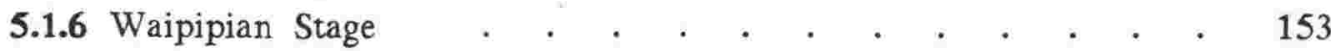

5.1.7 Mangapanian Stage . . . . . . . . . . . . 154

5.1.8 Nukumaruan Stage . . . . . . . . . . . . 155

5.1.9 Castlecliffian Stage . . . . . . . . . . . . . 156

5.2 RADIOLARIAN ZONATION . . . . . . . . . . . . . 156

5.2.1 Introduction . . . . . . . . . . . . . . . . . 156

5.2.2 Diartus hughesi Zone . . . . . . . . . . . 156

5.2.2.1 Heliodiscus umbonatum Subzone . . . . . . 156

5.2.2.2 Didymocyrtis laticonus Subzone . . . . . . . 157

5.2.2.3 Heliodiscus asteriscus forma large pores Subzone . . 157

5.2.2.4 Anthocyrtidium ehrenbergi pliocenica Subzone . . . 158

5.2.3 Didymacyrtis sp. A Zone . . . . . . . . . . 158

5.2.4 Didymocyrtis tetrathalmus tetrathalmus Zone . . . . . 159

5.2.4.1 Lychnocanium sp. aff. grande Subzone . . . . . 159

5.2.4.2 Lamprocyrtis hannai Subzone . . . . . . . 160

5.2.5 Lamprocyrtis heteroporos Zone . . . . . . . . . 160

5.2.6 Lamprocyclas gamphonycha Zone . . . . . . . . 161

5.2.7 Radiolarian lineages . . . . . . . . . . . . 161

5.3 REAL AGE ESTIMATES OF RADIOLARIAN ZONAL BOUNDARIES • 163

5.3.1 Radiometric ages . . . . . . . . . . . . 163

5.3.2 Paleomagnetic ages . . . . . . . . . . . . . 163

5.3.3 Summary . . . . . . . . . . . . . . 164

5.4 ANTARCTIC ZONATIONS . . . . . . . . . . . . 165

5.5 TROPICAL ZONATIONS . . . . . . . . . . . . . . 167

5.6 NORTH PACIFIC ZONATIONS . . . . . . . . . . . . 167

5.7 CORRELATION OF NEW ZEALAND RADIOLARIAN OCCURRENCES

TO INTERNATIONAL RANGES . . . . . . . . . . . . . 168

5.7.1 LAD's of Cyrtocapsella japonica and C. tetrapera . . . . 168

5.7.2 Transition from Stichocorys delmontensis to S. peregrina . . 169

5.7.3 LAD of Lychnocanium sp. aff. grande . . . . . . . 170

5.7.4 LAD of Anthocyrtidium ehrenbergi pliocenica . . . . . 170

5.7.5 Range of Spongaster pentas . . . . . . . . . 171

5.7.6 Members of the genus Eucyrtidium . . . . . . . . 171

5.7.7 Members of the genus Antarctissa . . . . . . . . 172

5.7.8 Upper Pliocene to Pleistocene transition from Lamprocyrtis spp.

to Lamprocyclas gamphonycha . . . . . . . . . . 172

5.7.9 The Didymocyrtis lineage . . . . . . . . . . 173

5.7.10 The LAD of members of the Diartus hughesi group . . . 174

5.8 STATISTICAL ANALYSIS . . . . . . . . . . . . 176 
5.8.1 Introduction . . . . . . . . . . . . . . 176

5.8.2 Principal components . . . . . . . . . . . 177

5.8.3 Canonical discriminants . . . . . . . . . . . 178

5.8.4 Graphical technique . . . . . . . . . . . . 178

5.8.5 Discriminant analysis . . . . . . . . . . . 178

5.8.6 Statistical summary . . . . . . . . . . . . 179

CHAPTER 6 CONCLUSION AND DIRECTION FOR FUTURE STUDIES . 180

6.1 SUMMARY OF MAIN POINTS . . . . . . . . . . . . $\quad 180$

6.2 DIRECTIONS FOR FUTURE RESEARCH . . . . . . . . 182

REFERENCES . . . . . . . . . . . . . . . . . . . . . . . 184

APPENDIX A SECTION AND SITE DESCRIPTIONS $\quad$. . . . . . . . A1

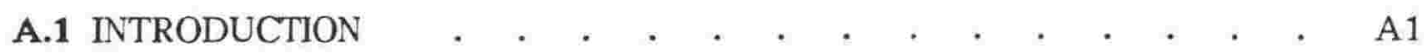

A.2 EAST CAPE SECTION . . . . . . . . . . . . . . A3

A.3 ORUTUA RIVER SECTION . . . . . . . . . . . . A4

A.4 WAIMATA RIVER SECTION . . . . . . . . . . . A4

A.5 CAVES ROAD SECTION . . . . . . . . . . . . . . A5

A.6 KATTI BEACH SECTION . . . . . . . . . . . . . A5

A.7 HANGAROA RIVER SECTION . . . . . . . . . . . . A7

A.8 RUAKITURI RIVER SECTION . . . . . . . . . . . . . A9

A.9 WAIKAREMOANA - ARDKEEN SECTION . . . . . . . . A10

A.10 MANGAPOIKE - TUKEMOKIHI SECTION . . . . . . . A10

A.11 MAHIA PENINSULA SITE . . . . . . . . . . . A16

A.12 WALATAI VALLEY SECTION $. \quad . \quad$. . . . . . . . . . . $\quad$ A17

A.13 WAIROA-NUHAKA ROAD SITES . . . . . . . . . A18

A.14 TAHAENUI-KOHUKOHU ROAD SECTION . . . . . . . . . A19

A.15 CRICKLEWOOD ROAD SECTION . . . . . . . . . . A19

A.16 WAIHUA VALleY SECTION . . . . . . . . . . . . A20

A.17 WAIKOAU-DARKIES SPUR SECTION . . . . . . . . A21

A.18 DEVILS ELBOW SECTION . . . . . . . . . . . A21

A.19 ONEKAWA DRILLHOLE . . . . . . . . . . . . . . A21

A.20 MARAETOTARA RIVER SECTION . . . . . . . . . A22

A.21 HAWEA STREAM SECTION . . . . . . . . . . . . A24

A.22 TAMUMU SECTION . . . . . . . . . . . . . . A24

A.23 PAKIPAKI SITE . . . . . . . . . . . . . . . A24

A.24 WAIPATIKI SECTION . . . . . . . . . . . . . . . A25

A.25 MANGAORANGA SECTION . . . . . . . . . . . A25

A.26 PUTARA SECTION . . . . . . . . . . . . . . . . A25

A.27 JACKSONS LINE SITES . . . . . . . . . . . . . . A26

A.28 CLELLANDS ROAD SECTION . . . . . . . . . . . A26

A.29 BRANCEPETH SECTION . . . . . . . . . . . . . . A26

A.30 WAINUIORU RIVER SITES . . . . . . . . . . . . A26

A.31 MAUNGATEPOPO STREAM SITE . . . . . . . . . A27 
A.32 "HALLOWEEN" STREAM SITE

A.33 KOURARAU-WESTMERE ROAD SECTION

A.34 PARIWHARIKI TRIG SECTION

A.35 MILLERS ROAD SITES

A.36 ERINGA SITE

A.37 MORRISONS SECTION

A.38 RUAMAHANGA RIVER SECTION

A.39 HINAKURA-HIKAWERA SECTION

A.40 POINT RANGE SITES

A.41 WHAKAPUNI TRIBUTARY SECTION

A.42 "FITTALL" STREAM SECTION

A.43 MANGAOPARI-WHAKAPUNI STREAM AREA SITES

A.44 LOWER MANGAOPARI STREAM SECTION

A.45 UPPER MANGAOPARI STREAM SECTION

A.46 PALLISER BAY SECTION

A.47 BLIND RIVER SECTION

A.48 UPTON BROOK SECTION

A.49 LEADER TRIBUTARY SECTION

A.50 NORTH OF LEADER TRIBUTARY SITE . . . . . . . . A41

A.51 ATHLONE STREAM SITE

A.52 TONGAPORUTU COASTAL SECTION

A.53 TAHORA SECTION

A.54 WANGANUI RIVER SECTION

A.55 RANGITIKEI RIVER SECTION

\section{APPENDIX B SAMPLE DESCRIPTIONS}

B.1 INTRODUCTION

B.2 EAST CAPE SECTION

B.3 KAITI BEACH SECTION

B.4 HANGAROA RIVER SECTION . . . . . . . . . . . A46

B.5 RUAKITURI RIVER SECTION

B.6 MANGAPOIKE RIVER SECTION . . . . . . . . . . A47

B.7 WALATAi VAlley SECTION . . . . . . . . . . . A50

B.8 TAHAENUI-KOHUKOHU ROAD SECTION . . . . . . . . A52

B.9 CRICKLEWOOD ROAD SECTION . . . . . . . . . . A53

B.10 WaIHUA VAlley SECTION . . . . . . . . . . . . A54

B.11 MARAETOTARA RIVER SECTION . . . . . . . . . A54

B.12 KOURARAU-WESTMERE ROAD SECTION . . . . . . . A56

B.13 MORRISONS SECTION . . . . . . . . . . . . . A56

B.14 RUAMAHANGA RIVER SECTION . . . . . . . . . A58

B.15 HINAKURA-HIKAWERA SECTION . . . . . . . . . A59

B.16 WHAKAPUNI TRIBUTARY SECTION . . . . . . . . . A59

B.17 UPPER MANGAOPARI STREAM SECTION . . . . . . . A60

B.18 PALLISER BAY SECTION . . . . . . . . . . . . A62 
B.19 LEADER TRIBUTARY SECTION . . . . . . . . . . A63

B.20 WAIMATA VALLEY SITE . . . . . . . . . . . . A64

B.21 CAVES ROAD SITE . . . . . . . . . . . . . A64

B.22 WAIROA-NUHAKA ROAD SITES . . . . . . . . . A65

B.23 MAHIA PENINSULA SITE . . . . . . . . . . . A65

B.24 WAinUiORU VAlley SITES . . . . . . . . . . . A65

B.25 MILLERS ROAD SITES . . . . . . . . . . . . A66

B.26 MANGAOPARI-WHAKAPUNI AREA SITES . . . . . . . A66

B.27 NORTH OF LEADER SITE . . . . . . . . . . . . A67

APPENDIX C TECHNIQUES PAPER . . . . . . . . . . . . . . . . . . A68

APPENDIX D PRESENCE AND ABSENCE DATA * . . . . . . . A72

APPENDIX E RAW AND REDUCED DATA SETS . . . . . . . . A136

E.1 INTRODUCTION . . . . . . . . . . . . . . . . . A 136

E.2 RAW COUNTING DATA . . . . . . . . . . . . . A136

E.3 LIST OF FACTORS FOR STATISTICAL SAMPLES . . . . . $\quad$ A145

E.4 REDUCED DATA SET • . . . . . . . . . . . . A149

E.5 PALLISER BAY TUFF SAMPLES . . . . . . . . . . A 155

PLATES OF RADIOLARIA . . . . . . . . . . . . . . . A157 


\section{LIST OF FIGURES}

\section{f signifies facing page}

1.1 Major Neogene sedimentary basins in New Zealand . . . . . . . 3f

1.2 Schematic cross-section of a radiolarian . . . . . . . . . . 4f

1.3 Location of on-land, upper Neogene, radiolarian bearing sediments in the world . . . . . . . . . . . . . . . $10 \mathrm{f}$

1.4 Location of upper Neogene, radiolarian bearing deep-sea cores in the southwest Pacific . . . . . . . . . . . . . . . $12 f$

1.5 Size classification of sediments . . . . . . . . . . . . $15 f$

1.6 Late Neogene section of the New Zealand Cenozoic time scale . . . . $16 f$

1.7 Marine ecologic zones . . . . . . . . . . . . . . . $16 f$

1.8 Definition of biostratigraphic zones . . . . . . . . . . . . 17

2.1 Sample preparation flow chart . . . . . . . . . . . . $18 \mathrm{f}$

2.2 Apparatus used for density separation . . . . . . . . . . $22 \mathrm{f}$

2.3 Apparatus used for random settling of radiolarians on a coverslip . . . 23f

2.4 Technique for making glass slides using a randomly coated coverslip . . 24f

3.1 Amorphous silica distribution in the surface layer of bottom sediments . . $28 \mathrm{f}$

3.2 Components of the silica cycle in the ocean . . . . . . . . . $29 \mathrm{f}$

3.3 Dissolution profiles for radiolarian skeletons and planktic foraminifera tests $33 f$

3.4 Palliser Bay tuff : glass shards vs. stratigraphic distance . . . . . $39 \mathrm{f}$

3.5 Palliser Bay tuff : radiolarian skeletons vs. stratigraphic distance . . . $39 \mathrm{f}$

5.1 Correlation of Late Neogene calcareous bioevents to the

New Zealand time scale . . . . . . . . . . . . . . . $149 \mathrm{f}$

5.2 Correlation of New Zealand Late Neogene radiolarian biozones

to foraminiferal biozones . . . . . . . . . . . . . . . $156 \mathrm{f}$

5.3 Ranges of some of the radiolarian taxa studied . . . . . . . . $157 \mathrm{f}$

5.4 Summary of important radiolarian lineages in the New Zealand
Late Neogene . . . . . . . . . . . . . . . . . . . .

5.5 Correlation of some radiolarian and calcareous microfossil bioevents
to the paleomagnetic time scale . . . . . . . . . . . . . . $163 f$

5.6 Antarctic radiolarian zonations . . . . . . . . . . . . $165 f$

5.7 Tropical Pacific radiolarian zonations . . . . . . . . . . . $167 f$

5.8 North Pacific radiolarian zonations . . . . . . . . . . . $168 \mathrm{f}$

5.9 Variation in the percentage of Stichocorys peregrina with time . . . . $169 \mathrm{f}$

5.10 Full radiolarian data set : principal component 1 vs. principal component 2 .

5.11 Miocene data set : principal component 1 vs. principal component 2 . . $178 \mathrm{f}$

5.12 Post-Miocene data set : principal component 1 vs. principal component 2 . $178 \mathrm{f}$

5.13 Miocene data set : canonical variable 1 vs. canonical variable 2 . . . $178 \mathrm{f}$

5.14 Post-Miocene data set : canonical variable 1 vs. canonical variable 2 . . $178 \mathrm{f}$

5.15 Full data set : bar chart comparison between radiolarian biozones . . . $179 \mathrm{f}$

6.1 Sample summary comparing foraminiferal to radiolarian abundance . . . $182 \mathrm{f}$ 
A.1 Late Neogene radiolarian bearing sections in New Zealand

A.2 Late Neogene radiolarian bearing sites in New Zealand

A.3 Location of sections : East Cape region . . . . . . . . . . A3f

A.4 Stratigraphic column : East Cape Section . . . . . . . . . A3f

A.5 Location of sections : Gisborne region . . . . . . . . . . A4f

A.6 Stratigraphic column : Kaiti Beach Section . . . . . . . . . A5f

A.7 Location of sections and sites : Northern Hawke's Bay . . . . . . A6f

A.8 Stratigraphic column : Hangaroa Section . . . . . . . . . . A7f

A.9 Stratigraphic column : upper part of Hangaroa Section . . . . . . A8f

A.10 Stratigraphic column : Ruakituri Section . . . . . . . . . A9f

A.11 Stratigraphic column : Mangapoike River - Tukemokihi Stream composite - A10f

A.12 Stratigraphic column : Tukemokihi Stream (in part) . . . . . . A11f

A.13 Stratigraphic column : Tukemokihi Stream (in part) . . . . . . A11

A.14 Stratigraphic column : Mangapoike River - Tukemokihi Stream (in part) - A12f

A.15 Stratigraphic column : Mangapoike River (in part) . . . . . . . A13f

A.16 Stratigraphic column : Mangapoike River (in part) . . . . . . . A13

A.17 Stratigraphic column : Mangapoike River (roadcut section) . . . . . A14f

A.18 Stratigraphic column : Waiatai Valley Section . . . . . . . . A17f

A.19 Stratigraphic column : Waihua Valley Section . . . . . . . . A20f

A.20 Location of sections : Tutira area (central Hawke's Bay) . . . . . A21f

A.21 Location of sections and site : Hastings area . . . . . . . . A22f

A.22 Stratigraphic column : Maraetotara Section . . . . . . . . . A23f

A.23 Stratigraphic column : radiolarian bearing portion of Maraetotara Section . A23

A.24 Location of section : Waipatiki (northern Wairarapa) . . . . . . A25f

A.25 Location of sections and sites : Mauriceville area (northern Wairarapa) . A25f

A.26 Location of sections and sites : southern Wairarapa . . . . . . A26f

A.27 Location of sedtions and sites : Wainuioru Valley area . . . . . A26f

A.28 Location of sections and sites : Mangaopari area . . . . . . . A28f

A.29 Stratigraphic column : Morrisons Section . . . . . . . . . A29f

A.30 Stratigraphic column : Ruamahanga River Section . . . . . . . A30f

A.31 Stratigraphic column : Hinakura-Hikawera Section . . . . . . . A31f

A.32 Stratigraphic column : Whakapuni Tributary Section . . . . . . A33f

A.33 Stratigraphic column : Upper Mangaopari Stream Section . . . . . A35f

A.34 Stratigraphic column : detail of radiolarian bearing portion of the

Upper Mangaopari Stream Section . . . . . . . . . . . . . A36

A.35 Stratigraphic column : Palliser Bay Section . . . . . . . . . A37f

A.36 Stratigraphic column : detail of radiolarian bearing portion of the
Palliser Bay Section

A.37 Location of sections : Marlborough area . . . . . . . . . . A39f

A.38 Location of section and sites : northern Canterbury area . . . . . A39f

A.39 Stratigraphic column : Leader Tributary Section . . . . . . . A40f

A.40 Stratigraphic column : detail of radiolarian bearing portion of the
Leader Tributary Section . . . . . . . . . . . . . . . . A41f

A.41 Location of sections : West Coast, North Island . . . . . . . A42f

A.42 Location of sections : West Coast, South Island . . . . . . . A43f 


\section{LIST OF TABLES}

f signifies facing page

1.1 Comparison of the characteristics of major microfossil groups . . . . $2 f$

3.1 Magnitudes of components of the silica cycle . . . . . . . . $29 \mathrm{f}$

3.2 Abundance of components of the sediment surrounding the tuff in the Palliser Bay Section . . . . . . . . . . . . . . $38 \mathrm{f}$

4.1 Variations in radiolarian taxonomy . . . . . . . . . . . . . $40 \mathrm{f}$

5.1 Counting groups : reduction for statistical analysis . . . . . . . $176 f$

5.2 Full data set : principal component eigenvalues . . . . . . . . $177 \mathrm{f}$

5.3 Full data set : principal component eigenvectors . . . . . . . . $177 \mathrm{f}$

5.4 Post-Miocene data set : canonical variables in the total canonical structure . $179 \mathrm{f}$

5.5 Classification summary from discriminant analysis $. . \quad . \quad . \quad . \quad . \quad . \quad 179$ 


\section{LIST OF PLATES}

$f$ signifies facing page

C3.1 Centimetre-scale bioturbation in a tuff . . . . . . . . . . $36 f$

C3.2 Tuff in the Palliser Bay Section . . . . . . . . . . . $38 \mathrm{f}$

A1.1 Tukemokihi Stream : example of exposure . . . . . . . . . A15f

A1.2 Mangapoike River : example of exposure . . . . . . . . . A15f

A1.3 Mangapoike River Section : angular unconformity in the road-cut section . A15

A1.4 Mangapoike River Section : line of glauconitic nodules marking the unconformity in the road-cut section . . . . . . . . . . . . A15

A1.5 Mokotahi Point : south end of Mahia Beach . . . . . . . . A16

A1.6 Palliser Bay Section : looking east . . . . . . . . . . . A38

PLATES 1-30 New Zealand Late Neogene Radiolaria :

scanning electron microscope and transmitted light photographs . . A157 onward 


\section{Chapter I \\ INTRODUCTION}

\subsection{PREAMBLE}

Radiolarians are free-living, marine, pseudopod-bearing protozoans. They are exclusively holoplanktic with the exception of one benthic acantharian. Most are solitary but two families, the Collosphaeridae and Sphaerozoidae, have colonial forms. Present in all the major oceans and meditteranean seas they occupy niches from the surface to the abyss in equatorial to polar waters, being most abundant in epipelagic and upper mesopelagic depth zones ( 0 to 300 metres) (Petrushevskaya, 1971b). Occurring in all marine waters of normal salinity the number of large individuals is approximately equivalent to that of planktic foraminifera (Cifelli and Sachs, 1966) and the number of smaller individuals is considerably greater (Beers and Stewart, 1971).

Like most other planktic taxa, radiolarians are most abundant in regions of high biological productivity associated with the equatorial current system, eastern and western boundary currents and the east-flowing currents in latitudes higher than about $40^{\circ} \mathrm{S}$ (Riedel and Sanfilippo, 1977). After the diatoms, radiolarians are the second major producer of suspended amorphous silica in the oceans with variations from 16,000 individuals per cubic metre in the equatorial Pacific to tens or hundreds of individuals per cubic metre in Antarctic waters (Lisitzin, 1972).

Radiolarians are distinguished from other protistans by the organisation of their cell which is divided into an inner and outer zone by a membrane. Until recently it was generally accepted that the membrane strongly controlled the shape of the skeleton, but Anderson (1976c) has reported cases in which the relationship is slight.

Geologists are mainly concerned with polycystine Radiolaria. The order Polycystina have coherent skeletons of opaline silica and are the only group with a substantial fossil record. They are divided into two suborders : the "spherical" Spumellaria and "ring or cap-shaped" Nassellaria.

The order Phaeodaria (Tripylea) occur as fossils in some Neogene sediments (Riedel, 1963; Dumitrica, 1964; Reshetnyak, 1971; Stadum and Ling, 1969), but only where the siliceous preservation is exceptionally good. Their skeletons are constructed of tubular opaline silica admixed with organic material and are readily dissolved during early 


\section{TABLE 1.1}

Comparison of the characteristics of the major microfossil groups used in marine geological work

Foraminifera Radiolaria nannoplankton Diatoms

* Taxonomy

* General diversity

* Diversity sufficiently high for polar Cenozoic paleoceanographic studies

* Diversity sufficiently high for subpolar Cenozoic paleoceanographic studies

* Biostratigraphy known

* Biological controls known

* Modern vertical and geographic distribution known

* Species and assemblage patterns match surface water masses

* Morphological variation related to environmental change

* Tests resistant to dissolution

* Census data can provide data on original assemblages

* Tests resistant to lateral displacement

* Commonly found over wide areas in Cenozoic sediments

* Relative simplicity of counting

* Tests suitable for isotopic measurements

$\begin{array}{llll}3 & 1 & 3 & 1 \\ 2 & 3 & 1 & 2 \\ 2 & 3 & 1 & 3\end{array}$

3

3

3

3

3

3

2

2

1

3

3

1

3

2

3

3

3

3

3

1

2

1

1

2

3

2

2

3

2

1

3

3

3

2

3

3

3

3

1

3

3 = relatively high values, or well known

2 = moderately high values, or only partially known

$1=$ relatively low values, or poorly known

after Kennett, 1982. 
diagenesis (Riedel and Sanfilippo, 1977). No tripylean Radiolaria have been found as fossils in New Zealand Upper Neogene sediments.

The Acantharia have skeletons made of celestite (strontium sulphate) and are never found as fossils (Kling, 1978). They were removed from the subclass Radiolaria by Deflandre (1952).

Radiolaria are less often preserved as fossils than the calcareous microfossils but are still useful as climatic and stratigraphic indicators (Foreman, 1981). Table 1.1 (reproduced from Kennett, 1982: p.637) compares some characteristics of the major microfossil groups used in marine geology. Radiolaria are geologically important because they are abundant and diverse in deep-sea sediments. More than 7,000 species have been described but this figure is probably inflated by excessive taxonomic splitting (Kennett, 1982: p.573).

The oldest known Radiolaria are from the early Ordovician of Spitzbergen (Fortey and Holdsworth, 1971). Possible Pre-Cambrian occurrences have been reported from France, Australia, and India but the age of the rocks is uncertain (Deflandre, 1952).

The total number of radiolarian species living at any given time in the Cenozoic was approximately 100 to 200 (Riedel and Sanfilippo, 1977). Their wide geographic distribution and rapid evolution should make them stratigraphically useful, but their stratigraphic application is inhibited by an unsatisfactory taxonomic classification, the limited number of Cenozoic radiolarian fossil localities on land, and the incomplete descriptions of most known fossil assemblages (Riedel and Sanfilippo, 1977).

Between 400 and 500 polycystine species are living in the seas today (Casey, Gust, Leavesley et al., 1979) compared with about 40 species of planktic foraminifera (P. Vella, pers. comm.) and 38 species of pteropods (Kennett, 1982: p.562). Radiolarians are more diverse because they occupy more niches.

Radiolarians are sensitive to small variations of physical and chemical conditions in the ocean. The large number of species, a tendency towards endemism, and subspecific morphological changes correlated with changes in oceanographic conditions, make the fossils fairly precise paleoceanographic indicators (Casey, 1971a). Distributional studies include Nigrini (1967), Casey (1971a), Sachs (1973), Moore (1973a), Lozano and Hays (1976), Casey (1977), Nigrini and Moore (1979), and Johnson and Nigrini (1980).

In some cases, because of the imperfect taxonomy, researchers have used ill-defined and/or inadequately illustrated, poly-specific and even poly-generic "counting groups" which 
Figure 1.1

Major Neogene sedimentary basins in New Zealand. East Coast Deformed Belt (the area of study) is highlighted.

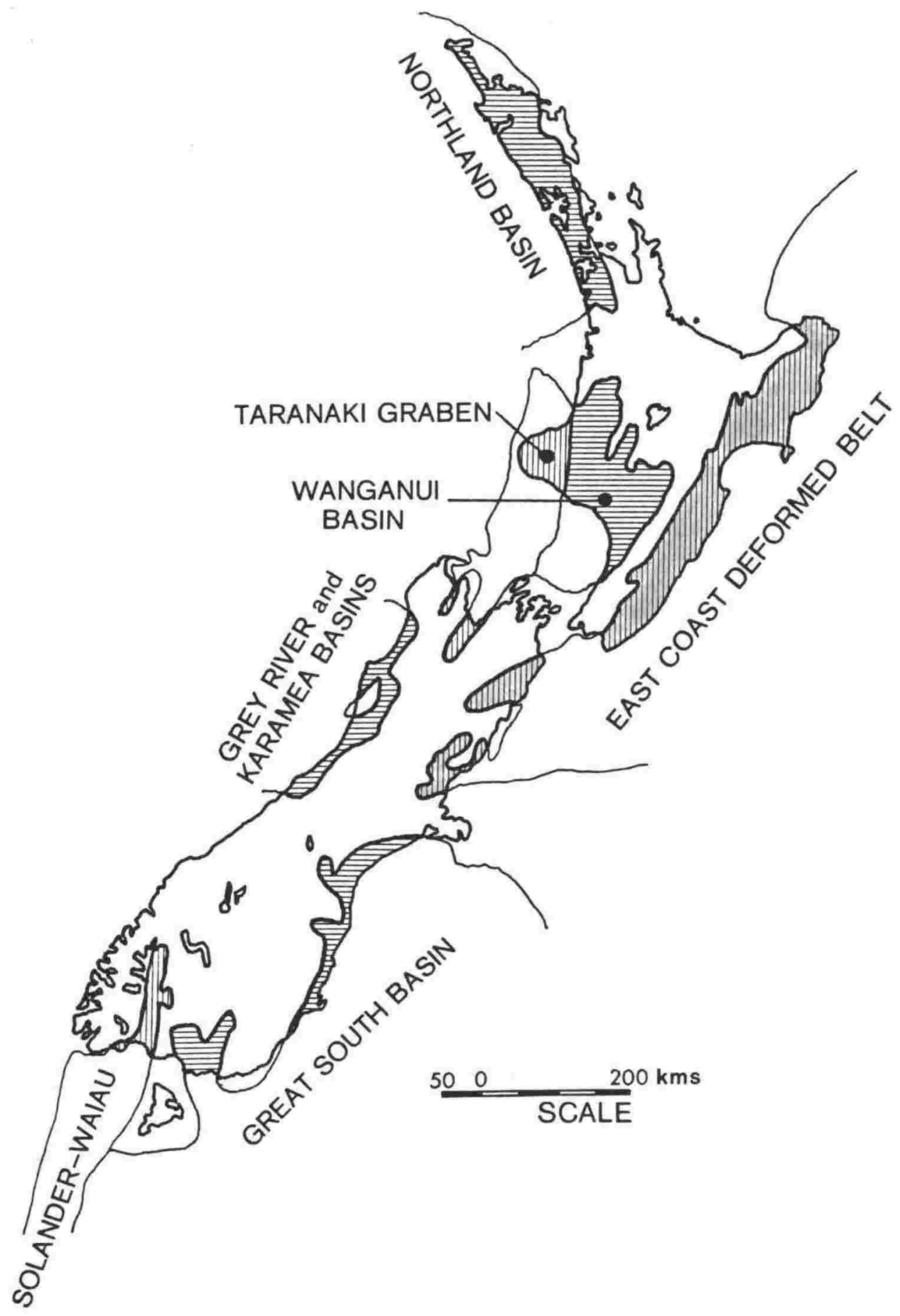


blur distributional patterns and make it hard for one researcher to duplicate or use the results of another (Nigrini and Moore, 1979).

\subsection{AIM AND SCOPE}

The main aim of this thesis is to set up a radiolarian biostratigraphic framework for the New Zealand Late Neogene. The term Neogene represents the interval from the base of the Miocene to the present time. The Late Neogene encompasses the interval since the beginning of the Late Miocene, about eleven million years ago (Berggren, 1972a). All the rocks studied in this thesis outcrop above sea-level and uplift rates have not been fast enough to expose any radiolarian-bearing rocks less than approximately 1.5 million years old in the study area. The rocks studied are restricted to the East Coast Deformed Belt (figure 1.1). Within that region there are a number of Late Neogene sedimentary basins with relatively deep-water mudstones which at places contain abundant radiolarian skeletons. Some of the sections studied are relatively continuous and well exposed providing ideal sites for microfossil, macrofossil, paleomagnetic, and tephrochronological studies. The East Coast Deformed Belt encompasses about a $6^{\circ}$ paleolatitudinal spread in an area only five degrees north of the present Subtropical Convergence.

In the course of this study techniques have been developed to extract and quantitatively study fossil Radiolaria from relatively barren shelf/slope sediments, taxa described, and a local biostratigraphic zonation developed and correlated with previously described Late Neogene biostratigraphic schemes. The geological usefulness of fossil radiolarians in the study of the New Zealand Late Neogene is evaluated at the end of this thesis.

\subsection{RADIOLARIAN BIOLOGY}

\subsubsection{Introduction}

Relatively little is known about the cytoplasmic structure and life cycle of radiolarians. A serious limiting factor is the failure of nearly all attempts to keep radiolarians alive in laboratory cultures. Specimens of the colonial radiolarian, Thalassicola nucleata, survived three weeks in a laboratory culture but its life span is thought to be longer (Anderson, 1978a). Casey, Partridge, and Sloan (1971) reported life spans of one month for two endemic Southern Californian species. Colonial radiolarians have been studied more than solitary species because they are larger and easier to culture. In the absence of successful culturing experiments spanning the complete life cycle, interpretations of morphologic data are still a major source of life cycle information (Kling, 1971a). 


\section{Figure 1.2}

Schematic cross-section of a spumellarian radiolarian showing cytoplasmic features in relation to a hypothetical spherical skeleton.

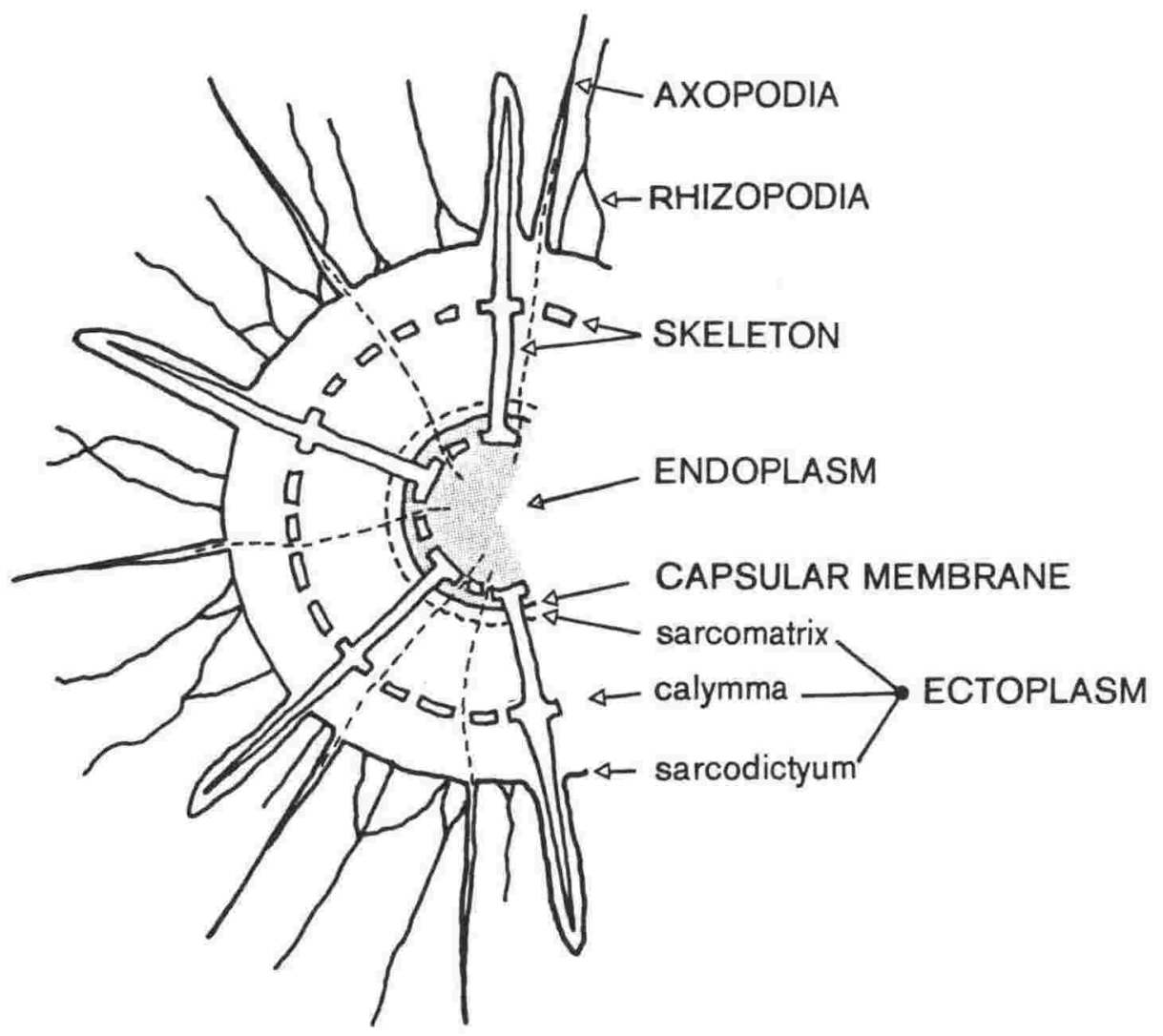


Diverse nutritional habits, highly differentiated cytoplasm and the specialised network of skeletal cytoplasmic sheaths suggest that the Radiolaria, though unicellular organisms, are highly advanced in their physiological development, which may help to explain their wide geographic distribution and relative abundance over a large geologic time span (Anderson, 1976c).

\subsubsection{Cytoplasmic structure}

\subsubsection{Preamble}

The following short review of radiolarian cytoplasmic structure is based on the following sources: Campbell, 1954; Pokorny, 1963; Anderson, 1976c; Riedel and Sanfilippo, 1977; Kling, 1978; Goll and Merinfeld, 1979; Kennett, 1982; and other specifically referenced papers.

Little attention has been given to radiolarian cytoplasmic morphology although it is clear that the ultimate explanation for skeletal secretion and architectural design is biological. Ultrastructural characteristics of the axopodial apparatus and the position of the nucleus varies between different radiolarian groups and should be important in radiolarian taxonomy (Petrushevskaya, 1975). Radiolarian cytoplasm can be divided into three units:

1. ectoplasm (extracapsular cytoplasm),

2. endoplasm (intracapsular cytoplasm), and

3. central capsular membrane.

The central capsule is a distinctive structure in Radiolaria and separates them from close relations such as the Heliozoa.

Figure 1.2 is a schematic cross-section of a spumellarian radiolarian showing the major cytoplasmic features in relation to a hypothetical spherical skeleton.

\subsubsection{Ectoplasm}

The ectoplasm consists of three units. The assimilative layer (sarcomatrix) lies immediately next to the central capsule and is thought to be the area where food is assimilated into the cytoplasm. Surrounding it is a frothy layer (calymma) which makes up the bulk of the ectoplasm. Its frothy appearence is due to the presence of numerous alveoli which are probably carbon dioxide saturated and aid buoyancy. Covering the protoplasm, including the distal skeletal elements, is a protoplasmic sheath (sarcodictyum) which prevents silica dissolution in the living radiolarian.

Radiolarians have two principal kinds of pseudopodia which aid in flotation, food capture, and respiration. 
1. The axopodia are long, straight, radially aligned pseudopodia that are stiffened by microtubules (very fine protein rodlets) which can also be found as supporting structures in other parts of the cytoplasm. The axopodia extend through the ectoplasm and central capsular membrane to the interior of the endoplasm.

2. The rhizopodia are thin, delicate extensions of the peripheral cytoplasm and are approximately radial but may anastomose, particularly towards the base. Cytoplasmic streaming in the rhizopodia is differentiated. Prey can be carried in one direction while symbiotic zooxanthellae can be held stationary or moved in an opposite direction (Anderson, 1978a).

\subsubsection{Endoplasm}

The endoplasm contains the nucleus, or nuclei (multiple nuclei are not uncommon), of the radiolarian. Radiolarian nuclei can have large numbers of chromosomes, up to 1500 having been reported. The endoplasm also contains lipid droplets of varying composition and albumenoid spherules containing crystals presumed to be proteins and is involved in reproduction, biochemical synthesis, and energy production.

\subsubsection{Central capsular membrane}

The central capsular membrane is a single layer (double layer in the Phaeodaria) of chitinous or mucoid material between the endoplasm and ectoplasm. Its shape varies considerably from species to species and is frequently related to the shape of the skeleton. In living radiolarians the membrane is usually pigmented and easily visible. Pores in the membrane permit exchange between the endoplasm and ectoplasm and act as exits from the endoplasm for the axopodia.

\subsubsection{Reproduction}

The life cycle is believed to include both asexual binary fission and sexual reproduction involving flagellated gametes.

Pokorny (1963) described asexual reproduction as nuclear, central capsular, and ectoplasmic division and finally, in some forms, skeletal division. In species with complex skeletons one daughter cell retains the original skeleton while the other leaves and secretes a new one. Kling (1971a) gives examples of two spherical lattice skeletons still joined and suggests the pairs could have been secreted "accidentally", before completion of fission. This phenomenon is reported to occur in several species.

Sexual reproduction has never been fully observed. Anderson gives accounts of the cytoplasmic separation of flagellated swarmers, each with its own nucleus, lipid (food) 
reserves and cytoplasm, at the periphery of two colonial radiolarians Sphaerozoum punctatum and Thalassicola nucleata (in 1976b and 1978a respectively). The swarmers did not survive in the laboratory.

\subsubsection{Skeleton}

Radiolarian skeletons are generally within the size range 50 to 400 microns. Members of the polycystine family Orosphaeridae (solitary) produce skeletons as large as $5 \mathrm{~mm}$ in diameter (Friend and Riedel, 1967). Rare orosphaerid fragments are preserved in New Zealand upper Neogene sediments. By far the largest known solitary species is the phaeodarian Coelothamnus maximus Haeckel (1887), with a skeletal diameter of $32 \mathrm{~mm}$.

All polycystine radiolarians produce skeletons made of amorphous silica most of which is in the form of solid bars (attached at both ends) and spines (attached at one end). Some radiolarians produce hollow spines (Petrushevskaya, 1975). The phaeodarians utilise amorphous silica admixed with organic matter in their skeleton elements which are usually hollow. The skeleton is never in direct contact with sea water in a living radiolarian, even the extremities of long spines being encased in a layer of ectoplasm (see section 1.3.2.2).

Four basic wall structures exist:

1. Latticed wall - a network of bars forming closely spaced pores.

2. Spicule - a network of widely spaced bars.

3. Spongy wall - an intricate interlacing of relatively thin bars in a thick, seldom regular, three-dimensional network with pore patterns not well defined.

4. Perforate plate wall - a solid uniformly thin wall penetrated by widely spaced pores.

Ontogeny has seldom been observed in living radiolarians. Some closely related fossil forms may be adult, intermediate, and juvenile stages (Kling, 1978). There is some evidence of skeletal elements thickening through the life span of a radiolarian (Kennett, 1982).

Anderson (1976c) considered that skeletal architecture bears little relationship to the organisation of the cytoplasm but reported that radial spines and concentric lattice skeletal elements are foreshadowed by a similar pattern of organisation of the soft parts. The constant association of skeletal framework with a surrounding cytoplasmic sheath suggests that skeletal deposition occurs within this envelope. The presence of a silica depositing sheath (silicalemma), has been clearly established in diatoms (Reimann, 1964: after Anderson, 
1976c).

The polycystine Radiolaria are divided into two groups according to skeletal morphology. The Spumellaria are basically spheres with the external skeleton called the cortical and inner/inners the medullary/medullaries. Variations on the spherical shape include ellipsoidal (one axis lengthened), discoidal (one axis shortened), and coiled. The Nassellaria have axial symmetry. It is characteristic of most radiolarians that the radial elements never meet at the centre (Kling, 1978). Silica deposition in growing spumellarians probably occurs concentrically outwards as the animal grows, with the skeleton always preceeding the central capsule (Pokorny, 1963). During development of the nassellarians the cephalis and thorax form first followed by later segments which are divided internally by fairly complete septa. On the exterior, the septa are normally marked by constrictions.

\subsubsection{Nutrition}

Radiolarians were originally assumed to be herbivores grazing exclusively on diatoms and other algae even though Haeckel (1887) had observed a tintinnid within the protoplasm of a radiolarian (Anderson, 1976c). Radiolarians are now known to be omnivorous, feeding on various kinds of planktic organisms including microflagellates and other protozoans, diatoms, and possibly forms as large and as active as copepods (Campbell, 1954; Kling, 1978). Anderson (1978a) studied Thalassicolla nucleata, a colonial radiolarian, and found it receives nutrition from diatoms, colourless flagellates, pigmented unicellular algae, and crustacea. This radiolarian has the ability to sort out its food, unwanted material being released within several minutes.

Food is captured as it floats into contact with the rhizopodia and is transported by cytoplasmic streaming into the digestive region (Anderson, 1978a; Goll and Merinfeld, 1979). Anderson (1978a) gives an account of the capture and breakdown of a crustacean. Rhizopodia quickly entangle the struggling prey which is eventually enclosed in rhizopodial envelopes. Segments of rhizopodia, in immediate contact with the surface of the prey, contain numerous microfilaments which can break open the prey's exoskeleton. Coelopods (hollow specialised extensions of the rhizopodia) penetrate and start digesting the flesh under the exoskeleton.

Anderson (1978b) presents $\mathrm{C}^{14}$ isotope evidence for transfer of organic substances from zooxanthellae to host in Collosphaera globularis, a colonial radiolarian. The predation of symbiotic zooxanthellae is also noted by Anderson (1976a, 1976c, 1977) and Casey (1977). This nutrient source may partially explain the high abundance of radiolarians in 
oligotrophic regions of the oceans (Anderson, 1976c, 1978b).

\subsubsection{Radiolarian mobility}

Radiolarians have no method of swimming to allow for lateral movement. They can move vertically by varying their buoyancy, either by altering the carbon dioxide content of the alveoli (Campbell, 1954; Riedel and Sanfilippo, 1977; Kling, 1978), or by altering the amount of fat in globules (Riedel and Sanfilippo, 1977), or by a combination of both.

\subsection{HISTORY OF STUDY}

Meyen (1834) was the first to recognise radiolarians in plankton and described two species. In a series of papers from 1838 to 1875, Ehrenberg described fossil Radiolaria from Quaternary and Tertiary sediments. From the 1850 's to the 1880 's there were extensive descriptions of living radiolarians mainly from the Mediterranean Sea (e.g. Muller, 1858; Haeckel, 1860a, 1860b, 1862) and fossil assemblages (e.g. Ehrenberg, 1854, 1872a, 1872b, 1873, 1875; Zittel, 1876; Stohr, 1880). There were repeated attempts to form a taxonomic system capable of accommodating the rapidly increasing number of forms discovered (e.g. Muller, 1858; Haeckel, 1862, 1881; Butschli, 1882a, 1882b). Hertwig (1879) established the unicellular nature of radiolarians and divided the major radiolarian groups on the basis of the morphology of the central capsule.

The HMS Challenger Expedition of 1873-1876 collected large numbers of plankton and bottom sediment samples from all the world's oceans. The Challenger Report on the Radiolaria (Haeckel, 1887) was a monographic treatment which has remained the most important single reference on the subclass (Riedel and Sanfilippo, 1977). In it Haeckel set up an exhaustive classification but at the time virtually nothing was known about the biology, stratigraphy, or phylogeny of the group. The classification was artificial and based on morphologic subdivisions that cut across natural generic and species groupings (Kennett, 1982), and for nearly a century obscured the natural relationships of radiolarians (Kling, 1978). Oceanographic expeditions of the late 19th century and early 20th century initiated an explosion in the study of radiolarians, the main contributions being by Popofsky, Cleve, Haecker, and Dreyer.

Haeckel (1887) assumed that his bottom sediment samples were all Recent in age, but some of them are now known to be Paleocene. Consequently Haeckel, and many subsequent authors, assumed that many species have long time ranges and the Radiolaria were not regarded as useful stratigraphic indicators. A good example is an assemblage from the Indonesian island of Rotti, originally described as Pliocene (Tan Sin Hok, 1927), even 
oligotrophic regions of the oceans (Anderson, 1976c, 1978b).

\subsubsection{Radiolarian mobility}

Radiolarians have no method of swimming to allow for lateral movement. They can move vertically by varying their buoyancy, either by altering the carbon dioxide content of the alveoli (Campbell, 1954; Riedel and Sanfilippo, 1977; Kling, 1978), or by altering the amount of fat in globules (Riedel and Sanfilippo, 1977), or by a combination of both.

\subsection{HISTORY OF STUDY}

Meyen (1834) was the first to recognise radiolarians in plankton and described two species. In a series of papers from 1838 to 1875, Ehrenberg described fossil Radiolaria from Quaternary and Tertiary sediments. From the 1850 's to the 1880 's there were extensive descriptions of living radiolarians mainly from the Mediterranean Sea (e.g. Muller, 1858; Haeckel, 1860a, 1860b, 1862) and fossil assemblages (e.g. Ehrenberg, 1854, 1872a, 1872b, 1873, 1875; Zittel, 1876; Stohr, 1880). There were repeated attempts to form a taxonomic system capable of accommodating the rapidly increasing number of forms discovered (e.g. Muller, 1858; Haeckel, 1862, 1881; Butschli, 1882a, 1882b). Hertwig (1879) established the unicellular nature of radiolarians and divided the major radiolarian groups on the basis of the morphology of the central capsule.

The HMS Challenger Expedition of 1873-1876 collected large numbers of plankton and bottom sediment samples from all the world's oceans. The Challenger Report on the Radiolaria (Haeckel, 1887) was a monographic treatment which has remained the most important single reference on the subclass (Riedel and Sanfilippo, 1977). In it Haeckel set up an exhaustive classification but at the time virtually nothing was known about the biology, stratigraphy, or phylogeny of the group. The classification was artificial and based on morphologic subdivisions that cut across natural generic and species groupings (Kennett, 1982), and for nearly a century obscured the natural relationships of radiolarians (Kling, 1978). Oceanographic expeditions of the late 19th century and early 20th century initiated an explosion in the study of radiolarians, the main contributions being by Popofsky, Cleve, Haecker, and Dreyer.

Haeckel (1887) assumed that his bottom sediment samples were all Recent in age, but some of them are now known to be Paleocene. Consequently Haeckel, and many subsequent authors, assumed that many species have long time ranges and the Radiolaria were not regarded as useful stratigraphic indicators. A good example is an assemblage from the Indonesian island of Rotti, originally described as Pliocene (Tan Sin Hok, 1927), even 
though it is most similar to known Mesozoic assemblages. The Pliocene age was accepted because of the mistakenly presumed long time ranges. Riedel (1953) finally showed that the Rotti assemblage is Mesozoic although one sample did contain a mixture of post-upper Miocene and obviously reworked Mesozoic specimens.

In the early 1950's, Riedel began studies of deep-sea samples collected by the Swedish Deep-Sea Expedition and on-land fossil samples from tropical localities. It soon became obvious that many of the sea-floor sediments contained fossil or mixed fossil and Recent assemblages (Riedel, 1952, 1957a).

Since the early 1960's cores from the Deep Sea Drilling Project have proved the usefulness of radiolarians in biostratigraphy. The rate of evolution of Radiolaria is comparable to that of other microfossil groups. The legacy of Haeckel's classification is the a major problem in applying Radiolaria to biostratigraphy.

At present the taxonomy is being revised by Riedel, Petrushevskaya, Nigrini, Goll and others. Emphasis has been on the revision and refinement of the taxonomy of certain forms, particularly those species and evolutionary lineages which have proven to be useful in biostratigraphy (Nigrini and Moore, 1979). Petrushevskaya (1975) stressed the value of incorporating into the present classifications based on the hard parts, the recent biological investigations which have shown that radiolarians can be divided into several major groups with differing cytoplasmic characteristics, especially in connection with the form of the axopodia and the position of the nucleus.

Future studies will still require a large taxonomic component until a phylogenetic classification is achieved. Paleoecological studies will be increasingly important as the taxonomy improves. Emphasis will increase on establishing the statistical relationships between the distribution of species (or species groups) and quantitative measurement of their environmental parameters (Nigrini and Moore, 1979). Another potential area of research is the protein-containing matrix preserved in radiolarian skeletons. The protein could be used for dating by amino acid epimerisation-racemisation reactions and for the tracing of evolutionary lineages by the analysis of species specific amino acid patterns (King, 1974). 


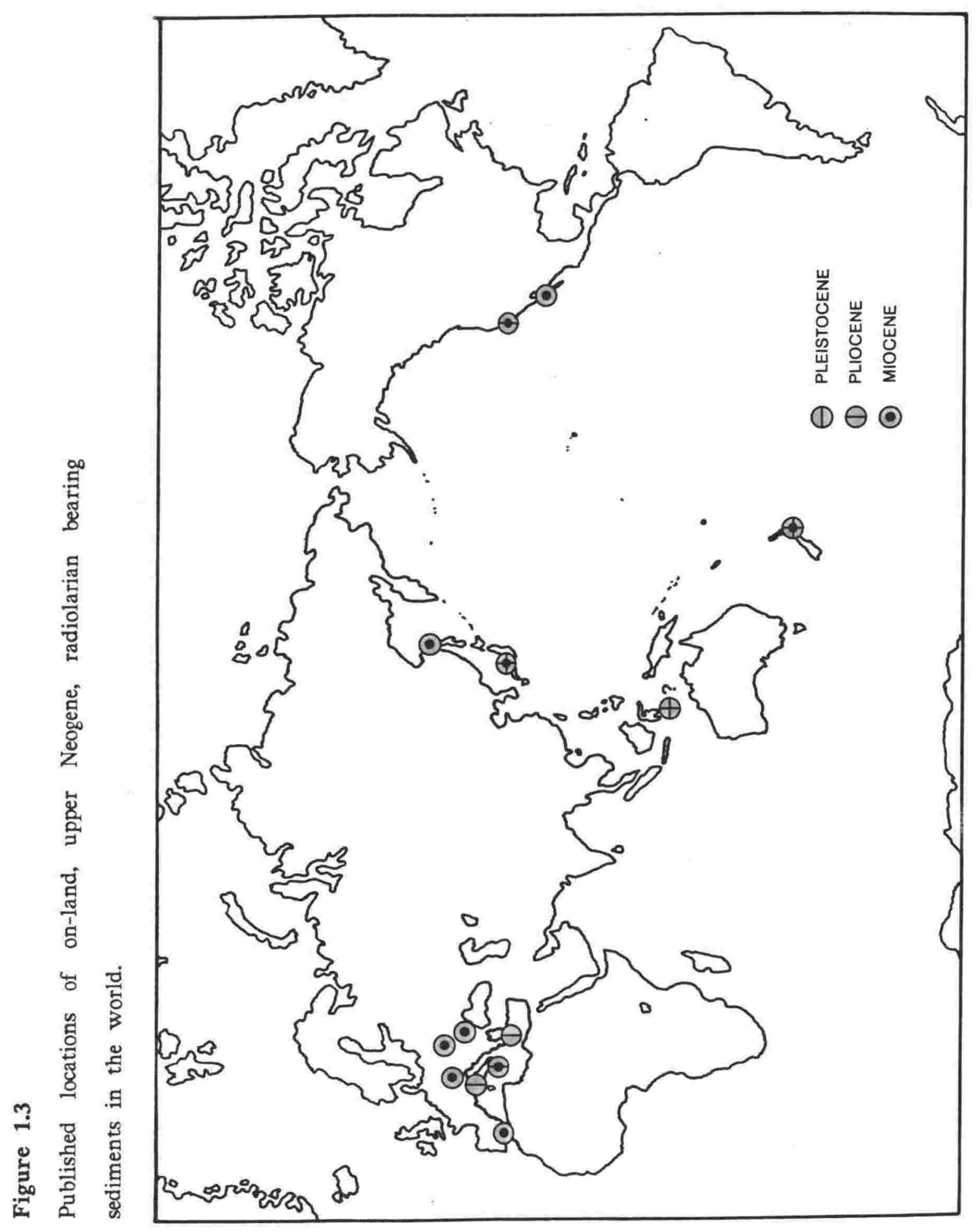




\subsection{PREVIOUS WORK}

\subsubsection{Land-based sections}

New Zealand is one of the few places in the world where upper Neogene radiolarian-bearing rocks outcrop in well exposed land based sections and is probably the only situation where Late Neogene southern temperate assemblages can be found in on-land outcrops (see Figure 1.3).

The following is a list of known upper Neogene land based radiolarian bearing localities and references.

\subsubsection{Europe}

\section{Northern Italy}

Tabianian - stratotype: Lower Pliocene Sanfilippo 1971.

Sanfilippo, Burckle, Martini, and Riedel 1973.

Southern Italy

Calabria - Zanclean: Pliocene

Seguenza 1880.

Calabria - Tortonian: Upper Miocene Pantanelli and Stefani 1880.

Sicily

Torrente Rossi: Upper Miocene

Sanfilippo 1971.

Sanfilippo, Burckle, Martini, and Riedel 1973.

Capodarso - 10km west of Pasquasia (location of the neostratotype Messinian). Samples from just below the Messinian evaporites - Tortonian: Upper Miocene Sanfilippo 1971.

Capo Rossello - near Agrigento - "Trubi" marls which define the stratotype Zanclean: Pliocene

Riedel, Sanfilippo, and Cita 1974.

Riedel and Sanfilippo 1978.

Grotte - Girgenti Province - Tortonian: Upper Miocene Stohr 1880.

Crete

Late Pliocene

Sanfilippo and Riedel 1975.

\section{Austria}

Northeast Austria - Tortonian: Upper Miocene Bachmann 1961. 
Spain

El Cuervo section, Andalusia: early Late Miocene Berggren et al. 1976.

\section{Rumania}

Tortonian of the Subcarpathians - mainly Phaeodaria described: Upper Miocene

Dumitrica 1964.

\section{Poland}

Vicinity of Krakow and Bochnia, southern Poland - central part of the Carpathian foothills: Upper Miocene Barwicz-Piskorz 1978.

\subsubsection{Asia}

Russia

Northern Sakhalin: Upper Miocene Kozlova 1960.

\section{Rotti}

Near Timor: one possible Plio-Pleistocene sample Riedel 1953.

\section{Japan}

On the west coast of Japan there are a series of Neogene Basins. The formations listed below are defined from the Oga Peninsula Section, Akita Sedimentary Basin (after Nakaseko, 1959) and are typical of the lithologies represented in many of these Neogene basins.

Shibikawa Fmn. - late Pliocene and Pleistocene Blue coarse-medium sands, mollusca, some lignite seams.

Waikimoto Fmn. - Pliocene Fine sands, mollusca.

Kitaura Fmn. - late Miocene to early Pliocene Massive dark grey mudstones with sandstone and tuff layers.

Funakawa Fmn. - late Miocene

Black mudstone with tuffs.

Onnagawa Fmn. - middle to late Miocene Hard siliceous shales.

Fossil Radiolaria are present in all these formations Nakaseko (1955, 1959, 1960).

Ling (1971) described some Radiolaria from the Onnagawa Formation.

\subsubsection{America}

\section{California}

The Newport Bay area has been well studied. The Late Neogene radiolarian-bearing rocks are the Malaga Mudstone (late Miocene) and the Capistrano Formation (latest Miocene and early Pliocene) where numbers are as high as 10,000 radiolarians per gram of sediment (Ingle and Barron, 1978). The main references are: Campbell and Clark 1944. Casey 1972.

Casey, Price and Swift 1972. Ingle and Barron 1978. 
Figure 1.4

Location of upper Neogene, radiolarian bearing deep-sea cores in the south-west Pacific.

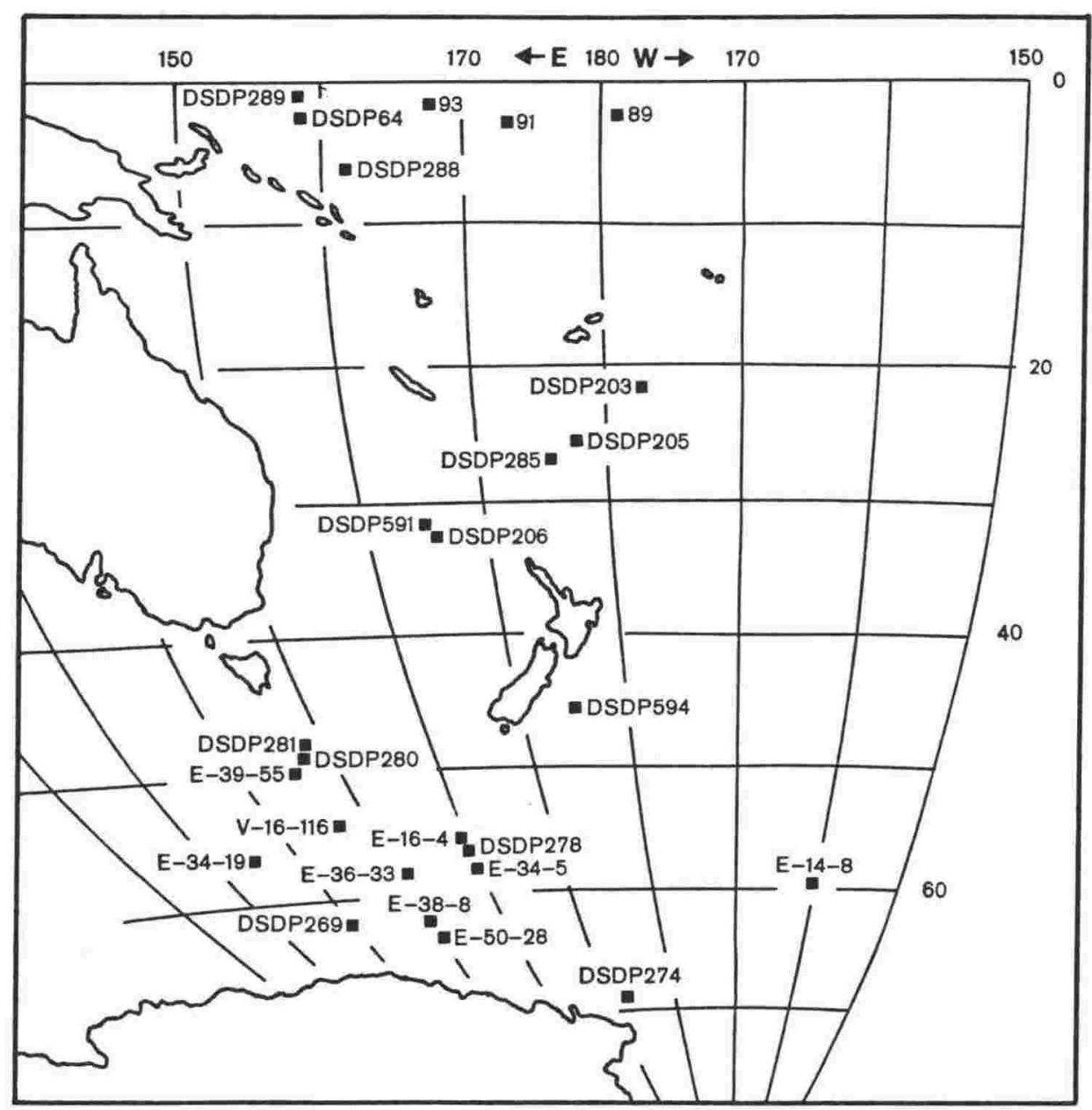


The Mission Hills area has upper Miocene faunas in the Modelo Formation (late Miocene).

Barron and Ingle 1978.

The Centerville Beach section located in the Humboldt Basin along the coast of northern California.

Radiolarians present in the late Miocene-early Pliocene

Pullen Formation.

Weaver, Casey, and Perez 1981.

Bahia de Asuncion, Baja California - diatomites with

late Miocene radiolarians.

Weaver, Casey, and Perez 1981.

Maria Madre Islands: late Miocene.

Weaver, Casey, and Perez 1981.

\subsubsection{Deep-sea cores}

Most of the work on late Neogene Radiolaria has been done on deep-sea cores. The following cores in the southwest Pacific contain late Neogene Radiolaria (see figure 1.4 for locations). A biostratigraphic discussion of some of these and other deep-sea cores will be presented in Chapter Five. If any author/s worked on only a part of the radiolarian-bearing sequence from the cores the age range of the material they worked on is shown.

\subsubsection{Deep Sea Drilling Project sites}

\section{Ontong-Java Plateau}

Radiolarians are common and well preserved through the late Neogene. This part of the sequence appears to be uninterrupted.

Winterer, Riedel, Moberly et al. 1971.

Riedel and Sanfilippo 1971.

\section{Lau Basin}

Rare to few, well preserved in the upper Pleistocene and very rare and corroded in the lower Pleistocene. Burns, Andrews, van der Lingen et al. 1973a. Dumitrica 1973.

\section{South Fiji Basin}

Very rare to common, moderately well preserved late

Miocene faunas. Phaeodarians present.

Burns, Andrews, van der Lingen et al. 1973b.

Dumitrica 1973.

\section{New Caledonia Basin}

Quaternary to middle Oligocene sequence. Although rare to common, radiolarians are persistent throughout and coexist with rich nannofossil and planktic foraminiferal assemblages.

Burns, Andrews, van der Lingen et al. 1973c.

Dumitrica 1973.

Westberg and Riedel 1978. 
269 Southeastern edge of the South Indian Abyssal Plain

Few to common and well preserved post-Miocene specimens.

Sparse and moderately preserved in the upper Miocene.

Chen 1974.

Hayes, Frakes, Barrett et al. 1975a.

Chen 1975.

274 Near the Antarctic Continental Margin

Pleistocene - few and well preserved.

Pliocene and uppermost Miocene - common and well

preserved.

Miocene - rare and moderately preserved.

Chen 1974.

Hayes, Frakes, Barrett et al. 1975b.

Chen 1975.

278 South Emerald Basin

Almost complete Pleistocene to middle Oligocene sequence.

$172 \mathrm{~m}$ of radiolarian/diatom and diatom ooze.

Late Pliocene to Recent.

$214 \mathrm{~m}$ of alternating siliceous nannofossil ooze and

nannofossil rich siliceous ooze.

Earliest Miocene to early Pliocene.

Kennett, Houtz, Andrews et al. 1975b.

Petrushevskaya 1975.

Keany and Kennett 1975 - Plio-Pleistocene.

Weaver 1976a - late Miocene to early Pliocene.

280 South of the South Tasman Rise

$1 \mathrm{~m}$ of late Pleistocene overlying $5 \mathrm{~m}$ of late Miocene to early Pliocene sediments containing radiolarians.

Kennett, Houtz, Andrews et al. 1975c.

Petrushevskaya 1975.

\section{South Tasman Rise}

Scattered, well preserved specimens in late Miocene to Pleistocene sediments.

Kennett, Houtz, Andrews et al. 1975d.

Petrushevskaya 1975.

285 Central South Fiji Basin

Some late Miocene faunas.

Andrews, Packham, Eade et al. 1975a.

Holdsworth 1975.

\section{Ontong-Java Plateau}

Few to trace in Pleistocene and late Pliocene sediments. Andrews, Packham, Eade et al. $1975 \mathrm{~b}$. Holdsworth 1975.

\section{Ontong-Java Plateau}

Complete Neogene sequence with radiolarians present throughout.

Andrews, Packham, Eade et al. 1975c.

Holdsworth 1975.

Westberg and Riedel 1978. 


\section{New Caledonia Basin}

Uncommon but persistent throughout the late Neogene sequence.

J.P. Kennett (pers. comm.).

\section{Southern Chatham Rise}

Well represented faunas from middle Miocene to Holocene.

From latest Miocene to Holocene there is a sequence of oscillations between dark hemipelagic and lighter pelagic biogenic sediments which are probably climatically controlled.

J.P. Kennett (pers. comm.).

\subsubsection{Eltanin cores}

E-14-08 Flank of the Mid-Pacific Ridge

Hays and Opdyke 1967 - late Miocene to Holocene.

Bandy, Casey and Wright 1971 - late Miocene to Holocene.

Hays and Donahue 1972 - late Miocene to early Pliocene.

Weaver 1976a - late Miocene to Pliocene.

Keany 1979 - early Pliocene.

\section{E-16-04 Emerald Basin}

Weaver 1976a - late Miocene to Pliocene.

Keany 1979 - early Pliocene.

\section{E-34-05 Flank of the Macquarie Ridge}

Weaver 1976a - late Miocene.

Keany 1979 - early Pliocene.

E-34-19 South of the Indian-Antarctic Ridge

Weaver 1976a - late Miocene to early Pliocene.

Keany 1979 - early Pliocene.

\section{E-36-33 Macquarie Swell}

Weaver 1976a - Pliocene.

Keany 1979 - early Pliocene.

\section{E-38-03 Base of the Antarctic Continental Rise}

Weaver 1976a - Pliocene.

Keany 1979 - early Pliocene.

\section{E-39-55 Macquarie Swell}

Weaver 1976a - Pliocene.

E-50-28 Base of the Antarctic Continental Rise

Weaver 1976a - Pliocene.

Keany 1979 - early Pliocene.

\subsubsection{Vema core}

V-16-116 Flank of the Indian-Antarctic Ridge

Hays 1965 - Pliocene to Holocene. 


\section{Figure 1.5}

Size classification of sediments (after Folk, 1974). All radiolarian bearing sediments from the late Neogene of New Zealand fit into one of the three categories highlighted.

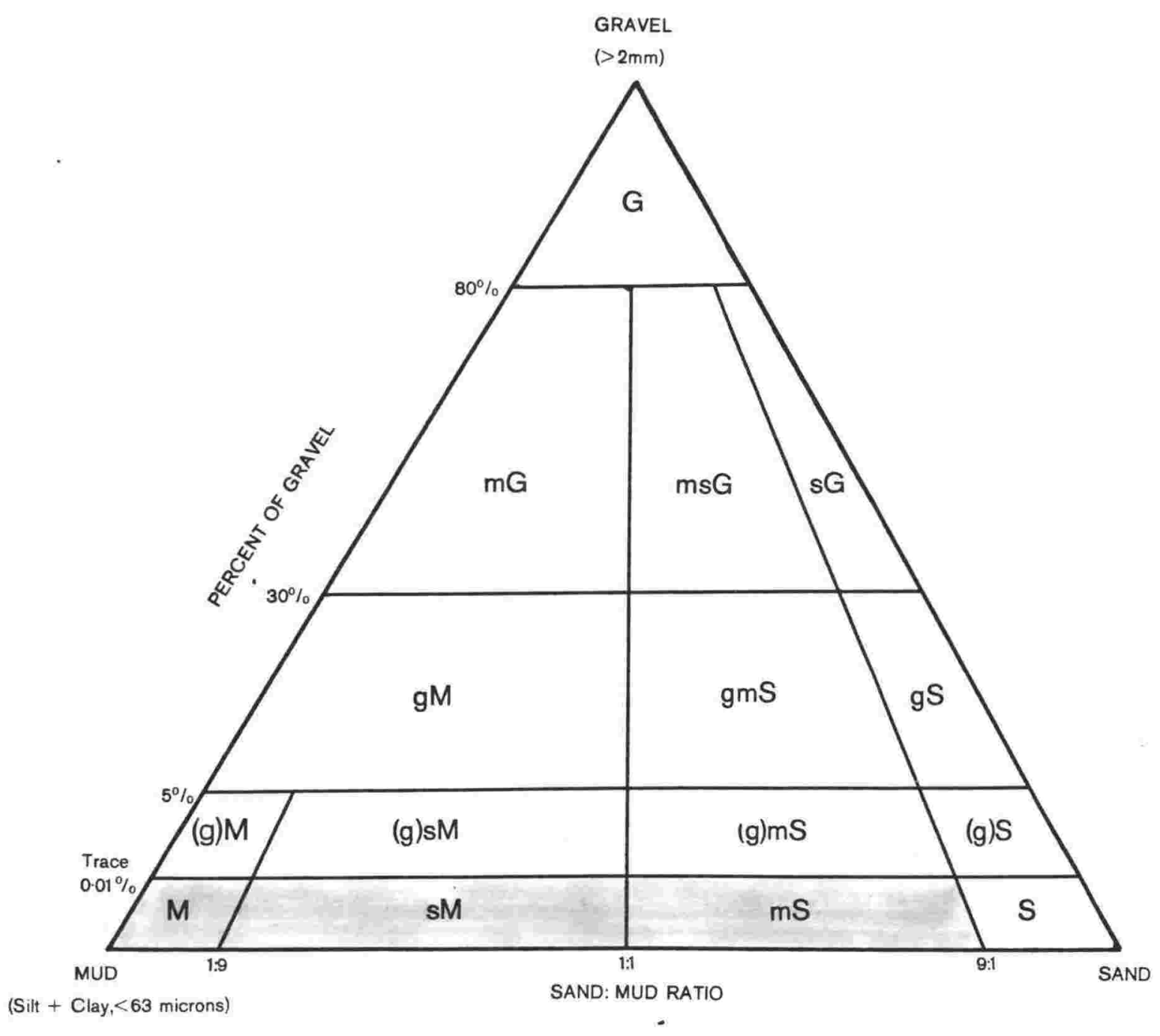




\subsubsection{Swedish Deep Sea Expedition cores}

89 Central Pacific Basin

Quaternary fauna (abundant and well preserved) overlying a mixture of Quaternary, middle Tertiary and late Tertiary forms. Riedel 1957a.

91 Gilbert Ridge

Upper $2-3 \mathrm{~m}$ contain an abundant, well preserved Quaternary assemblage disconformable on middle Tertiary sediments. Riedel 1957a.

\section{Nauru Basin}

Probably entirely Quaternary containing abundant and well preserved specimens with some rare reworked early, middle and late Tertiary species.

Riedel 1957a.

\subsubsection{New Zealand}

Previous work on New Zealand Late Neogene Radiolaria is virtually nonexistent. Eggo (1979) attempted to determine the radiolarian biostratigraphy in the upper Mangaopari Stream section (upper Miocene to lowermost Pliocene), but was unable to define any datums because his extraction technique was not good enough to obtain sufficient well preserved specimens. Improved techniques have allowed the writer to obtain good assemblages from that section. Ashby (1978) illustrated some species from Pliocene sediments in Wairarapa. No other taxonomic or biostratigraphic work has been done on New Zealand Late Neogene Radiolaria.

The writer located radiolarian-bearing sections and samples mainly by discussion with other micropaleontologists working on New Zealand Late Neogene sediments and by sampling horizons with high preservation potential (see Chapter Three). A number of localities were gleaned from scattered references in publications, theses, and New Zealand Fossil Record Forms.

\subsection{NOMENCLATURE}

The following list of publications contain some important definitions used in this thesis.

\subsubsection{Size classification of sediments}

Reference: Folk (1974).

Figure 1.5 shows this classification where fifteen major textural groups are defined on the basis of the gravel content and sand to mud ratio. Nearly all the samples studied in this thesis contain no gravel size material and have a sand to mud ratio of less than 9:1 so the number of groups available for classification is reduced to three. For samples lacking 
Figure 1.6

Upper Neogene section of the New Zealand Cenozoic time scale.

\begin{tabular}{|c|c|c|c|c|c|}
\hline & SERIES & STAGE & & \multicolumn{2}{|c|}{ SUBSTAGE } \\
\hline HOLOCENE & HAWERA & & & & \\
\hline \multirow{4}{*}{ PLEISTOCENE } & \multirow{7}{*}{ WANGANUI } & Cantiontian & We & Putikian & $W_{u}$ \\
\hline & & Castlecifilan & Wc & \begin{tabular}{|l|} 
Okehuan \\
\end{tabular} & $W_{k}$ \\
\hline & & Nukumaruan & $W_{0}$ & Marahauan & $W_{a}$ \\
\hline & & 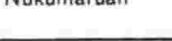 & & Hautawan & $W_{h}$ \\
\hline \multirow{3}{*}{ PLIOCENE } & & Mangapanian & $\mathrm{Wm}_{\mathrm{m}}$ & & \\
\hline & & Waipipian & $W_{p}$ & & \\
\hline & & Opoitian & Wo & & \\
\hline \multirow{3}{*}{ MIOCENE } & \multirow{2}{*}{ TARANAKI } & Kapitean & Tk & & \\
\hline & & Tongaporutuan & $T \mathrm{t}$ & & \\
\hline & SOUTHLAND & Waiauan & Sw & & \\
\hline
\end{tabular}

\section{Figure 1.7}

Marine ecologic zones: all depths in metres (after Edwards, 1979).

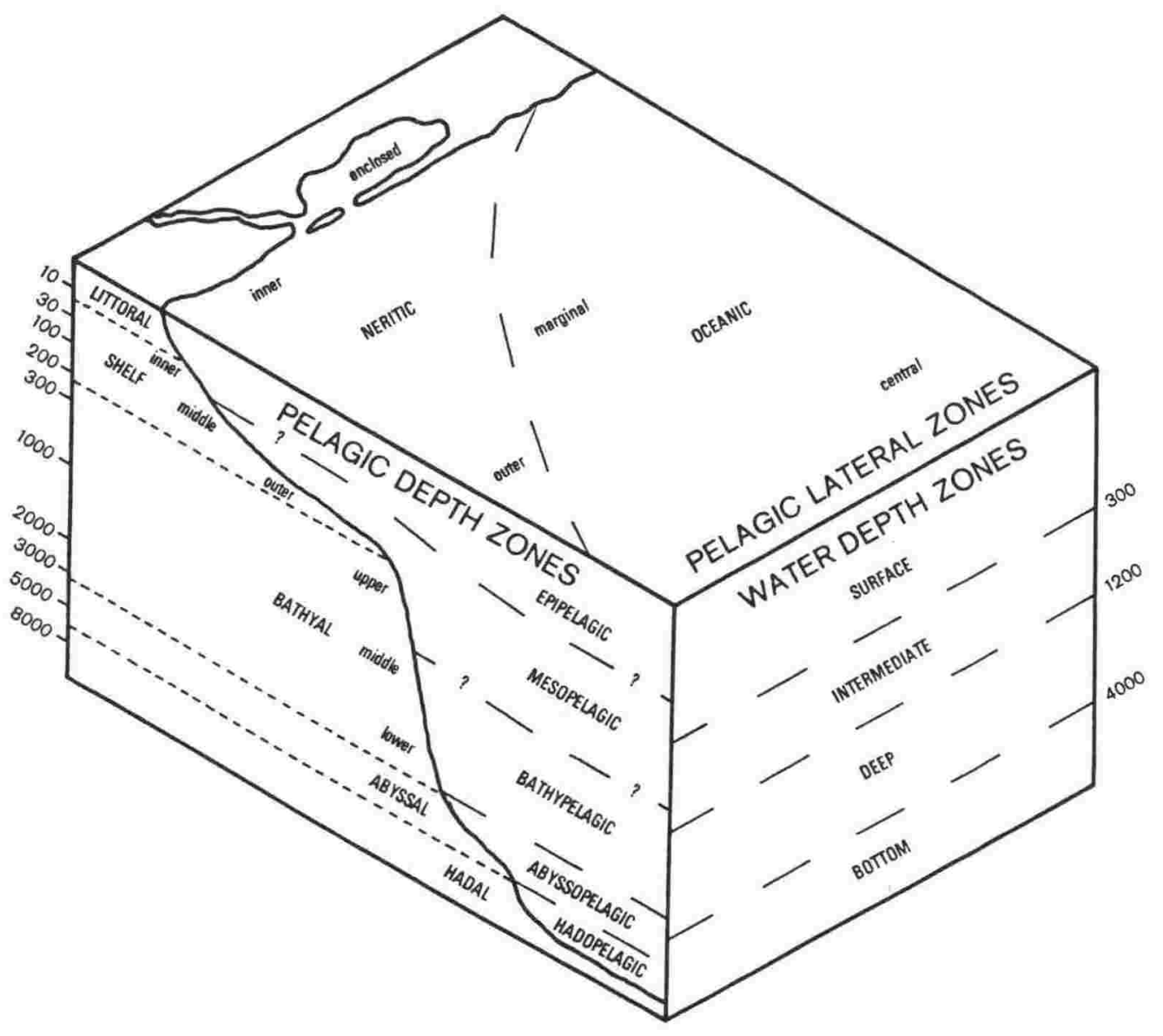


gravel, Folk defines a furthur ten groups based on sand percentage and clay to silt ratio. As the clay to silt ratio in the mud size fraction was not determined for the samples studied this "subclassification" can not be used.

\subsubsection{Lithologic symbols and abbreviations}

Reference: Andrews (1982).

\subsubsection{New Zealand Cenozoic Time Scale}

Reference: Hoskins (1982).

The late Neogene portion of the time scale, with the standard abbreviations used, is reproduced in figure 1.6.

\subsubsection{Definition of type sections}

Reference: Hoskins (1982: pp.72-73).

\subsubsection{Nomenclature pertaining to type specimens}

Reference: Hornibrook (1968a: p.20).

\subsubsection{Ecologic zones}

Reference: Edwards (1979), reproduced in Kennett (1982: p.258).

The ecologic zones are outlined in figure 1.7.

\subsubsection{Biostratigraphic zones}

Reference: Hedberg (1976).

The definitions of the zones are outlined in figure 1.8 .

\subsubsection{Paleomagnetic zones}

All the paleomagnetic zones discussed in this thesis are based on the paleomagnetic time-scale whereby Anomaly $5=$ Chron 9. The paleomagnetic usage of "Epoch" is retained to conform to the usage in most of the references cited.

\subsubsection{Use of planktic, nektic, and benthic}

Reference: Martinnsen (1975).

This usage is accepted. 
Figure 1.8

Definitions of biostratigraphic zones (after Hedberg, 1976).

RANGE ZONES:

A group of strata representing the stratigraphic range of some selected element/s of the total assemblage of fossil forms present.

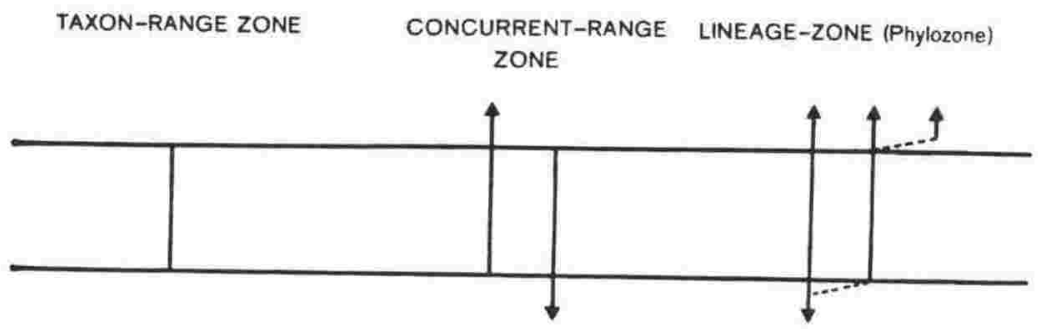

INTERVAL ZONES (Interbiohorizon Zone)

The stratigraphic interval between two biohorizons.

'SUCCESSIVE APPEARANCE' 'SUCCESSIVE DISAPPEARANCE' GAP

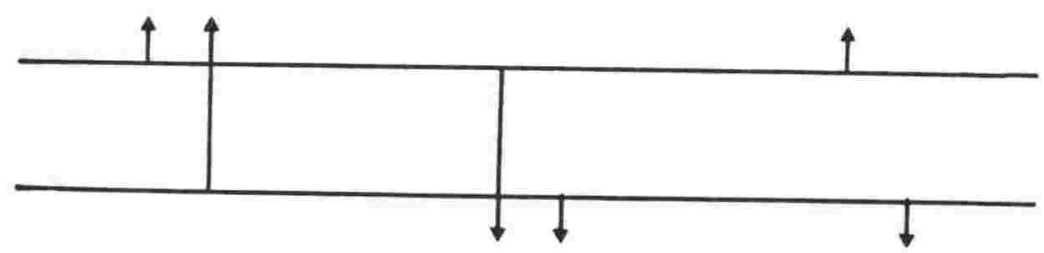

ACME ZONE:

A group of strata based on the abundance or development

of certain forms, regardless of either association or range.

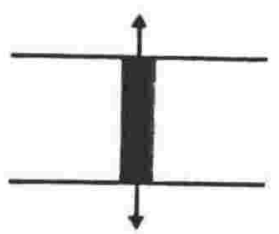

ASSEMBLAGE ZONE:

A group of strata characteriscd by a distinctive natural assemblage of all forms present or of the forms present of a certain kind or kinds. 


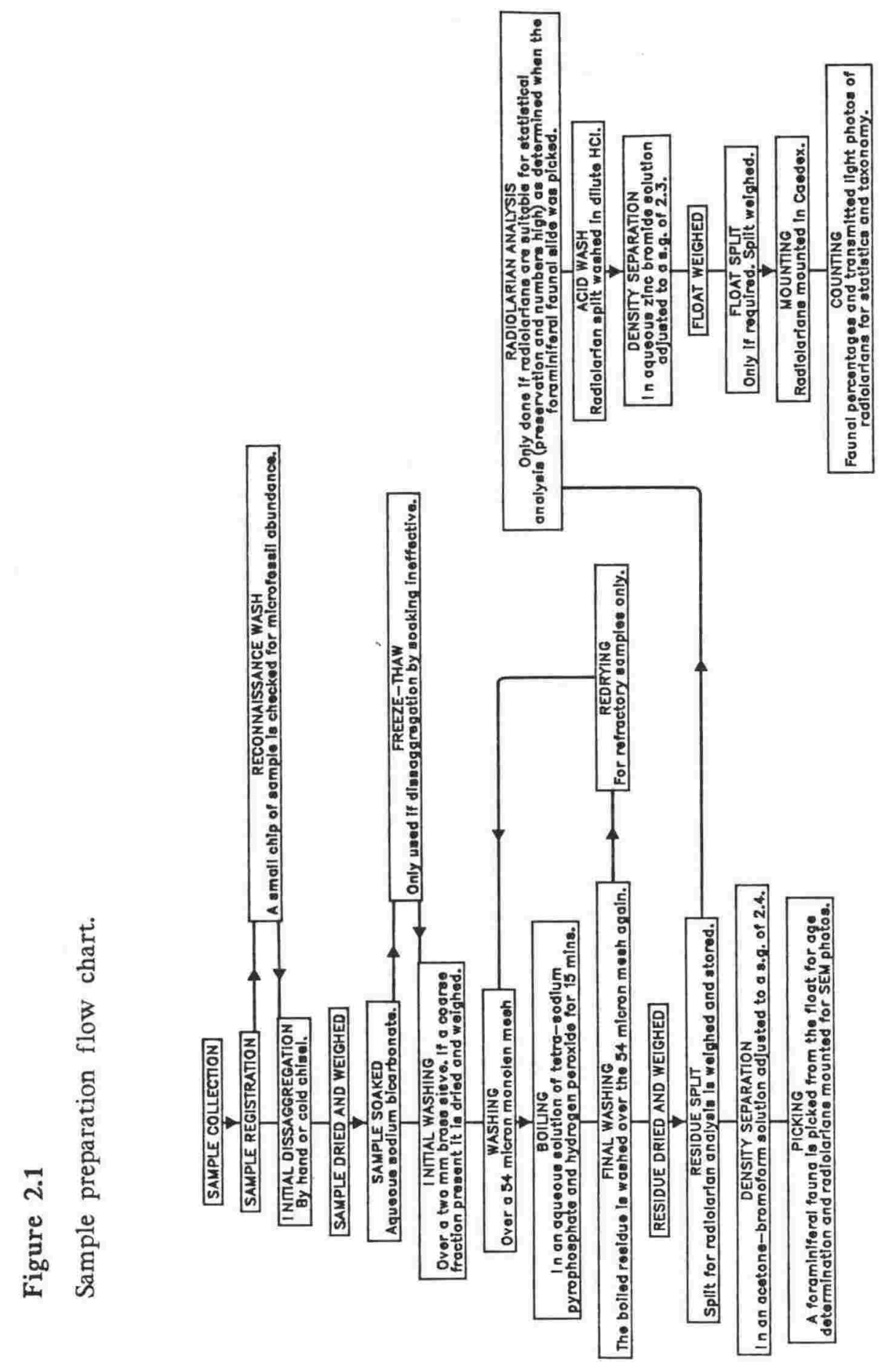




\section{Chapter II \\ TECHNIQUES}

\subsection{PREAMBLE}

It was found necessary, because of the relatively low abundance of radiolarians in the samples studied, to improve upon standard techniques and develop new methods for the qualitative analysis of microfossils and the quantitative analysis of radiolarians. Some of these developments are outlined in Appendix C (Ashby, 1983) which is reproduced within appropriate sections in this chapter to enhance readibility. A flow chart showing the sample procedure used in this thesis is presented in figure 2.1.

All computing was done on the IBM 4341 at the Computing Services Centre, Victoria University of Wellington. The following software packages were used during the course of this study:

SAS - both the graphics and statistical sections used.

TELAGRAF - for high quality output of graphs.

SCRIPT - word processing.

Procedures for collection do not differ substantially from those employed in collecting for other types of microfossils. Usually about $0.5 \mathrm{~kg}$ of sample was collected and the site marked on aerial photographs. It is usually impossible to determine, by use of a hand-lens in the field, whether or not radiolarians are present in sedimentary rocks because generally they can not be distinguished on the rougher surfaces of less indurated rocks (Riedel and Sanfilippo, 1977). It soon became apparent that rhyolitic glass shards, often present in of New Zealand Upper Neogene sediments enhance the preservation potential of the radiolarian skeletons (see Chapter Three) and horizons about 0.5 to 1 metres above rhyolitic tuff beds in hemipelagic mudstones were found to be likely to contain well preserved Radiolaria. Some samples were obtained from Geological Survey and University collections.

Samples were registered in the New Zealand Fossil Record File. A small chip of sample was quickly disaggregated using an ultrasonic tank and washed over a $54 \mu$ brass mesh to check for microfossil abundance if this was not already known. 


\subsection{DISAGGREGATION}

\subsubsection{Initial disaggregation}

The sample was first broken into half centimetre pieces. Pokorny (1963) recommended wrapping the sample in several layers of paper and hammering it on a solid base. This method is not ideal as uneven crushing occurs and the microfossils contained in the dust produced by the first few blows can be damaged by later blows. Using a mortar and pestle has the same result. Less damage occurs if the rock is broken by gradual pressure from a vice (Glaessner, 1948).

It was found that a compacted mudstone can be broken easily and quickly using a cold chisel, with only a minimum of damage to the contained microfossils. Some mudstones were found to be moderately friable when damp and could be easily broken by finger pressure.

The samples were then oven dried overnight at $35^{\circ} \mathrm{C}$ and weighed. At higher temperatures baking inhibited disaggregation in some samples.

\subsubsection{Chemical disaggregation}

The chemicals most commonly recommended to enhance disaggregation by soaking include: sodium bicarbonate to enhance deflocculation (Franke, 1935), 10-15\% hydrogen peroxide which requires no preliminary drying of the sample (Wick, 1947), petrol followed by water on a dry sample (Layne, 1950), sodium sulphate which disaggregates the sample by crystallisation (Pokorny, 1963), and disaggregation by acid treatment (Burma, 1965).

After weighing, the dried sample was immersed in a warm aqueous sodium bicarbonate solution and left to soak overnight. It was found that sodium bicarbonate is effective for disaggregating most New Zealand Late Neogene mudstones. Occasionally hydrogen peroxide was used.

\subsubsection{Freeze-thaw disaggregation}

Hanna and Church (1928) described a freeze-thaw method for breaking down samples which proved to be effective in reducing samples to approximately two millimetres. The formation of ice crystals appears to have no effect on the preservation of the foraminiferal and radiolarian specimens. This method was used only when the initial soaking had proved ineffective. 


\subsubsection{Initial washing}

Initial washing over a two millimetre brass mesh removed lumps that were proving difficult to break down, such as cemented fossil burrows. Material that remained on this mesh was dried and its weight subtracted from the initial weight of the sample.

\subsection{WET SIEVING}

Separation of microfossils from sediment by the decantation method has advantages in that there is only slight breakage of specimens. However, the process is very time consuming and there is a danger that the better preserved microfossils will float away if they are filled with air. Wet sieving over brass or stainless steel meshes is preferred by most laboratories. At Scripps Institute of Oceanography the meshes are cleaned between samples by washing in strong jets of water and rubbing vigorously with a paper towel to break and dislodge any skeletons. The sieves have to be repaired fairly of ten (W.R. Riedel, pers. comm.).

The composition and open pore structure of many radiolarian skeletons means that the common staining techniques used to detect contamination, such as dipping the mesh in methylene blue, are ineffective.

Baker (1951) described a technique using cloth (organdie and silk) sieves for separating microfossils from muddy matrix. The cloth has a cushioning effect which reduces damage and can be cleaned easily because of its flexibility.

The writer used a monolen mesh held taut in a PVC frame. Even after repeated use the monolen still retained pore size characteristics comparable to research brass sieves used for grain size analysis in the Sedimentology Laboratory at this institution (P. Barrett, pers. comm.). Monolen is a very durable, polyester and nylon combination resistent to $40 \%$ hydrofluoric acid. To prevent contamination the mesh was immersed in $20 \%$ aqueous hydrofluoric acid after each preparation, dissolving any attached skeletons, and then neutralised in a sodium bicarbonate solution.

The sediment that passed through the $2 \mathrm{~mm}$ brass mesh was washed over a $54 \mu$ monolen mesh which retains the smallest radiolarians and identifiable fragments. The fraction coarser than $54 \mu$ is usually not completely disaggregated at this stage. Gentle rubbing between the fingers helps to complete the disaggregation and damages the microfossils only slightly (Glaessner, 1948).

The sample may be boiled in a variety of solutions to complete disaggregation. The 
procedure used by Frizzell and Middour (1951), as described by Riedel (1959), has been adopted by the writer. The sample is boiled in water and tetrasodium pyrophosphate added (three to five grams per $50 \mathrm{ml}$ of water), then $30 \%$ hydrogen peroxide is added by eye dropper until the boiling solution starts to foam. Boiling is continued for 15 minutes. Care must be taken at this stage because if the sample is sandy the boiling may become explosive. The boiled sample is then washed back over the $54 \mu$ mesh using a fine jet of water at low pressure. Too great a water pressure can damage the specimens (Pokorny, 1963). Some more refractory samples required redrying, resoaking, and reboiling. The residue was then washed into a bowl and left to dry. The excess water was never decanted off as many of the microfossils float, e.g. planktic foraminifera and spongodiscid radiolarians. The dried residue was then weighed. Splits for foraminiferal and radiolarian analysis were taken using a modified Otto microsplitter for large samples and a small, non-laminated sample splitter (Humphries, 1961) for small samples.

\subsection{DENSITY SEPARATION}

Residues of New Zealand Upper Neogene mudstones almost always contain sand sized inorganic mineral grains. In most cases the siliceous biogenic component is small, requiring concentration by density separation. If quantitative data on the radiolarians is required, the separate must be representative of the assemblage in the sample.

Howe (1941) described a method of separating calcareous microfossils from the residue by boiling in a soapy solution and stirring to form a froth on which the calcareous specimens float. The concentrated specimens can be decanted off. Glaessner (1948) described the technique developed by Bataafsche Petroleum Maatschappij (The Hague) which utilises hot pyridine solution to remove oily matter from sandy residues before using the soap foam flotation. This method works equally well with foraminifera and radiolarians but the separation is size selective and incomplete.

Density separations using a heavy liquid is the usual method of concentration. Carbon tetrachloride has a maximum specific gravity of 1.6 at $20^{\circ} \mathrm{C}$, insufficient to give good density separations of foraminifera and radiolarian skeletons. Solutions of bromoform (tribromoethane) adjusted to a density of $2.2-2.4$ are suitable for separating foraminiferal specimens (Gibson and Walker, 1967).

To concentrate radiolarian samples for quantitative analysis, flotation in aqueous solutions of zinc bromide has been found to be very effective. Zinc bromide solution is commonly used in palynology and Brady (1977) described its use for the flotation of 
Figure 2.2

Apparatus used for density separation of radiolarian skeletons and foraminiferal tests.

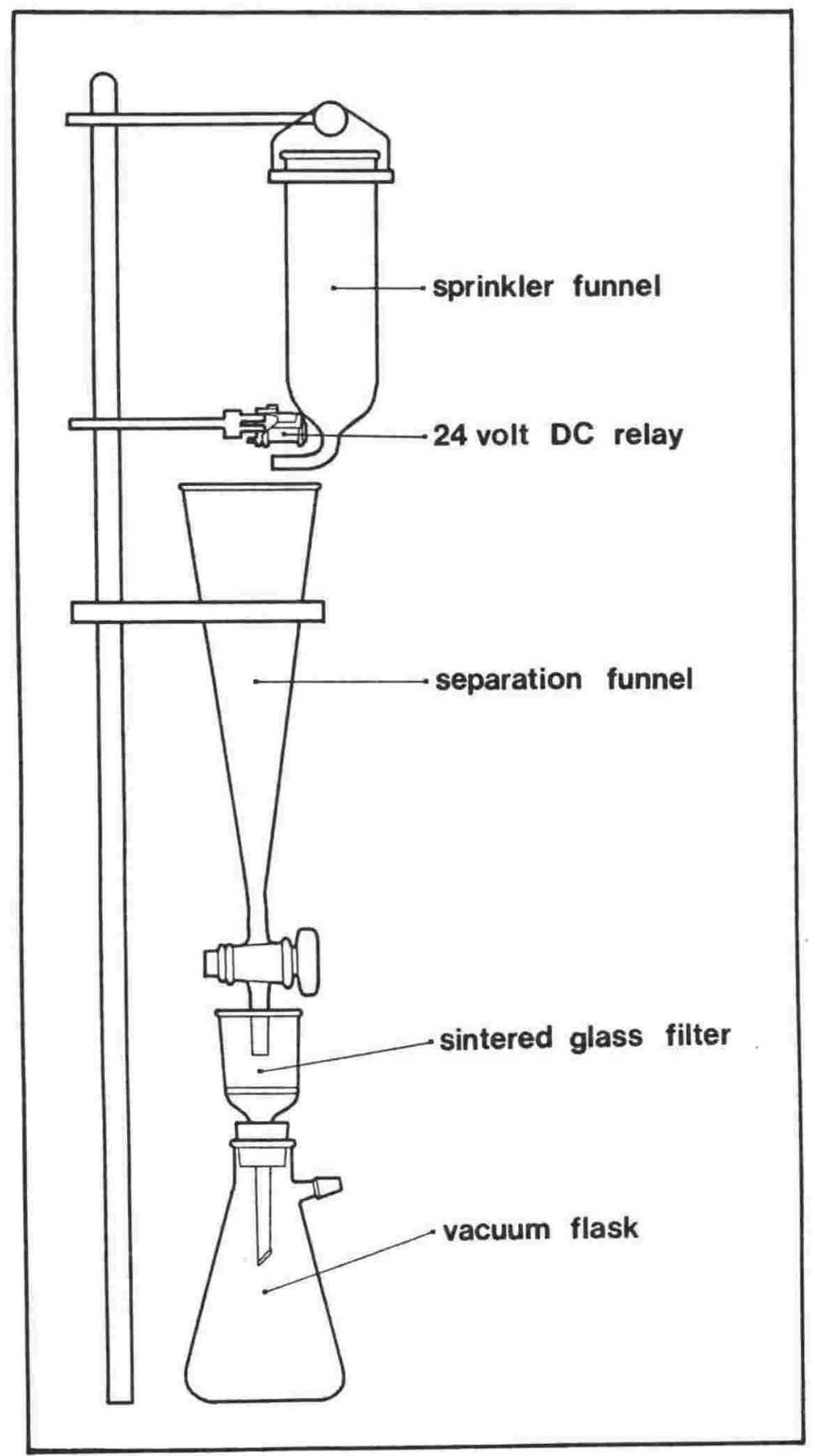


diatom frustules. The maximum density obtainable at $18^{\circ} \mathrm{C}$ is 2.64 . Its advantages over bromoform is that it is miscible in water, is relatively non-toxic and is more viscous, allowing for slower and therefore more accurate separation. Zinc bromide solutions are made up using $10 \%$ hydrochloric acid to prevent the precipitation of zinc hydroxide, and to prevent discolouration of the solution by ferric ions from the residues. Hydrogen ions in the acid solutions reduce ferric complexes to ferrous chloride, which is almost colourless (a slight yellow tinge may develop after prolonged use). The acid in the heavy liquid makes it unusable for foraminiferal flotation. The density of the zinc bromide solution can be adjusted by evaporating or adding water.

Each split for radiolarian analysis was washed in dilute hydrochloric acid, then rinsed and dried. In the apparatus for density separation (figure 2.2), a separating funnel is used in a way similar to that described by Hecht (1933). The separating funnel is filled with zinc bromide solution (specific gravity of 2.3) and the acid washed residue sprinkled onto the surface of the liquid and stirred in. A slow-feed device similar to that described by Faul and Davis (1959) was used if there was a relatively large residue to be floated. The quantity of the residue in the heavy liquid must be low to prevent radiolarians from being trapped under inorganic grains and pushed to the bottom of the separating funnel. After separation is complete (approx. two hours) the stopcock is opened and the heavy fraction is allowed to run off into a sinter glass filter placed on top of a vacuum flask. The zinc bromide solution is then vacuumed into the flask. Next the heavy fraction is washed off the sinter glass filter with a jet of water. The filter is rinsed in acetone and dried. The light fraction, containing most of the radiolarians, is then allowed to run off on to the glass filter and the zinc bromide solution vacuumed into the flask as before. The use of the vacuum flask enables approximately $99 \%$ of the heavy liquid to be retained without change in its specific gravity. The sinter glass filter, containing most of the light fraction is then placed on a different vacuum flask and the rest of the light fraction, left clinging to the sides of the funnel, is washed through onto the filter with water from a wash bottle. The filtrant is discarded and the filtrate washed into a beaker with a jet of water. Filter paper cannot be used with zinc bromide solution because the paper fibres swell and burst. In any case, filter papers should not be used to collect radiolarian residues as the specimens tend to stick to the paper (Burma, 1965). Contamination from the sinter glass filter is eliminated by scrubbing with a stiff paintbrush and thorough rinsing after each sample treatment. 
Figure 2.3

Apparatus used for the random settling of radiolarian

skeletons onto a gelatine and Caedex coated coverslip.

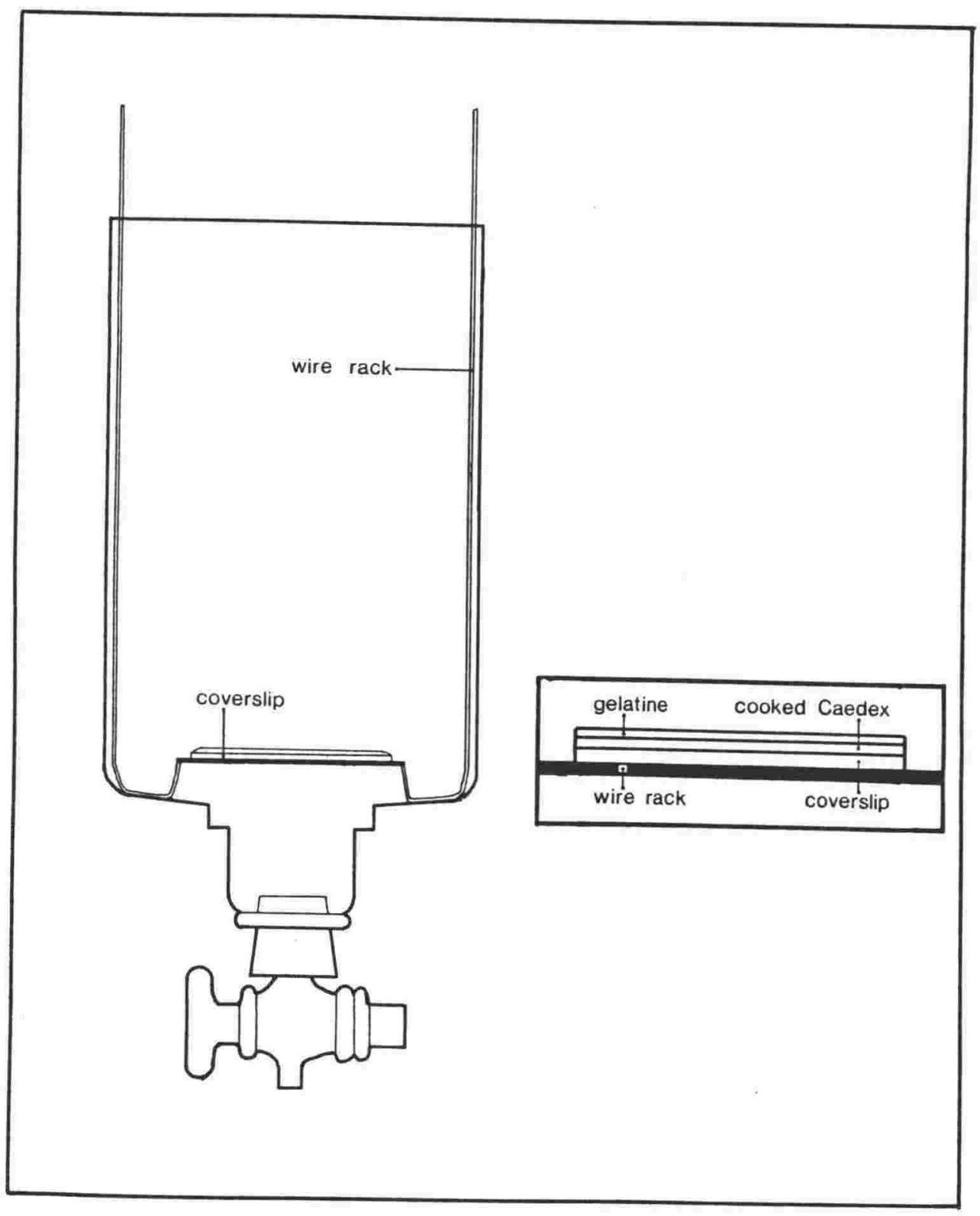




\subsection{MOUNTING METHOD}

For quantitative work, radiolarian residues were mounted in Caedex. The following method works equally as well using Canada Balsam, but it is advisable to cook the balsam at a slightly lower temperature $\left(85-90^{\circ} \mathrm{C}\right)$ than normal $\left(100-110^{\circ} \mathrm{C}\right)$ and for a longer time. At the lower temperature the balsam remains slightly more fluid, making it easier to put on the coverslip without enclosing air bubbles.

The common method of using a pipette to place a drop of radiolarian skeletons suspended in water onto a glass slide, results in the heavy skeletons sinking to the bottom of the drop and remaining at the centre of the slide, while delicate forms are carried to the sides. The distribution of skeletons on the slide cannot be randomised by stirring with a probe (Moore, 1973). Radiolarian skeletons are too large to be sprayed onto the slide like pollen grains (McIntyre et al., 1967). Moore (1973) described a technique for making glass slide mounts using a random settling technique. Laws (1983) quantitatively assessed the differences in counts made from slides prepared by the pipetting technique and the random settling technique, using known mixtures of calibrated microspheres as a sample. Results indicate that slides prepared by the pipetting method yield erroneous data, whereas the random settling technique (as used by the author and outlined below) produces an accurate sample of the original material. Moore's (1973) technique utilises a gelatine coated slide placed at the bottom of a container filled with water. The residue is placed in the water which is then stirred with a vertical motion. The radiolarians are allowed to settle. Then all but $1 \mathrm{~cm}$ of water is siphoned out of the container and the rest dried under an infra-red lamp. When the surface of the slide is dry (in about two hours), the coverslip can be mounted using the preferred medium.

The writer modified Moore's method by using a coverslip instead of a glass slide at the bottom of the settling container, by adding a thin film of cooked Caedex between the gelatine and the coverslip, by using a settling container with a stopcock at its base, and by placing the coverslip on a wire rack in the settling container. The apparatus used is shown in figure 2.3 .

The coverslip is prepared by smearing about five drops of a 1:10 Caedex to Xylene mixture onto the coverslip and placing it onto a hotplate. When the Caedex is cooked and cooled the surface is scored with fine emery paper and a thin film of gelatine solution (10-20mg in $50 \mathrm{ml}$ of water) is brushed onto the Caedex. The gelatine solution is left to dry on the Caedex coated coverslip, then placed on the wire rack in the settling container. The container is then filled with water and the residue added. The water is stirred with a 


\section{Figure 2.4}

Technique for making glass slides using the randomly coated coverslip.
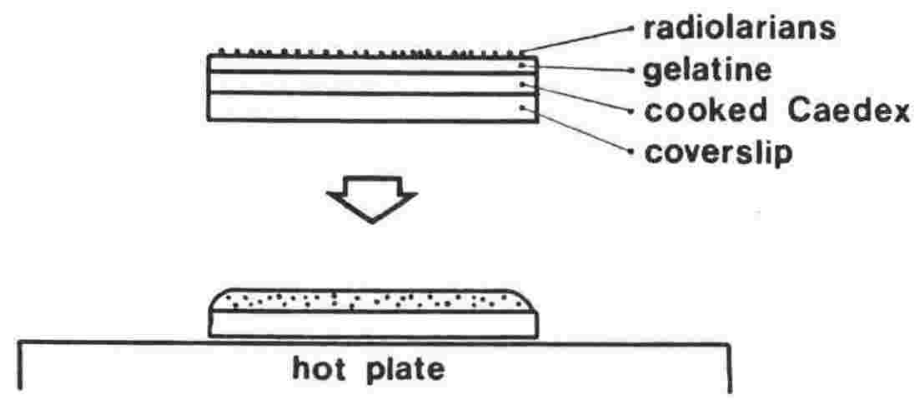

The coverslip is placed on a hotplate, melting the Caedex which embeds the radiolarians.

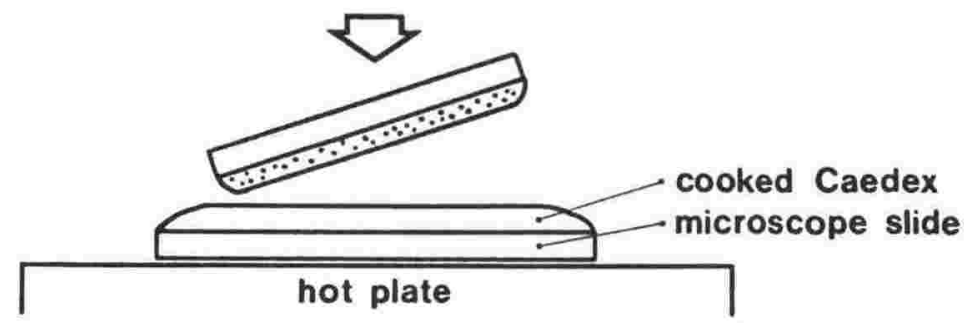

The coverslip is then inverted and lowered onto a Caedex coated microscope slide.

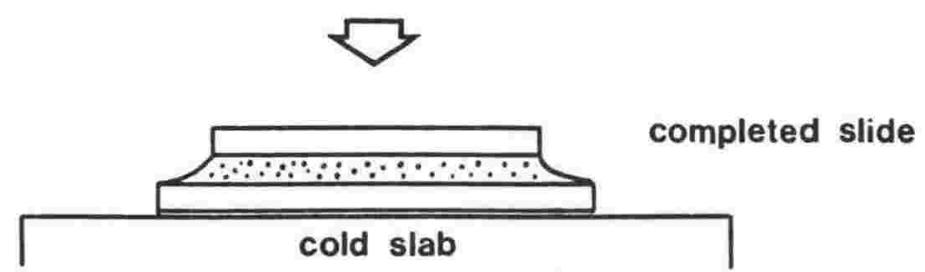


vertical motion as recommended by Moore. After the specimens have settled onto the coverslip the stopcock is opened and the container emptied. Turbulence is avoided by emptying the container slowly. The stopcock is closed to a drip as the falling water level reaches the surface of the coverslip, in order to avoid runoff carrying specimens off the slide. By releasing the water in this way specimens which have not sunk due to entrapment of air are deposited randomly on the coverslip. The wire rack makes it easier to emplace and remove the coverslip.

The coverslip is then dried, the gelatine gluing the specimens to the coverslip. The coverslip is placed on a hotplate (figure 2.4) and the skeletons drop into the Caedex when it melts. The coverslip can then be inverted without losing specimens. A slide is prepared with Caedex and the inverted coverslip lowered slowly onto it. Duplicate slides can be prepared either by splitting the original radiolarian float or saving and resuspending the specimens that were not collected on the first coverslip.

\subsection{STATISTICAL COUNTING}

Galehouse (1971) outlined three methods for the counting of grains on a grain mount. In the first method the entire slide is counted. This is the best statistical approach for counting the assemblage but is too time consuming when the number of specimens on the slide is large (approx. 64000 specimens on slide JAA380 : sample MO13). This counting method was used if there were less than 300 specimens on a slide (6 cases).

Second is the line method where all the grains traversed by a cross-hair are counted on randomly chosen lines. With this technique a number frequency is obtained and not a number percent because larger specimens are counted preferentially. This method does not provide numbers suitable for statistical analysis and was not used by the writer.

Third is the area or "ribbon" method where every specimen within one or more specified areas of the slide is counted. Typically the slide is moved along and all individuals between two lines counted. As the specimens on the slides counted for this thesis are considered to be randomly distributed the placement of the "ribbons" was not considered to be important. If the "ribbon" width is considerably larger than the largest grain this method gives a number percent.

Using the "ribbon" counting method, the first 300 specimens encountered were recorded from each slide. Three hundred was chosen as an optimum number because below 300 the probable error in the numbers increases rapidly and above 300 it decreases slowly and therefore was considered to give the maximum accuracy for the minimum investment of 
time. Only specimens with at least half of their skeleton inside the bounds of the "ribbon" were counted, and only specimens with at least half of the skeleton preserved were counted.

The great variation of preservation and abundance in New Zealand Late Neogene samples precludes the accuracy of constant numerator percentage estimates for uncommon species by the method of Riedel and Sanfilippo (1978a).

\subsection{QUALITATIVE STUDIES}

Foraminiferal specimens were floated from the second spilt using bromoform, adjusted to a specific gravity of $2.2-2.3$, using the same apparatus and method as for the Radiolaria. With bromoform, acetone is used instead of water for washing the equipment, etc.. If quantitative work is required on the foraminifera the dried floated light fraction can be split down to approximately 300 specimens and the entire split counted. From this fraction, radiolarian specimens were picked and mounted on polyvinyl acetate coated stubs for scanning electron microscopy.

\subsection{PHOTOGRAPHY OF RADIOLARIAN SPECIMENS}

Transmitted light photographs of the radiolarians were taken on a Leitz Orthoplan microscope with an Orthomat-W fully automatic camera attachment. Positions of photographed specimens were recorded by use of an England Finder. Ilford FP4 film was used with the shutter speed adjusted to three to five seconds by the use of light filters.

All scanning electron microscope work was done in the Electron Microscope Facility, Victoria University of Wellington. Initially a Cambridge Stereoscan 600 was used, but this was later replaced by a Phillips 505. All the scanning electron microscope photographs in this thesis were taken on the latter machine at an accelerating voltage of $30.0 \mathrm{kv}$.

The heavy oil immersion technique for taking both transmitted light and scanning electron microscope (SEM) photographs of the same specimen (Empson-Morin, 1981; Boltovsky, Kotzian, and Pedrozo, 1983) was utilised in studying selected taxa. 
To calculate the number of radiolarians per gram of sediment the following data was necessary.

$\begin{array}{lll}\text { Weight of sample } & =\text { SAM } & \text { error }=0.1 \% \\ \text { Weight of wash } & \text { W WAS } & \text { error }=2.0 \% \\ \text { Weight of split } & \text { S SPL } & \text { error }=0.1 \% \\ \text { Weight of float } & \text { FLO } & \text { error }=0.1 \% \\ \text { Weight of float split } & =\text { FSP } & \text { error }=0.2 \%\end{array}$

Note: FSP not always required.

The errors on the above weights are variable due to variations in the weights measured and the varying precision of different balances used.
Area of settling container
$=6894.1 \mathrm{sq} \mathrm{mm}$
$=4.155 \mathrm{sq} \mathrm{mm}$
$\begin{array}{ll}\text { Area of field of view } & =4.155 \\ \text { Number of fields of view searched } & =\text { FOV }\end{array}$
error $=4.1 \%$
error $=1.7 \%$ no error
$=$ NUM
Number of radiolarians counted

The error in NUM is derived from problems in counting fragments and those at the edge of the field of view and also completely missing some specimens.

The following calculations can then be made:

$$
\begin{gathered}
\begin{array}{c}
\text { Number of radiolarians in the container } \\
\text { and therefore in the float split. }
\end{array} \\
\mathrm{A}=\mathrm{NUM} \times\left[\begin{array}{l}
694.1 /(\mathrm{FOV} \times 4.155)] \quad \text { error }=10.8 \% \\
\begin{array}{c}
\text { Number of radiolarians in the float } \\
\text { and therefore in the initial split. }
\end{array} \\
\mathrm{B}=\mathrm{A} \times[\mathrm{FLO} / \mathrm{FSP}] \\
\mathrm{Number} \text { of radiolarians in the residue } \\
\text { and therefore in the sample. }
\end{array}\right. \\
\mathrm{C}=\mathrm{B} \times[\text { WAS } / \mathrm{SPL}] \\
\text { Number of radiolarians per gram of sediment } \\
=\mathrm{C} / \mathrm{SAM} \quad \text { [error }=13.3 \%]
\end{gathered}
$$

The assumptions in this method are:

(a) All radiolarians are caught on the 54 micron mesh.

(b) All radiolarians floated in the density separation.

(c) The radiolarians were randomly distributed in the water column and therefore on the slide.

(d) No radiolarians were washed off the coverslip as the container emptied.

The assumptions most likely to be wrong in part are (a) and

(b) and could conceivably increase the final error to $20 \%$.

The calculated radiolarian numbers per gram of sediment are presented in Appendix E (raw statistical data). 


\section{Chapter III}

\section{RADIOLARIAN PRESERVATION}

\subsection{SILICA DISTRIBUTION PATTERNS}

There is a strong correlation between planktic productivity and the accumulation of biogenic opal in underlying bottom sediments (Lisitzin, 1972; Heath, 1974; Riedel and Sanfilippo, 1977; Kennett, 1982: p.476). The amount of opal produced in the surface water $(0-200 \mathrm{~m})$ is controlled by plankton productivity (Lisitzin, 1971) which is in turn controlled by the essential plant nutrients, phosphate and nitrate. High concentrations of nutrients occur in regions of upwelling and surface mixing (Heath, 1974). Renz (1976) reported a probable direct relationship between the amount of dissolved silica and the size and abundance of radiolarians in central Pacific plankton. However, it appears that the availability of silica seldom limits the growth of siliceous organisms, the only likely place where that happens being the North Atlantic where dissolved silica concentrations approach, at places, zero. The availability of nutrients favours the production of protoplasm and this in turn favours the biologic fixation of opaline silica even where dissolved silica concentration is very low (Kennett, 1982: p.474).

The calcite compensation depth, CCD, below which calcium carbonate does not accumulate on the ocean floor, is the level where the rate of solution of calcium carbonate is balanced by the rate of supply. Silica usually becomes a quantitatively important component only in sediments near or below the CCD. The depth of the CCD is known to have varied with time and consequently siliceous accumulation patterns have also varied. Reasons for the movement of the CCD are unknown but two possible mechanisms are:

1. The spread of a particularly successful calcareous planktic organism may suddenly remove large amounts of calcium carbonate from marine waters.

2. Marine transgressions, which increase the volume of shelf-sea carbonates, also subtract calcium carbonate from the oceans.

In both cases the depletion of calcium carbonate could be balanced by a rise in the CCD causing solution of increased amounts of pelagic carbonate (Jenkyns, 1978: p.318).

Radiolarian skeletons accumulate in abundance in equatorial sediments where productivity is high in the water column above. High productivity in equatorial waters is attributed to the divergence of surface waters caused by an asymmetric pattern of surface winds about the geographic equator which create extensive upwelling bringing nutrients to 


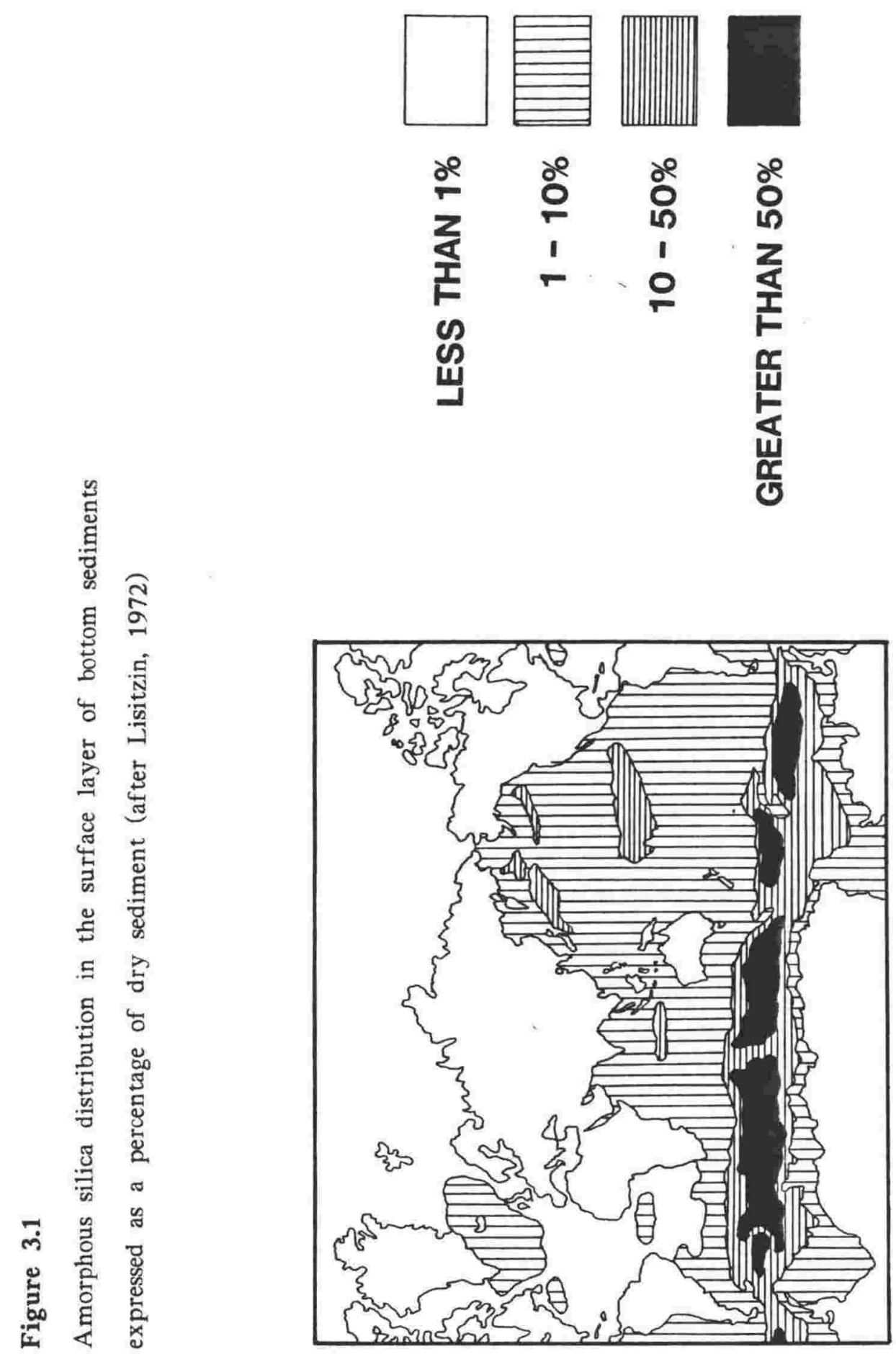


the surface (Kennett, 1982: p.477). Because the productivity of all organisms is high in the equatorial upwelling belt, radiolarians are often masked in the bottom sediments by large quantities of foraminifera and calcareous nannoplankton (Kling, 1978). In equatorial regions the abundance of calcareous material depresses the CCD (Jenkyns, 1978: p.318). Siliceous sediments in equatorial regions occur in areas that are deeper than the CCD (figure 3.1) although Goll and Bjorklund (1974) found that on a calcium carbonate free basis, radiolarians are equally abundant in some calcareous oozes as they are below the lysocline. North and south of the biogenic rich equatorial belt siliceous oozes grade into brown clay (Kennett, 1982: p.478).

The main areas of siliceous deposition are below the high latitude productivity belts. In fact about $75 \%$ of all oceanic silica accumulation occurs beneath the southern belt (Lisitzin, 1972). In these areas radiolarians are normally subordinate to diatoms (Lisitzin, 1971; Lisitzin, 1972; Kling, 1978) which is the reverse of the equatorial relative abundances. The southern belt, which extends completely around the globe, is 900 to $2000 \mathrm{~km}$ wide, its northern boundary being the Antarctic convergence. To the south the siliceous sediments grade into glacio-marine sediments (Kennett, 1982: p.477). The northern high latitude belt is discontinuous and poorly developed (Lisitzin, 1971). Siliceous concentrations are lower in the northern belt than around Antarctica because of a greater terrigenous input (Kennett, 1982: p.476). Siliceous oozes in the high latitudes are produced mainly by high productivity but an added factor is that the CCD is relatively shallow and there is not as much masking of the siliceous component in the sediments by calcareous material. The depth of the CCD ranges from a few hundred metres in the Ross Sea to greater than five kilometres in the equatorial Pacific (Heath, 1974).

In the central parts of the oceans between the northern, equatorial, and southern high productivity belts, the rates of accumulation of the terrigenous sedimentary component are low, depths are generally below the CCD (Kling, 1978), and the water masses are stably stratified and less productive biologically (Riedel and Sanfilippo, 1977; Kling, 1978). Lengthy exposure of siliceous material at the sediment-water interface results in more complete dissolution and barren pelagic brown clays accumulate (Kling, 1978).

Radiolarians are generally rare or absent in continental margin sediments because they are diluted by large influxes of terrigenous material, which may provide a chemical sink for silica (Heath, 1974). For example, on the continental shelf off the western United States, radiolarians can be found in near surface sediments, but not in deeper sediments (Kling, 1978). Hemipelagic sediments, which are a mixture of terrigenous clays and biogenic 
TABLE 3.1

Magnitudes of components of the silica cycle.

Units $10^{13} \mathrm{gram} /$ year.

The number of significant figures results from material balance calculations and not from the real precision of the data.

\section{Input components}

River influx

Deuteric/hydrothermal $0.004-0.540$

Halmyrolysis of basalt

Escape of interstitial silica

Oxidative dissolution

Non-oxidative dissolution

$350-380$

TOTAL INPUT

approx. 2500

\section{Output components}

Biologic fixation

Inorganic absorption

Burial of opaline skeletons

TOTAL OUPUT

approx. 2600

after Heath (1974)

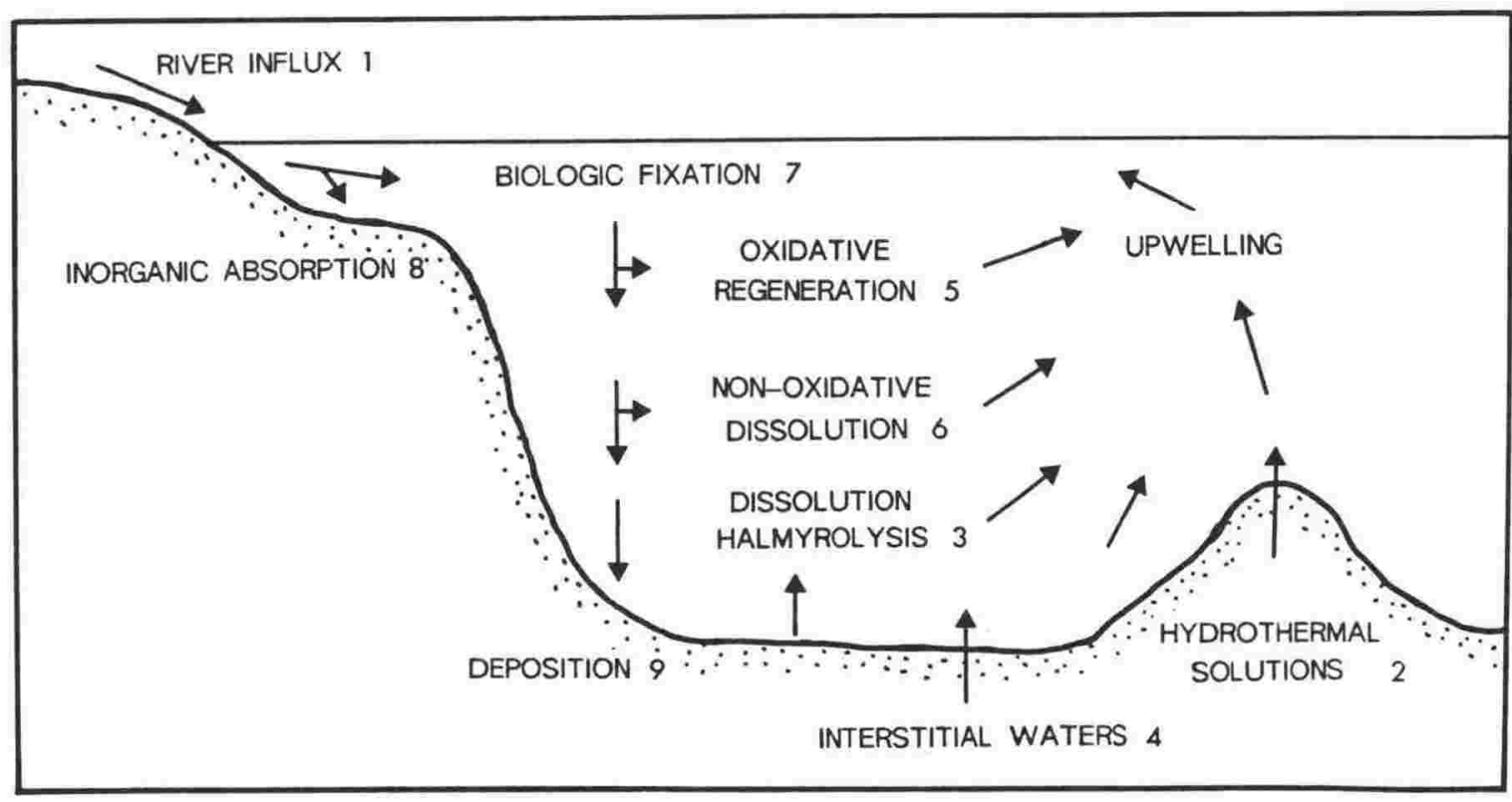

Figure 3.2

Components of the cycle of dissolved silica in the oceans. Numbers refer to text subdivisions of section 3.2 "Silica budget". 
material can provide sites for the preservation of radiolarians on the slope and rise portion of the continental margin. There is also a rapid rise in the CCD towards continents. Since productivity is generally high around continents, because of upwelling and mixing processes delivering nutrients to surface waters, the rise in the CCD must be entirely due to greatly intensified carbonate dissolution, despite the increased burial rates provided by terrigenous material. This increased dissolution is probably due to the development of copius carbon dioxide from a rich supply of organic matter, which is responsible for a considerable lowering of $\mathrm{pH}$. Also the activity of abundant benthic organisms stirs the sediment, preventing the interstitial waters from becoming saturated in calcium carbonate (Berger and Winterer, 1974).

High silica accumulation rates prevail at present in areas on the continental shelf and slope beneath regions of local upwelling, high nutrient input and corresponding high productivity. The Santa Barbara Basin has laminated anaerobic sediments rich in radiolarians and other siliceous microfossils accumulating in water depths of about $500 \mathrm{~m}$ (Kling, 1978). Similar deposits are forming in the Gulf of California (Calvert, 1966) and fiords along the coasts of western North America and Norway (Kling, 1978).

Differences in silica accumulation exist between ocean basins. The Atlantic has an equatorial siliceous belt but the accumulation rate of silica is relatively low compared to the Pacific. Berger (1970) and Berger and Winterer (1974) report that the Atlantic tends to collect "young" surface-type waters which are depleted in nutrients, relatively warm, oxygen-rich and carbon dioxide-poor. It is characterised by carbonate sedimentation and has the deepest CCD. Conversely, the Pacific has a relatively shallow CCD, its deeper water being "old", relatively cold and rich in carbon dioxide. The water mass differences are maintained by fractionation processes resulting from biological activity and from the water exchange pattern between the basins. The Pacific gains deep water from other oceans and loses surface water that has largely been stripped of silica by opal secreting plankton whereas the Altantic loses deep water in exchange for silica poor surface water from other oceans (Heath, 1974).

\subsection{SILICA BUDGET}

The following text is subdivided into sections based on the silica cycle diagrammatically shown in figure 3.2. Heath's (1974) silica budget values are shown in table 3.1. 


\subsubsection{River input}

Silica rich terrestrial rocks are the greatest source of silica. Weathering and erosion of these rocks supplies dissolved silica to rivers and consequently to the oceans (Kennett, 1982: p.478).

\subsubsection{Submarine volcanic sources}

Most submarine volcanic rocks are basic and they have only recently been considered a likely source of much silica. The association of bedded cherts with large masses of volcanic material in the geological record has been taken as evidence of a genetic relationship. Primary quartz is known in sediments from the crest of the East Pacific Rise (Peterson and Goldberg, 1962). Silica could be released in a volatile aqueous fraction left over after crystallisation of the basalt, or could be freed by the deuteric alteration of hot lava by seawater entering fractures resulting from thermal contraction (Heath, 1974). Edmond, Measures, McDuff et al. (1979) calculated that the amount of silica added from submarine sources in the Galapagos area is equal to $50 \%$ of that added by rivers. Mottl (1983), pointed out that Edmond et al. (1979) were dealing with an abnormally fast and hot spreading ridge and the likely input of silica from a normal spreading ridge would be about one sixth of their estimate (i.e. approximately $8 \%$ of river input). Heath (1974) estimated the total submarine volcanic input to be $1 \%$ of the river input.

\subsubsection{Low temperature reactions at the sea floor}

Heath (1974) divides this input into three main classes:

(i) Dissolution of opaline tests

At present, dissolution of opaline tests at the sea floor cannot be distinguished from non-oxidative dissolution within the water column (Heath, 1974) and in this discussion the two are treated together in section 3.2.6.

(ii) Low temperature alteration (halmyrolysis) of oceanic basalt.

Heath (1974) calculates an input rate $20 \%$ that of the river influx based on data of silica loss by Hart (1970) assuming that the low temperature alteration of oceanic tholeiitic basalts proceeds to a depth of only $100 \mathrm{~m}$ and supplies silica to the ocean only in areas of thin or no sediment cover.

(iii) Halmyrolysis of detrital silicate phases

This does not appear to be a major source of silica. Keller et al. (1963) crushed a 
number of common silicate minerals and determined the concentration of silica after equilibrium at $20^{\circ} \mathrm{C}$. If temperatures are reduced to $2{ }^{\circ} \mathrm{C}$ (temperature of bottom waters) it appears that only the pyroxenes among the common detrital minerals could provide much soluble silica (Heath, 1974). The persistence of pyroxenes in Tertiary deep-sea cores (Heath, 1969) suggests little alteration.

\subsubsection{Release of interstitial waters}

Most marine interstitial waters are richer in silica than overlying sea water. The concentration gradient across the sediment water interface must cause upward diffusion of dissolved silica. There must also be physical expulsion of interstitial water during compaction. Heath (1974) calculated a figure approximately twice as much as river input.

\subsubsection{Oxidative dissolution}

Most opaline skeletons are fragile and dissolve once their protective organic coating disappears. The process is referred to as oxidative dissolution because it seems to be controlled primarily by the oxidation of the protoplasm. Heath (1974) derived a value for oxidative dissolution by assuming a steady state with silica deposition rates balancing the amount of new silica entering the oceans. Although this steady state is believed to be the case for modern and late Quaternary oceans (Kennett, 1982: p.475) the depositional rate of silica (see section 3.2.9) is still poorly known and Heath's oxidative dissolution value is not reliable.

\subsubsection{Non-oxidative dissolution}

The silica content of deep ocean waters rises steadily with time as long as the waters remain below the biological uptake zone which approximates to the photic zone (Heath, 1974). The source of this silica is largely from dissolving opaline skeletons falling through the water column and resting on the sea floor. All deep ocean water is undersaturated relative to opal, and the dissolution must be rate limited rather than governed by chemical equilibrium. Two key factors in dissolution are the surface area of the solid phase and the movement of the water, which is required to maintain the maximum concentration gradient against the silica particles (Heath, 1974). The calculated rate of input from non-oxidative dissolution is one order of magnitude greater than river input. It was determined by subtracting volcanic input, interstitial water input and halmyrolytic input from Berger's (1970) value for the non-oxidative silica content of the deep ocean which in turn, was determined using phosphate-silica plots (Heath, 1974). 


\subsubsection{Biological fixation}

Most of the biological fixation of silica takes place in the photic zone. Diatoms probably extract an order of magnitude more silica than radiolarians (Heath, 1974). The rate of biological fixation of silica is calculated from the known uptake of carbon in the worlds oceans and the known silica to organic carbon ratio in diatoms (2.3/1). The assumptions are that this ratio relects the relative rates of fixation of the two components and that diatom productivity is 50 to $70 \%$ of the total primary productivity. It is calculated to be 40 to 75 times the annual river input (Heath, 1974).

\subsubsection{Inorganic absorption}

Bien et al. (1959) showed that part of the dissolved silica load of the Mississippi is lost by reaction with particulate matter as the river enters the Gulf of Mexico but did not quantitatively assess the effects of biogenic uptake on the system. Liss and Spencer (1970) reported a 10-20\% abiotic loss of dissolved silica from the River Conway in Wales but Maeda (1952), Kobayashi (1967) and Fanning and Pilson (1973) show no or little abiotic loss. Heath (1974) used a value for inorganic absorption of silica of about $10 \%$ of the annual river input.

\subsubsection{Deposition}

Knowledge of depositional rates of biogenic opal in the deep ocean is still poor but is improving with increased paleomagnetic and biostratigraphic resolution. The lack of accurate opal determinations in dated cores makes global depositional rates hard to determine. Heath (1974) calculated a value based on the assumption of a steady state in the silica cycle.

\subsection{SILICA DISSOLUTION IN THE WATER COLUMN}

There is no critical depth like the CCD for silica dissolution (Lisitzin, 1972). All ocean water is undersaturated in silica (Heath, 1974; Goll and Merinfeld, 1979). It is less undersaturated in bottom waters. All exposed polycystine skeletons are subject to dissolution. The degree of undersaturation varies from essentially $100 \%$ in warm surface water because of biologic depletion to $85 \%$ in Antactic bottom waters. Amorphous silica dissolves in either fresh or marine water to the extent of 100 to $140 \mathrm{ppm}$ at ordinary temperatures. This is a true solution, not colloidal dispersion, most or all of the silica being in the form of monosilicic acid (Krauskopf, 1959).

The main factors affecting silica dissolution are:

temperature: solubility increases with temperature (Krauskopf, 1959; Hurd, 1972; Heath, 1974), 


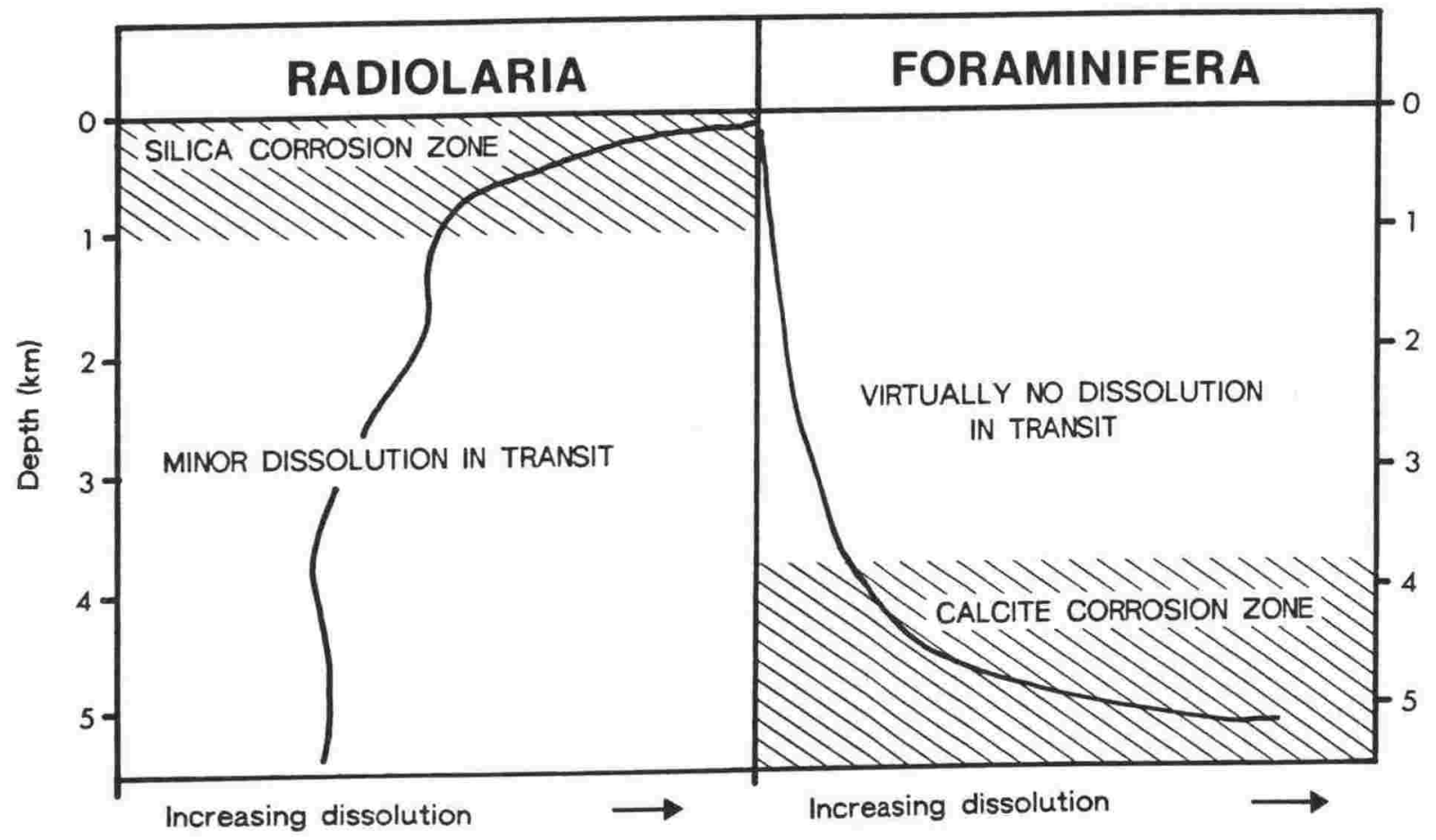

Figure 3.3

Comparison of dissolution profiles of radiolaria and planktic foraminifera based on field experiments. Most dissolution of radiolaria (and diatoms) occurs in shallow waters. In contrast, most dissolution of carbonate microfossils occurs on the sea floor at depths greater than $3.5 \mathrm{~km}$ (Berger, 1976). 
pressure: solubility increases slightly with pressure (Heath, 1974),

degree of saturation: (Hurd, 1972),

surface area of the solid phase: (Hurd, 1972; Heath, 1974), and

agitation of the water: necessary to maintain maximum concentration gradients against silica particles (Heath, 1974).

The $\mathrm{pH}$ of the water, which is controlled by the carbon dioxide - carbonate system (Pytkowicz, 1967) has little affect on silica solubility in the range 0 - 9 but causes it to increase abruptly at higher values because of the ionization of monosilicic acid (Krauskopf, 1959).

The presence of metal coatings on diatom frustules is known to retard dissolution (Lewin, 1961) and electron microprobe analyses of radiolarian skeletons indicate $\mathrm{Mg}, \mathrm{Ca}, \mathrm{Na}$, and $\mathrm{Al}$ as minor elements present in concentrations up to $4 \%$ by weight (Stanley, 1973). Different uptake of these elements might cause different dissolution rates from one species to another.

Variations in internal ordering and specific surface area of different forms of opaline silica cause varing solubilities (Hurd and Theyer, 1975) but silica gel (which biogenic silica resembles the most) and vitreous silica both have similar solubilities which are an order of magnitude greater than that of quartz.

Silica dissolution is usually greatest near the surface and decreases with depth (figure 3.3) in accordance with the normal bathymetric distributions of dissolved silica and temperature (Berger, 1976). Most of the siliceous skeletons dissolve rapidly in the water column and at the sea floor and only about 4\% survive long enough to be buried (Heath, 1974). The bulk are returned to the water column as dissolved monosilicic acid in the upper $1000 \mathrm{~m}$ (Kennett, 1982: p.480). Particles with high specific surface area such as diatom frustules, are preferentially dissolved and the survival rate for radiolarians is relatively high (Lisitzin, 1971).

\subsection{FAECAL PELLET DEPOSITION}

Faecal pellets produced by invertebrate plankton are important in preventing dissolution before deposition of very small skeletal remains such as coccoliths and most diatom frustules (Kennett, 1982: p.483), but are thought to be unimportant for radiolarian skeletons. Settling velocity is determined mainly by particle mass, size and shape and to a minor extent by water density (Lisitzin, 1972). The average-sized coccolith would take about 100 years to fall from the photic zone to the deep sea floor (Kennett, 1982: p.483), whereas 
copepod faecal pellets take only a few days or a few weeks (Smayda, 1971), and consequently the time available for solution of contained skeletons is two to three orders of magnitude shorter. Settling tube experiments (after Casey, Spaw, Kunze et al., 1979) have shown that radiolarian skeletons have settling velocities similar to those of copepod faecal pellets.

The protection against dissolution given by the organic binding material of faecal pellets is uncertain. In the case of radiolarian skeletons it would probably be counterbalanced in part or entirely by fragmentation, and consequent increase in specific surface area, in the gut of the feeding invertebrate.

\subsection{SILICA DISSOLUTION IN SEDIMENTS}

A decrease in the number of empty skeletons with increasing depth in the water column indicates most dissolve before reaching the ocean floor (McMillen and Casey, 1978). However, dissolution does not stop below the sediment-water interface.

Dissolved silica concentrations in interstitial waters range from 3 to $81 \mathrm{ppm}$, the larger values usually occurring in diatomaceous oozes, and being close to equilibrium solubility levels at $2-3^{\circ} \mathrm{C}$ (Calvert, 1968). Siliceous remains may be preserved in sediments in which most of the pore water is undersaturated either by sea floor mechanical processes or as a result of localised extra dissolved silica from, for example, the devitrification of a rhyolitic tuff. The biogenic opal solution rate in near surface sediments of the central Equatorial Pacific is 3 to 8 orders of magnitude slower than in the water column (Hurd, 1973). Other important factors in dissolution within the sediments are the sedimentation rate and the degree of disturbance by infauna (Hurd, 1972). Burrowing can maintain high concentration gradients between siliceous particles and the interstitial waters but siliceous particles may also be concentrated in burrows.

Areas of high biological productivity also supply much organic matter to the sediments which can result in a pore-water chemistry that favours the preservation of biogenic silica (Kennett, 1982: p.475). Although carbonaceous fragments are common in New Zealand Upper Neogene sediments no sapropels have been detected by the writer.

Diffusive, not advective, processes are chiefly responsible for the removal of dissolved silica in sediments (Hurd, 1973) but Johnson (1976), in his study of cores in a small area of the eastern Tropical Pacific, found a down-core increase in clay (smectite) aggregates corresponding with a down-core decrease in radiolarian skeletons. Some of these clay aggregates are reported to be radiolarian casts. The transformation of less stable biogenic 
silica into more stable smectitic lattices is probably important in the dissolution of siliceous skeletons at depth, e.g. $50 \mathrm{~cm}$ in the sediment, where a strong concentration gradient with the bottom water and intense bioturbation is lacking. Only about $4 \%$ of biogenic opal particles survive water column transit and after dissolution within the sediment only $0.3 \%$ are preserved (Heath, 1974).

\subsection{MECHANICAL PROCESSES AFFECTING SILICA PRESERVATION}

In addition to gravity settling, bottom currents and bioturbation affect the preservation of radiolarian skeletons.

\subsubsection{Bottom currents}

Density driven bottom currents reflect the net northward movement of Antarctic bottom water in most of the abyssal parts of the oceans. Even at the relatively slow speeds of two to five $\mathrm{cm} / \mathrm{sec}$ (Siebold, 1978) these currents can have an effect on radiolarian preservation. Huang and Watkins (1977) determined the grain size distribution of deep-sea bottom sediments and concluded that those sediments with skewness values more positive than -0.2 indicate high bottom current influence and those more negative than -0.2 indicate dominant pelagic settling. As an example of New Zealand upper Neogene sediments, samples from the Mangapoike River section are in all cases more positively skewed than -0.2 (I.C. Wright, pers. comm.) but were deposited on the outer continental shelf and slope. They have had coarse components filtered out in estuaries and on the inner shelf and are positively skewed when supplied to the pelagic environment. The relative influence of high bottom currents and pelagic sedimentation can not be determined without additional data.

Shelf and upper slope sedimentation is well above the influence of bottom water currents, but can be influenced strongly by contour currents, up to $55 \mathrm{~cm} / \mathrm{sec}$ (Rupke, 1978: p.389), and tidal currents of even greater velocity.

Johnson (1976) showed that the resuspension and/or hydraulic sorting of skeletons by ocean currents can cause preferential deposition of radiolarian skeletons in topographic depressions, even where the bottom currents are quite slow, therefore increasing the net biogenic silica input into depressions relative to "highs" on the ocean floor. Benthic organisms may stir sediment particles back into suspension to be transported by weak bottom currents (Seibold, 1978). In areas of low depositional rates, bottom currents must have a greater effect because sediment is exposed to them for relatively long periods. 


\section{Plate C3.1}

Centimetre-scale bioturbation in a Lower Tongaporutuan tuff exposed at Gable End Foreland, $28 \mathrm{kms}$ north of Gisborne (photo: Greg Gosson).

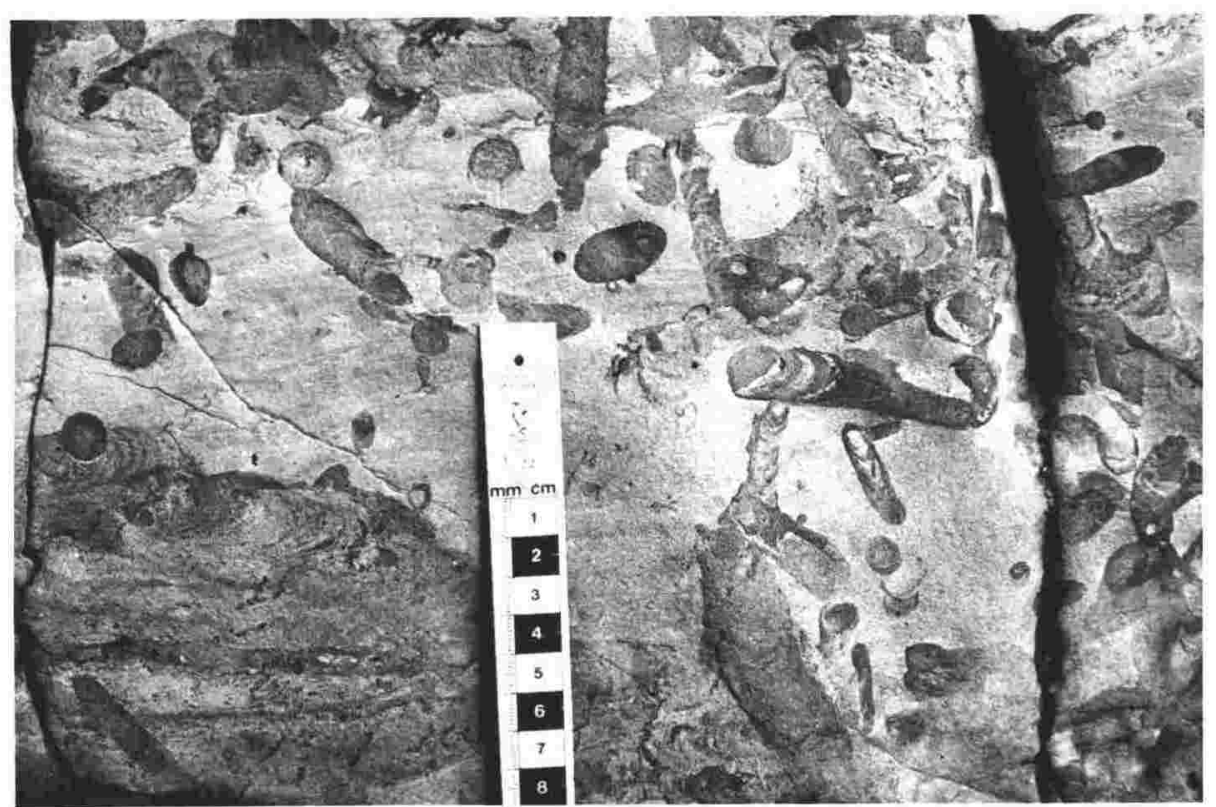




\subsubsection{Bioturbation}

Various estimates have been made of the depth below the sediment-water interface, to which bioturbation has an effect on sediment.

(a) Ruddiman and Glover (1972): Based on the dispersion of ice-rafted debris from known Icelandic and Jan Meyen volcanic episodes in North Atlantic deep sea cores, 17 to $66 \mathrm{~cm}$.

(b) Arrhenius (1963): Up to $30 \mathrm{~cm}$ based on mixing across unconformities. The mean mixing depth, i.e. the depth above which $50 \%$ of the extraneous material is located is about $5 \mathrm{~cm}$.

(c) Noshkin and Bowen (1973): Up to $12 \mathrm{~cm}$ of mixing in the last ten years based on plutonium (fallout from the previous ten years) dispersion in six Mediterranean and Atlantic cores.

(d) Glass (1969): Based on the microtextite dispersion in deep-sea cores from the Atlantic and Indian Oceans and the Caribbean Sea, up to $90 \mathrm{~cm}$ of a geologically mixed zone with mixing occurring up to $40 \mathrm{~cm}$ below the surface.

The most important factors influencing the magnitude of the bioturbation effect are assumed to be the type and number of the burrowing organisms, the sediment type, and the depositional rate. Many of the samples studied for this thesis showed signs of bioturbation, usually mm-scale mottles on freshly broken surfaces of the mudstone. Some tuffaceous horizons show intense burrowing by larger organisms ( $\mathrm{cm}$ scale) which are occasionally detectable in the encompassing mudstone (see plate C3.1).

With depositional rates of, for example, approximately $55 \mathrm{~cm} / \mathrm{kyr}$ in the Mangapoike section (I.C. Wright, pers. comm.), the effect of the mixed zone is insignificant with respect to the stratigraphic sampling interval and the faunal events discussed.

Burrowing organisms can concentrate siliceous skeletons in their burrows thereby enhancing biogenic silica preservation by locally increasing the amount of silica per gram of sediment.

\subsection{SELECTIVE SPECIES DISSOLUTION}

As expected, the most fragile, thinly silicified radiolarians tend to disappear entirely during settling and many bottom sediment assemblages are impoverished relicts of the original surface water assemblages (Kennett, 1982: p.480). Petrushevskaya (1971a, 1971b) divided 
radiolarians into three groups:

(a) thin walled, delicate skeletons which are more abandunt in plankton than sediments,

(b) sturdier skeletons which are normally well preserved, and

(c) sturdiest, most solution resistant which are less abundant in plankton than sediments.

Group (b) specimens are the most reliable indicators in the sediments of the ecologic conditions in the water above. Berger (1968) outlined the results of an experiment where radiolarian skeletons were placed at several depths on the taut mooring wire of a buoy in the central Pacific for four months. He found that the Acantharia dissolved completely at all depths, the tripyleans seemed less resistant than polycystines, and that recent radiolarian sediments dissolved at appreciable rates at depths less than $2000 \mathrm{~m}$. Johnson (1974) carried out a quantitative study of the dissolution of different radiolarian species and diatoms. On a scale of 0 (least resistant) to 70 (most resistant), the small diatoms ranged from 0 to 7 , radiolarians from 5 to 70, and sponge spicules 58. Moore (1969) also quantitatively studied species dissolution rates by dissolving faunas of different geological ages in a standard $2 \mathrm{~N}$ solution of sodium hydroxide. Dissolution variations between species is similar to that described for planktic foraminifera (Hecht, Eslinger and Garmon, 1975; Yamashiro, 1975) in that those that fall faster are heavier and thicker and more resistant to solution.

\subsection{SILICA DIAGENESIS}

In the marine environment the initial silica phase is mostly biogenic opal-A (Kastner and Gieskes, 1983). This transforms to metastable opal-CT by a solution precipitation mechanism where a magnesium hydroxide compound serves as a nucleus for opal-CT crystallisation (Kastner and Gieskes, 1983). The opal-CT is commonly massive but may occur as lepispheres ( 3 to $4 \mu$ ) in cavities (Kastner and Gieskes, 1983). Opal-CT orders to cristobalite during burial diagenesis. The two forms co-xist in the Neogene Monterey Shale of California (Murata and Larson, 1975; Oehler, 1975). Cristobalite will eventually recrystallise to quartzose chert (Tada and lijima, 1983).

Under early diagenetic conditions, in the relatively cold pelagic environment, the reaction from opal-A to opal-CT is very slow and most probably quantitatively insignificant within a period of a few thousand years but will be significant in less than one million years (Kastner and Gieskes, 1983). With burial, the rate of reaction will increase. The hard "silicified" nature of some of the New Zealand Upper Neogene mudstones and tuffs is presumably due to the partial crystallisation of cristobalite from the original biogenic and volcanic opal-A. 
TABLE 3.2

Averages of various components (coarser than 54 microns) in the sediment surrouding the tuff in the Palliser Bay Section

expressed in number per gram of sediment

The "above tuff" averages are divided into two sets. One set is calculated using all the "above tuff" samples and the other set deleting the first three samples immediately above the tuff where the glass shard numbers are very high and the counting accuracy of the other components was not good.

\begin{tabular}{lrcc} 
& BELOW TUFF & \multicolumn{2}{c}{ ABOVE TUFF } \\
& $\mathrm{n}=10$ & $\begin{array}{c}\text { all samples } \\
\mathrm{n}=9\end{array}$ & $\begin{array}{c}\text { upper samples } \\
\mathrm{n}=6\end{array}$ \\
Benthic foraminifera & 610 & 1048 & 1063 \\
Planktic foraminifera & 83 & 244 & 237 \\
Sponge spicules & 291 & 263 & 245 \\
Radiolaria & 763 & 835 & 968 \\
Glass shards & 627 & 6036 & 855
\end{tabular}

Raw data is presented in Appendix F.

Plate C3.2

Tuff exposed in the coastal cliffs in the Palliser Bay Section (grid. ref. S28/94317357). Note that samples taken up to $80 \mathrm{~cm}$ above the top of the tuff contain over $50 \%$ glass shards in the residue coarser than 54 microns. The pick head is $30 \mathrm{~cm}$ in length.

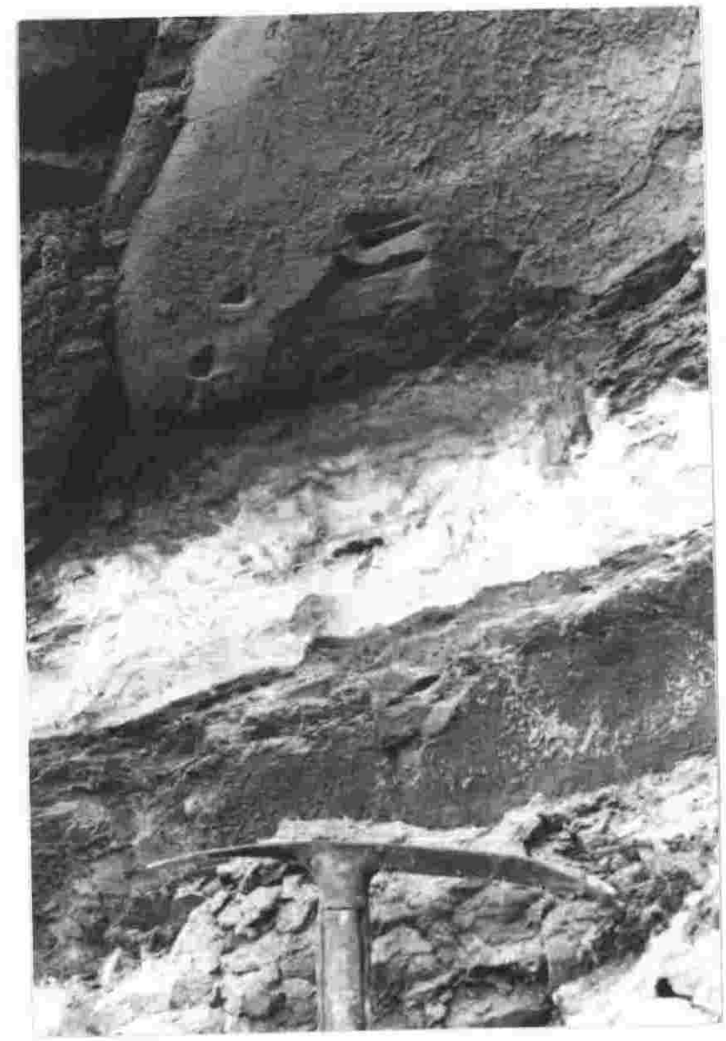




\subsection{VOLCANIC ASSOCIATION}

The input of silica from volcanic sources has been cited as an important factor in the production of siliceous organisms which subsequently contribute their remains to sediments (e.g. Taliaferro, 1933; Bramlette, 1946).

Garrison (1974) commented that the precise field relationships between eugeosynclinal bedded cherts and spatially associated igneous rocks are usually unclear. Tectonic shearing tends to be concentrated along contacts between massive igneous rocks and thinly bedded cherts thereby obliterating primary relationships, but most detailed descriptions of unsheared contacts indicate that cherts rest depositionally upon submarine extrusive rocks. Clearly some genetic relationship exists but the lack of any significant petrological differences between cherts occurring in ophiolite sequences and those in non-volcanic sections suggest that the cherts associated with volcanic rocks are not formed from local inorganic precipitation of silica.

Enrichments of dissolved silica, thermal upwelling and associated plankton blooms in the vicinity of active volcanoes have been reported but are of limited spatial and temporal extent (Kling, 1978). Volcanism may contribute to skeletal preservation by addition of silica to the interstitial environment either by direct fluid emanations or the alteration of volcanic glass (Kling, 1978).

Considering the siliceous organism's ability to develop in waters of extremely low dissolved silica concentrations, the preservation factor is probably the major influence. Volcanic ash layers create local conditions favourable to radiolarian preservation by increasing the sedimentation rate in deep-sea areas and more importantly by increasing the concentration of dissolved silica in the interstitial waters (Riedel and Sanfilippo, 1977). Free silica is derived from the devitrification of tuffaceous volcanic material (Wise, Weaver and Guven, 1973) and has been the most important factor in preservation of radiolarian skeletons in New Zealand Upper Neogene sediments. In the deep-water mudstone of the Palliser Bay section, radiolarian skeletons are present only in samples containing glass shards. The same radiolarian/glass shard correlation is true for most of the deep-water mudstone sections and samples examined by the writer.

Exceptions to this rule, are samples from the Upper Miocene Ruamahanga section which have well preserved, high diversity radiolarian assemblages but no glass shards. It is passible that these samples were deposited beneath an area of local upwelling where productivity was more important than the input of glass in preserving the skeletons. 


\section{PALISER BAY TUFF}

Frequency percent of glass shards in the residue vs. stratigraphic distance from base of tuff

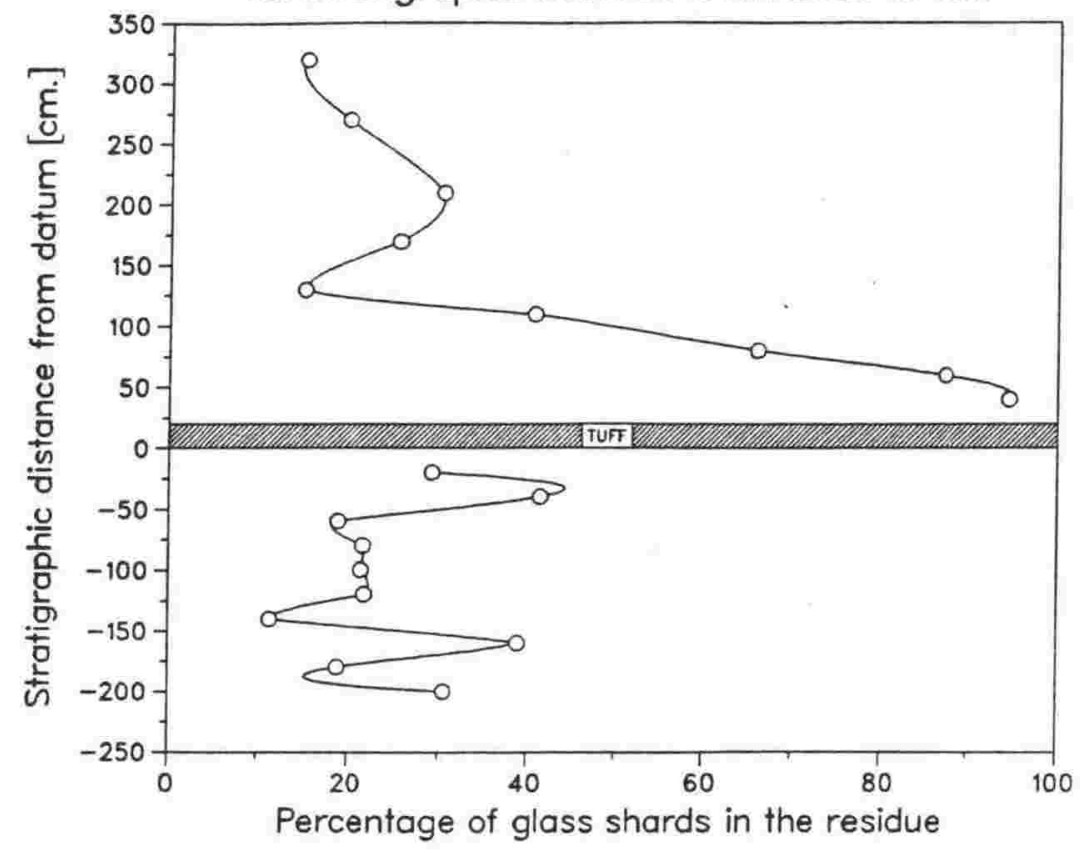

Figure 3.5

PALLISER BAY TUFF

Number of radiolarians per gram of sediment vs. stratigraphic distance from base of tuff.

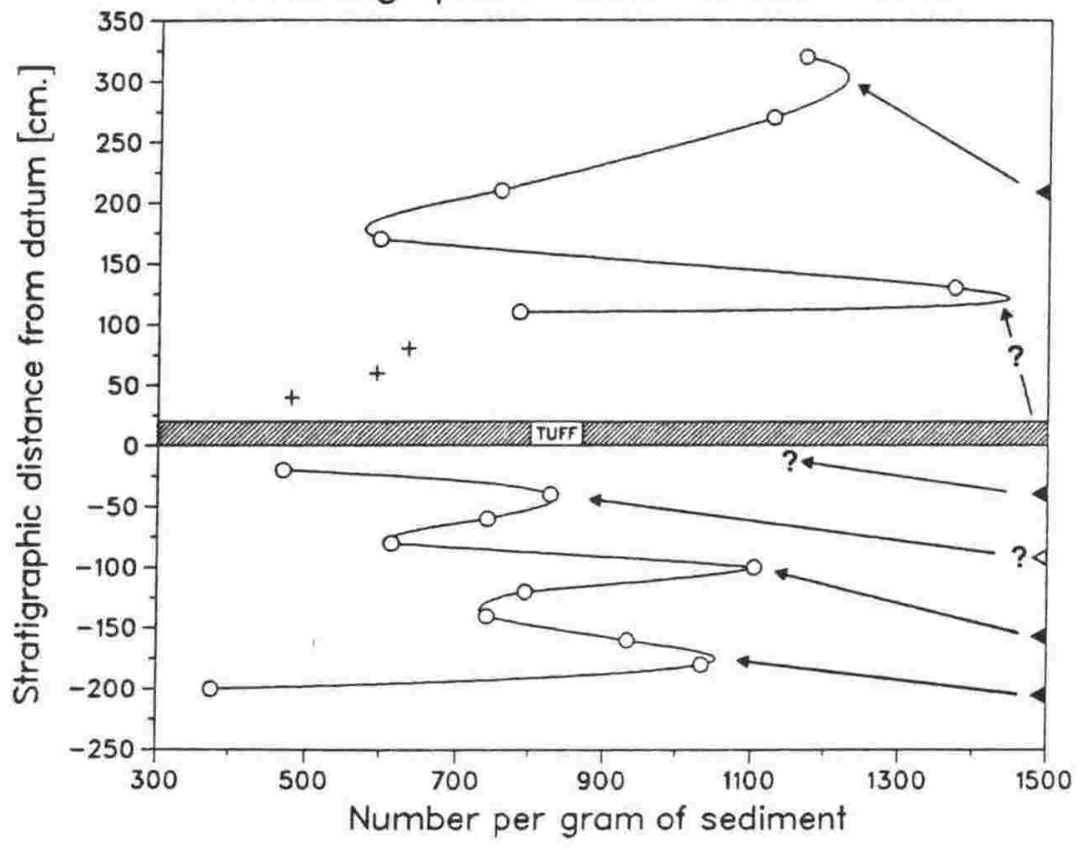

The samples marked by crosses are those with high biogenic counting errors due to large numbers of glass shards in the residue. The arrows define the correspondence between glass shard "highs" (see figure 3.4 ) and peaks in radiolarian numbers above. 
Microfossil abundances determined in a closely sampled section through sediments enclosing a tuff in the Palliser Bay section (plate C3.2) are presented in table 3.2. Nine samples above and ten samples below the tuff were collected at about $20-30 \mathrm{~cm}$ intervals and numbers for the five major components of the fraction coarser than $54 \mu$ determined. The raw counts on the planktic and benthic foraminifera, sponge spicules, radiolarian skeletons and glass shards are presented in Appendix E.5. The three samples immediately above the tuff have large errors on the biogenic component counts and have been disregarded in the calculation of one set of average numbers above the tuff. Their residues contained a large proportion of glass shards and it was impractical to count sufficent numbers of grains to make reliable estimates of the biogenic component.

Overall, the biogenic silica component in the sediment is hardly affected by the incoming of the volcanic ash, and radiolarian numbers are generally good in all the samples because the rhyolitic glass shard component is relatively high.

Figures 3.4 and 3.5 show the variation in glass shard percentage and radiolarian numbers stratigraphically away from the tuff. The peaks in radiolarian abundance are generally displaced from the glass shard "highs". The devitrification of glass shards is known to release free silica into interstitial waters (Wise, Weaver and Guven, 1973). The devitrification takes place after hydration of the glass during early stage of diagenesis (Barker, 1983: p.110). The glass shard "highs" would, therefore, be buried by the time free silica is released. The depth of burial would depend on the depositional rate and time elapsed. The dissolved silica released would tend to move upwards in the sediment due to the presence of a dissolved silica concentration gradient between sediments and the water column and also the upward physical expulsion of interstitial waters due to compaction. Any effect of relatively high dissolved silica values would tend to be displaced upwards as supported by the presence of radiolarian peaks above each glass shard "high". Sampling in other sections is needed to confirm it as a general process. Furthermore, the chemistry of the interstitial waters, is more likely to be controlled by the finer particles which will have higher specific surface areas than the $>54 \mu$ particles examined. The $<54 \mu$ fraction constitutes about $98 \%$ of the sediment in the samples studied from this section.

As a general rule samples were collected near tuffs to increase the chance of radiolarian preservation and if possible at least one metre above thicker tuffs to avoid the masking effects of large numbers of glass shards in the residues. 


\section{TABLE 4.1}

Variations in radiolarian taxonomy

Haeckel $(1883,1887)$

Campbell (1954)

Dreyer (1913)

Deflandre (1952)

Cachon-En jumet (1961)

Riedel (1967a)

RADIOLARIA
$\frac{\text { Porulosida }}{\text { Acantharia Spumellaria }}$

RADIOLARIA

\begin{tabular}{lll}
\hline Acantharia & Polycystina & Phaeodaria \\
\cline { 2 - 3 } & Spumellaria Nassellaria &
\end{tabular}

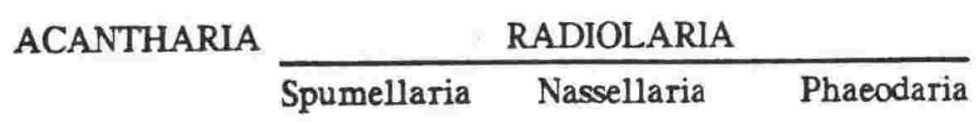

ACANTHARIA $\frac{\text { RADIOLARIA }}{\text { Spumellaria Nassellaria }}$ PHAEODARIA

ACANTHARIA RADIOLARIA

(implied)

$\begin{array}{cc}\text { Polycystina } & \text { Phaeodaria } \\ \text { Spumellaria Nassellaria } & \end{array}$

after Goll and Merinfeld (1979) 


\section{Chapter IV}

\section{TAXONOMY}

\subsection{INTRODUCTION}

The name Radiolaria was first proposed by Muller (1858) for marine Sarcodina with radial symmetry, this configuration being used to distinguish them from the foraminifera. Haeckel (1862) emended the definition to include organisms containing a central capsular membrane because many organisms included in the group do not possess radial symmetry.

The most important, comprehensive, taxonomic monograph on radiolarians is the $H M S$ Challenger Report of Haeckel (1887). The taxonomic system outlined has provided the framework within which most radiolarian assemblages have since been described, despite the fact that it has long been recognised as not adequately reflecting true relationships (Riedel and Sanfilippo, 1977). Campbell (1954) re-examined the entire Haeckelian classification in order to accommodate later work and to conform to the Code of Zoological Nomenclature. Although his Treatise conveniently summarises the Haeckelian system it is flawed by innumerable errors (Riedel and Sanfilippo, 1977; Goll and Merinfeld, 1979). The main variations in radiolarian taxonomy are summarised in Table 4.1.

The taxonomic subdivision within the morphologically distinct Spumellaria and Nassellaria is still in a state of confusion. Taxonomists have attempted, since Haeckel's time, to erect classifications for the Polycystina. In recent years changes in the system have been proposed on the basis of two types of study : comparative morphology and phylogeny. Comparative morphology studies involve a re-evaluation of the significance of certain elements of skeletal structure, without regard to geologic time (Riedel and Sanfilippo, 1977) and have resulted in revisions of the classification at the family and generic levels : e.g. genera of the Orosphaeridae (Friend and Riedel, 1967) and families, subfamilies, and genera of the Nassellaria (Petrushevskaya and Kozlova, 1972: p.530) Phylogenetic studies are more firmly substantiated at the generic and species level and have become more common since deep-sea cores have been available for study. Taxonomic revisions are best based on the phylogenetic studies rather than the comparative morphologic studies because of the lack of supporting stratigraphic evidence for the latter (Riedel and Sanfilippo, 1977).

Classifications based on comparative cytoplasmic studies may foreshadow major revisions 
in polycystine taxonomy and are strongly at variance with classifications based exclusively on skeletal morphology (Hollande and Enjumet, 1960). These schemes are difficult to apply because they require cytological examination of thin-sections and the number of species analysed is too small to validate the proposed classification (Goll and Merinfeld, 1979).

The first major reassessment of polycystine taxonomy is that of Riedel (1967a, 1971) and that classification and subsequent emendations (e.g. Actinommidae and Coccodiscidae by Sanfilippo and Riedel (1980) and Artostrobiidae by Foreman (1973)) is followed wherever possible in the following account.

\subsection{SYSTEMATIC SECTION FORMAT}

For each of the species included in the systematic section the following information is given where possible:

Name, author, and figure identification.

Synonomies of the taxa identified are not complete and are restricted to the original description, any revised concept of the species, plus easily accessible, important, modern references.

\section{Description.}

Dimensions are all in microns unless otherwise stated. If a reasonable number of well preserved specimens were available for study the dimensions were measured and are presented. If, however, the species are represented by either low numbers or are poorly preserved, previously reported dimensions are presented and referenced. Any variation in dimensions between specimens from this study and those previously reported are noted.

Remarks include notes on distinguishing characteristics and taxonomic placement.

Recorded range presents important previously reported range or time occurrence data. Ages quoted as Theyer et al. (1978) have been adjusted by Nigrini and Lombari (1984) to conform to the time scale published by Ness et al. (1980).

Observed range was determined from this study. Presence or absence data is presented in Appendix D.

Geographic distribution for species is presented and referenced. 
The format for the plate captions is species name : magnification : sample number : reference number.

In the case of the SEM photos the reference number corresponds to the stub number (e.g. AA4) and the line number on the stub in which the specimen is located (e.g. 6). The stub number and line number are separated by a "/". With the transmitted light photos the reference number is an England Finder coordinate for the specimen on the transmitted light slide. In some cases the transmitted light sample number is followed by a "d" (e.g. HR04d) and this indicates that the specimen is on the duplicate slide for that particular sample. Also, some transmitted light photos have "RIO" as their reference number and this indicates the specimen was photographed whilst immersed in refractive index oils prior to mounting on a stub. 


\subsection{CHECKLIST OF SPECIES}

Suborder SPUMELLARIA Ehrenberg 1875

Family OROSPHAERIDAE Haeckel 1887

Genus Oropelex Friend and Riedel 1967

? Oropelex sp.

Family COLLOSPHAERIDAE Muller 1858

Genus Collosphaera Muller 1855

Collosphaera cf. polygona Haeckel

Collosphaera sp. aff. huxleyi Muller

Collosphaera sp. A

Genus Acrosphaera Haeckel 1881

Acrosphaera spinosa echinoides (Haeckel)

Acrosphaera spinosa spinosa (Haeckel)

Genus Siphonosphaera Muller 1858

Siphonosphaera polysiphonia Haeckel

Genus Otosphaera Haeckel 1887

Otosphaera polymorpha Haeckel

Family ACTINOMMIDAE Haeckel 1862

emended Sanfilippo and Riedel 1980

Genus Actinomma Haeckel 1860a

Actinomma antarcticum (Haeckel)

Actinomma leptodermum (Jorgensen)

Actinomma polycanthum (Muller) group

Genus Cladococcus Muller 1857

Cladococcus dentata (Mast)

Cladococcus stalactites Haeckel

Genus Cenosphaera Ehrenberg 1854b

Cenosphaera cristata Haeckel

Cenosphaera spp.

Genus Acanthosphaera Ehrenberg 1858

Acanthosphaera dodecastyla Mast

Acanthosphaera sp. A

Acanthosphaera sp. B

Genus Hexacontium Haeckel 1881

Hexacontium enthacanthum Jorgensen

Hexacontium laevigatum Haeckel

Genus Thecosphaera Haeckel 1881

Thecosphaera cf. akitaensis Nakaseko

Thecosphaera grecoi Vinassa de Regny group 
Genus Prunulum Haeckel 1887

Prunulum spp.

Genus Styptosphaera Haeckel 1881

Styptosphaera stupacea Haeckel

Styptosphaera spumacea Haeckel

Genus Stylatractus Haeckel 1887

"Stylatractus" neptunus Haeckel forma large pores

"Stylatractus" universus Hays

Genus Sphaerostylus Haeckel 1881

"Sphaerostylus" sp. aff. timmsi (Campbell and Clark)

Genus Xiphatractus Haeckel 1887

"Xiphatractus" sp. A

Genus Prunopyle Dreyer 1889

? Prunopyle antarctica Dreyer

Prunopyle sp. A

Genus Spongurus Haeckel $1860 \mathrm{~b}$

Spongurus pylomaticus Riedel

Spongurus sp. A

Genus Spongocore Haeckel 1887

Spongocore puella Haeckel

Spongocore sp. A

Family PHACODISCIDAE Haeckel 1881

Genus Heliodiscus Haeckel 1882

Heliodiscus asteriscus Haeckel

Heliodiscus umbonatum (Ehrenberg)

Family COCCODISCIDAE Haeckel 1862 emended Sanfilippo and Riedel 1980

Genus Didymocyrtis Haeckel 1860 a

Didymocyrtis antepenultima (Riedel and Sanfilippo)

Didymocyrtis laticonus (Riedel)

Didymocyrtis virgineum (Haeckel)

Didymocyrtis sp. A

Didymocyrtis tetrathalmus tetrathalmus (Haeckel)

Genus Diartus Sanfilippo and Riedel 1980

Diartus hughesi (Campbell and Clark) group 
Family SPONGODISCIDAE Haeckel 1862 emended Riedel 1967a

Genus Amphirhopalum Haeckel 1881

Amphirhopalum cf. ypsilon Haeckel

Genus Dictyocoryne Ehrenberg 1860

Dictyocoryne profunda Ehrenberg

Genus Hymeniastrum Ehrenberg 1847b

Hymeniastrum euclidis Haeckel

Genus Spongaster Ehrenberg 1860

Spongaster pentas Riedel and Sanfilippo

Genus Stylodictya Ehrenberg 1847

Stylodictya validispina Jorgensen

Stylodictya cornuspira Campbell and Clark

Genus Porodiscus Haeckel 1881

Porodiscus sp. A

Porodiscus sp. B

Genus Stylochlamydium Haeckel 1881

Stylochlamydium asteriscus Haeckel

Genus Spongotrochus Haeckel $1860 \mathrm{~b}$

Spongotrochus glacialis Popofsky

Family PYLONIIDAE Haeckel 1881

Genus Hexapyle Haeckel 1881

Hexapyle cf. dodecantha Haeckel

Genus Tetrapyle Muller 1858a

Tetrapyle octacantha Muller group

Family LARNACIDAE Haeckel 1887

Genus Larnacilla Haeckel 1887

Larnacilla typus Haeckel

Family THOLONIIDAE Haeckel 1887

Genus Cubotholus Haeckel 1887

Cubotholus rhombicus Haeckel 
Genus Lithelius Haeckel $1860 \mathrm{~b}$

Lithelius minor Jorgensen

Lithelius nautiloides Popofsky

Lithelius sp. A

Lithelius sp. B

Genus Pylospira Haeckel 1887

Pylospira octopyle Haeckel

Suborder NASSELLARIA Ehrenberg 1875

Family PLAGONIIDAE Haeckel 1881

emended Riedel 1967a

Genus Antarctissa Petrushevskaya 1967

Antarctissa antedenticulata Chen

Antarctissa conradae Chen

Antarctissa longa (Popofsky)

Antarctissa strelkovi Petrushevskaya

Genus Lithomelissa Ehrenberg 1847b

(?) Lithomelissa setosa Jorgensen

Genus Lophophaena Ehrenberg 1847b

Lophophaena macrencephala Clark and Campbell group

Family ACANTHODESMIIDAE Hertwig 1879

Genus Desmospyris Haeckel 1881

Desmospyris rhodospyroides Petrushevskaya

Desmospyris sp. aff. rhodospyroides Petrushevskaya

Desmospyris (?) sp. A.

Genus Gorgospyris Haeckel 1881

Gorgospyris sp. aff. perizostra Sanfilippo and Riedel

Genus Phormospyris Haeckel 1881

Phormospyris stabilis (Goll) antarctica (Haecker) group

Phormospyris stabilis (Goll) scaphipes (Haeckel) group

Family CARPOCANIIDAE Haeckel 1881 emended Riedel 1967a

Genus Carpocanarium Haeckel 1887

Carpocanarium papillosum (Ehrenberg)

Carpocanarium sp. A

Genus Carpocanistrum Haeckel 1887

Carpocanistrum sp. A

Genus Cystophormis Haeckel 1887

Cystophormis sp. A

Cystophormis sp. B 
Family THEOPERIDAE Haeckel 1881

emended Riedel 1967a

Genus Cornutella Ehrenberg 1838

Cornutella profunda Ehrenberg

Genus Plectopyramis Haeckel 1881

Plectopyramis dodecomma Haeckel

Genus Dictyophimus Ehrenberg 1847a

Dictyophimus hirundo (Haeckel) group

Genus Pseudodictyophimus Petrushevskaya 1971c

Pseudodictyophimus gracilipes (Bailey)

Genus Lychnocanium Ehrenberg 1847a

Lychnocanium sp. aff. grande Campbell and Clark

Genus Lychnocanella Haeckel 1887

Lychnocanella conicum (Clark and Campbell)

Genus Archipilium Haeckel 1881

Archipilium macropus (Haeckel)

Genus Cyrtocapsella Haeckel 1887

Cyrtocapsella japonica (Nakaseko)

Cyrtocapsella tetrapera (Haeckel)

Genus Cyrtolagena Haeckel 1887

Cyrtolagena laguncula (Haeckel)

Genus Stichophormis Haeckel 1881

Stichophormis cornutella Haeckel

Genus Theocalyptra Haeckel 1881

Theocalyptra bicornis (Popofsky)

Theocalyptra davisiana davisiana (Ehrenberg)

Genus Lampromitra Haeckel 1881

Lampromitra butschlii (Haeckel)

Lampromitra erosa Cleve

Lampromitra tiara Dumitrica

Genus Theocampe Haeckel 1887

? Theocampe cf. mongolfieri (Ehrenberg)

Genus Eucyrtidium Ehrenberg 1847a

Eucyrtidium acuminatum (Ehrenberg)

Eucyrtidium cienkowskii Haeckel group

Eucyrtidium hexagonatum Haeckel

Eucyrtidium calvertense Martin

Eucyrtidium inflatum Kling

Eucyrtidium punctatum (Ehrenberg) group

Eucyrtidium cf. montiparum Ehrenberg

Eucyrtidium sp. A

Eucyrtidium vincentense (Campbell and Clark) 
Genus Stichocorys Haeckel 1881

Stichocorys peregrina (Riedel)

Stichocorys delmontensis (Campbell and Clark)

Stichocorys sp. A

Genus Gondwanaria Petrushevskaya 1975

Gondwanaria dogeli (Petrushevskaya) group

Genus Artostrobus Haeckel 1887

“Artostrobus" (?) pretabulatus Petrushevskaya

Family PTEROCORYTHIDAE Haeckel 1881

emended Riedel 1967a

Genus Anthocyrtidium Haeckel 1881

Anthocyrtidium ehrenbergi (Stohr) pliocenica (Seguenza)

? Anthocyrtidium ? sp. A

Anthocyrtidium zanguebaricum (Ehrenberg)

Genus Lamprocyclas Haeckel 1881

Lamprocyclas gamphonycha (Jorgensen)

Lamprocyclas maritalis Haeckel

Lamprocyclas (?) sp. A

Lamprocyclas sp. B

Lamprocyclas sp. C

Lamprocyclas sp. D

Lamprocyclas sp. E

Genus Lamprocyrtis Kling 1973

Lamprocyrtis (?) apollinis (Haeckel)

Lamprocyrtis hannai (Campbell and Clark)

Lamprocyrtis heteroporos (Hays)

Lamprocyrtis (?) junonis (Haeckel)

Family ARTOSTROBIIDAE Riedel 1967a

emended Foreman 1973

Genus Botryostrobus Haeckel

Botryostrobus aquilonaris (Bailey)

Botryostrobus auritus-australis (Ehrenberg) group

Botryostrobus bramlettei (Campbell and Clark)

Genus Phormostichoartus Campbell 1951

Phormostichoartus fistula Nigrini

Phormostichoartus sp. A

Genus Siphocampe Haeckel 1881

Siphocampe arachnea (Ehrenberg) group

Siphocampe lineata (Ehrenberg) group

Siphocampe nodosaria (Haeckel)

Genus Siphostichartus Nigrini 1977

Siphostichartus corona (Haeckel)

Genus Spirocyrtis Haeckel 1881

Spirocyrtis subscalaris Nigrini 
Family CANNOBOTRYIDAE Haeckel 1881 emended Riedel 1967a

Genus Botryopyle Haeckel 1881

Botryopyle dictyocephalus Haeckel group 


\title{
4.4 SYSTEMATICS
}

Phylum Protozoa

Class Actinopoda

Subclass Radiolaria

\author{
Order Polycystina Ehrenberg 1838 \\ emended Riedel 1967a \\ Radiolaria with a skeleton of opaline silica \\ without admixed organic compounds.
}

Suborder Spumellaria Ehrenberg 1875

Family Orosphaeridae Haeckel 1887

Skeleton consisting of a lattice shell, or two approximately concentric shells, and radial spines which are almost invariably circular in cross-section. In some forms a double spicule is present at or near the shell apex. The shell in some members is subspherical, but actually monaxon-allopolar in all well-known forms. Lattice is generally robust and irregular, with commonly angular or subangular pores (Friend and Riedel, 1967).

\section{Genus Oropelex Friend and Riedel 1967}

Orosphaeridae with a subcylindrical to conical single lattice shell with hemispherically closed upper end and ribs or bars prolonged to form spines at the lower open end. Some specimens have a latticed wall transversely subdividing the cavity.

Type-species: Oropelex pagoda Friend and Riedel 1967

\section{? Oropelex sp.}

Plate 1 , figure 1

? Oropelex pagoda Friend and Riedel 1967 p.224, pl.2, figs.1-4.

Description: Fragments of a lattice wall with subtriangular to subquadrangular (10-80 $\mu)$ pores. At least one prominent rib usually present.

Dimensions: Fragments up to $4 \mathrm{~mm}$.

Remarks: These fragments appear to be related to O. pagoda.

Observed range: Sporadic occurrences in Miocene samples with excellent siliceous preservation (e.g. Morrisons, Ruamahanga, and Leader sections). One post-Miocene occurrence in the dextral G. crassaformis - G. crassula overlap zone at Waiatai (WA08). Too rare to be of biostratigraphic use. 
Family Collosphaeridae Muller 1858

Colonial spumellarians with lattice and plate perforate shells and one genus without skeletal elements.

Genus Collosphaera Muller 1855

Collosphaeridae with simple shells, smooth on the inside and outside without any spines or tubuli.

Type-species: Collosphaera huxleyi Muller 1855 : designated by Campbell 1954

\section{Collosphaera cf. polygona Haeckel \\ Plate 2, figure 1}

Collosphaera polygona Haeckel 1887, p.96, p1.5, fig.13.

Description: Subspherical lattice shell, thin walled, smooth surface with approximately nine subangular pores on the half equator. Pores large (up to $25 \mu$ ), variable in size, and bars approximately $7 \mu$ in width.

Remarks: The rare specimens found have pores not quite as polygonal as in Haeckel's figured specimen.

Observed range: Restricted to Miocene samples but too rare to be of use biostratigraphically.

Collosphaera sp. aff. huxleyi Muller

Plate 1, figures 3,4: Plate 2, figure 5

Collosphaera huxleyi Muller 1858, p.55, p1.8, fig.7.

Collos phaera huxleyi Muller: Goll 1980, p.436, pl.1, figs.16-17.

Collosphaera sp. aff. C. huxleyi Muller: Johnson and Nigrini 1980, p.147, pl.1, fig.6, pl.4, fig.14.

Description: Shell spherical to slightly ellipsoidal, thick-walled, smooth surface with a moderate number (6-8 on the half equator) of circular to subcircular pores irregularly scattered.

Dimensions: Based on eight specimens. Diameter 110. Pores 5-25. Bars 10-30.

Remarks: Goll (1980) notes that he has doubt about calling his specimens C. huxleyi as his forms (and the forms described herein) differ from Muller's figured form in having fewer pores on the half equator. Johnson and Nigrini (1980) differentiate between C. huxleyi and C. sp. aff. C. huxleyi on the lesser number of pores in the latter species. Some forms which have larger pores and thinner bars approach C. macropora Popofsky (1917).

Recorded range: Goll (1980) places the FAD of Collosphaera huxleyi at $1.8 \mathrm{Ma}$ in the eastern tropical Pacific. 
Observed range: Apart from uncertain occurrences with $G$. dehiscens in SWR4, LT05, LT06, and RK04, there are only two positive identifications older than the LAD of G. dehiscens in samples $\mathrm{KB} 01$ and SPA1. The highest positive identification is in East Cape Section at the level of the FAD of G. crassaformis. Sporadic uncertain identifications as high as sample WA02 (Waiatai). A good indication of upper Miocene age if found in a sequence of samples. See Acrosphaera spinosa echinoides.

Geographic distribution: Johnson and Nigrini (1980) show C. huxleyi is present between $18^{\circ} \mathrm{S}$ and $37^{\circ} \mathrm{S}$ and Collosphaera sp. aff. C. huxleyi consistently present in samples north of about $5^{\circ} \mathrm{N}$ with scattered occurrences of small, impoverished forms between $0^{\circ}$ and $10^{\circ} \mathrm{S}$ (western Indian Ocean).

Collosphaera sp. A

Plate 1, figure 2

Description: Shell slightly ellipsoidal, thick walled, smooth surface with 4-5 large subelliptical pores, 50 to $100 \mu$ long with the long axis of each pore aligned subparallel to the long axis of the ellipse. Two smaller subcircular pores are present at the polar ends. Bars consistently about $12 \mu$ broad.

Dimensions: Based on four specimens. Length of long axis 105. Breadth of ellipse 80 .

Observed range: Restricted to southern Wairarapa samples with good preservation in the age range post-LAD G. dehiscens to slightly above the local FAD of B. compressa sensu stricto. Too rare to be of use biostratigraphically.

\section{Genus Acrosphaera Haeckel 1881}

Collosphaeridae with simple shells, the outer surface of which is covered with radial, irregularly scattered spines, but no external tubes.

Type-species: Acrosphaera echinoides Haeckel 1887 : designated by Bjorklund and Goll 1979

\section{Acrosphaera spinosa echinoides (Haeckel)}

Plate 1, figure 5: Plate 2, figure 3

Acrosphaera echinoides Haeckel 1887, p.100, pl.8, fig.1.

Acrosphaera spinosa echinoides Haeckel: Bjorklund and Goll 1979, p.1311, pl.1, figs.12-13, pl.4, figs.1-4,7,8 (only).

Description: Lattice shell, thick walled, approximately spherical with numerous conical wall protuberances and alternating depressions. Protuberances $15-20 \mu$ in diameter, perforated by irregular subangular pores up to $8 \mu$ in diameter (especially around the base). Simple spines, $5-10 \mu$ long, project from the summit of each protuberance. Intervening depressions of lattice shell broad, sparsely perforated by small round pores.

Remarks: This subspecies shows a pronounced size decrease in the Upper Miocene (Bjorklund and Goll, 1979) and the form described here differs somewhat from Haeckel's illustrated form in being smaller and there being not so many pores in the depressions. 
Recorded range: FAD in lower Miocene and persists in variable frequencies into the lower Pliocene (Bjorklund and Goll, 1979).

Observed range: Tends to be found only in samples with excellent preservation. Apart from one uncertain identification between the LAD of $G$. dehiscens and the FAD of $B$. compressa at Hangaroa (HR06) all other occurrences are above the base of the Opoitian. A moderately useful Plio-Pleistocene indicator. It appears A. spinosa echinoides may be a descendant of $C$. sp. aff. huxleyi and/or A. spinosa spinosa with the protuberances getting longer. This trend is opposite to that suggested by Bjorklund and Goll (1979).

Geographic distribution: Loads highest in subtropical areas, its present maximum abundance in the middle of the subtropical gyre (Morley, 1977, south Atlantic).

Present in all samples except southernmost $\left(48^{\circ} \mathrm{S}\right)$ and northernmost $\left(19^{\circ} \mathrm{N}\right)$ being particularly abundant at about $20^{\circ} \mathrm{S}$ (Johnson and Nigrini, 1980, western Indian Ocean, Acrosphaera spinosa).

\section{Acrosphaera spinosa spinosa (Haeckel) \\ Plate 1, figure 6}

Collosphaera spinosa Haeckel 1862, p.536, pl.34, figs.12,13.

Polysolenia spinosa (Haeckel): Dumitrica 1973, pl.18, fig.2.

Polysolenia spinosa (Haecke1): Nigrini and Moore 1979, p.S19, pl.2, fig.5.

Acrosphaera spinosa spinosa (Haeckel): Bjorklund and Goll 1979, p.1308, pl.1, figs.8,9.

Description: Shell thin walled, smooth, spherical, with irregularly scattered subcircular pores of variable size, half to two times as broad as the bars. Short spines, usually mounted on conical elevations, project randomly over the shell surface. Spines usually conical but may be quite sharp.

Dimensions: Diameter of shell usually 81-128 (Nigrini, 1967).

Remarks: Differs from A. spinosa echinoides in having smaller pores and also the lattice protuberances are lower and spines shorter (Bjorklund and Goll, 1979).

Recorded range: First appears in the Upper Miocene Didymocyrtis penultima Zone (DSDP Site 77 , core 12 , Ommatartus penultimus Zone). It is assumed to have evolved from $A$. spinosa echinoides (Bjorklund and Goll, 1979). See A. spinosa echinoides.

Observed range: Most occurrences are limited to upper Tongaporutuan samples with only one pre-LAD G. dehiscens (KB01). Four positive post-Miocene identifications. Too sporadic to be of use biostratigraphically. See Acrosphaera spinosa echinoides.

Geographic distribution: Same as A. spinosa echinoides.

\section{Genus Siphonosphaera Muller 1858}

Collosphaeridae with simple shells, the pores of which are prolonged into external simple radial tubuli with solid wall; outer mouth of the tubuli truncated, smooth.

Type-species: Collosphaera tubulosa Muller 1855 
Siphonosphaera polysiphonia Haeckel

Plate 2, figure 2

Siphonosphaera polysiphonia Haeckel 1887, p.106.

Siphonosphaera polysiphonia Haeckel: Dumitrica 1973, p.832, pl.18, fig.3.

Siphonosphaera polysiphonia Haeckel: Nigrini and Moore 1979, p.S21, pl.1, figs.6a,b.

Siphonosphaera polysiphonia Haeckel: Johnson and Nigrini 1980, p.119, pl.1, fig.12.

Description: Shell spherical, rather thick walled with somewhat rough or pitted surface and numerous, small, irregularly scattered, subcircular pores. Four to ten poreless tubules, thin walled, cylindrical, having no definite arrangement. Tubules usually broader than long and smoothly truncated.

Dimensions: Diameter of shell 81-119 (Nigrini, 1967).

Remarks: Tubules usually longer but poorer preservation could have reduced their length in the samples studied.

Observed range: Found in only two Pliocene samples (SWR1 and WA16).

Geographic distribution: Loads most highly in subtropical waters, absent south of $40^{\circ} \mathrm{S}$ (Morley, 1977, south Atlantic).

Most abundant in low latitudes (Johnson and Nigrini, 1980, western Indian Ocean).

\section{Genus Otosphaera Haeckel 1887 \\ emended Nigrini 1967}

Collosphaeridae with simple shells, some of the pores of which are prolonged into simple external radial tubules with fenestrate walls; outer mouth of the tubules armed with a single tooth or spine. Emended by Nigrini (1967) to include forms having a spine on the distal end of the tubules.

Type-species: Otosphaera polymorpha Haeckel 1887 : designated by Campbell 1954

\section{Otosphaera polymorpha Haeckel}

Plate 2, figure 4

Otosphaera polymor pha Haeckel 1887, p.116, pl.7, fig.6.

Otos phaera polymorpha Haeckel: Renz 1974, pl.13. fig.15.

Trisolenia megalactis megalactis (Ehrenberg): Bjorklund and Goll 1979, p.1321, p1.5, figs.1-21 (in part).

Otosphaera polymorpha Haeckel: Nigrini and Moore 1979, p.S9, pl.1, fig.5.

Description: Shell smooth, thin walled, subspherical, with numerous very small pores, much smaller than the bars. Tubules, 2-4, are truncated obliquely, one side prolonged into an acute tooth.

Dimensions: Diameter of shell 100-146. Maximum length of tubules (including tooth) 18-45. Maximum breadth of tubules 27-36 (after Nigrini, 1967). 
Remarks: Bjorklund and Goll (1979) defined T. megalactis megalactis to include a number of forms, one of which is $O$. polymorpha.

Recorded range: Quaternary (Renz, 1974). Neogene (Bjorklund and Goll, 1979)

Observed range: Found rarely in samples ranging in age from early Tongaporutuan (LT09) to middle Opoitian (SMR1).

Geographic distribution: Too rare to determine accurately (Molina-Cruz, 1975, southeast Pacific).

Family Actinommidae Haeckel 1862

emended Sanfilippo and Riedel 1980

Solitary spumellarians with shells spherical or ellipsoidal or modifications of those shapes, but not discoidal, nor equatorially constricted ellipsoids, usually without internal spicule and generally much smaller than the orosphaerids.

\section{Genus Actinomma Haeckel 1860a \\ emended Bjorklund 1977}

Actinommidae with three or four lattice spheres and 10-20 unbranched spines of either uniform or irregular length.

Type-species: Haliomma trinacrium Haeckel 1860a

Actinomma antarcticum (Haeckel)

Plate 1, figures 7-10: Plate 2, figure 6

Spongoplegma antarcticum Haeckel 1887, p.90.

Cladococcus aquaticus Popofsky 1908, p.214, pl.23, figs.3,4.

Diploplegma banzare Riedel 1958, p.223. pl.1, figs.3,4.

Spongoplegma antarcticum Haeckel: Chen 1975, p.454, pl.22, figs.3,4.

Spongoplegma sp. Chen 1975, p.454, pl.22, figs.1,2.

Spongoplegma antarcticum Haeckel: Keany 1979, p.53, pl.2, fig.1.

Actinomma antarcticum (Haeckel): Nigrini and Moore 1979, p.S25, pl.3, figs.1a,b,2a,b,3.

Actinomma antarcticum (Haeckel): Boltovskoy and Riedel 1980, p.109, p1.2, fig.2.

Description: Cortical shell large, spherical to ellipsoidal with either a rough surface; a surface covered in small thorns; a surface with very heavy short radial beams with tuberculate ends, arising from the nodes of intervening bars; or a double cortical shell. Cortical pores circular to rounded polygonal, irregular in shape and pattern but generally subequal in size, 14-26 across the half equator. Cortical shell or shells connected to a loose, subspherical, spongy medullary meshwork by numerous radial, thin, three-bladed beams. Central shell not visible. Very often medullary meshworks are preserved intact with no cortical shell attached.

Dimensions: Based on twelve specimens. Diameter of cortical shell (includes average diameter of ellipsoidal specimens) 172-292. Diameter of medullary shell (based on 16 specimens) $40-94$. 
Remarks: Nigrini (1967) described A. medianum as a species having characteristics intermediate between the cold (Antarctic) A. antarcticum and the warm (low latitude) A. arcadophorum. A. medianum is distinguished from $A$. antarcticum by a generally smaller size, a simply latticed cortical shell with 9-12 pores on the half equator and a more delicate medullary meshwork. Although some of the specimens described herein approach $A$. medianum (Plate 1, figure 11, Plate 2, figure 7) none could be described as $A$. medianum sensu stricto.

Recorded range: Chen (1975) believed his Miocene Spongoplegma sp. may be an ancestor to the Pliocene-Recent Spongoplegma antarcticum. Chen's two forms are herein considered conspecific.

Pliocene to Pleistocene (Keany, 1979). Miocene? to Recent (Hays, 1965).

Observed range: Normally only medullary found. Generally only lacking in those samples with poor preservation. Found throughout Late Neogene. Specimens referable to $A$. cf. medianum are found in five Miocene samples but are too rare to be of use biostratigraphically.

Geographic distribution: "One of the most abundant species in the Antarctic fauna and in several samples constitutes over 50\% of the species counted."; "there seems to be a tendency for this species to reach its greatest relative abundance in the vicinity of the Polar Front" (Hays, 1965, Spongoplegma antarcticum, Antarctic seas).

"In the Indian Ocean it is found in some samples north of the subtropical convergence but invariably they can be interpreted as being transported by bottom currents or as intermediate forms which could be classified as Actinomma medianum" (Lozano, 1974).

\section{Actinomma leptodermum (Jorgensen)}

Plate 1, figures 12,13

Echinomma leptodermum Jorgensen 1900, p.57, 1905, p.116, pl.8, figs.33a-c. non: Echinomma leptodermum Jorgensen: Hays 1965, p.169, pl.1, fig.2.

Echinomma leptodermum Jorgensen: Bjorklund 1976, pl.1, figs.13,14, pl.2, figs.1-6. Actinomma leptodermum Jorgensen: Nigrini and Moore 1979, p.S35, pl.3, fig.7.

Description: Cortical shell delicate spherical to subspherical, thin walled with circular to subelliptical pores, uneven in size, $8-10$ on the half equator. In some specimens the pores are infilled with a thin siliceous membrane (probably a artifact of preservation). Outer medullary subspherical to spherical connected to cortical by thin, three-bladed radial beams. Inner medullary not seen. Main spines, three-bladed, 10-15 in number; thinner shorter by-spines may also be present. Rare forms show traces of transverse processes on the main spines (especially in forms with longer spines) indicating a large outer shell may be present in living specimens.

Dimensions: Based on seven specimens. Diameter of cortical shell 88-103. Maximum length of main spines 37-80 (average $=43$ ).

Remarks: Echinomma antarctica (Dreyer)? as illustrated by Dumitrica (1973, pl.20, fig.4) may be conspecific. 
Observed range: The oldest sample containing positive A. leptodermum is MSO3 (uppermost Tongaporutuan). There are sporadic occurrences in the Pliocene. Becomes more common in the Pleistocene. The form with no by-spines, tabulated under $A$. cf. leptodermum, occurs with G. dehiscens in sample SWR4 (Wainuioru Valley) and has a highest positive occurrence in sample WA19 (about $100 \mathrm{~m}$ above the LAD of C. molestus at Waiatai). It occurs sporadically in the Miocene and maybe an environmental variant or ancestor of $A$. leptodermum sensu stricto.

Geographic distribution: There is considerable variation between authors concerning the limits of this species. Comparison of distributional data should be made with caution (Nigrini and Moore, 1979). Bjorklund (1977) concluded that A. leptodermum was restricted to the North Atlantic and proposed that the southern form, A. haysi (=Echinomma leptodermum of Hays, 1965) is a new species. Boltovskoy and Riedel (1980) in their study from the southwestern Atlantic Ocean did not support this view stating that "the very few specimens observed in our material were much more like E. leptodermum than $A$. haysi."

\section{Actinomma polycanthum (Muller) group}

Plate 2, figure 8: Plate 3, figures 1-5

Haliomma polycanthum Muller 1858, p.36, pl.1 fig.10,11.

Actinomma yosii Nakaseko 1959b, p.10, pl.2, fig.8a,b,9a,b.

Actinomma mediterranensis Hollande and Enjumet 1960, p.110, p1.54, figs.2-4.

Actinomma mediterranensis Hollande and Enjumet: Dumitrica 1973, p.832, pl.20, fig.3.

Actinomma tanyacantha Chen 1975, p.450, pl.11, figs.5,6.

Description: Three concentric lattice spheres and eight or more strong, three-bladed radial spines. The cortical shell is generally spherical, rarely ellipsoidal. Cortical pores normally circular to subcircular, subhexagonally arranged and deeply set in a relatively thick cortical wall, 11-16 on the half equator. Rare forms have a very rough, thorny surface and in these specimens the pores tend to be more irregular. Outer medullary shell spherical to rounded polygonal, 0.3 to 0.4 the cortical diameter. Inner medullary normally indistinct, subspherical, 0.15 to 0.2 the cortical diameter. Radial spines, three-bladed, strong, occasionally all intact. Rare specimens have needle-like by-spines. Most specimens have more radial spines than radial beams connecting the cortical and outer medullary shell.

Dimensions: Based on twenty specimens. Diameter of cortical shell 90-135. Length of spines 35-88.

Remarks: In sediments it is very common for the forms to have some of their spines broken. The species in the synonymy have the following number of spines according to the original description:

Haliomma polycanthum Muller - approximately 20

Actinomma tanyacantha Chen - 14

Actinomma yosii Nakaseko - 12

Actinomma mediterranensis Hollande and Enjumet - approximately 14.

It is very difficult to count the number of spines, especially in poorly preserved specimens or in those with a large number of spines so the forms were described together under the one name. 
Recorded range: Chen (1975) used the first occurrence of $A$. tanyacantha to define the base of his Middle Miocene Actinomma tanyacantha Zone. This appears to be the oldest occurrence of members of this group. Extends up to the Recent.

Observed range: Persistent throughout the Late Neogene. Occurs in $83 \%$ of the radiolarian-bearing samples studied.

Geographic distribution: Cosmopolitan?

Genus Cladococcus Muller 1857

Actinommidae with a single shell: radial spines branched but the stem not forked.

Type-species: Cladococcus arborescens Muller 1858

\section{Cladococcus dentata (Mast) \\ Plate 3, figure 6}

Heteracantha dentata Mast 1910, p.37, pl.18, fig.47.

Cladococcus lychnosphaerae Hollande and Enjument 1960, p.115, p1.55, figs.1,2.

Heteracantha dentata Mast: Bjorklund 1976, pl.14, figs.10-12.

Anomalacantha dentata (Mast): Nigrini and Moore 1979, p.S37, pl.4, fig.4.

Anomalacantha dentata (Mast): Johnson and Nigrini 1980, pl.1, fig.16.

Description: Spherical lattice shell from which orginate 8-12, rarely more, long broad, regularly arranged, three-bladed radial spines, each with thorns or small branches at 2-4 places. Pores circular to subcircular, of equal size, 6-7 on the half equator. Surface of shell smooth to thorny.

Dimensions: Based on 30 specimens. Diameter of shell 53-69. Length of radial spines 166-246. Breadth at their bases 6-12 (Benson, 1966).

Remarks: The forms described have a slightly larger cortical shell than those previously described. The genus Heteracantha (Type-species: Heteracantha dentata Mast 1910 : designated by Campbell 1954) has, according to Campbell (1954), two concentric lattice shells. Nigrini and Moore (1979) and herein report that dentata has only one lattice shell. Therefore this species should be placed in the genera Cladococcus. Nigrini and Moore's (1979, p.S37) description is under the generic name Anomalacantha proposed by Loeblich and Tappan (1961) because they found the name Heteracantha to be previously occupied.

Recorded range: ?Middle to late Miocene? (Bjorklund, 1976, DSDP Site 338) to Recent.

Observed range: Rare but persistent in the Miocene. Lowest occurrence in association with G. dehiscens at Leader River. Highest occurrence is in the middle Pliocene at Waimata.

Geographic distribution: "Belongs to a transitional assemblage derived by recurrent group analysis of North Pacific samples" (Nigrini, 1970).

"loads on the Transition (Southernmost) factor" (Sachs, 1973, subarctic Pacific).

"It is absent north of about $46^{\circ} \mathrm{N}$ except for rare occurrences in three samples" (Robertson, 1975, northwest Pacific).

"Bimodal distribution north of about $12^{\circ} \mathrm{S}$ and between about $30^{\circ} \mathrm{S}$ and $45^{\circ} \mathrm{S}$ " (Johnson and Nigrini, 1980, western Indian Ocean). 
Cladococcus stalactites Haeckel

Plate 3, figure 7

Cladococcus stalactites Haeckel 1887, p.227, pl.27, fig.4.

Cladococcus megaceros Hollande and Enjumet 1960, pl.58, fig.4.

Cladococcus sp. cf. C. stalactites Haeckel or C. abietinus Haeckel: Riedel, Sanfilippo and Cita 1974, pl.61, fig.8.

Actinommidae gen. et sp. indet. Riedel and Sanfilippo (in Berggren et al., 1976) pl.12, fig.1.

Cladococcus megaceros Hollande and Enjumet: Boltovskoy and Riedel 1980, p.110, pl.2, fig.6.

Description: Spherical lattice shell, thick walled from which arise about 18 or more long, three-bladed radial spines each of which has thorns or small branches at 1-2 places. Pores very irregular in shape, subequal in size, 10-13 on the half equator.

Dimensions: Based on five specimens. Diameter of shell 92-153. Maximum length of spines 175.

Remarks: Distinguished from C. dentata by the larger shell and more irregular pores.

Recorded range: Riedel and Sanfilippo's (1976) form is from the early Late Miocene of Spain. Known from the Recent.

Observed range: Not found with G. dehiscens. Sporadic occurrences up to the Pleistocene. Too rare to be of use biostratigraphically. Generally only found in samples with excellent siliceous preservation.

\section{Genus Cenosphaera Ehrenberg 1854b}

Actinommidae consisting of a single, lattice, spherical shell; without spines on the shell surface.

Type-species: Cenosphaera plutonis Ehrenberg 1854b

\section{Cenosphaera cristata Haeckel}

Plate 3, figure 8

Cenosphaera cristata Haeckel 1887, p.66.

Cenosphaera cristata Haeckel: Riedel 1958, p.223, pl.1, figs.1,2.

Cenosphaera cristata Haeckel: Keany and Kennett 1975, p1.3, fig.9.

Cenosphaera cristata Haeckel group: Petrushevskaya 1975, p.567, pl.1, figs.3,4, pl.17, fig.2.

? Cenosphaera cristata Haeckel: Nigrini and Lombari 1984, p.S15, p1.2, fig.2.

Description: Shell spherical (rarely subspherical), thick walled, thorny. Pores subcircular to circular, variable in size, 10-17 on the half equator, two, rarely five, times as wide as the intervening bars. Pores surrounded by indistinct polygonal frames, bearing short thorns at the intersections of the frames.

Dimensions: Based on 32 specimens. Diameter of shell 115-230 (Riedel, 1958).

Remarks: Both Petrushevskaya (1975) and Nigrini and Lombari (1984) have noted the presence of internal microspheres in some specimens very similar to those found in the genus Lonchosphaera. 
Recorded range: Miocene-Recent (Petrushevskaya, 1975).

Observed range: Sporadic occurrences throughout the Late Neogene.

Geographic distribution: "This species loads most heavily in factor 3 (transitional). At the present this species is most abundant in a band between about $40^{\circ} \mathrm{N}$ and $45^{\circ} \mathrm{N}$ " (Robertson, 1975, northwest Pacific).

"Present throughout the temperate Miocene sections examined, rare in the early Miocene" (Nigrini and Lombari, 1984, CENOP Project).

\section{Cenosphaera spp.}

Description: The specimens included in this group include several forms which all have spherical shells lacking any internal structure. A variety of pore size, shape and pattern and wall thicknesses are represented. Four main forms are most common:

Cenosphaera sp. A

Plate 3, figure 10: Plate 4, figure 1

Description: Relatively small thick-walled, with small subcircular pores which approach Cenosphaera nagatai Nakaseko but differ in that the pores are smaller and the intervening bars broader (see Nakaseko 1959b, p.6, pl.2, figs.1a,b,2. and Hays 1965, p.165, p1.2, fig.6.)

Observed range: Sporadic occurrences throughout the Late Neogene. Rare in the Plio/Pleistocene with only three questionable identifications from Waiatai.

\section{Cenosphaera sp. B}

\section{Plate 4, figure 2}

? Cenosphaera mellifica Haeckel 1887, p.62, pl.12, fig.9.

Description: Moderately thick-walled with very regular circular pores and pronounced hexagonal frames.

Observed range: Sporadic occurrences in Miocene and Lower Pliocene samples. Only one higher occurrence in WA07 (Waiatai).

Cenosphaera sp. C

Plate 3, figure 9

Cenosphaera sp. Nigrini and Moore 1979, pl.4, fig.3d (only).

Description: Very distinctive, delicate, large pored forms. Pores subelliptical to circular, 9-11 on half equator.

Observed range: Rare throughout the Late Neogene.

Cenosphaera sp. D

Plate 4 , figure 3

Description: Small, thorny forms with regular subcircular pores and broad intervening bars. The length of the thorns is variable and some forms with long thorns would probably be better placed in the genus Acanthosphaera. 
Observed range: Rare but limited to Miocene and basal Opoitian strata except for one tentative occurrence in the middle Opoitian (SWM1).

\section{Genus Acanthosphaera Ehrenberg 1858}

Actinommidae with a single lattice shell and eight or more, normally more than twelve radial spines.

Type-species: Acanthosphaera haliphormis Ehrenberg 1861

Note: Haeckel (1887) differentiated between the genera Acanthosphaera and Heliosphaera on the basis of one type of spines versus the presence of two kinds of spines (main and by-spines). This separation was considered unjustified by Boltovskoy and Riedel (1980: p.107).

\section{Acanthosphaera dodecastyla Mast}

$$
\text { Plate 4, figure } 4
$$

Heliosphaera minuta Cleve 1900, p.8, pl.6, fig.2.

Acanthosphaera dodecastyle Mast 1910, p.16, pl.14, fig.1.

Acanthosphaera dodecastyla Mast: Boltovskoy and Riedel 1980, p.108, pl.1, fig.21.

Description: Single lattice shell, relatively thick walled. Circular to subcircular pores with very conspicuous, protruding hexagonal frames. Bars slightly narrower than pores. Six or seven pores on the half equator. At some nodal points strong, three-bladed spines of variable length project radially.

Dimensions: Based on three specimens. Diameter of shell 61-66.

Remarks: Distinguished by distinctive hexagonal frames around pores. Boltovskoy and Riedel (1980) point out that Heliosphaera minuta (Cleve) is a junior homonym of $H$. minuta Rust (1898).

Recorded range: Recent.

Observed range: Rare in the Late Neogene.

Geographic distribution: North, and tropical Atlantic, and tropical Indian Ocean (Boltovskoy and Riedel, 1980).

Acanthosphaera sp. A

Plate 3, figures 11,12: Plate 4, figure 5

Description: Shell spherical, latticed. Pores circular to subcircular, with no hexagonal framing, 10-12 on the half equator. From most of the nodal points arise a strong, three-bladed radial spines (some of which are slightly curved).

Dimensions: Based on six specimens. Diameter of cortical shell 96-140. Maximum length of spines (normally with broken ends) 40. 
Remarks: Tabulated in two forms based on the number of spines. Generally the species has up to 25 spines (Plate 4, figure 5). Rarer specimens have spines arising from nearly all the nodal points (Plate 3, figure 11). Intermediate forms are present (Plate 3, figure 12).

Observed range: The "few spined" form is relatively common and persistent in samples from throughout the Late Neogene. The "many spined" form is found in only six Miocene samples, all post-LAD G. dehiscens and one Pliocene sample (TM06). Too rare to be of use biostratigraphically.

\section{Acanthosphaera sp. B}

Plate 3, figure 13: Plate 4, figure 6

Description: Shell very thick walled with very heavy three-bladed spines, the blades of which normally coalesce giving deep set subcircular to circular pores.

Dimensions: Based on four specimens. Diameter of shell 130-142. Longest spine 117.

Remarks: Superficially this form is very similar to Haeckeliella inconstans Dumitrica illustrated by Riedel, Sanfilippo and Cita (1974, p1.54, figs.2,3) from the Sicilian Pliocene. The forms described herein do not have the distinct, large, internal shell with hexagonal pores. There is a possibility that the delicate internal shell may have been lost due to solution although some of the specimens come from samples with excellent preservation. Some specimens have an indistinct lateral spinule near the termination of its longest spine.

Recorded range: Pliocene (Riedel, Sanfilippo and Cita, 1974) to Quaternary (Dumitrica, 1973, original definition of $H$. inconstans).

Observed range: Sporadic occurrences throughout the Late Neogene.

\section{Genus Hexacontium Haeckel 1881}

Actinommidae with three concentric lattice shells and six main radial spines in two planes, meeting at right angles. Main spines all similar and unbranched.

Type-species: Hexacontium phaenaxonium Haeckel 1887

\section{Hexacontium enthacanthum Jorgensen}

Plate 4, figure 7: Plate 5, figures 2-4,6

Hexacontium enthacanthum Jorgensen 1900, p.52, pl.2, fig.14, pl.4, fig.20.

Hexacontium pachydermum Jorgensen: Bjorklund 1976, pl.1, figs.4-9.

Hexacontium enthacanthum Jorgensen: Bjorklund 1976, pl.1, figs.1-3.

Hexacontium enthacanthum Jorgensen: Nigrini and Moore 1979, p.S45, p1.5, figs.1a,b.

Description: Cortical shell generally subspherical to subquadrate, rarely spherical. Surface smooth but with tiny thorns which arise from the nodes of the intervening bars as well as along the bars. Pores generally circular to subelliptical, occasionally subpolygonal; generally irregular in size and arrangement; 8-12 on the half equator. Outer medullary shell small, 0.2 to 0.3 the diameter of cortical shell, subspherical. Inner medullary about 0.1 the diameter of cortical shell, subspherical, normally indistinct. Six, mutually perpendicular radial beams arise from the surface of the inner medullary, become relatively heavy, 
three-bladed between the second and cortical shells, and pierce the cortical shell. All six spines of nearly equal length and breadth.

Dimensions: Based on twenty specimens. Diameter of cortical shell 146-194: of outer medullary shell 38-50. Length of spines 28-74.

Remarks: Nigrini and Lombari (1984, p.S19, Hexacontium spp.) noted that the Miocene specimens in this species group are generally larger than the Recent specimens. Robertson (1975) also notes that the inner shell was "frequently difficult to discern". Bjorklund (1976) distinguished between $H$. enthacanthum and $H$. pachydermum on thickness of shell. There is a tendency for forms with larger pores to dominate in upper Pliocene and Pleistocene faunas.

Recorded range: Present throughout the Miocene sections examined from both tropical and temperate latitudes (Nigrini and Lombari, 1984, Hexacontium spp., CENOP Project).

Observed range: Tabulated in three forms. $H$. enthacanthum sensu stricto is common throughout the Late Neogene, being present in $67 \%$ of the radiolarian-bearing samples studied. Absence generally related to poor siliceous preservation. There is an apparent tendency for the cortical bars to get thinner in younger specimens. The "oval" form is found in eleven samples throughout the Late Neogene, eight of which also contain $H$. enthacanthum sensu stricto. The "quadrate" form occurs in nine Tongaporutuan samples, one of which contains G. dehiscens (KB01). See $H$. laevigatum for discussion of transitional forms.

Geographic distribution: "This genus (Hexacontium spp.) loads most heavily in factor 3 (transitional). At present its higher abundances generally occur south of $45^{\circ} \mathrm{N}$ " (Robertson, 1975, northwest Pacific).

\section{Hexacontium laevigatum Haeckel}

Plate 5 , figures $1,5,7,8$

Hexacontium laevigatum Haeckel 1887, p.193, pl.24, fig.6.

Hexacontium laevigatum Haeckel: Nigrini and Moore 1979, p.S47, p1.5, figs.2a,b.

Description: Similar to Hexacontium enthacanthum but differs in the following respects: the cortical shell is generally more spherical, and the pores are more numerous (14-18 on the half equator), being nearly equal circular pores on the cortical shell.

Dimensions: Based on ten specimens. Diameter of cortical shell 130-170. Length of main spines $40-81$.

Remarks: Some forms with very long spines differ from previously described forms. No specimens exhibited the "presence of numerous thin by-spines concentrated at one pole of the shell" reported by Benson (1966) but these may have been lost by subsequent solution. Forms transitional between $H$. laevigatum and $H$. enthacanthum are present. Hexacontium hootsi Campbell and Clark (1944, p.14, pl.2, fig.5) which is distinguished by deeply set, fairly well spaced pores in "thick, ridged subhexagonal meshwork with tall funnels" is probably conspecific. 
Recorded range: Miocene (Campbell and Clark, 1944) to Recent.

Observed range: Tabulated in four forms. $H$. laevigatum sensu stricto occurs in $51 \%$ of the radiolarian-bearing samples throughout the Late Neogene. More common in Tongaporutuan Wairarapa sections than those of a similar age in Hawkes Bay (e.g. absent from Hangaroa). The "oval" form is found in 14 Tongaporutuan samples and two Pleistocene (WA02, WA03) and is normally associated with $H$. laevigatum sensu stricto. The "quadrate" form is restricted to late Tongaporutuan samples. The "long-spined" form has sporadic occurrences throughout the Late Neogene. The latter three forms (especially the "quadrate" and "long-spined" forms) make up higher percentages of $H$. laevigatum populations in the Tongaporutuan than in Plio/Pleistocene samples. Forms transitional between $H$. laevigatum and $H$. enthacanthum occur in $30 \%$ of the radiolarian-bearing samples studied and are normally found in association with at least one of the two species.

\section{Genus Thecosphaera Haeckel 1881}

Actinommidae with a cortical shell without radial spines and two medullary shells. Type-species: Thecosphaera tripodictyon Haeckel 1887

\section{Thecosphaera cf. akitaensis Nakaseko \\ Plate 5, figure 9}

Thecosphaera akitaensis Nakaseko 1971, p.63, pl.1, figs.4a,b.

Description: Rare forms with three concentric lattice shells and a distinctive very thick, very rough cortical surface. Cortical pores subcircular to circular, subregularly arranged, subuniform in size. Outer medullary about one-third diameter of cortical.

Dimensions: Based on four specimens. Diameter of cortical shell 85-104.

Remarks: Tentatively placed in this species because of the smaller size of the forms studied than those described by Nakaseko (1971). Other features are very similar.

Recorded range: Middle Miocene to middle Pliocene (Nakaseko, 1971, Japan).

Observed range: Found sporadically up to the FAD of G. crassula at Waiatai. Too rare to be of use biostratigraphically.

Thecosphaera grecoi Vinassa de Regny group

Plate 5, figure 10: Plate 6, figure 1

Thecosphaera grecoi Vinassa de Regny 1900, p.568, pl.1, fig.8.

Thecosphaera miocenica Nakaseko 1959b, p.7, pl.2, fig.3.

Thecosphaera grecoi Vinassa de Regny: Riedel, Sanfilippo and Cita 1974, p.707, pl.56, fig.3, pl.62, figs.2-4.

Actinomma spp. Nigrini and Lombari 1984, p.S13, pl.2, figs.1a-c (only).

Description: Shell consists of three concentric lattice shells. Cortical shell moderately thick with 15 to 20 pores on the half equator, pores circular, regular in arrangement, uniform in shape and size and sometimes with hexagonal frames. Outer medullary about one-third the 
diameter of the cortical shell, subspherical, connected to cortical by 10 or more radial spines. Inner medullary, subspherical to subellipsoidal, 0.15 the diameter of the cortical shell.

Dimensions: Based on ten specimens. Diameter of cortical shell 85-150.

Remarks: This group covers all specimens with a cortical/outer medullary shell ratio of $1 / 0.4$ or less; with cortical pores exhibiting a regular size, shape and pattern. The cortical wall may be smooth or show a distinct hexagonal frame around each pore and this feature appears to be dependent on degree of dissolution in a sample. Nakaseko (1971) described eight members of this genus. The variation and intergradation of forms seen in the samples studied indicates that Thecosphaera dedoensis and $T$. japonica, both described by Nakaseko (1971), would be included in this group. Thecosphaera radians Hollande and Enjumet (as illustrated by Dumitrica, 1973, pl.5, figs.5,6, pl.6, fig.3) is also possibly conspecific.

Recorded range: Early Miocene to Pliocene (Nakaseko, 1971, Japan).

Riedel, Sanfilippo and Cita (1974) described forms from the Sicilian Lower Pliocene.

Dumitrica (1973) illustrates forms from the Quaternary.

Nakaseko and Sugano (1973) used the first occurrence of Thecosphaera japonica to define the base of the Thecosphaera japonica Zone, the youngest of four radiolarian zones established for Neogene formations in Japan. Sakai (1980) found the base of $T$. japonica occurred at the base of the Stichocorys peregrina Zone (DSDP Site 436).

Observed range: Present in $79 \%$ of radiolarian-bearing samples (includes a relatively high number of uncertain identifications) throughout the Late Neogene.

\section{Genus Prunulum Haeckel 1887}

Actinommidae with three or more ellipsoidal concentric, lattice shells without radial spines or tubules; network regular.

Type-species: Prunulum coccymelium Haeckel 1887 : designated by Campbell 1954

Prunulum spp.

Plate 5, figure 11: Plate 6, figures 2-4

Description: Shell consists of four concentric lattice shells, outer two ellipsoidal (rarely spherical); inner two subspherical to subellipsoidal. Outer shell generally has circular to subcircular pores in a subregular arrangement. Each concentric shell is connected by numerous radial beams; the distance between each shell being subequal. Specimens with only three concentric shells and with numerous short radial beams on the surface (commonly clustered at each pole) are common.

Dimensions: Based on ten specimens. Length of outer shell 65-150. Breadth of outer shell 54-135.

Remarks: Generally two forms are represented; a delicate form with irregular pores and a more robust form with more regular pores. Some forms included in this group may be members of the genus Sphaeropyle but have an indistinct pylome. 
Observed range: Present in $68 \%$ of the radiolarian-bearing samples studied throughout the Late Neogene. Tends to be slightly more sporadic in the Plio-Pleistocene.

\section{Genus Styptosphaera Haeckel 1881}

Actinommidae with a spherical spongy framework. No medullary shell. Type-species: Styptosphaera spumacea Haeckel 1887.

\section{Styptosphaera stupacea Haeckel \\ Plate 5, figure 12}

Styptosphaera stupacea Haeckel 1887, p.87.

Description: Spherical skeleton consisting of a loose spongy meshwork with roundish meshes, pore size up to seven times the width of the bars; bar thickness regular. Surface rough with short thornlike spines.

Dimensions: Based on two specimens. Diameter of shell 213-241.

Remarks: Differs from $S$. spumacea in its rough surface and smaller size.

Observed range: Rare throughout the Late Neogene.

Geographic distribution: South Pacific (Haeckel, 1887).

\section{Styptosphaera spumacea Haeckel \\ Plate 5, figure 13}

Styptosphaera spumacea Haeckel 1887, p.87.

Styptosphaera (?) spumacea Haeckel: Nigrini and Lombari 1984, p.S37, p1.5, fig.3.

Description: Very similar to Styptosphaera stupacea but differs in having a smooth surface.

Dimensions: Based on ten specimens. Diameter of shell 141-173.

Remarks: Haeckel's (1887) shell diameter is almost twice that of the specimens described herein. Nigrini (1970) described species about the same size as those found here and questionably placed her forms in this species. Nigrini and Lombari (1984) report larger specimens in Miocene sediments, almost approaching the size of Haeckel's forms. It appears there is a considerable size variation in this species. Forms tentatively assigned to $S$. spumacea by Nigrini and Moore (1979, p.S71) are alot smaller than those described by Haeckel (1887).

Observed range: Occurs sporadically in samples younger than the LAD of G. dehiscens. Too rare to be of use biostratigraphically.

Geographic distribution: "belongs to a subarctic assemblage" (Nigrini, 1970, north Pacific). "This species loads heavily in factor 3 (transitional). At present this species is most abundant in a band between $37^{\circ} \mathrm{N}$ and $45^{\circ} \mathrm{N}$ " (Robertson, 1975, northwest Pacific).

"Present in all samples between about $37^{\circ} \mathrm{S}$ and $46^{\circ} \mathrm{S}$ " (Johnson and Nigrini, 1980, western Indian Ocean). 


\section{Notes on the Stylosphaerids}

The problems with generic placement of the stylosphaerids within the Actinommidae are discussed by Nigrini and Lombari (1984). Parts of their discussion are reproduced here to outline the problem. There are a number of described genera having the following generalised definition; up to four concentric lattice shells, either ellipsoidal or spherical. The shells are connected by radial beams which may be arranged in a set pattern or may be randomly placed. There are two opposite polar spines which may be three-bladed or cylindrical, similar or dissimilar, of equal or unequal length. The cortical shell is perforated by some number of similar or dissimilar pores and may be smooth or thorny. To accommodate species of this general form Haeckel (1887) lists a number of genera and subgenera in three different families. Riedel (1967a) and Petrushevskaya (1975) placed all the forms in one family. Petrushevskaya (1975) combined many of Haeckel's genera into three genera. While this simplification has advantages, it has the disadvantage that her generic definitions do not always conform with the illustrations of the type species of the genus. A complete taxonomic revision of these forms is apparently needed but in the absence of such a study the forms described herein all have the generic assignment placed in quotation marks indicating my uncertainty regarding the generic position of the species.

\section{Genus Stylatractus Haeckel 1887}

Actinommidae with an ellipsoidal lattice cortical shell and double medullary shell. Two opposite similar polar spines.

Type-species: Stylatractus neptunus Haeckel 1887 : designated by Campbell 1954

Note: Amphisphaera Haeckel (1882) has the same genotype designated by Campbell (1954) under the name Amphisphaera neptunus Haeckel 1887 (pl.17, fig.6).

\section{"Stylatractus" neptunus Haeckel forma large pores Plate 6, figure 6: Plate 7, figures 1-4}

Stylatractus neptunus Haeckel 1887, p.328, pl.17. fig.6 (in part).

Stylatractus neptunus Haeckel: Riedel 1958, p.226, pl.1, fig.9.

Amphisphaera sp. aff. Stylatractus neptunus Haeckel: Petrushevskaya 1975, p.570, p1.28, fig.5 (only).

Stylatractus neptunus Haeckel: Keany 1979, p.53, pl.2, fig.2 (only).

Description: Shell consists of 3 concentric lattice shells with two polar spines. Medullary shell spherical. Inner cortical shell subspherical to subellipsoidal, with 7-8 circular pores on the half equator; connected to the medullary shell by a number of radial beams. Outermost (cortical) shell ellipsoidal, moderately thick walled, thorny with 7-8 circular to subcircular pores on the half equator, connected to the middle shell by numerous radial beams. Pores normally 2-3 times as broad as the intervening bars. Polar spines heavy, usually three-bladed. Rare teratological specimens observed with two diverging spines at one end. Polar spines normally equal in length, occasionally with the longer being 1.25 to 2 times as long as the other. 
Dimensions: Based on ten specimens. Diameter of inner shell 23-28. Length of middle shell 68-81: of cortical shell 107-142: of longest spine 48-103: of shortest spine 33-65. Breadth of cortical shell 98-129.

Remarks: This form differs from that illustrated by Haeckel (1887, pl.17, fig.6) which has 12 pores on the half equator. Riedel (1958) included both forms his species definition ("7-16 pores on half equator"). Petrushevskaya (1967) suggested the pores overgrow ontogenetically. No examples of the small pored form were found in the sediments studied suggesting the two forms are in fact different species with differing ecological niches. Specimens with only two lattice shells and numerous short spines projecting from the surface are often seen. They are presumed to be representatives of this species with the cortical shell missing. This is supported by their dimensions and that the double shelled forms of ten exhibit small thorns on the polar spines where the cortical shell would expect to be connected.

Recorded range: Neogene (Keany, 1979). Quaternary (Petrushevskaya, 1975).

Observed range: Relatively common throughout the Late Neogene.

\author{
"Stylatractus" universus Hays \\ Plate 6, figure 9: Plate 7, figures 5,6
}

Stylosphaera angelina Campbell and Clark 1944, p.12, pl.1, figs.14-20.

Stylatractus sp. Hays 1965, p.167, pl.1, fig.6.

Stylatractus universus Hays 1970, p.215, pl.1, figs.1,2.

Axoprunum angelinum (Campbell and Clark): Kling 1973, p.634, p1.1, figs.13-16, p1.6, figs.16-17 (only).

Axoprunum angelinum (Campbell and Clark): Weaver, Casey and Perez 1981, pl.3, figs.3,4. Stylatracta universa Hays: Keany and Kennett 1975, pl.1, fig.1.

Stylosphaera sp. Bjorklund 1976, pl.14, fig.15,16.

Axoprunum angelinum (Campbell and Clark): Sakai 1980, p.704, pl.2, figs.1a,b.

"Stylatractus universus" Hays: Nigrini and Lombari 1984, p.S29, pl.4, fig.3.

Description: Skeleton consists of one subspherical cortical shell (at least three times larger than the outer medullary) and two subspherical medullary shells. Medullary shells thin walled with pores regular to irregular in size and shape. Cortical shell wall thick: pores subcircular with two types of wall found: (a) normally has 14-16 pores on a half equator, pores of equal size, hexagonally framed with small thorns projecting from the intersections of the frames and, (b) normally has $10-11$ pores on a half equator, pores unequal size and not regularly patterned. Transitional forms are common. Outer medullary shell connected to cortical by stout radial beams, two lying along the major axis project through the cortical shell as stout, polar, cylindro-conical spines. Some of the other beams rarely penetrate the cortical shell and form short spines. The nearly equal polar spines are normally as long as to half as long as the major axis of cortical shell.

Dimensions: Based on 40 specimens. Diameter of innermost shell 15-20: of second shell 40-50: of cortical shell (minor axis) 103-125 (major axis) 103-131. Length of spines 86-114 (Hays, 1965). 
Remarks: Nigrini and Lombari (1984, p.S27) outline the Stylatractus universus Axoprunum angelinum problem which typifies the generic/specific definitions of many members of the stylosphaerids.

Recorded range: Morley and Shackleton (1978) find that Stylatractus universus becomes extinct within the transition zone between oxygen-isotope stages 12 and 11 (approximately $0.425 \mathrm{Ma}$ ) in two deep-sea cores in the mid-and low-latitude Atlantic. Its upper limit is used in the Antarctic to mark the boundary between the $\Omega$ and $\Psi$ Zones. The age of this boundary is estimated to be $0.4 \mathrm{Ma}$ (within the Brunhes Normal Epoch). In the North Pacific the mean age of the upper limit of this species is about $0.4 \mathrm{Ma}$. In four equatorial Pacific cores an average age for its disappearance is estimated to be $0.341 \mathrm{Ma}$ (Hays, 1970).

Observed range: Tabulated in two forms. The "small pored" variety is found sporadically throughout the Late Neogene. The "large pored" form has a similar age range and is slightly more common overall. There is a tendency to the "small pored" form to be more common in the Pleistocene.

Geographic distribution: "Present throughout the Miocene sections examined from both tropical and temperate latitudes" (Nigrini and Lombari, 1984, CENOP Project).

\section{Genus Sphaerostylus Haeckel 1881}

Actinommidae with two concentric lattice shells and two free polar spines which are different in size and form.

Type-species: Sphaerostylus zittelii Rust 1885

\section{"Sphaerostylus" sp. aff. timmsi (Campbell and Clark)}

Plate 6, figures 8,10: Plate 7, figures 8-10

(?) Lithatractus timmsi Campbell and Clark 1944, p.18, pl.2, figs.18-19.

(?) Actinommid gen. et sp. indet. Sanfilippo and Riedel 1973. p1.25, fig.11.

(?) Stylosphaera coronata coronata Ehrenberg: Chen 1975, p.455, p1.5, figs.1,2. (plates under Stylasphaera)

non: Stylosphaera coronata Ehrenberg 1873, p.258: 1875, pl.25, fig.4.

Lithatractus timmsi Campbell and Clark: Weaver, Casey and Perez 1981, pl.4, figs.3,4.

Description: Shell consists of a medullary and cortical lattice shell with one major spine and a number of smaller spines clustered on the opposite half of the cortical shell. Medullary shell subspherical connected to the cortical by up to eight radial beams which pierce the cortical shell. Cortical shell thick, subcircular to slightly "balloon-shaped" with the major spine rising from the apex of the "balloon" in the latter forms. Cortical pores subcircular, usually hexagonally framed and subhexagonally arranged, 13 to 17 on the half equator. Major spine three-bladed, rarely cylindrical, 1.25 to 2 times the diameter of the cortical shell. Minor spines variable in length up to 0.5 the diameter of the cortical shell, up to eight projecting from the half of the cortical shell which is distal from the major spine. Minor spines, three-bladed commonly broken at base leaving normally 2-4. Normally one of the minor spines is directly opposite the major spine but some specimens shown no sign of one being in this position. Rare small thornlike spines may project from the cortical shell. Teratological forms with a double major spine occur rarely. 
Dimensions: Based on 16 specimens. Diameter of medullary shell 20-25: of cortical shell 74-93. Length of major spine 78-125: of minor spines 25-42.

Remarks: Campbell and Clark (1944) state that in their specimen "one polar spine was broken off near the base but assumed to be a duplicate of the other". The Oligocene/Eocene forms illustrated by Riedel and Sanfilippo (1973) and Chen (1975) are slightly thicker walled and have less pores and are both related to Stylosphaera coronata Ehrenberg. They could be ancestors of the form described herein. Sanfilippo, Caulet and Riedel (1978, p.757, pl.1, fig.10) illustrate forms from the Middle Miocene DSDP Leg42A (Mediterranean) under the name Stauroxiphos communis Carnevale (1908), which differ from those described by Carnevale in having a pear-shaped medullary shell and more than three radial bars prolonged as short spines. The latter feature makes them partially synonymous with the species described herein.

Recorded range: Morphologic top of L. timmsi near the Epoch 6/5 boundary (Weaver, Casey and Perez, 1981, California).

Observed range: Common in Miocene samples, being more sporadic in Plio-Pleistocene samples. Highest occurrence is in sample WA03 (Waiatai). Replaced in Plio-Pleistocene sediments by a more "symmetrical" form with heavier by-spines, which is found in Cricklewood, Tahaenui-Kohukohu, Waihua, and Waiatai, with its lowest common occurrence in TK05, which contains C. molestus and is near the top of the Waipipian, about 50m below the FAD of dextral G. crassaformis. There is one identification of this "symmetrical" form in the Miocene (RM06: see Plate 7, figure 10).

\section{Genus Xiphatractus Haeckel 1887 \\ emended herein}

Actinommidae with an ellipsoidal lattice cortical shell and double medullary shell; two opposite polar spines of unequal length. Emended herein to include forms with a spherical cortical shell.

Type-species: Xiphatractus armadillo Haeckel 1887 : designated by Campbell 1954

\section{“Xiphatractus" sp. A}

Plate 6, figures 5,7: Plate 7, figure 7

Axoprunum angelinum (Campbell and Clark): Kling 1973, p.634, p1.6, figs.14,15,18 (only). Stylosphaera angelina Campbell and Clark: Riedel, Sanfilippo and Cita 1974, pl.56, fig.2. Stylosphaera angelina Campbell and Clark: Riedel and Sanfilippo 1978a, p.108, pl.3, figs.1-3.

Description: Very similar to small pored forms of "Stylatractus" universus, the only difference being the length of the polar spines. In these forms the ratio of lengths of the two polar spines is 1:2 or greater. Forms with ratios less than this were placed in "S." universus.

Dimensions: Same as "S." universus except the ratio of lengths of the two polar spines is $1: 2$ or greater. 
Recorded range: Probably included in populations of "Stylatractus" universus by most authors. The forms illustrated by Riedel and Sanfilippo (1978a) and Riedel, Sanfilippo and Cita (1974) are from the Sicilian Lower Pliocene.

Observed range: Sporadic throughout the Late Neogene. Similar age distribution to $S$. universus to which it is probably related.

Geographic distribution: See "Stylatractus" universus.

\section{Genus Prunopyle Dreyer 1889}

Actinommidae with two or more ellipsoidal lattice shells; the outermost shell at least has a large pylome.

Type-species: Prunopyle pyriformis Dreyer 1889 : designated by Campbell 1954

\section{? Prunopyle antarctica Dreyer \\ Plate 9, figures 4,10}

? Prunopyle antarctica Dreyer 1889, p.24, pl.5, fig.75.

? Prunopyle antarctica Dreyer: Riedel 1958, p.225, pl.1, figs.7,8.

? Echinomma antarctica (Dreyer) ?: Dumitrica 1973, p.832, p1.21, fig.1 (only).

? Prunopyle antarctica Dreyer: Chen 1975, p.454, pl.23, figs.5,6.

Description: Shell ovate with small circular to subcircular subhexagonally arranged pores in a thick shell. Shell surface rough with a bunch of strong three-bladed spines surrounding a pylome and a bunch of smaller, three-bladed spines projecting from the opposite pole. Internal structure consists of a loose concentric spongy network similar to Prunopyle sp. A and Spongurus sp. A.

Dimensions: Based on three specimens. Length of cortical shell 137-144. Breadth of cortical shell 116-122. Maximum length of polar spines 29-33.

Remarks: The taxonomic relationship between forms with a bunch of spines at each pole seen under SEM imagery to those seen in transmitted light, which are similar to heavily spinose forms of Spongurus sp. A, is uncertain.

Recorded range: Pleistocene to Recent (Chen, 1975).

Observed range: Sporadic throughout the upper Neogene but slightly more common in Plio-Pleistocene sediments.

Geographic distribution: "No form resembling $P$. antarctica has been found in the tropical parts of the Pacific and Indian Oceans. Thus this species may possibly be restricted to high northern and southern latitudes." Riedel (1958).

\section{Prunopyle sp. A}

Plate 7, figures 11,14: Plate 8 , figures 3,4 
Description: All forms with a "loose" internal concentric shell layering and a distinct pylome on the outermost shell included in this species. Shell outline is commonly elliptical.

Dimensions: Based on three specimens. Length 108-125. Breadth 74-78.

Remarks: Forms intermediate between Spongurus sp. A and Prunopyle sp. A are present. The forms present here may be related to the forms assigned to Prunopyle titan Campbell and Clark as described by Hays (1965, p.173, p1.2, fig.4), Chen (1975, p.454, pl.23, figs.1,2), and Weaver (1976a, p.100, pl.9, fig.3) which show a loose, sometimes spiralled, internal structure. Campbell and Clark (1944) described and illustrated P. titan as lacking an inner concentric medullary shell.

Observed range: Found sporadically throughout the upper Neogene but slightly more common in Miocene sediments. This range pattern is the opposite of P. antarctica.

\section{Genus Spongurus Haeckel 1860b}

Actinommidae with a spongy ellipsoidal or cylindrical shell without equatorial strictures; lacking an internal latticed medullary shell; without polar spines or lattice mantle but the surface armed with radial spines.

Type-species: Spongurus cylindricus Haeckel 1862

\section{Spongurus pylomaticus Riedel \\ Plate 9, figures 2,5}

Spongurus pylomaticus Riedel 1958, p.226, pl.1, figs.10,11.

Spongurus (?) pylomaticus Riedel: Petrushevskaya 1975, p.577, pl.7, fig.4.

Spongurus pylomaticus Riedel: Ling et al. 1971, p.711, pl.1, fig.5.

Spongurus pylomaticus Riedel: Keany 1979, p.54, p1.2, fig.11.

Spongurus pylomaticus Riedel: Nigrini and Moore 1979, p.S65, pl.8, figs.3a,b.

Description: Shell subcylindrical or elongate ellipsoidal, approximately twice as long as broad. An inner spongy core is surrounded by a narrow mantle of less dense meshwork which varies from being finely to sparsely perforate, the sparsely perforate forms have large pores. At one pole is a pylome surrounded by short irregular teeth and short thornlike spines are usually present at the opposite end.

Dimensions: Based on four specimens. Length of shell 136-142. Maximum breadth of shell 71-75.

Remarks: These specimens are smaller than those described by Riedel (1958) and Ling et al. (1971) from the Antarctic and Bering Seas respectively.

Recorded range: Neogene (Keany, 1979). Pliocene to Recent (Petrushevskaya 1975).

Observed range: Sporadic occurrences throughout Late Neogene. Not many positive identifications as a lot are specimens which tend to be variants of a more common Spongurus sp. A population. 
Geographic distribution: "cold-water and bipolar" (Ling et al., 1971).

\section{Spongurus sp. A}

Plate 8, figures 1,2: Plate 9, figures 1,3

Description: Similar to Spongurus pylomaticus but differs in two respects. The shell outline is definitely elliptical and the inner spongy meshwork is looser with a concentricity commonly visible in optical section.

Dimensions: Based on six specimens. Length 137-185, width 112-133.

Remarks: Similar to Spongurus (?) sp. A of Nigrini and Lombari (1984, p.S33) but the concentricity is a lot tighter in their figured specimens. As with their specimens it is hard to determine whether the internal structure is trizonal or concentric. The internal structure is very similar to those found in Prunopyle sp. A.

Observed range: Present in $62 \%$ of the radiolarian-bearing samples studied. Tends to be more common in the Miocene.

\section{Genus Spongocore Haeckel 1887 \\ emended herein}

Actinommidae with an ellipsoidal or cylindrical (sometimes three jointed) shell of solid spongy framework, without internal cavity and without latticed medullary shell. Polar spines absent. An outer lattice-mantle is connected with the spongy shell by radial beams. Emended herein to include forms without the lattice-mantle preserved.

Type-species: Spongocore velata Haeckel 1887 : designated by Campbell 1954 (under S. vellata)

\section{Spongocore puella Haeckel}

Plate 8, figures 5,6: Plate 9, figures 6-8

Spongocore puella Haeckel 1887, p.347, pl.48, fig.6.

Spongocore lata Campbell and Clark 1944, p.22, pl.3, figs.5-6.

Spongocore puer Campbell and Clark 1944, p.22, pl.3, figs.7-9.

Spongurus cylindricus Haeckel: Dumitrica 1973, p.834, pl.11, fig.2 (only).

Spongocore puella Haeckel: Kling 1973, p.635, pl.7, figs.18-22.

Spongocore diplocylindrica Haeckel: Renz 1974, pl.15, fig.4.

Spongocore puella Haeckel: Nigrini and Moore, 1979, p.S69, pl.8, figs.5a-c.

Spongocore puella Haeckel: Johnson and Nigrini 1980, pl.1, fig.22.

Description: Test cylindrical, opaque, spongy, with three joints separated by two constrictions. The middle joint normally 1 to 2 times the length of the terminal joints. Numerous, thin, conical, radial stubs may arise from the surface of all three joints. Rarely the middle joint and proximal halves of the terminal joints are covered by a relatively smooth, thin walled, lattice-mantle bearing small, irregularly arranged subcircular pores; mantle supported by numerous radial spines that arise from the middle joint. In some specimens the skeleton is bent at one of the constrictions. 
Dimensions: Based on 30 specimens. Length of skeleton 188-363: diameter of middle joint 37-71: of terminal joints 30-68. Length of lattice mantle 123-191: of radial spines 2-25. Maximum breadth 74-111 (Benson, 1966).

Remarks: Benson (1966) and Dumitrica (1973) noted that the skeleton, although appearing spongy actually consists of closely spaced concentric shells (at least on the middle joints). Petrushevskaya (1975) synonymised Spongocore with Ommatogramma for this reason. No sign of any layering in the arms could be seen in any of the specimens studied although one specimen showed a regularity in the pore structure under SEM imagery which could indicate a regularity in chamber arrangement internally.

Recorded range: Miocene Calocycletta costata Zone (from Kling, 1973) to Recent.

Observed range: Present in $67 \%$ of the radiolarian-bearing samples studied throughout the Late Neogene.

Geographic distribution: "Belongs to a tropical assemblage derived by recurrent group analysis of North Pacific sediments, but the species ranges too far north to be useful in downcore analysis" Nigrini (1970).

\section{Spongocore sp. A}

Plate 9, figure 9

? Spongolena sp. Renz 1974, pl.15, fig.5.

Description: Rare specimens very similar to Spongocore puella with long middle joints (five times the length of the terminal joints).

Recorded range: Renz (1974) recorded her specimen from the Quaternary of DSDP Site 262.

Observed range: Very rare occurrences in Wairarapa and Leader River Tongaporutuan samples. Too rare to be of use biostratigraphically.

\section{Family Phacodiscidae Haeckel 1881}

Discoidal, biconvex to flat skeletons with a latticed outer shell which separates them from other discoidal families.

\section{Genus Heliodiscus Haeckel 1882}

emended Nigrini 1967

Phacodiscidae with a simple or double medullary shell and with numerous ( 7 to 20 or more) simple radial spines on the margin of the disc. Spines variable in number and irregularly disposed. The definition of the genus was emended by Nigrini (1967) to include forms having a double medullary shell and as few as seven radial spines.

Type-species: Heliodiscus inchoatus Rust 1885 


\section{Heliodiscus asteriscus Haeckel}

Plate 8, figures 7,9: Plate 9, figures 11-13

Heliodiscus asteriscus Haeckel 1887, p.455, pl.33, fig.8.

Heliodiscus asteriscus Haeckel: Hays 1965, p.171, pl.2, fig.7.

Heliodiscus sp. A: Petrushevskaya 1975, p.576, pl.1, fig.16.

Heliodiscus asteriscus Haeckel: Weaver 1976a, p.107, pl.6, figs.9,10.

Heliodiscus asteriscus Haeckel: Nigrini and Lombari 1984, p.S39, pl.5, fig.4.

Description: Cortical shell forms a discoidal biconvex lens. Pores circular to subcircular, sometimes hexagonally framed, fairly regularly arranged over most of the smooth shell surface, more irregularly arranged near the centre of the disc; 7-12 pores on a radius. Medullary shell spherical to ellipsoidal with diameter approximately one-third that of the cortical shell, pores approximately same size as those on cortical; attached to the cortical shell by small bars. Inner medullary shell occasionally visible, always attached eccentrically to the inner wall of the outer medullary. Radial spines (10 to 16), sometimes well developed, straight, three-bladed near disc, becoming cylindrical distally, placed more or less regularly around margin of the cortical shell. Spine length up to one-third diameter of cortical shell. Usually a few short slender marginal by-spines present. No marginal girdle or by-spines on the cortical surface.

Dimensions: Based on 20 specimens. Average diameter of cortical shell 140.

Remarks: Some forms approach H. echiniscus Haeckel (Plate 9, figure 14), a form with numerous by-spines some of which can be present on the cortical shell near the equatorial line. $H$. echiniscus is considered by some to be a morphologic variant of $H$. asteriscus (Morley, 1977).

Recorded range: Late Miocene and Pliocene (Weaver, 1976a).

Miocene both in temperate and tropical sectors (Nigrini and Lombari, 1984, CENOP Project). Recent (Nigrini and Moore, 1979).

Observed range: Three forms tabulated. The "large pored" form (Plate 9, figure 13) is restricted to the late Tongaporutuan, occurring in 30 upper Tongaporutuan samples in both Hawkes Bay and Wairarapa. The "small pored" form (Plate 9, figure 12) occurs in 65\% of the radiolarian-bearing samples throughout the Late Neogene but is rare in Plio-Pleistocene sediments. The "long spined" form has one tentative Miocene identification in MSO4, and nine positive Plio-Pleistocene identifications. Although rare, it appears to evolve from the "small pored" form in the early Pliocene. Also twelve Tongaporutuan samples contain rare forms attributed to $H$. cf. echiniscus.

Geographic distribution: Absent south of the Polar Front (Hays, 1965).

Absent south of $46^{\circ} \mathrm{S}$ (Morley, 1977, south Atlantic).

\section{Heliodiscus umbonatum (Ehrenberg) \\ Plate 9, figure 15}

Haliomma umbonatum Ehrenberg 1873, p.236: 1875, pl.27, fig.4.

Heliodiscus cingillum Haeckel 1887, p.448, pl.33, fig.7 (in part).

Periphaena decora Ehrenberg: Sanfilippo and Riedel 1973, p.523, pl.27, fig.5 (only). 
Description: Same as Heliodiscus asteriscus but with smaller pores (12 to 16 on the cortical radius). Well developed hyaline marginal girdle from which flat triangular spines arise.

Remarks: Nigrini and Lombari (1984, p.S39) mention an early Miocene form of $H$. asteriscus similar to the form described herein.

Recorded range: Mid Buryella clinata Zone to near top of Thyrsocyrtis bromia Zone (Eocene and lowermost Oligocene) (Sanfilippo and Riedel, 1973).

Observed range: Found only in the two oldest samples studied: KB04 (Kaiti) and LT09 (Leader).

Family Coccodiscidae Haeckel 1862

emended Sanfilippo and Riedel 1980

Discoidal forms consisting of a lenticular cortical shell enclosing a small single or double medullary shell, and surrounded by an equatorial zone of spongy or concentrically-chambered structure, OR forms with ellipsoidal cortical shell, usually equatorially constricted, and enclosing a single or double medullary shell, the opposite poles of the shell generally bearing spongy columns and/or single or multiple latticed caps.

\section{Genus Didymocyrtis Haeckel 1860a \\ emended herein}

Coccodiscidae with an ellipsoidal cortical shell, normally equatorially constricted in all but the earliest forms. Extra-cortical caps, when present, never more than two or three on each pole. Outer medullary shell commonly lenticular (Sanfilippo and Riedel, 1980). Emended herein to include nonconstricted Late Miocene forms.

Type-species: Haliomma didymocyrtis Haeckel 1862 : illustrated under the invalid name Didymocyrtis ceratospyris.

\section{Didymocyrtis antepenultima (Riedel and Sanfilippo) \\ Plate 10 , figure 5}

Panarium antepenultimum, conditional manuscript name proposed by Riedel and Funnell 1964, p.311.

Ommatartus antepenultimus Riedel and Sanfilippo 1970, p.521, pl.14, fig.4.

Ommatartus antepenultimus Riedel and Sanfilippo: Riedel and Sanfilippo 1971, p.1588, pl.1c, fig.11 (only).

Ommatartus antepenultimus Riedel and Sanfilippo: Westberg and Riedel 1978, pl.2, figs.4,5.

Ommatartus antepenultimus Riedel and Sanfilippo: Sakai 1980, p.708, pl.3, figs.6a-b.

Didymocyrtis antepenultima (Riedel and Sanfilippo): Nigrini and Lombari 1984, p.S55, pl.7, figs.2a,b.

Description: Cortical twin shell slightly constricted equatorially, with circular to subcircular pores. Distal chambers lenticular-hemispherical, as caps on either end of cortical twin shell. The proportion of the height of the polar cap to the length of the cortical shell is between 0.20 and 0.25 (Westberg and Riedel, 1978). Inner medullary shell 
spherical and outer medullary spherical to slightly compressed.

Dimensions: Based on four specimens. Length of cortical shell 90-120. Maximum breadth of cortical shell 85-105. Breadth of outer medullary shell 27-32.

Remarks: Some of the forms included herein did not have the spongy columns on the caps preserved. The forms placed into this species adhere to the ratio of height of polar cap to length of cortical shell restriction outlined by Westberg and Riedel (1978).

Recorded range: Riedel and Sanfilippo (1970, Ommatartus antepenultimus) showed the evolutionary transition from $D$. laticonus to $D$. antepenultima to lie at the base of the Didymocyrtis antepenultima Zone and they show the evolutionary transition from $D$. antepenultima to $D$. penultima to lie within the Didymocyrtis penultima Zone (Late Miocene). Later (1978b), they altered the definition of this zone to the range of Diartus hughesi because of the problem in defining cap height, especially in poorly preserved specimens.

Reynolds (1980, Ommatartus antepenultimus, western North Pacific), defines the Didymocyrtis antepenultima Zone by the range of $D$. antepenultima subsequent to its transition from $D$. laticonus and prior to its transition to $D$. penultima.

Theyer et al. (1978, Ommatartus antepenultimus) dated the first occurrence of $D$. antepenultima at $11.4 \mathrm{Ma}$ and the last occurrence at $5.7 \mathrm{Ma}$.

Observed range: Found associated with G. dehiscens at Kaiti, Wairarapa (SWR4, MS19), and Leader, and is found sporadically in Tongaporutuan samples. Last appearance is at the Miocene/Pliocene boundary unconformity at Mangapoike in sediments containing a tuff dated $5.80 \pm 0.55 \mathrm{Ma}$, this age being supported by magnetostratigraphy (I.C. Wright, pers. comm.). Not associated with G. sphericomiozea. Five samples in the Wairarapa and Leader Miocene contain forms transitional between $D$. laticonus and $D$. antepenultima.

Geographic distribution: "Abundant in all tropical Late Miocene sections examined" (Nigrini and Lombari, 1984, CENOP Project).

\section{Didymocyrtis laticonus (Riedel)}

Plate 10, figure 1: Plate 11, figure 1

Cannartus laticonus Riedel 1959, p.291, pl.1, fig.5.

Cannartus laticonus Riedel: Riedel and Sanfilippo 1971, pl.1c, figs.13,14.

Cannartus laticonus Riedel: Sakai 1980, p.705, pl.3, figs.7a-b, 8a-b.

Didymocyrtis laticonus (Riedel): Sanfilippo and Riedel 1980, p.1009, text-fig.1e.

Didymocyrtis laticonus (Riedel): Nigrini and Lombari 1984, p.S53, pl.7, figs.1a-c.

Description: Cortical twin shell, with subcircular to circular pores, 10 to 15 on the half equator. On the broader parts of the shell, on either side of the equatorial constriction are moundlike protuberances, at which the shell wall is thickened. At each pole of the shell arises a broadly subconical, densely spongy column, which is almost as broad at its base as the polar surface of the twin shell. There are no pronounced caps as in D. antepenultima but a parallel sided clear zone is sometimes present separating the cortical shell from the columns. An extra-cortical, small pored, plate perforate wall is sometimes partially preserved. 
Dimensions: Based on 20 specimens. Length of polar columns 45-70: of cortical shell 93-125. Median breadth 28-40. Maximum breadth 68-113. Breadth of outer medullary shell 30-35 (Riedel, 1959).

Remarks: Westberg and Riedel (1978: p.20, Cannartus laticonus) outlined that the name D. laticonus should only be applied to specimens "in which the height of the clear zone below the spongy column is less than 0.2 the length of the cortical shell".

Recorded range: Theyer et al. (1978, Cannartus laticonus) dated the first occurrence of D. laticonus at $13.5 \mathrm{Ma}$ and the last occurrence at $9.6 \mathrm{Ma}$. In a study of Didymocyrtis spp. from DSDP Site 503A in the eastern tropical Pacific, Riedel and Westberg (1982) show that the increase in cap height during most of the upper Miocene and Pliocene is slight, if it exists at all, though above and below this interval the increase through time is pronounced.

Observed range: Found associated with G. dehiscens at Kaiti, Mangaopari, and Leader. The LAD of this species is a useful middle Tongaporutaun bioevent. The LAD is well defined in Upper Mangaopari Stream (at MS12) although there is one questionable occurrence in MSO5.

Geographic distribution: "Common in all tropical Middle Miocene sections" (Nigrini and Lombari, 1984, CENOP Project).

\section{Didymocyrtis virgineum (Haeckel)}

Plate 8, figure 8: Plate 11, figures $10,11,13,14$

Cyphonium virgineum Haeckel 1887, p.363, pl.39, fig.12.

Cannartus sp. Riedel and Sanfilippo 1971, pl.1D, fig.1.

Ommatartus sp. Foreman 1975, pl.8, figs.17,18.

Ommatartus ? sp. Sakai 1980, pl.5, figs.3a-3b.

Description: Twin cortical shell, occasionally with a slight equatorial constriction, each side of which is subhemispherical. Pores circular in a subregular pattern. No polar caps or columns. Outer medullary shell subspherical to lenticular. Some forms have a tuberculate (knobby) surface.

Dimensions: Based on ten specimens. Length of cortical shell 110-139. Maximum breadth of cortical shell 100-114.

Remarks: Some specimens included in this taxa could be poorly preserved specimens (without polar caps or columns) of Didymocyrtis sp. A, D. antepenultima, or D. laticonus.

Observed range: Tabulated into three forms. The "non-constricted" form is common in the Tongaporutuan and very rare in the Plio/Pleistocene. The highest occurrence is at Cricklewood (CR03) in the dextral G. crassaformis - G. crassula overlap zone. The "constricted" form is not as common as the "non-constricted" but has a similar range, the only Plio/Pleistocene occurrence being between the LAD of C. molestus and the FAD of G. crassula at Waiatai (WA18). The "tuberculate" form is generally restricted to Miocene sediments but occurs rarely into the Pleistocene. 
Didymocyrtis sp. A

Plate 10, figures 2,4: Plate 11, figures 2-9

Cannartiscus marylandicus ? Martin: Bandy, Casey, and Wright 1971, p1.1, fig.5.

Cannartus sp. D Sakai 1980, p.708, pl.5, figs.10a-b (only).

Cannartus laticonus Riedel: Sanfilippo, Burckle et al. 1973, pl.1, fig.6 (only).

Ommatartus antepenultimus Riedel and Sanfilippo: Sanfilippo, Burckle et al. 1973, pl.1, figs.13,15 (only).

Description: This form is comparable to both D. laticonus and D. antepenultima. Robust twin-cortical shell, normally without an equatorial constriction and normally with " $D$. laticonus type" clear zones between the cortical shell and spongy column.

Remarks: Sakai (1980) could not separate Cannartus laticonus (=Didymocyrtis laticonus) and Ommatartus antepenultimus (=Didymocyrtis antepenultima) stratigraphically because of their morphological continuity and the presence of transitional forms over a long stratigraphic interval. Kling (1978, p.237) also notes transitional forms are present.

Recorded range: Mid Dorcadospyris alata Zone to mid Stichocorys peregrina Zone (Sakai, 1980, middle to late Miocene, DSDP Site 436: cores 37-29).

Bandy, Casey, and Wright (1971) have their form dying out in the middle Gilbert.

Observed range: Tabulated into four forms. The most common is the "non-constricted" form, which is persistent throughout the Tongaporutuan. Its highest occurrence is at Millers Road (SMR1) where it is associated with forms approaching G. inflata (middle Opoitian). It is rare in basal Opoitian sediments. The "constricted" form is not as abundant and last appears before the FAD of G. sphericomiozea. The "spherical" form is found only in four upper Tongaporutuan samples and is too rare to be of biostratigraphic use. The "narrow" form is only in the Diartus hughesi Zone.

\section{Didymocyrtis tetrathalmus tetrathalmus (Haeckel)}

Plate 10, figures 6,7: Plate 11, figure 12

Panartus tetrathalmus Haeckel 1887, p.378, p1.40, fig.3.

Panartus tetrathalmus Haeckel: Nigrini 1967, p.30, p1.2, figs.4a-d.

Ommatartus tetrathalmus (Haeckel): Riedel and Sanfilippo 1971, p.1588, pl.1C, figs.5-7.

Ommatartus tetrathalmus tetrathalmus (Haecke1): Nigrini and Moore 1979, p.S49, p1.6, figs.1a-d.

Didymocyrtis tetrathalmus (Haeckel): Sanfilippo and Riedel 1980, text-fig.1g.

Description: Cortical twin-shell, constricted equatorially, with subcircular to subangular pores having no definite arrangement. Surface usually rough, spiny. Polar caps, when present, are hemispherical to conical, approximately the same breadth as the cortical twin-shell, supported by about ten spines. Caps generally more delicate with smaller pores. No spongy columns.

Dimensions: Length of cortical twin-shell 90-136: of polar caps 36-63. Maximum breadth of cortical twin-shell 72-109 (Nigrini, 1967), 
Remarks: Differentiated from D. tetrathalmus coronatus (Haecke1) by the absence of stout, unbranched, three-bladed spines at the distal ends of the cortical twin-shell and/or polar caps. Didymocyrtis avitus (Riedel) which is a transitional form between D. tetrathalmus tetrathalmus and D. penultima (Riedel) has a tuberculate (knobby) cortical shell.

Recorded range: 4 Ma to present (Casey and Reynolds, 1980).

Observed range: Oldest occurrence is in Wainuioru Valley (SWR1), basal Opoitian. Found sporadically in Plio/Pleistocene sediments.

Geographic distribution: "Abundant in low latitudes, forming up to 29\% (usually $9 \%$ to $22 \%$ ) of the described populations. South of $35^{\circ} \mathrm{S}$ only very few specimens have been observed" (Nigrini, 1967, Indian Ocean).

"absent south of $35^{\circ} \mathrm{S}$ " (Morley, 1977, south Atlantic).

"Present in all samples except southernmost (about $48^{\circ} \mathrm{S}$ ), abundant in low latitudes but very rare between $37^{\circ} \mathrm{S}$ and $46^{\circ} \mathrm{S}$ " (Johnson and Nigrini, 1980, western Indian Ocean).

Genus Diartus Sanfilippo and Riedel 1980

Coccodiscidae with the cortical shell generally tending to be subcylindrical, because of the concentration of protuberances in a single ring at each pole. When extra-cortical caps are present, there are of ten more than two or three on a pole. Outer medullary shell commonly spherical.

Type-species: Ommatacampe hughesi Campbell and Clark 1944

Diartus hughesi (Campbell and Clark) group

Plate 9, figures 16,17: Plate 10, figure 3

Ommatacampe hughesi Campbell and Clark 1944, p.23, pl.3, fig.12.

Ommatartus hughesi (Campbell and Clark): Riedel and Sanfilippo 1970, p.521.

Amphymenium challengeri Weaver 1976a, p.104, p1.8, figs.4,5.

Diartus hughesi (Campbell and Clark): Sanfilippo and Riedel 1980, p.1009, text-fig.1i.

Diartus hughesi (Campbell and Clark): Nigrini and Lombari 1984, p.S43, pl.6, fig.2.

Description: Shell with cylindrical centre and seven to nine chambers at each end; in most specimens the central cortical section is partially obscured by a raised patagium enveloping the central section but it appears to be about 0.2 total length; peripheral cortical shell increases in breadth distally with seven to nine chambers on each opposite pole; these chambers slightly kidney shaped especially towards distal end. Pores generally subspherical and increasing in size distally. Distal most chamber on each end has two or three projecting spines, two of which (one on either pole) appear to arise from near the central cortical section.

Dimensions: Based on four specimens. Total length 200. Maximum breadth (across peripheral arm) 51. Minimum breadth (in cortical section) 25.

Remarks: The presence of a patagium around the cortical section is atypical of $D$. hughesi. There is no problem in placing the forms in the genus Diartus as Sanfilippo and Riedel (1980) do not discount the presence or absence of a patagium. However, the original description of this species (Campbell and Clark, 1944) and subsequent descriptions and 
It is accepted that the treatment of the two variants under the name Diartus hughesi differs from most previously published work. As both variants appear to have the same stratigraphic range in the New Zealand Late Neogene this treatment does not affect the stratigraphic comparison with previously published ranges. 
illustrations show no sign of a patagium being present, except in one case (Riedel and Sanfilippo, pl.12, fig.4. in Berggren et al., 1976). This feature is common in the genus Amphymenium Haeckel (1881) but again no mention is made of it in the original generic description. The main difference between the two genera is the make-up of the central cortical section; Diartus having an equatorial constriction with the cortical shell comprising two hemispherical halves and Amphymenium being composed of a concentrically formed central section. Unfortunately the central section is poorly defined in most specimens found in this study. Of the members of Amphymenium, the closest to the forms described herein would be $A$. challengeri Weaver. As it was found to be difficult to define the form of the central cortical section and the patagium was often lost due to poor preservation, all forms were lumped together in the one group even if it was clear that some specimens (e.g. Plate 9, figure 17: Plate 10, figure 3) were more related to Amphymenium than Diartus. See note on facing page.

Recorded range: Riedel and Sanfilippo (1978b, Ommatartus hughesi) define the lower limit of the Didymocyrtis antepenultima Zone by the evolutionary bottom of $D$. hughesi. The upper limit of the zone is defined by the morphotypic top of $D$. hughesi (Late Miocene). Reynold's (1980) Diartus hughesi Zone in the western North Pacific is defined at its base by the evolutionary transition from $D$. petterssoni to $D$. hughesi. The top of the zone is defined by the evolutionary transition from $D$. laticonus to $D$. antepenultima. According to Reynolds the zone is not reported by Riedel and Sanfilippo, because at lower latitudes the transition from Diartus petterssoni to $D$. hughesi and Didymocyrtis laticonus to $D$. antepenultima are coeval.

Theyer et al. (1978, Ommatartus hughesi) date the first occurrence of D. hughesi at 11.4 $\mathrm{Ma}$ and the last occurrence at $9.0 \mathrm{Ma}$ but DSDP Leg 85 results suggest that this age should be $8.2 \mathrm{Ma}$ (after Nigrini and Lombari, 1984).

Observed range: Occurs with G. dehiscens at Kaiti (KB01) and Leader (LT05, LT06). Its LAD is a useful biostratigraphic event in Wairarapa, disappearing abruptly at Mangaopari (MS08). Northern samples that should contain this species are generally lacking it (e.g. TM20-23). See biostratigraphic discussion. See note on facing page.

Geographic distribution: Common to abundant in the early Late Miocene sections examined. Absent from temperate latitude sites (Nigrini and Lombari, 1984, CENOP Project).

\section{Family Spongodiscidae Haeckel 1862 emended Riedel 1967a}

Discoidal, spongy or finely-chambered skeleton, with or without surficial pore-plate, often with radiating arms of marginal spines, and without a large central phacoid shell. Large, polyphyletic group, for which no satisfactory classification has been proposed.

\section{Genus Amphirhopalum Haeckel 1881 emended Nigrini 1967}

Spongodiscidae with a concentrically chambered central disc. Margin of disc has two radially chambered arms opposite each other in one main axis. Both arms forked (or one simple, other forked). Patagium may or may not be present. 


\section{Amphirhopalum cf. ypsilon Haeckel \\ Plate 12, figure 5}

Amphirrhopalum ypsilon Haeckel 1887, p.522.

Amphirhopalum ypsilon Haeckel: Nigrini 1967, p.35, p1.3, figs.3a-d.

Amphirhopalum ypsilon Haeckel: Casey and McMillen 1977, pl.1, fig.11.

Amphirhopalum ypsilon Haeckel: Nigrini and Moore 1979, p.S75, pl.10, figs.1a-e.

Description: Shell with two opposite, chambered arms, one of which is forked distally, central structure appears as a concentrically annulated disc. (Central structure actually composed of two inner spherical shells and an outer oblate sphaeroidal shell (Nigrini, 1967). Arms elliptical in cross-section. Unforked arm is narrow proximally and expands distally then narrows slightly. Usually about 7-9 distinct chambers, slightly convex distally. Forked arm expands distally and branches at maximum breadth, the chamber arrangement being the same as the unforked arm.

Dimensions: Total length 236-307. Radius of simple arm 119-155: of forked arm 119-155. Maximum breadth of simple arm 63-119: of branches on forked arm 36-63 (Nigrini, 1967).

Remarks: Nigrini (1967) notes that patagium may be attached to the shell. Nigrini (1971) notes that "specimens from the upper part of the cores examined average four or five proximal chambers on the forked arm before it bifurcates. Lower down in the cores this number decreases, and forms with two or three (sometimes one) such chambers predominate". Specimens found herein appear to fork after only one or two proximal chambers so could be early members of this species. The likely ancestor to this species, $A$. virchowii, has smoother, more distinct and more rounded chambers.

Recorded range: "there is a transition from $A$. virchowii to $A$. ypsilon near the Plio-Pleistocene boundary" (Nigrini, 1974, p.1065).

Observed range: Found sporadically in Plio-Pleistocene sediments. Its lowest occurrence (tentative) is in sample SWR1 where it is associated with a basal Opoitian planktic foraminiferal fauna.

Geographic distribution: "Present in samples north of about $35^{\circ} \mathrm{S}$ " (Nigrini, 1967, Indian Ocean).

"Belongs to a tropical assemblage derived by recurrent group analysis of North Pacific samples, but the species does range as far north as $40^{\circ} \mathrm{N}$ in the western Pacific" (Nigrini, 1970).

\section{Notes on the genera Hymeniastrum and Dictyocoryne}

The taxonomic subdivision of these genera is discussed by Nigrini and Moore (1979) the main points being:

1. Development of patagium is of no consequence taxonomically.

2. All the forms of this general type possess some degree of central sphaeroidal and/or discoidal structure, but this may be obscured by spongy material. The degree of visibility may be of generic significance. 
3. Some forms exhibit bilateral symmetry while others have equiangular displacement between arms and this feature may be of generic significance.

\title{
Genus Dictyocoryne Ehrenberg 1860 sensu Nigrini and Moore 1979
}

Spongodiscidae with three simple, undivided, spongy arms, with or without terminal spines, equally to bilaterally disposed. Patagium may or may not be present. Central structure of ten obscured by spongy meshwork, but consisting of 5 to 10 or more concentric discoidal shells.

Type-species: Dictyocoryne profunda Ehrenberg 1872a

\author{
Dictyocoryne profunda Ehrenberg \\ Plate 12, figures 1,2: Plate 13, figures 1-4
}

Dictyocoryne profunda Ehrenberg 1872a, p.288: 1872b, pl.7, fig.23.

Dictyocoryne profunda Ehrenberg: Ling and Anikouchine 1967, p.1489, pls.191,192, fig.6.

Rhopalastrum profunda (Ehrenberg): Petrushevskaya and Kozlova 1972, p.529, pl.17, figs.4-6, pl.20, fig.8.

Rhopalastrum profundum (Ehrenberg): Keany 1979, p.54, pl.2, figs.6,7, pl.5, fig.6.

Dictyocoryne profunda Ehrenberg: Nigrini and Moore 1979, p.S87, pl.12, fig.1.

Description: Arms approximately of equal size and equidistant to bilaterally arranged, club-shaped, from 2.5 to 3 times as broad at the ends as in the narrowest part although in poorly preserved forms, arm ends not as broad. Length of arms 2.5 to 3 times the diameter of the central disc; central disc normally covered by a spongy meshwork but 5-7 concentric rings present in some specimens. Patagium may or may not be present, reaches almost to the ends of the arms in well preserved specimens, rarely showing a crude chambering.

Dimensions: Based on ten specimens. Length of arms from geometric centre to distal end 120-158. Maximum breadth of arms 60-100. Minimum breadth of arms (measurable in only three of the specimens 35-37).

Remarks: Plate 13, figs.1-4 shows the gradual loss of patagium in specimens of $D$. profunda. This supports the view proposed by Ling (1966) and Nigrini and Moore (1979) that patagium is of no generic significance. Differs from $D$. truncatum in that the arms are not as broad proximal to the centre.

Recorded range: Early Miocene to Recent (Petrushevskaya and Kozlova, 1972).

Neogene (Keany, 1979).

Observed range: Found in $83 \%$ of the radiolarian-bearing samples examined. Tends to be more sporadic in Plio-Pleistocene sediments (see $H$. euclidis).

Geographic distribution: "Present in most samples north of about $25^{\circ} \mathrm{S}$ : very rare occurrences as far south as about $33^{\circ} \mathrm{S}^{\prime}$ (Johnson and Nigrini, 1980, western Indian Ocean). 
Spongodiscidae with three simple, undivided, chambered arms, with or without terminal spines. Triangular shell, equiangular displacement between arms. Patagium may or may not be present. Central structure often obscured by spongy meshwork, but consisting of 4 to 5 concentric shells (after Nigrini and Moore, 1979). Emended herein to include forms without an equiangular displacement between arms but still possessing a bilateral symmetry. Hymeniastrum pythagorae Ehrenberg (1854, pl.36, fig.31), although nearly equiangular, shows bilateral symmetry, the angles between the arms being 125, 125 and 110 degrees. Type-species: Hymeniastrum pythagorae Ehrenberg 1854a

Note: "It is entirely possible that Dictocoryne and Hymeniastrum are cogeneric" (Nigrini and Moore, 1979).

\section{Hymeniastrum euclidis Haeckel}

Plate 12, figures 3,4: Plate 13, figure 5

Hymeniastrum euclidis Haeckel 1887, p.531, pl.43, fig.13.

Euchitonia furcata Ehrenberg: Ling and Anikouchine 1967, p.1484, pls.189,190, figs.5,6,7 (only).

Cyclastrum ? sp. Ling and Anikouchine 1967, p.1487, pls.191,192, figs.1,2.

Hymeniastrum euclidis Haeckel: Ling and Anikouchine 1967, p.1488, pl.191,192, fig.3.

Hymeniastrum euclidis Haeckel: Nigrini and Moore 1979, p.S91, pl.12, fig.3.

Description: Discoidal skeleton with three arms of nearly equal size and similar shape. Arms chambered, chambers especially visible in area proximal to centre. Normally equiangular displacement of arms but very rare forms have one angle at about $80^{\circ}$ but still possess bilateral symmetry. Central region circular to subtriangular in outline, consisting of 4-5 concentric discoidal latticed shells. Patagium may or may not be present.

Remarks: Some forms deviate from $H$. euclidis sensu stricto in the non-equiangular displacement of the arms. Differs from Dictyocoryne profunda in having conspicuously chambered arms.

Recorded range: "Present throughout most of the Miocene sections examined from both tropical and temperate latitudes: rare in temperate latitudes and absent from the Early Miocene sections of DSDP Site 173. Increasingly abundant in younger sediments" (Nigrini and Lombari, 1984, Hymeniastrum spp., CENOP Project).

Recent (Nigrini and Moore, 1979).

Observed range: A lot of the forms found are transitional with $D$. profunda and there are not many positive $\boldsymbol{H}$. euclidis sensu stricto identifications. Tends to be more common in Plio-Pleistocene sediments where it is perhaps replacing $D$. profunda.

Geographic distribution: "Present in all samples except southernmost (about $48^{\circ} \mathrm{S}$ )" (Johnson and Nigrini, 1970, western Indian Ocean).

"belongs to a tropical assemblage derived by recurrent group analysis of North Pacific samples, but the species ranges too far north to be useful in down core analysis" (Nigrini, 1970) 
Spongodiscidae with flattened, obsoletely radiate-stellate shell. Median disc spongy, and the stellate radii swollen at the apex.

Type-species: Spongaster tetras Ehrenberg 1860

\section{Spongaster pentas Riedel and Sanfilippo \\ Plate 13, figure 6}

Spongaster pentas Riedel and Sanfilippo 1970: p.523, pl.15, fig.3.

Spongaster pentas Riedel and Sanfilippo: Nigrini and Lombari 1984, p.S65, p1.9, fig.2.

Description: Spongy pentagonal disc. Rays from centre to marginal angles slightly thicker. Central area (one-third of disc diameter) more dense, thicker with indefinite concentric structure.

Dimensions: Diameter 170-290 (Riedel and Sanfilippo, 1970).

Recorded range: Riedel and Sanfilippo (1978b) define the base of the Spongaster pentas Zone (early Pliocene) by the evolutionary transition from Spongaster berminghami to $S$. pentas.

First occurrence dated by Theyer et al. (1978) at $4.7 \mathrm{Ma}$ and last occurrence at $3.7 \mathrm{Ma}$.

Casey and McMillen (1977) noted that tropical Atlantic, Gulf of Mexico and Caribbean plankton tows and Holocene sediment samples have yielded Rose Bengal stained specimens of Spongaster pentas and $S$. berminghami. These specimens are believed to represent a relict radiolarian fauna. This presents biostratigraphic problems with the suggestion that the occurrence of this species in the tropical Pacific late Neogene may be provincial.

Observed range: One specimen found in the upper Tongaporutuan (HR01).

\section{Notes on the genera Stylodictya, Porodiscus and Stylochlamydium.}

These genera are abundant, but their identification is difficult. Their morphological characteristics are frequently gradational and incomplete specimens numerous. According to some classification schemes, rotation of the specimen is necessary to confirm the specific identification; clearly this is impossible when counting specimens in a fixed slide. Kozlova (in Petrushevskaya and Kozlova, 1972) presented a generic revision based primarily on the nature of the central structure. Unfortunately the central structure is quite of ten covered by a spongy meshwork. The major generic differences used herein are

Stylodictya: Concentric rings. First system clearly visible in well preserved specimens.

Porodiscus: Concentric rings. First system and proximal rings covered by a spongy meshwork and therefore opaque in well preserved specimens.

Stylochlamydium: Concentric rings normally increasing in breadth distally. Strong radial spines and an equatorial marginal girdle. 
emended Kozlova 1972 (in Petrushevskaya and Kozlova, 1972).

Spongodiscidae with a skeleton that is flat or slightly concave with round outline; consists of equatorial and sagittal girdles (frontal girdle is not developed), wings of the rings are displaced at $45^{\circ}$ in relation to the main axes; at their merging point they do not envelope each other and thus form girdles of regular round or scalloped form, especially distinctive in the first systems. The first system is clearly visible, cupolas do not overlap each other, and are not submerged into the skeleton; the distance between systems is greater than or equal to the diameter of the central chamber. The main and additional spines are well developed and often extend as external spines. Rim of the disc is smooth with 4,8 or more spines.

Type-species: Stylodictya gracilis Ehrenberg 1854

\section{Stylodictya validispina Jorgensen}

Plate 12, figures 6,8,9: Plate 15 , figure 1

Stylodictya validispina Jorgensen 1905, p.119, pl.10, fig.40.

Stylodictya validispina Jorgensen: Keany and Kennett 1975, pl.3, fig.7.

Stylodictya sp. Petrushevskaya 1975, pl.40, figs.3,4.

Stylodictya stellata Bailey group: Petrushevskaya 1975, p.576, pl.6, fig.9.

Stylodictya validispina Jorgensen: Nigrini and Moore 1979, p.S103, pl.13, figs.5a,b.

Description: Skeleton in form of a flat disc not thickened in the middle. Central chamber distinctly visible. Concentric rings of chambers disposed regularly, usually number 5-6; their width hardly increases to the periphery of the disc. Pores on the walls of chambers subregular, usually 2-2.5 pores located in the width of one ring. Pores on the peripheral rings somewhat larger than those on the central rings. Irregularly arranged radial needles extend from the margin of the disc, some appear to be extensions of faintly visible radial bars which pierce the outer 2 to 3 rings. More commonly the needles are broken off at their base. Rare forms include those with a quadrate outline and heavily spinose forms.

Dimensions: Diameter of central chamber 12-15: of disc with five rings 140 (Nigrini and Moore, 1979).

Remarks: Differs from $S$. aculeata Jorgensen by having a greater number of narrower, more regularly concentric chambers and smaller pores.

Recorded range: "Present throughout the late Early to Late Miocene sections examined from both tropical and temperate latitudes" (Nigrini and Lombari, 1984, CENOP Project). Known from the Recent.

Observed range: Tabulated into three forms. S. validispina sensu stricto is present in $72 \%$ of the radiolarian-bearing samples examined. Tends to be slightly more sporadic in younger sediments. The "spinose" form has a highest occurrence below the LAD of C. molestus at Waiatai but is too rare to be of biostratigraphic use. The "quadrate" form is found in only eleven samples from throughout the Late Neogene. 
Geographic distribution: "prefers Northern (Polar factor) conditions" (Sachs, 1973, Late Pleistocene subarctic Pacific).

"this species loads most heavily in factor 3 (transitional) but also loads in factor 1 (subpolar). The greatest abundances for this species are to the north of $40^{\circ} \mathrm{N}$ " (Robertson, 1975, northwest Pacific).

\section{Stylodictya cornuspira Campbell and Clark}

Plate 12 , figure 7

Stylodictya cornuspira Campbell and Clark 1944, p.27, pl.3, fig.22.

Description: Same as Stylodictya validispina except the rings form a spiral from the centre.

Observed range: Rare sporadic occurrences throughout the Late Neogene.

\section{Genus Porodiscus Haeckel 1881 \\ emended herein}

Spongodiscidae with a skeleton that is flat or slightly concave in its centre, has a rounded outline, and is composed of annular equatorial rings. The first system has a central chamber and one ring, very rarely submerged in the skeleton; distance between the annular rings is less than or equal to the diameter of the initial chamber. Main spines are indistinct and as a rule cannot be distinguished from secondary spines. The rim of the skeleton is either smooth or covered by numerous spines (Kozlova, in Petrushevskaya and Kozlova, 1972). Emended herein to include only forms that have a spongy meshwork covering the central chambers and proximal rings in well preserved specimens.

Type-species: Flustrella concentrica Ehrenberg 1838

\section{Porodiscus sp. A}

Plate 14, figures 1,2: Plate 15 , figures 2,3

Porodiscus sp. A Nigrini and Moore 1979, p.S107, pl.14, figs.1,2b (only).

Perichlamidium sp. Petrushevskaya 1975, pl.40, figs.1,2.

Description: Skeleton in form of a disc thickened in the central part and therefore opaque. Central structure obscured by spongy meshwork. Chambers normally disposed in concentric rings, rings number 7 to 9 , width of chambers not increasing to periphery of disc. Rounded pores, subregularly arranged and slightly smaller in the central region.

Dimensions: Based on seven specimens. Diameter of central opaque part of shell 50-94: of shell with six rings 150-260.

Remarks: Differs slightly from Nigrini and Moore's (1979) specimens in having less number of pores per concentric ring width and being slightly larger. Some forms have smaller pores on the outer surface (from SEM studies) than others but this may be related to differing preservation. Differs from Stylodictya validispina in having a thickened opaque central region. 
Observed range: Present in $86 \%$ of the radiolarian-bearing samples examined from throughout the Late Neogene. A "spiralling" form was found in eleven samples also throughout the time range studied.

\section{Porodiscus sp. B}

Plate 14, figures 3,4 : Plate 15 , figures $4-6$

Porodiscus sp. A Nigrini and Moore 1979, p.S107, pl.14, fig.2a (only).

Description: Skeleton slightly smaller than Porodiscus sp. A with more rings (approximately 10) which show less concentricity. Under SEM imagery the pores also show a tendency towards a more random distribution.

Dimensions: Based on five specimens. Diameter of central part of shell 80: of skeleton 150 . Remarks: This form with a large number of rings could be the same as those found by Petrushevskaya (1967) in the Pacific Ocean sector of the Antarctic Ocean.

Observed range: Present throughout the Late Neogene. Tends to be more abundant in Miocene sediments but is not common enough to determine accurately.

\section{Genus Stylochlamydium Haeckel 1881}

emended herein after Nigrini and Moore (1979)

Spongodiscidae with skeleton that is flat or slightly concave in its centre, has a rounded outline. Central structure consists of concentric rings, often covered by a spongy meshwork. Numerous (five or more, commonly eight to twelve) solid radial spines, regularly or irregularly disposed on the margin of the circular or polygonal disc; margin of the disc surrounded by a thin, porous (but not chambered), equatorial girdle. Spines may or may not pierce the equatorial girdle.

Type-species: Stylochlamydium asteriscus Haeckel 1887

\section{Stylochlamydium asteriscus Haeckel \\ Plate 14 , figure 5}

Stylochlamydium asteriscus Haeckel 1887, p.514, pl.41, fig.10.

Stylochlamydium asteriscus Haeckel: Nigrini and Moore 1979, p.S113, pl.14, fig.5.

Description: Circular disc with centre somewhat thickened. Concentric rings surround a central chamber (which is often covered by a spongy meshwork). Rings increase in breadth toward shell margin. Pores are subcircular, approximately the same size and evenly spaced, 1-3 per ring. Marginal band is a thin porous, equatorial girdle (normally present). Radial needle-like spines (up to 15) extend from at or near the centre to the periphery and beyond, subdividing the concentric rings into chambers.

Dimensions: Based on 20 specimens. Diameter of central shell 10-12: of shell with five bands 94-110 (after Lombari, in Nigrini and Lombari, 1984). Shell with equatorial girdle 140. 
Recorded range: "common to abundant throughout the Miocene sections examined from both tropical and temperate latitudes" (Nigrini and Lombari, 1984, CENOP Project). Known from Recent.

Observed range: Sporadic occurrences throughout the upper Neogene.

Geographic distribution: Molina-Cruz (1975) subdivided forms under this name into three variants. One variant "has an opaque centre and is mostly abundant in the equatorial region" and is most like the forms described herein.

\section{Genus Spongotrochus Haeckel 1860b}

Spongodiscidae with a discoidal or lentiform, biconvex skeleton with innumerable small branches forming a dense or loose web (without concentric rings or latticed plate). With five or more marginal spines in the plane of the disc as well as spines radiating from both surfaces of the disc.

Type-species: Spongotrochus brevispinus Haeckel 1862

\section{Spongotrochus glacialis Popofsky}

Plate 14, figures 6-9: Plate 15, figures 7-11

Spongotrochus glacialis Popofsky 1908, p.228, pl.26, fig.8, pl.27, fig.1, pl.28, fig.2.

Spongotrochus ? glacialis Popofsky: Riedel 1958, p.227, pl.2, figs.1,2.

Spongotrochus glacialis Popofsky: Keany and Kennett 1975, pl.1, fig.12.

Spongotrochus glacialis Popofsky group: Petrushevskaya 1975, p.575, pl.5, fig.8, pl.35, figs.1-6.

Spongotrochus glacialis Popofsky: Keany 1979, p.54, pl.2, figs.9,10, pl.5, fig.8.

Spongotrochus glacialis Popofsky: Casey and Reynolds 1980, pl.2, fig.15.

Spongotrochus glacialis Popofsky group: Nigrini and Lombari 1984, p.S79, p1.11, fig.2.

Description: Shell biconvex-discoidal, consisting of a disc of spongy structure, thickened in its central portion (a quarter to half of its total diameter); with rarely preserved numerous acicular or acutely conical spines of different lengths around its circumference and also near the thickened central portion. Rarely an enclosing lenticular lattice shell is in contact with the disc by short bars, at or near its circumference. The lattice shell has an uneven surface with small subcircular to circular pores (smaller than the pores in the underlying spongy mass) randomly distributed over its surface. Very poorly preserved (thin) specimens shown an indefinite radial alignment of pores in the spongy network.

Dimensions: Based on 17 specimens. Average diameter of shell 211 (range 109-300).

Remarks: There is a possibility that specimens of Spongopyle oculosa Dreyer without its characteristic pylome tube preserved, have been included in this species. Riedel (1958) notes a wide variation in the forms he described, probably including the abundant Antarctic form which Popofsky identified as Stylotrochus arachnius (Haeckel) and some forms described by Popofsky (1908) as Spongodiscus favus Ehrenberg maxima which Riedel considers to be no more than incompletely developed forms of $S$. glacialis. 
Recorded range: Miocene to Recent (Petrushevskaya, 1975).

Neogene (Keany, 1979).

Observed range: Present in $92 \%$ of the radiolarian-bearing samples studied. Very persistent and occurs in samples with very poor siliceous preservation.

Geographic distribution: "Present throughout the Miocene sections examined from both tropical and temperate latitudes" (Nigrini and Lombari, 1984, CENOP Project).

"Higher percentage values are generally found under subantarctic waters where, with few exceptions, it constitutes over $10 \%$ of the total Radiolaria"; "The southern boundary of the area with more than $10 \% \mathrm{~S}$. glacialis being coincident with the average position of the Antarctic Polar Front. The northern limit of the area with over $10 \% \mathrm{~S}$. glacialis cuts the isotherms and separates the subtropical Atlantic fauna with less than $10 \% \mathrm{~S}$. glacialis from that of the subtropical Indian Ocean where it generally constitutes over $10 \%$ of the total Radiolaria" (Lozano, 1974).

\section{Family Pyloniidae Haeckel 1881}

Regular, incompletely latticed cortical shell, distinguished by two to four or more symmetrically disposed gates or large fissures remaining between one to three latticed dimensive girdles (perpendicular one to another). One, two, or three concentric systems of such girdles (each system with three girdles) may be developed.

\section{Genus Hexapyle Haeckel 1881}

Pyloniidae with a simple spherical central chamber surrounded by two concentric tri-radial girdles. Six gates between three double arm-chambers (three inner and three outer); no chambered marginal girdle; faces of the gates simple or in well preserved specimens barred by a latticed equatorial girdle.

Type-species: Hexapyle triangula Haeckel 1887

\section{Hexapyle cf. dodecantha Haeckel \\ Plate 14, figure 11}

Hexapyle dodecantha Haeckel 1887, p.569, pl.48, fig.7.

Hexapyle dodecantha Haeckel: Renz 1974, pl.13, fig.7.

Hexapyle dodecantha Haeckel: McMillen and Casey 1978, p1.2, fig.22.

cf. Hexapyle spp. Nigrini and Moore 1979, p.S121, pl.16, figs.1a-c.

Description: Test consisting of a double pylodiscid shell. Shell subtriangular in outline with three relatively large gates at the apex of each angle. Outer lattice has large subcircular pores and is normally thorny, the long, slender, cylindrical spines being broken off. Innermost structure within first pylodiscid shell not observed. This may consist of a central node from which radiate three radial beams (after Benson, 1966).

Dimensions: Length of base of inner triangular pylodiscid shell 18-43: of outer pylodiscid shell 80-137 (Benson, 1966). 
Remarks: Completely developed shells with outer lattice covering not found. This form is only tentatively placed in this species because the inner pylodiscid shell is about twice the size of the gates whereas all the figured specimens in the synonomy have gates the same size as the inner shell. Identification of this species would depend on its orientation.

Recorded range: Renz's (1974) specimens are from Quaternary sediments.

Observed range: Only positively identified in Tongaporutuan samples although there are two tentative identifications in Opoitian samples (SWR3, SMR1). Too rare to be of use biostratigraphically.

\section{Genus Tetrapyle Muller 1859}

Pyloniidae with two systems of concentric girdles, medullary trizonal. Cortical shell with two perfect girdles and four simple gates.

Type-species: Tetrapyle octacantha Muller 1858

Tetrapyle octacantha Muller group

Plate 13, figures 9-13: Plate 14, figures 10,12

Tetrapyle octacanta Muller 1858, p.33, pl.2, figs.12,13, pl.3, figs.1-12.

Phorticium pylonium Haeckel 1887, p.709, pl.49, fig.10.

Phorticium pylonium Haeckel: Cleve 1899, p.31, pl.3, fig.2.

Tetrapylonium clevei Jorgensen 1900, p.64.

Tetrapyle (?) sp. Dumitrica 1973, pl.6, fig.5.

Phorticium clevei (Jorgensen): Bjorklund 1976, pl.4, figs.6-10.

Phorticium clevei (Jorgensen): Keany and Kennett 1975, pl.3, fig.6.

Phorticium clevei (Jorgensen) group: Petrushevskaya 1975, p.573.

Tetrapyle octacantha Muller: McMillen and Casey 1978, pl.3, figs.2a,b.

Pylonidae genn. et. spp. indet. Riedel and Sanfilippo 1978a, pl.3, figs.13-15.

Phorticium clevei (Jorgensen): Keany 1979, p.54, p1.2, fig.5.

Tetrapyle octacantha Muller: Nigrini and Moore 1979, p.S125, pl.16, figs.3a-b.

Phorticium pylonium Haeckel: Nigrini and Lombari 1984, p.S85, pl.12, figs.2a,b.

Description: Cortical shell irregular, ellipsoidal, about three times as large as the enclosed ellipsoidal to spherical inner shell. Cortical shell in various stages of development but even in the most developed forms there are still some subspherical gates present; connected to the inner shell by radial beams and irregular latticed girdles. Surface of shell spiny. One specimen has a subspherical (third girdle) preserved (Plate 14, figure 12).

Dimensions: Based on twelve specimens. Length of major axis of outermost shell 78-140: of minor axis 46-85. Length of major axis of inner shell 23-55: of minor axis 15-47.

Remarks: I have lumped together all forms with an ellipsoidal outer shell, in various stages of development, with gates and with simple or Larnacilla-type inner shell because of the difficulty in determining the shape of the central structure. 
Recorded range: "Common to abundant in all the Miocene sections examined from both tropical and temperate latitudes" (Nigrini and Lombari, 1984, CENOP Project, P. pylonium).

"Present throughout the Late Miocene sections examined from both tropical and temperate latitudes. Rare in material from temperate latitudes; abundant in tropical material" (Nigrini and Lombari, 1984, CENOP Project, T. octacantha).

Riedel and Sanfilippo's (1978a) forms are from the Sicilian Lower Pliocene.

Neogene (Keany, 1979, P. clevei).

Miocene to Recent (Petrushevskaya, 1975, P. clevei group).

Observed range: Present in $65 \%$ of the radiolarian-bearing samples examined from throughout the Late Neogene. Tends to be more sporadic in Plio-Pleistocene sediments.

Geographic distribution: Cosmopolitan.

Family Larnacidae Haeckel 1887

Regular, completely latticed lentelliptical cortical shell, without open gates or annular constrictions; either cortical or medullary trizonal, composed of three elliptical, latticed dimensive girdles of different sizes, perpendicular to one another.

\section{Genus Larnacilla Haeckel 1887}

Larnacidae with a simple lentelliptical cortical shell connected by the lateral wings of a latticed transverse girdle with the simple, spherical or lentelliptical medullary spines. Surface without radial spines.

Type-species: Larnacilla typus Haeckel 1887

\section{Larnacilla typus Haeckel}

Plate 13 , figure 7

Larnacilla typus Haeckel 1887, p.617, pl.50, fig.1.

Description: Shell outline rounded square to parallelogram. Cortical shell smooth with subcircular to circular pores in a subhexagonal arrangement, about ten on the half equator. Gates (between transverse and lateral girdles) roundish rectangular; radial beams support side of gate. Medullary not seen but according to Haeckel is spherical, scarcely one-third as broad as the lentelliptical cortical shell.

Dimensions: Based on one specimen. Length of shell 175. Breadth of shell 154. Height of gate 18.

Remarks: Slightly larger than the specimens described by Haeckel 1887.

Observed range: Only two positive identifications in Tongaporutuan samples (PB04, LT06) the latter with G. dehiscens and one tentative identification in LT01 where it is associated with Didymocyrtis tetrathalmus tetrathalmus. 
Family Tholoniidae Haeckel 1887

Regular, completely latticed cortical shell, which is composed of two to six or more hemispherical or cap-shaped domes (vaulted chambers or cupolas). The domes lie opposite in pairs on the poles of the three dimensive axes; are separated by annular constrictions; and surround a simple or Larnacilla-shaped central chamber.

\section{Genus Cubotholus Haeckel 1887}

Tholoniidae with simple cortical shell (without external veil), composed of six hemispherical cupolas, opposite in pairs on the poles of three axes perpendicular to one another, covering six sides of the cuboidal central chamber (with medullary shell).

Type-species: Cubotholus regularis Haeckel 1887 : designated by Campbell 1954

\section{Cubotholus rhombicus Haeckel}

Plate 13 , figure 8

Cubotholus rhombicus Haeckel 1887, p.681.

Cubotholus sp. Dumitrica 1973, p1.7, fig.3.

Cubotholus rhombicus Haeckel: McMillen and Casey 1978, pl.3, fig.19.

Description: Distinctive four-cupola shell outline. All three fundamental axes unequal i.e. the principal cupolas are larger than the transverse cupolas, which are larger than the sagittal cupolas. Surface thorny with the bases of short, thin, cylindrical spines present. Pores subcircular generally slightly larger than the bar width. Pores in the constrictions are generally larger and more irregular, eight to twelve in the base semicircle of each cupola.

Dimensions: Based on two specimens. Length of principal axis 121-124: of transverse axis 90-94.

Remarks: These two specimens are about $25 \%$ smaller than Haeckel's (1887) forms.

Recorded range: Quaternary occurrence (Dumitrica, 1973).

McMillen and Casey's (1978) specimen is from Recent sediments.

Observed range: Found sporadically throughout the Late Neogene but tends to be more common in upper Pliocene and Pleistocene sediments.

\section{Family Litheliidae Haeckel 1862}

Symmetrical spiral shell, divided by the spiral plane into two symmetrical halves; all windings of the spiral lie in this plane. Primordial chamber either simple or Larnacilla-shaped.

\section{Genus Lithelius Haeckel $1860 b$}

Litheliidae with simple, spherical or subspherical medullary shell and lentelliptical or subspherical spirally constructed cortical shell, surface covered with numerous, simple or branched radial spines.

Type-species: Lithelius spiralis Haeckel 1862 : designated by Campbell 1954 
Lithelius minor Jorgensen

Plate 13, figures 14,15: Plate 16, figure 5

Lithelius minor Jorgensen 1900, p.65, pl.5, fig.24.

Lithelius minor Jorgensen: Nigrini and Lombari 1984, p.S95, pl.14, figs.1a,b.

Description: Ellipsoidal to spherical skeleton consisting of approximately five concentric shells, separated by subequal distances. In certain orientations the internal structure appears as a double spiral. Lozano (1974) notes that the single spiral position is very difficult to photograph as the shell never adopts this orientation in permanent slides. Shells supported by thin radial beams which give the outer shell a thorny appearance. Pores subcircular with a subregular arrangement, approximately 15 on the minor circumference of the outermost shell.

Dimensions: Major diameter of skeleton 79-148: minor diameter 70-132 (Benson, 1966).

Remarks: In general the specimens found to the north of the subtropical convergence have more shells, four to seven, most frequently four to five, whereas under southern subantarctic waters specimens with three to four shells are common (Lozano, 1974). Differs from $L$. nautiloides in having a tighter concentricity.

Recorded range: Common in most of the Miocene sections examined from both tropical and temperate latitudes (Nigrini and Lombari, 1984, CENOP Project) to Recent.

Observed range: Found in $64 \%$ of the radiolarian-bearing samples examined throughout the Late Neogene.

Geographic distribution: "Generally absent south of the Antarctic Polar Front", "it is always found in samples under subantarctic and subtropical waters" (Lozano, 1974).

"This species appeared very cosmopolitan. It probably needs a taxonomic review since the specimens may represent more than one species with markedly different ecological responses" (Molina-Cruz, 1975).

\section{Lithelius nautiloides Popofsky \\ Plate 16, figures 1,6}

Lithelius nautiloides Popofsky 1908, p.230, p1.27, figs.2-4.

Lithelius nautiloides Popofsky: Riedel 1958, p.228, pl.2, fig.3 (only), text-fig.2.

Spirema sp. Kling 1973, p.635, p1.7, figs.23-25.

Lithelius nautiloides Popofsky: Nigrini and Lombari 1984, p.S97, pl.14, figs.2a,b.

Description: Shell subspherical, consisting of a small, spherical medullary shell surrounded by an involute spiral of three to five whorls. The whorls of the spiral generally increase in width outward. The shell wall is of moderate thickness with rounded pores normally about $5 \mu$ in diameter. In certain orientations a double spiral is exhibited.

Dimensions: Based on six specimens. Diameter of medullary shell 15-20: of entire shell of four whorls $96-118$. 
Remarks: As noted by Riedel (1958) the radial spines (extensions of radial bars penetrating through the shell surface) are mostly broken off in specimens from sediments. The bases of some of these spines are still preserved. Rare specimens show no increase in whorl width outward, like Kling's (1973, pl.7, figs.23-25, Spirema sp.) specimens, but no examples were found where the specimens are evolute and close up near the edge (as in Lithelius sp. Nigrini and Lombari 1984, p.S99, pl.14, figs.3a-c.).

Recorded range: Calocycletta costata Zone (Kling, 1973) to Recent.

Observed range: Found in 50\% of the radiolarian-bearing samples examined throughout the Late Neogene.

Geographic distribution: "It is always present under Antarctic waters and generally present under southern sub-antarctic waters. When found close to or north of the subtropical convergence it is generally as a product of reworking or northern transport by bottom waters" (Lozano, 1974).

Lithelius sp. A

Plate 16, figure 3

Description: Specimens of a litheliid with a double spiral of two wings as in Larcospira but apparently without the development of an inner trizonal shell, one of the characteristics of that genus.

Observed range: Found in only nine samples ranging from MS19 (with G. dehiscens) to about $40 \mathrm{~m}$ below the FAD of $\mathrm{G}$. crassula at Waiatai.

Lithelius sp. B

Plate 16 , figure 4

Description: Specimens with a very indistinct internal spiral and subelliptical outer shell outline included in this species.

Dimensions: Length of shell 125: breadth 109.

Observed range: Found in only seven samples from just above the LAD of G. dehiscens at Mangaopari Stream to WA02 at Waiatai.

\section{Genus Pylospira Haeckel 1887}

Litheliidae with double, trizonal or Larnacilla-shaped medullary shell; cortical shell subspherical or lentelliptical, constructed of a single or double spiral of the lateral girdle (or second cortical girdle); the spiral lamellae revolving round the sagittal axis.

Type-species: Pylospira octopyle Haeckel 1887 : designated by Campbell 1954

\section{Pylospira octopyle Haeckel \\ Plate 16, figure 2}

Pylospira octopyle Haeckel 1887 p.698, pl.49, fig.4.

? Pylospira octopyle Haeckel: Nigrini and Lombari 1984, p.S101, pl.14, fig.4. 
Description: Shell elliptical to oval in outline. Composed of a series of spiralling chambers supported by numerous cylindrical radial beams which pierce the outer shell margin. Outer shell thorny with subcircular pores, irregular in size and distribution.

Dimensions: Based on ten Quaternary specimens. Length of major axis 101-122: of minor axis 79-106. Miocene forms are larger, the dimensions based on 20 specimens being, 145-220 and 105-163 respectively (Nigrini and Lombari, 1984).

Remarks: The forms found are more similar in size to Quaternary than Miocene specimens.

Recorded range: Miocene to Recent (after Nigrini and Lombari, 1984).

Observed range: Appears to be restricted to the Tongaporutuan. Found with G. dehiscens at Wainuioru (SWR4), Leader and SPA1, and Kaiti. Not found above the Tongaporutuan except for one one tentative identification at SWM1 which is well above $(410 \mathrm{~m})$ the FAD of $G$. crassaformis at Waimata.

Suborder Nassellaria Ehrenberg 1875

\section{Family Plagoniidae Haeckel 1881 \\ emended Riedel 1967a}

Skeleton consisting entirely of spicule with median bar, apical and dorsal spines, vertical spine, primary lateral spines and sometimes other spines; or having a lattice skeleton including a large cephalis within which this spicule is well developed. Large probably polyphyletic group subject to future subdivision (Riedel, 1967a; Kling, 1978).

\section{Genus Antarctissa Petrushevskaya 1967}

Plagoniidae consisting of a cephalis and thorax. Cephalis smaller than thorax, the lower part being submerged in the thorax. Thorax generally widens gradually distally although in some mature specimens it is closed. Surface rough. All internal spines well developed. No horns on cephalis. Axostyle very long, uneven. Spines $\mathrm{Lr}$ and $\mathrm{Ll}$ are arranged symmetrically to MB (contrary to Lithomelissa) (after Petrushevskaya, 1967).

Type-species: Lithobotrys denticulata Ehrenberg 1844a

\section{Antarctissa antedenticulata Chen}

Plate 16, figures $7,9,11$

Antarctissa antedenticulata Chen 1975, p.456, pl.18, figs.1,2.

Description: Cephalis spherical, with randomly distributed, small subcircular pores. Collar stricture variable, depends on the thickness of shell, but generally marked by change in contour. Thorax subcylindrical or inflated cylindrical, about the same width as the cephalis or slightly wider with subcircular pores of various dimensions.

Dimensions: Based on 20 specimens. Length of cephalis 27-45: of thorax 36-54. Width of cephalis 36-45: of thorax 54-63 (Chen, 1975). 
Remarks: Evolved into A. denticulata (Ehrenberg) in the Lower Pliocene and differs from it in having a cephalis and thorax of almost equal width and a shell of smaller dimensions (Chen, 1975).

Recorded range: Middle to Upper Miocene (Chen, 1975).

Observed range: At least one record with G. dehiscens (LT05) and one tentative at KB01. Found sporadically through to Waiatai Valley Pleistocene sediments.

\section{Antarctissa conradae Chen \\ Plate 16 , figure 8}

Antarctissa conradae Chen 1975, p.457, pl.17, figs.1-5.

Botryopera deflandrei Petrushevskaya 1975, p.592, pl.11, figs.30-32.

Antarctissa deflandrei (Petrushevskaya): Nigrini and Lombari 1984, p.N5, pl.15, figs.3a,b.

Description: Cephalis thick walled, ovate, with scattered small, subcircular pores. Thorax cylindrical, slightly tapering at base in some specimens, separated from the cephalis by a distinct collar constriction. Thoracic pores circular to elliptical, scattered, and about the same size as those of the cephalis.

Dimensions: Based on 35 specimens. Length of cephalis 27-36: of thorax 45-63. Width of cephalis 25-32: of thorax 35-54 (Chen, 1975).

Remarks: Evolved into Antarctissa longa (Popofsky) in the lower Pliocene and distinguished from it in arbitary size limit of thorax i.e. specimens having a thorax less than $54 \mu$ will be assigned to conradae (Chen, 1975). This evolutionary sequence was not observed in the North Pacific CENOP samples where A. longa is present in early Middle Miocene samples but $A$. deflandrei (=conradae) is absent from the samples (Nigrini and Lombari, 1984)

Recorded range: Middle to Upper Miocene (Chen, 1975).

Observed range: Found with G. dehiscens at Wainuioru (SWR4) and Leader River. Sporadic occurrences up to ECO2 which marks the FAD of G. crassaformis at East Cape.

\section{Antarctissa longa (Popofsky) \\ Plate 16, figure 10}

Helotholus longus Popofsky 1908, p.282, pl.34, fig.2.

Antarctissa (?) longa (Popofsky): Petrushevskaya 1975, p.591, pl.11, figs.8-10, pl.18, fig.6. non Antarctissa longa (Popofsky) Keany 1979, p.55, pl.3, figs.5,6, pl.5, fig.11.

Antarctissa longa (Popofsky): Nigrini and Lombari 1984, p.N7, pl.15, figs.4a,b.

Description: Almost identical to A. strelkovi except the relation between the cephalis and thorax is different. Ratio of width of cephalis to thorax is $1: 1.5$ or less. Thin walls with delicate pores and some secondary thorns on the surface.

Dimensions: Length of first segment 60-70: width 70-85. Length of second segment 100-120: width 100-120. Total length 160-200 (Petrushevskaya, 1967). 
Remarks: Keany's (1979) identification is considered invalid and should have been put under A. strelkovi. His Antarctissa longa Zone is an acme zone in that it is "marked by high abundances of $A$. longa and by increases in percentages of $A$. strelkovi and $A$. denticulata".

Recorded range: "Absent from most of the Miocene sections examined from both tropical and temperate latitudes. Rare in the early Miocene of DSDP Site 173; common in the late Miocene of DSDP Site 173" (Nigrini and Lombari, 1984, CENOP Project).

Pliocene to Recent (Chen, 1975).

Observed range: Sporadic occurrences throughout Late Neogene.

\section{Antarctissa strelkovi Petrushevskaya}

Antarctissa strelkovi Petrushevskaya 1967, p.89, pl.51, figs.3,4.

Antarctissa (?) strelkovi Petrushevskaya 1975, p.591, pl.18, fig.5.

Antarctissa longa (Popofsky): Keany 1979, pl.3, figs.5,6, pl.5, fig.11.

Antarctissa strelkovi Petrushevskaya: Nigrini and Lombari 1984, p.N9, pl.15, figs.5a-c.

Description: Cephalis subspherical to ovate, separated from thorax by a slight constriction. Ratio of cephalis width to thorax is $1: 1.5-2$. Pores on both segments are rounded, randomly distributed; their sizes vary greatly. Shell walls comparatively thin. Surface spines usually broken off at base.

Dimensions: Length of the first segment (externally) 45-55: width 60-65. Length of the second segment 70-90: width 70-110. Overall length of the shell is up to 150 (Petrushevskaya, 1967).

Recorded range: Mid-Thvera to at least 3 Ma (Keany, 1979).

"Common in the early and late Miocene of DSDP Site 173" (Nigrini and Lombari, 1984, CENOP Project).

Pliocene to Recent (Chen, 1975).

Miocene to Recent (Petrushevskaya, 1975).

Observed range: Sporadic occurrences above the LAD of G. dehiscens.

Geographic distribution: "generally restricted to south of the Polar Front" (Hays, 1965, Helotholus histricosa).

"between 12 to $37 \%$ of the fauna south of the Polar Front."; "Values of over $3 \%$ close to the Subtropical Convergence."; "Practically absent under waters warmer than $10^{\circ} \mathrm{C}$ in the Atlantic (Lozano, 1974).

"present in all samples south of about $37^{\circ} \mathrm{S}$ (Johnson and Nigrini, 1980, Antarctissa spp., western Indian Ocean).

\section{Genus Lithomelissa Ehrenberg 1847b}

Plagoniidae with a single stricture. Thoracic ribs prolonged as lateral wings or spines. Thorax latticed, without terminal feet. With one or more apical horns.

Type-species: Lithomelissa microptera Ehrenberg 1854a : by subsequent monotypy Foreman and Riedel 1972 
(?) Lithomelissa setosa Jorgensen

Plate 18 , figures $1-3$

Lithomelissa setosa Jorgensen 1900, p.81.

Lithomelissa setosa Jorgensen 1905, p.135, pl.16, figs.81-83, pl.18, fig.108 (in part).

Lithomelissa setosa Jorgensen: Bjorklund 1976, pl.8, figs.1-13.

Lithomelissa sp. C Chen 1975, p.458, pl.11, figs.1,2.

Description: Cephalis globular, partially imbedded in thorax. Collar stricture distinct. Thorax subcylindrical to inflated, relatively long, approximately twice as broad as the cephalis. Dorsal and two lateral spines rarely visible. No apical spines preserved. Pores circular to subelliptical, generally irregularly sized and arranged. Termination ragged. In rare specimens the thorax ribs are prolonged as indistinct feet.

Dimensions: Based on five specimens. Breadth of cephalis 25-38. Length of cephalis 23-27. Maximum breadth of thorax 48-59. Length of thorax 59-70.

Remarks: These forms are related to $L$. setosa but do not have the delicate apical spines preserved. The dorsal or two lateral spines are rarely preserved. Distinguished from $A$. strelkovi by the distinct collar stricture. Lithomelissa stigi Bjorklund has a very small cephalis (one third the diameter of the thorax) and L. hystrix Jorgensen has a very indistinct collar stricture. The forms with indistinct feet resemble those illustrated in Berggren et al. (1976, Plagoniidae gen. et sp. indet., pl.13, figs.12-14) from the Late Miocene of Spain. These forms appear to be related to $L$. setosa but do not conform to the generic definition because of the feet development.

Recorded range: Early late Miocene (Berggren et al., 1976) to Recent.

Observed range: Rare occurrences restricted to Tongaporutuan sediments. The "tri-legged" form is more common and has the same distribution as L. setosa sensu stricto.

\section{Genus Lophophaena Ehrenberg 1847b}

Plagoniidae with a single stricture, the last segment being a broad aperture. No spiny ribs. Cephalis separated by an external stricture (often crested). With no posterior corona of spines.

Type-species: Lophophaena galeaorci Ehrenberg 1854a : by subsequent monotypy Foreman and Riedel 1972

\section{Lophophaena macrencephala Clark and Campbell group \\ Plate 16, figure 12}

Lophophaena macrencephala Clark and Campbell 1945, p.41, pl.7, figs.6-9.

Lophophaena sp. cf. L. macrencephala Clark and Campbell: Petrushevskaya 1971c, fig.56/10. Lophophaena sp. Riedel, Sanfilippo and Cita 1974, p.709, p1.59, fig.6 (only).

Peromelissa sp. McMillen and Casey 1978, pl.5, fig.3.

Description: Shell with distinct subglobular cephalis, no horns intact but bases present. Cephalic pores subcircular, increasing in size distally. Collar stricture distinct. Thorax flaring rapidly but in some forms is an inverted U-shape. 
Dimensions: Based on two specimens. Length of cephalis 55. Maximum breadth of cephalis 53: of thorax 61-65.

Remarks: Petrushevskaya (1971c) gives a detailed analysis of this generic group. Clark and Campbell (1945) show a wide variation in degree of thoracic flaring and the specimens encountered in this study support this and indicate that this is a polyspecific group.

Recorded range: Clark and Campbell's (1945) form is from the Californian Eocene. The forms illustrated by Riedel, Sanfilippo and Cita (1974) and McMillen and Casey (1978) are from the Sicilian Lower Pliocene and Recent respectively.

Observed range: Relatively common throughout the late Neogene although it is only found in one sample associated with G. dehiscens. In Upper Mangaopari Section it suddenly appears in sample MS15, above the LAD of G. dehiscens.

\section{Family Acanthodesmiidae Hertwig 1879}

Nassellaria possessing a sagittal ring. Forms range from simple rings to latticed chambers consisting of lobes developed on either side of the D-ring. This family has been revised by Goll $(1968,1969)$ under the name Trissocyclidae.

\section{Genus Desmospyris Haeckel 1881}

Acanthodesmiidae with bilocular cephalis and a thorax; thorax usually narrower than cephalis, no real feet and generally no horns.

Type-species: Desmospyris mammilata Haeckel 1887

\section{Desmospyris rhodospyroides Petrushevskaya}

Plate 15, figure 14: Plate 18, figures 4,5

Desmospyris rhodospyroides Petrushevskaya 1975, p.593, pl.10, figs.27-29,31,32.

Description: Sagittal ring is enclosed in the cephalis with no less than 9-10 pores near the ring on one lobe of the cephalis. Sagittal constriction rarely expressed externally. Thorax and cephalis are nearly the same width. Termination usually ragged, occasionally constricted. Cephalic and thoracic pores irregular, rounded polygonal, tending to increase in size towards the sagittal ring and collar stricture. Cephalic surface is rougher than thoracic in some forms.

Dimensions: Based on three specimens. Height of sagittal ring 36-42. Breadth of thorax 68-74: of cephalis 72-84.

Remarks: Petrushevskaya's specimens have larger more closely spaced pores.

Recorded range: Antarctic Miocene (Petrushevskaya, 1975).

Observed range: Apart from two tentative identifications in the Pleistocene and uppermost Pliocene it is only found in Tongaporutuan samples, four of which also contain $G$. dehiscens. 
Description: Similar to D. rhodospyroides but there are four differences: (a) the thorax is always broader than the cephalis (up to twice as broad); (b) the cephalis wall is alot rougher and thicker than the thorax; (c) there is a distinct collar stricture; and (d) the thorax has smaller, more sparsely scattered pores.

Dimensions: Based on five specimens. Height of cephalis 43-54. Breadth of cephalis 67-73. Maximum breadth of thorax 95-129.

Remarks: There is an intergradation of forms between this form and D. rhodospyroides.

Observed range: About as common as D. rhodospyroides and is normally assocated with it. No Plio-Pleistocene occurrences.

\section{Desmospyris (?) sp. A}

Plate 18 , figures 7,8

Spyrid gen. et sp. indet. Riedel, Sanfilippo, and Cita 1974, pl.59, fig.1, pl.62, fig.5. Spyrid gen. et sp. indet. Riedel and Sanfilippo 1978a, pl.4, fig.1.

Description: Similar to Gorgospyris sp. aff. perizostra but with a well developed apical dome and a fully developed hemispherical thorax, the shell outline being similar to Cubotholus rhombicus. Pores over the entire shell surface are irregular in size, distribution, and shape but generally sparse.

Dimensions: Based on six specimens. Height of apical dome 21-27: of cephalis 31-39: of thorax 31-39. Maximum breadth of apical dome 43-51: of cephalis 66-81: of thorax 47-70.

Remarks: Distinguished by the well developed apical dome and hemispherical thorax.

Recorded range: The forms illustrated by Riedel et al. (1974) and Riedel and Sanfilippo (1978a) are from the Sicilian lower Pliocene.

Observed range: Five occurrences (one tentative) in samples which are all from upper Tongaporutuan sediments in northern Hawkes Bay.

\section{Genus Gorgospyris Haeckel 1881}

Acanthodesmiidae with a bilocular cephalis, without apical cupola or dome or thorax. With seven to twelve or more basal feet. No apical horn.

Type-species: Gorgospyris medusa Haeckel 1887

Note: Used herein to differentiate with Desmospyris whose forms have a definite thorax.

Gorgospyris sp. aff. perizostra Sanfilippo and Riedel Plate 15, figure 13: Plate 18, figure 6

? Gorgospyris perizostra Sanfilippo and Riedel 1973: in Sanfilippo, Burckle et al. 1973, p.218, pl.3, figs.4,5. 
Description: Shell anteroposteriorly compressed, horse-shoe shaped in outline. No externally expressed sagittal constriction. On the apical surface of the shell, about three lamellar ridges run transversely to the plane of the sagittal ring and extend slightly above the space normally expressed as the sagittal constriction. Shell wall smooth, perforated by subcircular rather sparse pores. Thorax (?) consists of a band of sparsely perforated shell connected to the cephalis along the basal edge parallel to the sagittal ring.

Dimensions: Based on three specimens. Length of shell including distal band 80-90. Height of sagittal ring 39-47. Maximum breadth of shell 54-58.

Remarks: Differs from G. perizostra in having a weaker thoracic development.

Recorded range: G. perizostra occurs in the early to middle Miocene Calocycletta costata and Dorcadospyris alata Zones. It immediately succeeds G. schizopodia in the Pacific sequence, and may have evolved directly from it (Sanfilippo et al., 1973). The form described herein may be the Upper Miocene representative of a long lineage.

Observed range: Rare with only five positive identifications all in upper Tongaporutuan sediments near the local incoming of $B$. compressa sensu stricto. Two tentative identifications in samples with G. dehiscens (LTO5, LT06).

\section{Genus Phormospyris Haeckel 1881}

Acanthodesmiidae with bilocular cephalis and sagittal constriction but without apical cupola. Thorax present. Three basal feet.

Type-species: Phormospyris tricostata Haeckel 1887

\section{Phormospyris stabilis (Go11) antarctica (Haecker) group Plate 17, figures 1,2: Plate 18, figures 9,11}

Phormospyris antarctica Haecker 1907, p.124, fig.9.

Triceraspyris antarctica (Haecker): Riedel 1958, p.230, text-figs.3-5, pl.2, figs.6,7.

Triospyris antarctica Goll and Bjorklund 1974, text-fig.8.

Triceraspyris antarctica (Haecker) group: Petrushevskaya 1975, p.593, pl.8, fig.1.

Triceraspyris antarctica (Haecker): Petrushevskaya 1975, pl.27, figs.1,2.

Tristylospyris sp. cf. antarctica Petrushevskaya 1975, pl.27, fig.3.

Desmospyris (?) haysi Petrushevskaya 1975, p.593, pl.27, figs.4-5 (only).

Phormospyris stabilis (Goll) antarctica (Haecker): Nigrini and Moore 1979, p.N17, p1.20, figs.1a-d.

Description: Shell heavy, nut-shaped, with unequal rounded pores, generally smooth surface, and a slight or pronounced sagittal constriction. Four large basal pores. Three basal feet, three-bladed or circular in section normally one half as long as the cephalis. Rare signs of thoracic lattice work.

Dimensions: Height of sagittal ring 63-90. Maximum breadth of bilocular cephalis 80-125 (Riedel, 1958). 
Remarks: All forms with large pores (generally larger than the intervening bars on the cephalis) with three feet are placed in this subspecies. Other forms which have smaller pores (almost a plate perforate wall) on the cephalis are referred to $P$. stabilis scaphipes. Transitional forms are present.

Recorded range: Miocene to Recent (Petrushevkaya, 1975).

Observed range: Sporadic occurrences throughout Late Neogene. Tends to be more abundant in southern Miocene sections.

Geographic distribution: "exclusively southern cold-water species" (Riedel, 1958).

"It has the distribution which is characteristic of the Antarctic assemblage" (Lozano, 1974, southern Atlantic/Indian Ocean).

"This species loads highest in factor 2 (polar). At present it is most abundant under polar waters south of $45^{\circ} \mathrm{S}$ ' (Morley, 1977, south Atlantic).

\section{Phormospyris stabilis (Goll) scaphipes (Haeckel) group \\ Plate 18, figures 10,12}

Tristylospyris scaphipes Haeckel 1887, p.1033, pl.84, fig.13.

Tholospyris scaphipes (Haecke1): Goll 1969, p.328, pl.58, figs.1-8,13,14.

Phormospyris stabilis (Goll) scaphipes (Haeckel): Nigrini and Moore 1979, p.N19, pl.20, figs.2a-d.

Description: Similar to $P$. stabilis antarctica group in shell outline and size. All specimens with average bar width larger than the average pore size on the parts of the cephalic wall farthest away from the sagittal ring are referred to this subspecies.

Recorded range: Miocene (from some of the Acanthodesmiidae gen. et sp. indet. of Kling (1973)) to Recent.

Observed range: Rare occurrences throughout Miocene and Pliocene up to the LAD of $C$. molestus at Waiatai. Too rare to be of use biostratigraphically.

Geographic distribution: "is abundant north of the Antarctic Convergence and is absent north of latitude $15^{\circ} \mathrm{N}$ " (Goll and Bjorklund, 1971, Atlantic Ocean, Tholospyris scaphipes).

\section{Family Carpocaniidae Haeckel 1881 emended Riedel 1967a}

Cephalis small, not sharply distinguished in contour from the thorax, and tending to be reduced to a few bars within the top of the thorax.

\section{Genus Carpocanarium Haeckel 1887 \\ sensu Riedel and Sanfilippo 1971}

Carpocaniidae with hemispherical cephalis, distinct collar stricture, ovate thorax with rather few, rather large pores and occasionally three short spine-like wings in its proximal half, and a poreless subcylindrical peristome which in some specimens is irregularly terminated to give the impression of a corona of teeth. 


\section{Carpocanarium papillosum (Ehrenberg) \\ Plate 20, figures 1,2}

Eucyrtidium papillosum Ehrenberg 1872a, p.310: 1872b, pl.7, fig.10.

Carpocanium calycothes Stohr 1880, p.96, pl.3, fig.8.

Dictyocephalus papillosus (Ehrenberg): Haeckel 1887, p.1307.

Dictyocephalus papillosus (Ehrenberg): Riedel 1958, p.236, p1.3, fig.10, text-fig.8.

Tricolocapsa papillosa (Ehrenberg) group: Petrushevskaya 1975, p.588, pl.13, fig.13.

Carpocanarium papillosum (Ehrenberg) group: Nigrini and Moore 1979, p.N27, p1.21, fig.3.

Description: Cephalis approximately hemispherical, with small scattered, subcircular pores; set off from the thorax by a change in contour. Some specimens have a small, inconspicuous lateral tubule projecting slightly from the cephalis near its junction with the thorax. Thorax ovate, usually with a rough surface, and with a conspicuous subcylindrical or flared hyaline peristome surrounding the mouth which is approximately one-half to two-thirds as broad as the thorax. Thoracic pores subcircular to circular, in a subregular hexagonal arrangement separated by rather wide, often thick, intervening bars.

Dimensions: Length of cephalis 18-25: of thorax (including peristome) 60-90. Maximum breadth of thorax 58-70 (Riedel, 1958).

Remarks: None of the specimens show signs of "three, usually conspicuous longitudinal ribs, which in many specimens terminate in three short, solid, triangular lateral wings at or above the level at which the thorax reaches its maximum breadth" (Riedel, 1958).

Recorded range: Miocene to Recent (Petrushevskaya, 1975).

Observed range: Relatively common throughout Late Neogene. More sporadic in upper Pliocene and Pleistocene samples.

Geographic distribution: "Bimodal distribution: present in most samples north of about $15^{\circ} \mathrm{S}$ and very rare in three samples between about $37^{\circ} \mathrm{S}$ and $41^{\circ} \mathrm{S}$ " (Johnson and Nigrini, 1980, western Indian Ocean).

"very sparsely distributed in both low and middle latitudes, never forming more than $1 \%$ of the described population" (Nigrini, 1967, Indian Ocean).

\section{Carpocanarium sp. A}

Plate 20, figure 3

Description: Rare forms very similar to C. papillosum but without the distinctive poreless peristome and tending to have smaller, more widely spaced, thoracic pores are referred to this species.

Observed range: Same distribution as C. papillosum. 
Carpocaniidae with a campanulate-ovate shell, without radial ribs. Cephalis entirely lost, no apical horn. Mouth with a corona of radial feet. Emended herein to include forms with very rudimentary, if any, terminal feet.

Type-species: Carpocanistrum evacuatum Haeckel 1887 : designated by Riedel and Sanfilippo 1971

\section{Carpocanistrum sp. A}

Plate 17, figures 3,5,8: Plate 20, figure 5

Description: Shell consisting of a cap-shaped cephalis and thorax, cephalis normally hidden at the top of the thorax. Thorax subspherical; pores subcircular, hexagonally arranged. Some forms have an indefinite longitudinal arrangement transitional with Cystophormis sp. A (Plate 17, figure 8). Peristome hyaline, variable from a short cylindrical tube surrouding a very constricted $(10 \mu)$ mouth (Plate 17, figure 5) to a narrow band surrounding a constricted mouth (Plate 17, figure 3). Termination sometimes undulatory giving the impression of terminal teeth.

Dimensions: Based on eight specimens. Total length of shell (including peristome) 82-100. Maximum breadth 78-90.

Remarks: Distinguished by the hexagonal pore arrangement and toothless peristome. The form with a very constricted mouth is similar to Carpocanistrum (?) odysseus (Haeckel) as illustrated by Dumitrica (1973, pl.15, fig.10).

Observed range: Tabulated in three forms. The "toothless" form has sporadic occurrences throughout the Late Neogene. The "toothed" form is found in only seven samples from LT06 (with G. dehiscens) to WA19 (about 105m above the LAD of C. molestus). The form with the very constricted mouth is rarer than the "toothless" form but has a similar distribution, its highest occurrence being in the Mangapanian at Waiatai.

\section{Genus Cystophormis Haeckel 1887}

emended herein

Carpocaniidae with an ovate or urn-shaped to campanulate shell. Radial ribs present. Mouth constricted. Without apical horn. Emended herein to include forms with terminal teeth as well as those without teeth.

Type-species: Cystophormis pila Haeckel 1887 : designated by Campbell 1954

\section{Cystophormis sp. A}

Plate 17, figures 6,7,9: Plate 20, figure 4

Carpocanistrum spp. Riedel and Sanfilippo 1971, pl.1G, figs.2,8,12 (only).

Description: Shell consisting of a cap-shaped cephalis and a thorax; cephalis hidden at the top of the thorax, a few specimens show a slight change in contour on the surface at the collar stricture. Thorax generally ovate to subspherical. Thoracic pores slightly larger than 
cephalic pores, elliptical to subcircular, aligned in longitudinal rows (11 to 18 rows on the half circumference) separated by prominent longitudinal ridges which are generally twice as broad as the pores. Mouth constricted, in most specimens surrounded by a hyaline peristome commonly with approximately 12 , flat, sharp, triangular teeth which are slightly inwardly converging. In some specimens a smooth rounded peristome is present. In poorly preserved specimens the peristome is etched with furrows which appear to be extensions of the longitudinal ridges.

Dimensions: Based on 15 specimens. Length of shell (including peristome) 95-115. Length of cephalis approximately 10.

Remarks: Some forms with a large number of longitudinal rows approach Carpocanistrum (?) azyx Sanfilippo and Riedel 1973, p.530, pl.35, fig.9.

Recorded range: The forms figured by Riedel and Sanfilippo (1971) come from the Didymocyrtis antepenultima Zone, Stichocorys peregrina Zone and Quaternary of DSDP Site 66 (western tropical Pacific).

Observed range: Tabulated in two forms. The "toothed" form occurs rarely throughout the upper Neogene, the highest occurrence being in the Mangapanian at Waiatai. More sporadic in the Pliocene than Miocene. The "toothless" follows the distribution of the "toothed" form but is rarer and occurs in Pleistocene sediments. Too rare to be of use biostratigraphically.

\section{Cystophormis sp. B \\ Plate 17, figure 4}

Description: Very similar to Cystophormis sp. A but the thorax is divided into three longitudinal sections at the cephalic end and there are about 20 longitudinal rows of smaller pores with relatively wide intervening bars.

Remarks: Similar (in part) to Nigrini and Moore's (1979, p.N25) description of Carpocanistrum sp. A where "primary lateral and dorsal spines extend to the thoracic wall and draw it inwards, thus making the upper part of the shell trilobate".

Observed range: Only two positive identifications and three tentative. Specimens have probably been identified as Cystophormis sp. A. because the tri-lobes are hard to see under transmitted light. All occurrences are upper Tongaporutuan but too rare to be of use biostratigraphically.

\section{Family Theoperidae Haeckel 1881 emended Riedel 1967a}

Cephalis relatively small, approximately spherical, of ten poreless or sparsely perforate. The internal spicule, homologous with that of the plagoniids, is reduced to a less conspicuous structural element than in the latter group. A large, probably polyphyletic, group containing the majority of ordinary cap or helmet-shaped nassellarians (Kling 1978). 
Theoperidae with conical skeleton, gradually dilated to a wide open mouth. Apex armed with a horn. Cephalis very small, rudimentary, hyaline, without distinct collar septum. Ehrenberg and Haeckel regarded members of this genus as monocyrtid. Nigrini (1967) emended the genus to be best regarded as dicyrtid.

Type-species: Cornutella clathrata Ehrenberg 1938

\section{Cornutella profunda Ehrenberg}

Plate 17, figures 10,11: Plate 20, figure 6

Cornutella clathrata $\beta$ profunda Ehrenberg 1854, pl.35B/IV, fig.21.

Sethoconus profundus Haeckel 1887, p.1294.

Sethoconus woodfordi Campbell and Clark 1944, p.43, pl.6, fig.9.

Cornutella profunda Ehrenberg: Riede1 1958, p.232, pl.3, figs.1,2.

Cornutella profunda Ehrenberg: Nigrini 1967, p.60, pl.6, figs.5a-5c.

Cornutella profunda Ehrenberg: Petrushevskaya and Kozlova 1972, p.551, pl.30, figs.18-20 (figs. under Cornutella $\beta$ profunda group).

Cornutella profunda Ehrenberg group: Petrushevskaya 1975, p.587, pl.13, figs.32,33.

Cornutella profunda Ehrenberg: Keany and Kennett 1975, pl.2, fig.5.

Description: Skeleton slender, conical, with smooth surface. Cephalis small, hyaline, poreless. Apical horn never preserved but there is often a small bulbous stub at the apex. Subcircular pores of the thorax are regularly arranged in alternating latitudinal rows Aperture always broken but is reported to be irregular. Most specimens are slightly contracted at the distal end. Appears to be two distinct populations, one with three pores on the half equator and the other with six.

Dimensions: Based on ten specimens. Length of cephalis 9-12: of thorax 124-160. Maximum breadth of thorax $30-50$.

Remarks: This appears to be the one common, widespread species of a probably conspecific group described by Ehrenberg and Haeckel (Riedel, 1958) and this was confirmed by Nigrini (1967) after she viewed the topotypic material. Riedel (1958) notes that some specimens appear to have a heavier wall, with wider intervening bars which are slightly contracted in the distal one third or one quarter. These specimens are the predominant form found here probably because of the increased preservation potential due to their heavier walls.

Recorded range: Miocene to Recent (Petrushevskaya and Kozlova, 1972).

Observed range: Most common form is the "six-pored" form. Found in 37\% of radiolarian-bearing samples studied throughout Late Neogene. Tends to get rarer through the Upper Tongaporutuan becoming sparse in the Plio-Pleistocene. The "three-pored" form is not as common but its distribution is the same as that of the "six-pored" form.

Geographic distribution: Widespread occurrence in the Indian Ocean (Riedel, 1958; Nigrini, 1967) and localities in tropical parts of the Pacific and northern Pacific (Riedel, 1958). Appears to be cosmopolitan. 
Theoperidae with numerous straight or slightly curved radial ribs in the wall of the pyramidal thorax. Network double, the large primary meshes being fenestrated by a fine secondary network. Cephalis commonly without horn. Without outer mantle.

Type-species: Polycystina magnifica Haeckel 1887

\section{Plectopyramis dodecomma Haeckel}

Plate 17, figures 12,13: Plate 20, figures 7,8

Plectopyramis dodecomma Haeckel 1887, p.1258, pl.54, fig.6.

Bathropyramis woodringi Campbell and Clark 1944, p.39, p1.5, figs.21,22.

Plectopyramis dodecoma Haeckel: Keany and Kennett 1975, pl.1, fig.15.

Plectopyramis dodecomma Haeckel: Keany 1979, pl.4, fig.11.

Plectopyramis dodecomma Haeckel: Nigrini and Moore 1979, p.N31, p1.21, fig.5.

Description: Test consisting of small, sub-hemispherical, poreless cephalis, without apical spine preserved and a smooth, long, conical thorax, broad at the base, consisting of 8-11 heavy, longitudinal bars or ribs, subcircular in section and joined by transverse bars that are continuous around the circumference. Thoracic pores subrectangular, increasing in size distally; in the proximal half the pores are either infilled with silica or by a thin, reticulate, secondary meshwork. Some forms taper and others flare slightly at the distal end.

Dimensions: Based on 10 specimens. Maximum length of skeleton 310: of cephalis 10 . Maximum breadth of thorax 200: of cephalis 8 .

Remarks: Differs from Peripyramis circumtexta Haeckel in the absence of branched spines arising from the thorax and in the presence of transverse bars that are continuous around the circumference. Rare forms with transverse bars that are not continuous around the circumference (transitional with Peripyramis circumtexta) are referred to as Peripyramis cf. circumtexta.

Recorded range: Neogene (Keany, 1979).

Observed range: Found in $42 \%$ of the radiolarian-bearing samples studied from throughout the Late Neogene. The form transitional with Peripyramis circumtexta is found in five samples, four in Upper Mangaopari Section and one with G. dehiscens at Kaiti (KB01).

Geographic distribution: Cosmopolitan.

\section{Genus Dictyophimus Ehrenberg 1847a} emended Nigrini 1967

Theoperidae with three complete thoracic ribs, prolonged into three solid divergent wings. Cephalis with an apical horn. Members of this genus are regarded as tricyrtid. Haeckel and Ehrenberg thought them to be dicyrtid.

Type-species: Dictyophimus crisiae Ehrenberg 1854a : designated by Nigrini 1967 
Dictyophimus hirundo (Haeckel) group

Plate 19, figures 1,2: Plate 20, figures 10-12

Pterocorys hirundo Haeckel 1887, p.1318, pl.71, fig.4.

Pterocorys hirundo Haeckel: Riedel 1958, p.238, pl.3, fig.11, pl.4, fig.1.

Dictyophimus hirundo (Haeckel) group: Petrushevskaya 1975, p.583.

Dictyophimus hirundo (Haeckel) group: Nigrini and Moore 1979, p.N35, pl.22, figs.2,3a,3b,4.

Description: Cephalis subglobular, with smooth surface, and numerous small pits which are probably small pores infilled with silica. Apical horn thin, vertical, eccentrically situated, sometimes as long as the thorax but normally broken. Thorax truncate-conical to slightly campanulate with large subcircular to circular pores arranged in irregular longitudinal rows; its surface bearing short thorn-like spines. Abdomen normally only consisting of one, maybe two, rows of subcircular pores preserved in discontinuous patches below the lumbar stricture. No peristome observed. In the wall of the thorax are three weak ribs, continuous with three three-bladed, acute, divergent, straight or slightly curved feet.

Dimensions: Length of apical horn 7-36: of cephalis 16-27: of thorax 30-70: of feet 35-125. Breadth of thorax 50-90 (Riedel, 1958).

Remarks: Distinguished by its relatively large pores, truncate-conical thorax, and straight feet. D. crisiae Ehrenberg has an unusually robust shell and the appendages are definitely wings, not feet and project from the thorax above the lumbar stricture.

Recorded range: Miocene to Recent (Petrushevskaya, 1975).

Observed range: Relatively common throughout the Late Neogene.

Geographic distribution: May be cosmopolitan (Riedel, 1958).

Genus Pseudodictyophimus Petrushevskaya 1971c

Theoperidae with three complete thoracic ribs, prolonged into three solid divergent wings. Cephalis with an apical horn. Erected by Petrushevskaya to include only two segmented forms in the one genus after Nigrini emended the genus Dictyophimus to include three segmented forms.

Type-species: Dictyophimus gracilipes Bailey 1856

\section{Pseudodictyophimus gracilipes (Bailey) \\ Plate 21, figure 1}

Dictyophimus gracilipes Bailey 1856, p.4, pl.1, fig.8.

Dictyophimus gracilipes Bailey: Riedel 1958, p.233, pl.3, fig.5.

Pseudodictyophimus gracilipes (Bailey): Petrushevskaya 1971c, p.93, figs.47-49.

Pseudodictyophimus gracilipes (Bailey): Riedel, Sanfilippo and Cita 1974, p.709, pl.59, fig.8.

Pseudodictyophimus gracilipes (Bailey): Bjorklund 1976, pl.9, figs.1-5, pl.11, figs.6,7.

Pseudodictyophimus sp. aff. P. gracilipes (Bailey): Bjorklund 1976, pl.16, figs.1-5. 
Description: Two segmented shell with subglobular to cap-like cephalis, rarely thorny, with scattered relatively large circular to subcircular pores; bearing an eccentric apical spine. Thorax campanulate to truncate-conical, in some specimens constricted distally; thoracic pores subcircular to subelliptical, variable in size. In thorax wall three ribs which are prolonged to form three, divergent, three-bladed, convex outwards feet. Rare specimens have a lattice mantle covering the cephalis and thorax with no constriction.

Dimensions: Based on 8 specimens. Length of apical horn 7-55: of cephalis 13-35: of thorax 25-40: of feet 27-95. Breadth of cephalis 30-46: of thorax 48-70.

Recorded range: Bjorklund (1976) finds forms with affinities to $P$. gracilipes from the upper Oligocene to Recent (DSDP Site 338, Norwegian Sea).

Observed range: Restricted to Tongaporutuan samples.

\section{Genus Lychnocanium Ehrenberg 1847a}

emended herein

Theoperidae with two chambers, a transverse stricture separating the first and second segments. Open triradiate, three feet, all acute, solid, without ribs. Second segment simply latticed. Emended herein to include only those forms with a distinct collar stricture and a globe shaped thorax. Emended by Riedel (1959) to include forms with two feet. Type-species: Lychnocanium falciferum Ehrenberg 1854a : designated by Campbell 1954

Lychnocanium sp. aff. grande Campbell and Clark

Plate 19, figures 3-5: Plate 21, figures 3,4

Lychnocanium grande Campbell and Clark 1944, p.42, p1.6, figs.3,6 (only).

Lychnocanium cf. grande Campbell and Clark: Nakaseko 1955, p.100, pl.8, figs.6a,6b,7.

Lychnocanium sp. aff. L. grande Campbell and Clark: Petrushevskaya 1975, pl.12, fig.4.

Lychnocanoma sp. Chen 1975, p.462, pl.1, figs.8,9 (plates under Lychnocanium sp.).

Description: Cephalis hemispherical, with small subcircular pores arranged subhexagonally (frequently infilled); bearing a stout, cylindrical, sharp, central apical horn up to three times the length of the cephalis. Collar stricture very distinct with an abrupt change in contour. Thorax hemispherical to cupola-shaped (subconical above, inflated below). Thoracic pores hexagonally arranged and framed, increasing slightly in size distally, circular, 8-10 in a vertical tier. Mouth slightly constricted surrounded by a narrow, heavy, hyaline peristome. Rarely a flat plate of pore bearing shell surrounds the peristome. Three basically thick, three bladed feet emerge from the thorax immediately below its broadest part. Feet range from being nearly straight and vertical to convex-outward curved and divergent.

Dimensions: Based on ten specimens. Length of apical horn 19-52: of cephalis 14-23: of thorax: 57-80: of feet 97-129. Maximum breadth of cephalis 32-36: of thorax 88-110.

Remarks: Differs from typical $L$. grande in that the feet are normally convexly-outward curved. In other respects very similar to the species described by Campbell and Clark (1944). 
Recorded range: $L$. grande sensu stricto ranges from at least the Calocycletta costata Zone (Kling, 1973, Lychnocanoma grande). The upper limit of this species in Antarctic cores is approximately upper Gauss (Bandy, Casey, and Wright, 1971), at the same level as determined from the equatorial core V-24-59 by Casey and Reynolds (1980). However, the LAD is recorded in basal Epoch 5 in the Newport Section, California by Weaver, Casey, and Perez (1981). Kling (1973, Lychnocanoma sp. cf. L. grande, pl.4, figs.9,10) records forms from sediments younger than 0.9 Ma in the eastern North Pacific.

Observed range: Tabulated into two forms. The form with diverging feet has its highest positive occurrence in sample SMR2 which is close to the FAD of G. inflata (middle Opoitian). Occurs commonly below this level. One tentative occurrence at Waiatai (WA17) could be an aberrant form of Lychnocanella conicum which occurs in the same sample. The form with vertical feet is rarer but has a similar distribution although it never occurs above the FAD of G. sphericomiozea, disappearing at the Miocene/Pliocene unconformity at Mangapoike.

Geographic distribution: Cosmopolitan.

\section{Genus Lychnocanella Haeckel 1887 \\ sensu Petrushevskaya 1975}

Theoperidae with two chambers, a transverse stricture separating the first and second segments. Open triradiate, three feet, all acute, solid without ribs. Second segment simply latticed. Includes only those forms with a pear-shaped thorax (after Petrushevskaya, 1975). Type-species: Lychnocanium lanterna Haeckel 1887 : designated by Campbell 1954

\section{Lychnocanella conicum (Clark and Campbell)}

Plate 19, figure 6: Plate 21, figure 5

Lynchnocanium conicum Clark and Campbell 1942, p.71, pl.9, fig.38.

Lychnocanella conica (Clark and Campbel1): Petrushevskaya 1975, p.583, pl.12, figs.2,11-15.

Description: Similar to Lychnocanium sp. aff. grande but differs in two respects: the collar stricture is not as pronounced externally giving the thorax a pear-shaped outline, and although some forms with long feet are present, most of the specimens have short feet.

Dimensions: Based on seven specimens. Length of apical horn 19-23: of cephalis 23-32: of thorax 49-62: of feet 45-48 (atypical 125). Maximum breadth of cephalis 36-39: of thorax 100-106.

Remarks: Distinguished by the distinctive pear-shaped thorax. Similar to the genus type-species Lychnocanium lanterna Haeckel.

Recorded range: "Antarctic Oligocene specimens forma typica are larger, have a thicker skeleton, and more pores ( $8-10$ between two feet) than smaller Miocene specimens which have only 6-7 pores" (Petrushevskaya, 1975). The forms described herein tend towards the Miocene pore number. Petrushevskaya (1975) mentions other Antarctic Miocene specimens with longer feet and more pores. These forms are "very similar to $L$. grande, but the thoracic pores are a bit larger, and the feet may be curved". This description corresponds well to the atypical "long feet" members of this species found in the samples studied. 
Observed range: Found sporadically throughout the Late Neogene.

Geographic distribution: Cosmopolitan?

\section{Genus Archipilium Haeckel 1881}

Theoperidae with a single chamber (very small cephalis), without strictures, open triradiate; three simple lateral spines. Aperture margins smooth or truncate.

Type-species: Archipilium orthoptermum Haeckel 1887

\section{Archipilium macropus (Haeckel) \\ Plate 21, figure 2}

Sethopilium macropus Haeckel 1887, p.1203, p1.97, fig.9.

Archipilium sp. aff. A. macropus (Haeckel) group: Petrushevskaya 1975, p.584, pl.12, fig.9, pl.43, figs.3-5.

? Archipilium sp. aff. A. macropus (Haeckel) group: Renz 1974, p.788, pl.17, figs.11a,b.

Description: Shell has conical top and cylindrical bottom. Cephalis very small hemispherical, hidden in top of the shell. No apical horn. Thorax truncate-conical proximally and subcylindrical distally. Thoracic pores relatively large, subelliptical to subcircular in an irregular pattern which is nearly symmetrical about a line which bisects the angle made between two feet. Termination ragged. Three thoracic ribs prolonged into stout, sharp, long, cylindrical feet; thoracic ribs normally leave the shell about halfway down the shell.

Dimensions: Based on four specimens. Length of shell (cephalis and thorax) 52-67: of feet 22-79. Breadth of thorax where feet leave the shell 68-78: of thorax termination 44-52.

Remarks: "Some Miocene specimens are similar in shell outline and dimensions to Dictyophimus archipilium. The difference is in the absence of a distinct abdomen in A. macropus" (Petrushevskaya, 1975).

Recorded range: "This species-group exists from the latest Oligocene, being most numerous from the middle and late Miocene and Pliocene. In Quaternary they are rather rare" (Petrushevskaya, 1975).

Observed range: Rare occurrences (5) in the Tongaporutuan.

\section{Genus Cyrtocapsella Haeckel 1887}

Theoperidae with three or four segments and without radial apophyses. Very restricted mouth resembling a large terminal pore surrounded by a differentiated ring. A small apical horn is commonly present, and some specimens have an additional, usually more delicate, generally closed conical segment below the constricted one.

Type-species: Cyrtocapsa tetrapera Haeckel 1887 : designated by Campbell 1954

Cyrtocapsella japonica (Nakaseko)

Plate 19, figure 12: Plate 21, figures 6,8

Eusyringium japonicum Nakaseko 1963, p.193, text-figs.20-21, pl.4, figs.1-3. 
Eusyringium isozakiense Nakaseko 1963, p.194, pl.4, figs.5-7,11,12.

Cyrtocapsella japonica (Nakaseko): Sanfilippo and Riedel 1970, p.452, pl.1, figs.13-15.

Cyrtocapsella japonica (Nakaseko): Nigrini and Lombari 1984, p.N107, p1.23, figs.4a-c.

Description: Shell consisting of three segments increasing in width, with a constricted mouth. Cephalis spherical, poreless, rarely bearing a small thorn-like horn. Collar stricture indistinct because the base of the cephalis is generally enclosed in the thoracic wall. Thorax hemispherical. Abdomen slightly inflated distally, with a constricted mouth. Pores of thorax and abdomen generally similar, circular, usually closely spaced but occasionally sparser, rather regular in size and arrangement. Wall of abdomen and thorax thick, with rough surface. The lumbar stricture is not deep but is marked by a corresponding change in contour. Some specimens have an inverted truncate-conical fourth segment with thinner wall and less regular pores.

Dimensions: Based on 30 specimens. Total length (excluding horn and fourth segment) 110-135. Maximum breadth 55-100. Ratio of length of abdomen to length of thorax 1.2-3.4:1 (Sanfilippo and Riedel, 1970).

Remarks: Distinguished from C. tetrapera by having the aperture of the third segment constricted, rather than that of the fourth.

Recorded range: A variety of ranges have been recorded for this species (see Nigrini and Lombari, 1984). The youngest occurrence is in the Didymocyrtis antepenultima Zone in the Sea of Japan (Ling, 1975).

Observed range: All positive identifications in Upper Tongaporutuan sediments but occurs tentatively in four other samples, one older (SPA1) and three younger Plio-Pleistocene samples (WA03, WA15, LT01). The form with the rounded abdomen, C. japonica sensu stricto, is found in only three northern Hawke's Bay samples; KB01 (with G. dehiscens), SMH1 (associated tuff $6.3 \mathrm{Ma}$ ) and HR04 (about $60 \mathrm{~m}$ below the local FAD of $B$. compressa sensu stricto).

Cyrtocapsella tetrapera (Haeckel)

Plate 19, figures 10,13: Plate 21, figures 7,9

Cyrtocapsa tetrapera Haeckel 1887, p.1512, pl.78, fig.5.

Cyrtocapsella tetrapera Haeckel: Sanfilippo and Riedel 1970, p.453, pl.1, figs.16-18.

Cyrtocapsella tetrapera (Haeckel): Nigrini and Lombari 1984, p.N109, p1.23, fig.5.

- see Sanfilippo and Riedel (1970) for extensive synonymy.

Description: Shell of four segments, with rounded to abruptly constricted termination. Cephalis spherical, poreless with a short eccentric apical horn (normally not preserved). Collar stricture moderately pronounced. Thorax conical to hemispherical; abdomen annular or inflated; fourth segment slightly inflated with an abrupt change in contour towards a constricted mouth. Second to fourth segments thick walled with subcircular to circular pores; rather irregular in size and arrangement. Strictures rather pronounced to indefinite. Some specimens have an inverted conical to hemispherical segment with a thinner wall and less regular pores attached to the constricted fourth segment. 
Dimensions: Based on 35 specimens. Total length (excluding horn and fifth segment) 100-140. Length of thorax 25-45: of abdomen 25-40: of fourth segment 30-55. Maximum breadth 75-105 (Sanfilippo and Riedel, 1970).

Remarks: Some specimens with a moderately pronounced change in contour between the thorax and abdomen approach C. cornuta Haeckel. Forms with an abruptly constricted fourth segment are very similar to Cyrtocapsa subconica (Nakaseko 1955, p.120, pl.11, fig.9) which Sanfilippo and Riedel (1970) synonymised with C. tetrapera.

Recorded range: Riedel and Sanfilippo (1978b) define the lower limit of the Cyrtocapsella tetrapera Zone (early Miocene) by the first appearence of this species. Riedel and Sanfilippo (1971) and Holdsworth (1975, DSDP Site 289) show the last occurrence of this species to be near the top of the Dorcadospyris alata Zone (early middle Miocene). Theyer et al. (1978) date the first occurrence at $21.75 \mathrm{Ma}$ and the last occurrence at $11.95 \mathrm{Ma}$, but DSDP Leg 85 results suggest that the latter date should be 12.4-12.7Ma (after Nigrini and Lombari, 1984). Sanfilippo and Riedel (1970, table 1) show rare occurrences up into the upper Miocene (at about the FAD of Stichocorys peregrina) and Holdsworth (1975) reports rare C. tetrapera forms higher than the top of the Dorcadospyris alata Zone. Kling (1973) notes the occurrence of C. tetrapera and C. japonica up into the Didymocyrtis antepenultima Zone (upper Miocene).

Observed range: Sporadic occurrences in Tongaporutuan. Rare in upper Tongaporutuan sediments (above the $20 \%$ five chambered Globorotalia miotumida level) and found in only one sample with G. dehiscens (LTO6). This distribution pattern is especially pronounced in the Mangapoike Section. Both this species and $C$. japonica tend to be more abundant in Hawkes Bay sections.

Geographic distribution: "Common to abundant throughout the early Miocene sections examined from both tropical and temperate latitudes" (Nigrini and Lombari, 1984, CENOP Project)

\section{Genus Cyrtolagena Haeckel 1887}

emended herein

Theoperidae with three or more strictures. Terminal mouth fenestrated. No solid lateral ribs but may have three rows of lateral spines or combs.

Type-species: Cyrtolagena laguncula Haeckel 1887

Note: The primary difference in the original definitions of Cyrtolagena and the related genera (Stichophormis and Stichopera) was the composition of the basal segment, i.e. either open or closed. It appears that there is an intergration of forms with a wide, open mouth, a constricted mouth, and a fully closed mouth. Futhurmore, specimens in sediments are of ten preserved with the basal segment missing, making generic placement difficult. Another important difference is in the makeup of the lateral spines, combs or ribs. Again the spines or combs are of ten lost in specimens from sediments. Herein the main distinguishing characteristic of this genera is the absence of the lateral ribs. 


\section{Cyrtolagena laguncula (Haeckel)}

Plate 22, figure 1

Cyrtopera laguncula Haeckel 1887, p.1451, pl.75, fig.10.

Stichopera pectinata Haeckel 1887, p.1449, pl.75, fig.11.

Stichopera pectinata Haeckel group: Kling 1973, p.638, pl.3, figs.25-27, pl.10, figs.1-5.

Cyrtolagena laguncula Haeckel: Petrushevskaya 1975, p.583, pl.14, figs.3,4.

Theoperidae gen. et sp. indet. Riedel and Sanfilippo 1978a, pl.4, fig.6.

Cytopera laguncula Haeckel: Weaver, Casey and Perez 1981, pl.6, fig.6.

Description: Shell has a strongly conical outline. Cephalis subspherical with scattered small pores. Post-cephalic segments greater than nine in number, each segment of nearly equal length and very slightly inflated. Postcephalic pores circular to subcircular, arranged in a regular hexagonal pattern, two to three transverse rows per segment, increasing in size distally. Termination ragged. No lateral ribs. Very rare forms have a definite spiral structure.

Dimensions: Based on two specimens. Length of cephalis 16-17: of shell 94-130. Breadth of cephalis 15-16: of base of shell 43-55.

Remarks: In rare specimens the spiral nature of the postcephalic segments differs from the species as described by Haeckel but it appears to be so closely related in all other aspects that it is herein considered to be a variant of this species. No forms with a constricted last segment seen.

Recorded range: Calocycletta costata Zone to Recent (Kling, 1973, DSDP Site 173) and Miocene to Recent (Petrushevskaya, 1975). Riedel and Sanfilippo's (1978a) specimen is from the lower Pliocene of Sicily.

Observed range: Found in only four Tongaporutuan samples. The spiralling form was found in only one sample (RM07).

Geographic distribution: Cosmopolitan. Weaver, Casey and Perez (1981, p.75) regard this as a deep living species.

Genus Stichophormis Haeckel 1881

emended herein

Theoperidae with three or more strictures. Mouth wide open. Lateral ribs prolonged into terminal feet. Emended herein to include forms with a slightly constricted mouth.

Type-species: Stichophormis pyramidalis Haeckel 1887

Note: See remarks under the generic definition of Cyrtolagena.

\section{Stichophormis cornutella Haeckel}

Plate 19 , figure 11

Stichophormis cornutella Haeckel 1887, p.1455, pl.75, fig.9. 
Description: Very similar to Cyrtolagena laguncula but with six lateral, solid ribs projecting as cylindrical terminal feet. The feet project where the shell constricts slightly towards the mouth. All the specimens studied have more regular pore shape and pattern in the upper half of the shell. No spiralling forms seen.

Dimensions: Based on four specimens. Length of cephalis 18-19: of shell (excluding feet) 257-289: of feet about 50. Maximum breadth of shell 156-160.

Remarks: Differs from Haeckel's illustrated form in that the shell has a constricted mouth.

Observed range: Only one occurrence at Leader River (LTO3).

\section{Genus Theocalyptra Haeckel 1881}

Theoperidae with a shell divided by two transverse strictures into cephalis, thorax, and abdomen. Abdomen discoidal, basal shell mouth open without basal apophyses. One or two apical horns.

Type-species: Theocalyptra veneris Haeckel 1887

Note: Nigrini and Moore (1979, p.N51) outline the problems involved with the generic placement of bicornis and davisiana into Theocalyptra (as opposed to the genus Cycladophora). Essentially the problem is related to poorly or non-illustrated type specimens.

\section{Theocalyptra bicornis (Popofsky) \\ Plate 22, figure 4}

Pterocorys bicornis Popofsky 1908, p.228, pl.34, figs.7,8.

Theocalyptra bicornis (Popofsky): Riedel 1958, p.240, pl.4, fig.4.

Clathrocyclas bicornis (Popofsky) group: Petrushevskaya 1975, p.586, pl.15, fig.26, pl.23, fig.2.

Theocalyptra bicornis (Popofsky): Chen 1975, p.462, pl.13, figs.1,2.

Theocalyptra bicornis (Popofsky): Keany 1979, p.56, pl.4, figs.1,2.

Theocalyptra bicornis (Popofsky): Nigrini and Lombari 1984, p.N137, pl.26, figs.1a-c.

Description: Shell conical campanulate, consisting of two or three segments. Cephalis subglobose, with scattered small pores, bearing two three-bladed spines; approximately the same length as the cephalis. Collar stricture slight. Thorax conical proximally, campanulate distally, with subcircular to polygonal pores separated by narrow intervening bars. Pores increase in size distally, arranged in up to twelve transverse rows. Well preserved specimens have a third segment (?) marked by a flaring in the thorax wall and by an internal septal ring. This abdomen? normally consists of one transverse row of polygonal pores.

Dimensions: Based on 14 specimens. Length of cephalis 15-27: of thorax 80-97. Maximum breadth 95-120 (Riedel, 1958).

Remarks: Differs from T. davisiana davisiana in having lighter walls, larger thorax, and more prominent cephalic horns. Hays (1965) described a form under the name Clathrocyclas bicornis. Superficially it resembles $T$. bicornis but the length/width ratio of $C$. bicornis is less, it has a much thicker wall, and the internal structure differs. 
Recorded range: Miocene to Recent (Petrushevskaya, 1975; Keany, 1979). Middle Miocene to Recent (Chen, 1975)

Observed range: All positive identifications restricted to three southern Wairarapa sections: Mangaopari Stream, Morrisons and Ruamahanga sections close to the local FAD of $B$. compressa.

Geographic distribution: "seems to increase in relative abundance in a belt approximately coincident with the Antarctic Polar Front" (Lozano, 1974).

"At present it is most frequently found in samples from under the subantarctic waters" (Morley, 1977, south Atlantic).

"Present in all samples south of about $37^{\circ} \mathrm{S}$. There is a similar, but diminutive, form in lower latitudes" (Johnson and Nigrini, 1980, western Indian Ocean).

\section{Theocalyptra davisiana davisiana (Ehrenberg)}

Plate 19, figure 8: Plate 22, figures 5,6

Cycladophora ? davisiana Ehrenberg 1861, p.297: 1873, p1.2, fig.11.

Theocalyptra davisiana (Ehrenberg): Riedel 1958, p.239, p1.4, figs.2,3, text-fig.10.

Diplocyclas (?) davisiana (Ehrenberg): Petrushevskaya 1975, p.587.

Cycladophora davisiana Ehrenberg: Chen 1975, p.459, pl.13, fig.3.

Cycladophora davisiana Ehrenberg: Weaver 1976a, p.117, pl.1, fig.4.

Cycladophora davisiana Ehrenberg: Keany 1979, p.56, pl.4, figs.3,4.

Theocalyptra davisiana (Ehrenberg): Nigrini and Moore 1979, p.N57, pl.24, figs.2a,b.

Theocalyptra davisiana davisiana (Ehrenberg): Nigrini and Lombari 1984, p.N139, pl.26, fig.2.

Description: Shell conical-campanulate of moderately heavy structure. Cephalis subglobose, with small sparse pores and bearing two short spines. Collar stricture slight. Thorax truncate-conical proximally, then flares slightly in the middle, then subcylindrical to truncate-conical distally. In some specimens an internal septal ring is present where the thorax begins to flare. Thoracic pores subcircular proximally, becoming polygonal distally, arranged in 7-8, indefinite, transverse rows. In some specimens a third? segment is present below a transverse septal ring. This abdomen? is short, truncate-conical, usually flared at a wider angle than the thorax, with one or two transverse rows of polygonal pores.

Dimensions: Based on seven specimens. Length of cephalis usually 17-25: of thorax 40-80: of abdomen: 15-35. Maximum breadth of shell 70-130 (Riedel, 1958).

Remarks: Shell is an irregular cone, made up of a cephalis with two prominent horns and a post-cephalic part with poorly defined segmentation and subcircular pores of variable size and arrangement. The subspecies $T$. davisiana (Ehrenberg) cornutoides Kling has a more regular conical outline.

Recorded range: Miocene to Recent (Petrushevskaya, 1975).

Pliocene to Recent (Chen, 1975; Keany, 1979).

"Rare or absent in most of the Miocene sections examined from both tropical and temperate latitudes; common in the latest Miocene of DSDP Site 173" (Nigrini and Lombari, 1984, CENOP Project). 
Observed range: Sporadic occurrences throughout the Late Neogene.

Geographic distribution: "Its distribution does not show a preferentially latitudinal pattern but its lowest values of relative abundance occur under subtropical waters" (Lozano, 1974, Antarctic seas). Lozano also notes it is probably a deep living species.

Genus Lampromitra Haeckel 1881

emended herein

Theoperidae with shell divided into cephalis and thorax by a transverse stricture. Three divergent lateral ribs in wall of flat, conical, discoidal, or pyramidal thorax. With apical horn. Basal shell mouth open with a prominent spiny corona. Emended herein to include forms with the three lateral ribs absent or indefinitely expressed.

Type-species: Lampromitra coronata Haeckel 1887

\section{Lampromitra butschlii (Haeckel) \\ Plate 22, figure 3}

Dictyophimus butschlii Haeckel 1887, p.1201, pl.60, fig.2 (in part).

Dictyophimus cienkowskii Haeckel 1887, p.1200, pl.60, fig.1 (in part).

Description: Very delicate shell. Cephalis spherical with subcircular to polygonal pores, narrow intervening bars; surface rough with the bases of broken spines (?). Collar stricture very distinct, $90^{\circ}$ change in shell contour. Thorax flatly conical with a number of radial beams connected by randomly scattered transverse and oblique beams of about the same thickness. Rare small spines arise from thoracic beams.

Dimensions: Based on one specimen. Height of cephalis 14. Breadth of cephalis 15. Length of thorax (minimum) 31. Breadth of thorax 46.

Remarks: The form described has the distinct spherical cephalis and collar stricture of $D$. butschlii and the irregular, large, polygonal pore pattern of $D$. cienkowskii.

Observed range: Rare occurrences throughout the Late Neogene.

\section{Lampromitra erosa Cleve \\ Plate 22, figure 2}

Lampromitra erosa Cleve 1900, p.10, pl.4, figs.2,3.

Lampromitra erosa Cleve: Dumitrica 1973, p.838, p1.24, figs.8,9.

non: Lampromitra erosa Cleve: Riedel, Sanfilippo and Cita 1974, p1.59, fig.13, p1.62, fig.7.

Description: Shell flatly conical. Cephalis subspherical, with collar stricture distinct. Apical horn small (if present). Cephalic pores small, irregular, subcircular. Thoracic pores irregular, circular to subelliptical, increasing in size distally. Termination ragged.

Dimensions: Based on three specimens. Length of cephalis 20-28. Breadth of cephalis 30-32: of thorax 113-142. 
Remarks: L. erosa limited to those forms with a distinct cephalis. Forms with an indistinct cephalis are referred to $L$. tiara. Also differs from $L$. tiara in that the thoracic wall is heavier with wider intervening bars between the pores. No forms found with the distinctive double corona of downwardly and laterally directed branches around the peristome.

Recorded range: Dumitrica's (1973) specimens are from Quaternary sediments.

Observed range: Restricted to the Miocene but too rare (6 samples) to be of biostratigraphic use.

\section{Lampromitra tiara Dumitrica}

Plate 19, figure 7: Plate 20, figure 9

Lampromitra tiara Dumitrica 1973, p.838, pl.23, figs.9,10.

Lampromitra erosa Cleve: Riedel, Sanfilippo and Cita 1974, pl.59, fig.13, pl.62, fig.7.

? Ceratocyrtis sp. aff. Cornutella cucullaris Ehrenberg: Petrushevskaya 1975, p.591, pl.11, fig.2.

Description: Shell inflated conical. Cephalis subhemispherical, indistinct. Collar stricture externally expressed as only a slight change in contour. Apical horn small. Cephalic pores small, subcircular, scattered. Thoracic pores subcircular to rounded polygonal, increasing in size distally. In one specimen the thoracic pores show a fenestrated infilling with up to 13 subpores per pore (Plate 19, figure 7). Thoracic surface has common short, thornlike spines arising from the bar nodes. Termination ragged.

Dimensions: Based on one specimen. Length of shell 123. Maximum breadth of thorax (at base) 177.

Remarks: See $L$. erosa. No specimens found with peristome preserved. Petrushevskaya's (1975) specimen is narrower than typical L. tiara.

Recorded range: Dumitrica's (1973) specimens are from Quaternary sediments. Riedel, Sanfilippo, and Cita (1974) figure a specimen from the Sicilian lower Pliocene.

Observed range: Two forms tabulated. The "flaring" form is found sporadically throughout the Late Neogene. The "U-shaped" form is rare with one positive identification in sample WA19 (Mangapanian), all other occurrences being in the Tongaporutuan. More common in southern Wairarapa Tongaporutuan samples.

\section{Genus Theocampe Haeckel 1887 \\ emended Burma 1959}

Theoperidae with shell divided by two transverse strictures into cephalis, thorax and abdomen. Without basal apophyses and basal shell mouth constricted. Swollen, ovate abdomen. No apical horn. Abdominal pores show a strong tendency to be arranged in a square horizontal and vertical grid.

Type-species: Dictyomitra ehrenbergii Zittel 1876 : designated by Campbell 1954 


\section{? Theocampe cf. mongolfieri (Ehrenberg)}

Plate 19, figure 9

? Eucyrtidium mongolfieri Ehrenberg 1854a, pl.36, fig.18B.

? Sethamphora mongolfieri (Ehrenberg): Haeckel 1887, p.1251.

? Sethamphora costata Haeckel 1887, p.1251, pl.62, fig.3.

? Sethamphora mongolfieri (Ehrenberg): Riedel 1957, p.81, pl.1, fig.7.

? Theocampe mongolfieri (Ehrenberg): Sanfilippo and Riedel 1971, p.1601, pl.3E, fig.13.

Description: Cephalis and thorax merged together so as to obliterate collar stricture with scattered, subcircular to elliptical pores, irregular in size and pattern. No apical horn. Lumbar stricture indistinct. Abdomen truncate-ovate with about 12 transverse rows of subcircular pores, and also in about 11 longitudinal rows (on the half equator); separated by pronounced flat-topped ridges giving the pores a rectangular arrrangement. Mouth one-third to one-half as wide as the maximum shell breadth. Termination ragged.

Dimensions: Based on one specimen. Length of cephalis and thorax 37: of abdomen 81 . Maximum breadth 108 .

Remarks: The outline of the shell is more similar to Theocampe armadillo (see Sanfilippo and Riedel 1971, p.1601, pl.3E, figs.3-6.) but is placed in T. mongolfieri because of the distinctive pore pattern. Differs from $T$. mongolfieri sensu stricto in having a small thorax with no externally distinct lumbar stricture. This specimen is only tentatively placed in this species due to the absence of a specimen visible under transmitted light.

Recorded range: Eocene (Riedel, 1957). The first appearence of $T$. mongolfieri marks the base of the Theocampe mongolfieri Zone (early Eocene) (Riedel and Sanfilippo, 1978b). Foreman (1973) has T. mongolfieri from early Eocene to the late Eocene Thyrsocyrtis bromia Zone.

Observed range: Only one specimen found in one sample, a reconnaisance sample stratigraphically very close to MS05 (Upper Mangaopari Section).

\section{Genus Eucyrtidium Ehrenberg 1847a emended Nigrini 1967}

Theoperidae without radial apophyses. Ovate or spindle-shaped shell, the mouth of which is constricted and, rarely, may be prolonged into an irregular short terminal tube. Tube much less well developed than that of genus Eusyringium. Emended by Nigrini (1967) to include forms having a short terminal tube.

Type-species: Lithocampe acuminata Ehrenberg 1844a : designated by Frizzell (in Frizzell and Middour 1951)

\section{Eucyrtidium acuminatum (Ehrenberg)}

Plate 23, figures 3,7,9: Plate 26, figure 1

Lithocampe acuminatum Ehrenberg 1844a, p.84.

Eucyrtidium acuminatum (Ehrenberg): Ehrenberg 1847b, p.43.

Stichopilium annulatum Popofsky: Hays 1965, p.181, pl.3, fig.6 (in part).

Eucyrtidium acuminatum (Ehrenberg): Kling 1973, p.636, pl.4, figs.20-23. 
Eucyrtidium acuminatum (Ehrenberg): Johnson 1974, p.550, pl.10, fig.15.

Eucyrtidium cienkowskii Haeckel group: Riedel,Sanfilipo and Cita 1974, p.710, pl.59, fig.11. cf. Eucyrtidium acuminatum (Ehrenberg) group: Petrushevskaya 1975, p.581, pl.14, fig.28.

Eucyrtidium acuminatum (Ehrenberg): Nigrini and Moore 1979, p.N61, pl.24, figs.3a,b.

Description: Cephalis subspherical, simple, with scattered small subcircular pores. Short conical apical horn usually present. Rarely the primary lateral and dorsal spines become external, forming wings in the lower thorax, upper abdomen (see Plate 23, figure 7). Collar stricture indistinct. Thorax small, conical, sometimes very slightly inflated with scattered subcircular pores aligned more or less longitudinally. Lumbar stricture not indented externally. Abdomen and 4-5 post-abdominal segments of approximately equal length, expanding distally to a maximum breadth at about the lower second or third post-abdominal segment. Pores small, subcircular, arranged longitudinally, 4-6 per segment in a vertical row. Final segments with scattered, smaller, subcircular pores, taper abruptly to a constricted mouth with no peristome or terminal teeth, but rarely, with a short cylindrical terminal tube.

Dimensions: Total length 119-182. Diameter of cephalis 9-13. Length of thorax 9-18. Maximum breadth 63-81 (Nigrini, 1967).

Remarks: Complete specimens are rarely preserved. Distinguished by the indistinct lumbar stricture and maximum breadth at about the third post-abdominal segment.

Recorded range: Lower Pliocene to Recent (after Kling, 1973). Kling (1973, pl.10, figs.21-23) figures three specimens under Eucyrtidium sp. cf. E. acuminatum. Only the youngest one, from his unzoned interval (Upper Miocene), is considered to be like the forms described herein, the other two being referable to E. cienkowskii. Sanfilippo, Burckle et al. (1973, pl.5, fig.10) and Riedel and Sanfilippo (1978a, pl.4, fig.12) illustrate two forms from the Italian and Sicilian lower Pliocene. Both forms show no indentation at the lumbar stricture but are broadest at the first post-abdominal segment and are considered to be transitional between $E$. acuminatum and $E$. cienkowskii herein.

Observed range: Sporadic occurrences in Tongaporutuan. Only two occurrences in Plio-Pleistocene (one tentative).

Geographic distribution: "Very sparsely distributed in low latitudes, but is abundant in middle latitudes. It appears to be a reliable and potentially useful member of the middle latitude assemblage" (Nigrini, 1967, Indian Ocean).

"Patchy distribution, dominantly in Transitional waters" (Sachs, 1973, subarctic Pacific).

"It does not occur south of the Polar Front and is most abundant in the cores raised from beneath the warmest surface waters in the area." (Hays, 1965, Antarctic seas).

"Very rare in Antarctic and subantarctic Tertiary sediments" (Petrushevskaya, 1975).

\section{Eucyrtidium cienkowskii Haeckel group}

Plate 23, figures 4-6,12: Plate 24, figures 5,6

Eucyrtidium cienkowskii Haeckel 1887, p.1493, pl.80, fig.9.

Eucyrtidium sp. cf. E. acuminatum: Kling 1973, pl.10, figs.22,23 (only).

Eucyrtidium cienkowskii Haeckel group: Sanfilippo, Burckle et al. 1973, p.221, pl.5, figs.9,11 (only). 
Eucyrtidium cienkowskii Haeckel group: Riedel and Sanfilippo 1978a, p.114, pl.4, fig.10 (only).

Eucyrtidium cienkowskii Haeckel group: Sakai 1980, pl.7, figs.9,10 (only).

Eucyrtidium asanoi Sakai 1980, pl.7, figs.13a,b,c,14a,b (only).

Eucyrtidium cienkowskii Haeckel group: Weaver, Casey and Perez 1981, pl.1, figs.6-8.

Eucyrtidium cienkowskii group Haeckel: Nigrini and Lombari 1984, p.N111, pl.23, fig.6.

Description: Very similar to $E$. acuminatum but with an externally distinct lumbar stricture and reaches maximum breadth at the first post-abdominal segment then tapers slightly distally.

Dimensions: Based on eight specimens. Length to end of fourth abdominal segment 148-178. Length of thorax 23-32. Maximum breadth 58-85.

Remarks: Eucytidium asanoi Sakai was separated because of the "Iongitudinal ridges separating pores into sets" and is considered to be partly conspecific as many forms present in the samples studied show both strongly and poorly developed longitudinal ridges and transitional forms.

Recorded range: Dorcadospyris alata Zone to Didymocyrtis antepenultima Zone (after Kling 1973).

Weaver, Casey and Perez (1981) have the morphologic top of the E. cienkowskii group in mid Epoch 14 from the Newport Bay Section, California.

"Common in the Early Miocene sections examined from tropical and eastern temperate latitudes. Rare in the Late Miocene sections examined from tropical and eastern temperate latitudes" (Nigrini and Lombari, 1984, CENOP Project).

Riedel and Sanfilippo (1978a) recorded E. cienkowskii from the Lower Pliocene of Sicily. Miocene (Petrushevkaya and Kozlova, 1972).

Observed range: Relatively common throughout Late Neogene. Sparser in the Plio-Pleistocene.

\section{Eucyrtidium hexagonatum Haeckel}

Plate 23, figure 10: Plate 26, figure 3

Eucyrtidium hexagonatum Haeckel 1887, p.1489, pl.80, fig.11.

Eucyrtidium hexagonatum Haeckel: Johnson 1974, p.551, pl.10, fig.14.

Eucyrtidium hexagonatum Haeckel: Renz 1974, pl.16, fig.3.

Eucyrtidium cienkowskii Haeckel group: Riedel and Sanfilippo 1978a, p.114, pl.4, fig.11 (only).

Eucyrtidium hexagonatum Haeckel: Nigrini and Lombari 1984, p.N115, pl.23, fig.8.

Description: Very similar to $E$. acuminatum but with an externally distinct lumbar stricture. Reaches maximum breadth at about the second or third post-abdominal segment.

Dimensions: Total length (excluding apical horn) 146-209. Diameter of cephalis 9-18. Length of thorax 9-18. Breadth of thorax 27-36: maximum breadth 72-128 (Nigrini, 1967). 
Remarks: Distinguished from E. cienkowskii by a shorter thorax and reaching maximum breadth at the second or third post-abdominal segment. Rare forms are transitional between $E$. hexagontum and $E$. cienkowskii and between $E$. hexagonatum and $E$. acuminatum but there is generally a distinctive difference between the representative populations of each species.

Recorded range: "Absent from all Early Miocene sections examined from both tropical and temperate latitudes. Usually absent in Late Miocene material examined" (Nigrini and Lombari, 1984, CENOP Project).

Riedel and Sanfilippo (1978a) record this form from the Sicilian lower Pliocene.

Recorded from the Recent (see Nigrini and Moore, 1979, p.N63).

Johnson (1974) considers E. hexagontum to be related to $E$. acuminatum, the latter being the mid-latitude equivalent, They occur rarely in Pliocene and Quaternary cores. The first appearance datum of both species in the late Tertiary may prove to be useful stratigraphic datum planes but these levels were not determined for the DSDP Leg 22 cores because of the uncertain relationships of the various forms of the genus Eucyrtidium.

Observed range: Sparse occurrences throughout the Late Neogene. Tends to be rarer in Plio-Pleistocene.

Geographic distribution: "is rather sparsely distributed in low latitudes (1\% to $4 \%$ of the described population), and is practically absent in middle latitudes. Though rather rare in Recent sediments, it appears to be a useful member of the low latitude assemblage" (Nigrini, 1967, Indian Ocean).

\section{Eucyrtidium calvertense Martin}

Plate 22, figure 10: Plate 23, figures 1,2: Plate 24, figure 1

Eucyrtidium calvertense Martin 1904, p.450, pl.130, fig.5.

Eucyrtidium calvertense Martin: Hays 1965, p.181, pl.3, fig.4.

Eucyrtidium calvertense Martin: Hays 1970, p.213, pl.1, fig.6.

Eucyrtidium calverstnse Martin: Bandy, Casey and Wright 1971, pl.1, fig.1.

Eucyrtidium calvertense Martin: Kling 1973, p.636, pl.4, figs.16,18,19, pl.11, figs.1-5.

Eucyrtidium calvertense Martin: Casey and McMillen 1977, pl.2, fig.9.

Eucyrtidium calvertense Martin group: Sakai 1980, p.710, pl.7, figs.2a,b,4a-6b.

Eucyrtidium calvertense Martin: Keany 1979, p.56, pl.4, figs.7,8.

Description: Very similar to $E$. inflatum but distinguished from it by being broadest in the first post-abdominal segment. More specimens of this form are complete, tapering from the first post-abdominal segment to a subcylindrical peristome with longitudinally arranged subcircular pores but less distinct sharp-crested ridges between the pore rows.

Dimensions: Based on 65 specimens. Total length 175-220. Maximum breadth 90-110. Length of cephalis 10-17: of thorax 20-30 (Hays 1965).

Remarks: Rare forms are found with large pores in the collar stricture and with irregularly sized pores (similar to Eucyrtidium vincentense but with more strictures). Other rare forms are found that are transitional between these and E. calvertense sensu stricto. Kling (1973, p.637) shows histograms of the maximum breadth of specimens of $E$. calvertense and E. matuyamai (Hays), its evolutionary descendant. While absolute values are 
Upper Miocene to Lower Pliocene (Chen, 1975).

Sakai (1980) records the LAD of $E$. inflatum in the middle Miocene and Reynolds (1980) reports its dissappearence before the FAD of Diartus hughesi.

Observed range: Highest occurrence in the lower Pliocene (Wainuioru SWR1). Rare but useful biostratigraphically. Transitional forms with $E$. calvertense have a range similar to E. in flatum.

Eucyrtidium punctatum (Ehrenberg) group

Plate 23, figures 11,13,14: Plate 24, figures 2-4

cf. Lithocampe punctata Ehrenberg 1844, p.84.

Lithocampe sp. Nakaseko 1955, p.116, pl.10, figs.6a,b.

Lithocampe heptacola Haeckel: Dumitrica 1973, p.839, p1.24, fig.10 (only).

Eucyrtidium punctatum (Ehrenberg) group: Sanfilippo, Burckle et al. 1973, p.221, pl.5, figs.15,16.

Eucyrtidium punctatum (Ehrenberg) group: Sanfilippo, Caulet and Riedel 1978, p.756, pl.1, fig.3.

Eucyrtidium punctatum (Ehrenberg) group: Riedel and Sanfilippo 1978a, p.114, pl.4, figs.14-16.

cf. Lithocampe sp. Nigrini and Moore 1979, p.N65, pl.24, figs.5a,b.

Description: Small, subspherical cephalis rarely bearing a short, stout apical horn. Collar stricture normally indistinct with the cephalis submerged into the top of the thorax. Thorax long, conical, attains the same width as the subsequent (3-5) subcylindrical segments. Lumbar stricture indistinct. Cephalic pores small, subcircular, scattered. Thoracic pores subcircular, subarranged in longitudinal rows. In rare smooth walled forms the thoracic pores are only slightly bigger than cephalic pores. Abdominal and post-abdominal pores subcircular, normally arranged either hexagonally or in slightly bifurcating longitudinal rows. Post-abdominal strictures normally indistinct, occasionally marked by a slight change in contour and/or a change in pore pattern and size. Last segment tapers abruptly to a constricted mouth (usually less than one-third of the shell diameter) surrounded by a narrow, hyaline peristome.

Dimensions: Based on ten specimens. Length of shell 137-184. Maximum breadth of shell 67-93.

Remarks: This group probably includes more than one species but is distinctive because of the long, conical thorax which attains the same width as the following subcylindrical segments. Nigrini and Moore's (1979) Lithocampe sp. from Recent sediments has 8 segments and could be a Recent descendant of pre-middle Pleistocene forms of Eucyrtidium punctatum like those described herein, those from the Miocene of Japan (Nakaseko, 1955) and similar forms from the Mediterranean early Miocene (Sanfilippo, Burckle et al., 1973). Riedel and Sanfilippo (1978a) figure both five and seven segmented forms from the Lower Pliocene of Sicily. The forms with seven or more segments (e.g. Plate 24, figure 2) from the Miocene of New Zealand tend to be forms transitional with E. cienkowskii. 
Recorded range: Lower and middle Miocene (Weaver and Dinkelman, 1978, DSDP Site 391A).

Early Miocene to Late Miocene/middle Late Pliocene? (Sanfilippo et al., 1973). See Remarks.

Observed range: Present in 54\% of the radiolarian-bearing samples examined from throughout the Late Neogene.

Geographic distribution: "sparsely distributed in low latitudes but is abundant (2\% to $16 \%$ of the described population) south of $30^{\circ} \mathrm{S}$. It appears to be a reliable and potentially useful member of the middle 1atitude assemblage" (Nigrini, 1967, Indian Ocean).

"belongs to a transitional assemblage derived by recurrent group analysis of North Pacific samples; has been observed rarely in a few tropical samples" (Nigrini, 1970).

"rarely found under subantarctic waters" (Lozano, 1974).

\section{Eucyrtidium cf. montiparum Ehrenberg}

Plate 22, figure 9: Plate 26, figure 2

(?) Eucyrtidium montiparum Ehrenberg 1873, p.230,: 1875, pl.9, fig.11.

(?) Eucyrtidium sp. aff. E. montiparum Ehrenberg: Petrushevskaya and Kozlova 1972, p.548, pl.26, figs.2-4.

Description: Cephalis hemispherical, poreless. Collar stricture indistinct. Thorax small, truncate-conical. Thoracic pores subcircular to circular, hexagonally arranged. Lumbar stricture distinct, step-like, with upper part of abdomen wider than lower thorax. Abdominal pores larger than thorax, less regularly arranged in upper abdomen. Post-abdominal segments subcylindrical (fourth segment may be truncate conical), occasionally inflated. Pores hexagonally arranged, subcircular to circular, 11-13 on half equator. Widest part of shell fourth or fifth segment. Strictures between abdomen and post-abdominal segments normally indistinct. Termination ragged, appears to taper inwards slightly in sixth or seventh segment.

Dimensions: Based on two specimens. Length of cephalis and thorax 22-29: of shell to end of fifth segment 125-132. Maximum breadth (fourth or fifth segment) 57-71.

Remarks: E. montiparum sensu stricto has more inflated segments.

Recorded range: Eocene (Petrushenskaya and Kozlova, 1972).

Observed range: Present in Tongaporutuan samples. Highest occurrence in basal Pliocene samples. Probably evolved into Eucyrtidium sp. A.

\section{Eucyrtidium sp A.}

Plate 22, figure 7: Plate 25, figure 15

(?) Eucyrtidium lagena Haeckel 1862, p.325, pl.4, fig.11.

(?) Stichopodium (?) sp. group aff. Eucyrtidium matuyamai Hays: Petrushevskaya and Kozlova 1972, p.549, pl.26, figs.5,6. 
Description: Cephalis hemispherical, bearing a very short apical horn. Collar stricture distinct. Thorax truncate-conical, slightly inflated near base; pores subcircular, hexagonally arranged. Lumbar stricture marked by slight change in contour. Abdomen truncate-conical. Abdominal and post-abdominal pores subcircular, irregular in size, subhexagonally arranged, increasing in size distally, intervening bars 0.5 to 0.1 times the large pore breadth. Post-lumbar strictures indistinct externally, sometimes oblique. Broadest part of shell in fourth segment. Post-abdominal segments subcylindrical, tapering inwards slightly. Termination ragged.

Dimensions: Length of shell to end of fourth segment 117. Maximum breadth of shell 63 .

Remarks: Petrushevskaya and Kozlova (1972) synonomized their forms with E. matuyamai Hays (Kling, 1971, pl.1, fig.4) which has indistinct longitudinal ribbing and has a maximum breadth of $124 \mu$, while their form has a maximum breadth of $70-90 \mu$. The form described herein differs from that described by Petrushevskaya and Kozlova in that it has a relatively short abdomen. See remarks under $E$. calvertense for a more complete discussion of size ranges.

Recorded range: Pliocene (Petrushevskaya and Kozlova, 1972).

Observed range: Apart from two tentative Miocene occurrences (in samples TM20, TM21 above the local FAD of $B$. compressa), all other occurrences Plio-Pleistocene. See E. montiparum.

\section{Eucyrtidium vincentense (Campbell and Clark)}

Plate 22, figure 8

Eusyringium vincentense Campbell and Clark 1944, p.57, pl.7, fig.22 (plate spelling vicentense).

Description: Shell spindle-shaped. Cephalis hemispherical, partly hidden in thorax. Short, thorn-like apical horn. Collar stricture indistinct, marked by relatively large collar pores. Thorax truncate conical with small, scattered, circular pores. Lumbar stricture indistinct. Abdomen truncate-conical. Abdominal and post-abdominal pores subcircular, increase in size to maximum breadth of shell, subhexagonally arranged (10 on half equator), well separated, deep set. Post-lumbar stricture indistinct. Greatest breadth in middle of the shell (upper part fourth segment), above and below tapers with slight convexity. Termination an inverted truncate-conical peristome. Forms with smaller, more irregular pores referred to as E. cf. vincentense (Plate 25, figure 9).

Dimensions: Based on three specimens. Length of shell 145-156. Maximum breadth 70-81.

Remarks: Not a typical species of the genus.

Recorded range: Found in the Californian Miocene (Campbell and Clark, 1944).

Observed range: Both small and large pored forms found in only three Tongaporutuan samples. Too rare to be of biostratigraphic use. 
Theoperidae without radial apophyses. Basal shell mouth open. Multisegmented, in which the first three or four segments constitute a conical upper portion of the shell and the subsequent segments (narrower than the greatest width of the conical portion) constitute a cylindrical lower portion. Apical horn small, simple.

Type-species: Stichocorys wolffii Haeckel 1887

\section{Stichocorys peregrina (Riedel)}

Plate 25, figures 2-5,7: Plate 26, figures 4,6,8

Eucyrtidium elongatum peregrinum Riedel 1953, p.812, pl.85, fig.2.

Stichocorys peregrina (Riedel): Sanfilippo and Riedel 1970, p.451, pl.1, fig.10.

Stichocorys peregrina (Riedel): Riedel and Sanfilippo 1978b, p.74, p1.9, fig.11.

Stichocorys peregrina (Riedel): Westberg and Riedel 1978, p.22, pl.3, figs.6-9.

Stichocorys peregrina (Riedel): Nigrini and Lombari 1984, p.N133, p1.25, fig.6.

Description: Shell with seven (or more) segments distinctly separated by constrictions (commonly broken at the fifth or sixth joint). The first four segments form a conical section, the subsequent segments an approximately cylindrical section. Cephalis subspherical to spherical, with scattered small pores, and rarely bearing an eccentric straight or slightly curved horn of the same length. Thorax hemispherical having 9-11 subspherical, irregularly arranged pores on the half equator. Third segment truncate-conical to inflated, usually longer than any other. Fourth segment usually inflated. Segments subsequent to the fourth are generally shorter and narrower, subcylindrical to inflated. In well preserved specimens last segment normally subcylindrical, narrow, with scattered small subcircular pores.

Dimensions: Length of the first four segments 125-135. Greatest breadth (in the lower part of the third segment, or the middle of the fourth) 70-80. Breadth of cephalis 20: of thorax 35-40: of fifth segment 60-65. Length of cephalis 12-15: of thorax 20-25: of third segment 35-50: of fourth segment 30-40: of subsequent segments 20-45 (Riedel, 1953).

Remarks: "The upper conical part of the shell consists of three segments, and the fourth is equally robust. The third segment is long, truncate-conical and the thorax short" (Riedel and Sanfilippo, 1978b).

"The width of the top quarter of the fourth segment must be at least as great as the maximum width of the third segment" (Westberg and Riedel, 1978). The form illustrated by Sanfilippo and Riedel (1970, pl.1, fig.10) does not conform to this requirement but has the typical truncate-conical third segment of $S$. peregrina.

Kling (1973) also notes the presence of specimens with a less markedly conical third segment from DSDP Site 173 (North Pacific).

Recorded range: Riedel and Sanfilippo (1978b) define the lower limit of the Stichocorys peregrina Zone (Late Miocene) by the evolutionary bottom of $S$. peregrina. They define the upper limit of the Spongaster pentas Zone (Pliocene) by the last occurrence of $S$. peregrina.

Kling (1973) finds the extinction of $S$. peregrina at the base of the upper Pliocene Lamprocyrtis heteroporos (Hays, 1970) Zone with a radiometric-paleomagnetic age of 2.8 Ma. 
Theyer et al. (1978) date the first occurrence of this species at $6.4 \mathrm{Ma}$ and the last occurrence at $2.4 \mathrm{Ma}$.

Observed range: Found in $70 \%$ of the radiolarian-bearing samples examined including occurrences with G. dehiscens in Leader, Wainuioru, Kaiti, Ruakituri and Mangaopari samples.

Geographic distribution: "Abundant in all the Late Miocene material examined from both tropical and temperate latitudes" (Nigrini and Lombari, 1984, CENOP Project).

Stichocorys delmontensis (Campbell and Clark)

Plate 25, figures 1,6,8: Plate 26, figure 5

Eucyrtidium delmontense Campbell and Clark 1944, p.56, pl.7, figs.19,20.

Stichocorys delmontensis (Campbell and Clark): Sanfilippo and Riedel 1970, p.451, pl.1, fig.9.

Stichocorys delmontensis (Campbell and Clark): Riedel and Sanfilippo 1978b, p.74, p1.9, fig.10.

Stichocorys delmontensis (Campbell and Clark): Westberg and Riedel 1978, p.22, p1.3, figs.1-5.

Stichocorys delmontensis (Campbell and Clark): Nigrini and Lombari 1984, p.N129, p1.25, fig.4.

Description: Similar to Stichocorys peregrina but is distinguished from it in that the "third segment inflated-annular; rather than truncate-conical as in its direct evolutionary descendant, S. peregrina" (Riedel and Sanfilippo, 1978b).

Dimensions: Total length 200. Diameter of cylindrical abdomen 70 (Campbell and Clark, 1944).

Remarks: "The third segment is typically inflated annular, but specimens with conical third segments are admitted here if the fourth segment is not as wide as the third" (Westberg and Riedel, 1978).

Recorded range: Riedel and Sanfilippo (1978b) show the first occurrence of this species in the Early Miocene. The lower limit of the Stichocorys peregrina Zone (Late Miocene) is defined by the evolutionary transition from $S$. delmontensis to $S$. peregrina.

Theyer et al. (1978) date the first occurrence of this species at $20.6 \mathrm{Ma}$ and the last occurrence at $6.1 \mathrm{Ma}$.

Observed range: Common in Tongaporutuan samples. Present in some lower Pliocene samples. Highest occurrence is at the LAD of C. molestus at Waiatai (WA23). Transitional forms mimic the distributions of both $S$. peregrina and $S$. delmontensis.

Geographic distribution: "Rare or absent throughout the Miocene sections examined from temperate latitudes. Abundant in all the Miocene sections examined from tropical latitudes" (Nigrini and Lombari, 1984, CENOP Project). 
Stichocorys sp. A

Plate 26, figure 7

Description: Rare specimens of Stichocorys with a strange chamber arrangement in its upper portion.

Observed range: Found in only three northern Tongaporutuan samples (SCV1, RK02, RK04). Too rare to be of use biostratigraphically.

\section{Genus Gondwanaria Petrushevskaya 1975}

Theoperidae with a globe-shaped cephalis, settled on the "neck". Thorax cupola-chaped. Spines may form three ribs in the upper walls of the thorax. There are no real "sethoperid" plates connecting these three spines with the apical horn. Abdomen may be more or less developed (and divided from the thorax). Pores irregular or in longitudinal rows.

Type-species: Sethoconus (?) dogeli Petrushevskaya 1967

\section{Gondwanaria dogeli (Petrushevskaya) group \\ Plate 26, figure 9}

Sethoconus (?) dogeli Petrushevskaya 1967, p.95, pl.53, fig.1,2.

Lipmanella (?) dogeli (Petrushevskaya): Petrushevskaya and Kozlova 1972, p.542, pl.37, fig.10.

Gondwanaria dogeli (Petrushevskaya) group: Petrushevskaya 1975, p.585.

Sethoconus (?) dogieli (Petrushevskaya): Weaver 1976a, p.124, pl.1, fig.7.

Description: Cephalis subspherical, with three-bladed apical horn and scattered small pores. Collar stricture is a distinct "neck". Thorax cupola-shaped (conical above, inflated below) with normally at least one horizontal short three-bladed spine visible just above the broadest point. Lumbar stricture marked by a slight change in contour. Thoracic and abdominal pores large, subelliptical to circular, in a subregular pattern increasing in size distally. Termination ragged.

Dimensions: Average of three specimens. Length of cephalis and neck 40: of thorax 57: of shell 164. Maximum breadth 92 .

Remarks: Differs from the other members of this genus by its overall campanulate shell outline, the indistinct subdivision into thorax and abdomen, and its large pores.

Very similar to Lithomelissa campanulaeformis Campbell and Clark (1944, p.41, p1.6, fig.1) but differs in being smaller (Campbell and Clark's form has thorax length 180, maximum breadth 180).

Recorded range: "This species appears in the Antarctic early Miocene in an atypical form, and is known to exist up to Recent" (Petrushevskaya, 1975).

Pliocene (Weaver, 1976a).

Pliocene to Quaternary (Petrushevskaya and Kozlova, 1972). 
Observed range: Occurs in nine samples from throughout the Late Neogene.

\author{
Genus Artostrobus Haeckel 1887 \\ sensu Petrushevskaya 1975
}

Theoperidae with a small cigar-shaped, not conical shell outline. No separation into a thorax and abdomen (two-segments). Included in the theoperids to accomodate $A$. pretabulatus which lacks the transverse pore alignment characteristic of the artostrobiids. Type-species: Cornutella annulata Bailey 1856

\title{
"Artostrobus" pretabulatus Petrushevskaya \\ Plate 30 , figure 15
}

\begin{abstract}
Artostrobus (?) pretabulatus Petrushevskaya 1975, p.580, pl.10, figs.2,3.
\end{abstract}
Description: Skeleton cylindrical, two segments. Cephalis subspherical, small. Collar stricture indistinct with no change of contour in the shell outline. Thorax cylindrical, tapering very slightly distally. Thoracic wall slightly thicker than cephalic. Pores subelliptical to subcircular, increasing in size towards the broadest part of the thorax and then decreasing slightly in size distally. Long axis of subelliptical pores arranged horizontally. Pores also arranged in longitudinal rows; about five on a half equator. Termination ragged.

Dimensions: Based on three specimens. Shell length 100-112: width of broadest part of thorax 36-41.

Remarks: Similar in shell outline to Tricolocampe sanpedroana Campbell and Clark (1944, p.50, pl.7, fig.5) which has very small abdominal pores in transverse rows with a subvertical wrinkle associated with every pore. Differs from A. annulatus (Bailey) in having a longitudinal pore arrangement rather than a transverse arrangement. This species is best placed among the theoperids as it lacks the transverse pore alignment characteristic of the artostrobiids.

Recorded range: Oligocene to Miocene (Petrushevskaya, 1975).

Observed range: Four occurrences, two of which are in samples with G. dehiscens at Kaiti and Leader. Other two occurrences are from the upper Tongaporutuan in Wairarapa.

\section{Family Pterocorythidae Haeckel 1881 emended Riedel 1967a}

Cephalis subdivided into three lobes by two obliquely downward directed lateral furrows arising from the apical spine in the manner described for Anthocyrtidium cineraria Haeckel and Calocycletta virginis Haeckel by Riedel (1957).

Genus Anthocyrtidium Haeckel 1881

Pterocorythidae with two segments. The second segment is ovate and the aperture constricted. A subterminal corona of spines above the apertural margin which itself is provided with a corona of teeth. 


\section{Anthocyrtidium ehrenbergi (Stohr) pliocenica (Seguenza) \\ Plate 25, figure 12: Plate 26, figure 10}

Anthocyrtis ehrenbergii Stohr pliocenica Seguenza 1880, p.232.

Anthocyrtium ehrenbergii (Stohr) pliocenica (Seguenza): Riedel 1957, p.84, p1.2, figs.4,5.

Anthocyrtidium ehrenbergi (Stohr) pliocenica (Seguenza): Nigrini and Lombari 1984, p.N149, pl.27, figs.2a,b.

Description: Cephalis elongate, ovate-subcylindrical, with scattered subcircular to circular pores, bearing an eccentrically positioned three-bladed apical horn approximately the same length as the cephalis. Thorax usually with flat surface, campanulate, inflated with constricted mouth, having circular to subcircular pores hexagonally arranged. Nearly equally well developed peristomal and subterminal teeth. Up to 16 moderately well-developed, sharp, diverging subterminal teeth. Surrounding the constricted mouth is a hyaline peristome which usually bears 10-14 well-developed, flat, triangular, converging to vertical terminal teeth.

Dimensions: Length of apical horn 32-60: of cephalis 35-40: of thorax 90-115: of terminal teeth 5-20. Breadth of cephalis 25-32: of thorax 90-120 (Riedel, 1957).

Remarks: These rare forms are distinguished from $A$. ehrenbergi ehrenbergi by the subterminal and terminal teeth development. Nigrini and Lombari (1984, p.N148) indicate that it seems likely A. ehrenbergi ehrenbergi, A. ehrenbergi pliocenica and A. ophirense constitute an evolutionary sequence ranging from the late Miocene to the Recent. The details of such a sequence have not been well documented.

Recorded range: "may be restricted to the upper Tertiary" (Riedel, 1957).

Miocene to Lower Pliocene (Keany, 1979, Anthocyrtidium ehrenbergi).

Weaver, Casey and Perez (1981) show the morphotypic top of A. ehrenbergi in mid Epoch 5 from the Newport Bay Section.

Observed range: In Upper Mangaopari Section the abundance gradually increases until it becomes quite abundant at about the local FAD of $B$. compressa. This occurrence pattern is supported by data from Mangapoike, Morrisons, Palliser and perhaps Ruakituri. Not found with G. dehiscens. Highest occurrence in basal Opoitian apart from two tentative occurrences in Waiatai (WA03, WA17).

\section{Anthocyrtidium (?) sp. A}

Plate 25, figures 10,11: Plate 26, figure 11

Description: Cephalis elongate, ovate-cylindrical, with scattered subcircular to circular pores bearing a three-bladed apical horn usually of the same length or shorter than the cephalis. Thorax campanulate to inflated, with a constricted mouth. Thoracic pores circular, usually hexagonally arranged, often with a strong longitudinal ribbing developed on the surface of the thorax, which in some specimens extends onto the cephalic surface. Most specimens have moderate to well-developed subterminal teeth (14-16) projecting downwards. Surrounding the constricted mouth is a hyaline peristome which usually bears 6-8, 
well-developed, flat, triangular, terminal teeth either projecting vertically or slightly converging.

Dimensions: Based on twelve specimens. Length of apical horn 18-34: of cephalis 22-56: of thorax 59-93. Breadth of cephalis 24-31: of thorax 88-118.

Remarks: This species differs from the Anthocyrtidium ehrenbergi (Stohr) group in having longitudinally aligned thoracic ribs. Variations in the development of the subterminal and terminal teeth indicate that subspeciation may be possible. Tentatively placed in the genus because of different definitions; i.e., Haeckel (1881) makes no mention of the presence or absence of ribbing, allowing entry of this form into the genus on all counts, but in Haeckel (1887) the definition states "no ribs on thorax" which would exclude this form. The type-species has no thoracic ribbing.

Observed range: Restricted to Tongaporutuan samples.

\section{Anthocyrtidium zanguebaricum (Ehrenberg)}

Plate 25 , figures 13,14

Anthocyrtis zanguebarica Ehrenberg 1872a, p.301.

Sethocorys sp. Kling 1973, pl.12, fig.15.

Anthocyrtidium zanguebaricum (Ehrenberg): Johnson and Nigrini 1980, pl.3, fig.19.

Anthocyrtidium zanguebaricum (Ehrenberg): Nigrini and Moore 1979, p.N69, p1.25, fig.2.

Description: Similar to $A$. ehrenbergi pliocenica but with a less campanulate, more cylindrical thorax with poorly developed subterminal teeth and terminal teeth either absent, or in the form of small triangular teeth directed inwards. Thoracic pores may be hexagonally framed.

Dimensions: Length of apical horn 18-36: of cephalis 27-36: of thorax 63-90. Maximum breadth of cephalis 18-27: of thorax 63-81 (Nigrini, 1967).

Recorded range: Kling's (1973) figured form of Sethocorys sp. is from his Upper Miocene Zone. Known from the Recent.

Observed range: Rarer than the other members of this genus. Thirty-one occurrences are all in Tongaporutuan samples.

Geographic distribution: "Present in most samples north of about $45^{\circ} \mathrm{S}$ " (Johnson and Nigrini, 1980, western Indian Ocean).

Genus Lamprocyclas Haeckel 1881

emended Nigrini 1979 (in Nigrini and Moore, 1979)

Pterocorythidae with a double corona of solid terminal teeth around the mouth. Thoracic ribs present. The distal projections of members of this genus are regarded as teeth rather than radial apophyses.

Type-species: Lamprocyclas nuptialis Haeckel 1887 
Note: Within this genus there are a number of forms recognised, some of which are intergradational. Some do not strictly adhere to the generic description but the presence of transitional forms indicates some relationship to forms that can be confidently placed within the genus. More detailed work on the phylogeny of the group would be needed to confirm or deny the following morphologic speciation.

\section{Lamprocyclas gamphonycha (Jorgensen)}

Plate 27, figure 1

Pterocorys gamphonyxos Jorgensen 1900, p.86.

Androcyclas gamphonycha (Jorgensen) 1905, p.139, pl.18, figs.92,93.

Androcyclas gamphonycha (Jorgensen): Hays 1965, p.178, pl.3, fig.2.

Description: Test campanulate to subcylindrical, with three (?) segments and a heavy three-bladed apical horn. Cephalis elongate, merges with thorax without any definite stricture. Cephalic pores arranged in subparallel rows. Thorax campanulate, pores becoming more hexagonally arranged, and increasing in size distally. Very slight change in contour at lumbar stricture, sometimes with internal septal ring. Abdomen cylindrical to conical, with larger pores (8-10 on half equator), irregular to subregular in size and shape, 5-8 times the width of bars. Subterminal teeth short, divergent, around broadest part of abdomen. Mouth constricted about three-quarters the diameter of the broadest part of abdomen, with 9-11 short, sharp, vertical teeth.

Dimensions: Based on 25 specimens. Length of apical horn 30-60: of cephalis 18-30: of thorax 25-45: of abdomen 25-100. Maximum breadth 90-130 (Hays, 1965).

Remarks: Placed in this genus due to presence of the double corona of teeth. Differs from Lamprocyrtis heteroporos (Hays) in tooth development and a more gradual change in pore size across the lumbar stricture. Appears to have evolved from $L$. heteroporos.

Kling (1973) documents $L$. heteroporos evolving into $L$. neoheteroporos. Lamprocyclas gamphonycha differs from $L$. neoheteroporos in having more regularly arranged pores and stronger tooth development. L. neoheteroporos also lacks a septal ring, similar to some of the forms described herein. There appears to be a relationship between the two taxa and they may even be ecologic variants of the same morphotype.

Recorded range: Found above $\Phi$ zone of Hays (1965) (base of Olduvai Event to Recent: after Keany and Kennett, 1975).

Observed range: Only two positive occurrences in Waiatai (WA03, WA07). A tentative occurrence in WA15 is midway between the LAD of C. molestus and FAD of G. crassula.

Geographic distribution: "Observed only in sediment samples taken north of the Polar Front" (Hays, 1965)

"Present in most samples between about $30^{\circ} \mathrm{S}$ and $46^{\circ} \mathrm{S}$ " (Johnson and Nigrini, 1980, western Indian Ocean).

Lamprocyclas maritalis Haeckel

Plate 27, figure 3

Lamprocyclas maritalis Haeckel 1887, p.1390, pl.74, figs.13,14. 
Lamprocyclas maritalis Haeckel: Hays 1965, p.180, pl.3, fig.11.

Lamprocyclas maritalis (Haecke1) polypora Nigrini 1967, p.76, pl.7, fig.6.

Lamprocyclas maritalis Haeckel group: Petrushevskaya and Kozlova 1972, pl.36, fig.13.

Lamprocyclas maritalis Haeckel: Casey, Price and Swift 1972, p1.2, fig.17.

Lamprocyclas aegles (Ehrenberg): Dumitrica 1973, pl.14, fig.1, pl.26, fig.8 (only).

Lamprocyclas maritalis (Haeckel) polypora Nigrini: Johnson 1974, pl.10, fig.12.

Lamprocyclas maritalis Haeckel group (in part): Nigrini and Lombari 1984, p.N163, pl.30, figs.1a,b.

Description: Cephalis elongate, trilocular, with scattered subcircular pores sometimes arranged in longitudinal rows, bearing a strong three-bladed apical spine. Collar stricture indistinct. Thorax cupola-shaped (conical above, inflated below) with hexagonally framed circular to subcircular pores, sometimes arranged in longitudinal rows, increasing slightly in size distally. Lumbar stricture distinct. Abdomen inflated, a lot broader than thorax with circular to subcircular pores arranged hexagonally, sometimes in longitudinal rows. Outer teeth on abdomen just above peristome, well developed, conical, horn-like, divergent to vertical. Peristome hyaline, with occasionally well-developed, sharp, conical, vertical to convergent teeth.

Dimensions: Based on 6 specimens. Length of horn 54-73: of cephalis 33-38: of thorax 34-45: of abdomen 46-63. Maximum breadth of thorax 89-96: of abdomen 115-137.

Remarks: Distinguished by the difference in abdominal and thoracic breadth and well developed subterminal teeth.

Recorded range: Absent in Early Miocene tropical and temperate cores, rare in most Late Miocene sections (after Nigrini and Lombari, 1984).

Pliocene to Quaternary (Petrushevskaya and Kozlova, 1972).

Observed range: $L$. maritalis sensu stricto positively found in only one sample (WA17) midway between the LAD of C. molestus and FAD of G. crassula. Forms herein referred to as L. cf. maritalis (Plate 27, figure 2) are sparse in the Miocene with $68 \%$ of the 19 samples containing this form from Plio-Pleistocene sediments.

Geographic distribution: "It is thus cosmopolitan in modern seas but has not been observed south of the South Polar Front” (Hays, 1965).

\section{Lamprocyclas (?) sp. A}

Plate 27, figures 4,8

Description: Cephalis elongate, trilocular, subcircular pores in longitudinal rows, 4-6 pores per row, bearing a strong, slightly eccentric, cylindrical apical horn. Collar stricture distinct. Thorax cupola-shaped (conical above, inflated below). Thoracic pores subcircular, 12-14 on half equator, hexagonally arranged, bars 1-2 times width of pores. Some forms show increasing irregularity in pore shape distally (some pores approach kidney-shaped: see Plate 27, figure 8) Lumbar stricture distinct. Abdomen short, cylindrical, slightly narrower than thorax, tapering abruptly at the mouth. Abdominal pores normally subcircular and rarely subelliptical with an indistinct hexagonal arrangement. Abdomen has scattered small conical, divergent spines normally clustered in a ring (approximately 16) just above the peristome. Heavy, hyaline, smooth, narrow peristome surrounds mouth. Mouth constricted to two-thirds 
the width of the abdomen.

Dimensions: Based on 5 specimens. Length of apical horn 60-67: of cephalis 33-42: of thorax 55-69: of abdomen 33-50. Maximum breadth of thorax 111-128: of abdomen 103-126.

Remarks: Placed tentatively in this genus because the forms have only no terminal teeth. This form could have its ancestry in the Calocycletta lineage (Moore 1972). Distinguished by its cylindrical, narrower abdomen.

Observed range: Not common. Restricted to Tongaporutuan.

Lamprocyclas $\mathrm{sp} . \mathrm{B}$

Plate 27, figures 5,6

Description: Cephalis elongate to conical, trilocular, with scattered small subcircular pores sometimes arranged in longitudinal rows, bearing a strong, cylindrical to three-bladed apical horn. Collar stricture indistinct. Thorax subconical to slightly campanulate with hexagonally to longitudinally arranged subcircular pores. Lumbar stricture indistinct. Abdomen subcylindrical to inflated with hexagonally to longitudinally arranged subcircular pores which are slightly bigger than thoracic pores. Abdomen tapers towards mouth which is three-quarters to two-thirds the breadth of the abdomen. Outer teeth moderately to well developed, divergent, short, heavy, conical projections. Mouth surrounded by heavy, hyaline peristome which occasionally has up to 8 poorly developed vertical teeth.

Dimensions: Based on 6 specimens. Length of apical horn 63-91: of cephalis 28-45: of thorax 37-50: of abdomen 50-62. Maximum breadth of thorax 83-96: of abdomen 104-125.

Remarks: Distinguished by indistinct collar and lumbar strictures and better developed outer teeth.

Observed range: Not common. Restricted to the Tongaporutuan except tentative identifications at Waiatai.

Lamprocyclas sp. C

Plate 28, figures 1-7: Plate 30, figure 2

non: Podocyrtis aegles Ehrenberg 1854a, pl.35/B.4, fig.18: 1854b, p.245.

Lamprocyclas aegles (Ehrenberg): Dumitrica 1973, pl.15, figs.3,4, pl.26, fig.7 (only).

Lamprocyclas aegles (Ehrenberg) group: Petrushevskaya 1975, p.584, pl.16, figs.2-4 (only).

Lamprocyclas aegles (Ehrenberg) group: Weaver 1976a, p.123, pl.6, figs.4-6.

Description: Cephalis elongate, trilocular, scattered subcircular pores, bearing a strong, slightly eccentric, initially three-bladed, cylindrical, apical horn. Collar stricture indistinct. Thorax inflated, normally conical above the broadest part with subcircular, hexagonally arranged pores which tend to increase in size distally. Occasional forms bear a thoracic wing just below the cephalis. Lumbar stricture very distinct (deep furrow on the outer surface). Abdomen inflated, normally only slightly broader and longer than the thorax. Abdominal pores subcircular, hexagonally arranged, about the same size as largest on thorax. Outer teeth divergent, poorly to well developed, approximately 12, just below broadest part of abdomen. Mouth constricted to half the diameter of the maximum breadth of abdomen. 
Peristome hyaline, heavy; bearing 7-9 well developed sharp, conical, vertical teeth.

Dimensions: Based on 20 specimens. Length of apical horn 38-61: of cephalis 30-36: of thorax 38-62: of abdomen 51-75. Maximum breadth of thorax 90-103: of abdomen 103-117.

Remarks: Distinguished by similar size of thorax and abdomen and well developed terminal teeth.

Recorded range: Pliocene (?) to Quaternary (Petrushevskaya, 1975).

Late Miocene and Pliocene (Weaver, 1976a).

Observed range: Found in 58\% of the radiolarian-bearing samples examined. Quite common in the lower Pliocene and Miocene, very rare in the upper Pliocene and Pleistocene. Highest occurrence is in sample WA03. The distribution of transitional forms with Lamprocyclas sp. D generally mimics the distribution pattern of Lamprocyclas sp. C and Lamprocyclas sp. D.

Lamprocyclas sp. D

Plate 27, figures 12,14

Theocorythium ex. gr. amicae (Haecke1): Dumitrica 1973, pl.26, fig.5 (only).

Description: Cephalis elongate, trilocular, with scattered subcircular pores, bearing a strong, slightly eccentric, cylindrical apical horn. Collar stricture distinct. Thorax campanulate with hexagonally arranged subcircular pores which tend to increase in size distally. Lumbar stricture pronounced to indistinct. Abdomen slightly inflated, not much broader than thorax, tapering abruptly to mouth. Abdominal pores subcircular, hexagonally arranged, same size as largest on thorax. Outer teeth divergent, conical, poorly developed in a ring just above the peristome. Terminal teeth, if present, are small, triangular, convergent extensions of a hyaline peristome ( 6 in a ring). Mouth constricted to between two-thirds and one-half the maximum breadth of the abdomen.

Dimensions: Based on 5 specimens. Length of apical horn 36-65: of cephalis 30-40: of thorax 37-65: of abdomen 35-65. Maximum breadth of thorax 89-120: of abdomen 100-135.

Remarks: As with Lamprocyclas sp. C this form is distinguished by similar size of abdomen and thorax. Differs from the former in having poorly developed teeth.

Observed range: Found in $26 \%$ of the radiolarian-bearing samples examined. Distribution pattern mimics that of Lamprocyclas sp. C.

\section{Lamprocyclas sp. E}

Plate 27, figure 7: Plate 30, figure 1

? Calocyclas margatensis Campbell and Clark: Riedel 1953, p.811, pl.85, fig.8.

Description: Very similar to Lamprocyclas sp. B but with a slightly more pronounced lumbar stricture and larger abdomen. Peristomal region heavily silicified with well developed, vertical, subterminal and terminal teeth joined by heavy hyaline "ridges". 
Dimensions: Based on four specimens. Length of apical horn 61-80: of cephalis 36-39: of thorax 37-41: of abdomen 72-92. Maximum breadth of thorax 88-92: of abdomen 120-128.

Remarks: Easily distinguished by the heavy hyaline ridges in the terminal area.

Observed range: Restricted to Tongaporutuan samples apart from one positive identification in SWR2.

\section{Genus Lamprocyrtis Kling 1973}

This genus was erected by Kling (1973) to accomodate the lineage from Lamprocyrtis heteroporos through $L$. haysi, with $L$. (?) hannai a possible ancestor of the lineage. It is difficult to characterise because of rather marked differences between initial and latest members of the lineage. Included are two- (later) and three- (earlier) segmented forms with a usually open, indistinctly three-lobed cephalis, bearing one stout, three-bladed apical horn. Post-cephalic pores increase in size distally with earlier species displaying a distinctive discontinuity in pore size. The shells terminate in a single, irregular row of teeth which sometimes occupy a weakly developed peristome. Teeth occasionally occur outside the terminal row, but do not constitute a distinct second row as in Lamprocyclas. Type-species: Lamprocyclas heteroporos Hays 1965

\section{Lamprocyrtis (?) apollinis (Haeckel) \\ Plate 27, figure 11}

Theocorys apollinis Haeckel 1887, p.1418, pl.69, fig.3.

Description: Cephalis hemispherical to elongate, trilocular with a heavy three-bladed apical horn. Collar stricture indistinct. Thorax campanulate with subcircular pores arranged in longitudinal rows, 5-6 pores per row, bars as wide as pores. Lumbar stricture not pronounced. Abdomen inflated, broadest at about two-thirds down from the lumbar stricture. Pores slightly larger than thorax, increasing slightly in size distally but decreasing in size abruptly before mouth. Pores 1-2 times wider than bars, with less pronounced longitudinal alignment. Mouth constricted, about two-thirds diameter of the broadest part of abdomen, weak hyaline peristome.

Dimensions: Based on three specimens (average). Length of cephalis 23: of thorax 40: of abdomen 70. Maximum breadth of abdomen 94 .

Remarks: Tentatively placed in this genus due to slight increase in pore size distally and weak peristome.

Observed range: Rare upper Tongaporutuan occurrences in Wairarapa and the Leader Tributary Section samples. One tentative identification in the Pleistocene (WA03).

\section{Lamprocyrtis hannai (Campbell and Clark) \\ Plate 27, figure 10}

Calocyclas hannai Campbell and Clark 1944, p.48, pl.6, figs.21,22.

Calocyclas margatensis Campbell and Clark: Casey, Price and Swift 1972, pl.3, figs.16,18, $19,21,22$ (only). 
Lamprocyrtis (?) hannai (Campbell and Clark): Kling 1973, p.638, pl.5, figs.12-14, pl.12, figs.10-14.

Lamprocyrtis hannai Campbell and Clark: Foreman 1975, p.620, p1.9, figs.17-19.

Lamprocyrtis (?) hannai Campbell and Clark: Nigrini and Moore 1979, p.N83, pl.25, fig.8.

Description: Cephalis elongate, trilocular with subcircular pores and strong, eccentric, three-bladed apical horn. Cephalis open apically. Collar stricture indistinct. Thorax campanulate with circular pores increasing in size distally. Lumbar stricture not pronounced. Abdomen slightly inflated with circular to subcircular pores increasing in size distally. Smallest pore on abdomen approximately equal in size to largest on thorax. Ten pores on abdominal half equator. Peristome not preserved.

Dimensions: Based on 20 specimens. Length of cephalis 20-45: of thorax 30-70: of abdomen 25-162. Maximum breadth of thorax 75-100: of abdomen 90-152 (Nigrini in Nigrini and Moore, 1979).

Remarks: This form was only tentatively placed in this genus by Kling (1973) as he was unsure of its position in the $L$. heteroporos - $L$. haysi lineage. On the basis of morphology it is considered to be part of the genus herein. This species is distinguished from its probable descendant $L$. heteroporos by a slightly more inflated abdomen and more gradational change in pore size across the lumbar stricture.

Recorded range: Calocycletta costata Zone to Recent (Kling, 1973, DSDP Site 173).

Stichocorys peregrina Zone to Recent (Foreman, 1975, DSDP Site 310).

Evolved into $L$. heteroporos at about the Miocene/Pliocene boundary in southern California (Casey, Price and Swift, 1972).

Observed range: Sporadic Miocene occurrences concentrated in Wairarapa sections. Only one other occurrence (WA19), is at the level where it appears to have evolved into $L$. heteroporos.

Geographic distribution: "Consistently present in samples north of about $10^{\circ} \mathrm{S}$ with scattered occurrences as far south as $30^{\circ} \mathrm{S}$ " (Johnson and Nigrini, 1980, western Indian Ocean).

\section{Lamprocyrtis heteroporos (Hays)}

Lamprocyclas heteroporos Hays 1965, p.179, p1.3, fig.1.

Lamprocyrtis heteroporos (Hays): Kling 1973, p.639, pl.5, figs.19-21.

Lamprocyrtis heteroporos (Hays): Foreman 1975, p.620, p1.9, fig.20.

Description: Shell campanulate with indistinct collar stricture but distinct lumbar stricture. Cephalis hemispherical bearing a long three-bladed apical horn, as long as or up to three times as long as the cephalis. Thorax campanulate with pore size similar to cephalis and pores arranged in irregular longitudinal rows and increasing in size distally. Abdomen cylindrical to slightly conical with maximum diameter just above the mouth. Pores large, irregular in size and shape and separated by thick bars. Abdominal pores 2-3 times the size of thoracic. Aperture slightly constricted, 3-5 poorly developed short teeth extend downward from a thick peristomal ring. 
Dimensions: Length of apical horn 22-60: of cephalis 15-25: of thorax 48-65: of abdomen 55-70. Maximum width of shell 88-100.

Remarks: As with Foreman (1975) this species is interpreted rather strictly as described by Hays. The pores of the abdomen must be large as well as regular.

Recorded range: Lower Pliocene to mid-Pleistocene (Foreman, 1975).

Hays (1970) defined the Lamprocyclas heteroporos Zone as the range of $L$. heteroporos subsequent to the extinction of Eucyrtidium elongatum peregrinum (=Stichocorys peregrina) and dated this zone as 2.8 to $2.0 \mathrm{Ma}$ with $L$. heteroporos becoming extinct near the base of the Olduvai. He also suggested that $L$. heteroporos evolved into Androcyclas gamphonycha and also concluded that $L$. heteroporos seems to have disappeared from Antarctic sediments 0.5 Ma before its final occurrence in North Pacific sediments.

Kling (1973, DSDP Site 173) shows the LAD of $L$. heteroporos at approximately $1.3 \mathrm{Ma}$.

Observed range: Restricted to Waiatai and Waihua. Highest positive occurrence at WA07 at the top of the dextral G. crassaformis - G. crassula overlap zone. Tentative identifications in sample WA03 associated with a population of Lamprocyclas gamphonycha. See $L$. hannai.

Geographic distribution: Occurrences "suggest that it was a warm water species, not tolerant of colder waters that lay to the south (of the Polar Front)" (Hays, 1965).

\section{Lamprocyrtis (?) junonis (Haeckel) \\ Plate 27, figures 9,13}

Theoconus junonis Haeckel 1887, p.1401, pl.69, fig.7.

Lamprocyclas junonis (Haeckel) group: Petrushevskaya and Kozlova 1972, p.545, pl.36, fig.8.

Description: Cephalis hemispherical to elongate, trilocular with subcircular pores and a short, eccentric, three-bladed apical horn. Collar stricture indistinct. Thorax truncate-conical to campanulate with subcircular pores increasing slightly in size distally. Lumbar stricture not pronounced. Abdomen inflated, narrowing sharply at the distal end. Abdominal pores subcircular, irregular in size and pattern but tending to increase in size towards the broadest part of the abdomen, then decrease in size distally. Peristome distinct, hyaline, with about twelve very poorly developed teeth.

Dimensions: Based on two specimens (average). Length of cephalis 19: of thorax 41: of abdomen 85. Maximum breadth of abdomen 95: of mouth 65 .

Remarks: The peristomal development in the form described is perhaps too great to place it in this genus. Differs from $L$. hannai in its more irregular pore pattern, greater peristomal development, and generally shorter horn. Some forms with an "up-ended-cupola" shaped (expanded above, conical below) abdomen are referred to as $L$. cf. junonis.

Recorded range: Pliocene to Quaternary (Petrushevskaya and Kozlova, 1972).

Observed range: Restricted to nine Wairarapa upper Miocene samples from Morrisons, Ruamahanga and Mangaopari and one Mangapoike sample. The form $L$. cf. junonis appears to be also restricted to the Miocene except for one positive identification in sample WA16 (Mangapanian). 
Radiolarians with six collar pores, a well-developed vertical tube, no appendages, and the pores of at least one major segment arranged in transverse rows. They may have a smooth or ridged surface, and the last segment is not flared.

\section{Genus Botryostrobus Haeckel \\ emended Nigrini 1977}

Artostrobiidae having more than four segments, separated by rounded constrictions and having numerous rows of pores on each post-thoracic segment; cephalis bearing both an apical horn and a cylindrical vertical tube.

Type-species: Lithostrobus botryocyrtis Haeckel 1887 : designated by Campbell 1954

\section{Botryostrobus aquilonaris (Bailey) \\ Plate 29, figure 3}

Eucyrtidium aquilonaris Bailey 1856, p.4, pl.1, fig.9.

- see Nigrini 1977, p.246, for extensive synonomy.

Description: Shell heavy, thick-walled. Constrictions unevenly spaced and usually obscure externally. Shell spindle-shaped with four to five post-cephalic segments, the fourth being widest. Cephalis hemispherical with small irregular pores; vertical tube robust, cylindrical, directed obliquely upwards at about $45^{\circ}$. Apical horn rarely preserved, short, thorn-like. Thorax inflated with two or three transverse rows of large subcircular pores. Subsequent segments with three to six (usually four) transverse rows of closely spaced circular pores. Shell narrows distally, terminating in a smooth peristome, which may have a single row of pores. Termination smooth or undulating.

Dimensions: Based on 20 specimens. Total length 110-155. Maximum breadth 60-90 (Nigrini, 1977).

Remarks: The name is used only for heavy, thick-walled forms.

Recorded range: Stichocorys peregrina Zone to Recent (Nigrini, 1977).

Observed range: Occurs sporadically throughout the upper Neogene.

Geographic distribution: "Bimodal distribution: consistently present between about $35^{\circ} \mathrm{S}$ and $46^{\circ} \mathrm{S}$, scattered occurrences between about $0^{\circ}$ and $20^{\circ} \mathrm{S}$ " (Johnson and Nigrini, 1980, western Indian Ocean).

\section{Botryostrobus auritus-australis (Ehrenberg) group}

Plate 29, figure 9: Plate 30, figure 4

Lithocampe aurita Ehrenberg 1844a, p.84.

Lithocampe australe Ehrenberg 1844b, p.187.

- see Nigrini 1977, p.246, for extensive synonomy. 
Description: Shell approximately cylindrical. Cephalis hemispherical with a few subcircular pores, small thorn-like apical horn, and well developed vertical tube directed obliquely upward at about $45^{\circ}$. Collar stricture indistinct. Thorax inflated with 3 to 4 transverse rows of subcircular pores. Lumbar stricture distinct and marked, as are subsequent strictures by a poreless band. Three or more post-thoracic segments of more or less uniform size with four or five transverse rows of subcircular pores per segment. Termination ragged.

Dimensions: Based on 20 specimens. Total length 123-195. Maximum breadth 53-70 (Nigrini, 1977).

Remarks: Petrushevskaya (1975) attempted to distinguish individuals which were widest at the fourth segment ( $B$. australis). Too many specimens are nearly cylindrical to make this distinction with certainty (Nigrini, 1977). In younger sediments (Pliocene-Recent) specimens tend to be more conical, and there is also a tendency for there to be more individuals with a smaller number of pore rows per segment (Nigrini, 1977).

Recorded range: Cannartus (?) petterssoni Zone (upper to middle Miocene) to Recent (Nigrini, 1977).

Observed range: Two positive identifications in samples with G. dehiscens (SWR4, LT05). Ranges into Pleistocene generally getting more abundant in younger samples. Opposite of $B$. bramlettei which it appears to replace in younger samples.

Geographic distribution: "Present in all samples" (Johnson and Nigrini, 1977, western Indian Ocean).

\section{Botryostrobus bramlettei (Campbell and Clark) \\ Plate 29, figure 6: Plate 30, figures 3,5}

Lithomitra bramlettei Campbell and Clark 1944, p.53, pl.7, figs.10-14.

- see Nigrini 1977 , p.248, for extensive synonomy.

Description: Shell usually thick-walled, surface rough. Cephalis hemispherical with a few subcircular pores and well developed vertical tube. Rarely a thorn-like apical horn present. Collar stricture indistinct. Thorax inflated, bearing three transverse rows of subcircular pores. Lumbar stricture apparent. Abdomen and first post-abdominal segment similar in shape to thorax but somewhat larger, fourth segment being the largest in both length and breadth. Four transverse rows of subcircular pores on abdomen; three to six on fourth segment. First four segments form a cone; shell then narrows sharply to an approximately cylindrical segment. Termination may be poreless band with or without small terminal teeth.

Dimensions: Based on 15 specimens. Total length 105-130. Maximum breadth 60-65 (Nigrini, 1977).

Remarks: Distinguished from $B$. aquilonaris by its more pronounced strictures and the characteristic change in shape from conical to cylindrical and from $B$. auritus-australis group by the latter's more overall cylindrical shape. 
Recorded range: Cannartus (?) petterssoni Zone to Stichocorys peregrina Zone (Nigrini, 1977).

Observed range: A positive identification in WA01, but generally more abundant in Miocene samples. See B. auritus-australis.

Geographic Distribution: Absent from the Late Miocene of the central temperate Pacific; rare in the Late Miocene of the western and central tropical Pacific; common in the Late Miocene of the eastern tropical and eastern temperate Pacific (Nigrini and Lombari, 1984, CENOP Project).

\section{Genus Phormostichoartus Campbell 1951 emended Nigrini 1977}

Artostrobiidae having four segments, shell cylindrical. Mouth slightly constricted with well developed peristome. Vertical tube well developed, cylindrical, lying along the thorax. No apical horn.

Type-species: Cyrtophormis cylindrica Haeckel 1887 : designated by Campbell 1954

\section{Phormostichoartus fistula Nigrini \\ Plate 29, figure 4}

Phormostichoartus fistula Nigrini 1977, p.253, pl.1, figs.11-13.

Description: Shell thick-walled, smooth, subcylindrical, consisting of four segments. Cephalis hemispherical with a well developed, poreless vertical tube, few subcircular pores, no apical horn. Collar stricture indistinct. Thorax short, truncate-conical with two to three transverse rows of relatively large subcircular pores. Lumbar and post-lumbar strictures not pronounced. Abdomen subcylindrical elongate with five to seven closely spaced transverse rows of subcircular pores. Fourth segment approximately the same width or narrower than abdomen; pores similar in size and shape to those on the abdomen, usually in three or four transverse rows. Segment narrowing to poreless peristome, sometimes with small, poorly developed terminal teeth.

Dimensions: Based on 15 specimens. Total length 110-190. Length of cephalis and thorax 35-40: of abdomen 35-53: of fourth segment 35-70. Maximum breadth 65-83 (Nigrini, 1977).

Remarks: May be an ancestor of Phormostichoartus corbula (Nigrini, 1977).

Recorded range: Thyrsocyrtis bromia Zone to Spongaster pentas Zone (Nigrini, 1977).

Observed range: Sporadic throughout Late Neogene. Rare in Plio-Pleistocene samples.

\section{Phormostichoartus sp. A}

Plate 29, figures 1,2: Plate 30, figure 7

Description: Similar to Phormostichoartus fistula but slightly smaller with an inflated fourth segment, smaller pores, longitudinal ridges on the thorax and abdomen, and a narrower mouth. 
Remarks: Rare forms exhibit a very narrow, slightly inflated fifth segment forming just before the peristome.

Dimensions: Based on seven specimens. Length of shell 87-137. Maximum breadth of shell 53-77.

Observed range: Restricted to Miocene samples. Relatively common in the Wairarapa Miocene.

\author{
Genus Siphocampe Haeckel 1881 \\ emended Nigrini 1977
}

Artostrobiidae having three segments, the third of which is more or less cylindrical and may develop a series of rounded constrictions alternating with transverse rows of pores; vertical tube short, cylindrical. No apical horn.

Type-species: Siphocampe annulosa Haeckel 1887 : designated by Strelkov and Lipman 1959

\title{
Siphocampe arachnea (Ehrenberg) group
}

Plate 28, figure 12: Plate 30, figure 9

Lithocampe lineata Ehrenberg 1838, p.130 (in part).

Eucyrtidium lineatum arachneum Ehrenberg 1861, p.299 (in part).

- see Nigrini 1977, p.255, for extensive synonomy.

Description: Shell small, bullet-shaped, consisting of cephalis, thorax and abdomen; abdomen usually marked by a series of five or six rounded constrictions alternating with one transverse row of small subcircular pores. There is a well developed surface network of both longitudinal and transverse ridges. Cephalis subspherical with a few irregularly scattered pores; no apical horn; vertical tube short. Collar stricture indistinct. Thorax slightly inflated with two transverse rows of indistinct subcircular pores. Lumbar stricture not well developed. Post-thoracic segments usually marked by indentations, more pronounced proximally than distally, between pore rows. Termination ragged.

Dimensions: Based on 17 specimens. Total length 110-160. Maximum breadth 47-60 (Nigrini, 1977).

Remarks: The most distinctive feature of the species is the network of longitudinal and transverse ridges on the shell surface. Possibly a descendant of $S$. nodosaria (Nigrini, 1977).

Recorded range: Stichocorys wolffii Zone to Recent (Nigrini, 1977).

Observed range: Sporadic occurrences restricted to the Tongaporutuan.

Geographic distribution: Caulet (in Nigrini, 1977) has observed that cool-water forms of $S$. arachnea have one pore row per segment, whereas warm-water forms have two pore rows per segment. The forms found in New Zealand normally have one pore row per segment. 
Siphocampe lineata (Ehrenberg) group

Plate 28, figures 9-11: Plate 30, figure 10

Lithocampe lineata Ehrenberg 1838, p.130 (in part).

- see Nigrini 1977, p.256 for synonomy.

Description: Shell smooth, consisting of a cephalis, thorax and a cylindrical to somewhat inflated abdomen. Cephalis spherical with a few irregularly scattered pores. Vertical tube well developed. Collar stricture indistinct. Thorax slightly inflated with two or three transverse rows of subcircular pores. Lumbar stricture indistinct to distinct, very pronounced in a lot of specimens. Abdomen usually smooth without indentations, bearing seven to nine rather regularly spaced transverse rows of subcircular pores. Considerable variation in pore size and distance between pore rows is allowed within the species group. Specimens with longitudinal striations are more common than not. Termination normally ragged, rarely smooth.

Dimensions: Based on 20 specimens. Total length 120-160. Maximum breadth 45-70 (Nigrini, 1977).

Remarks: Specimens with a very inflated thorax and very pronounced lumbar stricture (e.g. Plate 28, figure 10) are common in the samples studied.

Recorded range: Thyrocyrtis bromia Zone (possibly earlier) to Recent (Nigrini, 1977).

Observed range: Two forms tabulated. The form with the distinct lumbar stricture is more common (occurs in $46 \%$ of samples studied) than the smooth form (33\%). Distribution patterns generally mimic one another. Found throughout the upper Neogene but definitely rarer in the upper Pliocene and Pleistocene.

Geographic distribution: "Present in most samples north of about $15^{\circ} \mathrm{S}$, scattered occurrences between about $15^{\circ} \mathrm{S}$ and $26^{\circ} \mathrm{S}$ and very rare occurrences between about $37^{\circ} \mathrm{S}$ and $46^{\circ} \mathrm{S}$ " (Johnson and Nigrini, 1980, western Indian Ocean).

\section{Siphocampe nodosaria (Haeckel) \\ Plate 28, figure 8: Plate 30, figure 8}

Lithomitra nodosaria Haeckel 1887, p.1484, pl.79, fig.1.

- see Nigrini 1977, p.256 for synonomy.

Description: Similar to $S$. arachnea but with more pronounced abdominal indentations. There may be one or two transverse rows of pores between each indentation. Between pore rows there are prominent longitudinal ridges, but no cross bars between ridges as in $S$. arachnea. Termination ragged. Shell generally larger than other species of Siphocampe.

Dimensions: Based on 17 specimens. Total length 130-177. Maximum breadth 53-75 (Nigrini, 1977).

Recorded range: Thyrsocyrtis triacantha Zone (middle Eocene) to Recent (Nigrini, 1977). 
Observed range: As with other members of this genus, mainly found in Miocene sediments. Only two upper Pliocene - Pleistocene occurrences (WA15, WA26).

\title{
Genus Siphostichartus Nigrini 1977
}

Artostrobiidae having four segments, ovate to spindle-shaped; mouth constricted, no terminal feet; vertical tube flared; apical horn present.

Type-species: Cyrtophormis corona Haeckel 1887

\author{
Siphostichartus corona (Haeckel) \\ Plate 29, figure 5: Plate 30, figure 6
}

Cyrtophormis corona Haeckel 1887, p.1462, pl.77, fig.15.

- see Nigrini 1977, p.257, for synonomy.

Description: Shell smooth, hyaline, conical, compressed laterally. Cephalis hemispherical with a few circular pores, base of a well developed three-bladed apical horn sometimes present. Prominent "duck-billed" vertical tube. Thorax inflated, slightly heavier than the rest of the shell with two or three transverse rows of small circular pores. Abdomen inflated with four to six transverse rows of small circular pores. Fourth segment considerably larger than the others, usually contracting distally without a differentiated peristome; seven or more transverse rows of small circular pores. Termination ragged. Intersegmental strictures curved, poreless.

Dimensions: Based on 20 specimens. Total length (excluding apical horn) 135-190. Length of abdomen 30-40: of fourth segment 70-105. Maximum breadth (across fourth segment) 70-95 (Nigrini, 1977).

Remarks: Appears to have developed from $S$. praecorona in which the third segment has only two rows of pores and a less prominent apical horn and vertical tube (Nigrini, 1977).

Recorded range: Stichocorys wolffii Zone to last rare occurrences in the Stichocorys peregrina Zone (Nigrini, 1977).

Observed range: Sporadic occurrences in Miocene. Only two tentative Plio-Pleistocene occurrences at Waiatai.

Geographic distribution: "Rare in all Late Miocene sections examined from both tropical and temperate latitudes" (Nigrini and Lombari, 1984, CENOP Project).

Genus Spirocyrtis Haeckel 1881

emended Nigrini 1977

Artostrobiidae with more than four segments, expanding distally; intersegmental constrictions sharply rounded to angular; vertical tube flared; apical horn or tube present. Type-species: Spirocyrtis scalaris Haeckel 1887 : designated by Campbell 1954 
Spirocyrtis subscalaris Nigrini

Plate 29, figures 7,8: Plate 30, figure 11

Spirocyrtis subscalaris Nigrini 1977, p.259, pl.3, figs.1,2.

- see Nigrini 1977 for synonomy.

Description: Shell conical, smooth with four to six post-cephalic segments. Cephalis hemispherical with a few subcircular pores, a strong apical horn nearly as long as the cephalis, and a well developed, flared vertical tube. Collar stricture indistinct. Thorax inflated with three or four transverse rows of subcircular pores. Thorax surface normally rougher than the rest of the shell. Lumbar and post-lumbar strictures clearly visible and of ten marked by a poreless band. Abdomen and post-abdominal segments inflated, normally increasing in size distally, rare specimens taper slightly after the fourth segment. Each segment bears four to six transverse rows of subcircular pores of variable size. Termination usually ragged, with occasionally a short poreless peristome present.

Dimensions: Based on 15 specimens. Total length (excluding apical horn) 123-165. Maximum breadth 65-83 (Nigrini, 1977).

Remarks: Distinguished from $S$. gyroscalaris, which has more segments and is wider, $S$. scalaris which has angular segments, and $S$. subtilis which is narrower. The specimens which are broadest at the fourth and fifth segment are very similar to Kling's (1973) Spirocyrtis sp. aff. S. scalaris, which he figures (pl.5, figs.24,25,26) from the lower Pliocene to Recent. Specimens studied herein support the view that there is a tendency towards distally contracting forms in the Pliocene and Pleistocene.

Recorded range: Calocycletta costata Zone to Recent (Nigrini, 1977).

Observed range: Present throughout Late Neogene. Unlike most of the other Artostrobiids, shows no decrease in abundance in the Plio-Pleistocene.

Family Cannobotryidae Haeckel 1881

emended Riedel 1967a

Cephalis consisting of two or more unpaired lobes, only one of which is homologous with the cephalis of the theoperids.

\section{Genus Botryopyle Haeckel 1881}

Cannobotryidae with cephalis and thorax. Lacks cephalic tubules. Thorax open. Type-species: Botryopyle sethocorys Haeckel 1887

\section{Botryopyle dictyocephalus Haeckel group \\ Plate 30 , figures $12-14$}

Botryopyle dictyocephalus Haeckel 1887, p.1113, pl.96, fig.6.

Botryocella multicellaris Haeckel 1887, p.1117, p1.96, fig.12.

Botryopyle dictyocephalus Haeckel group: Riedel and Sanfilippo 1971, p.1602, pl.1J, figs.21-26, pl.2J, figs.16-18, pl.3F, figs.9-12. 
Botryopyle sp. A Petrushevskaya 1975, p.589, pl.13, fig.22.

Description: Group includes all forms with a large antecephalic chamber, small to large post-cephalic chamber, and a subcylindrical thorax, and without prominent cephalic tubes. The shell wall is variable, some are densely porous and others only very sparsely perforate, the pores being subcircular, small, irregular in size.

Dimensions: Based on eight specimens. Length of antecephalic chamber 35-44: of post-cephalic chamber 19-31: of thorax 43-66. Maximum breadth of thorax 43-55.

Remarks: A moderately variable group in terms of shell wall and thorax dimensions.

Recorded range: Riedel and Sanfilippo (1971) figure specimens from the Late Eocene Thyrsocyrtis bromia Zone to Quaternary. Petrushevskaya's (1975) Botryopyle sp. A, which has a large eucephalic lobe is noted by her as being a Late Miocene form and is comparable to a few of the specimens found in this study.

Observed range: Present throughout the Late Neogene although abundance slightly less in Plio-Pleistocene samples. The "normal" form is found in $35 \%$ of the radiolarian-bearing samples examined. The "large lobed" form is present in $19 \%$ of the samples occurring in only one upper Pliocene sample WA15, the rest being Miocene occurrences. 
Figure 5.1

List of the main calcareous bioevents used in correlating sections in the New Zealand Late Neogene and correlations with the New Zealand Stages. All events are foraminiferal except two calcareous nannofossil (C) and two molluscan (M). Sources of information are predominantly from Edwards 1985 (ㅁ) with alternative ages from the differing paleomagnetic interpretation of Hornibrook 1981a (*).

$\mathrm{Ma}$

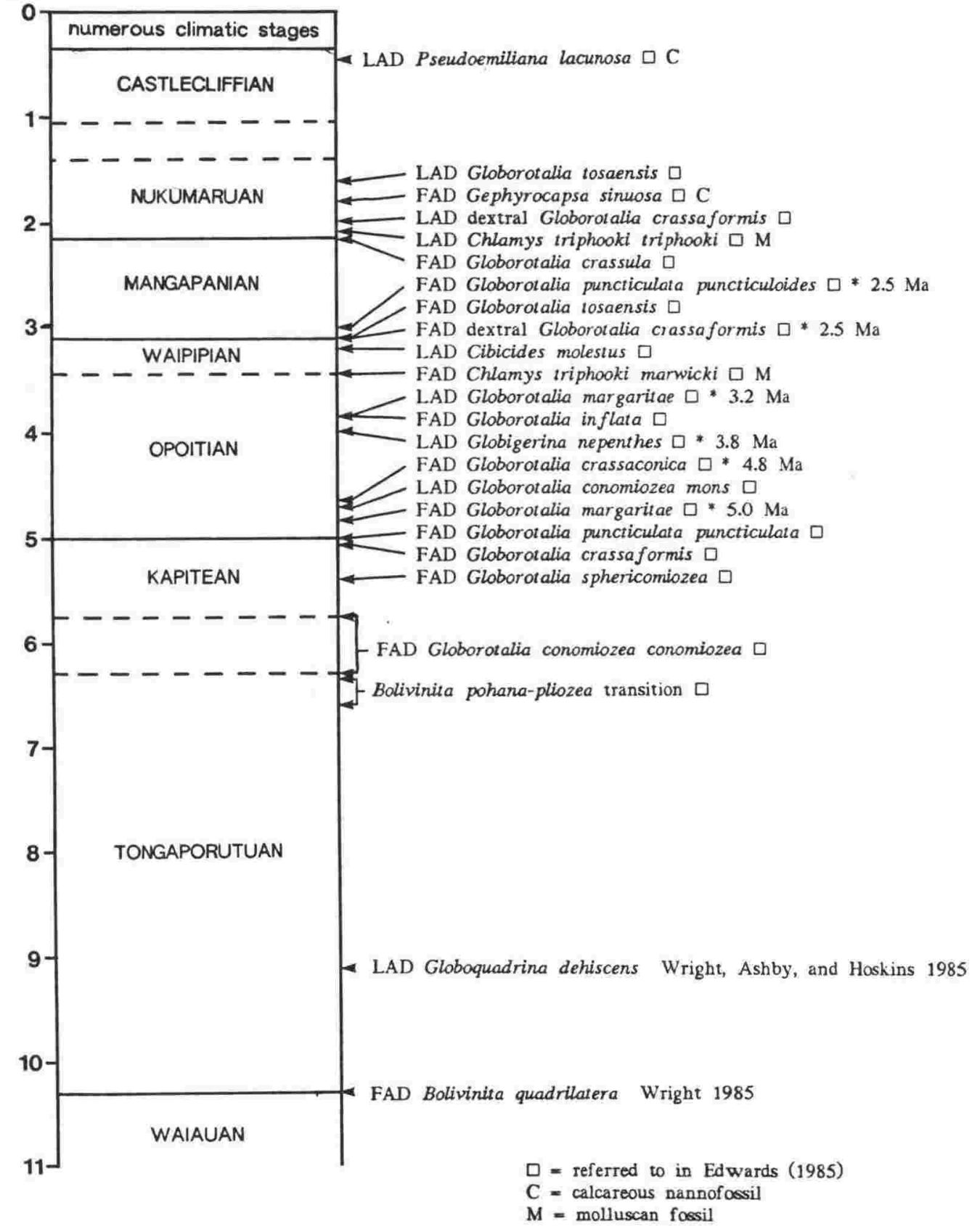




\section{Chapter V \\ BIOSTRATIGRAPHY}

\subsection{PALEONTOLOGICAL CRITERIA FOR DEFINING NEW ZEALAND LATE NEOGENE STAGES}

\subsubsection{Introduction}

Finlay and Marwick (1940, 1947), whose pioneering work on defining the New Zealand stages helped in local correlations, did not always adhere to strict type-locality definitions. New Zealand stages are largely based on changes in lithofacies, facies controlled mollusca and shallow water benthic foraminifera. The stages as defined here are only approximations of the original stage definitions and are based predominantly on deeper water benthic foraminifera and open ocean planktic foraminifera and form the basis of the stage usage discussed in this thesis. The datums are summarised in figure 5.1.

Hornibrook (1958) recognised an increasing trend towards biogeographic provincialism in New Zealand during the late Tertiary, which was probably climatically controlled. As a result few of the fossils are useful for world-wide correlation. Global markers, such as magnetostratigraphic datums have improved correlation, but reliable paleontological datums are still scarce even for correlation within New Zealand. Foraminiferal datums used in this thesis are outlined in this section.

\subsubsection{Waiauan Stage}

Top : FAD of Bolivinita quadrilatera

Base : FAD of Globigerina nepenthes

The Waiauan was originally defined by Finlay and Marwick (1947) as "that part of the section marked by the presence of Loxostomum truncatum Finlay. The lower limit is marked also by the lowest occurrence of Cibicides deliquatus Finlay"; the holostratotype being at Clifden, Southland. C. deliquatus is now known down to upper Altonian (Hoskins, 1978). At many places L. truncatum occurs with Bolivinita quadrilatera (Schwager), the basal Tongaporutuan marker. The only useful planktic foraminiferal datum is the first appearance of Globigerina nepenthes Todd at the base of the Waiauan. The moderately shallow water benthic foraminiferal species L. truncatum, Anomalina spherica, and Euvigerina rodleyi rodleyi all appear at the base of the Waiauan. 


\subsubsection{Tongaporutuan Stage}

Top : FAD of Globorotalia conomiozea conomiozea

Base : FAD of Bolivinita quadrilatera

The name Tongaporutuan was first used, without definition, by Marwick (1924a) although it was thought to represent the Tongaporutuan Beds of Grange (1927) in northern Taranaki (Hornibrook, in Fleming, 1959). Allan (1933) proposed the Taranakian System to include both the Tongaporutuan and Urenuian Stages. Finlay and Marwick (1940) adopted the name as Taranaki Series, including in it the Tongaporutuan Stage represented by the Tongaporutuan Formation (= Mt. Messenger Sandstone of Hay, 1967) exposed on the North Taranaki coast between the underlying Mohakatino Formation and the overlying Urenui Siltstone. By 1947, Finlay and Marwick included the Urenui Siltstone in the upper Tongaporutuan. The choice of the North Taranaki coastal section as the holostratotype was unfortunate because fossil mollusca are not abundant and foraminifera only fair to poor, a fact recognised by Finlay and Marwick in 1940.

A tripartate subdivision of the Tongaporutuan based on Bolivinita of the quadrilatera lineage was founded by Vella (1954) on the successive appearance of $B$. quadrilatera, $B$. pohana, and $B$. compressa, corresponding to the lower, middle, and upper Tongaporutuan respectively. Although these subdivisions are workable in many local basins, they are imprecise for regional correlation due to a complex history of gradual morphological changes associated with both facies variation and speciation.

The Tongaporutuan is characterised by populations of the planktic species Globorotalia miotumida Jenkins. A reliable foraminiferal datum within the Tongaporutuan is the sudden disappearance of Globoquadrina dehiscens (Chapman, Parr and Collins) which in the East Coast Deformed Belt occurs below the FAD of $B$. compressa, except in two Gisborne sections, Caves Road and Kaiti Beach where G. dehiscens and B. compressa occur at the same horizon. An age of $9.2 \mathrm{Ma}$ for this Tongaporutuan bioevent has been paleomagnetically derived in the Mangapoike River Section (Wright, Ashby, and Hoskins, 1985). The recorded younger occurrences of G. dehiscens in the New Zealand region (Hornibrook, 1961; Collen and Vella, 1973) could be due to reworking but are more likely to be warm water re-entrants as first suggested by Collen and Vella.

A useful datum in the uppermost Tongaporutuan is the level at which five-chambered members of the Globorotalia miotumida - G. conomiozea conomiozea transition make up less than twenty percent of the transitional population. As definition of this datum requires a 
reasonable population of $G$. miotumida morphotypes it is not entirely satisfactory but it has been found by the author to be as recognisable as the FAD of G. conomiozea conomiozea sensu stricto. Malmgren and Kennett (1981) showed that members of the Globorotalia miotumida - conomiozea - sphericomiozea - puncticulata - inflata lineage in DSDP Site 284 can be distinguished on the basis of the mean number of chambers in the final whorl, with only two out of 72 samples being misclassifed. At the base of the Kapitean the mean number of chambers is 4.4 (Malmgren and Kennett, 1981: figure 2), which closely approximates the level at which less than $20 \%$ five chambered forms dominate.

\subsubsection{Kapitean Stage}

Top : FAD of Globorotalia crassaformis

Base : FAD of Globorotalia conomiozea conomiozea

As defined by Finlay and Marwick (1947) the Kapitean holostratotype at Kapitea Creek, Westland is marked by the FAD's of the mollusca Sectipecten wollastoni (Finlay) and Austrofusus coerulescens (Finlay) (= tuberculatus Marwick) which also range up to the incoming of the Opoitian foraminifera identifed by Finlay as Globorotalia "inflata" and Globorotalia "crassula" but now known to be Globorotalia puncticulata puncticulata (Deshayes) and Globorotalia crassaformis (Galloway and Wissler), respectively (Hornibrook, 1982). The original definition of the base of the Kapitean has caused trouble in identification for two reasons; the use of the FAD of a facies controlled molluscan species and the existence of a greensand, representing a period of slow deposition, in the lowest part of the holostratotype.

Kennett (1966a) suggested the planktic foraminiferal change to Globorotalia conomiozea conomiozea, a strongly conical member of the upper Miocene Globorotalia miotumida lineage, may be useful in defining the same stratigraphic interval as the range of Sectipecten wollastoni. Even in sections where there is no unconformity the FAD of Globorotalia conomiozea conomiozea is a relatively unsatisfactory datum because of the intergradation of populations and low frequency of occurrence (see section 5.1.3). Some interregional correlations probably have been based on forms incorrectly identified as G. conomiozea conomiozea (Scott, 1976a, 1980b). Differing interpretations of G. conomiozea conomiozea at Blind River (Kennett, 1966b; Kennett and Watkins, 1974; Scott, 1979a; Loutit, 1981) make its quantitative age range difficult to use in correlation.

Walters (1965) proposed Globorotalia miozea sphericomiozea (= Globorotalia sphericomiozea) for a transitional form between the upper Miocene - Pliocene representatives 
of the G. miotumida - inflata lineage. Jenkins (1967) equated the first appearance of this taxon with the base of the Kapitean. Scott (1982b) suggested a number of reasons for making the first appearance of G. sphericomiozea as a datum to define the top of the Kapitean.

1. It is recognised relatively precisely.

2. It is identifiable in New Zealand and in adjacent deep-sea cores.

3. It corresponds closely with the highest occurrence of the Kapitean mollusca cited originally by Finlay and Marwick (1947).

4. It occurs near the base of the Gilbert. Cita and Gartner (1973) and Ryan et al. (1974) considered that the base of the Zanclean stratotype (Capo Rossello, Sicily) lies very close to the Epoch 5/Gilbert boundary so a change in definition for the top of the Kapitean would align the Kapitean/Opoitian boundary with the international Miocene/Pliocene boundary.

Hornibrook (1984a) accepts the FAD of G. sphericomiozea as the Miocene/Pliocene boundary in New Zealand with no discussion as to the position of the Kapitean/Opoitian boundary. The proposal of Scott (1982b) would place the Kapitean/Opoitian boundary significantly below the previously accepted level and would make the base of the Opoitian at its lectostratotype locality, Mangapoike River, an unconformity.

The FAD of $G$. sphericomiozea is herein considered to be a reliable datum within the Kapitean which approximates the Miocene/Pliocene boundary.

\subsubsection{Opoitian Stage}

Top : Hard to determine using foraminiferal data

Base : FAD of Globorotalia crassaformis

Finlay (1939) first proposed the Opoitian for the interval of time represented by deposition of the beds described by Ongley (1930) as between the Mapiri "Series" (Formation) and the Waitotaran i.e. the Opoiti "Series" (Formation), 1ying within the Opoiti Survey District in the Wairoa Syncline. No particular stratotype was designated and the only microfossil index suggested for the base of the Opoitian was the FAD of Globorotalia "inflata", now recognised as Globorotalia puncticulata puncticulata (Deshayes), the four chambered ancestor of $G$. inflata d'Orbigny.

Finlay and Marwick (1940, 1947) added the first appearance of "modern Globigerinidae including Globigerinoides rubra (d'Orbigny) and G. sacculifer (Brady), Globorotalia crassula Cushman and Stewart and G. truncatulinoides (d'Orbigny)". Their G. crassula is now 
known to be G. crassaformis (Galloway and Wissler). Their G. truncatulinoides, whose FAD of typical populations in New Zealand is now dated at 2.9 Ma (Hornibrook, 1981a), was probably a misidentification of Globorotalia conomiozea mons Hornibrook, a basal Opoitian morphologic offshoot of Globorotalia conomiozea conomiozea.

Jenkins (1971) did not devise a workable zonation for the Pliocene and erected a single Globorotalia inflata Zone for the whole Pliocene and Quaternary with several subzones based on reversals in the coiling sense of Neogloboquadrina pachyderma (Ehrenberg).

The joint FAD's of $G$. puncticulata puncticulata and $G$. crassaformis is a reliable datum level for defining the base of the Opoitian although the former taxon is sometimes difficult to determine as it arises from the G. miotumida - conomiozea - sphericomiozea complex. Both taxa are widely distributed in Lower Pliocene strata beyond the tropics in both hemispheres and commonly have very close first appearance datums (Scott, 1982b). This dual FAD is significantly above the highest Kapitean Mollusca and does not coincide with any key molluscan or floral event (Scott, 1982b). The joint occurrence of G. puncticulata and G. crassaformis was used by Keller (1979) to identify the N18/N19 boundary in mid-latitude sequences in the North Pacific.

The FAD of typical $G$. inflata populations is a reliable datum in the upper Opoitian. Other datums defined by Hornibrook (1981a), e.g. the FAD of Globorotalia crassaconica Hornibrook and the FAD of Globorotalia margaritae Bolli and Bermudez in the lower Opoitian and the LAD of Globigerina nepenthes Todd in the upper Opoitian, have limited usefulness.

\subsubsection{Waipipian Stage}

Top : FAD of dextral Globorotalia crassaformis

Base : Hard to determine using foraminiferal data

Fleming (1953) comprehensively described the lithostratigraphy and macrofossil biostratigraphy in the Wanganui area, on which New Zealand Late Pliocene and Quaternary stages are based. The shallow water foraminiferal assemblages contain sparse planktic assemblages and are of limited use for correlation (Collen, 1972b), and do not enable direct correlation with East Coast sequences (Hornibrook, 1981b).

The Waitotaran Stage was originally proposed by Thomson (1916). Morgan in Withers (1924), on the basis of molluscan faunas, identified an Upper and Lower Waitotaran. Fleming (1953) formally defined these as the Waipipian and Mangapanian substages. 
Fleming followed a policy of defining stratotypes only in the middle of his biostratigraphic units and the Middle Waipipi Shellbed on the coast south of Waverley was nominated. The top of the Waipipian is marked by the LAD of the bivalve Mesopeplum crawfordi Hutton.

The planktic foraminifera differ little from those in the Opoitian and Mollusca are still the best criteria for definition (Hornibrook, 1981b). The pectinid Chlamys (Phialopecten) triphooki marwicki Beu has been used with success in defining the Waipipian in the Te Aute Limestone facies of Hawke Bay (Beu, Grant-Taylor and Hornibrook, 1980).

On micropaleontological grounds the Opoitian/Waipipian boundary is very poorly defined being above the FAD of G. inflata in the Mangapoike River Section and below the LAD of G. margaritae in the northern part of the East Coast Deformed Belt (Hornibrook, 1982). A species of Hyalinea close to $H$. balthica (Schroeter), which is considered to be a cool water species and a marker for the base of the Pleistocene in the Mediterranean, occurs at several Waipipian localities in Wanganui (Collen, 1974) and the Waipipian of Hawkes Bay (Hornibrook, 1981b).

\subsubsection{Mangapanian Stage}

Top : FAD of Globorotalia crassula

Base : FAD of dextral Globorotalia crassaformis

Fleming (1953) established the Mangapanian to include beds with faunas like those at Mangapani and Wilkies Bluff, in the Waitotara River Valley, the Mangapani Shell Conglomerate being designated the type formation. Being based on mollusca it is difficult to determine away from the type section although species of the gastropod Pelicaria have been used in southern Wairarapa for recognising Mangapanian strata (Vella, 1953) and Chlamys (Phialopecten) triphooki triphooki (Zittel) is a key species used in the Te Aute Limestone facies in Hawke Bay (Beu, Grant-Taylor and Hornibrook, 1980).

Cibicides molestus Hornibrook, a benthic foraminifer, is common in bathyal to mid-shelf facies and usually accompanies Mesopeplum crawfordi, the Waipipian marker, and their extinctions, plus the FAD of Globorotalia tosaensis (and rare forms resembling G. truncatulinoides), and the FAD of dextral G. crassaformis occur at the same level in the Raukawa Range section (Hornibrook, 1981b). The subspecies Globorotalia puncticulata puncticuloides Hornibrook also appears at about this level. 
The extinction of C. molestus and a change from predominantly sinistral or random to predominantly dextral populations of G. crassaformis, correlate from the East Coast to the Wanganui Basin and defines a good datum level at the base of the Mangapanian.

\subsubsection{Nukumaruan Stage}

Top : Hard to determine using micropaleontological data

Base : FAD of Globorotalia crassula

The Nukumaruian was introduced by Marwick (1924b), its name being emended to the present spelling by Marwick (1931). This stage filled in the gap between Thomson's (1916) Waitotaran and Castlecliffian. The type designated by Fleming (1953) is the Nukumaru Brown Sand, but the stage includes a much greater thickness of strata outcropping between Okehu and Waitotara River. The Hautawa Shellbed, at the base of the Nukumaruan, was designated the type of the Hautawan substage by Fleming (1953) and it is generally accepted that it represents a major cool episode, although there has been debate about its usefulness for correlation using the subantarctic pectinid, Chlamys delicatula (Hutton) (see Beu, 1969; Vella and Nicol, 1970).

The FAD of the planktic foraminifer Globorotalia crassula Cushman and Stewart has proved useful in East Coast deeper water sequences (Hornibrook, 1980, 1981b, 1982) for identifying the base of the Nukumaruan. It is extremely rare in the type section but there appears to be correlation with East Coast sequences (Hornibrook, 1981b). The basal part of the range of G. crassula overlaps with dextral G. crassaformis which in the East Coast Basin becomes sinistral and very rare within the lower Nukumaruan. The overlap also contains Chlamys delicatula. The earliest appearance of G. truncatulinoides within the Nukumaruan is not useful because of the gradual replacement of G. tosaensis (Hornibrook, 1976b). The FAD of the calcareous nannofossil Geophyrocapsa sensu stricto (= G. sinuosa) in the middle Nukumaruan Waipuru Shellbed, in the Rangitikei River, is a reliable datum and permits correlation between Wanganui and the East Coast Basin (Edwards, 1976).

The marked enrichment of $0^{18}$ between 60 and 50 metres in DSDP Site 284, which Shackleton and Kennett (1975b) considered represents the accumulation of Northern Hemisphere Ice, is within the dextral G. crassaformis - G. crassula overlap zone (Hornibrook, 1981b). Fleming (1953) placed the Pliocene/Pleistocene boundary at the the base of the Nukumaruan because of the evidence of the marked cold marine climatic episode but the position of the boundary is now slighty higher (middle Nukumaruan) to allow correlation with the Vrica Section, Italy (Beu and Edwards, 1984). 


\section{Figure 5.2}

Correlation of foraminiferal bioevents to the New Zealand radiolarian zones and

a listing of the radiolarian events defining the zones.

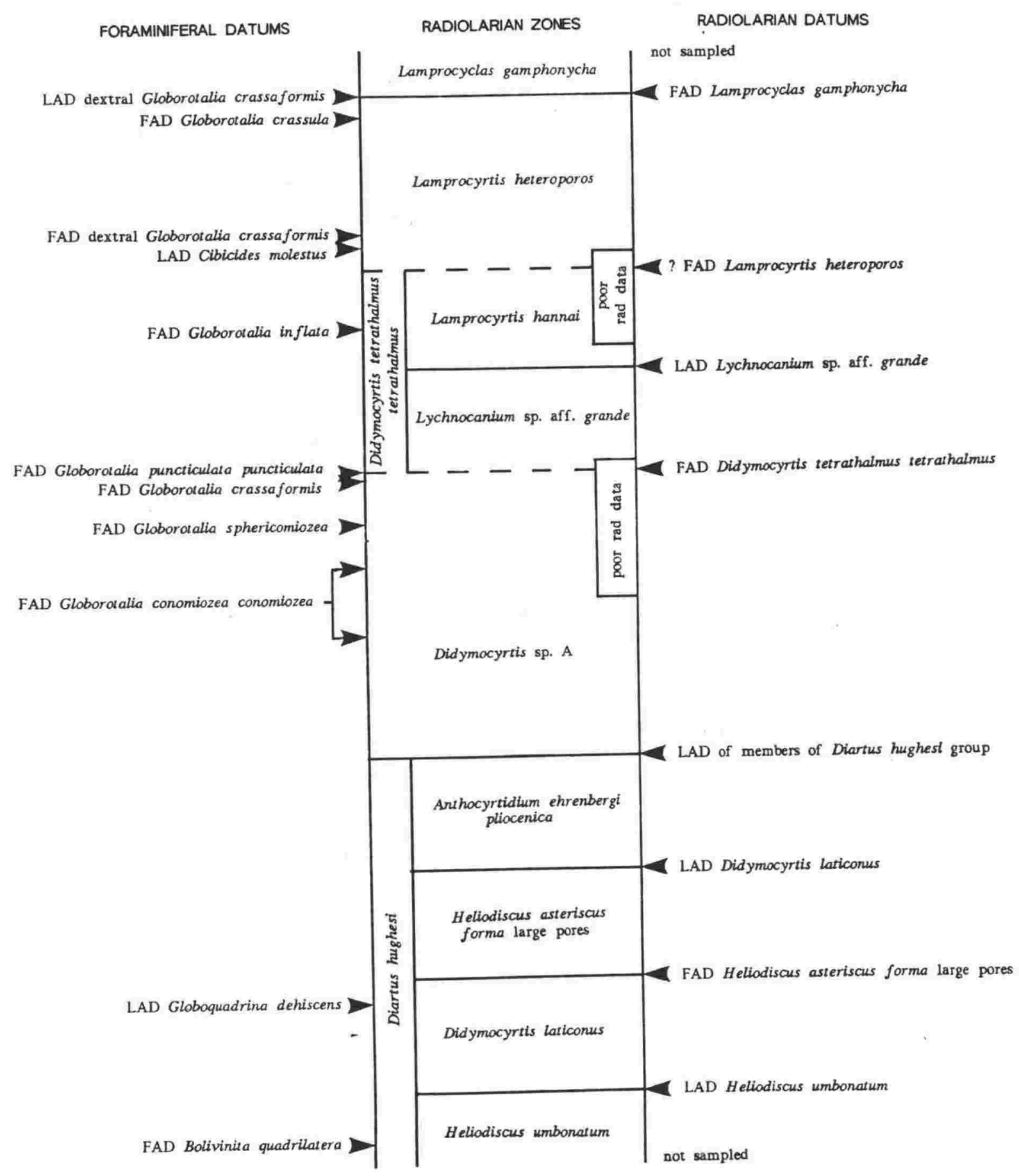




\section{1 .9}

Note: Boundaries hard to determine using micropaleontological data

Thomson (1916) based the Castlecliffian on the fossiliferous beds at Castlecliff, Wanganui. Benthic foraminiferal datums mentioned in Fleming (1959) are of limited usefulness. The only planktic foraminiferal datum (also of very limited value) is the LAD of G. tosaensis which occurs within the lower Castlecliffian (Hornibrook, 1982). The LAD of the calcareous nannofossil Pseudoemiliana lacunosa in the Upper Kai-Iwi Siltstone on the Castlecliff Coast has been used by Beu and Edwards (1984) to correlate with isotope stage 12 in deep-sea cores, near the top of the Castlecliffian.

\subsection{RADIOLARIAN ZONATION}

\subsubsection{Introduction}

Five major radiolarian biostratigraphic zones can be recognised in the upper Neogene of New Zealand with six subzones identifiable in samples with good preservation. The correlation between New Zealand Late Neogene foraminiferal and radiolarian bioevents is shown in figure 5.2. Figure 5.3 shows the ranges of some of the radiolarians studied.

\subsubsection{Diartus hughesi Zone}

Top : LAD of members of the Diartus hughesi group

Base : Evolutionary base of Diartus hughesi (not sampled)

This major taxon-range zone encompasses most of the Tongaporutuan Stage in New Zealand. The base of the zone was not sampled and it is highly probable that the zone extends down into the Waiauan. The top of the zone is well defined in Wairarapa sections but is not well defined in northern sections due to either a paleoceanographic exclusion of the taxon from the northern area or some diachroneity in the LAD of members of the Diartus hughesi group within New Zealand. These possibilities are further discussed in section 5.3.3.

This zone is equivalent to the Didymocyrtis antepenultima ( $=$ Ommatartus antepenultimus) Zone as defined by Riedel and Sanfilippo (1978b) and in New Zealand can be divided into the following four subzones.

\subsubsection{Heliodiscus umbonatum Subzone}

Top : LAD of Heliodiscus umbonatum

Base : Evolutionary base of Diartus hughesi (not sampled) 


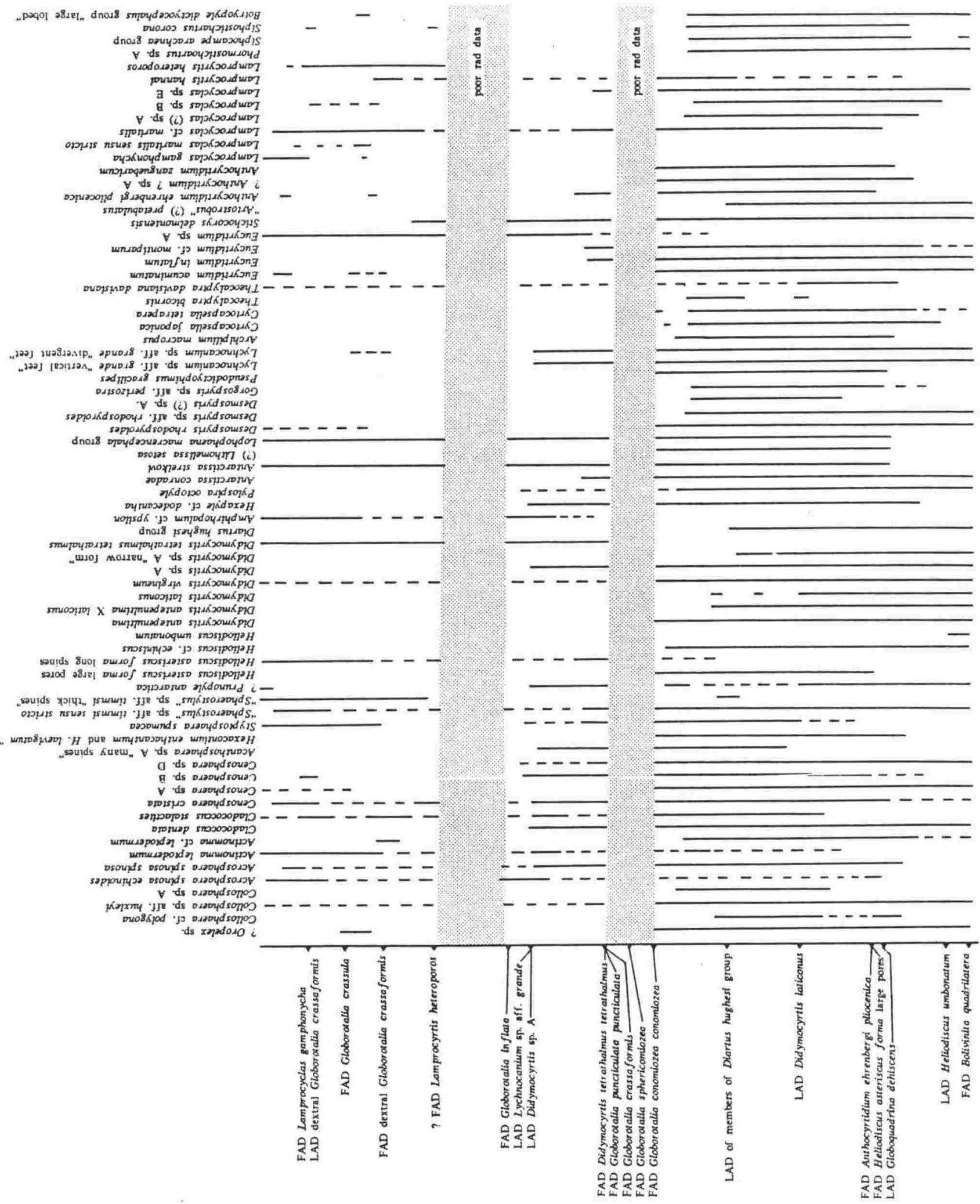


This is the oldest subzone and is probably a concurrent-range zone with $H$. umbonatum being very similar to an Early Miocene form of Heliodiscus asteriscus reported by Nigrini and Lombari (1984, p.S39). The zone occurs only in Leader River Section (northern Canterbury) and Kaiti Beach Section (Gisborne) in basal Tongaporutuan strata and is definable in only two samples (LT09 and KB04). Consequently its faunal makeup can not be fully assessed.

\subsubsection{Didymocyrtis laticonus Subzone}

Top : FAD of Heliodiscus asteriscus forma large pores

Base : LAD of Heliodiscus umbonatum

The FAD of Heliodiscus asteriscus forma large pores, normally occurring just above the LAD of Globoquadrina dehiscens, defines the top of this gap zone in the Tongaporutuan. The FAD of Anthocyrtidium ehrenbergi pliocenica is not as well defined but occurs at nearly the same level. Both Didymocyrtis antepenultima and D. laticonus occur in this subzone. Within this subzone, the FAD of quadrate forms of Hexacontium enthacanthum and $H$. laevigatum occurs below the LAD of Globoquadrina dehiscens. Other useful radiolarian bioevents that occur within this subzone include; the FAD's of Antarctissa strelkovi, Lithomelissa setosa, Lophophaena macrencephala, and of rare Pseudodictyophimus gracilipes, Archipilium macropus, and Hexapyle dodecantha, all at about the same level as the LAD of Globoquadrina dehiscens. Theocalyptra davisiana davisiana, Anthocyrtidium sp. A, Anthocyrtidium zanguebaricum, Lamprocyclas sp. A, and Siphostichartus corona all first appear within the top half of this subzone with Lamprocyclas sp. B first appearing in the bottom half. The first patchy records of Collosphaera polygona, Cenosphaera sp. B, and Gorgospyris sp. aff perizostra occur in this subzone. The large number of radiolarian bioevents at or near the LAD of Globoquadrina dehiscens adds support to the suggestion of Wright, Ashby and Hoskins (1985) that the sudden disappearance of Globoquadrina dehiscens in the Mangapoike Section is in response to a period of cooling, with the associated paleoceanographic change affecting a number of radiolarian species.

\subsubsection{Heliodiscus asteriscus forma large pores Subzone}

Top : LAD of Didymocyrtis laticonus

Base : FAD of Heliodiscus asteriscus forma large pores

The LAD of Didymacyrtis laticonus is a moderately well defined datum and provides a useful bioevent to define the top of this concurrent-range zone. The zone is marked by a 
relatively stable radiolarian fauna. The few radiolarian bioevents that occur within the subzone include the FAD of Desmospyris sp. A in northern sections and the FAD of rare Collosphaera sp. A. Also present are the first patchy records of Actinomma leptodermum and Styptosphaera spumacea.

\subsubsection{Anthocyrtidium ehrenbergi pliocenica Subzone}

Top : LAD of members of the Diartus hughesi group

Base : LAD of Didymocyrtis laticonus

This is the youngest subzone in the Diartus hughesi Zone, consequently both the zone and the subzone have the same top. Radiolarian bioevents that occur within this successive disappearance subzone include the FAD of rare Acanthosphaera sp. A, the LAD of the "narrow" variety of Didymocyrtis sp. A, and of rare "Artostrobus" pretabulatus, and the first relatively common appearance of Theocalyptra bicornis in Wairarapa.

\subsubsection{Didymacyrtis sp. A Zone}

Top : FAD of Didymocyrtis tetrathalmus tetrathalmus

Base : LAD of members of the Diartus hughesi group

The upper half of this gap zone is poorly defined by radiolarians as they are generally lacking in the shallow water sediments typical of the uppermost Miocene (Kapitean) in New Zealand. Consequently there is a gap in the the radiolarian fossil record between the FAD of Globorotalia conomiozea conomiozea and the joint FAD's of Globorotalia crassaformis and G. puncticulata puncticulata. The Bolivinita pohana - pliozea transition occurs in the bottom half of this zone. A number of radiolarian last appearance datums occur in the middle, being grouped at the base of the sampling gap. The grouping is most likely related to the lack of preservation in the Kapitean rather than a "mass" extinction level at the base of the Kapitean. The bioevents include the LAD of rare Collosphaera cf. polygona and Collosphaera sp. A, the last common Actinomma cf. leptodermum (there are some late Pliocene occurrences), last positive Cenosphaera sp. A (some tentative records in the late Pliocene and Pleistocene), the LAD of quadrate forms of Hexacontium laevigatum and $H$. enthacanthum, the LAD of Heliodiscus asteriscus forma large pores and the first tentative records of $\boldsymbol{H}$. asteriscus forma long spines, the LAD of Heliodiscus cf. echiniscus and Didymocyrtis antepenultima, the last positive occurrence of Pylospira actopyle (one tentative identification in the basal Pliocene), the LAD of Lithomelissa sp. aff. setosa, the last positive identification of Desmospyris rhodospyroides, the LAD of Desmospyris sp. aff. 
rhodospyroides, the LAD of rare Desmospyris sp. A (restricted to northern Hawkes Bay), the LAD of Gorgospyris sp. aff. perizostra and rare Pseudodictyophimus gracilipes, the LAD of rare Archipilium macropus, the last positive occurrence of Cyrtocapsella japonica (some tentative Plio/Pleistocene records), the LAD of Cyrtocapsella tetrapera, the LAD of Theocalyptra bicornis in Wairarapa, the LAD of Eucyrtidium acuminatum, the first tentative records of Eucyrtidium sp. A, the LAD of Anthocyrtidium sp. A and Anthocyrtidium zanguebaricum, the LAD of Lamprocyclas sp. A and the last positive occurrence of Lamprocyclas sp. B, the LAD of both Phormostichartus sp. A and rare Siphocampe arachnea, the last positive occurrence of Siphostichartus corona, and the last common occurrence of the large lobed form of Botryopyle dictyocephalus.

\subsubsection{Didymocyrtis tetrathalmus tetrathalmus Zone}

Top : ? FAD of Lamprocyrtis heteroporos

Base : FAD of Didymocyrtis tetrathalmus tetrathalmus

This successive appearance zone is relatively poorly defined in New Zealand because a large gap occurs in the radiolarian fossil record in the upper half of this zone. The didymocyrtids are relatively poorly preserved in the uppermost Miocene and lower Pliocene part of the New Zealand sequence and there is a possibility that forms transitional between $D$. tetrathalmus tetrathalmus and $D$. antepenultima, such as $D$. avitus and $D$. penultima have been included in forms described as $D$. tetrathalmus tetrathalmus because the polar caps are often not preserved. D. tetrathalmus tetrathalmus first occurs near the level of the joint FAD's of Globorotalia crassaformis and G. puncticulata puncticulata in basal Opoitian sediments, immediately just above the Kapitean interval lacking radiolarians.

The questionable top of this zone is the FAD of Lamprocyrtis heteroporos. This taxon is assumed to have evolved from Lamprocyrtis hannai, which is present in the Lamprocyrtis hannai Subzone and older sediments. The Didymocyrtis tetrathalmus tetrathalmus Zone can be divided into two subzones.

\subsubsection{Lychnocanium sp. aff. grande Subzone}

Top : LAD of Lychnocanium sp. aff. grande

Base : FAD of Didymocyrtis tetrathalmus tetrathalmus

This concurrent range zone is reasonably well represented by samples from Wairarapa but is poorly represented in northern samples. The LAD of Didymocyrtis sp. A occurs at about the same level as the LAD of Lychnocanium sp. aff. grande and is very useful in 
co-defining the top of the subzone.

The subzone marks the first relatively common appearance of Acrosphaera spinosa echinoides and apart from two occurrences in the Pleistocene at Waiatai the last appearance of Acrosphaera spinosa spinosa. The first relatively common Actinomma leptodermum sensu stricto occurs in the upper half of the subzone.

Other radiolarian bioevents occurring in the subzone include the LAD of Cladococcus dentata, last common Cenosphaera sp. B, the LAD of rare Acanthosphaera sp. A and Hexapyle dodecantha, the last positive occurrence of Collosphaera sp. aff. huxleyi and Cenosphaera sp. D near the base of the subzone, the FAD of Amphirhopalum cf. ypsilon, the LAD of Antarctissa conradae and Eucyrtidium inflatum, the transition from Eucyrtidium cf. montiparum to Eucyrtidium sp. A, the last positive occurrence of Anthocyrtidium ehrenbergi pliocenica and the LAD of Lamprocyclas sp. E.

\subsubsection{Lamprocyrtis hannai Subzone}

Top : ? FAD of Lamprocyrtis heteroporos

Base : LAD of Lychnocanium sp. aff. grande

This gap zone is very poorly defined in New Zealand, the number of samples from it being only two; SWM1 near the base and LT01 from about the middle. The oldest sample from Waiatai (WA26) is placed just above the top. Intrazonal radiolarian bioevents could not be determined but the FAD of Globorotalia inflata occurs within the lower half of the subzone.

\subsubsection{Lamprocyrtis heteroporos Zone}

Top : FAD of Lamprocyclas gamphonycha

Base : ? FAD of Lamprocyrtis heteroporos

This successive appearance zone is well defined in northern Hawkes Bay sections, but the transition from Lamprocyrtis hannai to $L$. heteroporos at the base is defined by only two samples from the base of the Waiatai Valley Section. The dextral Globorotalia crassaformis - G. crassula overlap Zone occurs near the top.

Radiolarian bioevents occurring within the zone include the last positive occurrence of Actinomma cf. leptodermum which is replaced by Actinomma leptodermum in the Pliocene, the FAD of the thicker spined form of "Sphaerostylus" sp. aff. timmsi (apart from one specimen from the Miocene), the FAD of Heliodiscus astericus forma long spines and the 
Figure 5.4

Generalised summary of the main radiolarian lineages and morphologic trends present in the New Zealand sequences.

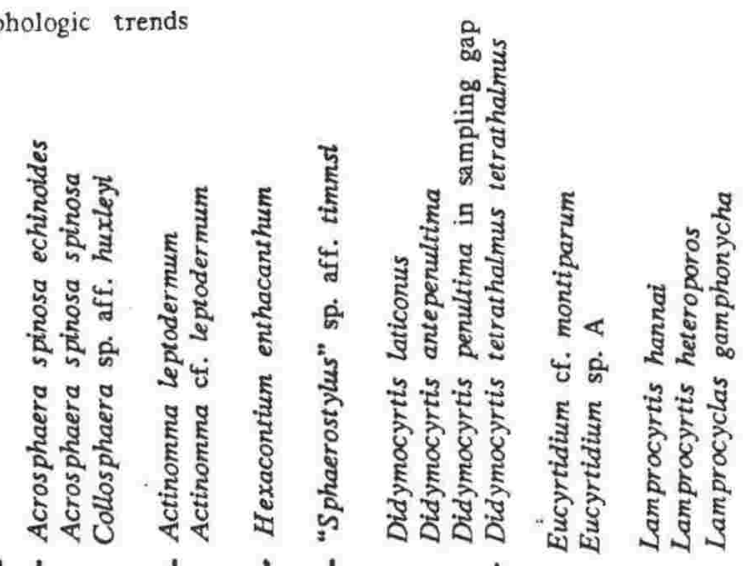

FAD Lamprocyclas gamphonycha LAD dextral Globorotalia crassaformis

FAD Globorotalia crassula

FAD dextral Globorotalia crassaformis

? FAD Lamprocyrtis heteroparos

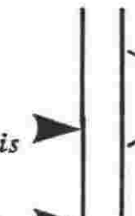

\section{.}

FAD Didymocyrtis tetrathalmus tetrathalmus

FAD Globorotalia puncticulata puncticulata $\longrightarrow$

FAD Globorotalia crassaformis -

FAD Globorotalia sphericomiozea

FAD Globorotalia conomiozea conomiozea

LAD of members of Diartus hughesi group

FAD Globorotalia in flata

LAD Lychnocanium sp. aff. grande

LAD Didymocyrtis sp.

LAD Didymocyrtis laticonus

FAD Arthocyrtidium ehrenbergi pliocenica-

FAD Heliodiscus asteriscus forma large pores-

LAD Globoquadrina dehiscens

LAD Heliodiscus umbonatum

FAD Bolivinita quadrilatera 
last positive occurrence of Stichocorys delmontensis. The Lamprocyclas fauna is dominated by Lamprocyclas cf. maritalis.

Hays (1970) defined the zone as the range of $L$. heteroporos subsequent to the extinction of Eucyrtidium elongatum peregrinum ( $=$ Stichocorys peregrina). Stichocorys peregrina (a tropical radiolarian) has a higher stratigraphic range in New Zealand (into the Lamprocyclas gamphonycha Zone) than in the north Pacific and Hay's (1970) definition is unusable in New Zealand.

\subsubsection{Lamprocyclas gamphonycha Zone}

Top : undefined in New Zealand

Base : FAD of Lamprocyclas gamphonycha

This range (?) zone is marked at the base by the evolutionary transition from Lamprocyrtis heteroporos to Lamprocyclas gamphonycha and is well defined in Waiatai Valley Section. The transition in that section corresponds with the change from dextral to rare sinistral Globorotalia crassaformis at the top of the dextral Globorotalia crassaformis - G. crassula overlap zone.

\subsubsection{Radiolarian lineages}

There are a number of possible radiolarian lineages present in the New Zealand Late Neogene. The following text outlines some of the more useful biostratigraphic transitions that help in determining ages at an "epoch" level.

Acrosphaera spinosa spinosa is replaced by Acrosphaera spinosa echinoides in the lower Pliocene, although there are two positive occurrences of the former taxon in the Pleistocene at Waiatai. The trend is opposite to that proposed by Bjorklund and Goll (1979) for Atlantic specimens. The trend involves a gradual increase in protuberance height and is supported by the restriction of positive occurrences of the smooth outlined Collosphaera sp. aff. huxleyi (which is probably related to Acrosphaera spinosa) to Miocene and basal Pliocene sediments. The appearance of Collosphaera sp. aff. huxleyi in Recent sediments in the Indian Ocean (Johnson and Nigrini, 1980) and the fact that this trend is opposite to that observed by Bjorklund and Goll indicates that the biostratigraphic transition may be an expression of differing ecological responses of two species with differing niches.

The Didymocyrtis lineage (laticonus - antepenultima - tetrathalmus) is well represented in the late Miocene and basal Pliocene in New Zealand although there is an abrupt change 
from antepenultima to tetrathalmus which may be related to very poor faunal preservation in the uppermost Miocene (see section 5.7.9).

Actinomma cf. leptodermum appears to evolve into the post-Miocene Actinomma leptodermum but there is one positive identification of the former taxon in the uppermost Pliocene.

The by-spines on "Sphaerostylus" sp. aff. timmsi become thicker, longer and more symmetrically disposed from the middle Pliocene onwards but there is one identification of the thicker spined form in the Miocene (RM07).

The opposing range patterns of Prunopyle sp. A (more common in the Miocene) and Prunopyle antarctica (more common post-Miocene) indicates a gradual morphologic change in this genus.

Although rare, the "long-spined" form of Heliodiscus asteriscus appears to have evolved, in the late Pliocene, from the more common "small pored" form.

Hexacontium enthacanthum has a tendency for the bars to get thinner in the Pliocene and Pleistocene.

There is also an apparent partial replacement of Dictyocoryne profunda in the Plio-Pleistocene with the arms becoming more conspicuously chambered (cf. Hymeniastrum euclidis). The apparent trend of the three-rayed spongodiscids becoming more conspicuously chambered in the Pliocene is supported by the appearance of well-chambered Amphirhopalum cf. ypsilon in Plio-Pleistocene samples. The reported transition from Amphirhopalum virchowii to A. ypsilon near the Plio-Pleistocene boundary (Nigrini, 1974) is not substantiated by this study. Samples lacking A. virchowii but containing A. cf. ypsilon occur in the lower Pliocene.

The opposing range patterns of members of the Botryostrobus auritus-australis group (more prominent post-Miocene) and B. bramlettei (Miocene) indicate the same gradual evolutionary transition that was reported Reynolds (1980).

A number of forms including Stylodictya validispina, the Tetrapyle octacantha group, the carpocaniids, Cornutella profunda, Eucyrtidium acuminatum, E. cienkowskii, and E. hexagonatum, members of the genus Lamprocyclas, and Siphocampe lineata and $S$. nodosaria tend to be found in a smaller percentage of younger samples. 
Figure 5.5

Correlation of radiolarian bioevents to the paleomagnetic time-scale with the age estimates from Ness et al. (1980). More recent age estimates on the paleomagnetic time-scale are presented in Berggren et al. (1985).

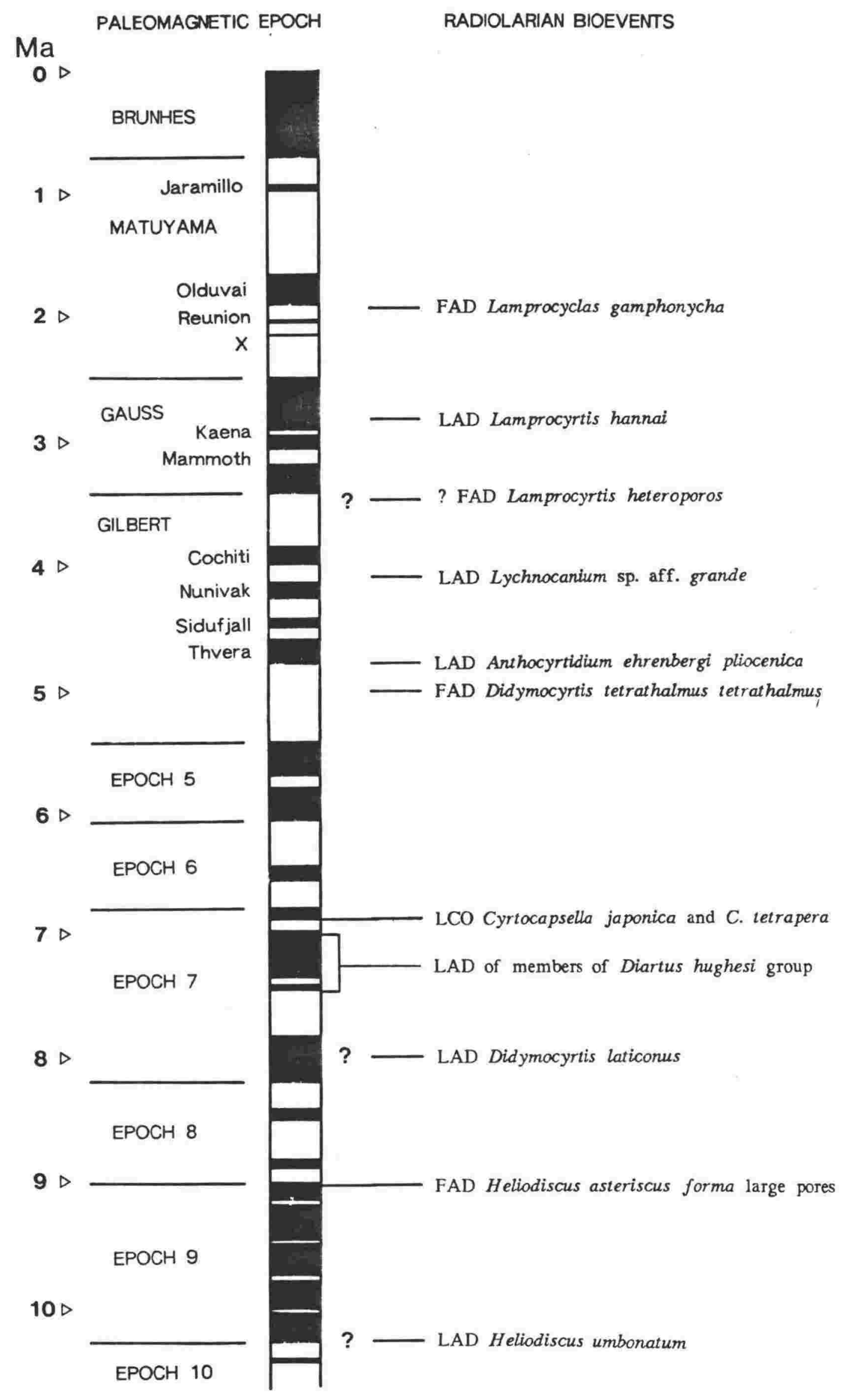




\subsubsection{Radiometric ages}

Radiometric dates for strata from the New Zealand Neogene are few in number. Two K/Ar dates from the Chatham Islands (Hornibrook, 1984a) are particularly relevant to this study. At Momoe-a-toa, a basalt dated at $5.2 \pm 0.2 \mathrm{Ma}$ appears to be interbedded with tuffaceous sediments containing rare Globorotalia crassaformis, rare G. pliozea, G. puncticulata puncticulata and G. conomiozea mons (basal Opoitian). At the other locality, Maunganui Bluff, a basalt dated at $5.33 \pm 0.2$ Ma overlies a thin calcareous sand containing a similar basal Opoitian planktic foraminiferal fauna. Problems with the magnetic polarity of the basalt need to be resolved (Hornibrook, 1984a).

Some fission track dating of volcanic tuffs from the upper Neogene marine sequences is available (e.g. Seward, 1974, pers. comm.; Hornibrook, 1984a). Originally, fission track ages were determined from volcanic glass (Seward, 1974) but track annealing has affected the resultant ages. Three fission track ages based on zircon crystals have particular relevance to this study. A thin tuff bed below an upper Miocene unconformity in the road cut exposure at Mangapoike River (see figure A.17) has been dated at $5.80 \pm 0.55 \mathrm{Ma}$ by Dr.D. Seward (in Hornibrook, 1984a). This tuff is in strata associated with predominantly four-chambered Globorotalia miotumida and is approximately $150 \mathrm{~m}$ above the Bolivinita pohana-pliozea transition as defined by Scott (1978b). Radiolaria from the sediments encompassing the tuff (below the unconformity) are from the Didymocyrtis sp. A Zone and Didymocyrtis antepenultima is also present. At Mahia Peninsula, sample SMH1 from the Didymocyrtis sp. A Zone was collected $3 \mathrm{~m}$ below a tuff (Hornibrook FT37) dated at 6.39 $\pm 1.14 \mathrm{Ma}$ (Dr.D. Seward, pers. comm.). The foraminiferal fauna of this sample contains a Globorotalia miotumida population with $50 \%$ five chambered forms, and Bolivinita pohana. At Palliser Bay a tuff (see Plate C3.2) from within the Anthocyrtidium ehrenbergi pliocenica Subzone has been dated at $7.27 \pm 1.28 \mathrm{Ma}$ (Dr.D. Seward, pers. comm.). The FAD of Bolivinita pliozea occurs $36 \mathrm{~m}$ above this tuff.

\subsubsection{Paleomagnetic ages}

Previous paleomagnetic studies include analyses of four Late Neogene sections in New Zealand:

(a) Blind River: Kennett and Watkins (1974)

(b) Hinakura-Hikawera: Lienert, Christoffel and Vella (1972)

(c) Lower Mangaopari: Kennett, Watkins and Vella (1971) 
(d) Mangapoike: Kennett and Watkins (1974), Wright (1985, in prep.)

The first three sections are not helpful in determining ages of radiolarian zonal boundaries as radiolarians are either lacking or very poorly represented. The radiolarian bearing zone in the Mangapoike River Section (Didymocyrtis sp. A Zone) encompasses the time interval of 7.7 to 6.0 Ma. Within this interval Wright (1985) has inferred a disconformity accounting for the time interval 6.86 to $6.42 \mathrm{Ma}$. It is at this disconformity that the last positive accurrence of Cyrtocapsella japonica and the last common occurrence of Cyrtocapsella tetrapera are located.

\subsubsection{Summary}

Edwards (1985) has integrated the wealth of biostratigraphic, lithostratigraphic, magnetostratigraphic, radiometric and stable isotope data from the uppermost Miocene to Pleistocene into a coherent model. Radiolarian datums can be correlated with this model by tying the radiolarian bioevents to foraminiferal bioevents. The integration of these events is outlined in figure 5.5. Tongaporutuan bioevents are not as well integrated into the radiometric time scale because of a paucity of paleomagnetic and radiometric age determinations, but empirical data suggest some complications in bioevent age determinations.

The LAD of members of the Diartus hughesi group in the Palliser Bay Section (see figure A.36) occurs above the FAD of Bolivinita pliozea, about midway between the FAD of G. conomiozea conomiozea and the Palliser Bay tuff dated at $7.27 \pm 1.28 \mathrm{Ma}$. If the sudden disappearance of Globoquadrina dehiscens (9.2 Ma in Mangapoike River: Wright, Ashby and Hoskins, 1985) is accepted as an isochronous event in New Zealand Tongaporutuan strata, an interpolated age for the LAD of members of the Diartus hughesi group in the Upper Mangaopari Stream Section (see figure A.34) would be 7.0 to 7.5 Ma. Diartus hughesi is absent from strata younger than 7.7 Ma (date from I.C. Wright, 1985 and pers. comm.) in Mangapoike River Section. Sediments older than this from Mangapoike River do not contain radiolarian skeletons. Two tentative identifications of $D$. hughesi from Hangaroa in sediments also containing Didymocyrtis laticonus are the only occurrences, post-LAD of Globoquadrina dehiscens, in northern Hawkes Bay. It appears that either paleooceanographic conditions excluded D. hughesi from northern Hawkes Bay or there is some diachroneity of its disappearance datum between northern Hawkes Bay and southern Wairarapa. The foraminiferal fauna from Mangapoike River Section indicates restricted oceanic circulation (Dr.B. Hoskins, pers. comm.) and the configuration of the Wairoa Syncline (plunging to the south) could easily accomodate basinal closure to the north in the 
Figure 5.6

Correlation of the main Anturctic radiolarian zonations to New Zealand

radiolarian zonations. The 'pre middle Gilbert' correlation of the Antarctic zones is in question as there appears to be substantial disconformities at the bases of sume of the key Antarctic piston cores (see section 5.7.10) Ma

PALEOMAGNETIC EPOCH

NEW ZEALAND ZONES

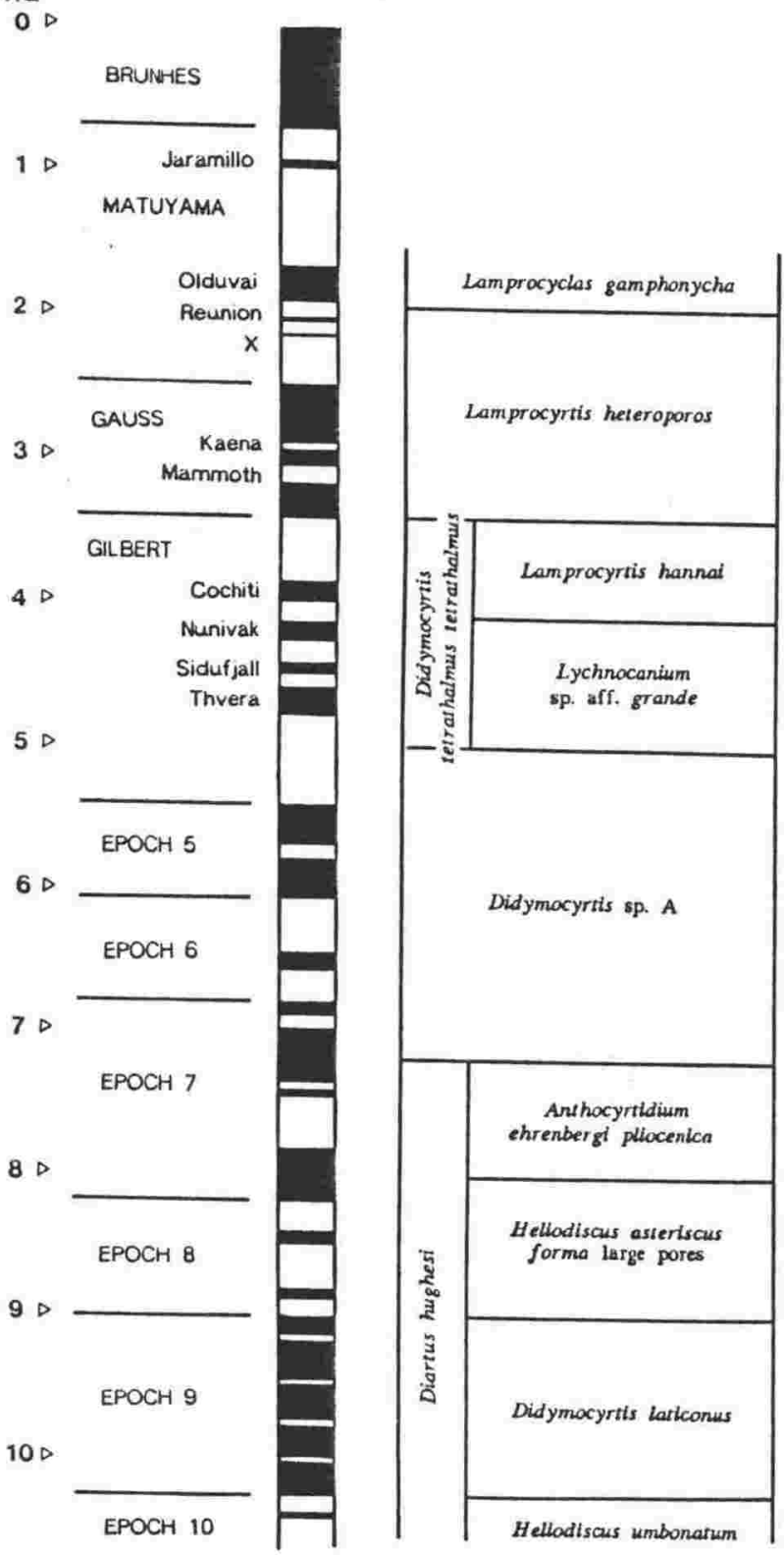

ANTARCTIC ZONES

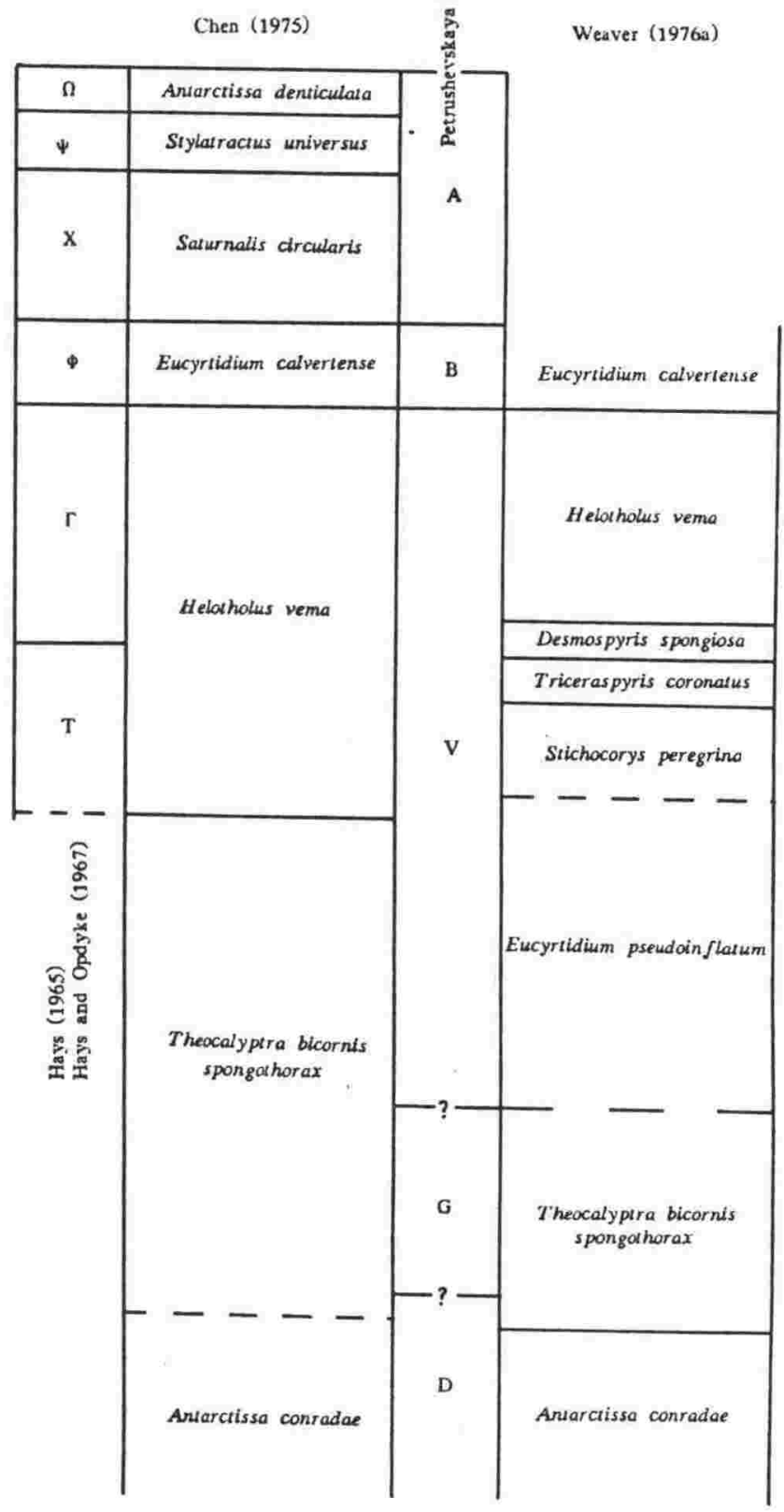


Miocene. Until more radiometric and paleomagnetic dating becomes available, the former hypothesis is preferred.

\subsection{ANTARCTIC ZONATIONS}

The correlation of the following Antarctic zones to New Zealand zones is outlined in figure 5.6.

Hays (1965) was the first to develop an Antarctic radiolarian biostratigraphic zonation. Utilising data from 65 piston cores (only 19 of which reached sediments containing species not living in Antarctic waters today) he established four radiolarian zones based on the upward sequential disappearance of several radiolarian species. Of the four zones, the youngest, Omega $(\Omega)$, consists of only Recent species and the older three zones, Psi $(\Psi)$, Chi $(\mathrm{X})$, and $\mathrm{Phi}(\Phi)$, are defined by fifteen indicator species. The boundary between the $\mathrm{X}$ and $\Phi$ zones, placed at the last common occurrence of Eucyrtidium calvertense in the Antarctic region, was tentatively correlated with the Pliocene/Pleistocene boundary. Opdyke et al. (1966) placed Hays' four zones into a time stratigraphic framework using magnetostratigraphy. They placed the boundary between the $\mathrm{X}$ and $\Phi$ zones just below the base of the Olduvai event which is in close approximation to the Pliocene/Pleistocene boundary as recognised by Ryan et al. (1974) and Berggren (1984). Hays and Opdyke (1967) extended Hays' initial zonation to include lower Pliocene sediments utilising the data from three long piston cores (E-13-17, E-14-8, E-13-3) and introduced two older radiolarian zones; the Upsilon $(\Gamma)$, and Tau $(T)$ zones, the base of the latter not being defined. Bandy, Casey and Wright (1971) attempted to increase the resolution of the six-fold zonation by dividing the $\Omega$ zone into two subzones, the $\Gamma$ zone into four subzones and the $T$ zone into two subzones. Regional implementation of their subzonation throughout the Southern Ocean has proven unsuccessful (Weaver, 1976a), probably because the Pliocene radiolarian zonations are essentially based on data from one of the cores (E-14-8) whose paleomagnetic signature has been interpreted differently (e.g. Weaver, 1976a and Keany, 1979).

Theyer (1972) proposed a zonal scheme for the Antarctic and subantarctic region in the late Neogene which utilised some elements of Riedel and Sanfilippo's (1970) tropical zonation. Legs 28 and 29 of the Deep Sea Drilling Project provided the first opportunity to examine radiolarians in a nearly complete Neogene sequence from the Southern Ocean. Two radiolarian zonations were developed from the cores by Chen (1974, 1975: Leg 28) and Petrushevskaya (1975: Leg 29). Chen's zonation is essentially based on two sites (265 and 266) and he defined 13 radiolarian zones for the Neogene, the upper seven of which 
correspond to the range studied in New Zealand. The upper five zones of Chen's have been correlated with Hays and Opdyke's (1967) zones and have improved the usage of the latter by employing fewer index species and using only first and last occurrences rather than the last common occurrence in defining zonal boundaries.

Petrushevskaya (1975) established a different tentative zonation. The Miocene portion is based primarily on Site 278. Recognising that the number of sections studied in the Antarctic is small and there are difficulties in deciding how synchronous the established periods of change in the radiolarian fauna are and also in what geographical ranges they occur. She defined a number of "biozones" using a large number of bioevents (the V/G and G/D boundaries essentally undefined). Both Petrushevskaya's and Chen's zonations have been hard to define regionally within the Southern Ocean due to the apparent diachroneity of certain biostratigraphic datums and the absence of several index species locally (Weaver 1976a), although Weaver (1976b) used Chen's zonation in defining the biostratigraphy of Leg 35 cores.

Weaver (1976a) developed a more detailed radiolarian biostratigraphy for the late Miocene-Pliocene of the subantarctic and Antarctic region in order to examine regional radiolarian paleobiogeography and Neogene paleoclimatology. This zonation utilised high resolution silicoflagellate and diatom Neogene biostratigraphies in conjunction with paleomagnetic stratigraphy to correlate cores.

Keany (1979) essentially used three Eltanin piston cores (E-14-8, E-16-4 and E-34-19) and DSDP Sites 265 and 266 to establish a detailed radiolarian zonation for the Gilbert, establishing five new partial-range zones.

Hiatuses, mixings and short-lived polarity events which do not correlate with the established paleomagnetic time-scale complicate most polarity logs and have resulted in differing paleomagnetic interpretations for Eltanin core E-14-8, one of the key Antarctic cores, (see Weaver 1976a and Keany 1979). The discovery of a substantial hiatus at 167.5m in DSDP Site 278 (Keany and Kennett, 1975) and the apparent disconformity between the Helotholus vema Zone and Theocalyptra bicornis spongothorax Zone in DSDP Site 266 (Keany 1979) indicates that as the stratigraphy gets more refined more hiatuses will be discovered and could account for the present inability to apply the zonations published. 
Figure 5.7

Correlation of Riedel and Sanfilippo's (1978b) tropical Pacific radiolarian zonation to the New Zealand zonation.

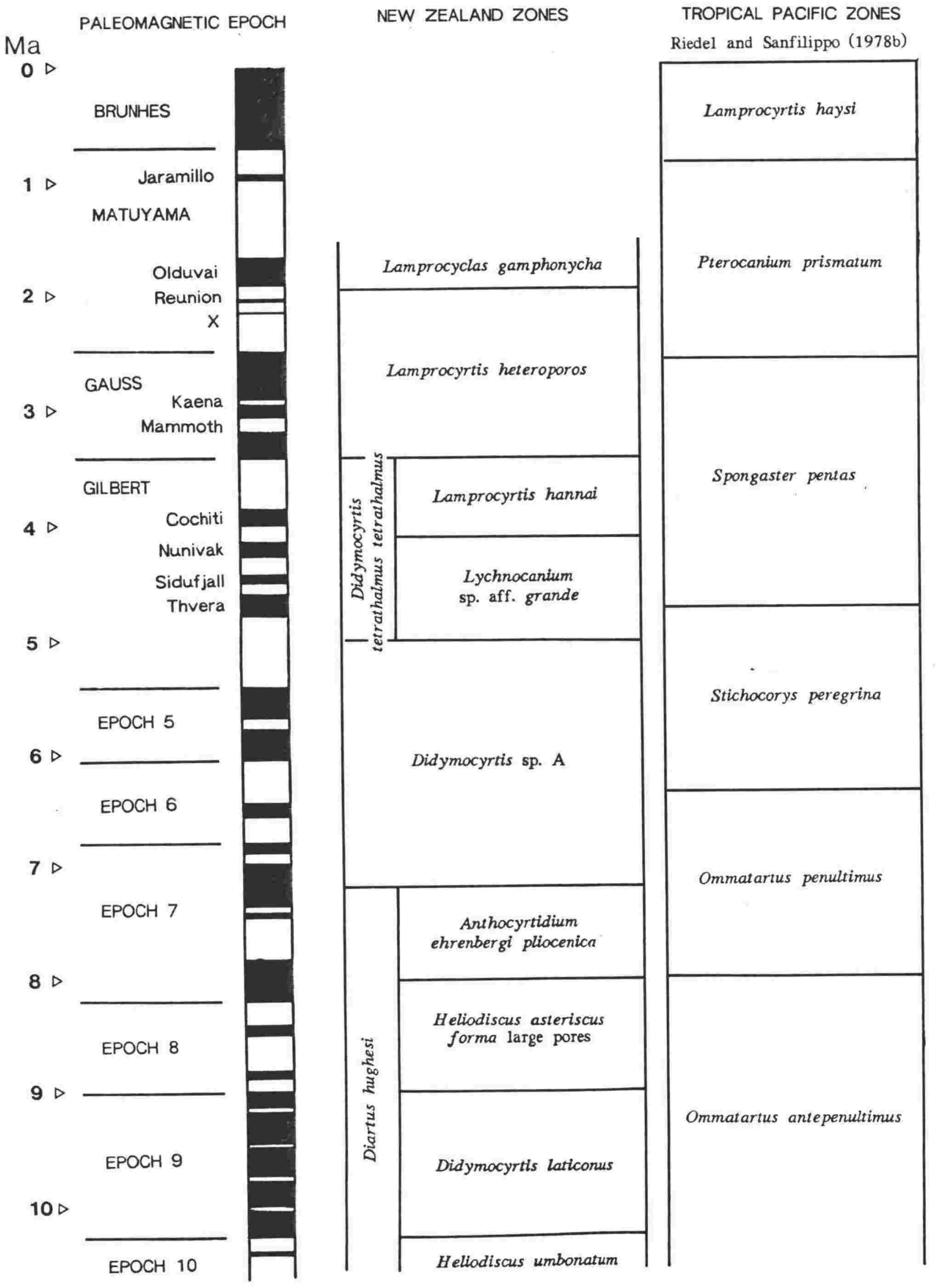


The correlation of Riedel and Sanfilippo's (1978b) tropical zones to New Zealand zones is outlined in figure 5.7 .

Riedel and Sanfilippo (1970) established a tropical zonation for the Cenozoic utilising data from the cores obtained on Leg 4 of the Deep Sea Drilling Project (eastern tropical Atlantic) and it was on this framework that much of the following tropical radiolarian work was based. This zonation left the portion younger than the LAD of Pterocanium prismatum unzoned. Nigrini (1971) filled in the unzoned "Quaternary" portion of Riedel and Sanfilippo's (1970) zonation utilising data from 17 piston cores from the equatorial Pacific. These zones were correlated to the paleomagnetic sequence by Johnson and Knoll (1975).

Goll (1972b) introduced a new Quaternary zone (the Tholospyris devexa devexa Zone) to replace Riedel and Sanfilippo's (1970) unzoned interval and partially replace the Pterocanium prismatum Zone after Goll (1972a) concluded that the top of the latter zone is diachronous, being older in the eastern equatorial Pacific.

Riedel and Sanfilippo (1978b) altered the definition of some of their 1970 zones as more continuous sequences became available for study. Theyer and Hammond (1974) tied the zonal boundaries to the magnetostratigraphy and later extended the age control by correlating a number of extra radiolarian bioevents to the magnetic stratigraphy (Theyer, Mato and Hammond, 1974). Goll (1980) recognised a gap between the Lamprocyrtis haysi Zone and the Pterocanium prismatum Zone in DSDP Hole 420 on the East Pacific Rise and defined another zonal stratigraphy for the Pleistocene.

\subsection{NORTH PACIFIC ZONATIONS}

Hays (1970) was the first to develop a radiolarian stratigraphy for Plio-Pleistocene sediments in the North Pacific. Hays and Berggren (1971) named these zones the $\Omega n, \Psi_{n}, X_{n}$, $\Phi n, \Gamma n$, and $T n$ zones, subscripting them with an " $n$ " to signify that the zones are restricted to the northern hemisphere, are based on different species than the Antarctic zones of Hays (1965) and do not necessarily represent the same period of time as the Antarctic zone with the same Greek letter designation. Foreman (1975) in DSDP Leg 32 in the northern Pacific between Japan and Hawaii recognised the late Miocene zones of Riedel and Sanfilippo (1970) but could not determine their post-Miocene zones. Also Nigrini's (1971) Quaternary zones were not usable so she introduced the Sphaeropyle langii Zone to accomodate the 
Correlation of north Pacific radiolarian zonations to New Zeoland radiolaran zoriations.

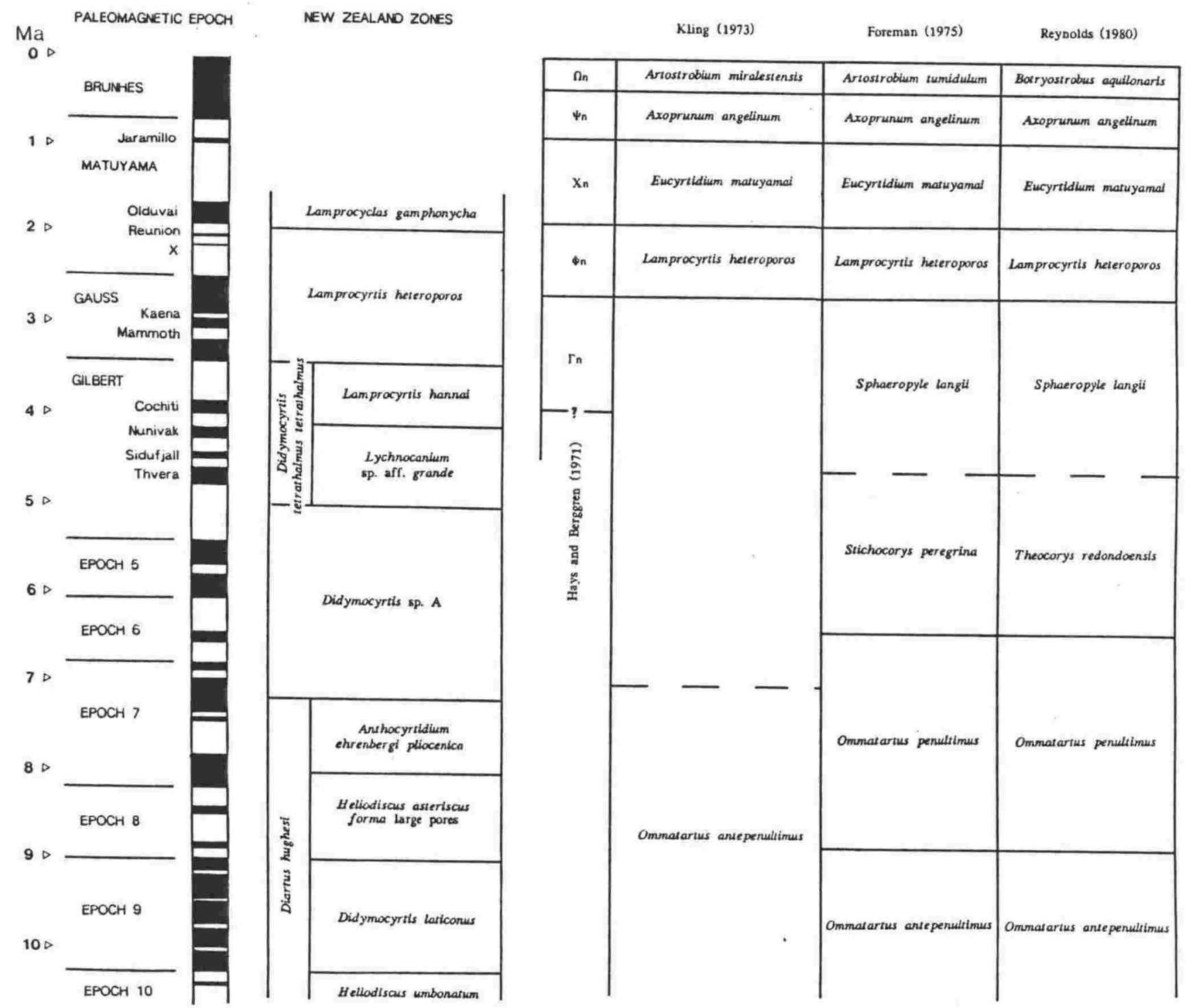


interval between the late Miocene and early Pliocene. This zone approximates the range of the Spongaster pentas Zone used in more southern tropical latitudes and underlies the Lamprocyrtis heteroporos Zone of Hays (1970). Kling (1973) in his study of the eastern north Pacific (especially Site 173) found, like Foreman, mixtures of equatorial and high latitude assemblages and applied both Hays' (1970) and Riedel and Sanfilippo's (1970) zonations with some emendations, especially changes of the zone names to conform to changes in the names of the taxa concerned. He also recorded an unzoned interval in the lower Pliocene and upper Miocene between the Lamprocyrtis heteroporos Zone and the Ommatartus antepenultimus (= Didymocyrtis antepenultima) Zone. Reynolds (1980) working on sediments from the western north Pacific used Kling's emendations to Hays' (1970) zones and also introduced some new late Miocene Zones. Other Late Neogene radiolarian zonations have been erected to cover local conditions; e.g. that for the Norwegian Sea (Bjorklund, 1976). Both the tropical and the North Pacific zonations have been applied to the on-land sequences in California (e.g. Casey, Price and Swift, 1972). Nakaseko and Sugano (1973) produced a very broadly defined zonal scheme for the late Neogene of Japan with two zones represented. The Thecosphaera japonica Zone essentially covers Pliocene and Pleistocene sediments and the Lychnocanium nipponicum Zone the upper Miocene. These two zones have been correlated to Foreman's (1975) zones by Sakai (1980: DSDP Leg 56).

\subsection{CORRELATION OF NEW ZEALAND RADIOLARIAN OCCURRENCES TO INTERNATIONAL RANGES}

\subsubsection{LAD's of Cyrtocapsella japonica and C. tetrapera}

Cyrtocapsella japonica and C. tetrapera have a well defined last appearance datum in the Mangapoike River Section in sample TM20. The datum falls immediately below a paleomagnetically inferred disconformity (6.86 to 6.42Ma) (Wright, 1985). Some other sections support this datum level in the upper Tongaporutuan although there are three tentative younger records of $C$. japonica in other sections with one as young as Pleistocene. These younger records could be variants of Stichocorys populations.

Riedel and Sanfilippo (1970) show the LAD of C. japonica to be synchronous with the LAD of Didymocyrtis laticonus within the Didymocyrtis antepenultima Zone. Casey (1972) shows the LAD of C. japonica to be in the middle Upper Miocene and the LAD of C. tetrapera within the Pliocene Spongaster pentas Zone in Mohole Samples. Casey, Price and Swift (1972) have the FAD's of Didymocyrtis laticonus, C. japonica and C. tetrapera together in Malaga Core samples whereas Reynolds (1980) show their LAD's to be just 


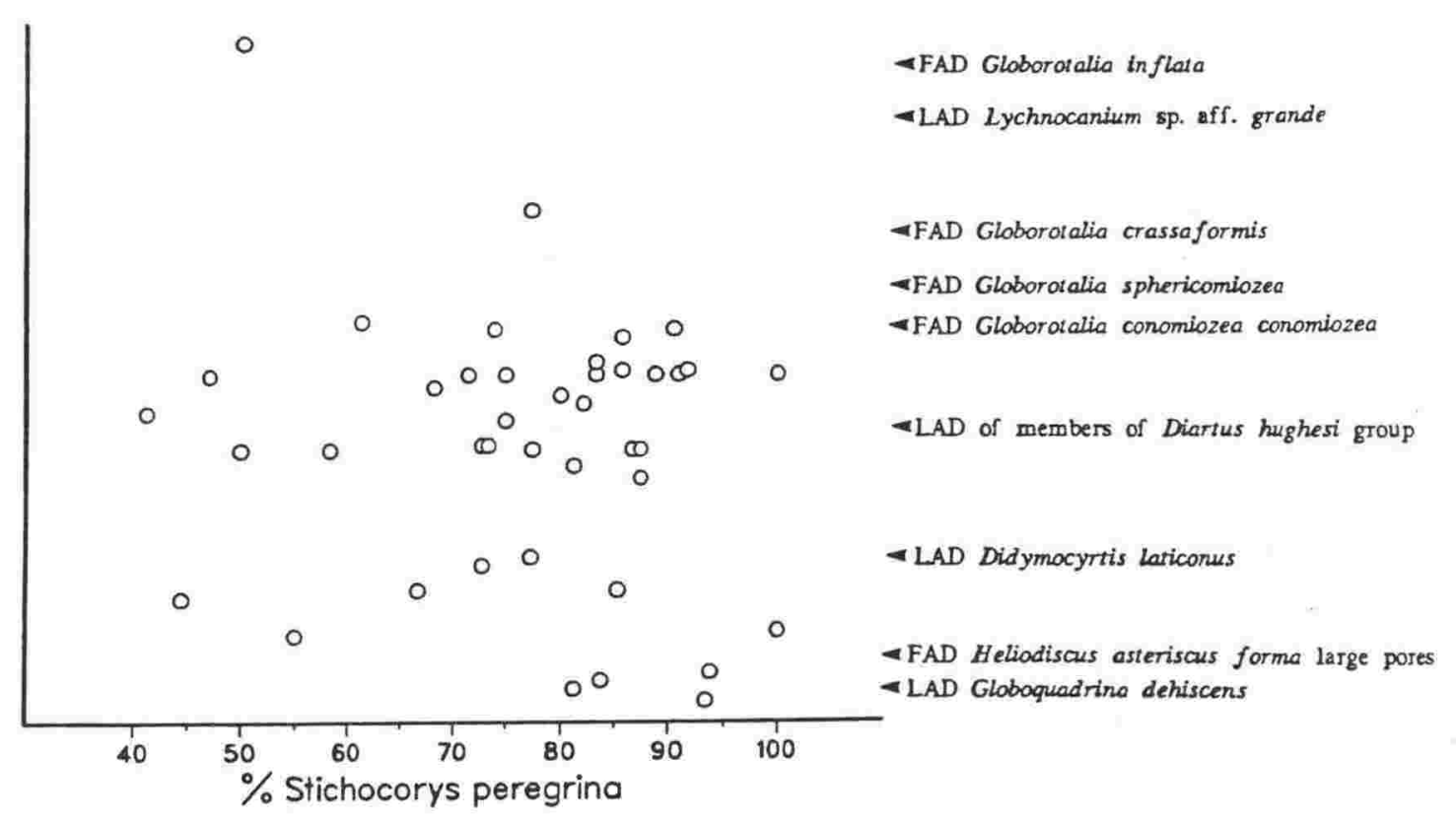

\section{Figure 5.9}

Variability in the percentage of Stichocorys peregrina in populations of 10 or more Stichocorys delmontensis - peregrina morphotypes (in 41 samples) from the LAD of Globoquadrina dehiscens (mid Tongaporutuan) to the FAD of Globorotalia inflata (mid Opoitian). The vertical axis is not scaled against time but the approximate position of a number of bioevents is indicated. It is apparent that there is no clear domination of one morphotype for a large time span in the New Zealand upper Miocene and lower Pliocene. 
before the LAD of Didymocyrtis Laticonus in the western North Pacific. Kling (1973) shows $C$. japonica and C. tetrapera to die out half way through the range of Diartus hughesi and considers this to be a higher occurrence than recorded in the tropics. Chen (1975) notes the disappearance of C. tetrapera in the Antarctic upper Miocene. Sakai (1980, northwest Pacific) records the LAD of C. tetrapera in the mid-Miocene with $C$. japonica dying out higher in the mid-Miocene. Weaver (1976a) reports Cyrtocapsella subconica (= tetrapera) in earliest Pliocene age sediments in E-14-08 and Kennett (1980) tabulates the top of C. tetrapera in subantarctic/Antarctic cores in the Cochiti Event (Kennett, 1980, table 5) and in the late Miocene (Kennett, 1980, table 7, under Cyrotocapsella). Casey and Reynolds (1980) show the LAD of C. tetrapera in the Cochiti Event (they included Cyrtocapsella cornuta in their counts). Weaver, Casey and Perez (1981) show the top of $C$. tetrapera to be in the top of Epoch 11 and the LAD of C. japonica in mid Epoch 10 at Newport Bay. In the equatorial Pacific, Johnson and Wick (1982) show the top of C. tetrapera to be within Epoch 11 and Epoch 12 and the LAD of C. japonica in the mid-top Epoch 11.

The LAD of these two species occurs later in New Zealand than in the tropics but appears to be younger than Antarctic occurrences. Substantial time missing in key Antarctic piston cores (see section 5.7.10) could make the Antarctic occurrences much older than reported and provide good correlation.

\subsubsection{Transition from Stichocorys delmontensis to $S$. peregrina}

Many authors have quoted the evolutionary transition from Stichocorys delmontensis to Stichocorys peregrina in middle Epoch 6. The lower limit of the Stichocorys peregrina Zone is defined as the evolutionary base of Stichocorys peregrina and the upper limit of the Spongaster pentas Zone as the last appearance of $S$. peregrina (Riedel and Sanfilippo, 1978b). Although the LAD of $S$. peregrina is considered isochronous in the tropical Pacific (Hays, 1970) the datum has been reported to occur at horizons ranging from the top of the Kaena Event (Ishida, 1978) to the top of the Olduvai Event (Ryan et al., 1974). Theyer, Mato and Hammond (1978) dated the first occurrence in the basal third of Epoch 6 and the last occurrence in latest Gauss. Weaver, Casey and Perez (1981) report the base of $S$. peregrina in mid Epoch 7 and the top of the taxon in the Sidufjall Event with the $S$. delmontensis - peregrina transition occurring during upper Epoch 6 and the last $S$. delmontensis in basal Epoch 5. Kling (1973) in the eastern North Pacific found $S$. delmontensis morphotypes well above the FAD of $S$. peregrina with the overlap covering a considerable stratigraphic interval with no distinct change in the dominance of one 
morphotype to another. Reynolds (1980) notes a long overlap zone from the upper Middle Miocene to Middle Pliocene in the western North Pacific.

In New Zealand, S. peregrina morphotypes occur with Globoquadrina dehiscens in basal Tongaporutuan strata and $S$. delmontensis morphotypes occur as high as the LAD of Cibicides molestus, indicating a very long overlap zone. $S$. peregrina is found in the youngest samples studied. Forty-one samples from the New Zealand upper Neogene contain more than ten specimens of either or both morphotypes in the statistical counts made of 300 specimens in 97 samples. The percentage of $S$. peregrina in the $S$. peregrina delmontensis population is shown in figure 5.15 and indicates a considerable variation in the numbers of each morphotype with no clear dominance of one morphotype over another from at least the LAD of Globoquadrina dehiscens to the FAD of Globorotalia inflata (a period of $5.5 \mathrm{Ma}$ ). The range of $S$. peregrina in New Zealand is at least $10 \mathrm{Ma}$ to $2 \mathrm{Ma}$. This indicates some provincialism for the tropical radiolarian zonation with supporting evidence from North Pacific cores. Antarctic cores generally lack members of this warm-water genus.

\subsubsection{LAD of Lychnocanium sp. aff. grande}

Lychnocanium grande has an LAD reported at middle or basal Gauss (Bandy, Casey and Wright, 1971; Casey, Price and Swift, 1972; Casey and McMillen, 1977; Kennett, 1980; Casey and Reynolds, 1980), although both Reynolds (1980) and Kling (1973) record specimens from Quaternary sediments in the North Pacific. Keany (1975) records the LAD of the subspecies Lychnocanium grande rugosum in the Thvera Event and Weaver, Casey and Perez (1981) report the LAD of Lychnocanium grande as low as Epoch 5 in Newport Bay Section.

The LAD in New Zealand is just below the FAD of Globorotalia inflata which has been dated as occurring in the Cochiti Event during the Gilbert by Edwards (1985). This level is lower than those previously reported. This discrepancy could be related to the poor preservation of radiolarian faunas between the FAD of $G$. inflata and the incoming of dextral Globorotalia crassaformis in middle Gauss.

\subsubsection{LAD of Anthocyrtidium ehrenbergi pliocenica}

The LAD of Anthocyrtidium ehrenbergi pliocenica has been reported in the Antarctic Lower Pliocene (Keany, 1975, A. ehrenbergi) and in mid Epoch 5 (Weaver, Casey and Perez, 1981, Newport Section). The LAD of this species in basal Opoitian strata (basal Gilbert) in New 
Zealand indicates that it may be a useful datum level for basal Pliocene correlations.

\subsubsection{Range of Spongaster pentas}

Riedel and Sanfilippo (1978b) defined the base of the Spongaster pentas Zone (early Pliocene) by the evolutionary transition from Spongaster berminghami to $S$. pentas. Theyer, Mato and Hammond (1978) dated its range in the equatorial Pacific from early to latest Gilbert and Berggren et al. (1985) record its FAD at the top of the Sidufjall Event within the Gilbert.

The occurrence of a single specimen in the upper Tongaporutuan supports the view of Casey and McMillen (1977) that the tropical zone is provincial as they found living specimens of $S$. berminghami and $S$. pentas in the tropical Atlantic, Gulf of Mexico, and Caribbean. Riedel and Sanfilippo (1978b) showed pentagonal forms of Spongaster occurring in sediments older than the early Pliocene at DSDP Site 77B.

\subsubsection{Members of the genus Eucyrtidium}

Within the genus Eucyrtidium there are a number of species which appear to be biostratigraphically useful.

In the Eucyrtidium cienkowskii, $E$. hexagonatum and $E$. acuminatum group there are varying interpretations of the species due to the transitional forms that sometimes exist, consequently there are variations in the recorded ranges. All three morphotypes occur throughout the Late Neogene in New Zealand but are rarer in post-Miocene sediments.

Various ages for the LAD of Eucyrtidium inflatum have been reported ranging from within Epoch 11 to the lower Pliocene (see taxonomic discussion). In New Zealand, the form is rare in the late Miocene but its highest occurrence is in basal Opoitian (basal Gilbert) strata. It appears as though $E$. inflatum evolved from $E$. calvertense and then died out in the basal Pliocene, the various levels reported for the LAD of $E$. inflatum being due to morphotypes being included in $E$. calvertense populations.

Eucyrtidium calvertense also evolved into $E$. matuyamai at the start of, or within the Olduvai Event. In some cases this has been recorded as an extinction of $E$. calvertense (especially in Antarctic populations) and in other cases as a morphologic offshoot of $E$. calvertense populations. The youngest samples studied in New Zealand contain $E$. calvertense populations with some forms approaching $E$. matuyamai but no true $E$. matuyamai morphotypes. As the LAD of $E$. calvertense and/or FAD of $E$. matuyamai 
appears to be a reliable isochronous radiolarian datum in the world's oceans, this indicates the youngest samples studied herein are only slightly older than basal Olduvai.

\subsubsection{Members of the genus Antarctissa}

Chen (1975) reported that Antarctissa antedenticulata and Antarctissa conradae evolved into Antarctissa denticulata and Antarctissa longa respectively, in the early Pliocene. Keany (1975) recorded the FAD of both $A$. denticulata and $A$. strelkovi in the Thvera Event of the Gilbert. Weaver, Casey and Perez (1981) record the LAD of A. conradae in mid Epoch 9 at Newport Bay Section. In Pacific CENOP samples A. longa is present in early Middle Miocene samples but A. conradae is absent and common A. strelkovi occurs in the early and late Miocene of DSDP Site 173 (Nigrini and Lombari, 1984).

In the New Zealand upper Neogene four members of the genus are found: $A$. antedenticulata, A. longa, A. conradae and A. strelkovi, with only the last two having restricted ranges. A. conradae is not found in sediments above the basal Opoitian (basal Gilbert) strata and A. strelkovi is not found below the LAD of Globoquadrina dehiscens. Keany $(1973,1978)$ and Keany and Kennett $(1971,1975)$ show the usefulness of members of this genus for paleoclimatic studies in Antarctic deep-sea cores. The climatic influence on the geographic presence of some of the species and a certain amount of taxonomic confusion in the genus accounts for the varying ages recorded.

\subsubsection{Upper Pliocene to Pleistocene transition from Lamprocyrtis spp. to} Lamprocyclas gamphonycha

Jorgensen (1900) originally defined Lamprocyclas gamphonycha (under Pterocorys gamphonyxos) from off the coast of Norway and suggested it to be a temperate oceanic form. This is supported by its absence in equatorial regions and areas south of the Polar Front (Hays, 1965). Johnson and Nigrini (1980) found it present in most samples between $30^{\circ} \mathrm{S}$ and $46^{\circ} \mathrm{S}$ in the western Indian Ocean.

Hays (1970) concluded that Lamprocyrtis heteroporos evolved into L. gamphonycha with the former taxon becoming extinct near the base of the Olduvai. This level has since been supported by evidence from the Malaga Core Section (Casey, Price and Swift, 1972) and the southern Ocean (Kennett, 1980). Weaver, Casey and Perez (1981) show the top of L. heteroporos to be near the top of the Olduvai Event at Newport Bay and within the Olduvai at Centreville Beach Section. 
The base of $L$. heteroporos is not as well defined, various levels having been reported. Casey, Price and Swift (1972) place its first occurrence at the top of the Kaena Event in Malaga Core Section. Casey and McMillen (1977) report its FAD in a primitive form in the Gilbert from Atlantic sediments. Sakai (1980) records the FAD at the same level as the FAD of Didymocyrtis tetrathalmus tetrathalmus. Casey and Reynolds (1980) put the FAD of true $L$. heteroporos at about middle Gauss but report morphotypes in the middle Gilbert. Weaver, Casey and Perez (1981) place the base of $L$. heteroporos at the base of the Gilbert before the Thvera Event. The widely varying levels are probably due to taxonomic confusion caused by the gradual evolution of L. heteroporos from Lamprocyrtis hannai. This transition was first suggested by Kling (1973) and although data are scarce its existence is supported herein. The LAD of $L$. hannai occurs in sample WA19 (Waiatai Valley Section) which also contains $L$. heteroporos. This level is immediately below the LAD of dextral Globorotalia crassaformis, which occurs at the top of the Mammoth Event (Edwards, 1985). The evolution of Lamprocyclas gamphonycha is well defined in the Waiatai Valley Section and occurs very near the top of the Globorotalia crassula - dextral Globorotalia crassaformis overlap zone. This level occurs between the Olduvai and Reunion Events (Edwards, 1985). The transition from $L$. heteroporos to $L$. gamphonycha appears to be an isochronous datum level in temperate radiolarian faunas of the northern and southern Pacific.

\subsubsection{The Didymocyrtis lineage}

The evolutionary lineage Didymocyrtis laticonus - antepenultima - penultima - tetrathalmus has been recognised previously as a biostratigraphically useful Miocene to Pliocene radiolarian lineage. The morphologic expression of this lineage is an increase in cap height with time (see Westberg and Riedel, 1978). Riedel and Sanfilippo (1970) used this lineage as the basis of part of their tropical Neogene radiolarian zonation. As with most zonal boundaries based on gradual evolutionary trends, the position of the last or first appearance of a particular morphotype is sometimes hard to determine. Consequently, the zonal definition was changed by Riedel and Sanfilippo (1978b) to counteract the problems in determining cap height level.

The oldest member of the lineage, Didymocyrtis laticonus, first appeared in latest Epoch 15 (Theyer, Mato, and Hammond, 1978). The morphotypic top of this species has been reported as isochronous with the base of Diartus hughesi (Kling, 1973) in middle Epoch 9 (Theyer, Mato and Hammond, 1978), and synchronous with the earliest Didymocyrtis antepenultima (its evolutionary descendent) (Riedel and Sanfilippo, 1970). Sakai (1980) 
could not detect the laticonus to antepenultima transition because of morphologic continuity and a similar problem exists in New Zealand. Events that appear to have been abrupt in deep-sea sequences can be represented by thick stratigraphic intervals in rapidly deposited shelf/slope sequences as already shown with the Globorotalia tosaensis - truncatulinoides transition in northern Hawke's Bay (Hornibrook, 1976b). The LAD of D. laticonus is well defined in Upper Mangaopari Section, occurring approximately midway between the LAD of Globoquadrina dehiscens and the LAD of members of the Diartus hughesi group.

Didymocyrtis antepenultima morphotypes are found with Globoquadrina dehiscens in a number of samples, indicating a long overlap range with D. laticonus in New Zealand. The FAD of D. antepenultima has been placed in latest Epoch 11 (Ryan et al., 1974; Theyer, Mato and Hammond, 1978; Johnson and Wick, 1982) which is in agreement with it being found in the oldest samples studied in New Zealand. Definition of the transition from $D$. antepenultima to $D$. penultima it is generally accepted as occurring above the LAD of Diartus hughesi (Riedel and Sanfilippo, 1971; Riedel and Sanfilippo, 1978b) although Reynolds (1980) shows the transition to be below the LAD of D. hughesi. This transition is not documented in New Zealand as it falls within the preservation gap at the top of the Miocene (Kapitean) above the LAD of $D$. hughesi. D. penultima is lacking below this gap but $D$. antepenultima is present in samples below it. The base of the preservation gap is at approximately 5.5 to $6.0 \mathrm{Ma}$.

Above the sampling gap Didymocyrtis tetrathalmus tetrathalmus occurs in basal Opoitian strata. There is a possibility that poorly preserved $D$. antepenultima/penultima morphotypes have been included in the $D$. tetrathalmus tetrathalmus populations. The FAD of D. tetrathalmus tetrathalmus occurs in strata dated as basal Gilbert (below the Thvera Event) by Edwards (1985). This is slightly lower than previously reported levels within the Nunivak and Cochiti Events (Ishida, 1978), at middle Gilbert (Theyer, Mato and Hammond, 1978), and at the base of Gilbert "b" Event (Casey and Reynolds, 1980) and could be explained by the poor preservation of specimens.

\subsubsection{The LAD of members of the Diartus hughesi group}

Riedel and Sanfilippo (1978b) redefined the Didymocyrtis antepenultima Zone to be the range of Diartus hughesi because of the inability to accurately define the cap height trend in the D. laticonus - antepenultima - penultima lineage. Reynolds (1980) introduced the Diartus hughesi Zone in the western north Pacific, defining the base as the evolutionary transition from Diartus petterssoni to Diartus hughesi and the top of the zone as the 
evolutionary transition from Didymocyrtis laticonus to $D$. antepenultima. Reynolds considered that this zone was not recorded by Riedel and Sanfilippo (1978b) because at lower latitudes the transiton from $D$. petterssoni to $D$. hughesi and $D$. laticonus to $D$. antepenultima are coeval.

The LAD of Diartus hughesi is generally accepted as falling near the base of Epoch 7 (Opdyke, 1972; Ryan et al., 1974; Vincent, Killingley and Berger, 1980) although Berggren et al., (1985) show it to be slightly higher. Theyer, Mato and Hammond (1978) report its LAD in latest Epoch 9 although DSDP Leg 85 results suggest that this age should be at the Epoch 7/8 boundary (after Nigrini and Lombari, 1984). In New Zealand the LAD of members of the D. hughesi group occurs within Epoch 7 (see section 5.3.3).

Substantially younger LAD's have been reported. Casey and Reynolds (1980) report D. hughesi into middle Gilbert (Nunivak) sediments in equatorial core V-24-59. At about this level in that core are a number of datums with the LAD of D. hughesi nearly at the same level as the FAD of Didymocyrtis tetrathalmus tetrathalmus and a slight overlap with the range of Lamprocyrtis heteroporos. This indicates a probable disconformity at the level of the LAD of $D$. hughesi which could make the normal event identified as Nunivak significantly older.

Bandy, Casey and Wright (1971) report Ommatocampe hughesi (=Diartus hughesi) from Gilbert age sediments in Eltanin Core E-14-08 (at 1750cm). Weaver (1976a) reports the presence of Amphymenium challengeri, a probably related form, at the same level. Casey (1972) suggested that the radiolarians at $1750 \mathrm{~cm}$ in E-14-08 could be as old as Diartus petterssoni Zone. This part of the core was designated the T (Tau) "b" subzone by Bandy, Casey and Wright (1971). The substantial diachroneity required in the LAD of $D$. hughesi between tropical/temperate areas and the Antarctic sediments to account for this difference is probably too great (middle Gilbert to basal Epoch 7). A more valid explanation is that the paleomagnetic interpretation for the lower part of E-14-08 is wrong and there is a substantial time break in that core. This time break could easily be placed at $1500 \mathrm{~cm}$ where there is a large shift in the paleotemperature curve (see Bandy, Casey and Wright, 1971, figure 6). This also explains the joint LAD's of Cannartiscus marylandicus (=Didymocyrtis sp. A) and D. hughesi. Additionally, in the other core on which the T "b" Subzone was based (E-13-17), there is a similar shift in the paleotemperature curve at $1930 \mathrm{~cm}$ (Bandy, Casey and Wright, 1971, figure 9) suggesting a substantial time break as well. Thus the $\mathrm{T}$ " $\mathrm{b}$ " subzone is herein considered to be older than previously thought, but the amount of time missing is hard to determine. 
Table 5.1

The left hand column is a list of the 59 counting groups originally used. The right hand column indicates the groupings made to reduce the data set to 30 variables. Of these 30 variables only 13 (those marked with an asterisk) consistently make up more than $2 \%$ of the radiolarian population. It was these 13 groups that were statistically manipulated.

\begin{tabular}{|c|c|}
\hline $\begin{array}{l}\text { Collosphaera spp. } \\
\text { Acrosphaera spp. }\end{array}$ & Collosphaeridae \\
\hline $\begin{array}{l}\text { Actinomma antarcticum } \\
\text { Actinomma leptodermum } \\
\text { Actinomma polycanthum group }\end{array}$ & Actinomma spp. * \\
\hline $\begin{array}{l}\text { Cladococcus spp. } \\
\text { Acanthosphaera spp. }\end{array}$ & Cladococcus and Acanthosphaera spp. \\
\hline Cenosphaera spp. & Cenosphaera spp. * \\
\hline $\begin{array}{l}\text { Hexacontium enthacanthum } \\
\text { Hexacontium laevigatum }\end{array}$ & Hexacontium spp. * \\
\hline Thecosphaera spp. & Thecosphaera spp. * \\
\hline Prunulum spp. & Prunulum spp. * \\
\hline $\begin{array}{l}\text { "Stylatractus" spp. } \\
\text { "Sphaerostylus" sp. aff. timmsi }\end{array}$ & Stylosphaerids * \\
\hline Prunopyle and Spongurus spp. & Prunopyle and Spongurus spp. \\
\hline Spongocore puella & Spongocore puella \\
\hline Hellodiscus spp. & Heliodiscus spp. \\
\hline $\begin{array}{l}\text { Didymacyrtis antepenultima } \\
\text { Didymocyrtis laticonus } \\
\text { Didymocyrtis virgineum } \\
\text { Didymocyrtis sp. A } \\
\text { Didymocyrtis tetrathalmus tetrathalmus } \\
\text { Diartus hughesi group }\end{array}$ & Coccodiscidae \\
\hline Dictyocoryne and Hymeniastrum spp. & Dictyocoryne and Hymeniastrum spp. * \\
\hline Stylodictya spp. & Stylodictya spp. * \\
\hline Porodiscus spp. & Porodiscus spp. * \\
\hline Spongotrochus glacialis & Spongotrochus glacialis * \\
\hline $\begin{array}{l}\text { Tetrapyle octacantha group } \\
\text { Cubotholus rhombicus }\end{array}$ & Pyloniidae and Tholoniidae \\
\hline $\begin{array}{l}\text { Lithelius minor } \\
\text { Lithelius nautiloides }\end{array}$ & Lithelius spp. \\
\hline $\begin{array}{l}\text { other Spumellarians } \\
\text { Styptosphaera spp. }\end{array}$ & other Spumellarians \\
\hline $\begin{array}{l}\text { Antarctissa and Lithomelissa spp. } \\
\text { Lophophaena spp. }\end{array}$ & Plagoniidae \\
\hline $\begin{array}{l}\text { Desmospyris and Gorgospyris spp. } \\
\text { Phormospyris spp. }\end{array}$ & Acanthodesmiidae \\
\hline Carpocaniidae & Carpocaniidae * \\
\hline $\begin{array}{l}\text { Cornutella profunda } \\
\text { Plectopyramis dodecomma }\end{array}$ & Cornutella and Plectopyramis spp. \\
\hline
\end{tabular}

Dictyophimus hirundo group Dictyophimus, Lychnocanium and Lychnocanella spp.

Lychnocanium and Lychnocanella spp.

Theocalyptra spp. Theocalyptra and Lampromitra spp.

Lampromitra spp.

E. acuminatum, E. cienkowskil group, and E. hexagonatum Eucyrtidium spp.

$E$. calvertense and $E$. inflatum

Eucyrtidium punctatum group

Eucyrtidium sp. A and E. montiparum

Cyrlocapsella japonica Cyrlocapsella and Stichocorys spp. *

Cyrtacapsella tetrapera

Stichocorys peregrina

Stichocorys delmontensis

Stichocorys spp. (transitionals)

Anthocyrtidium spp. Anthocyrtidium, Lamprocyclas and Lamprocyrtis spp.

Lamprocyclas and Lamprocyrtis spp.

Botryostrobus spp. Artostrobiidae *

Siphocampe spp.

Spirocyrtis subscalaris

Botryopyle dictyocephalus group Botryopyle dictyocephalus group 
As more unconformities in southern ocean deep-sea cores are discovered (e.g. Watkins and Kennett, 1972; Keany and Kennett, 1975; Kennett and Watkins, 1976; Ledbetter et al., 1983) the continuity of a number of the deep-sea reference cores must be questioned. The older paleomagnetic correlation postulated in this case has serious implications for the "preupper Gilbert" paleomagnetically determined real age estimates for the southern ocean diatom stratigraphy (McCollum, 1975) and silicoflagellate stratigraphy (Ciesielski, 1975) as they are essentially based on the paleomagnetic interpretation of E-14-08 and E-13-17. These stratigraphies have been utilised in discussions on early Pliocene Antarctic temperature changes (Ciesielski and Weaver, 1974) and used to date formations and drill core from the Antarctic continent (Webb et al., 1984; Barrett et al., 1985).

If the disconformities represent time intervals of similar magnitude to periods between polarity changes then they could explain the apparent correlation of radiolarian extinctions to paleomagnetic changes (Hays and Opdyke, 1967; Hays, 1971).

\subsection{STATISTICAL ANALYSIS}

\subsubsection{Introduction}

Transmitted light slides of the radiolarian faunas from 97 samples were made using the technique described by Ashby (1983). Counts of up to about 300 specimens or the total slide (whichever came first) were made using the "ribbon" method (see Section 2.6 for details of statistical counting). The specimens encountered were placed into one of 59 counting groups. These counting groups are of various types, ranging from specific, poly-specific, generic, polygeneric to, in one instance, family. The groups used are listed in table 5.1. It was soon evident that these "counting" groups were too precise considering the differing preservation in the samples studied. The value of $\mathrm{N}$ listed in Appendix E.3 gives an idea of the preservation of radiolarians in the samples as it is a measure of the number of counting groups filled. With high preservation the $\mathrm{N}$ value increases because more delicate forms are preserved. Low $\mathrm{N}$ values indicate that only the more robust species are preserved in samples with low preservation. The $\mathrm{N}$ values for the samples counted vary from 14 (TK05) to 44 (HR04). The 59 counting groups were reduced to 30 by combining either similar looking forms that could have been misclassified or rare forms that could be genetically related. The new groupings are outlined in table 5.1. Of the 30 variables all with a percentage consistently less than $2 \%$ were removed. These rarer groups were removed because, as counts were made to about 300 the percentage error involved in 


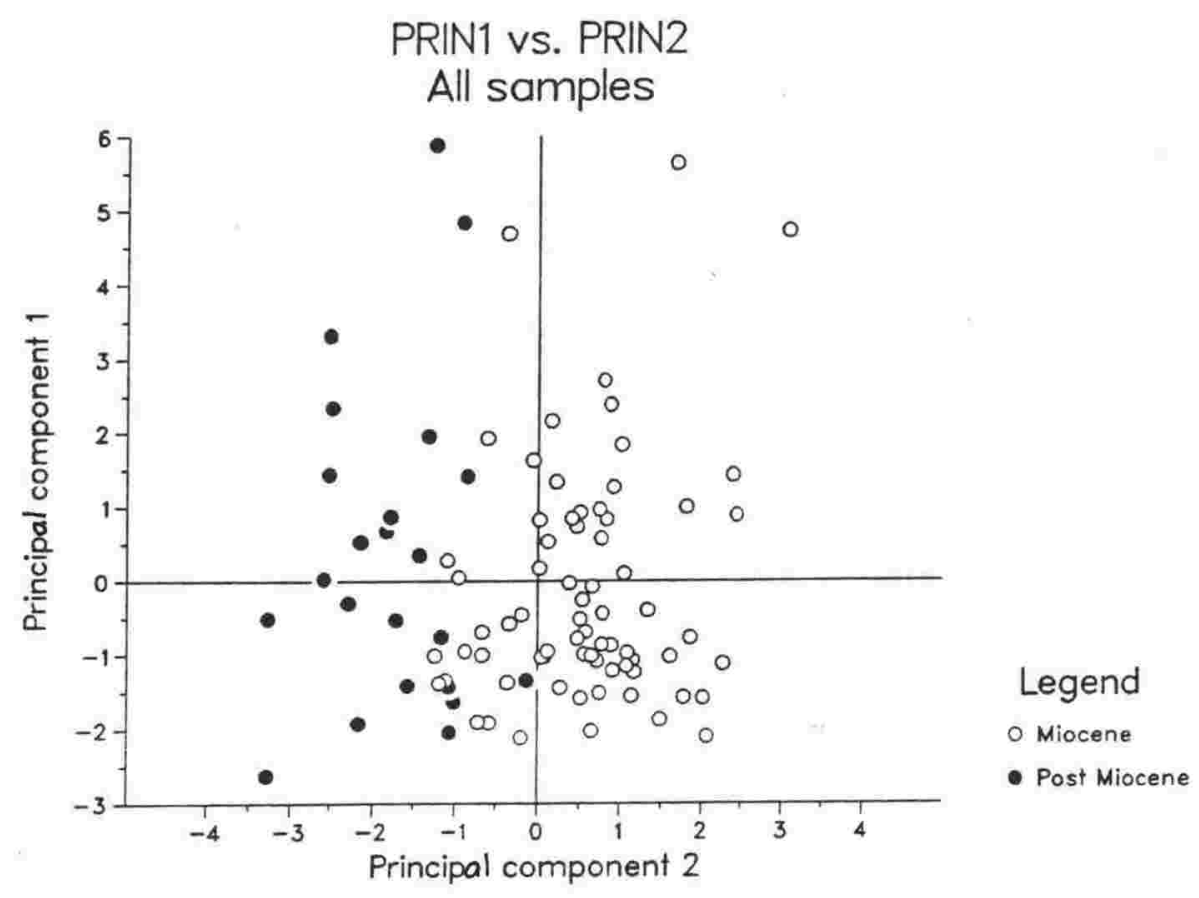

\section{Table 5.2}

Full radiolarian data set ( 94 samples) : eigenvalues for the twelve principal components in 13 dimensional space.

Eigenvalue Proportion Cumulative

$\begin{array}{lrrr} & \text { Eigenvalue } & \text { Proportion } & \text { Cumulativ } \\ \text { PRIN1 } & 3.11 & 23.94 & 23.94 \\ \text { PRIN2 } & 1.82 & 14.01 & 37.95 \\ \text { PRIN3 } & 1.76 & 13.55 & 51.50 \\ \text { PRIN4 } & 1.30 & 10.01 & 61.51 \\ \text { PRIN5 } & 1.01 & 7.78 & 69.29 \\ \text { PRIN6 } & 0.88 & 6.77 & 76.06 \\ \text { PRIN7 } & 0.74 & 5.70 & 81.76 \\ \text { PRIN8 } & 0.65 & 5.00 & 86.76 \\ \text { PRIN9 } & 0.58 & 4.46 & 91.22 \\ \text { PRIN10 } & 0.44 & 3.39 & 94.61 \\ \text { PRIN11 } & 0.41 & 3.16 & 97.77 \\ \text { PRIN12 } & 0.29 & 2.23 & 100.00\end{array}$

Table 5.3

Full radiolarian data set ( 94 samples) : values of the first four principle components for each of the variables in the data set.

ACTINS
HEXACO
THECOS
CENOSP
PRUNUM
STYLOS
PROFUN
VALIDI
PORODI
SGLACI
CARPOS
STICHS
ARTOST

$\begin{array}{rrrr}\text { PRIN1 } & \text { PRIN2 } & \text { PRIN3 } & \text { PRIN4 } \\ 0.33 & -0.29 & -0.33 & -0.10 \\ 0.35 & 0.14 & -0.14 & 0.47 \\ 0.24 & 0.00 & 0.35 & -0.19 \\ 0.39 & 0.04 & 0.29 & -0.10 \\ 0.13 & 0.05 & 0.47 & -0.15 \\ 0.38 & -0.13 & -0.29 & -0.12 \\ -0.31 & -0.32 & -0.04 & 0.12 \\ -0.18 & -0.07 & 0.20 & 0.65 \\ -0.40 & 0.12 & 0.02 & -0.24 \\ -0.18 & -0.46 & 0.19 & 0.06 \\ 0.05 & 0.54 & 0.28 & 0.20 \\ -0.25 & 0.41 & -0.24 & -0.31 \\ -0.01 & 0.30 & -0.39 & 0.23\end{array}$

$\begin{array}{ll}\text { ACTINS } & =\text { Actinomme spp. } \\ \text { HEXACO } & =\text { Hexacontium spp. } \\ \text { THECOS } & =\text { Thecosphaera spp. } \\ \text { CENOSP } & =\text { Cenosphaera spp. } \\ \text { PRUNUM } & =\text { Prunulum spp. } \\ \text { STYLOS } & =\text { Stylosphaerids } \\ \text { PROFUN } & =\text { Dictyocoryne and Hymeniastrum spp. } \\ \text { VALIDI } & =\text { Stylodictya spp. } \\ \text { PORODI } & =\text { Porodiscus spp. } \\ \text { SGLACI } & =\text { Spongotrochus glacialis } \\ \text { CARPOS } & =\text { Carpocaniidae } \\ \text { STICHS } & =\text { Cyrtocapsella and Stichocorys spp. } \\ \text { ARTOST } & =\text { Artostrobidae }\end{array}$


miscounting a specimen at the $2 \%$ level is too large (an extra one specimen at this level introduces a $17 \%$ change in that variables abundance). This reduced the data set to 13 variables. The main aim of the statistical work was to look for any sample variation using the 13 major faunal elements. Three samples were removed from the data set because radiolarian biozones could not initially be determined for the samples. Since the statistical work was completed one sample (SMA3) has been re-examined and assigned to the Didymocyrtis sp. A Zone.

\subsubsection{Principal components}

Principal components is a multivariate statistical technique which examines the relationships within a multidimensional set of data, the purpose being to derive a small number of linear combinations (principal components) that retain as much of the information in the original variables as possible. With a data "cloud" in n-dimensional space the best position axes for that "cloud" are obtained by computing the characteristic values (eigenvalues) and vectors (eigenvectors) of a covariance matrix or a correlation matrix from the data set. In this investigation the latter matrix was used. The first principal component corresponds to the axis with the largest amount of variance, and the remaining are ranked in order of decreasing values. In this form of analysis the principal components are always orthogonal. This analysis on the reduced data set defined a distinct difference between Miocene and post-Miocene faunas. The relatively low percentage of variance taken up by the first principal component (23.9\%) (see table 5.2 ) and the first three eigenvalues only absorbing $51 \%$ of the total variance indicates that the data "cloud" is quite "spherical" (in 13-dimensional space). From the graph of principal component 1 (PRIN1) versus principal component 2 (PRIN2) (see figure 5.10) it is obvious that the value of PRIN2 is "doing the work" in separating the data set and PRIN1 appears to reflect the general relationships among the variables with relatively high variation $(> \pm 0.3)$ for six of the variables (see table 5.3). PRIN2 has high variation for four variables: Dictyocoryne and Hymeniastrum spp., Stichocorys and Cyrtocapsella spp., Spongotrochus glacialis, and the Carpocaniidae. It is interesting to note that of these four the first two have definite warm-water affinities and the third a definite cold water. It appears, therefore, as though climatic difference is the major factor in controlling the faunal change. The data set was then split into two, Miocene and post-Miocene, and each had principal components run separately. Within each "epoch" principal component analysis could not distinguish differences in faunal makeup between each radiolarian biozone (see figures 5.11 and 5.12). 
Figure 5.11

PRIN1 vs. PRIN2

Miocene samples

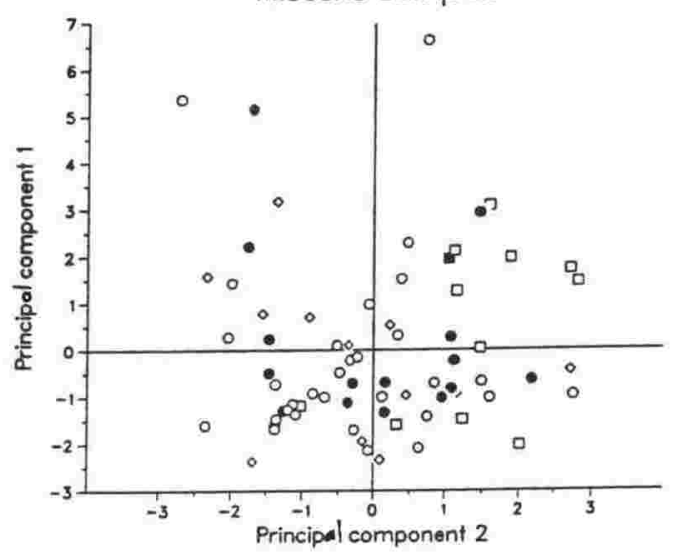

Figure 5.13

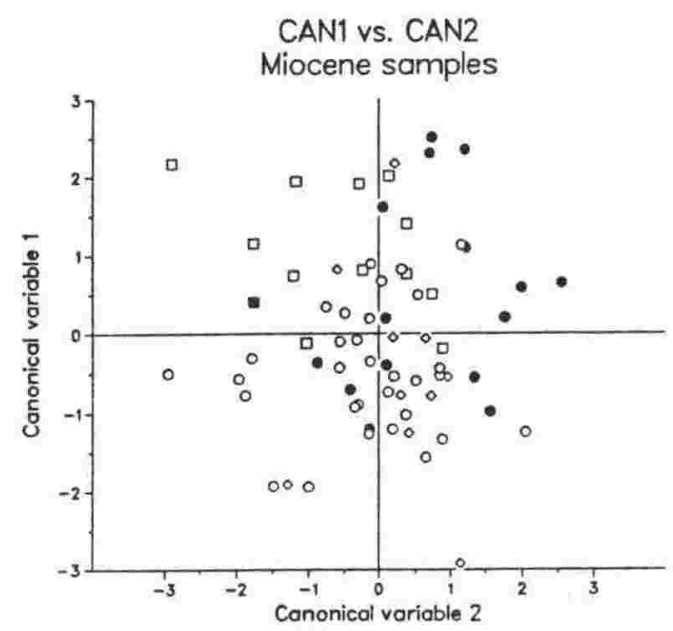

Figure 5.12

PRIN1 vs. PRIN2

Post Miocene samples

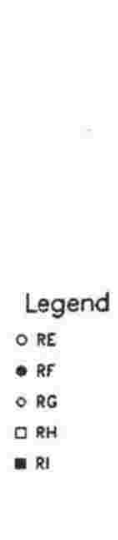

Figure 5.14

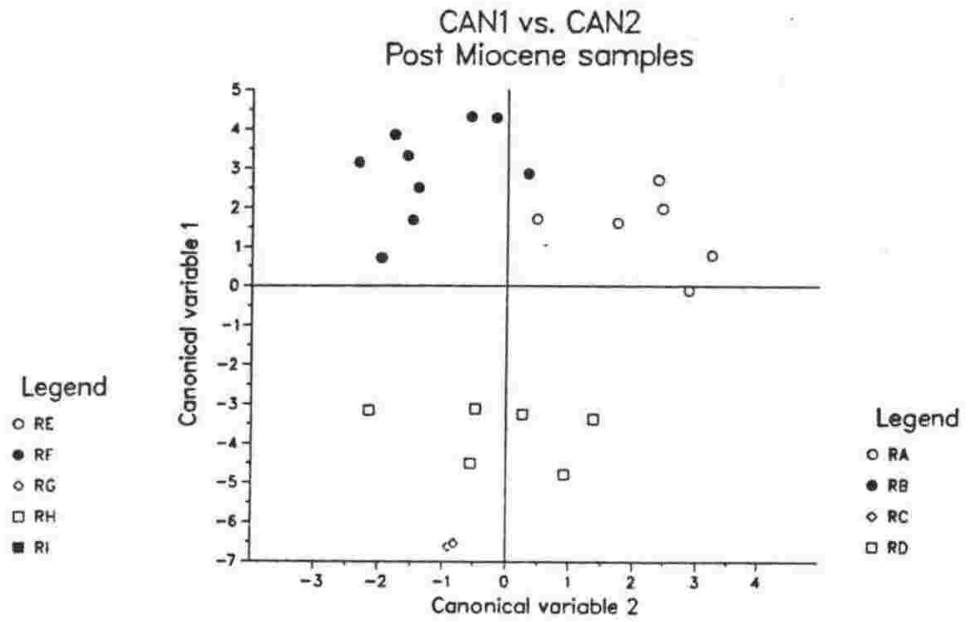

\footnotetext{
$\mathrm{RA}=$ Lamprocyclas gamphonycha Zone

$\mathrm{RB}=$ Lamprocyrtis heteroporos Zone

$\mathrm{RC} \quad=$ Lamprocyrtis hannai Subzone

$\mathrm{RD}=$ Lychnocarium sp. aff. grande Subzone MIOCENE/PLIOCENE BOUNDARY

$\mathrm{RE} \quad=$ Didymocyrtis sp. A Zone

$\mathrm{RF} \quad=$ Anthocyrtidium ehrenbergi pliocenica Subzone

RG = Heliodiscus asteriscus forma large pores Subzone

$\mathrm{RH}=$ Didymocyrtis laticonus Subzone

RI = Heliodiscus umbonatum Subzone
} 


\subsubsection{Canonical discriminants}

Canonical discriminant analysis was run on each of the two "epoch" data sets to see if it could distinguish any differences between the biozones. Canonical discriminant is another dimension reduction technique which finds a small number of linear combinations from each set of variables that have the highest possible between-set correlation. These canonical variables would best summarise the differences (if any) between the radiolarian biozones in much the same way as principal components summarise the total variation. These canonical variables are not necessarily orthogonal. This analysis failed to separate the biozones from within the Miocene (figure 5.13) but separated the post-Miocene biozones (figure 5.14) very well. With the post-Miocene samples the Lamprocyclas gamphonycha and Lamprocyrtis heteroporos Zones were separated from the Didymocyrtis tetrathalmus tetrathalmus Zone. This separation was caused by high variance for CAN1 $(> \pm 0.5)$ in the total canonical structure (see table 5.4) for Actinomma spp., Stylodictya spp., and Stichocorys and Cyrtocapsella spp., while the first two zones were separated by high variance in CAN2 for the Stylophaerids $(+0.53)$ and the variance on the Dictyocoryne and Hymeniastrum spp. group (- 0.49) would have had a marked effect.

\subsubsection{Graphical technique}

The previously mentioned variance is well shown graphically by a simple bar chart (figure 5.15) noting the variance in the mean for each radiolarian biozone from a "standard" fauna (in this case an average Miocene fauna). Obvious changes in faunal makeup take place between the Lychnocanium sp. aff. grande Subzone (basal Pliocene) and the Didymocyrtis sp. A Zone (upper Miocene) The variance between the Didymocyrtis laticonus Subzone and the Heliodiscus umbonatum Subzone is artificial as the mean of the Heliodiscus umbonatum. Subzone is based on only one sample and is not statistically comparable.

\subsubsection{Discriminant analysis}

Discriminant function analysis is made whereby an observation is classified assuming a multivariate normal distribution within each class (in this case radiolarian biozone) by computing linear or quadratic functions for classifying the observations into groups. Each observation can then be placed into the class from which it has the smallest generalised squared distance. Of the 94 samples studied only six were misclassified across the Miocene/Pliocene boundary (see table 5.5). Misclassification was common in Miocene samples but with post-Miocene samples only four of the 23 were misclassified indicating the time variance in the radiolarian faunas as previously shown. 
Post-Miocene data set (23 samples) : values of the first three canonical variables for each of the variables in the data set.

$\begin{array}{lrrrrll} & \text { CAN1 } & \text { CAN2 } & \text { CAN3 } & & \\ \text { ACTINS } & 0.55 & 0.06 & 0.01 & \text { ACTINS } & =\text { Actinomma spp. } \\ \text { HEXACO } & 0.36 & 0.18 & -0.10 & \text { HEXACO } & =\text { Hexacontium spp. } \\ \text { THECOS } & 0.31 & -0.25 & 0.28 & \text { THECOS } & =\text { Thecosphaera spp. } \\ \text { CENOSP } & 0.10 & 0.39 & -0.04 & \text { CENOSP } & =\text { Cenosphaera spp. } \\ \text { PRUNUM } & -0.18 & -0.14 & -0.07 & \text { PRUNUM } & =\text { Prunulum spp. } \\ \text { STYLOS } & 0.28 & 0.53 & -0.18 & \text { STYLOS } & =\text { Stylosphaerids } \\ \text { PROFUN } & -0.07 & -0.49 & 0.29 & \text { PROFUN } & =\text { Dictyocoryne } \text { and } \text { Hymeniastrum spp. } \\ \text { VALIDI } & -0.56 & -0.26 & 0.06 & \text { VALIDI } & =\text { Stylodictya spp. } \\ \text { PORODI } & -0.04 & -0.17 & -0.21 & \text { PORODI } & =\text { Porodiscus spp. } \\ \text { SGLACI } & -0.33 & 0.03 & 0.27 & \text { SGLACI } & =\text { Spongotrochus glacialis } \\ \text { CARPOS } & 0.34 & -0.18 & 0.51 & \text { CARPOS } & =\text { Carpocaniidae } \\ \text { STICHS } & -0.56 & -0.12 & 0.03 & \text { STICHS } & =\text { Cyrtocapsella and Stichocorys spp. } \\ \text { ARTOST } & 0.34 & -0.31 & -0.49 & \text { ARTOST } & =\text { Artostrobidae }\end{array}$

\section{Figure 5.15}

Bar chart indicating the variance in the 13 major radiolarian faunal elements between each radiolarian biozone. The variance shown is the ratio of the mean fauna for each radiolarian biozone against a standard fauna (in this case the mean Miocene fauna). As the ratio approaches 1 (the horizontal line), less variation is indicated.

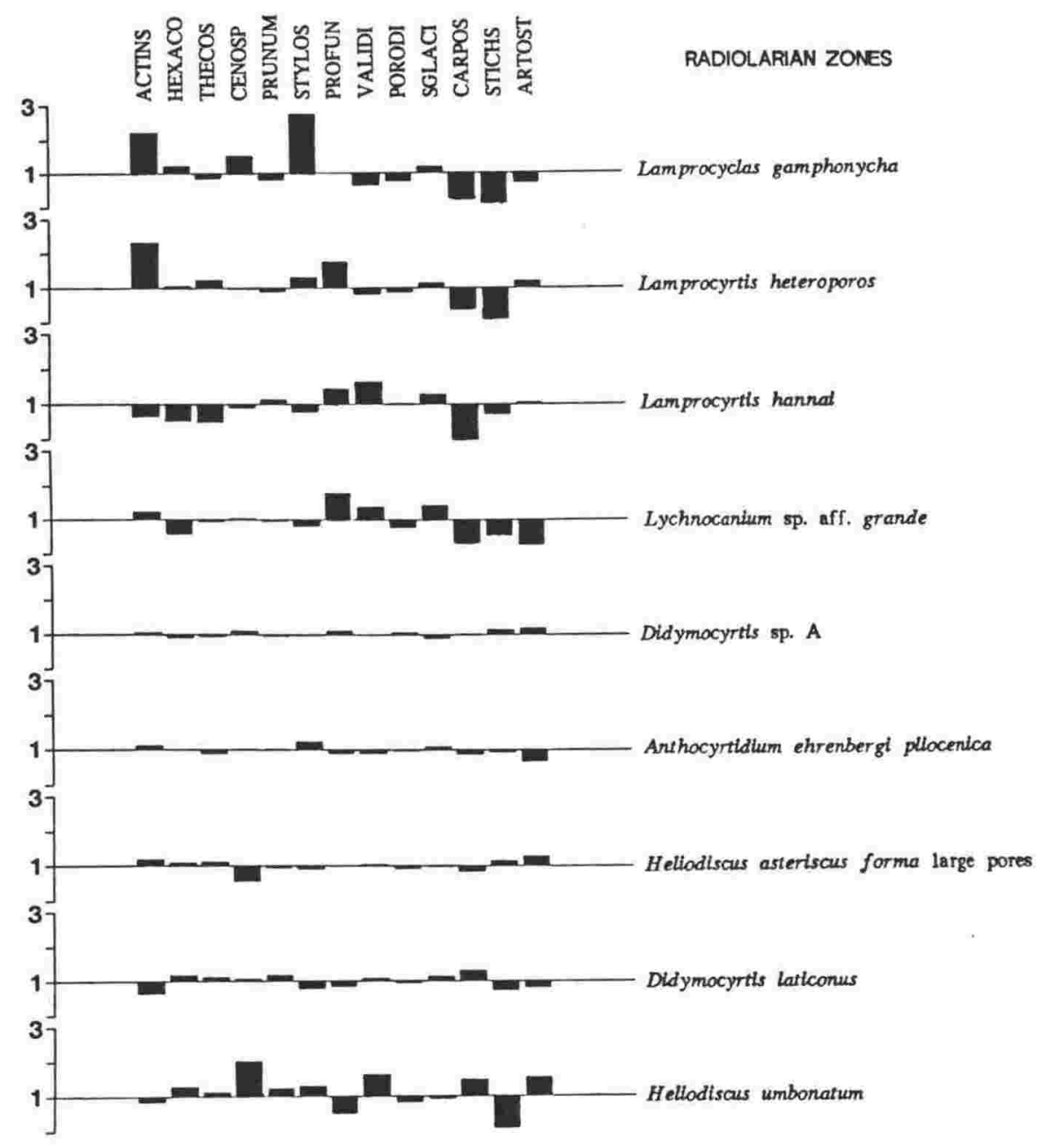




\subsubsection{Statistical summary}

In conclusion, statistical faunal analysis shows that during the Miocene there was not much change in the radiolarian faunas with time and a major change, probably climatically controlled, took place across the Miocene/Pliocene boundary. Variability in preservation has probably affected the faunas to obscure more precise time variation although post-Miocene faunas indicate that some is present.

\section{Table 5.5}

Full radiolarian data set (94 samples) : Discriminant analysis.

Classification of samples into radiolarian biozones from the biozones determined using presence or absence data.

To rad biozone

\begin{tabular}{|c|c|c|c|c|c|c|c|c|c|c|}
\hline & RA & RB & $\mathrm{RC}$ & $\mathrm{RD}$ & $\mathrm{RE}$ & $\mathrm{RF}$ & RG & $\mathrm{RH}$ & RI & TOTAL \\
\hline RA & 5 & 1 & . & . & . & . & . & . & . & 6 \\
\hline $\mathrm{RB}$ & . & 9 & . & . & . & . & . & . & . & 9 \\
\hline $\mathrm{RC}$ & . & . & 1 & 1 & . & . & . & . & . & 2 \\
\hline $\mathrm{RD}$ & . & . & 1 & 4 & 1 & . & . & . & . & 6 \\
\hline $\mathrm{RE}$ & . & . & 1 & . & 16 & 4 & 7 & 3 & . & 31 \\
\hline $\mathrm{RF}$ & . & . & . & 1 & 4 & 7 & 1 & 2 & . & 15 \\
\hline RG & . & 2 & . & . & 1 & 1 & 7 & 1 & . & 12 \\
\hline $\mathrm{RH}$ & . & . & 1 & . & 2 & 3 & 1 & 5 & . & 12 \\
\hline RI & . & . & . & . & . & . & . & 1 & . & 1 \\
\hline
\end{tabular}

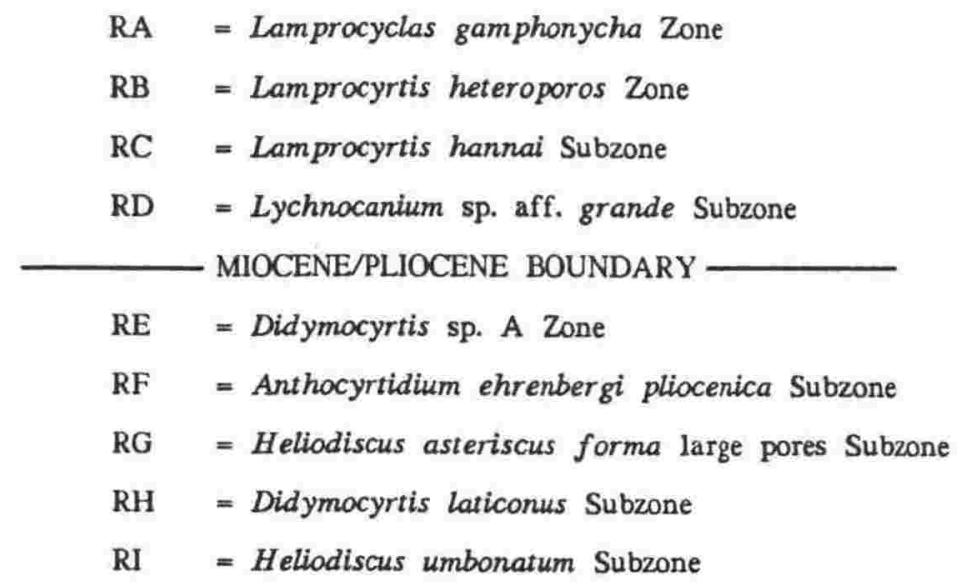




\section{Chapter VI \\ CONCLUSION AND DIRECTION FOR FUTURE STUDIES}

This chapter contains a summary of the principal findings of this thesis in regard to the presence, taxonomy, and biostratigraphy of radiolarians from the New Zealand Late Neogene. These points are examined briefly and guidelines for future research are outlined.

\subsection{SUMMARY OF MAIN POINTS}

1. Preservation of radiolarian skeletons requires the interstitial waters in marine sediments to become close to or completely saturated in silica. This is achieved by the buffering of the interstitial waters by partial dissolution of the accumulating siliceous mass. Silica can be provided by the high input of siliceous skeletons beneath high productivity belts or an influx of abiotic silica. It is the latter factor that has enhanced the preservation of radiolarian skeletons in the East Coast Deformed Belt, the silica being deposited in the form of rhyolitic glass shards. The presence of, in places, numerous volcanic tuffs in relatively deep-water basins away from the dilutory effects of terrigenous material in shallow water sequences makes the East Coast Deformed Belt the best area in New Zealand for Late Neogene radiolarian studies.

2. Relatively high uplift rates have allowed deep-water, relatively continuous, Late Neogene sequences to be exposed at many places from East Cape to northern Canterbury. At some places, the sediments are radiolarian bearing and are ideal for integrated magnetostratigraphic, paleontologic, and tephrostratigraphic analysis. In terms of global radiolarian biostratigraphy these sections are very important as they are the only known on-land sections containing southern temperate, Late Neogene, radiolarian faunas.

3. Most of the 138 taxa described can be identified at generic level, but 31 morphotypes can not be assigned specific names and may eventually prove to be new species. The classification is still mainly based on the Haeckelian morphologic system although some groups are more phylogenetically assigned. 
4. Five major radiolarian zones can be recognised in the New Zealand Late Neogene with six subzones identifiable in samples with good preservation. The radiolarian zonation presented is based on detailed analysis of 155 samples from 26 sections and sites ranging in age from basal Tongaporutuan (early Late Miocene) to middle Nukumaruan (early Pleistocene). Sediments of the Kapitean (uppermost Miocene) were generally deposited in shallow water environments or are missing in unconformities in the East Coast Deformed Belt, and consequently the radiolarian zonation is based on very poor data in this time segment. Also upper Opoitian and Waipipian (middle Pliocene) sediments, although in places deposited in relatively deep water, generally lack siliceous tuffs so that radiolarian preservation is poor. The zones are well correlated to the detailed planktic foraminiferal biostratigraphy and real ages can be estimated for the zone boundaries.

5. The correlation to radiolarian zonations from other parts of the globe raises a number of interesting points:

a. In New Zealand, $S$. peregrina morphotypes occur with Globoquadrina dehiscens in basal Tongaporutuan (basal upper Miocene) strata and $S$. delmontense morphotypes occur as high as the LAD of Cibicides molestus (middle Pliocene), indicating a very long overlap zone. $S$. peregrina is found in the youngest samples studied (lower Pleistocene). There is no clear dominance of one morphotype over another from at least the LAD of Globoquadrina dehiscens to the FAD of Globorotalia inflata (a period of $5.5 \mathrm{Ma}$ ). The range of $S$. peregrina in New Zealand is at least $10 \mathrm{Ma}$ to $2 \mathrm{Ma}$. This indicates, along with the presence of a single specimen of Spongaster pentas in upper Tongaporutuan (late upper Miocene) sediments, some provincialism in the tropical radiolarian zonation.

b. The evolution of Lamprocyclas gamphonycha from Lamprocyrtis heteroporos is well defined in the Waiatai Valley Section and occurs very near the top of the Globorotalia crassula - dextral Globorotalia crassaformis overlap zone which is dated at 2.0Ma (Edwards, 1985). The transition to $L$. gamphonycha appears to be an isochronous datum level in temperate radiolarian faunas in the northern and the southern Pacific.

c. In New Zealand the LAD of members of the Diartus hughesi group falls within Epoch 7. This is in good agreement with levels determined in tropical Pacific cores. However, the Antarctic T "b" Subzone of Bandy, Casey, and Wright (1971) is defined 


\section{SAMPLE SUMMARY}

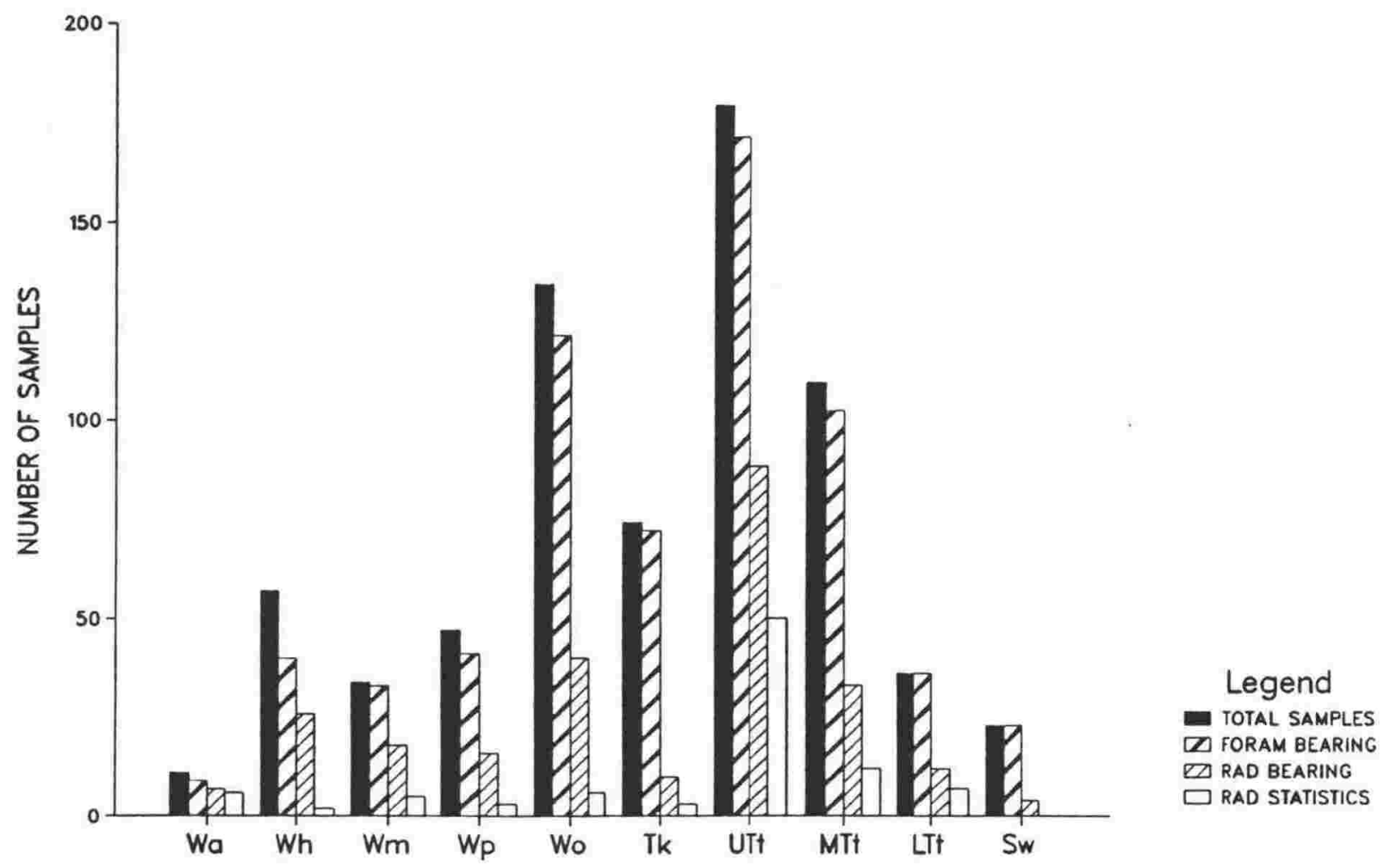

Figure 6.1

Bar chart indicating the number of possible radiolarian bearing samples looked at for each of the time intervals covered in this study. Of the samples, normally $90-100 \%$ contain foraminifera but generally only $50 \%$ contain Radiolaria. Of the radiolarian bearing samples only a small proportion of the faunas are well enough preserved for statistical analysis. 
by the presence of this taxon and was paleomagnetically dated at middle Gilbert. The implied magnitude of the diachroneity in the LAD of D. hughesi between tropical/temperate and Antarctic sediments is unacceptably large. A more likely explanation is that the paleomagnetic interpretation for the lower parts of E-14-08 and E-13-17 (on which the subzone is based) is wrong and there is a substantial time break in both cores. There is other evidence to suggest that that is the case. Thus the $\mathrm{T}$ " $\mathrm{b}$ " Subzone is herein suggested to be significantly older than previously thought, but the amount of time missing is hard to determine. As more unconformities in southern ocean deep-sea cores are discovered (e.g. Watkins and Kennett, 1972; Keany and Kennett, 1975; Kennett and Watkins, 1976; Ledbetter et al., 1983) the continuity of a number of the deep-sea reference cores must be questioned. The older paleomagnetic correlation postulated in this case has serious implications for the "preupper Gilbert" paleomagnetically determined real age estimates for the southern ocean diatom stratigraphy (McCollum, 1975) and silicoflagellate stratigraphy (Ciesielski, 1975) as they are essentially based on the paleomagnetic interpretation of E-14-08 and E-13-17.

7. Statistical faunal analysis shows that during the Miocene there was not much change in the radiolarian faunas with time and a major change, probably climatically controlled, took place across the Miocene/Pliocene boundary. Variability in preservation has probably affected the faunas to obscure smaller variations with time, but post-Miocene faunas indicate that some variation is present.

8. The Radiolaria, although not as common in the fossil record as the foraminifera (see figure 6.1), definitely contribute to New Zealand Late Neogene integrated stratigraphy and suggest that our knowledge could be further enhanced by the study of other siliceous microfossil groups.

\subsection{DIRECTIONS FOR FUTURE RESEARCH}

I conclude this thesis in the hope that the data presented here may act as a stimulus to future radiolarian biostratigraphic research, particularly in an integrated system using the many paleontologic, isotopic, radiometric, and paleomagnetic techniques now available. The first approach would best be the analysis of the diatom stratigraphy from the sequences 
studied. Large members of this fossil group were encountered in many of the samples studied and assuming that smaller forms are also preserved, a wealth of biostratigraphic information is present. Analysis of this group in the New Zealand sequences now seems essential to try to check the real age estimates of the Antarctic zonation which appear to be wrong. The information to be gained from this exercise could be comparable to that obtained from additional piston cores in the southern ocean. Secondly, enhancement of the zonation presented could be made in two ways : by extending the zonation into older (and if possible younger) on-land sequences and by better defining the zonal boundaries and other radiolarian bioevents. The integrated stratigraphic approach that must be made in all these suggestions can not be stressed enough. 


\section{REFERENCES}

ALLAN, R.S. 1933 : On the system and stage names applied to subdivisions of the Tertiary strata in New Zealand. Transactions of the New Zealand Institute 63 (2) : 81-108.

ANDERSON, O.R. 1976a : Ultrastructure of a colonial radiolarian Collozoum inerme and a cytochemical determination of the role of its zooxanthellae. Tissue and Cell 8 (2) : 195-208.

ANDERSON, O.R. 1976b : Fine structure of a collodarian radiolarian (Sphaerozoum punctatum Muller 1858) and cytoplasmic changes during reproduction. Marine Micropaleontology 1 : 287-297.

ANDERSON, O.R. 1976c : A cytoplasmic fine-structure study of two spumellarian Radiolaria and their symbionts. Marine Micropaleontology 1 : 81-99.

ANDERSON, O.R. 1977 : Cytoplasmic fine structure of nassellarian Radiolaria. Marine Micropaleontology 2 : 251-264.

ANDERSON, O.R. 1978a : Light and electron microscope observations of feeding behavior, nutrition, and reproduction in laboratory cultures of Thalassicolla nucleata. Tissue and Cell 10 (3) : 401-412.

ANDERSON, O.R. 1978b : Fine structure of a symbiont-bearing colonial radiolarian, Collosphaera globularis, and ${ }^{14} \mathrm{C}$ isotopic evidence for assimilation of organic substances from its zooxanthellae. Journal of Ultrastructure Research 62 : 181-189.

ANDREWS, J.E., PACKHAM, G., EADE, J.V. et al. 1975a : Site 285. in : Andrews, J.E., Packham, G. et al. (eds.), Initial Reports of the Deep Sea Drilling Project, Volume 30, United States Government Printing Office, Washington, pp 27-56.

ANDREWS, J.E., PACKHAM, G., EADE, J.V. et al. 1975b : Site 288. in : Andrews, J.E., Packham, G. et al. (eds.), Initial Reports of the Deep Sea Drilling Project, Volume 30, United States Government Printing Office, Washington, pp 175-230.

ANDREWS, J.E., PACKHAM, G., EADE, J.V. et al. 1975c : Site 289. in : Andrews, J.E., Packham, G. et al. (eds.), Initial Reports of the Deep Sea Drilling Project, Volume 30, United States Government Printing Office, Washington, pp 231-398.

ANDREWS, P.B. 1982 : Revised guide for recording field observations in sedimentary sequences. New Zealand Geological Survey Report 102, 74pp.

ARRHENIUS, G.O.S. 1963 : Pelagic sedimentation. in : Hill, W.M.N. (ed.), The Sea :

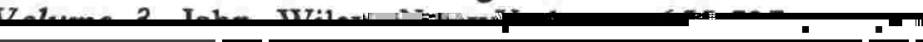


ASHBY, J.N. 1978 : Plio-Pleistocene geology of an area north of Longbush, Wairarapa. Unpublished BSc. Honours Project, Victoria University of Wellington Geology Library. 94pp.

ASHBY, J.N. 1983 : Improvements in the technique for the extraction and statistical faunal analysis of radiolarians from Neogene mudstones. Micropaleontology 29 (2) : 146-149.

ASHBY, J.N. 1985 : Upper Neogene radiolarian zonation for the East Coast Deformed Belt, New Zealand. in : Cooper, R. (ed.), Hornibrook Symposium, 3-5 December 1985, Christchurch, New Zealand : extended abstracts, New Zealand Geological Survey Record $9: 5-7$.

BACHMANN, A. 1961 : Methoden zur praparation fossiler mikroorganismen. Sonderdruck aus Erdoel-Zeitschrift 10 : 489-495.

BACHMANN, A., PAPP, A., and STRADNER, H. 1963 : Mikropalaontologische studien im "Badener Tegel" von Frattingsdorf N.O.. Sonderdruck aus Mitteilungen der Geologischen Gesellschaft in Wien 56 (1) : 117-210.

BAILEY, J.W. 1856 : Notice of microscopic forms found in the soundings of the Sea of Kamtschatka. American Journal of Science. Arts. series 2, volume 22 : 1-6.

BAKER, W.H.V. 1951 : A simple technique for extracting microfossils. The Micropaleontologist 5 (4) : 39-40.

BANDY, O.L. 1968 : Paleoclimatology and Neogene planktonic foraminiferal zonation. Giornale di Geologia 35 (2) : 277-290.

BANDY, O.L. 1968 : Cycles in Neogene paleoceanography and eustatic changes. Palaeogeography, Palaeoclimatology, Palaeoecology 5 : 63-75.

BANDY, O.L. 1975 : Messinian evaporite deposition and the Miocene/Pliocene boundary, Pasquasia-Capodarso sections, Sicily. in : Saito, T., Burckle, L.H. (eds.), Late Neogene Epoch Boundaries, Micropaleontology Special Publication 1, Micropaleontology Press, New York, pp 49-63.

BANDY, O.L. and CASEY, R.E. 1969 : Major Late Cenozoic planktonic datum planes, Antarctica to the tropics. Antarctic Journal of the United States 4 (5) : 170-171.

BANDY, O.L. and CASEY, R.E. 1970 : Late Cenozoic paleoclimatic cycles, Antarctica to the tropics, 1970. Antarctic Journal of the United States 5 (5): 177-178.

BANDY, O.L. and CASEY, R.E. 1972 : Major Quaternary Palaeoceanographic cycles : Antarctic to the tropics. in : Adie, R.J. (ed.), Antarctic Geology and Geophysics, IUGS Series B. No. 1, Universitetsforlaget, Oslo, pp 739-744.

BANDY, O.L., CASEY, R.E., and WRIGHT, R.C. 1971 : Late Neogene planktonic zonation, magnetic reversals and radiometric dates, Antarctic to the tropics. in : Reid, J.L. (ed.), Biology of the Antarctic Seas IV, Antarctic Research Series 15, American Geophysical Union, Washington, pp 1-26.

BANDY, O.L. and ECHOLS, RJ. 1964 : Antarctic foraminiferal zonation. in : Biology of the Antarctic Seas, Antarctic Research Series 1, American Geophysical Union, Washington, pp 73-91.

BANDY, O.L. and INGLE, J.C. 1970 : Neogene planktonic events and radiometric scale, California. in : Bandy, O.L. (ed.), Radiometric Dating and Paleontologic Zonation, Geological Society of America Special Paper 124, pp 131-172. 
BANDY, O.L. and WADE, M.E. 1967 : Miocene-Pliocene-Pleistocene boundaries in deepwater environments. in : Progress in Oceanography. Volume 4 - The Quaternary History of the Ocean Basins, Pergamon, Oxford, pp 51-66.

BARKER, D.S. 1983 : Igneous Rocks, Prentice-Hall, Englewood Cliffs, N.J., 417pp.

BARNARD, W.D. and McMANUS, D.A. 1973 : Planktonic foraminiferan-radiolarian stratigraphy and the Pleistocene-Holocene boundary in the northeast Pacific. Geological Society of America Bulletin $84: 2097-2100$.

BARRETT, P.J., PYNE, A.R., GOSSON, G., and ADAMS, C.J. 1985 : Late Cenozoic glacial sequence cored at Ciros-2, Ferrar Fjord, western McMurdo Sound. in : Abstracts from the workshop on Cenozoic Geology of the southern high latitudes, August 16-17, 1985. Sixth Gondwana Symposium, Ohio State University.

BARRON, J.A. and INGLE, J.C. 1978 : Neogene section at the Mission Hills. in : Addicott, W.O. (ed.), Neogene Biostratigraphy of selected areas in the California Coast Ranges, Field Conference on the Marine Neogene of California, International Geological Correlation Programme (IGCP), Project 114, Biostratigraphic Datum-planes of the Pacific Neogene, June 21-24, 1978. United States Geological Survey Open-file Report 78-446, pp 29-35.

BARRON, J.A., VON HUENE, R., and NASU, N. 1978 : Correlation of high and low latitude upper Miocene diatom datum levels at DSDP Site 438 in the northwest Pacific. in : Correlation of tropical through high latitude marine Neogene deposits of the Pacific Basin, International Geological Correlation Programme (IGCP), Project 114, Biostratigraphic Datum-planes of the Pacific Neogene, Third Working Group Meeting - Abstracts and Program, Stanford University Publications, Geological Sciences Volume 14, pp 5-7.

BARWICZ-PISKORZ 1978 : The Miocene Radiolaria from the Carpathian foredeep. Acta palaeontologica Polinca 23 (3) : 223-248.

BATES, T.E. 1967 : The geology of the northern Aorangi Range and part of Palliser Bay, Sheet N165. Unpublished MSc thesis, Victoria University of Wellington.

BAYLISS, D.D. 1975 : The stratigraphy of the type section for the Pliocene/Pleistocene boundary in Italy. in : Saito, T., Burckle, L.H. (eds.), Late Neogene Epoch Boundaries, Micropaleontology Special Publication 1, Micropaleontology Press, New York, pp 31-40.

BEERS, J.R. and STEWART, G.L. 1971 : Micro-zooplankters in the plankton communities of the upper waters of the eastern tropical Pacific. Deep-Sea Research $18: 861-883$.

BENSON, R.N. 1966 : Recent Radiolaria from the Gulf of California. Unpublished $\mathrm{PhD}$ thesis, Minnesota University, 577p.

BENSON, R.N. 1972 : Radiolaria, Leg 12, Deep Sea Drilling Project. in : Laughton, A.S., Berggren, W.A. (eds.), Initial Reports of the Deep Sea Drilling Project, Volume 12, United States Government Printing Office, Washington, pp 1085-1113.

BERGER, W.H. 1968 : Radiolarian skeletons : solution at depths. Science 159 : 1237-1238.

BERGER, W.H. 1970 : Biogenous deep-sea sediments : Fractionation by deep-sea circulation. Geological Society of America Bulletin 81 : 1385-1402. 
BERGER, W.H. 1976 : Biogenous deep-sea sediments : production, preservation, and interpretation. in : Riley, J.P., Chester.R. (eds.), Treatise on Chemical Oceanography, Volume 5, Academic Press, New York, pp 265-388.

BERGER, W.H. and WINTERER, E.L. 1974 : Plate stratigraphy and the fluctuating carbonate line. in : Jenkyns, H.C., Hsu, K.J. (eds.), Pelagic Sediments : On land and under the sea, Special Publication of the International Association of Sedimentologists 1, Blackwell, Oxford, pp 11-48.

BERGGREN, W.A. 1969 : Cenozoic chronostratigraphy, planktonic foraminiferal zonation and the radiometric time scale. Nature 224 (5224): 1072-1075.

BERGGREN, W.A. 1971 : Tertiary boundaries and correlations. in : Funnell, B.M., Riedel, W.R. (eds.), The Micropaleontology of the Oceans, Cambridge University Press, pp 693-808.

BERGGREN, W.A. 1972a : A Cenozoic time-scale - some implications for regional geology and paleobiogeography. Lethaia 5 : 195-215.

BERGGREN, W.A. 1972b : Cenozoic biostratigraphy and paleobiogeography of the north Atlantic. in : Laughton, A.S., Berggren, W.A. et al. (eds.), Initial Reports of the Deep Sea Drilling Project, Volume 12, United States Government Printing Office, Washington, pp 965-975.

BERGGREN, W.A. 1981 : Correlation of Atlantic, Mediterranean and Indo-Pacific Neogene stratigraphies : Geochronology and Chronostratigraphy. in : Proceedings of International Geological Correlation Programme (IGCP) 114, 6th Working Group on Pacific Neogene Biostratigraphy, November 25-29, 1981, Osaka, pp 29-60.

BERGGREN, W.A. 1984 : Correlation of Atlantic, Mediterranean, and Indo-Pacific Neogene stratigraphies : Geochronology and Chronostratigraphy. in : Ikebe, N. and Tsuchi, R. (eds.), Pacific Neogene Datum Planes : contributions to biostratigraphy and chronology, University of Tokyo Press, Tokyo, pp 93-110.

BERGGREN, W.A., BENSON, R.N., HAQ, B.U. et al. 1976 : The El Cuervo Section (Andalusia, Spain) : Micropaleontological anatomy of an early Late Miocene lower bathyal deposit. Marine Micropaleontology 1 : 195-247.

BERGGREN, W.A., BURCKLE, L.H., CITA, M.B. et al. 1980 : Towards a Quaternary time scale. Quaternary Research 13 (3) : 277-302.

BERGGREN, W.A., KENT, D.V., FLYNN, J.J., and VAN COUVERING, J.A. 1985 : Cenozoic geochronology. Geological Society of America Bulletin 96 : 1407-1418.

BERGGREN, W.A. and VAN COUVERING, J.A. 1974 : The Late Neogene. Biostratigraphy, geochronology, and paleoclimatology of the last 15 million years in marine and continental sequences. Palaeogeography, Palaeoclimatology, Palaeoecology $16(1 / 2): 1-216$.

BERRY, J.D. 1972 : Some aspects of Pliocene-Pleistocene geology of the KourarauWestmere new road cutting, Wairarapa. Unpublished BSc (Hons) project, Victoria University of Wellington.

BEU, A.G. 1969 : Index macrofossils and New Zealand Pliocene and lower Pleistocene time stratigraphy. New Zealand Journal of Geology and Geophysics 12 (4): 643-658.

BEU, A.G. 1970 : Bathyal upper Miocene mollusca from Wairarapa District, New Zealand. Transactions of the Royal Society of New Zealand - Earth Sciences 7 (12) : 209-240. 
BEU, A.G. 1974 : Molluscan evidence of warm sea temperatures in New Zealand during Kapitean (late Miocene) and Waipipian (middle Pliocene) time. New Zealand Journal of Geology and Geophysics 17 (2) : 465-479.

BEU, A.G. 1978 : Taxonomy and biostratigraphy of large New Zealand Pliocene Pectinidae (Phialopecten and Mesopeplum). New Zealand Journal of Geology and Geophysics 21 (2) : 243-269.

BEU, A.G. and EDWARDS, A.R. 1984 : New Zealand Pleistocene and late Pliocene glacio-eustatic cycles. Palaeogeography, Palaeoclimatology, Palaeoecology 46 : 119-142.

BEU, A.G., GRANT-TAYLOR, T.L., and HORNIBROOK, N.de B. 1977 : Nukumaruan records of the subantarctic scallop Chlamys delicatula and crab Jacquinotia edwardsii in central Hawkes Bay. New Zealand Journal of Geology and Geophysics 20 (2) : 217-248.

BEU, A.G., GRANT-TAYLOR, T.L., and HORNIBROOK, N.de B. 1980 : The Te Aute Limestone facies, Poverty Bay to northern Wairarapa. 1:250, 000 New Zealand Geological Survey Miscellaneous Series Map 13 (2 sheets) and notes (36pp). New Zealand Department of Scientific and Industrial Research, Wellington.

BIEN, G.S., CONTOIS, D.E., and THOMAS, W.H. 1959 : The removal of soluble silica from fresh water entering the sea. in : Ireland, H.A. (ed.), Silica in Sediments, Society of Economic Paleontologists and Mineralogists Special Publication Number 7 : 20-35.

BJORKLUND, K.R. 1976 : Radiolaria from the Norwegian Sea, Leg 38 of the Deep Sea Drilling Project. in : Talwani, M., Udintsev, G. et al. (eds.), Initial Reports of the Deep Sea Drilling Project, Volume 38, United States Government Printing Office, Washington, pp 1101-1168.

BJORKLUND, K.R. 1977 : Actinomma haysi, n.sp. its Holocene distribution and size variation in Atlantic Ocean sediments. Micropaleontology 23 (1) : 114-126.

BJORKLUND, K.R. and GOLL, R.M. 1979 : Internal skeletal structures of Collosphaera and Trisolenia : A case of repetitive evolution in the Collosphaeridae (Radiolaria). Journal of Paleontology 53 (6) : 1293-1326.

BOLLI, H.M. and KRASHENINNIKOV, V.A. 1977 : Problems in Paleogene and Neogene correlations based on planktonic foraminifera. Micropaleontology 23 (4) : 436-452.

BOLTOVSKOY, D., KOTZIAN, S.B., and PEDROZO, F.L. 1983 : Some new techniques for the preparation and illustration of Polycystina (Radiolaria). Micropaleontology 29 (4) : 382-390.

BOLTOVSKOY, E. and RIEDEL, W.R. 1980 : Polycystine Radiolaria from the southwestern Atlantic Ocean plankton. Revista Espanola de Micropaleontologia 12 (1) : 99-146.

BRADY, H.T. 1977 : Extraction of diatoms from glacial sediments. Antarctic Journal of the United States 12 (4) : 123-124.

BRAMLETTE, M.N. 1946 : The Monterey Formation of California and the origin of its siliceous rocks. United States Geological Survey Professional Paper 212:57pp.

BRONNIMANN, P., MARTINI, E., RESIG, J. et al. 1971 : Biostratigraphic synthesis : Late Oligocene and Neogene of the western tropical Pacific. in : Winterer, E.L., Riedel, W.R. et al. (eds.), Initial Reports of the Deep Sea Drilling Project, Volume 7, United States Government Printing Office, Washington, pp 1723-1735. 
BUKRY, D. 1978 : Biostratigraphy of Cenozoic marine sediment by calcareous nannofossils. Micropaleontology 24 (1) : 44-60.

BUKRY, D., DINKELMAN, M.G., and KANEPS, A. 1973 : Biostratigraphy of the equatorial east Pacific Rise. in : van Andel, T.H., Heath, G.R. et al. (eds.), Initial Reports of the Deep Sea Drilling Project, Volume 16, United States Government Printing Office, Washington, pp 915-935.

BUNOPAS, S. 1966 : Upper Miocene-Pleistocene stratigraphy and paleontology of Gladstone, Wairarapa, New Zealand. Unpublished MSc thesis, Victoria University of Wellington, 226pp.

BURCKLE, L.H. 1971 : Correlation of late Cenozoic marine sections in Japan and the equatorial Pacific. Transactions of the Palaeontological Society of Japan, new series $82: 117-128$.

BURCKLE, L.H., GARTNER, S., OPDYKE, N.D. et al. 1978 : Paleomagnetics, oxygen isotopes and biostratigraphy of a late Pliocene section from the central Pacific. in : Correlation of tropical through high latitude marine Neogene deposits of the Pacific Basin, International Geological Correlation Programme (IGCP), Project 114, Biostratigraphic Datum-planes of the Pacific Neogene, Third Working Group Meeting - Abstracts and Program, Stanford University Publications, Geological Sciences Volume 14, pp 10-11.

BURCKLE, L.H. and TODD, A. 1976 : Correlation of Late Neogene sections on the Noto and Oga Peninsulas, Japan. in : Takayanagi, Y, Saito, T. (eds.), Progress in Micropaleontology : Selected papers in honor of Prof. Kiyoshi Asano,

Micropaleontology Special Publication, Micropaleontology Press, New York, pp 20-26.

BURMA, B.H. 1959 : On the status of Theocampe Haeckel, and certain similar genera. Micropaleontology 5 (3) : 325-330.

BURMA, B.H. 1965 : Radiolarians. in : Kummel, B. and Raup, D. (eds.), Handbook of Paleontological Techniques, W.H. Freeman, San Francisco, pp 7-14.

BURNS, R.E., ANDREWS, J.E., van der LINGEN, G.J. et al. 1973a : Site 203. in : Burns, R.E., Andrews, J.E. et al. (eds.), Initial Reports of the Deep Sea Drilling Project, Volume 21, United States Government Printing Office, Washington, pp 17-32.

BURNS, R.E., ANDREWS, J.E., van der LINGEN, G.J. et al. 1973b : Site 205. in : Burns, R.E., Andrews, J.E. et al. (eds.), Initial Reports of the Deep Sea Drilling Project, Volume 21, United States Government Printing Office, Washington, pp 57-102.

BURNS, R.E., ANDREWS, J.E., van der LINGEN, G.J. et al. 1973c : Site 206. in : Burns, R.E., Andrews, J.E. et al. (eds.), Initial Reports of the Deep Sea Drilling Project, Volume 21, United States Government Printing Office, Washington, pp 103-196.

BUTSCHLI, O. 1882a : Radiolaria. in : Bronn, H.G. (ed.), Klassen und Ordnungen des Thier-Reichs, C.F. Winter'sche Veringshandiung, Leipzig, Volume 1 (1) : 332-478.

BUTSCHLI, O. 1882b : Beitrage zur Kenntnis der Radiolarienskelette, insbesondere der der Cyrtida. Zeitschrift fur Wissenschaftliche Zoologie 36 : 485-540.

CACHON-ENJUMET, M. 1961 : Contribution a l'etude des Radiolaires Phaeodaries. Archives de zoologie experimentale et generale $100: 151-237$. 
CALVERT, S.E. 1966 : Accumulation of diatomaceous silica in the sediments of the Gulf of California. Geological Society of America Bulletin 77 : 569-596.

CALVERT, S.E. 1968 : Silica balance in the ocean and diagenesis. Nature 219 : 919-920.

CALVERT, S.E. 1974 : Deposition and diagenesis of silica in marine sediments. in : Hsu, K.J. and Jenkyns, H.C. (eds.), Pelagic Sediments on Land and under the Sea, International Association of Sedimentologists Special Publication 1, Blackwell Scientific Publications, Oxford, pp 273-299.

CAMPBELL, A.S. 1951 : New genera and subgenera of Radiolaria. Journal of Paleontology 25 (4) : 527-530.

CAMPBELL, A.S. 1954 : Radiolaria. in : Moore, R.C. (ed.), Treatise on Invertebrate Paleontology. Part D. Protista 3. Protozoa (chiefly Radiolaria and Tintinnina), University of Kansas Press, Lawrence, Kansas, pp D11-D163.

CAMPBELL, A.S. and CLARK, B.L. 1944 : Miocene radiolarian faunas from southern California. Geological Society of America Special Paper 51, 76pp.

CARNEVALE, P. 1908 : Radiolarie e silicoflagellati di Bergonzano (Reggio Emilia). Memorie del Reale Istituto Veneto di Scienze, Lettere ed Arti 28 (3) : 1-46.

CASEY, R.E. 1971a : Distribution of polycystine Radiolaria in the oceans in relation to physical and chemical conditions. in : Funnell, B.M., Riedel, W.R. (eds.), The Micropaleontology of the Oceans, Cambridge University Press, pp 151-159.

CASEY, R.E. 1971b : Radiolarians as indicators of past and present water masses. in : Funnell, B.M., Riedel, W.R. (eds.), The Micropaleontology of the Oceans, Cambridge University Press. pp 331-341.

CASEY, R.E. 1972 : Neogene radiolarian biostratigraphy and paleotemperatures : Southern California, the experimental Mohole, Antarctic core E 14-8. Palaeogeography, Palaeoclimatology, Palaeoecology 12 : 115-130.

CASEY, R.E. 1977 : The ecology and distribution of Recent Radiolaria. in : Ramsay, A.T.S. (ed.), Oceanic Micropaleontology. Volume 2, Academic Press, London, pp 809-845.

CASEY, R.E., GUST, L., LEAVESLEY, A. et al. 1979 : Ecological niches of radiolarians, planktonic foraminiferans and pteropods inferred from studies on living forms in the Gulf of Mexico and adjacent waters. Transactions of the Gulf Coast Association of Geological Societies 29 : 216-223.

CASEY, R.E., McMILLEN, K., REYNOLDS, R. et al. 1979 : Relict and expatriated radiolarian fauna in the Gulf of Mexico and its implications. Transactions of the Gulf Coast Association of Geological Societies 29 : 224-227.

CASEY, R.E. and McMILLEN, KJ. 1977 : Cenozoic radiolarians of the Atlantic Basin and margins. in : Swain, F.M. (ed.), Stratigraphic Micropaleontology of Atlantic Basin and Borderlands, Elsevier Scientific Publishing, Amsterdam, pp 521-544.

CASEY, R.E., PARTRIDGE, T.M., and SLOAN, J.R. 1971 : Radiolarian life spans, mortality rates, and seasonality gained from Recent sediment and plankton samples. in : Farinacci, A. (ed.), Proceedings of the II Planktonic Conference, Roma, 1971, pp 159-165. 
CASEY, R.E., PRICE, A.B., and SWIFT, C.A. 1972 : Radiolarian definition and paleoecology of the late Miocene to early Pliocene in southern California. in : Stinemeyer, E.H. and Church, C.C. (eds.), Proceedings of the Pacific Coast Miocene Biostratigraphic Symposium, 47th Annual Pacific Section SEPM Convention, March 9-10, 1972, Bakersfield, California, pp 226-238.

CASEY, R.E. and REYNOLDS, R. 1980 : Late Neogene radiolarian biostratigraphy related to magnetostratigraphy and paleoceanography with suggested cosmopolitan radiolarian datums. Cushman Foundation for Foraminiferal Research Special Publication 19. Memorial to Orville L. Bandy, pp 287-300.

CASEY, R.E., SPAW, J.M., KUNZE, F. et al. 1979 : Radiolarian ecology and the development of the radiolarian component in Holocene sediments, Gulf of Mexico and adjacent seas with potential paleontological applications. Transactions of the Gulf Coast Association of Geological Societies 29 : 228-237.

CHARM, W.B. 1967 : Freeze drying as a rapid method of disaggregating silts and clays for dry particle size analysis. Journal of Sedimentary Petrology 37 (3): 970-971.

CHEN, P.H. 1974 : Some new Tertiary Radiolaria from Antarctic deep-sea sediments. Micropaleontology 20 (4) : 480-492.

CHEN, P.H. 1975 : Antarctic Radiolaria. in : Hayes, D.E., Frakes, L.A. et al. (eds.), Initial Reports of the Deep Sea Drilling Project, Volume 28, United States Government Printing Office, Washington, pp 437-513.

CHOONG, M.C. 1983 : Biostratigraphy of the Pliocene sequence containing the Hikawera, Missing, Seddelbahr, and Spooner Tuff, Wairarapa, New Zealand. Unpublished MSc (Hons) project, Victoria University of Wellington, 96pp.

CIESIELSKI, P.F. 1975 : Biostratigraphy and paleoecology of Neogene and Oligocene silicoflagellates from cores recovered during Antarctic Leg 28, Deep Sea Drilling Project. in : Hayes, D.E., Frakes, L.A. et al. (eds.), Initial Reports of the Deep Sea Drilling Project, Volume 28, United States Government Printing Office, Washington, pp 625-691.

CIESIELSKI, P.F. and WEAVER, F.M. 1974 : Early Pliocene temperature changes in the Antarctic Seas. Geology $2:$ 511-515.

CIFELLI, R. and SACHS, K.N. 1966 : Abundance relationships of planktonic foraminifera and Radiolaria. Deep-Sea Research $13:$ 751-753.

CITA, M.B. 1975 : The Miocene/Pliocene boundary : History and definition. in : Saito, T., Burckle, L.H. (eds.), Late Neogene Epoch Boundaries, Micropaleontology Special Publication 1, Micropaleontology Press, New York, pp 1-30.

CITA, M.B. 1976 : Planktonic foraminiferal biostratigraphy of the Mediterranean Neogene. in : Takayanagi, Y., Saito, T. (eds.), Progress in Micropaleontology : Selected papers in honor of Prof. Kiyoshi Asano, Micropaleontology Special Publication, Micropaleontology Press, New York, pp 47-68.

CITA, M.B. and GARTNER, S. 1973 : The stratotype Zanclean. Foraminiferal and nannofossil biostratigraphy. Revista Italiana di paleontologia e stratigrafia 79 : 503-558.

CLARK, B.L. and CAMPBELL, A.S. 1945 : Radiolaria from the Kreyenhagen Formation near Los Banos, California. Memoir of the Geological Society of America 10 : $1-66$. 
CLEVE, P.T. 1899 : Plankton collected by the Swedish expedition to Spitzbergen in 1898. Kongl. Svenska Vetenskaps-Akademiens Handlingar 32 (3) : 1-51.

CLEVE, P.T. 1900 : Notes on some Atlantic plankton-organisms. Kongl. Svenska Vetenskaps-Akademiens Handlingar 34 (1) : 1-22.

COLLEN, J.D. 1972a : New foraminifera from the Pliocene and Pleistocene of the Wanganui Basin, New Zealand. Journal of the Royal Society of New Zealand 2 (3) : 373-382.

COLLEN, J.D. 1972b : Studies in the Wanganui Series : Pliocene foraminifera from the Wanganui Basin. Unpublished $\mathrm{PhD}$ dissertation, Victoria University of Wellington Library, 547pp.

COLLEN, J.D. 1974 : Hyalinea cf. balthica from Pliocene sediments, New Zealand. New Zealand Journal of Geology and Geophysics 17 (4) : 907-912.

COLLEN, J.D. and VELLA, P. 1973 : Pliocene planktonic foraminifera, southern North Island, New Zealand. Journal of Foraminiferal Research 3 (1) : 13-29.

CRUNDWELL, M.P. in prep : Geology and foraminiferal biostratigraphy of the Wainuioru Valley, East Wairarapa. MSc thesis, Victoria University of Wellington.

DAVIES, T.A. and SUPKO, P.R. 1973 : Oceanic sediments and their diagenesis : some examples from deep sea drilling (carbonate and silicate diagenesis, nodules and bedded cherts). Journal of Sedimentary Petrology 43 (2) : 381-390.

DEFLANDRE, G. 1952 : Classe des Radiolaires. in : Piveteau, J. (ed.), Traite de Paleontologie, Masson, Paris, Volume 1 : 303-313.

DEVEREUX, I., HENDY, C.H., and VELLA, P. 1970. Pliocene and early Pleistocene sea temperature fluctuations, Mangaopari Stream, New Zealand. Earth and Planetary Science Letters 8 : 163-168.

DINKELMAN, M.G. 1973 : Radiolarian stratigraphy, Leg 16, DSDP. in : van Andel, T.H., Heath, G.R. et al. (eds.), Initial Reports of the Deep Sea Drilling Project, Volume 16, United States Government Printing Office, Washington, pp 747-814.

DOW, R.L. 1978, Radiolarian distribution and the late Pleistocene history of the southeastern Indian Ocean. Marine Micropaleontology 3 : 203-227.

DREYER, F. 1889 : Morphologische Radiolarienstudien. 1. Die Pylombildungen in vergleichend-anatomischer und entwicklungsgeschichtlicher Beziehung bei Radiolarien und bei Protisten uberhaupt, nebst System und Beschreibung neuer und der bis jetzt bekannten pylomatischen Spumellarien. Jenaische Zeitschrift fur Naturwissenschaft. Volume 23, new series Volume $16: 1-138$.

DREYER, F. 1913 : Die polycystinen der Plankton-Expedition. Ergebnisse der Plankton-Expedition der Humboldt-Stiftung. Band III, L.d.e. : 1-104.

DUMITRICA, P. 1964 : Asupra prezentei unor radiolari din famioia Challengeridae (ord. Phaeodaria) in Tortonianul din Subcarpati. Studii si Cercetari de Geologie, Geofizica, Geografie. Seria Geologie 9 (1) : 217-222.

DUMTRICA, P. 1973 : Cretaceous and Quaternary Radiolaria in deep sea sediments from the northwest Atlantic Ocean and Mediterranean Sea. in : Ryan, W.B.F., Hsu, K.J. et al. (eds.), Initial Reports of the Deep Sea Drilling Project, Volume 13 (2), United States Government Printing Office, Washington, pp 829-901. 
DZINORIDZE, R.N., JOUSE, A.P., KOROLEVA-GOLIKOVA, G.S. et al. 1978 : Diatom and radiolarian Cenozoic stratigraphy, Norwegian Basin, DSDP, Leg 38. in : White, S.M. (ed.), Initial Reports of the Deep Sea Drilling Project, Supplement to Volumes 38-41, United States Government Printing Office, Washington, pp 289-427.

EDMOND, J.M., MEASURES, C., McDUFF, R.E., CHAN, L.H. et al. 1979 : Ridge crest hydrothermal activity and the balances of the major and minor elements in the ocean : the Galapagos data. Earth and Planetary Science Letters $46: 1-18$.

EDWARDS, A.R. 1972 : Calcareous nannoplankton from Opoitian (Pliocene) Gauss Normal strata in Mangaopari Stream. New Zealand Journal of Geology and Geophysics 15 (1) : 172-176.

EDWARDS, A.R. 1973 : Southwest Pacific regional unconformities encountered during Leg 21. in : Burns, R.E., Andrews, J.E. et al. (eds.), Initial Reports of the Deep Sea Drilling Project, Volume 21, United States Government Printing Office, Washington, pp 701-720.

EDWARDS, A.R. 1975 : Southwest Pacific Cenozoic paleogeography and an integrated Neogene paleocirculation model. in : Andrews, J.E., Packham, G. et al. (eds.), Initial Reports of the Deep Sea Drilling Project, Volume 30, United States Government Printing Office, Washington, pp 667-684.

EDWARDS, A.R. 1976 : Gephyrocapsa and the Plio-Pleistocene boundary in the New Zealand region. Programme Abstracts of the Geological Society of New Zealand Conference, Hamilton. 2pp.

EDWARDS, A.R. 1979 : Classification of marine paleoenvironments. Geological Society of New Zealand Newsletter $48: 18$.

EDWARDS, A.R. 1985 : Stratigraphy model for the Late Neogene of New Zealand. in : Cooper, R. (ed.), Hornibrook Symposium, 3-5 December 1985, Christchurch, New Zealand : extended abstracts, New Zealand Geological Survey Record 9 : 41-43.

EGGIMANN, D.W., MANHEIM, F.T., and BETZER, P.R. 1980 : Dissolution and analysis of amorphous silica in marine sediments. Journal of Sedimentary Petrology 50 (1) : 215-225.

EGGO, A.J. 1979 : Biostratigraphic zonation within late Cenozoic mudstone, Mangaopari Stream, Wairarapa. Unpublished BSc. Honours Project, Victoria University of Wellington Geology Library. 36pp.

EHRENBERG, C.G. 1838 : Uber die Bildung der Kreidefelsen und des Kreidemergels durch unsichtbare Organismen. Abhandlungen der Koniglich Akademie der Wissenschaften zu Berlin. Jahre 1838 : 59-147.

EHRENBERG, C.G. 1844a : Uber 2 neue Lager von Gebirgsmassen aus Infusorien als Meeres-Absatz in Nord-Amerika und eine Vergleichung derselben mit den organischen Kreide-Gebilden in Europa und Afrika. Monatsberichte der Koniglich preussischen Akademie der Wissenschaften zu Berlin. Jahre 1844 : 57-97.

EHRENBERG, C.G. 1844b : Einige vorlaufige Resultate seiner Untersuchungen der ihm von der Sudpolreise des Captain Ross, so wie von den Herren Schayer und Darwin zugekommenen Materialien uber das Verhalten des kleinsten Lebens in den Oceanen und den grossten bisher zuganglichen Tiefen des Weltmeers. Monatsberichte der Koniglich preussischen Akademie der Wissenschaften zu Berlin. Jahre 1844 : 182-207. 
EHRENBERG, C.G. 1847a : Uber eine halibiolithische, von Herrn R. Schomburgk entdeckte, vorherrschend aus mikroskopischen Polycystinen gebildete, Gebirgsmasse von Barbados. Monatsberichte der Koniglich preussischen Akademie der Wissenschaften zu Berlin. Jahre 1846 : 382-385.

EHRENBERG, C.G. 1847b : Uber die mikroskopischen kieselschaligen Polycystinen als machtige Gebirgsmasse von Barbados. Monatsberichte der Koniglich preussischen Akademie der Wissenschaften zu Berlin. Jahre 1847 : 40-60.

EHRENBERG, C.G. 1854a : Mikrogeologie, Leipzig. 374pp.

EHRENBERG, C.G. 1854b : Die systematische Charakteristik der neuen mikroskopischen Organismen des tiefen Atlantischen Oceans. Monatsberichte der Koniglich preussischen Akademie der Wissenschaften zu Berlin. Jahre 1854 : 236-250.

EHRENBERG, C.G. 1858 : Kurze Characteristik der 9 neuen Genera und der 105 neuen Species des agaischen Meeres und des Tiefgrundes des Mittelmeeres. Monatsberichte der Koniglich preussischen Akademie der Wissenschaften zu Berlin. Jahre 1858: $10-40$.

EHRENBERG, C.G. 1860 : Uber den Tiefgrund des stillen Oceans zwischen Californien und den Sandwich-Inseln aus bis 15, 600 Tiefe nach Lieut. Brooke.

Monatsberichte der Koniglich preussischen Akademie der Wissenschaften zu Berlin. Jahre 1860 : 819-833.

EHRENBERG, C.G. 1861 : Uber die Tiefgrund-Verhaltnisse des Oceans am Eingange der Davisstrafse und bei Island. Monatsberichte der Koniglich preussischen Akademie der Wissenschaften zu Berlin. Jahre 1861 : 275-315.

EHRENBERG, C.G. 1872a : Mikrogeologischen studien als Zusammenfassung seiner Beobachtungen des kleinsten Lebens der Meeres-Tiefgrunde aller Zonen und dessen geologischen Einflufs. Monatsberichte der Koniglich preussischen Akademie der Wissenschaften zu Berlin. Jahre 1872 : 265-322

EHRENBERG, C.G. 1872b : Mikrogeologischen studien uber das kleinste Leben der Meeres-Tiefgrunde aller Zonen und dessen geologischen Einfluss. Abhandlungen der Koniglich Akademie der Wissenschaften zu Berlin. Jahre 1872 : 131-399.

EHRENBERG, C.G. 1873 : Grossere Felsproben des Polycystinen-Mergels von Barbados mit weiteren Erlauterungen. Monatsberichte der Koniglich preussischen Akademie der Wissenschaften zu Berlin. Jahre 1873 : 213-263.

EHRENBERG, C.G. 1875 : Fortsetzung der mikrogeologischen studien als GesammtUebersicht der mikroskopischen Palaontologie gleichartig analysirter Gebirgsarten der Erde, mit specieller Rucksicht auf den Polycystinen-Mergel von Barbados. Abhandlungen der Koniglichen Akademie der Wissenschaften zu Berlin. Jahre $1875: 1-226$.

EMPSON-MORIN, K.M. 1981 : Campanian Radiolaria from DSDP Site 313, Mid-Pacific Mountains. Micropaleontology 27 (3) : 249-292.

FANNING, K.A. and PILSON, M.E.Q. 1973 : The lack of inorganic removal of dissolved silica during river-ocean mixing. Geochimica et Cosmochimica Acta 37 : 2405-2415.

FAUL, H. and DAVIS, G.L. 1959 : Mineral separation with asymmetric vibrators. American Mineralogist 44 (10) : 1076-1082. 
FILLON, R.H. 1973 : Radiolarian evidence of late Cenozoic oceanic paleotemperatures, Ross Sea, Antarctica. Palaeogeography, Palaeoclimatology, Palaeoecology 14 : 171-185.

FINLAY, H.J. 1939 : New Zealand Foraminifera : key species in stratigraphy - no. 1. Transactions of the Royal Society of New Zealand 68 (4) : 504-533.

FINLAY, H.J. and MARWICK, J. 1940 : The divisions of the upper Cretaceous and Tertiary in New Zealand. Transactions of the Royal Society of New Zealand 70 (1) : 77-135.

FINLAY, H.J. and MARWICK, J. 1947 : New divisions of the New Zealand upper Cretaceous and Tertiary. New Zealand Journal of Science and Technology B68 (4) : 228-236.

FISCHER, A.G. and ARTHUR, M.A. 1977 : Secular variations in the pelagic realm. in : Cook, H.E., Enos, P. (eds.), Deep-water Carbonate Environments, Society of Economic Paleontologists and Mineralogists Special Publication 25, Tulsa, Oklahoma, pp 19-50.

FITTALL, M.E. 1979 : The geology of an area north of Mangaopari Stream, south east Wairarapa. Unpublished BSc. Honours Project, Victoria University of Wellington Geology Library. 44pp.

FLEMING, C.A. (ed.), 1959 : Lexique Stratigraphique International Volume 6 Oceanie, Fascicule 4. Centre National de la Recherche Scientifique, Paris, for the Commission de Stratigraphie, Congres Geologique International. 427pp.

FLEMING, C.A. 1953 : The geology of the Wanganui Subdivision. New Zealand Geological Survey Bulletin 52. 362pp.

FOLK, R.L. 1974 : Petrology of Sedimentary Rocks, Hemphill Publishing, Austin, Texas, 182pp.

FORD, R.M.D. 1975 : Characterisation and stratigraphy of some tuffs from northern Wairarapa, New Zealand. Unpublished BSc (Hons) project, Victoria University of Wellington, $31 \mathrm{pp}$.

FOREMAN, H.P. 1973 : Radiolaria of Leg 10 with systematics and ranges for the families Amphipyndacidae, Artostrobiidae, and Theoperidae. in : Worzel, J.L., Bryant, W. et al. (eds.), Initial Reports of the Deep Sea Drilling Project, Volume 10, United States Government Printing Office, Washington, pp 407-474.

FOREMAN, H.P. 1975 : Radiolaria from the north Pacific, Deep Sea Drilling Project, Leg 32. in : Larson, R.L., Moberly, R. et al. (eds.), Initial Reports of the Deep Sea Drilling Project, Volume 32, United States Government Printing Office, Washington, pp 579-676.

FOREMAN, H.P. 1981 : Radiolaria. in : Emiliani, C. (ed.), The Sea : ideas and observations on progress in the study of the seas, Volume 7 of The Oceanic Lithosphere, Wiley-Interscience Publication, John Wiley and Sons, New York, pp 1121-1144.

FOREMAN, H.P. and RIEDEL, W.R. 1972 : Catalogue of polycystine Radiolaria. American Museum of Natural History Special Publication, The American Museum of Natural History, New York. Two volumes.

FORTEY, R.A. and HOLDSWORTH, B.K. 1971 : The oldest known well preserved Radiolaria. Bollettino della Societa Paleontologica Italiana 10 (1) : 35-41. 
FRANKE, A. 1935 : Sammein, praparieren und aufbewahren von Mikrofossilien. Senckenbergiana $17:$ 124-137.

FRERICHS, W.E. 1971 : Evolution of planktonic foraminifera and paleotemperatures. Journal of Paleontology 45 (6) : 963-968.

FRIEND, J.K. and RIEDEL, W.R. 1967 : Cenozoic orosphaerid radiolarians from tropical Pacific sediments. Micropaleontology $13: 217-232$.

FRIZZELL, D.L. and MIDDOUR, E.S. 1951 : Paleocene Radiolaria from southeastern Missouri. Bulletin of the University of Missouri School of Mines and Metallurgy. Technical Series $77: 1-41$

GALEHOUSE, J.S. 1971 : Point counting. in : Carver, R.E. (ed.), Procedures in Sedimentary Petrology, John Wiley and Sons, New York, pp 385-407.

GARNER, D.M. and RIDGWAY, N.M. 1965 : Hydrology of New Zealand offshore waters. New Zealand Department of Scientific and Industrial Research Bulletin 162 - New Zealand Oceanographic Institute Memoir 12. 62pp.

GARRISON, R.E. 1974 : Radiolarian cherts, pelagic limestones, and igneous rocks in eugeosynclinal assemblages. in : Hsu, K.J. and Jenkyns, H.C. (eds.), Pelagic Sediments on Land and under the Sea, International Association of Sedimentologists Special Publication Number 1, Blackwell Scientific Publications, Oxford, pp 367-399.

GHENT, E.D. and HENDERSON, R.A. 1966 : Petrology, sedimentation, and paleontology of middle Miocene graded sandstones and mudstones, Kaiti Beach, Gisborne. Transactions of the Royal Society of New Zealand, Geology 4 (7) : 147-169.

GIBSON, G.W. 1963 : Some Miocene stratigraphy and paleontology - the Tongaporutuan Stage. Unpublished $\mathrm{PhD}$ thesis, Victoria University of Wellington, 235pp.

GIBSON, G.W. 1967 : Foraminifera and stratigraphy of the Tongaporutuan Stage in the Taranaki Coastal and six other sections. Part I. - Systematics and distribution. Transactions of the Royal Society of New Zealand. Geology 5 (1) : 1-70.

GIBSON, T.G. and WALKER, W.M. 1967 : Flotation methods for obtaining foraminifera from sediment samples. Journal of Paleontology 41 (5) : 1294-1297.

GLAESSNER, M.F. 1948 : Principles of Micropaleontology, 2nd edition, Melbourne University Press, Carlton, 296pp.

GLASS, B.P. 1969 : Reworking of deep-sea sediments as indicated by the vertical dispersion of the Australasian and Ivory Coast microtextite horizons. Earth and Planetary Science Letters 6 : 409-415.

GOLL, R.M. 1968 : Classification and phylogeny of Cenozoic Trissocyclidae (Radiolaria) in the Pacific and Caribbean Basins. Part I. Journal of Paleontology 42 (6) : 1409-1432.

GOLL, R.M. 1969 : Classification and phylogeny of Cenozoic Trissocyclidae (Radiolaria) in the Pacific and Caribbean Basins. Part II. Journal of Paleontology 43 (2): 322-339.

GOLL, R.M. 1972a : Leg 9 synthesis, Radiolaria. in : Hays, J.D., Cook, H.E. et al. (eds.), Initial Reports of the Deep Sea Drilling Project, Volume 9, United States Government Printing Office, Washington, pp 947-1058. 
GOLL, R.M. 1972b : Systematics of eight Tholospyris taxa (Trissocyclidae, Radiolaria). Micropaleontology 18 (4) : 443-475.

GOLL, R.M. 1976 : Morphological intergradation between modern populations of Lophospyris and Phormospyris (Trissocyclidae, Radiolaria). Micropaleontology 22 (4) : 379-418.

GOLL, R.M. 1980 : Pliocene-Pleistocene radiolarians from the east Pacific Rise and the Galapagos spreading center, Deep Sea Drilling Project Leg 54. in : Rosendahl, B.R., Hekinian, R. et al. (eds.), Initial Reports of the Deep Sea Drilling Project, Volume 54, United States Government Printing Office, Washington, pp 425-454.

GOLL, R.M. and BJORKLUND, K.R. 1971 : Radiolaria in the surface sediments of the north Atlantic Ocean. Micropaleontology 17 (4) : 434-454.

GOLL, R.M. and BJORKLUND, K.R. 1974 : Radiolaria in surface sediments of the south Atlantic. Micropaleontology 20 (1) : 38-75.

GOLL, R.M. and MERINFELD, E.G. 1979 : Radiolaria. in : Fairbridge, R.W. and Jablonski, D. (eds.), Encyclopedia of Paleontology, Encyclopedia of Earth Sciences, Volume VII, Hutchinson and Ross, Stroudsberg, pp 673-684.

GOSSON, G.J. in prep : Miocene-Pliocene silicic ash deposits in New Zealand. $\mathrm{PhD}$ thesis, Victoria University of Wellington.

GRANGE, L.I. 1927 : The geology of the Tongaporutu-Ohura Subdivision, Taranaki Division. New Zealand Geological Survey Bulletin 31 : 63pp.

GRANT-TAYLOR, T.L. and HORNIBROOK, N.deB. 1976 : Late Mesozoic to Cenozoic stratigraphy North Island (eastern Part) of New Zealand. Excursion guide No 54A. 25th International Geological Congress. 42pp.

HAECKEL, E. 1860a : Uber neue, lebende Radiolarien des Mittelmeeres. Monatsberichte der Koniglich preussischen Akademie der Wissenschaften zu Berlin. Jahre 1860 : 794-817.

HAECKEL, E. 1860b : Abbildungen und diagnosen neuer Gattungen und Arten von lebenden Radiolarien des Mittelmeeres. Monatsberichte der Koniglich preussischen Akademie der Wissenschaften zu Berlin. Jahre 1860 : 835-845.

HAECKEL, E. 1862 : Die Radiolarien (Rhizopoda Radiolaria). Eine Monographie. Riemer, Berlin, 572pp.

HAECKEL, E. 1881 : Entwurf eines Radiolarien - Systems auf Grund von Studien der Challenger-Radiolarien. Jenaische Zeitschrift fur Naturwissenschaft. Volume 15, new series Volume 8 (3) : 418-472.

HAECKEL, E. 1884 : Uber die ordnungen der radiolarien. Sitzungsberichte der Jenaischen Gesellschaft fur medicin und naturwissenschaft fur das Jahr 1883 : pp 18-36.

HAECKEL, E 1887 : Report on the Radiolaria collected by H.M.S. Challenger during the years 1873-76. in : Report on the Scientific Results of the Voyage of the H.M.S. Challenger During the Years 1873-76, Zoology, Volume 18, 1803pp, 140 plates.

HAECKER, V. 1907 : Altertumliche Spharollarien und Cyrtollarien aus grossen Meerestiefen. Archiv fur Protistenkunde 10 : 114-126. 
HAMMOND, S.R., THEYER, F., and SUTTON, G.H. 1974 : Paleomagnetic evidence of northward movement of the Pacific Plate in deep-sea cores from the central Pacific Basin. Earth and Planetary Science Letters 22: 22-28.

HANNA, G.D. and CHURCH, C.C. 1928 : Freezing and thawing to disintegrate shales. Journal of Paleontology $2: 131$.

HARPER, H.E. 1978 : Diatom biostratigraphy of the Miocene/Pliocene boundary in the North Pacific. in : Correlation of tropical through high latitude marine Neogene deposits of the Pacific Basin, International Geological Correlation Programme (IGCP), Project 114, Biostratigraphic Datum-planes of the Pacific Neogene, Third Working Group Meeting - Abstracts and Program, Stanford University Publications, Geological Sciences Volume 14, p 15.

HART, R. 1970 : Chemical exchange between sea water and deep ocean basalts. Earth and Planetary Science Letters $9:$ 269-279.

HAY, R.F. 1967 : Sheet 7, Taranaki (1st edition). 1:250, 000 Geological Map of New Zealand, Department of Scientific and Industrial Research, Wellington.

HAYES, D.E. and FRAKES, L.A., BARRETT, P.J. et al. 1975a : Site 269. in : Hayes, D.E., Frakes, L.A. et al. (eds.), Initial Reports of the Deep Sea Drilling Project, Volume 28, United States Government Printing Office, Washington, pp 179-210.

HAYES, D.E., FRAKES, L.A., BARRETT, PJ. et al. 1975b : Site 274. in : Hayes, D.E., Frakes, L.A. et al. (eds.), Initial Reports of the Deep Sea Drilling Project, Volume 28, United States Government Printing Office, Washington, pp 369-434.

HAYS, J.D. 1965 : Radiolaria and late Tertiary and Quaternary history of Antarctic seas. in : Biology of the Antarctic Seas, Part 2, Antarctic Research Series 5, American Geophysical Union, pp 125-183.

HAYS, J.D. 1967 : Quaternary sediments of the Antarctic ocean. in : Sears, M. (ed.), Progress in Oceanography, Volume 4, The Quaternary History of the Ocean Basins, Pergamon Press, London, pp 117-131.

HAYS, J.D. 1970 : Stratigraphy and evolutionary trends of Radiolaria in north Pacific deep-sea sediments. in : Hays, J.D. (ed.), Geological Investigations of the North Pacific, Geological Society of America Memoir 126, The Geological Society of America, Boulder, Colorado, pp 185-218.

HAYS, J.D. 1971 : Faunal extinctions and reversals of the Earth's magnetic field. Geological Society of America Bulletin 82 : 2433-2447.

HAYS, J.D. and BERGGREN, W.A. 1971 : Quaternary boundaries and correlations. in : Funnell, B.M., Riedel, W.R. (eds.), Micropaleontology of the Oceans, Cambridge University Press, pp 669-691.

HAYS, J.D. and DONAHUE, J.G. 1972 : Antarctic Quaternary climatic record and radiolarian and diatom extinctions. in : Adie, R.J. (ed.), Antarctic Geology and Geophysics, International Union of Geological Sciences Series B, No. 1, Universitetsforlaget, Oslo, pp 733-738.

HAYS, J.D. and OPDYKE, N.D. 1967 : Antarctic Radiolaria, magnetic reversals, and climatic change. Science 158 (3804) : 1001-1011.

HAYS, J.D., SAITO, T., OPDYKE, N.D., and BURCKLE, L.H. 1969 : Pliocene-Pleistocene sediments of the equatorial Pacific : Their paleomagnetic, biostratigraphic and climatic record. Geological Society of America Bulletin 80 : 1481-1514. 
HEATH, G.R. 1969 : Mineralogy of Cenozoic deep-sea sediments from the equatorial Pacific Ocean. Geological Society of America Bulletin 80 : 1997-2018.

HEATH, G.R. 1974 : Dissolved silica and deep-sea sediments. in : Hay, W.W. (ed.), Studies in Paleo-oceanography, Society of Economic Paleontologists and Mineralogists Special Publication 20, Tulsa, Oklahoma, pp 77-93.

HEATH, G.R., MOORE, T.C., and DAUPHIN, J.P. 1976 : Late Quaternary accumulation rates of opal, quartz, organic carbon, and calcium carbonate in the Cascadia Basin Area, Northeast Pacific. in : Cline, R.M., Hays, J.D. (eds.), Investigation of Late Quaternary Paleoceanography and Paleoclimatology, Geological Society of America Memoir 145, Geological Society of America, Colorado, pp 393-409.

HEATH, R.A. 1975 : Oceanic circulation and hydrology off the southern half of the South Island, New Zealand. New Zealand Oceanographic Institute Memoir 72. 36pp.

HECHT, A.D., ESLINGER, E.V., and GARMON, L.B. 1975 : Experimental studies on the dissolution of planktonic foraminifera. in : Sliter, W.V., Be, A.W.H., Berger, W.H. (eds.), Dissolution of Deep-Sea Carbonates, Cushman Foundation for Foraminiferal Research Special Publication Number 13, Allen Press, Lawrence, Kansas : 56-69.

HECHT, F. 1933 : Arbeitsweisen der Mikropalaontologie. Senckenbergiana 15 (6) : 346-362.

HEDBERG, H.D. (ed.), 1976 : International stratigraphic guide. A guide to stratigraphic classification, terminology, and procedure. by : International Union of Geological Sciences. International Subcommission on Stratigraphic Classification, John Wiley and Sons, New York, 200pp.

HERTWIG, R. 1879 : Der Organismus der Radiolarien, G.Fischer, Jena, 149pp.

HOLDSWORTH, B.K. 1975 : Cenozoic Radiolaria biostratigraphy : Leg 30 : tropical and equatorial Pacific. in : Andrews, J.E., Packham, G. et al. (eds.), Initial Reports of the Deep Sea Drilling Project, Volume 30, United States Government Printing Office, Washington, pp 499-538.

HOLLANDE, A. and ENJUMET, M. 1960 : Cytologie, evolution et systematique des Sphaeroides (Radiolaires). Archives du Museum National d'Histoire Naturelle. Septieme Serie, volume $7: 1-134$.

HORNIBROOK, N.de B. 1958 : New Zealand upper Cretaceous and Tertiary foraminiferal zones and some overseas correlations. Micropaleontology 4 (1): 25-38.

HORNIBROOK, N.de B. 1961 : Tertiary Foraminifera from the Oamaru district (N.Z.). Part 1 : Systematics and distribution. New Zealand Geological Survey Paleontological Bulletin 34 (1): 192pp.

HORNIBROOK, N.de B. 1968a : A handbook of New Zealand microfossils (Foraminifera and Ostracoda). New Zealand Department of Scientific and Industrial Research Information Series 62, 136pp.

HORNIBROOK, N.de B. 1968b : Stratotypes of New Zealand Tertiary stages. Stage Conference, Christchurch, 1968, 25pp.

HORNIBROOK, N.de B. 1976a : Kapitean-Opoitian boundary. New Zealand Geological Society Conference, Hamilton 1976. 
HORNIBROOK, N.de B. 1976b : Globorotalia truncatulinoides and the Pliocene Pleistocene boundary in northern Hawkes Bay, New Zealand. in : Takayanagi, Y., Saito, T. (eds.), Progress in Micropaleontology : Selected papers in honor of Prof. Kiyoshi Asano, Micropaleontology Special Publication, Micropaleontology Press, New York, pp 83-102.

HORNIBROOK, N.de B. 1977 : The Neogene (Miocene-Pliocene) of New Zealand. in : Proceedings of the First Pacific Neogene Congress, Tokyo, May 1976, Kaiyo Sappan, Tokyo, pp 145-150.

HORNIBROOK, N.de B. 1979 : Globorotalia crassaformis and G. crassula in the Pliocene of New Zealand and a Late Pliocene cool marine phase in the lower Nukumaruan stage. 49th ANZAAS Abstracts Volume 1: 131.

HORNIBROOK, N.de B. 1980 : ${ }_{1}$ forrelation of Pliocene biostratigraphy, magnetostratigraphy and $\mathrm{O}$ fluctuations in New Zealand and DSDP Site 284. Newsl. Stratigr. 9 (2) : 114-120.

HORNIBROOK, N.de B. 1981a : Evaluation of Pacific southern mid latitude and equatorial latitude planktic foraminiferal datum levels. New Zealand Geological Survey Report Pal 42. 13pp.

HORNIBROOK, N.de B. 1981b : Globorotalia (planktic Foraminiferida) in the Late Pliocene and Early Pleistocene of New Zealand. New Zealand Journal of Geology and Geophysics $24: 263-293$.

HORNIBROOK, N.de B. 1982 : Late Miocene to Pleistocene Globorotalia (Foraminiferida) from DSDP Leg 29, Site 284, Southwest Pacific. New Zealand Journal of Geology and Geophysics 25 : 83-99.

HORNIBROOK, N.de B. 1983 : Mangapoike River section. Field Trip Guide, Tour B1, Neogene Geology, North Island East Coast Basin, Third International Meeting of Pacific Neogene Stratigraphy (Miocene-Pliocene).

HORNIBROOK, N.de B. 1984a : Globorotalia (planktic foraminifera) at the Miocene/Pliocene boundary in New Zealand. Palaeogeography, Palaeoclimatology, Palaeoecology 46 : 107-118.

HORNIBROOK, N.de B. 1984b : Neogene stratigraphy and planktonic foraminiferal datum planes in New Zealand. in : Ikebe, N. and Tsuchi, R. (eds.), Pacific Neogene Datum Planes : contributions to biostratigraphy and chronology, University of Tokyo Press, Tokyo, pp 179-186.

HORNIBROOK, N.de B. and EDWARDS, A.R. 1971 : Integrated planktonic foraminiferal and calcareous nannoplankton datum levels in the New Zealand Cenozoic. in : Farinacci, A. (ed.), Proceedings of the 11 Planktonic Conference, Roma, 1970, Edizioni Technoscienza, Roma, pp 649-657.

HOSKINS, R.H. 1978 : New Zealand Middle Miocene Foraminifera : the Waiauan Stage. Unpublished $\mathrm{PhD}$ thesis, University of Exeter, 2 volumes, 388pp. : copy lodged at New Zealand Geological Survey Library, Lower Hutt.

HOSKINS, R.H. (ed.) 1982 : Stages of the New Zealand Marine Cenozoic : a synopsis. New Zealand Geological Survey Report 107, 74pp.

HOUTMAN, T.J. 1967 : Water masses and fronts in the southern ocean south of New Zealand. New Zealand Department of Scientific and Industrial Research Bulletin 174, New Zealand Oceanographic Institute Memoir 36. 40pp. 
HOWE, H.V. 1941 : Use of soap in the preparation of samples for micropaleontological study. Journal of Paleontology 15:691.

HUANG, T.C. and WATKINS, N.D. 1977 : Contrasts between the Brunhes and Matuyama sedimentary records of bottom water activity in the South Pacific. Marine Geology 23 : 113-132.

HUMPHRIES, D.W. 1961 : A non-laminated miniature sample splitter. Journal of Sedimentary Petrology 31 (3) : 471-473.

HUNT, T. 1980 : Basement structure of the Wanganui Basin, onshore, interpreted from gravity data. New Zealand Journal of Geology and Geophysics 23 (1) : 1-16.

HURD, D.C. 1972 : Factors affecting the solution rate of biogenic opal in seawater. Earth and Planetary Science Letters $15:$ 411-417.

HURD, D.C. 1973 : Interactions of biogenic opal, sediment and seawater in the central equatorial Pacific. Geochimica et Cosmochimica Acta 37 : 2257-2282.

HURD, D.C. and BIRDWHISTELL, S. 1983 : On producing a more general model for biogenic silica dissolution. American Journal of Science 283 : 1-28.

HURD, D.C. and THEYER, F. 1975 : Changes in the physical and chemical properties of biogenic silica from the central equatorial Pacific. I. Solubility, specific surface area, and solution rate constants of acid cleaned samples. in : Gibb, T.R.P. (ed.), Analytical Methods in Oceanography, Advances in Chemistry Series, Number 147, American Chemical Society, pp 211-230.

IKEBE, N. and CHIJ, M. 1978 : Evaluation of some important datum-planes of the Pacific Neogene. in : Correlation of tropical through high latitude marine Neogene deposits of the Pacific Basin, International Geological Correlation Programme (IGCP), Project 114, Biostratigraphic Datum-planes of the Pacific Neogene, Third Working Group Meeting - Abstracts and Program, Stanford University Publications, Geological Sciences Volume 14, p 21.

INGLE, J.C. and BARRON, J.A. 1978 : Neogene biostratigraphy and paleoenvironments of the San Joaquin Hills and Newport Bay areas, California. in : Addicott, W.O. (ed.), Neogene Biostratigraphy of selected areas in the California Coast Ranges, Field Conference on the Marine Neogene of California, International Geological Correlation Programme (IGCP), Project 114, Biostratigraphic Datum-planes of the Pacific Neogene, June 21-24, 1978. United States Geological Survey Open-file Report 78-446, pp 3-27.

ISAACS, C.M., PISCIOTTO, K.A., and GARRISON, R.E. 1983 : Facies and diagenesis of the Miocene Monterey Formation, California : A summary. in : Iijima, A., Hein, J.R., Siever, R. (eds.), Siliceous deposits in the Pacific Region, Developments in Sedimentology 36, Elsevier, Amsterdam, pp 247-282.

ISHIDA, S. 1978 : Paleoecology and stratigraphy of Neogene in some areas of Japan and Pacific. in : Correlation of tropical through high latitude marine Neogene deposits of the Pacific Basin, International Geological Correlation Programme (IGCP), Project 114, Biostratigraphic Datum-planes of the Pacific Neogene, Third Working Group Meeting - Abstracts and Program, Stanford University Publications, Geological Sciences Volume 14, pp 22-23.

JENKINS, D.G. 1967 : Planktonic foraminiferal zones and new taxa from the lower Miocene to the Pleistocene of New Zealand. New Zealand Journal of Geology and Geophysics 10 (4): 1064-1078. 
JENKINS, D.G. 1971 : New Zealand Cenozoic planktonic foraminifera. New Zealand Geological Survey Paleontological Bulletin 42. 278pp.

JENKINS, D.G. 1975 : The Pliocene/Pleistocene boundary in New Zealand and Australia. in : Saito, T., Burckle, L.H. (eds.), Late Neogene Epoch Boundaries, Micropaleontology Special Publication 1, Micropaleontology Press, New York, pp 94-100.

JENKYNS, H.C. 1978 : Pelagic environments. in : Reading, H.G. (ed.), Sedimentary Environments and Facies, Blackwell Scientific, Oxford, pp 314-371.

JOHNSON, D.A. 1974 : Radiolaria from the eastern Indian Ocean, DSDP Leg 22. in : van der Borch, C.C., Sclater, J.G. et al. (eds.), Initial Reports of the Deep Sea Drilling Project, Volume 22, United States Government Printing Office, Washington, pp 521-575.

JOHNSON, D.A. 1976 : Cenozoic radiolarians from the central Pacific, DSDP, Leg 33. in : Schlanger, S.O., Jackson, E.D. et al. (eds.), Initial Reports of the Deep Sea Drilling Project, Volume 33, United States Government Printing Office, Washington, pp 425-437.

JOHNSON, D.A. 1978 : Cenozoic Radiolaria from the eastern tropical Atlantic, DSDP Leg 41. in : Gardener, J. and Herring, J. (eds.), Initial Reports of the Deep Sea Drilling Project, Volume 41, United States Government Printing Office, Washington, pp 763-789.

JOHNSON, D.A. and NIGRINI, C. 1980 : Radiolarian biogeography in surface sediments of the western Indian Ocean. Marine Micropaleontology $5: 111-152$.

JOHNSON, D.A. and NIGRINI, C. 1982 : Radiolarian biogeography in surface sediments of the eastern Indian Ocean. Marine Micropaleontology 7 : 237-281.

JOHNSON, D.A. and WICK, B.J. 1982 : Precision of radiolarian datum levels in the middle Miocene, equatorial Pacific. Micropaleontology 28 (1) : 43-58.

JOHNSON, T.C. 1974 : The dissolution of siliceous microfossils in surface sediments of the eastern tropical Pacific. Deep-Sea Research $21: 851-864$.

JOHNSON, T.C. 1976 : Biogenic opal preservation of pelagic sediments in a small area of the eastern tropical Pacific. Geological Society of America Bulletin 87 : $1273-1282$.

JOHNSON, T.C. and KNOLL, A.H. 1974 : Radiolaria as paleoclimatic indicators : Pleistocene climatic fluctuations in the equatorial Pacific. Quaternary Research 4 : 206-216.

JOHNSON, T.C. and KNOLL, A.H. 1975 : Absolute ages of Quaternary radiolarian datum levels in the equatorial Pacific. Quaternary Research 5 : 99-110.

JOHNSON, T.C. and PARKER, F.L. 1972 : Tertiary Radiolaria and foraminifera from the equatorial Pacific. Micropaleontology 18 (2) : 129-143.

JORGENSEN, E. 1900 : Protophyten und Protozoen im Plankton aus der norwegischen Westkuste. Bergens Museums Aarbog 1899, number $6: 1-112$.

JORGENSEN, E. 1905 : The protist plankton and the diatoms in bottom samples. Bergens Museums Report on Hydrographical and Biological Investigations in Norwegian Fiords 1905 : 49-151, 195-225. 
KASTNER, M. and GIESKES, J.M. 1983 : Opal-A to Opal-CT transformation : A kinetic study. in : Iijima, A., Hein, J.R., Siever, R. (eds.), Siliceous deposits in the Pacific Region, Developments in Sedimentology 36, Elsevier, Amsterdam, pp 211-227.

KATZ, H.R. 1980 : Cretaceous-Cenozoic sedimentary basins of New Zealand. in : Prospectus for petroleum exploration in New Zealand, issued by the Ministry of Energy, Wellington, N.Z., June 1980, Government Printing Office, Wellington. 63pp.

KEANY, J. 1973 : New radiolarian palaeoclimatic index in the Plio-Pleistocene of the southern ocean. Nature 246 (5429) : 139-141.

KEANY, J. 1978 : Paleoclimatic trends in early and middle Pliocene deep-sea sediments of the Antarctic. Marine Micropaleontology $3: 35-49$.

KEANY, J. 1979 : Early Pliocene radiolarian taxonomy and biostratigraphy in the Antarctic region. Micropaleontology 25 (1) : 50-74.

KEANY, J. and KENNETT, J.P. 1972 : Pliocene-early Pleistocene paleoclimatic history recorded in Antarctic-Subantarctic deep-sea cores. Deep Sea Research 19 : 529-548.

KEANY, J. and KENNETT, J.P. 1975 : Pliocene-Pleistocene radiolarian biostratigraphy and paleoclimatology at DSDP Site 278 on the Antarctic Convergence. in : Kennett, J.P., Houtz, R.E. et al. (eds.), Initial Reports of the Deep Sea Drilling Project, Volume 29, United States Government Printing Office, Washington, pp 757-767.

KEIGWIN, L.D. 1978 : Middle Miocene to Pliocene stable isotopic datums in east equatorial and north central Pacific deep sea drilling (DSDP) sites. in : Correlation of tropical through high latitude marine Neogene deposits of the Pacific Basin, International Geological Correlation Programme (IGCP), Project 114, Biostratigraphic Datum-planes of the Pacific Neogene, Third Working Group Meeting - Abstracts and Program, Stanford University Publications, Geological Sciences Volume 14, pp 26-27.

KEIGWIN, L.D., BENDER, M.L., and KENNETT, J.P. 1979 : Thermal structure of the deep Pacific Ocean in the Early Pliocene. Science 205 : 1386-1388.

KELLER, G. 1978 : Late Neogene biostratigraphy and paleoceanography of DSDP Site 310 central north Pacific and correlation with the southwest Pacific. Marine Micropaleontology 3 : 97-119.

KELLER, G. 1979 : Late Neogene planktonic foraminiferal biostratigraphy and paleoceanography of the northwest Pacific DSDP. Palaeogeography, Palaeoclimatology, Palaeoecology 27 : 129-154.

KELLER, W.D., BALGORD, W.D., and REESMAN, A.L. 1963 : Dissolved products of artificially pulverised silicate minerals and rocks. Part I. Journal of Sedimentary Petrology 33 : 191-204.

KELLOGG, D.E. 1980 : Character displacement and phyletic change in the evolution of the radiolarian subfamily Artiscinae. Micropaleontology 26 (2) : 196-210.

KEMPTON, R.A. and WEDDERBURN, R.W.M. 1978 : A comparison of three measures of species diversity. Biometrics $34: 25-37$.

KENNETT, J.P. 1965 : The Kapitean Stage (upper Miocene) of New Zealand. PhD thesis, Victoria University of Wellington, 2 volumes, 394pp + appendices. 
KENNETT, J.P. 1966a : Stratigraphy and fauna of the type section and neighbouring sections of the Kapitean Stage, Greymouth, N.Z. Transactions of the Royal Society of New Zealand, Geology 4 (1) : 1-77.

KENNETT, J.P. 1966b : The Globorotalia crassaformis bioseries in north Westland and Marlborough, New Zealand. Micropaleontology 12 (2) : 235-245.

KENNETT, J.P. 1966c : Faunal succession in two upper Miocene-lower Pliocene sections, Marlborough, New Zealand. Transactions of the Royal Society of New Zealand, Geology 3 (15): 197-213.

KENNETT, J.P. 1966d : Biostratigraphy and paleoecology in upper Miocene-lower Pliocene sections in Wairarapa and southern Hawke's Bay. Transactions of the Royal Society of New Zealand, Geology 4 (3): 83-102.

KENNETT, J.P. 1966e : Four upper Miocene to lower Pliocene sections, Hawkes Bay to East Cape, New Zealand. Transactions of the Royal Society of New Zealand, Geology 4 (10) : 189-209.

KENNETT, J.P. 1977 : Cenozoic evolution of Antarctic glaciation, the circum-Antarctic Ocean, and their impact on global paleoceanography. Journal of Geophysical Research 82 (27) : 3843-3860.

KENNETT, J.P. 1978 : The development of planktonic biogeography in the southern ocean during the Cenozoic. Marine Micropaleontology 3 : 301-345.

KENNETT, J.P. 1980 : Paleoceanographic and biogeographic evolution of the southern ocean during the Cenozoic, and Cenozoic microfossil datums. Palaeogeography, Palaeoclimatology, Palaeoecology 31 : 123-152.

KENNETT, J.P. 1982 : Marine Geology, Prentice-Hall, New Jersey, 813pp.

KENNETT, J.P. and BRUNNER, C.A. 1973 : Antarctic late Cenozoic glaciation : Evidence for initiation of ice rafting and inferred bottom-water activity. Geological Society of America Bulletin 84 : 2043-2052.

KENNETT, J.P. and FILLON, R.H. 1970 : Micropaleontological and associated studies of southern ocean deep-sea cores. Antarctic Journal of the United States 5 (5) : 181.

KENNETT, J.P., HOUTZ, R.E., ANDREWS, P.B. et al. 1974 : Development of the Circum-Antarctic current. Science $186: 144-147$.

KENNETT, J.P., HOUTZ, R.E., ANDREWS, P.B. et al. 1975a : Cenozoic paleoceanography in the southwest Pacific Ocean, Antarctic glaciation, and the development of the circum-Antarctic current. in : Kennett, J.P., Houtz, R.E. et al. (eds.), Initial Reports of the Deep Sea Drilling Project, Volume 29, United States Government Printing Office, Washington, pp 1155-1169.

KENNETT, J.P., HOUTZ, R.E., ANDREWS, P.B. et al. 1975b : Site 278. in : Kennett, J.P., Houtz, R.E. et al. (eds.), Initial Reports of the Deep Sea Drilling Project, Volume 29, United States Government Printing Office, Washington, pp 121-190.

KENNETT, J.P. and HOUTZ, R.E., ANDREWS, P.B. et al. 1975c : Site 280. in : Kennett, J.P., Houtz, R.E. et al. (eds.), Initial Reports of the Deep Sea Drilling Project, Volume 29, United States Government Printing Office, Washington, pp 225-270.

KENNETT, J.P., HOUTZ, R.E., ANDREWS, P.B. et al. 1975d : Site 281. in : Kennett, J.P., Houtz, R.E. et al. (eds.), Initial Reports of the Deep Sea Drilling Project, Volume 29, United States Government Printing Office, Washington, pp 271-316. 
KENNETT, J.P. and VELLA, P. 1975 : Late Cenozoic planktonic foraminifera and paleoceanography at DSDP Site 284 in the cool subtropical south Pacific. in : Kennett, J.P., Houtz, R.E. et al. (eds.), Initial Reports of the Deep Sea Drilling Project, Volume 29, United States Government Printing Office, Washington, pp 769-799.

KENNETT, J.P. and WATKINS, N.D. 1970 : Geomagnetic polarity change, volcanic maxima and faunal extinction in the South Pacific. Nature 227 (5261) : 930-934.

KENNETT, J.P. and WATKINS, N.D. 1974 : Late Miocene - early Pliocene paleomagnetic stratigraphy, paleoclimatology, and biostratigraphy in New Zealand. Geological Society of America Bulletin 85: 1385-1398.

KENNETT, J.P. and WATKINS, N.D. 1976 : Regional deep-sea dynamic processes recorded by late Cenozoic sediments of the southeastern Indian Ocean. Geological Society of America Bulletin 87 : 321-339.

KENNETT, J.P., WATKINS, N.D., and VELLA, P. 1971 : Paleomagnetic chronology of Pliocene-Early Pleistocene climates and the Plio-Pleistocene boundary in New Zealand. Science $171:$ 276-279.

KING, K. 1974 : Preserved amino acids from silicified protein in fossil Radiolaria. Nature 252 (5485) : 690-692.

KINGMA, J.T. 1971 : Geology of Te Aute Subdivision. New Zealand Geological Survey Bulletin 70. 173pp.

KLING, S.A. 1971a : Dimorphism in Radiolaria. in : Farinacci, A. (ed.), Proceedings of the II Planktonic Conference, Roma, 1970, Edizioni Technoscienza, Roma, pp 663-672.

KLING, S.A. 1971b : Radiolaria : Leg 6 of the Deep Sea Drilling Project. in : Fischer, A.G., Heezen, B.C. et al. (eds.), Initial Reports of the Deep Sea Drilling Project, Volume 6, United States Government Printing Office, Washington, pp 1069-1117.

KLING, S.A. 1973 : Radiolaria from the eastern north Pacific, Deep Sea Drilling Project, Leg 18. in : Kulm, L.D., von Huene, R. et al. (eds.), Initial Reports of the Deep Sea Drilling Project, Volume 18, United States Government Printing Office, Washington, pp 617-671.

KLING, S.A. 1978 : Radiolaria. in : Haq, B.U. and Boersma, A. (eds.), Introduction to Marine Micropaleontology, Elsevier, New York, pp 203-244.

KLING, S.A. 1979 : Vertical distribution of polycystine radiolarians in the central north Pacific. Marine Micropaleontology $4:$ 295-318.

KLING, S.A. 1982 : Radiolarians from the Mariana Trough and Trench Region : Deep Sea Drilling Project Leg 60. in : Lee, M. and Powell, R. (eds.), Initial Reports of the Deep Sea Drilling Project, Volume 60, United States Government Printing Office, Washington, pp 537-555.

KOBAYASHI, J. 1967 : Silica in fresh water and estuaries. in : Golterman, H.L. and Clymo, R.S. (eds.), Chemical environment in the aquatic habitat, Uitgevers Maatschappij, Amsterdam, pp41-55.

KOZLOVA, G.E. 1960 : Radiolyarii srednego i verkhnego miotsena Severnogo Sakhalina. Trudy vses. neft. nauchno-issled. geol. -razv. Inst., vyp. 153, (Mikrofauna SSSR 11), $\mathrm{pp} 307-325$. 
KRASHENINNIKOV, V.A. and HOSKINS, R.H. 1973 : Late Cretaceous, Paleogene and Neogene planktonic foraminifera. in : Heezen, B.B. and MacGregor, I.D. et al. (eds.), Initial Reports of the Deep Sea Drilling Project, Volume 20, United States Government Printing Office, Washington, pp 105-203.

KRAUSKOPF, K.B. 1959 : The geochemistry of silica in sedimentary environments. in : Ireland, H.A. (ed.), Silica in Sediments, Society of Economic Paleontologists and Mineralogists Special Publication $7: 4-19$.

LAING, A.C.M. 1964 : The geology of the Waipatiki Area (N150/5). Unpublished MSc thesis, Victoria University of Wellington, 40pp.

LAWS, R.A. 1983 : Preparing strewn slides for quantitative microscopical analysis : a test using calibrated microspheres. Micropaleontology 29 (1) : 60-65.

LAYNE, N.M. 1950 : A procedure for shale disintegration. The Micropaleontologist 4 : 21.

LEDBETTER, M.T., CIESIELSKI, P.F., OSBORN, N.I., and ALLISON, E.T. 1983 : Bottomcurrent erosion in the southeast Indian and southwest Pacific oceans in the last 5.4 million years. in : Oliver, R.L., James, P.R., and Jago, J.B. (eds.) Antarctic Earth Sciences : proceedings of the Fourth International Symposium on Antarctic Earth Sciences, held at the University of Adelaide, South Australia, 16 to 20 August, 1982, Australian Academy of Science, Canberrra, pp 379-383.

LEWIN, J.C. 1961 : The dissolution of silica from diatom walls. Geochimica et Cosmochimica Acta 21 : 182-198.

LIENHART, B.R, CHRISTOFFEL, D.A., and VELLA, P. 1972 : Geomagnetic dates on a New Zealand Upper Miocene-Pliocene section. Earth and Planetary Science Letters 16 : 195-199.

LING, H.Y. 1966 : Notes on the patagium in the radiolarian genera Hymeniastrum and Dictyastrum. Micropaleontology 12 (4) : 489-492.

LING, H.Y. 1971 : Silicoflagellates and ebridians from the Shinzan diatomaceous mudstone member of the Onnagawa Formation (Miocene), Northeast Japan. in : Farinacci, A. (ed.), Proceedings of the II Planktonic Conference, Roma, 1970, Edizioni Tecnoscienza, Rome, pp 689-703.

LING, H.Y. 1973 : Radiolaria : Leg 19 of the Deep Sea Drilling Project. in : Creager, J.S., Scholl, D.W. et al. (eds.), Initial Reports of the Deep Sea Drilling Project, Volume 19, United States Government Printing Office, Washington, pp 777-797.

LING, H.Y. 1975 : Radiolaria : Leg 31 of the Deep Sea Drilling Project. in : Karig, D.E., Ingle, J.C. et al. (eds.), Initial Reports of the Deep Sea Drilling Project, Volume 31, United States Government Printing Office, Washington, pp 703-761.

LING, H.Y. 1979 : Radiolarians from the west flank of Reykjanes Ridge, Leg 49 of the Deep Sea Drilling Project. in : Shambach, J.D. (ed.), Initial Reports of the Deep Sea Drilling Project, Volume 49, United States Government Printing Office, Washington, pp 583-588.

LING, H.Y. 1980 : Radiolarians from the Emperor seamounts of the northwest Pacific : Leg 55 of the Deep Sea Drilling Project. in : Jackson, E.D. and Koisumi, I. et al. (eds.), Initial Reports of the Deep Sea Drilling Project, Volume 55, United States Government Printing Office, Washington, pp 365-373. 
LING, H.Y. and ANIKOUCHINE, W.A. 1967 : Some spumellarian Radiolaria from the Java, Philippine, and Mariana Trenches. Journal of Paleontology 41 (6) : 1481-1491.

LING, H.Y. and KURIHARA, K. 1972 : Radiolaria and silicoflagellates from the Hayama Group, Kanagawa Prefecture, Japan. Acta Geologica Taiwanica. Science Reports of the National Taiwan University $15: 31-40$.

LING, H.Y., STADUM, C.J., and WELCH, M.L. 1971 : Polycystine Radiolaria from Bering Sea surface sediments. in : Farinacci, A. (ed.), Proceedings of the II Planktonic Conference, Roma, 1970, pp 705-729.

LISITZIN, A.P. 1971 : Distribution of siliceous microfossils in suspension and in bottom sediments. in : Funnell, B.M., Riedel, W.R. (eds.), The Micropaleontology of the Oceans, Cambridge University Press, pp 173-195.

LISITZIN, A.P. 1972 : Sedimentation in the World Ocean, Society of Economic Paleontologists and Mineralogists Special Publication 17, George Banta, Menasha, Wisconsin. 218pp.

LISS, P.S. and SPENCER, C.P. 1970 : Abiological processes in the removal of silicate from sea water. Geochimica et Cosmochimica Acta 34 : 1073-1088.

LOEBLICH, A.R. and TAPPAN, H. 1961 : Remarks on the systematics of the Sarkodina (Protozoa), renamed homonyms and new validated genera. Proceedings of the Biological Society of Washington $74: 213-214$.

LOUTTT, T.S. 1981 : Late Miocene paleoclimatology : Subantarctic water mass, Southwest Pacific. Marine Micropaleontology $6: 1-27$.

LOUTTT, T.S. and KENNETT, J.P. 1979 : Application of carbon isotope stratigraphy to late Miocene shallow marine sediments, New Zealand. Science 204 : 1196-1199.

LOUTIT, T.S. and KENNETT, J.P. 1981 : New Zealand and Australian Cenozoic sedimentary cycles and global sea-level changes. The American Association of Petroleum Geologists Bulletin 65 (9) : 1586-1601.

LOZANO, J.A. 1974 : Antarctic sedimentary, faunal and sea surface temperature responses during the last 230, 000 years with emphasis on comparison between 18, 000 years and today. Unpublished $\mathrm{PhD}$ thesis, Columbia University, New York, 400pp.

LOZANO, J.A. and HAYS, J.D. 1976 : Relationship of radiolarian assemblages to sediment types and physical oceanography in the Atlantic and Western Indian Ocean Sectors of the Antarctic Ocean. in : Cline, R.M., Hays, J.D. (eds.), Investigation of Late Quaternary Paleoceanography and Paleoclimatology, Geological Society of America Memoir 145, Geological Society of America, Colorado, pp 303-336.

MAEDA, H. 1952 : The relationship between chlorinity and silicate concentration of water observed in some estuaries. Publications of the Seto Marine Biological Laboratory 2 : 249-255.

MALMGREN, B.A. and HAQ, B.U. 1982 : Assessment of quantitative techniques in paleobiogeography. Marine Micropaleontology $7: 213-236$.

MALMGREN, B.A. and KENNETT, J.P. 1981 : Phyletic gradualism in a Late Cenozoic planktonic foraminiferal lineage, DSDP Site 284, southwest Pacific. Paleobiology 7 (2) : $230-240$. 
MARTIN, G.C. 1904 : Radiolaria. in : Maryland Geological Survey, Miocene, The John Hopkins Press, Baltimore, pp 447-459.

MARTINSSON, A. 1975 : Planktic, nektic, benthic. Lethaia 8 (2) : 193-194.

MARWICK, J. 1924a : The Tertiary and Recent Naticidae and Naricidae of New Zealand. Transactions of the New Zealand Institute $55:$ 545-579.

MARWICK, J. 1924b : The Struthiolariidae. Transactions of the New Zealand Institute $55: 161-190$.

MARWICK, J. 1931 : The Tertiary Mollusca of the Gisborne District. New Zealand Geological Survey Paleontological Bulletin 13:159pp.

MARWICK, J. 1965 : Upper Cenozoic Mollusca of Wairoa District, Hawke's Bay. New Zealand Geological Survey Paleontology Bulletin 39, 83p.

MAST, H. 1910 : Die Astrosphaeriden der Deutschen Tiefsee-Expedition. InauguralDissertation zur Erlangung der Doktorwurde einer hohen naturwissenschaftlichen Fakultat der Universitat Tubingen. 68p.

MAURRASSE, F.J.-M.R. 1979 : Cenozoic radiolarian paleobiogeography : Implications concerning plate tectonics and climatic cycles. Palaeogeography, Palaeoclimatology, Palaeoecology 26 : 253-289.

McCOLLUM 1975 : Diatom stratigraphy of the southern ocean. in : Hayes, D.E., Frakes, L.A. et al. (eds.), Initial Reports of the Deep Sea Drilling Project, Volume 28, United States Government Printing Office, Washington, pp 515-571.

McDOUGALL, I. and PAGE, R.W. 1975 : Toward a physical time-scale for the Neogene - Data from the Australian region. in : Saito, T. and Burckle, L.H. (eds.), Late Neogene Epoch Boundaries, Micropaleontology Special Publication 1, Micropaleontology Press, New York, pp 75-84.

McINNES, B.A. 1964 : A detailed examination of microfaunas from a Miocene-Pliocene (Taranakian-Opoitian-Waitotaran) section on the Mangapoike River, northern Hawkes Bay. New Zealand Geological Survey Open-file Petroleum Report 350. 27pp.

McINNES, B.A. 1965 : Globorotalia miozea Finlay as an ancestor of Globorotalia inflata (d'Orbigny). New Zealand Journal of Geology and Geophysics 8 (1): 104-108.

McINTYRE, A., BE, A.W.H., and PREIKSTAS, R. 1967 : Coccoliths and the PliocenePleistocene boundary. in : Sears, M. (ed.), The Quaternary history of the ocean basins, Progress in Oceanography, Volume 4, Pergamon Press, New York. pp 3-25.

McMILLEN, KJ. 1979 : Radiolarian ratios and the Pleistocene-Holocene boundary. Transactions of the Gulf Coast Association of Geological Societies 29 : 298-301.

McMILLEN, K.J. and CASEY, R.E. 1978 : Distribution of living polycystine radiolarians in the Gulf of Mexico and Caribbean Sea, and comparison with the sedimentary record. Marine Micropaleontology $3: 121-145$.

MEYEN, FJ.F. 1834 : Uber das Leuchten des Meeres und Beschreibung einiger Polypen und anderer niederer Thiere, von demelben. in : Beitrage zur Zoologie, gesammelt auf einer Reise um die Erde, Novorum Actorum Academiae Caesareae Leopoldino Carolinae Naturae Curiosorum 16 (1) : 125-216. 
MILDENHALL, D.C. 1978 : Palynology of the Waipipian and Hautawan Stages (Pliocene and Pleistocene), Wanganui, New Zealand. (Note). New Zealand Journal of Geology and Geophysics 21 (6) : 775-777.

MILDENHALL, D.C. 1979 : Palynology of the Upton Group, late Miocene to early Pliocene age (Tongaporutuan to Waipipian), Blind River, Marlborough, New Zealand. New Zealand Geological Survey Palynology Section Report 41/79, 7pp.

MILDENHALL, D.C. and HARRIS, W.F. 1970 : A cool climate pollen assemblage from the type Waipipian (middle Pliocene) of New Zealand. New Zealand Journal of Geology and Geophysics 13 (3) : 586-591.

MILLER, K.G., AUBRY, M-P., KHAN, M.J. et al. 1985 : Oligocene-Miocene biostratigraphy, magnetostratigraphy, and isotope stratigraphy of the western North Atlantic. Geology 13 (4) : 257-261.

MOLFINO, B., KIPP, N.G., and MORLEY, J.J. 1982 : Comparison of foraminiferal, coccolithophorid, and radiolarian paleotemperature equations : assemblage coherency and estimate concordancy. Quaternary Research $17: 279-313$.

MOLINA-CRUZ, A. 1975 : Paleo-oceanography of the subtropical southeastern Pacific during Late Quaternary : a study of Radiolaria, opal and quartz contents of deep-sea sediments. Unpublished MSc thesis, Oregon State University, Corvallis, $179 \mathrm{pp}$.

MOLINA-CRUZ, A. 1977 : Radiolarian assemblages and their relationship to the oceanography of the subtropical southeastern Pacific. Marine Micropaleontology 2 : 315-352.

MOORE, T.C. 1969 : Radiolaria : change in skeletal weight and resistance to solution. Geological Society of America Bulletin 80 : 2103-2108.

MOORE, T.C. 1971 : Radiolaria. in : Tracey, J.I., Sutton, G.H. et al. (eds.), Initial Reports of the Deep Sea Drilling Project, Volume 8, United States Government Printing Office, Washington, pp 727-775.

MOORE, T.C. 1972 : Mid-Tertiary evolution of the radiolarian genus Calocycletta. Micropaleontology 18 (2) : 144-152.

MOORE, T.C. 1973 : Method of randomly distributing grains for microscopic examination. Journal of Sedimentary Petrology 43 (3) : 904-906.

MOORE, T.C. 1973a : Late Pleistocene-Holocene oceanographic changes in the northwestern Pacific. Quaternary Research 3 (1) : 99-109.

MOORE, T.C. 1973b : Radiolaria from Leg 17 of the Deep Sea Drilling Project. in : Winterer, E.L., Ewing, J.L. et al. (eds.), Initial Reports of the Deep Sea Drilling Project, Volume 17, United States Government Printing Office, Washington, pp 797-869.

MOORE, T.C. 1978 : The distribution of radiolarian assemblages in the modern and Ice-age Pacific. Marine Micropaleontology $3: 229-266$.

MOORE, T.C. and ROMINE, K. 1981 : In search of biostratigraphic resolution. in : Warme, J.E., Douglas, R.G. and Winterer, E.L. (eds.), The Deep Sea Drilling Project : A Decade of Progress, Society of Economic Paleontologists and Mineralogists Special Publication 32, Tulsa, Oklahoma, pp 317-334.

MOORE, T.C., VAN ANDEL, T.H., SANCETTA, C., and PISIAS, N.G. 1978 : Cenozoic hiatuses in pelagic sediments. Micropaleontology 24 (2) : 113-138. 
MORGANS, H.E.G. 1980 : Stratigraphy of the Neogene sequence at Blind River, Marlborough. New Zealand Geological Survey Report Pal 36. 18pp.

MORLEY, JJ. 1977 : Upper Pleistocene climatic variations in the South Atlantic derived from a quantitative radiolarian analysis : accent on the last 18,000 years. Unpublished $\mathrm{PhD}$ thesis, Columbia University, New York, 282pp.

MORLEY, J.J. and SHACKLETON, N.J. 1978 : Extension of the radiolarian Stylatractus universus as a biostratigraphic datum to the Atlantic Ocean. Geology $6: 309-311$.

MOTTL, M.J. 1983 : Metabasalts, axial hot springs, and the structure of hydrothermal systems at mid-ocean ridges. Geological Society of America Bulletin 94 : 161-180.

MUKHINA, V.V. 1979 : Diatom assemblages in the South-East Pacific. in : Simenson, R. (ed.), Proceedings of the 5th Symposium on Recent and Fossil Diatoms, Antwerp, September 3-8, 1978, Strauss and Cramer, Hirschberg, pp 463-471.

MULLER, J. 1855 : Uber Sphaerozoum und Thalassicola. Monatsberichte der Koniglich preussischen Akademie der Wissenschaften zu Berlin. Jahre 1855: 229-253.

MULLER, J. 1857 : Uber die Thalassicollen, Polycystinen und Acanthometren des Mittelmeeres. Monatsberichte der Koniglich preussischen Akademie der Wissenschaften zu Berlin. Jahre 1856 : 474-503.

MULLER, J. 1858 : Uber die Thalassicollen, Polycystinen und Acanthometren des Mittelmeeres. Abhandlungen der Koniglichen Akademie der Wissenschaften zu Berlin. Jahre $1858: 1-62$.

MULLER, J. 1859 : Einige neue bei St. Tropez am Mittelmeer beobachtete Polycystinen und Acanthometren. Monatsberichte der Koniglich preussischen Akademie der Wissenschaften zu Berlin. Jahre 1858 : 154-155.

MURATA, K.J. and LARSON, R.R. 1975 : Diagenesis of Miocene siliceous shales, Temblor Range, California. United States Geological Survey Journal of Research 3 : 553-566.

NAKASEKO, K. 1955 : Miocene radiolarian fossil assemblage from the southern Toyama Prefecture in Japan. Osaka University Scientific Reports 4 : 65-127.

NAKASEKO, K. 1959a : Applied micropaleontological research by means of radiolarian fossil in the oil bearing Tertiary, Japan (mainly Akita and Yamagata sedimentary basins): Part 1. Method, geological note and radiolarian assemblage in Akita sedimentary basin. Osaka University Science Reports 8 : 113-193.

NAKASEKO, K. 1959b : On Radiolaria from sediments in the sea near Antarctica, part 1: On Superfamily Liosphaericae (Radiolaria) from sediments in the sea near Antarctica. Special Publication of the Seto Marine Biological Laboratory, Biological Results of the Japanese Antarctic Research Expedition 2: 1-20.

NAKASEKO, K. 1960 : Applied micropaleontological research by means of radiolarian fossil in the oil bearing Tertiary, Japan (mainly Akita and Yamagata sedimentary basins) : Part 2. Radiolarian assemblage in Yamagata basin, discussion and conclusion. Osaka University Science Reports 9:149-185.

NAKASEKO, K. 1963 : Neogene Crytoidea (Radiolaria) from the Isozaki Formation in Ibaraki Prefecture, Japan. Osaka University Science Reports 12 (2) : 165-198.

NAKASEKO, K. 1971 : On some species of the genus Thecosphaera from the Neogene Formations, Japan. Osaka University Science Reports 20 (2) : 59-66. 
NAKASEKO, K. and SUGANO, K. 1973 : Neogene radiolarian zonation in Japan. Memoir of the Geological Society of Japan $8: 23-24$.

NEEF, G. 1984 : Late Cenozoic and early Quaternary stratigraphy of the Eketahuna District (N153). New Zealand Geological Survey Bulletin 96, 101pp + map.

NESS, G., LEVI, S., and COUCH, R. 1980 : Marine magnetic anomaly timescales for the Cenozoic and Late Cretaceous. A precis, critique, and synthesis. Geophysics and Space Physics Reviews 18 (4) : 753-770.

NIGRINI, C. 1967 : Radiolaria in pelagic sediments from the Indian and Atlantic Oceans. Bulletin of the Scripps Institute of Oceanography 11 : 1-106.

NIGRINI, C. 1968 : Radiolaria from eastern tropical Pacific sediments. Micropaleontology 14 (1) : 51-63.

NIGRINI, C. 1970 : Radiolarian assemblages in the north Pacific and their application to a study of Quaternary sediments in core V20-130. in : Hays, J.D. (ed.), Geological Investigations of the North Pacific, Geological Society of America Memoir 126, Geological Society of America, Boulder, Colorado, pp 139-183.

NIGRINI, C. 1971 : Radiolarian zones in the Quaternary of the equatorial Pacific Ocean. in : Funnell, B.M., Riedel, W.R. (eds.), The Micropaleontology of the Oceans, Cambridge University Press, pp 443-461.

NIGRINI, C. 1974 : Cenozoic Radiolaria from the Arabian Sea, DSDP Leg 23. in : Davies, T.A., Luyendyk, B.P. et al. (eds.), Initial Reports of the Deep Sea Drilling Project, Volume 26, United States Government Printing Office, Washington, pp 1051-1121.

NIGRINI, C. 1977 : Tropical Cenozoic Artostrobiidae (Radiolaria). Micropaleontology 23 (3) : 241-269.

NIGRINI, C. and LOMBARI, G. 1984 : A guide to Miocene Radiolaria. Cushman Foundation for Foraminiferal Research Special Publication Number 22, 308pp.

NIGRINI, C. and MOORE, T.C. 1979 : A guide to modern Radiolaria. Cushman Foundation for Foraminiferal Research Special Publication 16. 274pp.

NOSHKIN, V.E. and BOWEN, V.T. 1973 : Concentrations and distributions of longlived fallout radionuclides in open ocean sediments. in : Radioactive Contamination of the Marine Environment, International Atomic Energy Agency, Vienna. pp671-686.

OBRADOVICH, J.D., NAESER, C.W., and IZETT, G.A. 1978 : Geochronology of late Neogene marine strata in California. in : Correlation of tropical through high latitude marine Neogene deposits of the Pacific Basin, International Geological Correlation Programme (IGCP), Project 114, Biostratigraphic Datum-planes of the Pacific Neogene, Third Working Group Meeting - Abstracts and Program, Stanford University Publications, Geological Sciences Volume 14, pp 40-41.

OEHLER, J.H. 1975 : Origin and distribution of silica lepispheres in porcelanite from the Monterey Formation of California. Journal of Sedimentary Petrology 45 (1) : 252-257.

ONGLEY, M. 1930 : Wairoa Subdivision. New Zealand Geological Survey 24th Annual Report : 7-10.

OPDYKE, N.D. 1972 : Paleomagnetism of deep-sea cores. Reviews of Geophysics and Space Physics 10 (1) : 213-249. 
OPDYKE, N.D., GLASS, B., HAYS, J.D., and FOSTER, J. 1966 : Paleomagnetic study of Antarctic deep-sea cores. Science $154:$ 349-357.

ORBELL, G.E. 1962 : Geology of the Mauriceville District, New Zealand. Transactions of the Royal Society of New Zealand 1 (17): 253-267.

PANTANELll, D. and STEFANI, De 1879 : Radiolarie di Santa Barbera in Calabria. Atti della Societa Toscana di Scienze Naturali 2 : 59-60.

PARKER, F.L. 1974 : Upper Neogene biostratigraphy (planktonic foraminifera) of DSDP Sites 139 and 141. Journal of Foraminiferal Research 4 (1) : 9-15.

PETERSON, M.N.A. and GOLDBERG, E.D. 1962 : Feldspar distributions in South Pacific pelagic sediments. Journal of Geophysical Research $67: 3477-3492$.

PETRUSHEVSKAYA, M.G. 1967 : Radiolarians of the Orders Spumellaria and Nassellaria of the Antarctic Region (according to data of the Soviet Antarctic Expedition). Issled. Fauny Morei 4(12), Rez. biol. Issled. sov. antarkt. Eksped 1955-58, p.5-186.

PETRUSHEVSKAYA, M.G. 1971a : Radiolaria in the plankton and Recent sediments from the Indian Ocean and Antarctic. in : Funnell, B.M., Riedel, W.R. (eds.), The Micropaleontology of the Oceans, Cambridge University Press, pp 319-329.

PETRUSHEVSKAYA, M.G. 1971b : Spumellarian and nassellarian Radiolaria in the plankton and bottom sediments of the central Pacific. in : Funnell, B.M. and Riedel, W.R. (eds.), The Micropaleontology of the Oceans, Cambridge University Press, pp 309-317.

PETRUSHEVSKAYA, M.G. 1971c : Investigations of the Faunas of the Seas IX (XVII). Radiolarians of the World Ocean according to data of Soviet Expeditions. in : Strelkov, A.A. (ed.), Nauka, Leningrad Department, Leningrad, 1971. 418pp.

PETRUSHEVSKAYA, M.G. 1975 : Cenozoic radiolarians of the Antarctic, Leg 29, DSDP. in : Kennett, J.P., Houtz, R.E. et al. (eds.), Initial Reports of the Deep Sea Drilling Project, Volume 29, United States Government Printing Office, Washington, pp 541-675.

PETRUSHEVSKAYA, M.G. and KOZLOVA, G.E. 1972 : Radiolaria : Leg 14, DSDP. in : Hayes, D.E., Pimm, A.C. et al. (eds.), Initial Reports of the Deep Sea Drilling Project, Volume 14, United States Government Printing Office, Washington, pp 495-648.

PISIAS, N.G. and MOORE, T.C. 1978 : Cenozoic radiolarians from Deep Sea Drilling Project Leg 40. in : Bolli, H.M., Ryan, W.B.F. et al. (eds.), Initial Reports of the Deep Sea Drilling Project, Volume 40, United States Government Printing Office, Washington, pp 845-856.

POKORNY, V. 1963 : Principles of Zoological Micropaleontology, International Series of Monographs on Earth Sciences, Volume 10, Translated from Grundzuge der Zoologischen Mikropalaontologie, Bd. 1. 1958 by K.A. Allen, Pergamon Press, London, 652pp.

POPOFSKY, A. 1908 : Die Radiolarien der Antarktis (mit Ausnahme der Tripyleen). Deutsche Sudpolar-Expedition 1901-1903, volume 10 (Zoology vol. 2), number 3 : 183-305.

POPOFSKY, A. 1917 : Die Collosphaeriden, mit Nachtrag zu den Spumellarien und Nassellarien. Deutsche Sudpolar-Expedition 1901-1903, volume 16 (Zoology vol. 8), number $3: 235-278$. 
PYTKOWICZ, R.M. 1967 : Carbonate cycle and the buffer mechanism of recent oceans. Geochimica et Cosmochimica Acta 31 : 63-73.

QUILTY, P.G. 1978 : Comparison of tropical-Antarctic deep marine and land based late Tertiary sections, southwest Pacific. in : Correlation of tropical through high latitude marine Neogene deposits of the Pacific Basin, International Geological Correlation Programme (IGCP), Project 114, Biostratigraphic Datum-planes of the Pacific Neogene, Third Working Group Meeting - Abstracts and Program, Stanford University Publications, Geological Sciences Volume 14, p 44.

RENZ, G.W. 1974 : Radiolaria from Leg 27 of the Deep Sea Drilling Project. in : Veevers, J.J., Heirtzler, J.R. et al. (eds.), Initial Reports of the Deep Sea Drilling Project, Volume 27, United States Government Printing Office, Washington, pp 769-841.

RENZ, G.W. 1976 : The distribution and ecology of Radiolaria in the central Pacific plankton and surface sediments. Bulletin of the Scripps Institute of Oceanography $22: 1-267$.

RESHETNJAK, V.V. 1971 : Occurrence of Phaeodarian Radiolaria in Recent sediments and Tertiary deposits. in : Funnell, B.M., Riedel, W.R. (eds.), The Micropaleontology of the Oceans, Cambridge University Press, pp 343-349.

RESIG, J.M., LING, H.Y., and STADUM, C.J. 1970 : Micropaleontology of a Miocene core from the western tropical Pacific. Pacific Science 24 (4) : 421-432.

REYNOLDS, R. 1980 : Radiolarians from the western North Pacific, Leg 57, Deep Sea Drilling Project. in : von Huene, R., Nasu, N. et al. (eds.), Initial Reports of the Deep Sea Drilling Project, Volume 56-57 (2), United States Government Printing Office, Washington, pp 735-769.

REYNOLDS, R., SAKAI, T, and CASEY, R.E. 1980 : Synthesis of radiolarian results from DSDP Legs 56 and 57 and their relation to other North Pacific sections. in : von Huene, R., Nasu, N. et al. (eds.), Initial Reports of the Deep Sea Drilling Project, Volume 56-57 (2), United States Government Printing Office, Washington, pp 771-773

RIDD, M.F. 1964 : Succession and structural interpretation of the Whangara-Waimata Area. New Zealand Journal of Geology and Geophysics 7 (2) : 279-298.

RIEDEL, W.R. 1952 : Tertiary Radiolaria in western Pacific sediments. Goteborgs Kungl. Vetenskaps- och Vitterhets-samhalles, Sjatte Foljden, Series B, Band 6 (3): 1-18.

RIEDEL, W.R. 1953 : Mesozoic and late Tertiary Radiolaria of Rotti. Journal of Paleontology 27 (6) : 805-813.

RIEDEL, W.R. 1957 : Radiolaria : A preliminary stratigraphy. Reports of the Swedish Deep-Sea Expedition 1947-48, 6 (3) : 59-96.

RIEDEL, W.R. 1958 : Radiolaria in Antarctic sediments. Reports of the British, Australian, New Zealand Antarctic Research Expedition, series B, volume 6 (10) : 217-255.

RIEDEL, W.R. 1959 : Oligocene and lower Miocene Radiolaria in tropical Pacific sediments. Micropaleontology 5 (3) : 285-302.

RIEDEL, W.R. 1963 : Paleontology of pelagic sediments. in : Hill, M.N. (ed.), The Sea, Volume 3, Interscience, New York. pp 866-887. 
RIEDEL, W.R. 1967a : Protozoa, class Actinopoda : section on Radiolaria (Chapter 8). in : Harland, W.B. et al. (eds.), The Fossil Record : a symposium with documentation, Geological Society of London, pp 291-299.

RIEDEL, W.R. 1967b : Some new families of Radiolaria. Proceedings of the Geological Society of London $1640: 148-149$.

RIEDEL, W.R. 1971a : The occurrence of pre-Quaternary Radiolaria in deep-sea sediments. in : Funnell, B.M., Riedel, W.R. (eds.), The Micropaleontology of the Oceans, Cambridge University Press, pp 567-594.

RIEDEL, W.R. 1971b : Systematic classification of polycystine Radiolaria. in : Funnell, B.M., Riedel, W.R. (eds.), The Micropaleontology of the Oceans, Cambridge University Press, pp 649-661.

RIEDEL, W.R. and FUNNELL, B.M. 1964 : Tertiary sediment cores and microfossils from the Pacific Ocean floor. Quarterly Journal of the Geological Society of London $120: 305-368$.

RIEDEL, W.R. and HAYS, J.D. 1969 : Cenozoic Radiolaria from Leg 1. in : Ewing, M., Worzel, J.L. et al. (eds.), Initial Reports of the Deep Sea Drilling Project, Volume 1, United States Government Printing Office, Washington, pp 400-402.

RIEDEL, W.R. and SANFILIPPO, A. 1970 : Radiolaria, Leg 4, Deep Sea Drilling Project. in : Bader, R.G., Gerard, R.D. et al. (eds.), Initial Reports of the Deep Sea Drilling Project, Volume 4, United States Government Printing Office, Washington, pp 503-575.

RIEDEL, W.R. and SANFILIPPO, A. 1971 : Cenozoic radiolaria from the western tropical Pacific, Leg 7. in : Winterer, E.L., Riedel, W.R. et al. (eds.), Initial Reports of the Deep Sea Drilling Project, Volume 7, United States Government Printing Office, Washington, pp 1529-1672.

RIEDEL, W.R. and SANFILIPPO, A. 1973 : Cenozoic Radiolaria from the Caribbean, Deep Sea Drilling Project, Leg 15. in : Edgar, N.T., Saunders, J.B. et al. (eds.), Initial Reports of the Deep Sea Drilling Project, Volume 15, United States Government Printing Office, Washington, pp 705-751.

RIEDEL, W.R. and SANFILIPPO, A. 1974 : Radiolaria from the southern Indian Ocean, DSDP Leg 26. in : Davies, T.A., Luyendyk, B.P. et al. (eds.), Initial Reports of the Deep Sea Drilling Project, Volume 26, United States Government Printing Office, Washington, pp 771-813.

RIEDEL, W.R. and SANFILIPPO, A. 1977 : Cainozoic Radiolaria. in : Ramsay, A.T.S. (ed.), Oceanic Micropaleontology, Academic Press, London, pp 847-912.

RIEDEL, W.R. and SANFILIPPO, A. 1978a : Micropaleontological counting methods and techniques : An exercise on an eight metres section of the lower Pliocene of Capo Rossello, Sicily. Radiolaria. Utrecht Micropaleontological Bulletin 17 : 81-128.

RIEDEL, W.R. and SANFILIPPO, A. 1978b : Stratigraphy and evolution of tropical Cenozoic radiolarians. Micropaleontology 24 (1) : 61-96.

RIEDEL, W.R., SANFILIPPO, A., and CITA, M.B. 1974 : Studi sul Pliocene e sugli strati di passaggio dal Miocene al Pliocene. VI. Radiolarians from the stratotype Zanclean (lower Pliocene, Sicily). Rivista Italiana di Paleontologia e Stratigrafia 80 (4) : 699-734. 
RIEDEL, W.R. and WESTBERG, MJ. 1973 : Neogene radiolarians from the eastern tropical Pacific and Caribbean, Deep Sea Drilling Project Leg 68. in : Prell, W.C., Gardner, J.V. et al. (eds.), Initial Reports of the Deep Sea Drilling Project, Volume 68, United States Government Printing Office, Washington, pp 289-300.

RIEDEL, W.R., WESTBERG-SMITH, M.J., and BUDAI, A. 1985 : Late Neogene Radiolaria and Mediterranean paleoenvironments. in: Stanley, D.J. and Wezel, F-C. (eds.) Geological Evolution of the Mediterranean Basin : Raimondo Selli Commemorative Volume, Springer-Verlag, New York : pp 487-523.

ROBERTSON, J. 1975 : Glacial to interglacial oceanographic changes in the northwest Pacific, including a continuous record of the last 400,000 years. Unpublished $\mathrm{PhD}$ thesis, Columbia University, New York, 355pp.

RUDDIMAN, W.F. and GLOVER, L.K. 1972 : Vertical mixing of ice-rafted volcanic ash in north Atlantic sediments. Geological Society of America Bulletin 83 : 2817-2836.

RUPKE, N.A. 1978 : Deep clastic seas. in : Reading, H.G. (ed.), Sedimentary Environments and Facies, Blackwell Scientific, Oxford, pp 372-415.

RUST, D. 1885 : Beitrage zur Kenntniss der fossilen Radiolarien aus Gesteinen des Jura. Paleontographica $31: 269-321$.

RUST, D. 1898 : Neue Beitrage zur Kenntniss der fossilen Radiolarien aus Gesteinen des Jura und der Kreide. Paleontographica 45 : 1-67.

RYAN, W.B.F., CTTA, M.B., RAWSON, M.D. et al. 1974 : A paleomagnetic assignment of Neogene stage boundaries and the development of isochronous datum planes between the Mediterranean, the Pacific and Indian Oceans in order to investigate the response of the world ocean to the Mediterranean "salinity crisis". Rivista Italiana di Paleontologia e Stratigrafia 80 (4) : 631-688.

SACHS, H.M. 1973 : Quantitative radiolarian-based paleaceanography in Late Pleistocene subarctic Pacific sediments. Unpublished $\mathrm{PhD}$ dissertation, Brown University, Providence. 280p.

SACHS, H.M. 1976 : Nazca Plate radiolarian distributions : evidence from DSDP Sites 319, 320 and 321. in : Yeats, R.S., Hart, S.R. et al. (eds.), Initial Reports of the Deep Sea Drilling Project, Volume 34, United States Government Printing Office, Washington, pp 713-714.

SACHS, H.M. and HASSON, P.F. 1979 : Comparison of species vs. character description for very high resolution biostratigraphy using cannartid radiolarians. Journal of Paleontology 53 (5) : 1112-1120.

SAITO, T., BURCKLE, L.H., and HAYS, J.D. 1975 : Late Miocene to Pleistocene biostratigraphy of equatorial Pacific sediments. in : Saito, T., Burckle, L.H. (eds.), Late Neogene Epoch Boundaries, Micropaleontology Special Publication 1, Micropaleontology Press, New York, pp 226-244.

SAKAI, T. 1980 : Radiolarians from Sites 434, 435 and 436, northwest Pacific, Leg 56, Deep Sea Drilling Project. in : Lee, M. and Stout, L.N. (eds.), Initial Reports of the Deep Sea Drilling Project, Volume 56-57 (2), United States Government Printing Office, Washington, pp 695-733. 
SANCETTA, C. 1978 : Neogene planktonic provinces : a synthesis of DSDP material. in : Correlation of tropical through high latitude marine Neogene deposits of the Pacific Basin, International Geological Correlation Programme (IGCP), Project 114, Biostratigraphic Datum-planes of the Pacific Neogene, Third Working Group Meeting - Abstracts and Program, Stanford University Publications, Geological Sciences Volume 14, pp 47-48.

SANCETTA, C. 1978 : Neogene Pacific microfossils and paleoceanography. Marine Micropaleontology $3: 347-376$.

SANFILIPPO, A. 1971 : Neogene radiolarians of the Mediterranean and western Pacific. in : Farinacci, A. (ed.), Proceedings of the II Planktonic Conference, Roma, 1970, Edizioni Technoscienza, Roma, pp 1121-1127.

SANFILIPPO, A., BURCKLE, L.H., MARTINI, E., and RIEDEL, W.R. 1973 : Radiolarians, diatoms, silicoflagellates and calcareous nannofossils in the Mediterranean Neogene. Micropaleontology 19 (2) : 209-234.

SANFILIPPO, A., CAULET, J.P., and RIEDEL, W.R. 1978 : Radiolaria from Mediterranean sediments, DSDP Leg 42A. in : Hsu, K., Montadert, L. et al. (eds.), Initial Reports of the Deep Sea Drilling Project, Volume 42 (1), United States Government Printing Office, Washington, pp 753-760.

SANFILIPPO, A. and RIEDEL, W.R. 1970 : Post Eocene "closed" theoperid radiolarians. Micropaleontology 16 (4) : 446-462.

SANFILIPPO, A. and RIEDEL, W.R. 1973 : Cenozoic Radiolaria (exclusive of Theoperids, Artostrobiids and Amphipyndacids) from the Gulf of Mexico, Deep Sea Drilling Project, Leg 10. in : Worzel, J.L., Bryant, W. et al. (eds.), Initial Reports of the Deep Sea Drilling Project, Volume 10, United States Government Printing Office, Washington, pp 475-611.

SANFILIPPO, A. and RIEDEL, W.R. 1974 : Radiolaria from the west-central Indian Ocean and Gulf of Aden, DSDP Leg 24. in : Fischer, R.L., Bunce, E.T. et al. (eds.), Initial Reports of the Deep Sea Drilling Project, Volume 24, United States Government Printing Office, Washington, pp 997-1035.

SANFILIPPO, A. and RIEDEL, W.R. 1975 : Late Tertiary radiolarians from Crete. in : Proceedings of the VIth Congress Regional Committee on Mediterranean Neogene stratigraphy, Bratislava, 1975, pp 61-74.

SANFILIPPO, A. and RIEDEL, W.R. 1979 : Radiolaria from the northeastern Atlantic Ocean, DSDP Leg 48. in : Montadert, L., Roberts, D.G. et al. (eds.), Initial Reports of the Deep Sea Drilling Project, Volume 48, United States Government Printing Office, Washington, pp 493-511.

SANFILIPPO, A. and RIEDEL, W.R. 1980 : A revised generic and suprageneric classification of the Artiscins (Radiolaria). Journal of Paleontology 54 (5) : 1008-1011.

SANFILIPPO, A. and RIEDEL, W.R. 1982 : Revision of the radiolarian genera Theocotyle, Theocotylissa, and Thyrsocyrtis. Micropaleontology 28 (2) : 170-188.

SANFILIPPO, A., WESTBERG, M.J., and RIEDEL, W.R. 1981 : Cenozoic radiolarians at Site 462, Deep Sea Drilling Project Leg 61, western tropical Pacific. in : Shambach, J. and Stout, L.N. (eds.), Initial Reports of the Deep Sea Drilling Project, Volume 61, United States Government Printing Office, Washington, pp 495-505. 
SCOTT, G.H. 1976a : Globorotalia conomiozea : Taxonomy and dispersal. in : Takayanagi, Y., Saito, T. (eds.), Progress in Micropaleontology : Selected papers in honor of Prof. Kiyoshi Asano, Micropaleontology Special Publication, Micropaleontology Press, New York, pp 306-313.

SCOTT, G.H. 1976b : Globorotalia crassula (Foraminiferida) : Blow's interpretation considered biometrically. Palaeontology 19 (1) : 95-105.

SCOTT, G.H. 1978a : Shell design in Bolivinita quadrilatera, B. pohana, and $B$. compressa (Foraminiferida). New Zealand Journal of Geology and Geophysics 21 (1) : 85-95.

SCOTT, G.H. 1978b : Early history of Bolivinita pliozea Finlay (Foraminiferida, Neogene, New Zealand). New Zealand Journal of Geology and Geophysics 21 (5) : 617-634.

SCOTT, G.H. 1979a : The Late Miocene to Early Pliocene history of the Globorotalia miozea plexus from Blind River, New Zealand. Marine Micropaleontology 4 : 341-361.

SCOTT, G.H. 1979b : Variation in Bolivinita quadrilatera (Foraminiferida, upper Neogene, New Zealand). New Zealand Journal of Geology and Geophysics 22 (4) : 509-519.

SCOTT, G.H. 1980a : Globorotalia inflata lineage and G. crassaformis from Blind River, New Zealand : recognition, relationship, and use in uppermost Miocene-lower Pliocene biostratigraphy. New Zealand Journal of Geology and Geophysics 23 : 665-677.

SCOTT, G.H. 1980b : Upper Miocene biostratigraphy : does Globorotalia conomiozea occur in the Messinian?. Revista Espanola de Micropaleontologia 12 (3) : 489-506.

SCOTT, G.H. 1982a : Tempo and stratigraphic record of speciation in Globorotalia puncticulata. Journal of Foraminiferal Research 12 (1) : 1-12.

SCOTT, G.H. 1982b : Review of Kapitean Stratotype and boundary with Opoitian Stage (upper Neogene, New Zealand). New Zealand Journal of Geology and Geophysics 25 (4) : 475-485.

SEGUENZA, G. 1880 : Le formazioni terziarie nella provincia di Reggio (Calabria). Atti della $R$. accademia dei lincei anno CCLXXVII. Serie Terza. pp1-446.

SEIBOLD, E. 1978 : Mechanical processes influencing the distribution of pelagic sediments. Micropaleontology 24 (4) : 407-421.

SEWARD, D. 1974 : Age of New Zealand Pleistocene substages by fission-track dating of glass shards from tephra horizons. Earth and Planetary Science Letters 24 : 242-248.

SEWARD, D. 1978 : Palaeosalinities and palaeotemperatures from carbon and oxygen isotopes of carbonate shells in three Quaternary formations, Wanganui Basin, New Zealand. Palaeogeography, Palaeoclimatology, Palaeoecology 23 : 47-55.

SEWARD, D. 1979 : Comparison of zircon and glass fission-track ages from tephra horizons. Geology $7: 479-482$. 
SHACKLETON, N.J. and CITA, M.B. 1979 : Oxygen and carbon isotope stratigraphy of benthic foraminifers at Site 397 : detailed history of climatic change during the late Neogene. in : von Rad, U, Ryan, W.B.F. et al. (eds.), Initial Reports of the Deep Sea Drilling Project, Volume 47 (1), United States Government Printing Office, Washington, pp 433-445.

SHACKLETON, N.J. and KENNETT, J.P. 1975a : Paleotemperature history of the Cenozoic and the initiation of Antarctic glaciation: Oxygen and carbon isotope analyses in DSDP Sites 277, 279, and 281. in : Kennett, J.P., Houtz, R.E. et al. (eds.), Initial Reports of the Deep Sea Drilling Project, Volume 29, United States Government Printing Office, Washington, pp 743-755.

SHACKLETON, N.J. and KENNETT, J.P. 1975b : Late Cenozoic oxygen and carbon isotopic changes at DSDP Site 284: Implications glacial history of the northern hemisphere and Antarctica. in : Kennett, J.P., Houtz, R.E. et al. (eds.), Initial Reports of the Deep Sea Drilling Project, Volume 29, United States Government Printing Office, Washington, pp 801-807.

SLOAN, J. 1980 : Radiolarians from sediments of the Philippine Sea, Deep Sea Drilling Project Leg 58. in : deVries K, G., Kobayashi, K. et al. (eds.), Initial Reports of the Deep Sea Drilling Project, Volume 58, United States Government Printing Office, Washington, pp 587-595.

SMAYDA, TJ. 1971 : Normal and accelerated sinking of phytoplankton in the sea. Marine Geology 11 : 105-122.

SRINIVASAN, M.S. and KENNETT, J.P. 1981 : A review of Neogene planktonic foraminiferal biostratigraphy : Applications in the equatorial and south Pacific. in : Warme, J.E. and Douglas, R.G. and Winterer, E.L. (eds.), The Deep Sea Drilling Project : A Decade of Progress, Society of Economic Paleontologists and Mineralogists Special Publication 32, Tulsa, Oklahoma, pp 395-432.

STADUM, C.J. and LING, H.Y. 1969 : Tripylean Radiolaria in deep-sea sediments of the Norwegian Sea. Micropaleontology 15 (4) : 481-489.

STANLEY, E.M. 1973 : Minor trace element abundance in radiolarian tests. Geological Society of America Abstracts 5 (1) : 110.

STOHR, E. 1880 : Die Radiolarienfauna der Tripoli von Grotte, Provinz Girgenti in Sicilien. Palaeontographica 26 (series 3, volume 2) : 69-124.

STRELKOV, A.A. and LIPMAN, R.Kh 1959 : Podklass Radiolaria. Sistematicheskaya chast. in : Orlov, Yu, A (ed.), Osnovy Paleontologii, Moscow, Izdat. Akad. Nauk. SSSR, volume 1, Obshchaya chast', Prosteyshiye, pp 426-462.

TADA, R. and IIJMA, A. 1983 : Identification of mixtures of opaline silica phases and its implication for silica diagenesis. in lijima, A. and Hein, J.R., Siever, R. (eds.), Siliceous deposits in the Pacific Region, Developments in Sedimentology 36, Elsevier, Amsterdam, pp 229-245.

TALIAFERRO, N.L. 1933 : The relation of volcanism to diatomaceous and associated siliceous sediments. University of California. Bulletin of the Department of Geology 23 : 1-56.

TAN SIN HOK 1927 : Over de samenstelling en het onstaan van krijten mergelgesteenten van de Molukken. Jaarboek van het Mijnwezen in Nederlandsch-Indie, 1926. pp5-165.

THEYER, F. 1972 : Paleomagnetism and planktonic zonation of late Neogene subantarctic cores. Antarctic Journal of the United States 7 (5) : 195-197. 
THEYER, F. 1978 : Geochronology and stratigraphic reliability of Neogene radiolarian events, tropical Pacific. in : Correlation of tropical through high latitude marine Neogene deposits of the Pacific Basin, International Geological Correlation Programme (IGCP), Project 114, Biostratigraphic Datum-planes of the Pacific Neogene, Third Working Group Meeting - Abstracts and Program, Stanford University Publications, Geological Sciences Volume 14, p 59.

THEYER, F. and HAMMOND, S.R. 1974 : Paleomagnetic polarity sequence and radiolarian zones, Brunhes to Polarity Epoch 20. Earth and Planetary Science Letters 22 : 307-319.

THEYER, F. and LINEBERGER, P. 1981 : Radiolarian biostratigraphy of the Philippine Sea, Deep Sea Drilling Project Leg 59. in : Orlofsky, S. (ed.), Initial Reports of the Deep Sea Drilling Project, Volume 59, United States Government Printing Office, Washington, pp 581-585.

THEYER, F., MATO, C.Y., and HAMMOND, S.R. 1976 : Magnetostratigraphic and geochronologic calibration of Neogene radiolarian events, tropical Pacific. in : Abstracts of papers presented to the First International Congress on Pacific Neogene stratigraphy, Tokyo, Japan, 1976.

THEYER, F, MATO, C.Y., and HAMMOND, S.R. 1978 : Paleomagnetic and geochronologic calibration of latest Oligocene to Pliocene radiolarian events, equatorial Pacific. Marine Micropaleontology 3 : 377-395.

THOMSON, J.A. 1916 : On stage names applicable to the divisions of the Tertiary in New Zealand. Transactions of the New Zealand Institute $48: 28-40$.

VAN COUVERING, J.A., BERGGREN, W.A., DRAKE, R.E. et al. 1976 : The terminal Miocene event. Marine Micropaleontology 1 : 263-286.

VELLA, P. 1953 : The genus Pelicaria in the Tertiary of East Wairarapa. Transactions of the Royal Society of New Zealand 81 (1) : 35-48.

VELLA, P. 1954 : Tertiary mollusca from south-east Wairarapa. Transactions of the Royal Society of New Zealand 81 (4) : 539-555.

VELLA, P. 1963a : Foraminifera from upper Miocene turbidites, Wairarapa, New Zealand. New Zealand Journal of Geology and Geophysics 6 (5) : 775-793.

VELLA, P. 1963b : Size-sorting of foraminifera in graded beds, Wairarapa, New Zealand. New Zealand Journal of Geology and Geophysics 6 (5) : 794-800.

VELLA, P. 1973 : Ocean paleotemperatures and oscillations of the subtropical convergence zone on the eastern side of New Zealand. in : Fraser, R. (ed.), Oceanography of the South Pacific, New Zealand National Commission for UNESCO, Wellington, pp 315-318.

VELLA, P. 1974 : Pre-session tour to Hikawera and Ngahape, Wairarapa. Tour Guide for the Geological Society of New Zealand Conference, Wellington 1974. 16pp.

VELLA, P. 1975 : The boundaries of the Pliocene in New Zealand. in : Saito, T., Burckle, L.H. (eds.), Late Neogene Epoch Boundaries, Micropaleontology Special Publication 1, Micropaleontology Press, New York, pp 85-93.

VELLA, P. and BRIGGS, W.M. 1971 : Lithostratigraphic names, Upper Miocene to Lower Pleistocene, northern Aorangi Range, Wairarapa. New Zealand Journal of Geology and Geophysics 14 (2) : 253-274. 
VELLA, P.P. and COLLEN, J.D. 1984 : Four rhyolitic tuff marker beds, lower Pliocene, Wairarapa, New Zealand. Journal of the Royal Society of New Zealand 14 (2) : 133-138.

VELLA, P. and KENNETT, J.P. 1975 : Molluscan fossils and late Neogene paleotemperatures. New Zealand Journal of Geology and Geophysics 18 (1) : 197-202.

VELLA, P. and NICOL, E.R. 1970 : Chlamys delicatula and the Hautawan Stage. New Zealand Journal of Geology and Geophysics 13 (3) : 873-876.

VINCENT, E., KILLINGLEY, J.S., and BERGER, W.H. 1980 : The magnetic Epoch-6 carbon shift : A change in the oceans ${ }^{13} \mathrm{C}^{12} \mathrm{C}$ ratio 6.2 million years ago. Marine Micropaleontology 5 : 185-203.

VINASSA de REGNY, P.E. 1900 : Radiolari Miocenici Italiani. Memorie della $R$. Accademia delle Scienze dell'Istituto di Bologna, series 5, volume 8 : 565-595.

WALTERS, R. 1965 : The Globorotalia zealandica and G. miozea lineages. New Zealand Journal of Geology and Geophysics 8 (1) : 109-127.

WATKINS, N.D., KEANY, J., LEDBETTER, M.T., and HUANG, T.C. 1974 : Antarctic glacial history from analyses of ice-rafted deposits in marine sediments : New model and initial tests. Science 186 : 533-536.

WATKINS, N.D. and KENNETT, J.P. 1971 : Antarctic bottom water : Major change in velocity during the Late Cenozoic between Australia and Antarctica. Science 173 : 813-818.

WATKINS, N.D. and KENNETT, J.P. 1972 : Regional sedimentary disconformities and Upper Cenozoic changes in bottom water velocities between Australasia and Antarctica. in : Hayes, D.E. (ed.), Antarctic Oceanology II : The Australian New Zealand Sector, Antarctic Research Series, Volume 19, Washington, American Geophysical Union, pp 273-293.

WATKINS, N.D., KENNETT, J.P., and VELLA, P. 1973 : Palaeomagnetism and the Globorotalia truncatulinoides datum in the Tasman Sea and southern ocean. Nature Physical Science 244 (133) : 45-47.

WEAVER, F.M. 1976a : Late Miocene and Pliocene radiolarian paleobiogeography and biostratigraphy of the Southern Ocean. Unpublished Ph.D. thesis, Florida State University, $175 \mathrm{pp}$.

WEAVER, F.M. 1976b : Antarctic Radiolaria from the southeast Pacific Basin, Deep Sea Drilling Project, Leg 35. in : Hollister, C.D. and Craddock, C. et al. (eds.), Initial Reports of the Deep Sea Drilling Project, Volume 35, United States Government Printing Office, Washington, pp 569-603.

WEAVER, F.M., CASEY, R.E., and PEREZ, A.M. 1981 : Stratigraphic and paleoceanographic significance of early Pliocene to middle Miocene radiolarian assemblages from northern to Baja California. in : Garrison, R.E., Douglas, R.G. et al. (eds.), The Monterey Formation and related siliceous rocks of California, Proceedings of an SEPM Research Symposium dedicated to examine the paleontology, sedimentology, depositional environments and diagenesis of the Monterey Formation, pp 71-86.

WEAVER, F.M. and DINKELMAN, M.G. 1978 : Cenozoic radiolarians from the Blake Plateau and the Blake-Bahama Basin, DSDP Leg 44. in : Benson, W.E., Sheridan, R.E. et al. (eds.), Initial Reports of the Deep Sea Drilling Project, Volume 44, United States Government Printing Office, Washington, pp 865-885. 
WEBB, P.N., HARWOOD, D.M., McKELVEY, B.C., MERCER, J.H., and STOTT, L.D. 1984 : Cenozoic marine sedimentation and ice-volume variation on the East Antarctic craton. Geology 12 : 287-291.

WESTBERG, M.J. and RIEDEL, W.R. 1978 : Accuracy of radiolarian correlations in the Pacific Miocene. Micropaleontology 24 (1) : 1-23.

WESTBERG, M.J., SANFILIPPO, A., and RIEDEL, W.R. 1980 : Radiolarians from the Moroccan Basin, Deep Sea Drilling Project Leg 50. in : Lancelot, Y., Winterer, E.L. et al. (eds.), Initial Reports of the Deep Sea Drilling Project, Volume 50, United States Government Printing Office, Washington, pp 429-437.

WICK, W. 1947 : Aufbereitungsmethoden in der Mikropalaontologie. Naturhistoriche gesellschaft (Jahresbericht) 1942-1947 94-98:35-41

WILLIAMS, D.F. and KEANY, J. 1978 : Comparison of radiolarian/planktonic foraminiferal paleoceanography of the subantarctic Indian Ocean. Quaternary Research $9: 71-86$.

WINTERER, E.L., RIEDEL, W.R., MOBERLY, R.M. et al. 1971 : Site 64. in : Winterer, E.L., Riedel, W.R. et al. (eds.), Initial Reports of the Deep Sea Drilling Project, Volume 7, United States Government Printing Office, Washington, pp 473-606.

WISE, S.W., BUIE, B.F., and WEAVER, F.M. 1972 : Chemically precipitated sedimentary cristobalite and the origin of chert. Eclogae geologicae Helvetiae 65 (1) : 157-163.

WISE, S.W. and WEAVER, F.M. 1974 : Chertification of oceanic sediments. in : Hsu, K.J. and Jenkyns, H.C. (eds.), Pelagic Sediments on Land and under the Sea, Special Publication Number 1 of the International Association of Sedimentologists, Blackwell Scientific Publications, Oxford, pp 301-326.

WISE, S.W., WEAVER, F.M., and GUVEN, N. 1973 : Early silica diagenesis in volcanic and sedimentary rocks: Devitrification and replacement phenomena. in : Arceneaux, C.J. (ed.), 31st Annual Proceedings of the Electron Microscopy Society of America, New Orleans, 1973, page unknown.

WITHERS, T.H. 1924 : The fossil cirripedes of New Zealand. New Zealand Geological Survey Paleontological Bulletin $10: 47 \mathrm{pp}$.

WOLFART, R. 1981 : Neogene radiolarians from the eastern North Pacific (off Alta and Baja California), Deep Sea Drilling Project Leg 63. in : Yeats, R.S., Haq, B.U. et al. (eds.), Initial Reports of the Deep Sea Drilling Project, Volume 63, United States Government Printing Office, Washington, pp 473-506.

WRIGHT, I.C. in prep : Paleomagnetic studies from the Late Miocene Mangapoike River Valley, northern Hawkes Bay. $\mathrm{PhD}$ thesis, Victoria University of Wellington.

WRIGHT, I.C. 1985 : Mangapoike River : A Late Miocene magnetostratigraphic reference column for New Zealand. in : Cooper, R. (ed.), Hornibrook Symposium, 3-5 December 1985, Christchurch, New Zealand : extended abstracts, New Zealand Geological Survey Record 9 : 105-107.

WRIGHT, I.C., ASHBY, J.N., and HOSKINS, R.H. 1985 : An age for the sudden disappearence of Globoquadrina dehiscens in Mangapoike River Valley, New Zealand. in : Cooper, R. (ed.), Hornibrook Symposium, 3-5 December 1985, Christchurch, New Zealand : extended abstracts, New Zealand Geological Survey Record 9 : 102-104. 
YAMASHIRO, C. 1975 : Differentiating dissolution and transport effects in foraminiferal sediments from the Panama Basin. in : Sliter, W.V., Be, A.W.H., Berger, W.H. (eds.), Dissolution of Deep-Sea Carbonates, Cushman Foundation for Foraminiferal Research Special Publication Number 13, Allen Press, Lawerence, Kansas : 151-159.

ZEITSCHEL, B. 1978 : Oceanographic factors influencing the distribution of plankton in space and time. Micropaleontology 24 (2) : 139-159.

ZITTEL, K.A. 1876 : Ueber einige fossile Radiolarien aus der norddentschen Kreide. Zeitschrift der Deutschen geologischen Gesellschaft 28 : 75-86. 


\section{Appendix A \\ SECTION AND SITE DESCRIPTIONS}

\section{A.1 INTRODUCTION}

This appendix outlines all the stratigraphic sections and sites examined during the course of this study. Descriptions of non-radiolarian bearing sections and sites are also presented as this information will be invaluable to future workers wishing to locate likely samples with good siliceous preservation. Descriptions of sections examined from outside the East Coast Deformed Belt are also presented. Figures A.1 and A.2 are summary location maps for the radiolarian-bearing sections and sites respectively.

Detailed descriptions of the radiolarian bearing samples examined in this thesis are presented in Appendix B. Presence and absence data for the radiolarian faunas is presented in Appendix D. Counts on the radiolarian faunas are presented in Appendix E.

Within this appendix when a sample is said to be barren this only applies to the absence of radiolarian skeletons, unless otherwise qualified. Some of the numbers mentioned in the text are referenced by the following abbreviations:

NG $=$ number of radiolarians per gram of sediment in the sample

$\mathrm{N}=$ the number of counting groups filled after counting approximately 300 radiolarian specimens in a sample. This gives a measure of the preservation of the fauna because as dissolution increases the number of counting groups filled will decrease as more delicate forms get depleted from the sample. Numbers range from 0 (nil preservation) to 44 (highest preservation in sample HR04). As the samples chosen for statistical work are normally considered to have moderate or better preservation the range of $\mathrm{N}$ quoted in this appendix is 23 to 44 .

$\mathbf{Q}=$ diversity index. This index, as outlined in Appendix E, gives an indication of diversity of the fauna independent of the degree of preservation. Values quoted range from 3.71 (low diversity in sample SWR1) to 17.29 (high diversity in sample RM07).

The stratigraphic columns represented in this appendix generally follow the following format. The left hand column defines the bioevents located in the section. The next column is a graphic log then the lithological log. On the right hand side of the lithologic log, the position of samples studied are shown is short lines. Samples containing Radiolaria are depicted as lines with solid circles attached and those referred to in the thesis have designated numbers. The right hand column gives a brief description of the lithology. 
Figure A.1

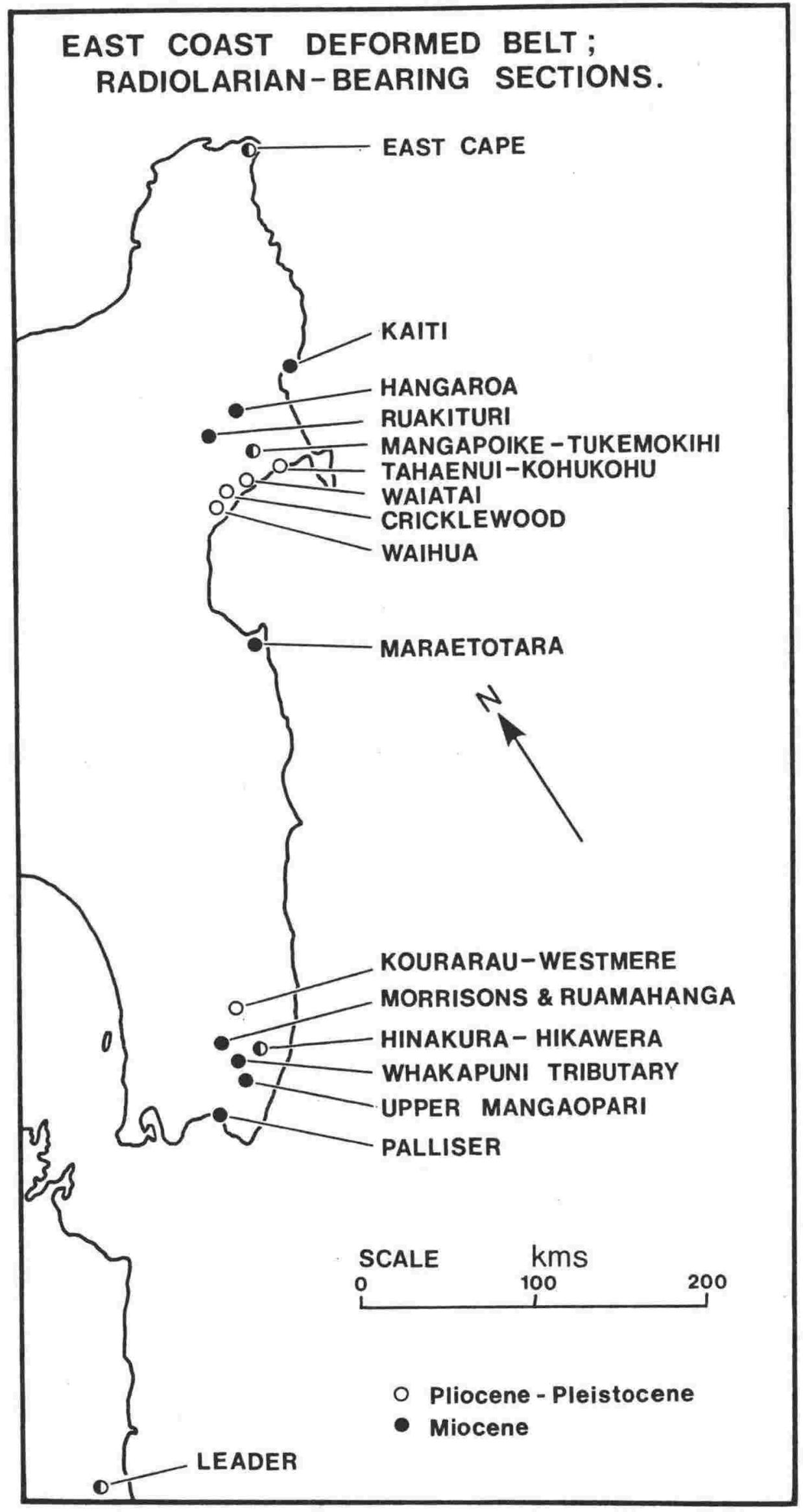


Figure A.2

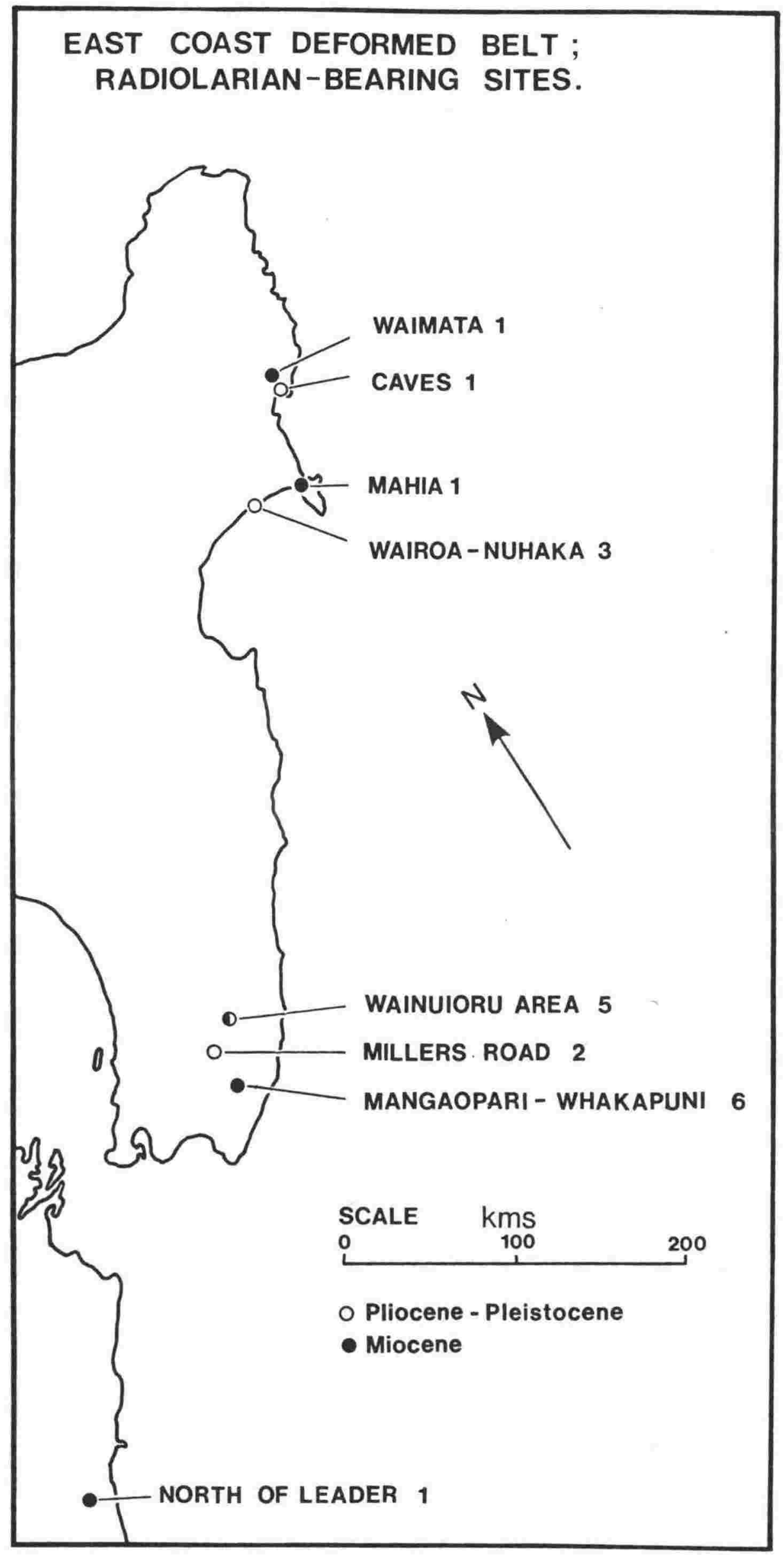


FIGURE A4

EAST CAPE SECTION

\section{Location: Figure $A 3$}
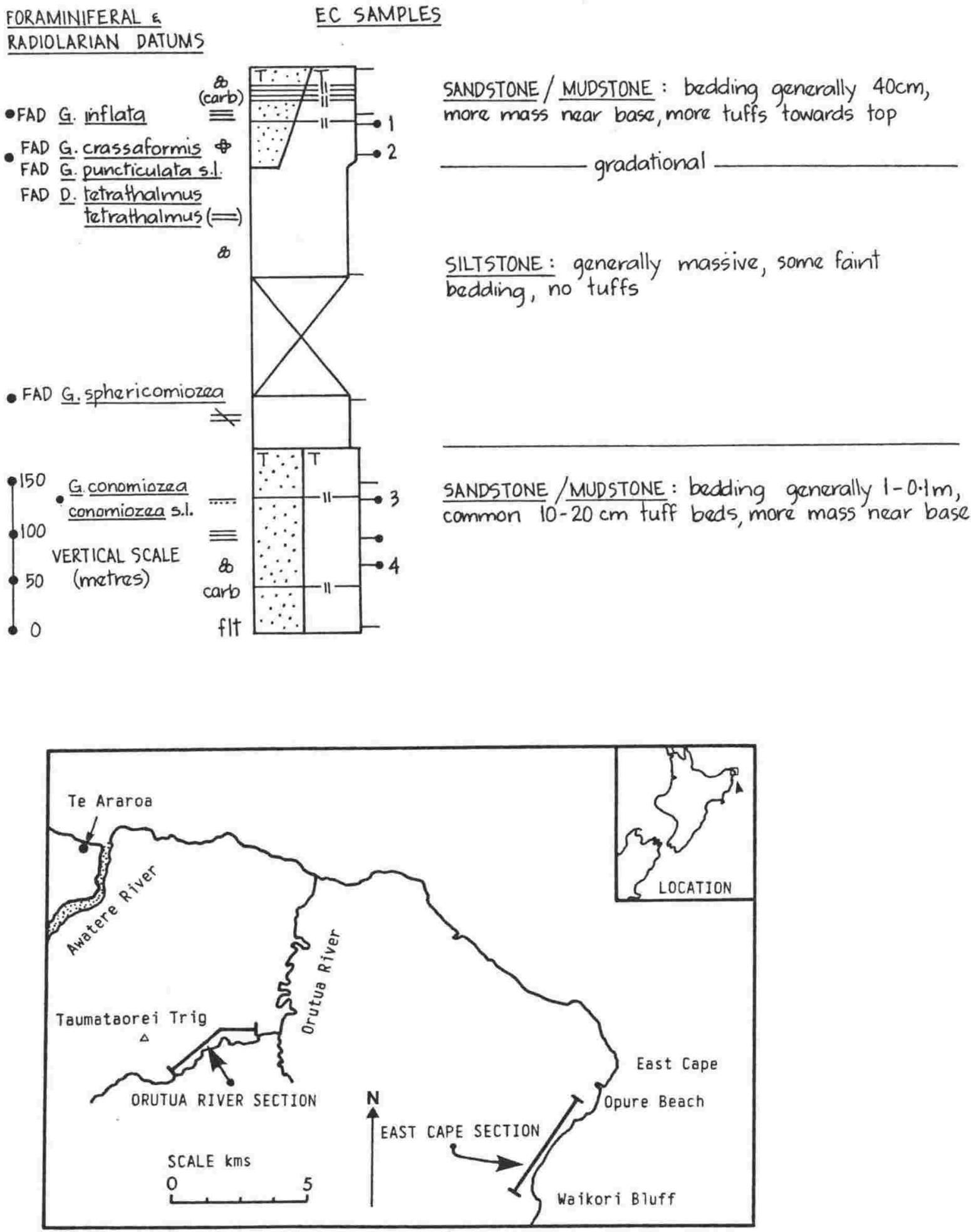

Figure A.3

Location of sections : East Cape region. 


\section{A.2 EAST CAPE SECTION}

Location: Coastal cliffs from the bluffs at the south end of Opure Beach to Waikori Bluff (from 1.5 to $5.0 \mathrm{~km}$ southwest of East Cape). See figure A.3.

Stratigraphic column: Figure A.4.

Lithology and Age: The basal unit comprises at least $190 \mathrm{~m}$ of interbedded fine sandstone and mudstone (more massive near the base) with common tuff beds. The foraminiferal faunas include predominantly $4 / 4.5$ chambered Globorotalia miotumida with some forms approaching $G$. conomiozea conomiozea.

Next is a $280 \mathrm{~m}$, massive to weakly bedded, slightly sandy mudstone unit with $130 \mathrm{~m}$ of nil exposure in the middle. The FAD of G. sphericomiozea is recorded about $43 \mathrm{~m}$ above the base of this unit ( $\mathrm{Z} 14 / \mathrm{f} 43)$.

Overlying is at least $110 \mathrm{~m}$ of interbedded mudstone and fine sandstone, and tuffs which becomes more massive towards the base and the tuffs more common towards the top. Planktic foraminiferal faunas from two samples in the lower half of the unit (Z14/f46, f38A) include Globorotalia conomiozea mons, G. crassaformis, common G. pliozea, G. cf. puncticulata, and mostly unkeeled G. sphericomiozea indicating a basal Opoitian age. The FAD of G. inflata is recorded $60 \mathrm{~m}$ from the base of this unit (Z14/f47).

Samples: Eleven samples from regular intervals throughout the section were examined. Three of five samples examined from the lower unit contain Radiolaria, two of which are studied in this thesis (ECO3, EC04). In the middle unit the two samples examined are barren, and in the upper unit the lower two of four samples contained Radiolaria and are used in this thesis (EC01, ECO2).

Radiolaria: Of the four samples examined, two samples (EC01 and EC03) contain very poor faunas comprising only resistent members of the Spongodiscidae, some stylosphaerids, and some members of the genus Thecosphaera. In the other two samples (ECO2 and EC04) preservation is relatively low ( $\mathrm{N}=27$ in both cases) and diversity is also low (Q= 6.68 and 5.66 respectively) although for the former sample these values are reasonably typical for the lower Pliocene. Sample ECO2 marks the FAD of Didymocyrtis tetrathalmus tetrathalmus in this section and although preservation is poor, the older age of sample ECO4 is considered to be the main factor in determining the absence of this species from EC04.

References: P. Moore, NZ Geological Survey (map and column), Gosson (in prep.). 


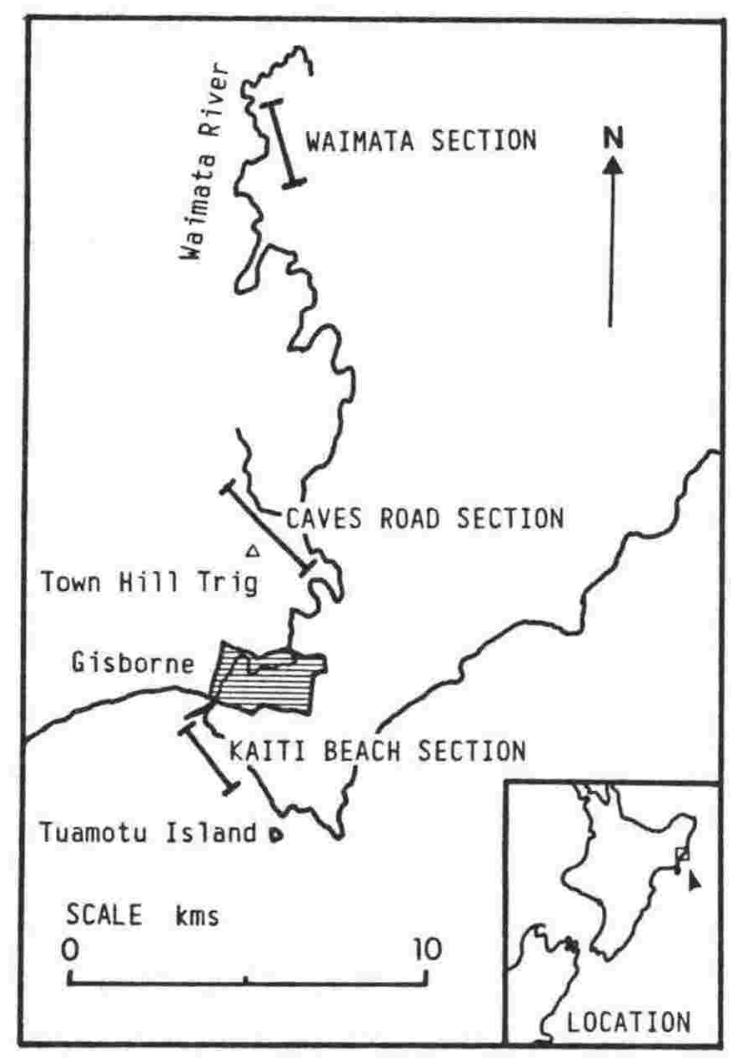

Figure A.5

Location of sections : Gisborne region. 


\section{A.3 ORUTUA RIVER SECTION}

Location: In the Orutua River Valley from $4 \mathrm{~km}$ due east to $1.5 \mathrm{~km}$ due southeast of Taumataorei Trig. About $11 \mathrm{~km}$ due east of the East Cape Section. See figure A.3.

Lithology and Age: The section comprises $1050 \mathrm{~m}$ of massive mudstones, weakly bedded in places and sandier in the basal third, with common tuff beds. The age of the strata extends from lower Lillburnian $(\mathrm{Z} 14 / \mathrm{f} 74)$ to upper Tongaporutuan - middle Kapitean (Z14/f84).

Samples: Nine samples at regular intervals from throughout the section were examined and all are barren.

References: Gosson (in prep.), P. Moore, NZ Geological Survey (map).

\section{A.4 WAIMATA RIVER SECTION}

Location: Along the Waimata River from 11 to $14.5 \mathrm{~km}$ north of Gisborne. Samples from river banks and road cuts. Poorly exposed. See figure A.5.

Lithology and Samples: The basal unit consists of at least $500 \mathrm{~m}$ of sandy mudstone with rare Mollusca and occasional sandy layers. Two tuffs are exposed near the base. The oldest sample examined (Y17/f5) is very close to Kennett's (N98/f525) which marks the LAD of Globoquadrina dehiscens in this section. This sample and one other (Y17/f6) from this unit are barren.

The next unit is a $350 \mathrm{~m}$ weakly bedded fine to medium sandstone which corresponds very closely to the Globorotalia conomiozea conomiozea Zone. Two samples from this unit (Y17/f7, f8) are barren.

Overlying is a $630 \mathrm{~m}$ massive sandy mudstone, sandier at the base, with occasional concretionary layers. The FAD of G. crassaformis is in the basal $100 \mathrm{~m}$ of this unit. Eight samples from the lower half of this unit (Y17/f10-17) were examined and all were barren. One sample from near the top of the unit (SWM1) contains Radiolaria and is used in this thesis.

Radiolaria: The Radiolaria in SWM1 are reasonably well preserved and diverse (NG = 310, $\mathrm{N}=30, \mathrm{Q}=8.93$ ). The tentative identification of Didymocyrtis tetrathalmus tetrathalmus indicates a post-Miocene age and the tentative identification of Didymocyrtis sp. A and no apparent Lychnocanium sp. aff. grande indicates an upper Opoitian age very near the boundary between the Lychnocanium sp. aff. grande Subzone and the Lamprocyrtis hannai Subzone, the latter zone being more likely. This age is supported by the sample being nearly $400 \mathrm{~m}$ above the FAD of Globorotalia crassaformis in strata comprising mainly massive light blue-grey mudstone.

References: Ridd (1964), Kennett (1966e). 
FIGURE AG

KAITI BEACH SECTION

Location: Fiqure $A 5$

FORAMINIFERAL AND

RADIOLARIAN DATUMS

D. laticonus

-G. dehiscens present G. miotumida $37 \%$

five chambered

- B. compressa s.l.

- LAD H. umbonatum

- possibly Waiauan

- Lillburnian
KB SAMPLES

BREAKWATER

SILTSTONE: maSS

SANDSTONE/MUDSTONE : ibdd, occ cgl beds $(0.2-0.3 \mathrm{~m})$, slumped a contorted layers in places

SILTSTONE: mass, cem in places, weakly bdd, comm tfc beds, sandier towards top.

"Cyclammina" Tuff

\section{SANDSTONE/MUDSTONE: ibdd, complete} Bouma sequences at base $(0.2$ to $1.0 \mathrm{~m}$ thick) sst units less frequent towards top. 
Location: Caves Road Valley and in part of the Waimata River Valley from where the "Caves Road" Stream meets the Waimata River, downstream to Goodwin Road. From $1.5 \mathrm{~km}$ north to $2 \mathrm{~km}$ west of Town Hill Trig in the hills behind Gisborne. See figure A.5.

Lithology and Age: An approximately $1000 \mathrm{~m}$ thick sequence of very poorly exposed silty mudstone was examined. Sample Y18/f171, 324m from the base of the section marks the LAD of Globoquadrina dehiscens which also occurs with Bolivinita compressa $142 \mathrm{~m}$ below (Y18/f172). The FAD of Globorotalia sphericomiozea is $43 \mathrm{~m}$ below the top of the section (Y18/f179).

Samples: Eleven samples were examined from regular intervals throughout the section. Sample Y18/f180, 74m below the FAD of $G$. sphericomiozea contained rare Radiolaria but was not used in this thesis. Sample SCV1, 265m above the LAD of G. dehiscens contains common Radiolaria and is used in this thesis. Of the twelve specimens of Globorotalia miotumida from this sample, $42 \%$ are five chambered forms.

Radiolaria: This sample, although lacking Anthocyrtidium ehrenbergi pliocenica contains the large pored form of Heliodiscus asteriscus and tentatively contains Didymocyrtis laticonus so is placed in the Heliodiscus asteriscus forma large pores Subzone. This is supported by the sample coming from strata between the LAD of Globoquadrina dehiscens and the FAD of Globorotalia sphericomiozea. Although the sample has a relatively high NG (596) the preservation and diversity $(\mathrm{N}=39, \mathrm{Q}=8.93)$ are only slightly above normal for this radiolarian subzone (35.75 and 8.82 respectively). No member of the Diartus hughesi group is present in the sample.

Reference: G. Scott, NZ Geological Survey (pers. comm.).

\section{A.6 KAITI BEACH SECTION}

Location: Well exposed section on the wave cut platform from the breakwater to a point halfway between the breakwater and Tuamotu Island to the southeast, at Kaiti Beach, Gisborne. See figure A.5.

Stratigraphic column: Figure A.6.

Lithology, Age, and Samples: The basal unit comprises $440 \mathrm{~m}$ of interbedded sandstones and mudstones, some being complete Bouma sequences, up to $1 \mathrm{~m}$ thick. The sandstone beds become less frequent and thinner towards the top. Sediments at the base are Lillburnian (Ghent and Henderson, 1966) and are possibly Waiauan at the top of this unit. Six samples from this unit were examined and are barren.

Next in the sequence is a $22 \mathrm{~m}$ concretionary horizon.

Overlying is a $540 \mathrm{~m}$ massive siltstone with common tuff beds and occasional sandstone beds which increase in frequency towards the top. The basal part of this unit may be Waiauan. Eighteen samples were examined from this unit and three contained Radiolaria and are used in this thesis (KB02-04). The oldest radiolarian bearing sample (KB04) has Globoquadrina dehiscens, a very poor population of Globorotalia miotumida, and no Bolivinita quadrilatera. The upper two radiolarian bearing samples from this unit (KBO2, 


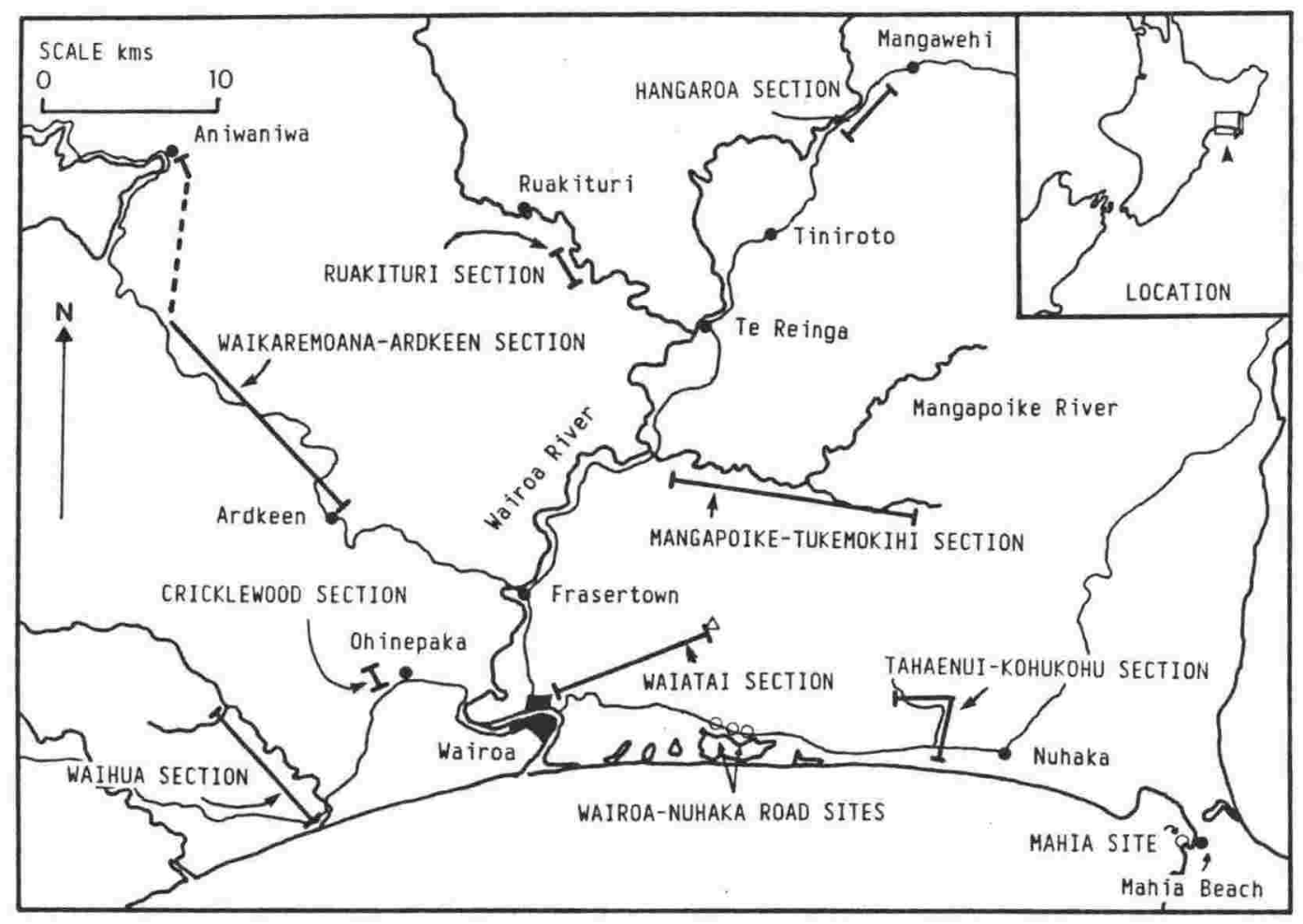

Figure A.7

Location of sections and sites : Northern Hawke's Bay. 
KB03) contain G. dehiscens, moderate populations of G. miotumida (27-50\% five chambered forms), and forms close to $B$. compressa.

Above this unit is a $112 \mathrm{~m}$ interbedded sandstone and mudstone unit with some conglomeratic and very shelly beds. The basal $68 \mathrm{~m}$ of this unit shows signs of soft-sediment deformation with many convoluted beds.

Overlying is at least $40 \mathrm{~m}$ of massive sandy mudstone but no exposure between the top of this unit and the breakwater. One sample (KB01) yielded G. dehiscens, G. panda, a good population of G. miotumida (37\% five chambered forms), and Bolivinita pohana. This sample also contained Radiolaria and is used in this thesis.

Radiolaria: Of the four samples studied the oldest three have very poor preservation with very few nassellarians preserved and faunas dominated by resistent forms such as the spongodiscids. The oldest sample (KBO4) is important in that it contains Heliodiscus umbonatum which is restricted to the oldest material studied in this thesis. The youngest sample in the section (KB01) has a relatively high abundance ( $N G=568, N=37$ ) and high diversity $(\mathrm{Q}=15.91)$ and contains both Didymocyrtis laticonus and members of the Diartus hughesi group but lacks Heliodiscus umbonatum, Anthocyrtidium ehrenbergi pliocenica, and the large pored form of Heliodiscus asteriscus. This indicates an age from within the Didymocyrtis laticonus Subzone. This lower Tongaporutuan age is supported by the presence of Globoquadrina dehiscens in this sample.

References: Ghent and Henderson (1966), NZGS Micropaleontology Section unpublished stratigraphic column. 
FIGURE A8

HANGAROA SECTION

\section{Location: Figure A7}

FORAMINIFERAL

DATUMS:

- FAD B.pliozea

- FAD B. compressa s.s.

HR SAMPLES:

- FAD B. compressa sl. gle

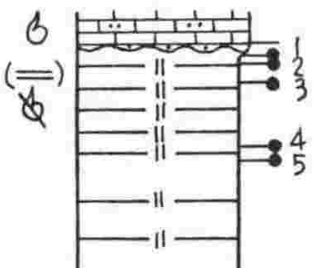

LIMESTONE: (s), It wh-br, hd, shelly, sft s at base

MUDSTONE: mass, tfc bands common, indistinctly bdd in top $200 \mathrm{~m}$, It gy-gn, (carb)

SEE FIGURE A.9 FOR DETAIL OF THE HR $\varnothing 1$ to HR $\varnothing 7$ PART OF THE SECTION

- LAD G. dehiscens $\left.\therefore\right|^{T} \| 6$

- B. quadrilatera FAD

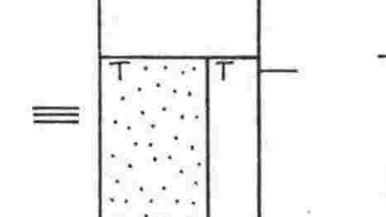

gradational

SANDSTONE/MUDSTONE: bedding generally $30-40 \mathrm{~cm}$, sst up to $1.5 \mathrm{~m}$, mst up to $3 \mathrm{~m}$.

- pumiceous fine sand

- G. mayeri, L. truncatum no Bolivinita
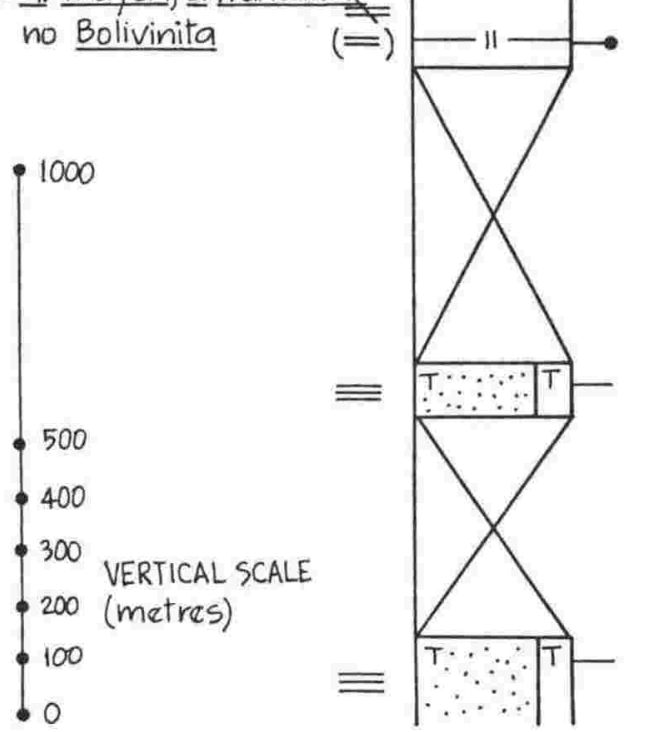

MUDSTONE: mass, some indistinct bedding, tfc

SANDSTONE/MUDSTONE: bedding generally $10-40 \mathrm{~cm}$, sst up to Im, mst up to $40 \mathrm{~cm}$. 
Location: Mainly roadcut and some river samples along the Hangaroa River Valley from approximately $8.5 \mathrm{~km}$ northeast of Tiniroto to about $1 \mathrm{~km}$ west of Mangawehi, on the inland Gisborne-Wairoa Highway. See figure A.7.

Stratigraphic columns: Figures A.8 and A.9.

Lithology and Samples: The basal half of the section $(1570 \mathrm{~m}$ ) is very poorly exposed with three short portions outcropping in roadcuts. The lower two portions expose interbedded sandstones and mudstones and are probably Southland Series in age. Two samples examined were barren of Radiolaria. The upper exposure contains a $2.5 \mathrm{~m}$ tuff. Two samples $(111 \mathrm{~m}$ above and $2 \mathrm{~m}$ below the tuff) both contain rare recrystallised Radiolaria in Waiauan mudstone (Globorotalia mayeri, Loxostomum truncatum, and no Bolivinita).

Next is a moderately well exposed, $760 \mathrm{~m}$, interbedded sandstone (up to $1.5 \mathrm{~m}$ ) and mudstone (up to $3 \mathrm{~m}$ ) unit with bedding generally $30-40 \mathrm{~cm}$. One tuff is exposed near the middle of this unit and rare pumiceous sands are also present. Sample X18/f17 (43m above the base of the unit) contains both Bolivinita quadrilatera and $B$. pohana and sample $\mathrm{X} 18 / \mathrm{f} 15$ (approximately $30 \mathrm{~m}$ below the top of this unit) marks the LAD of Globoquadrina dehiscens in this section. These two samples and one other (X18/f16, 15m below the tuff) are barren.

Overlying is a $930 \mathrm{~m}$, massive mudstone with common tuff bands. This unit is indistinctly bedded at the top. The FAD of populations of Bolivinita compressa s.s. is recorded $730 \mathrm{~m}$ above the base of this unit although forms close to $B$. compressa occur below this. The upper $30 \mathrm{~m}$ contains populations of $B$. pliozea. Poor to reasonable populations of Globorotalia miotumida, throughout the unit, have 50-66\% five chambered forms. Seven samples were examined from this unit, all contain Radiolaria and are used in this thesis (HR01-07).

At least $50 \mathrm{~m}$ of Opoitian limestone disconformably overlies the massive mudstone. A sample from a friable fine sandstone at the base of the limestone unit (X18/f7) is barren.

Radiolaria: The Radiolaria from the Waiauan strata and oldest Tongaporutuan sample (HR07) proved to be too recrystallised for even generic placement. Four of the other six Tongaporutuan samples are suitable for statistical analysis with moderate preservation $(\mathrm{N}=$ 29 to 44$)$ and moderate diversity $(Q=7.93$ to 11.21 ). The oldest radiolarian-bearing sample suitable for study (HR06), lacks Didymocyrtis laticonus but is below that taxa's LAD. The sample contains one tentative identification of Anthocyrtidium ehrenbergi pliocenica and probably comes from near the boundary between the Didymocyrtis laticonus Subzone and the Heliodiscus asteriscus forma large pores Subzone although this sample is approximately $700 \mathrm{~m}$ above the LAD of Globoquadrina dehiscens in this section. Samples HR05 to HR02 contain some Anthocyrtidium ehrenbergi pliocenica and the large pored form of Heliodiscus asteriscus. The LAD of Didymocyrtis laticonus occurs in sample HR04 and marks the transition into the Anthocyrtidium ehrenbergi pliocenica Subzone. There are only two tentative identifications of members of the Diartus hughesi group in samples HR04 and HR05 and although it should be present (on an age basis) in some of the younger samples it is lacking. Consequently the top of the Anthocyrtidium ehrenbergi pliocenica Subzone is unrecognisable in this section. The youngest radiolarian bearing sample in the section 
FIGURE A9

HANGAROA RIVER SECTION : upper part

FORAMINIFERA

Opoitian Limestone

- Fad B. pliozea

- FAD B. compressa s.S.

- FAD B. compressa s.l.

$\sim 700 \mathrm{~m}$ to LAD of

' ${ }^{\mathrm{G}}$. dehisens
RADIOLARIA

RAD ZONES

HR SAMPLES

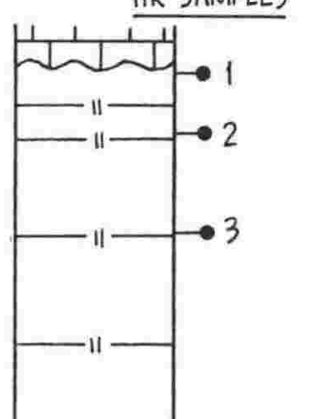

RE?

RF

LAD D. laticonus

Anthocyrtidium ehrenbergi pliocenica

Heliodiscus asteriseus

forma. large pores

$R G$ 
(HR01) has a very low diversity, lacking nassellarians and containing only recrystallised Spongodiscidae and didymocyrtids. This sample is interesting in that it contains Spongaster pentas (an early Pliocene tropical zonal taxa) in strata older than $6 \mathrm{Ma}$ (just above the Bolivinita pohana - pliozea transition) and supports the view presented by Casey and McMillen (1977), that the restricted presence of this taxa in the early Pliocene tropics may be provincial.

Reference: Gosson (in prep.), G. Scott, NZ Geological Survey. 
FIGURE A 10

RUAKITURI SECTION

\section{Location: Figure A7}

FORAMINIFERAL

DATUMS:

RK SAMPLES:

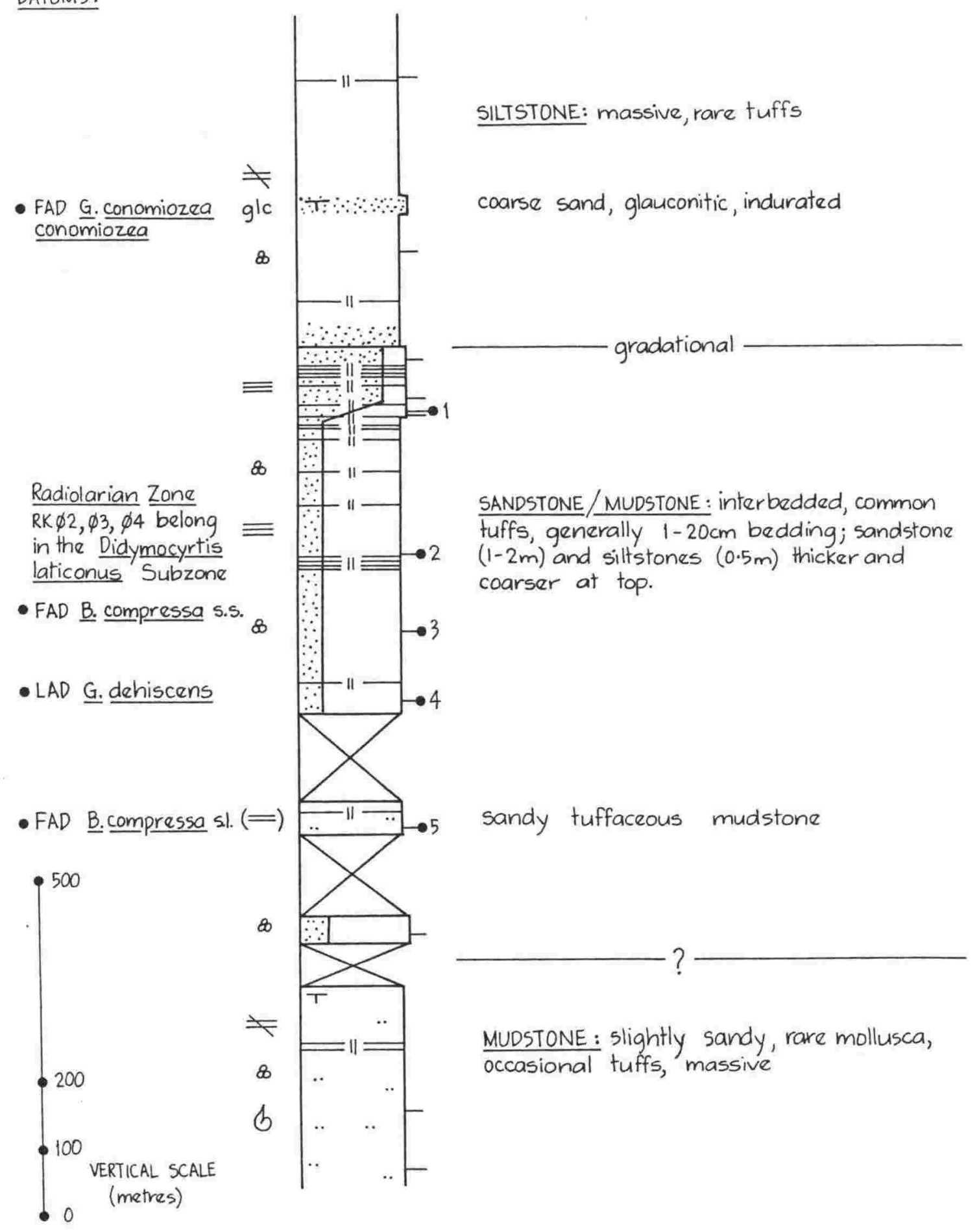


Location: Along Ruakituri River from 7 to $9 \mathrm{~km}$ northwest of Te Reinga. See figure A.7.

Stratigraphic column: Figure A.10.

Comment: The best exposures are on the eastern riverbank. The section is a composite of two with the oldest sediment exposed on the river bank upstream from Pihanga Station. The river then turns and runs along strike (above the radiolarian bearing zone), the younger sediments being exposed when the river again flows south from its confluence with Whakapune Stream.

Lithology and Age: The basal $300 \mathrm{~m}$ of the section is a massive sandy mudstone with minor amounts of tephric material, occasional tuffs and a two metre redeposited tuff.

Next in the sequence is a $840 \mathrm{~m}$ interbedded sandstone $(1-10 \mathrm{~cm})$ and mudstone $(5-20 \mathrm{~cm})$ unit with occasional tuff beds. This unit is poorly exposed in its lower half and well exposed in its upper half. Radiolaria are present except in the lower $100 \mathrm{~m}$ of this unit. The unit contains Bolivinita cf. compressa and predominantly five chambered Globorotalia miotumida in the lower half, and abundant, well preserved B. compressa s.s. and a larger percentage of $4 / 4.5$ chambered $G$. miotumida in the upper half. Globoquadrina dehiscens is very rare in the samples examined but Kennett's faunal slides of N106/f563 and f564 (between RK03 and RK04) contain good specimens. Kennett (1965) marks the LAD of G. dehiscens in sample $\mathrm{N} 106 / \mathrm{f} 563$.

The next unit has a gradational base and is represented by approximately $70 \mathrm{~m}$ of interbedded sandstones $(2 \mathrm{~m})$ and mudstones $(1.5 \mathrm{~m})$. The two legs of the section correlate within this unit.

Above this the section is generally poorly exposed except where the river cuts into some harder, sandier, glauconitic strata. The FAD of Globorotalia conomiozea conomiozea (N106/f553) is at or slightly above this greensand.

Samples: Twelve samples were examined from the basal two units (X18/f22-33), five of which contain Radiolaria and are used in this thesis (RK01-05). The five samples encompass LAD of G. dehiscens as recorded by Kennett (1965). One Opoitian sample (N106/f548) is barren.

Radiolaria: Of the five radiolarian bearing samples examined, the youngest (RK01) contains a fauna too poorly preserved for statistical study with only Thecosphaera spp. and some spongodiscids preserved. The oldest sample (RK05) contains a fauna too recrystallised for identification. The other three samples (RK02-04) have low numbers (NG = 161 to 223), moderate preservation ( $\mathrm{N}=25$ to 36 ), and low to moderate diversity ( $\mathrm{Q}=6.44$ to 9.70 ). All three samples belong to the Didymocyrtis laticonus Subzone with positive identifications of Didymocyrtis laticonus in RK02 and a tentative identification in RK04, and lacking Anthocyrtidium ehrenbergi pliocenica or the large pored form of Heliodiscus asteriscus. This radiolarian age agrees with the LAD of Globoquadrina dehiscens in sample RK04.

References: Kennett (1965, 1966e). 
FIGURE AII

MANGAPOIKE RIVER - TUKEMOKIHI STREAM COMPOSITE COLUMN

Left hand column shows the position of the more detailed columns (compiled with G.Gosson)

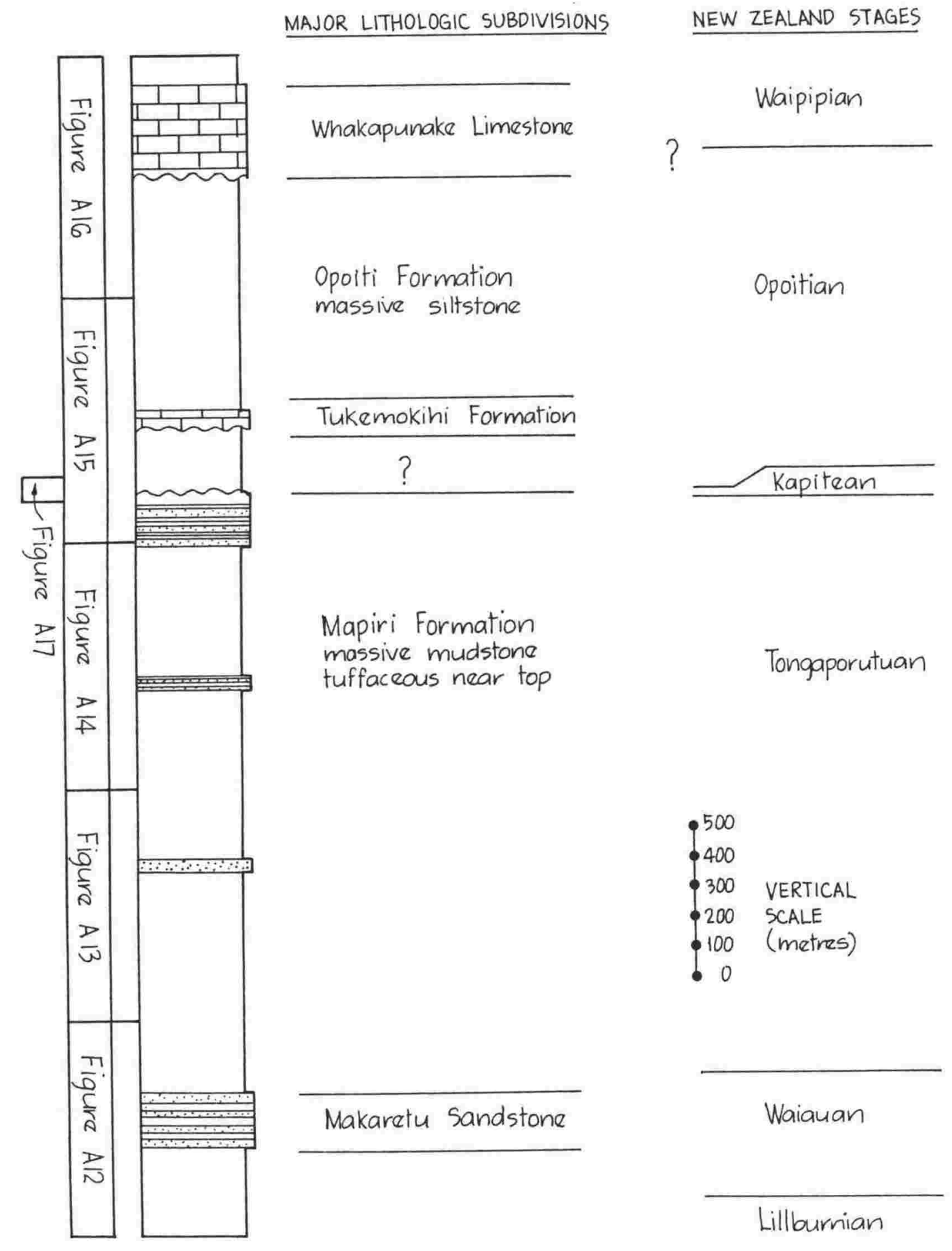


Location: Roadcut samples taken at large stratigraphic intervals on the road from Aniwaniwa to Ardkeen on the Lake Waikaremoana - Frasertown road. See figure A.7.

Samples: Three mudstone samples near Aniwaniwa containing Bolivinita pohana, Globorotalia miotumida and Globoquadrina dehiscens (lower Tongaporutuan) and six mudstone samples at regular intervals from Piripaua to Ardkeen (three Tongaporutuan, two Kapitean, one Opoitian) are all barren.

Reference: Grant-Taylor and Hornibrook, 1976.

\section{A.10 MANGAPOIKE - TUKEMOKIHI SECTION}

Location: Excellent exposure on the banks of the Mangapoike River and in Tukemokihi Stream from the confluence of the Mangapoike and Wairoa Rivers to the headwaters of the Tukemokihi Stream about $17 \mathrm{~km}$ due east. See figure A.7.

Stratigraphic columns: Figures A.11 - A.17

Lithology and Age: The basal unit is a generally massive siltstone with some thin sandy layers and packets (up to $30 \mathrm{~m}$ thick) of interbedded sandstone and siltstone. This unit is at least $320 \mathrm{~m}$ thick and is well exposed near its top but poorly exposed near its base. The lowest sample collected in the section X19/f39 is Lillburnian, sample X19/f40 ( $84 \mathrm{~m}$ above) is Waiauan. Two samples within the top $40 \mathrm{~m}$ of this unit are barren.

Overlying is a $182 \mathrm{~m}$, lithified, predominantly well-bedded sandstone unit, with some interbedded siltstones (Makaretu Sandstone). The sandstone is deeply gorged by Tukemokihi Stream. The contact with the underlying siltstone is gradational over about $50 \mathrm{~m}$ with the frequency of sandy layers increasing towards the top of the siltstone. No samples were examined for Radiolaria.

Overlying the Makaretu Sandstone is a $1373 \mathrm{~m}$ thick unit of massive siltstones with occasional sandy beds (commonly thin but one $34 \mathrm{~m}$ thick bed just below X19/f54), rare concretionary layers and occasional tuff beds in the upper $570 \mathrm{~m}$ which increase in frequency towards the top. Exposure is excellent in the banks of the entrenched Tukemokihi Stream and in the banks of the Mangapoike River with only one $35 \mathrm{~m}$ covered interval near the top of this unit. A sample $7 \mathrm{~m}$ above the Makaretu Sandstone (X19/f100) contains Loxostomum truncatum and sample X19/f98, 20m above, marks the incoming of the Bolivinita lineage (basal Tongaporutuan) which has been paleomagnetically dated at 10.3 Ma (Wright, 1985). Near the middle of this unit, sample $X 19 / f 110$ marks the LAD of Globoquadrina dehiscens, approximately $5 \mathrm{~m}$ above the $34 \mathrm{~m}$ sandstone (Wright, Ashby, and Hoskins, 1985). Five samples from regular intervals in this unit were barren of Radiolaria. Another 15 samples were taken from exposures of this unit along strike in the banks of Mangapoike River but contained no Radiolaria.

Next in the sequence is a $90 \mathrm{~m}$, interbedded sandstone (up to $5 \mathrm{~cm}$ ) and mudstone (up to $20 \mathrm{~cm}$ ) unit. One mudstone sample from near the middle of this unit is barren. 
FIGURE A12

TUKEMOKIHI STREAM (in part)

Location: Geographic-Figure A7 Stratigraphic-Figure All

FORAMINIFERAL

DATUMS and AGES

(B. Hoskins, pers. comm)

Figure $\mathrm{A} 134$

, pers.comm)

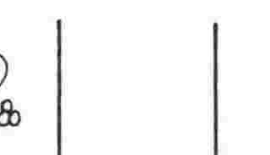

MUDSTONE: massive, sandier towards

base, indistinct $2 \mathrm{~m}$ bedding in places

cemented sandstone layers

Loxostomum truncatum

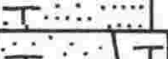

SANDSTONE/MUDSTONE : interbedded indurated sandstones and softer mudstones

- Waiauar

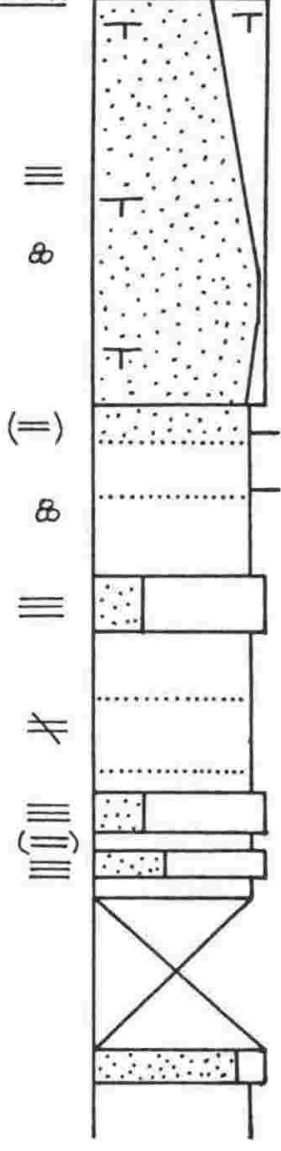

MUDSTONE: Massive, occassional sandy layers, packets of interbedded sands and muds present.

- Lillburnian

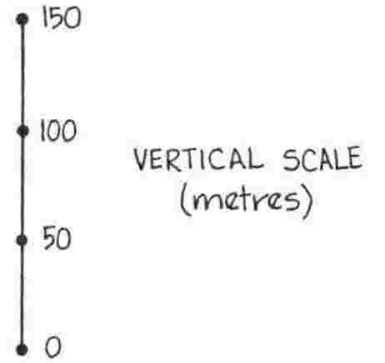


FIGURE AI3

TUKEMOKIHI STREAM (in part)

Location: Geographic-Figure A7 Stratigraphic-Figure All

FORAMINIFERAL

\section{DATUM:}

- LAD G. dehiscens
Figure Al4

MUDSTONE: massive, sandy in places

massive fine sandstone

concretions $(40 \mathrm{~cm})$
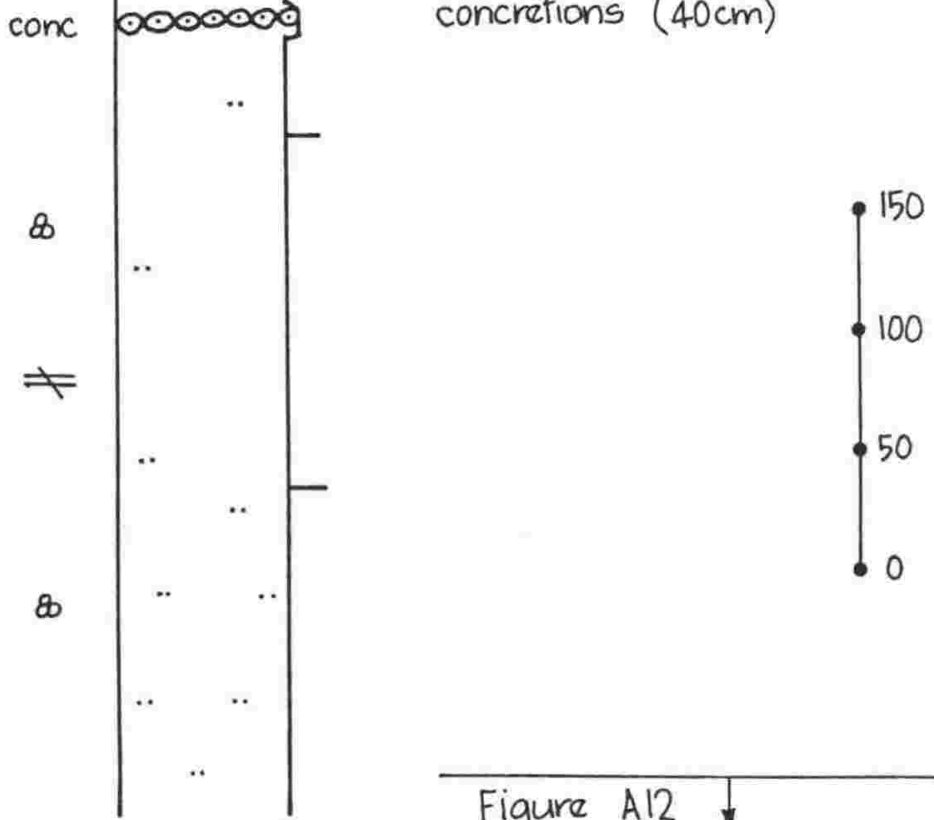

VERTICAL

SCALE

(metres)

Figure Al2 
FIGURE A 14

MANGAPOIKE RIVER - TUKEMOKIHI STREAM (in part)

Location: Geographic - Figure A7 Stratigraphic-Figure A11

FORAMINIFERAL AND

RADIOLARIAN DATUMS:

- LC.O Cyrtocapsella spp. TM SAMPLES:

G. miotumida $50 \%$ five chambered forms

- FAD B. compressa s.s. no Diartus hughesi

8

Non- 20 Figure AI5

8

$\neq$

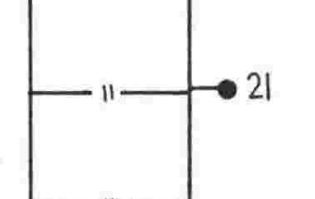

MUDSTONE: massive, common tuff beds

fault block

\}approximately 30 tuffs

MUDSTONE/SANDSTONE: interbedded medium sandstones ( $5 \mathrm{~cm}$ thick) and mudstone, approx 5 sandstone beds per metre. gradational
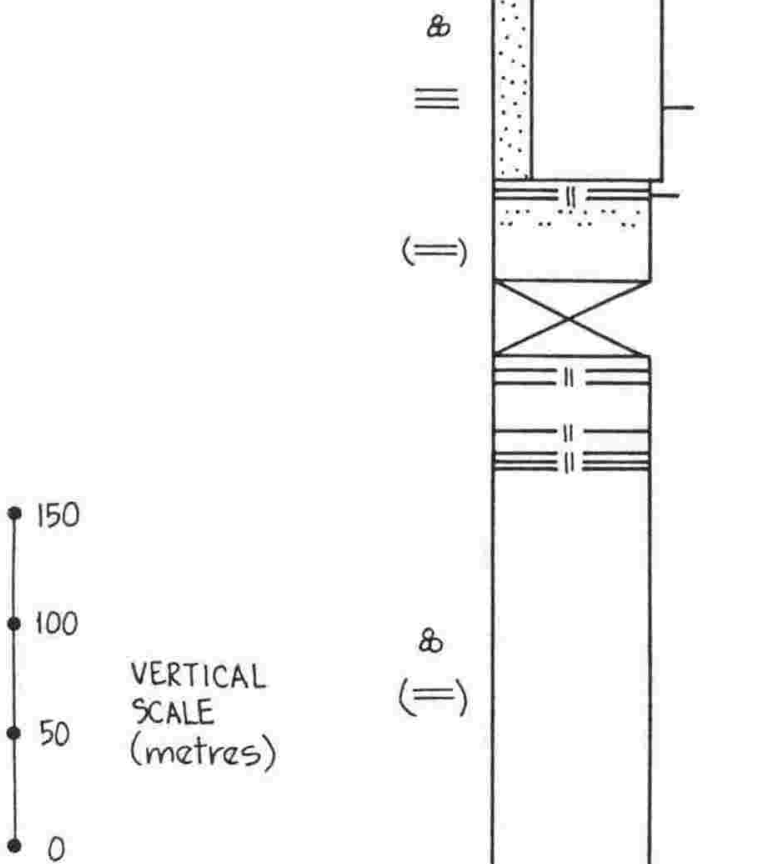

MUDSTONE: massive, some sandy layers towards top.

indistinct $3 m$ bedding

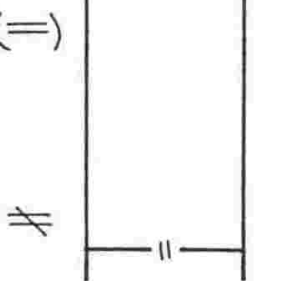

Figure $A 13$ 
Overlying this is a $404 \mathrm{~m}$, massive mudstone, sandy in places, with abundant tuff beds, especially near the base. There is a $28 \mathrm{~m}$ part of the unit which appears to represent a soft-sediment rotational slump with no appreciable loss of section (grid ref. X19/077448). Sample X19/f59 (TM23) marks the FAD of Bolivinita compressa s.s. and is the oldest radiolarian bearing sample in the section. Reasonable populations of Globorotalia miotumida have about $30-50 \%$ five chambered forms although the youngest sample in the unit contains only $16 \%$. Five samples were examined for Radiolaria from this unit and only the lowermost was barren, the other four being used in this thesis (TM20-TM23).

Next in the sequence is $168 \mathrm{~m}$ of alternating massive, hemipelagic mudstones $(10-29 \mathrm{~m}$ thick) and packets of interbedded sandstones and mudstones (16-21m thick). The base of the unit is marked by a layer of large concretions (up to $2 \mathrm{~m}$ ). A paleomagnetically inferred disconformity representing the period 6.42 to $6.86 \mathrm{Ma}$ is placed at this concretionary layer (Wright, 1985). The top of the unit is represented by an angular unconformity. There is no exposure of the unconformity on the banks of the Mangapoike River but good exposure on a roadcut section next to the river at grid reference X19/06754502. The unconformity pinches out to the south, the river section exposing approximately $30 \mathrm{~m}$ more section than the roadcut. This unit contains common tuff bands, one tuff band immediately below the unconformity in the roadcut has been dated at $5.80 \pm 0.55 \mathrm{Ma}$ by Dr. D. Seward (Hornibrook, 1984a). Sparse to good populations of G. miotumida are present, the good populations showing a variation from 8 to $20 \%$ five chambered forms. Globorotalia conomiozea conomiozea is lacking. Four river and ten roadcut samples were examined, 12 of which contained Radiolaria ( 4 and 8 respectively) and seven were used in this thesis (TM14, TM18-20 from the river and TM15-17 from the roadcut).

Unconformably overlying is a $230 \mathrm{~m}$, sandy mudstone to muddy sandstone unit which tends to get sandier towards the top, with rare macrofossils, occasional concretionary layers and tuff beds. The unconformity has a $5^{\circ}$ angular displacement and is marked, at the southern end of the roadcut, by a discontinuous line of glauconitic nodules up to $10 \mathrm{~cm}$ long, with scattered smaller nodules in the sandy mudstone up to $1 \mathrm{~m}$ above. At the northern end of the roadcut at least $1.5 \mathrm{~m}$ of glauconitic, sandy mudstone overlies the unconformity. Another period of slow deposition is marked by a $3 \mathrm{~m}$ glauconitic mudstone with scattered nodules about $65 \mathrm{~m}$ above the base of the unit. The basal part (c.25m) of this unit contains rare G. conomiozea conomiozea and common G. sphericomiozea. The FAD's of G. puncticulata puncticulata, G. crassaformis, and G. pliozea occur about $40 \mathrm{~m}$ above the unconformity. Five roadcut samples and six river samples were examined from this unit. One sample (TM13) from about $9 \mathrm{~m}$ above the unconformity in the roadcut contained rare, recrystallised Radiolaria, the rest are barren.

Overlying is the Tukemokihi Formation, a $43 \mathrm{~m}$, indurated, pebbly calcareous grit and sand which contains the mollusc, Phialopecten triphooki ongleyi. No samples were examined for Radiolaria. 
FIGURE A 15

MANGAPOIKE RIVER (in part)

Location: Geographic - Figure A7 Stratigraphic-Figure Al1

FORAMINIFERAL DATUMS: RADIOLARIAN ZONES:

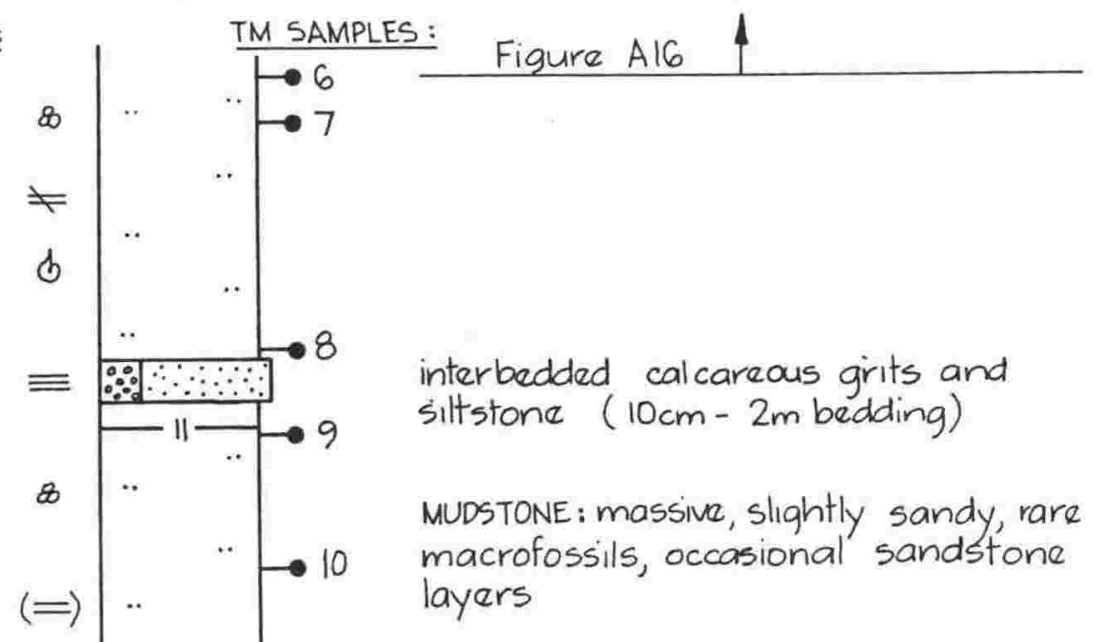

- FAD G. margaritae

$\Leftrightarrow$

layers

Lychnocanium grande

subzone

- G. puncticulata

G. crassaformis

\section{ande}

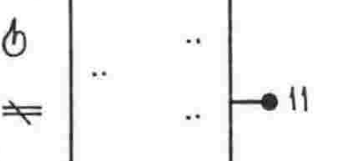

- LAD G. sphericomiozea =

FAD G.conomiozea mons

- FAD G. sphericomiozea

Didymocyrtis sp. A Zone

- G miotumida $20 \%$ five chambered

$$
\begin{aligned}
& \text { 三 } \\
& \text { 三 } \\
& \text { 흐 } \\
& \equiv \\
& \text { 하 } \\
& \equiv
\end{aligned}
$$

b

\section{pumiceous}

$\begin{array}{ll}\text { calcareous grit } & \text { TUKEMOKIHI } \\ \text { sandy mudstone, } 0.5 \mathrm{~m} \text { bedding } & \text { FORMATION }\end{array}$ calcareous grit bored surface

MUDSTONE: massive, sandy, occasional sandstone layers, scattered macrofossils

concretions

$5 m$ bedding

phosphatic

nodules

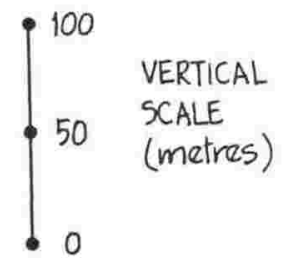

angular unconformity

see Figure A 17

Alternating packets of interbedded sandstone/mudstone and mudstone

Figure
A 14 $\quad \begin{gathered}\text { inferred disconformity } \\ \text { (paleomag) }\end{gathered}$ 
FIGURE AIG

MANGAPOIKE RIVER (in part)

Location: Geographic - Figure A7 Stratigraphic-Figure All

FORAMINIFERAL DATUMS:

- C. molestus

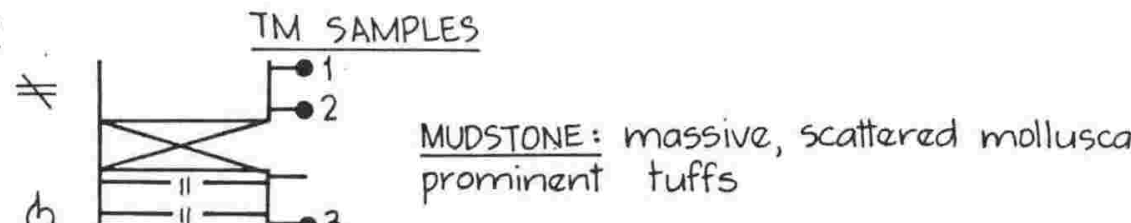

- abundant Phialopecten triphooki marwicki

LAD G. nepenthes

- FAD G.inflata

- LAD C. finlayi b

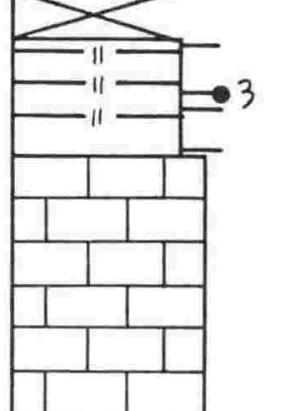$$
\equiv
$$
LIMESTONE: grey, shelly, detrital limestone with sandstone beds

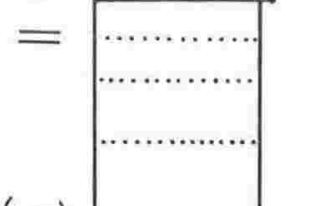

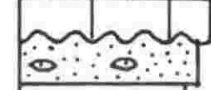

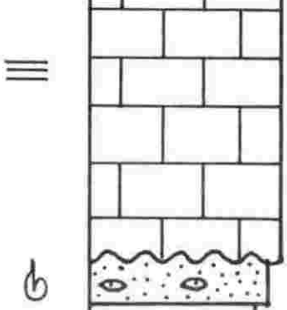

$(=$

8

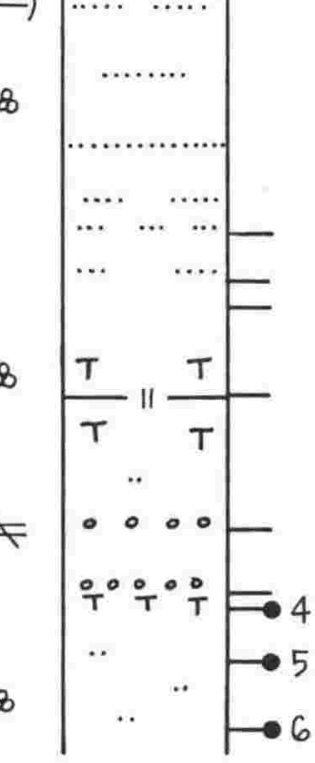

shelly concretionary sandstone

MUDSTONE: Massive, sandy, occasional sandstone layers and rare tuffs. Rare concretionary layers. Sandstone layers more common towards top.

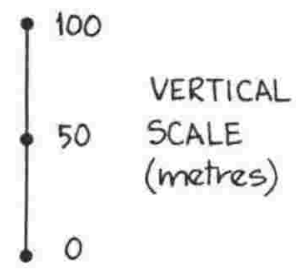

Figure A15 
FIGURE AI7

MANGAPOIKE: (road cut section)

Location: Geographic- Figure A7 Stratigraphic - Figure All

FORAMINIFERAL DATUMS:

- LAD G. conomiozea conomiozea S.S.

- FAD G.sphericomiozea

- FAD G. conomiozea conomiozea

- G. miotumida no five chambered forms

RADIOLARIAN ZONE:

Didymocyrtis sp. A

zone beneath the unconformity

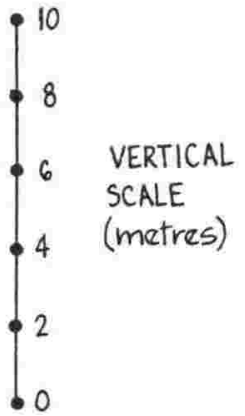

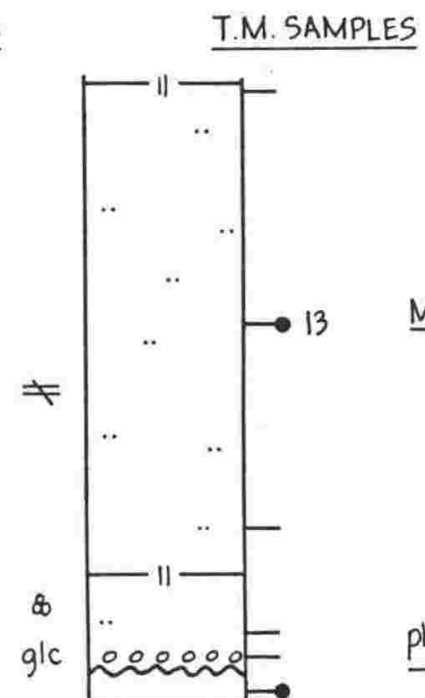

posphatic nodules angular unconformity

TUFF : $5.80 \mathrm{Ma}$

MUDSTONE: massive, occasional tuffs and sandy layers

MUDSTONE/SANDSTONE: interbedded sandstone $(0.5$ to $\mathrm{lm})$ mudstone (0.2 to $1 \mathrm{~m}$ ) 
Next is a $800 \mathrm{~m}$ massive sandy mudstone with occasional sandy layers (with an increasing frequency of calcareous sands towards the top), grits, concretionary bands, rare macrofossils and tuffs. The FAD of Globorotalia inflata is about $215 \mathrm{~m}$ from the top of this unit. Sixteen samples were examined for Radiolaria, the lower ten (TM04-12) containing rare specimens. The portion of this section from the LAD of G. conomiozea conomiozea to the top of this unit has been designated the Opoitian lectostratotype.

Overlying is a $300 \mathrm{~m}$ predominantly barnacle coquina (Whakapunake Limestone) which is deeply incised by the Mangapoike River through Haupatanga Gorge. This limestone contains abundant Phialopecten triphooki marwicki (Waipipian).

The youngest unit in the section is a massive silstone with scattered mollusca and tuff beds, at least $90 \mathrm{~m}$ thick, exposed in the Mangapoike River west of the Whakapunake Limestone (Kotare Road). This siltstone contains Cibicides molestus, Globorotalia crassaconica, and sinistral G. crassaformis. Five samples were examined, three of which contain Radiolaria (TM01-03).

Radiolaria: Of the 13 radiolarian bearing samples above the Miocene/Pliocene unconformity, only three (TM06,07,12) contain a radiolarian fauna with more than a few poorly preserved spongodiscids. Of these three TM06 was the only sample that warranted statistical analysis $(\mathrm{N}=28, \mathrm{Q}=6.32)$. This sample contains Lychnocanium sp. aff. grande and in TM07 there is a tentative identification of Didymocyrtis sp. A. Although no Didymocyrtis tetrathalmus tetrathalmus is present it is apparent that these samples are from the Lychnocanium sp. aff. grande Subzone being between the FAD of Globorotalia crassaformis and the FAD of Globorotalia inflata in this section. Sample TM12 contains a fauna too poor for zonal identification. Of the Miocene samples (TM14-23) only two contain assemblages too poor for statistical analysis (TM17,18), the other eight Miocene samples having faunas with moderate to good preservation $(\mathrm{N}=32-41)$ and poor to good diversity $(\mathrm{Q}=7.39-12.38)$. The samples lack Didymocyrtis laticonus or members of the Diartus hughesi group and nearly all contain Didymocyrtis sp. A and belong in the Didymocyrtis sp. A Zone. Cyrtocapsella japonica, and C. tetrapera dissappear at the inferred disconformity of Wright (1985).

References: McInnes (1964) - Pliocene and upper Miocene foraminifera

McInnes (1965) - Miocene/Pliocene boundary foraminifera

Kennett and Watkins (1974) - Pliocene paleomagnetics

Weaver (1976a) - Pliocene paleomagnetics

Beu et al (1980) - Limestone facies

Scott (1982b) - Tk/Wo boundary foraminifera

Hornibrook (1983) - Field trip guide

Hornibrook (1984a) - Miocene/Pliocene boundary

Wright (1985, and in prep.) - Miocene paleomagnetics

Gosson (in prep.) - Tephrostratigraphy

NZGS Micropaleontology Section stratigraphic columns 


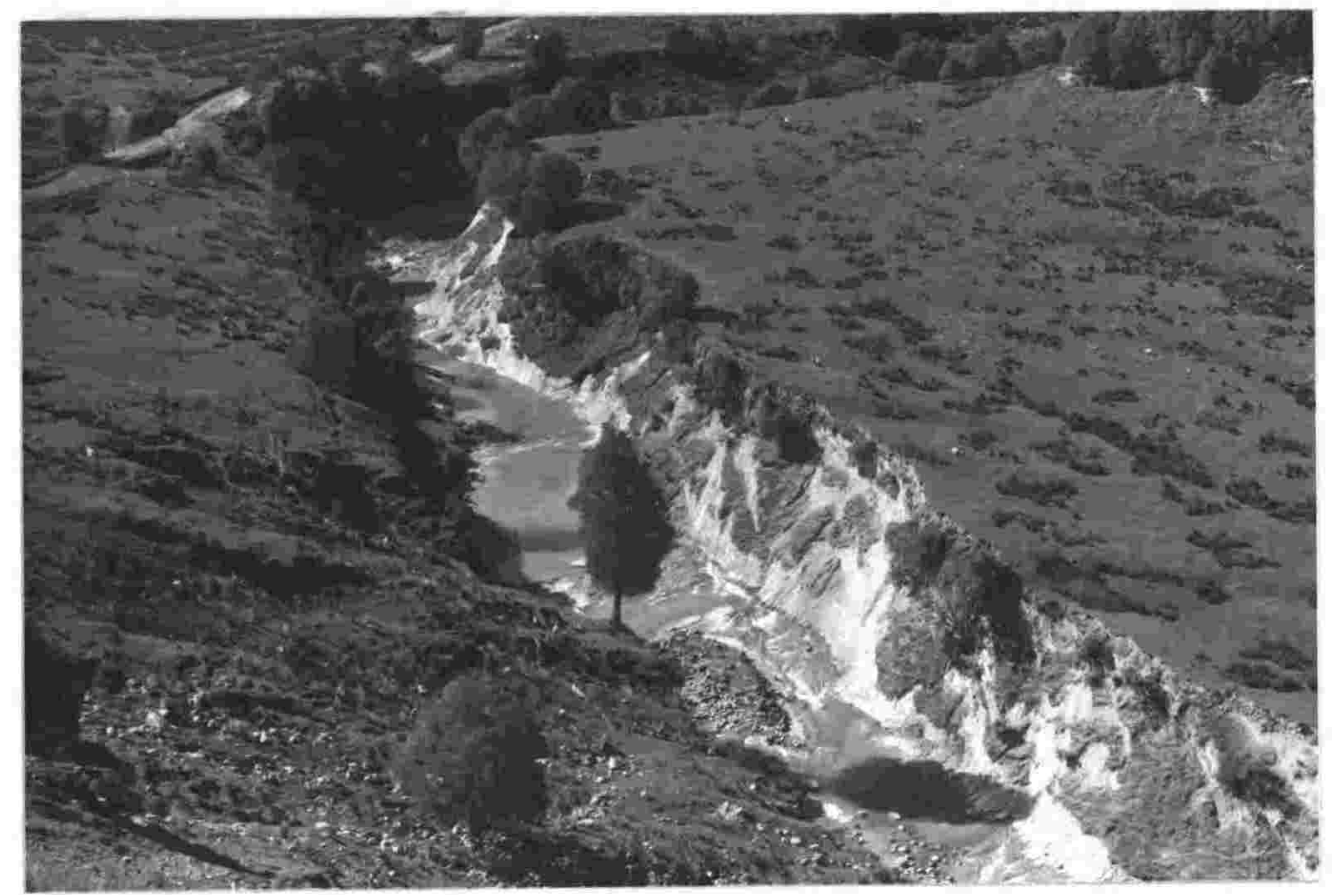

\section{Plate A1.1}

Example of exposure : the entrenched nature of Tukemokihi Stream gives $100 \%$ exposure for $1000 \mathrm{~m}$ of stratigraphic thickness above the Makaretu Sandstone.

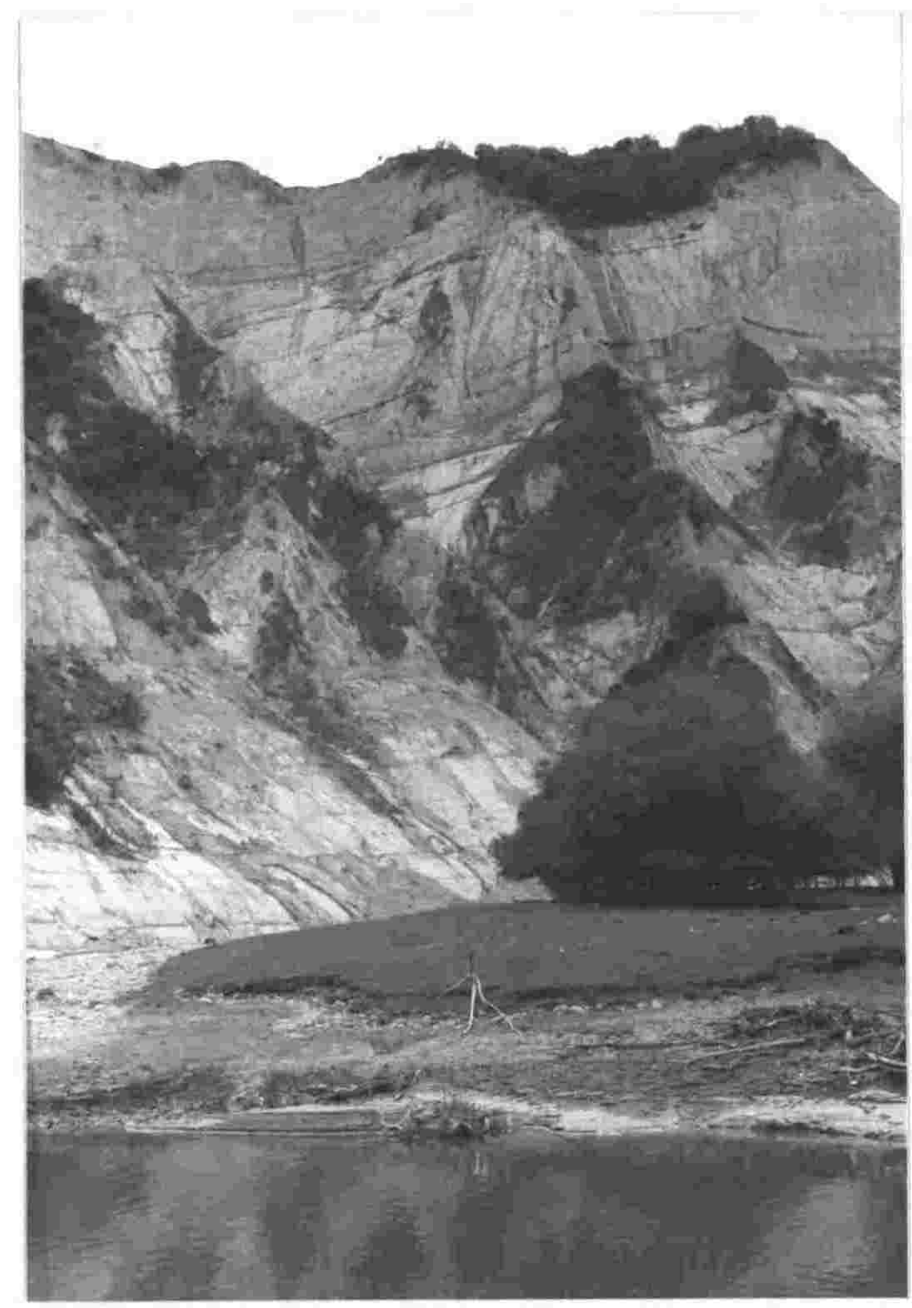

\section{Plate A1.2}

Example of exposure : although not part of the Tukemokihi Stream - Mangapoike River Section, these cliffs that expose strata along strike from Tukemokihi Stream give an indication of the type of exposure present in the banks of Mangapoike River. 


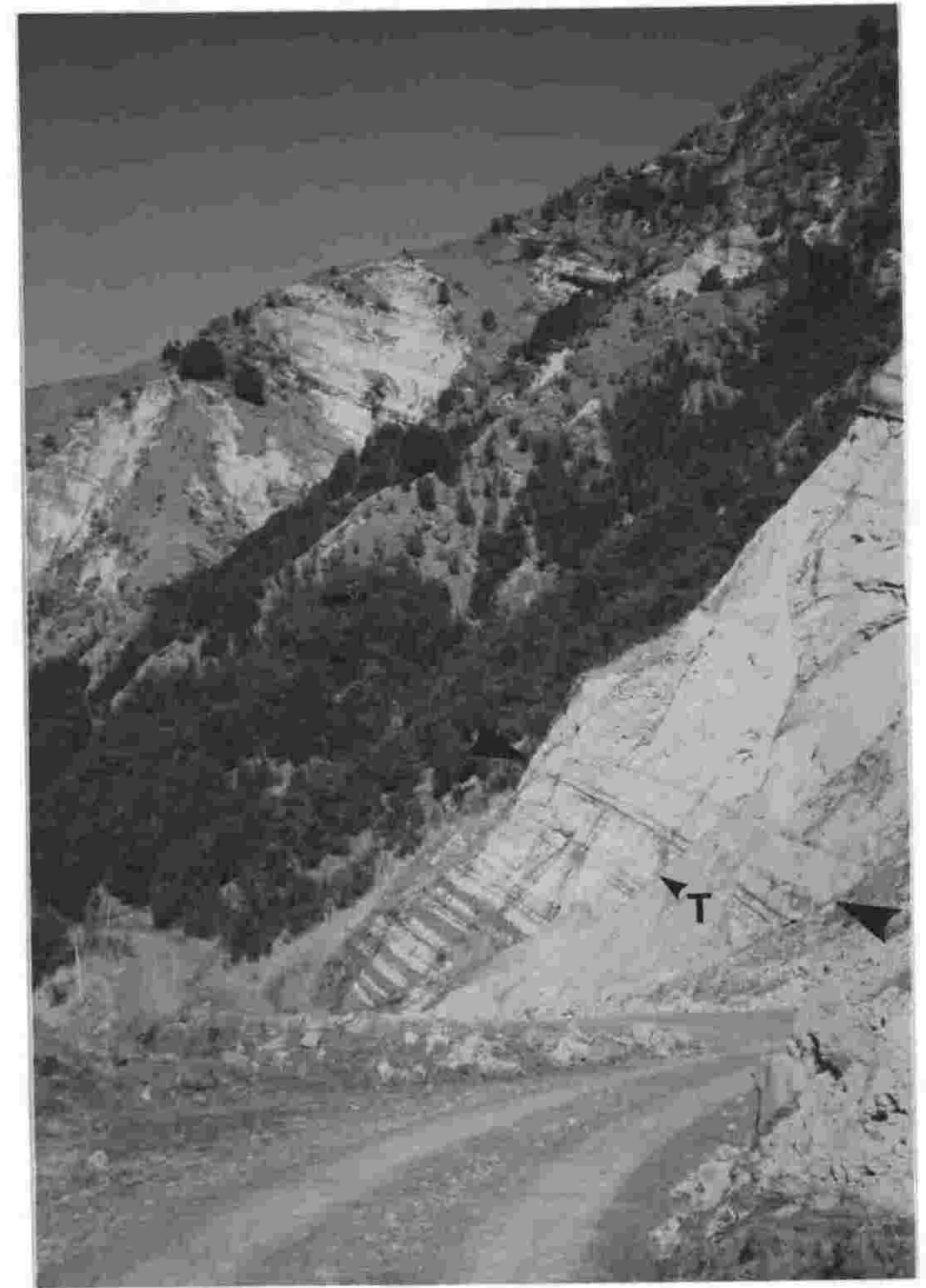

Plate A1.3

Roadcut unconformity : the unconformity (arrowed) with a $5^{\circ}$ angular discordance represents a possible Miocene/Pliocene boundary with Globorotalia sphericomiozea in strata immediately above. A tuff (marked T), immediately below the unconformity has been dated at $5.80 \pm 0.55 \mathrm{Ma}$ (Dr. D. Seward). Radiolarians are abundant in strata from below the unconformity (Didymocyrtis sp. A Zone), but are very poorly preserved, if present, above.

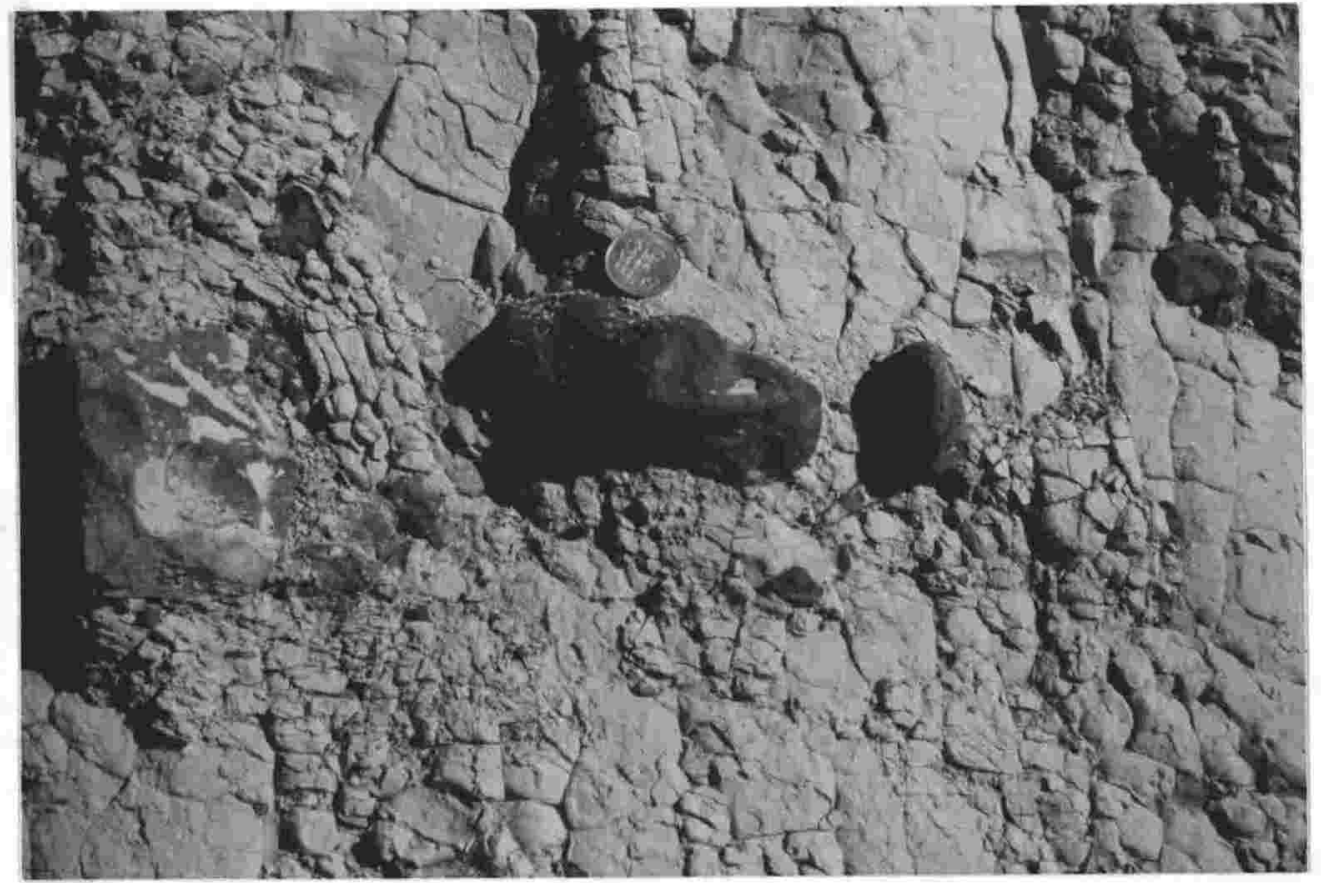

\section{Plate A1.4}

Roadcut unconformity : the angular unconformity is marked by a discontinuous line of glauconitic nodules up to $10 \mathrm{~cm}$ long, with scattered smaller nodules in the sandy mudstone up to $1 \mathrm{~m}$ above. The 50 cent piece is $32 \mathrm{~mm}$ in diameter. 


\section{A.11 MAHIA PENINSULA SITE}

Location: Mokotahi Point at the south end of Mahia Beach. See figure A.7.

Comment: Sample (SMH1) 3m below a tuff (Hornibrook FT37) dated at $6.39 \pm 1.14 \mathrm{Ma}$ (Dr. D. Seward, pers. comm.) contains abundant Radiolaria and is used in this thesis. The foraminiferal fauna includes Bolivinita pohana, Globorotalia miotumida (approximately 50\% five chambered) and lacks Globoquadrina dehiscens.

Radiolaria: This sample has moderate preservation and diversity $(\mathrm{N}=37, \mathrm{Q}=8.69)$. With Didymocyrtis sp. A present but lacking Didymocyrtis laticonus or members of the Diartus hughesi group, this sample belongs in the Didymocyrtis sp. A Zone.

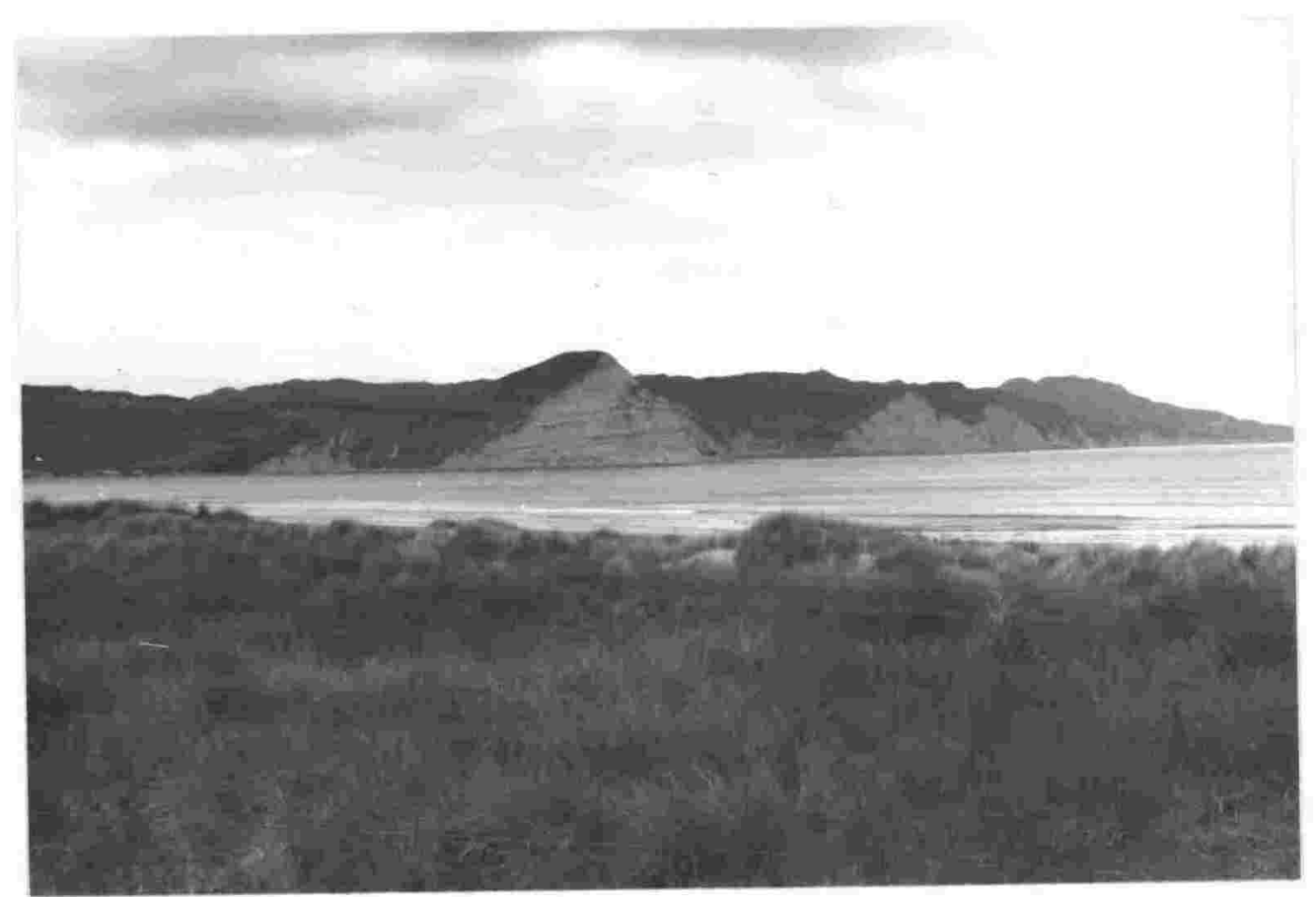

\section{Plate A1.5}

Mokotahi Point : strata from these cliffs at the south end of Mahia Beach contain Radiolaria from the Didymocyrtis sp. A Zone and a tuff dated 6.39 $\pm 1.14 \mathrm{Ma}$ (Dr. D. Seward). 
FIGURE A 18

WAIATAI VALLEY SECTION

Location: Figure A7

FORAMINIFERAL AND

RADIOLARIAN DATUMS:

- FAD G. crassula

\section{FAD L. gamphonycha}

- change from dextral to sinistral G. crassaformis

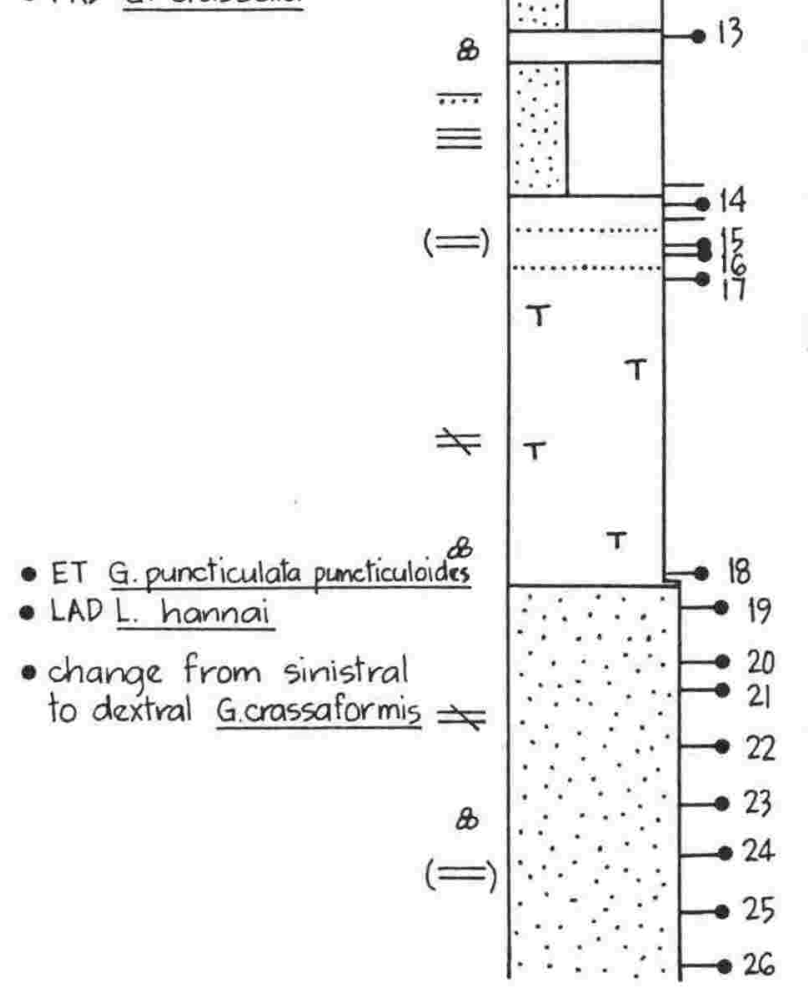

WA SAMPLES:

TOP OF TE UHI HILL

MUDSTONE: massive, occasional tuff beds, occasional sandy graded beds near base

SANDSTONE/MUDSTONE : interbedded, sandstones: soft, brown, graded

$7 m$ mudstone

15-20m mudstone

MUDSTONE: tuffaceous, occasional sandstone beds (some graded) near top, slightly carbonaceous

SANDSTONE: poorly bedded to massive, some prominent beds

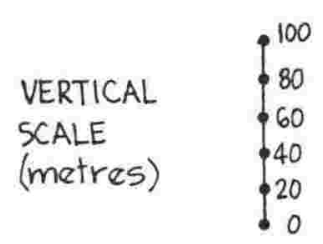




\section{A.12 WAIATAI VALLEY SECTION}

Location: On the northern slopes of Waiatai Valley and roadcuts on Te Uhi Hill between Trig $\mathrm{P}$ and the top Te Uhi Hill (10 to $1.5 \mathrm{~km}$ east of Wairoa). See figure A.7.

Stratigraphic column: Figure A.18.

Comment: The beds dip southwest at $5-6^{\circ}$ and exposure is generally poor so the thicknesses are difficult to measure accurately. The following text is taken in part from Hornibrook (1981b).

Lithology and Age: In the steep slopes below Trig $P$ is $208 \mathrm{~m}$ of poorly bedded silty sandstone containing small numbers of planktic foraminifera, including Globorotalia puncticulata puncticulata. Benthic foraminifera include Notorotalia kingmai, Cibicides molestus, the highest occurrence of which is adopted in this section as the principal benthic foraminiferal marker for the top of the Waipipian, is only in the lower half of the sandstone. Globorotalia crassaformis populations, coiling predominantly dextrally, are in the topmost $30 \mathrm{~m}$.

Above the poorly bedded sandstone, the lithology changes to a $217 \mathrm{~m}$ thick tuffaceous, carbonaceous mudstone containing occasional beds of sandstone, some of which show graded bedding. Planktic foraminifera are much more abundant in these beds and the typically deep water Notorotalia profunda replaces $N$. kingmai, apparently in response to a rapid

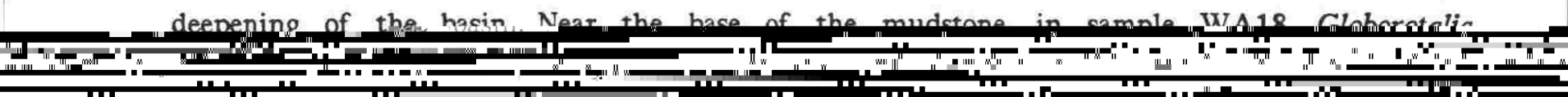


Radiolaria: Twenty-nine samples were examined from throughout the section, 27 contained Radiolaria and 26 are used in this thesis (WA01-WA26). The only two samples which are barren are from the top of the $217 \mathrm{~m}$ thick tuffaceous mudstone unit, immediately above a radiolarian rich horizon (WA15-17). Radiolaria are generally rare in the lower 230m of the section (WA18-WA26) but three samples proved suitable for statistical analysis (WA19,23,26) with low to moderate $N(24$ to 33 ) and low to moderate Q (4.33 to 7.28). All three samples contain Lamprocyrtis heteroporos although the identification is only tentative in WA26 (the oldest radiolarian bearing sample in the section) and this sample may mark the level of the transition from Lamprocyrtis hannai. The LAD of Lamprocyrtis hannai occurs in WA19. This places these samples within the Lamprocyrtis heteroporos Zone with WA26 probably near the base.

Above WA18 radiolaria are generally better preserved especially towards the top of the $217 \mathrm{~m}$ thick tuffaceous mudstone unit (WA15,16,17: $\mathrm{N}=31-38, \mathrm{Q}=6.01-8.21$ ), within thick mudstone beds in the $295 \mathrm{~m}$ thick interbedded sandstone and mudstone unit (WA13: $\mathrm{N}=35$, $\mathrm{Q}=8.45$ ), and from the youngest samples studied (WA01,03: $\mathrm{N}=29-34, \mathrm{Q}=6.23-8.50$ ). Of the other samples above WA18, one contained only a couple of unidentifiable spongodiscids (WA09) and the rest very low diversity faunas not suitable for statistical analysis (WA04-06,08,11,12,14). The FAD of Lamprocyclas gamphonycha occurs in WA07, although one sample (WA15) contains a form transitional with Lamprocyrtis heteroporos.

References: Hornibrook, 1981 ; NZGS Micropaleontology Section unpublished stratigraphic column.

\section{A.13 WAIROA-NUHAKA ROAD SITES}

Location: Sites collected from roadcuts on the northern side of the Wairoa-Nuhaka Highway (SH2) between Whakaki and Tuhara. See figure A.7.

Lithology and Age: Four samples of massive mudstones with occasional tuff bands were looked at, three of which contain Radiolaria and are used in this thesis (SWN1-SWN3). Stratigraphic distances between the sites are difficult to assess. Sample SWN2 is an approximate recollection of X19/f9523 (=N116/f523) which contains Globorotalia crassaformis, G. tosaensis, G. inflata, G. ruber, and G. puncticulata. The samples are from the lateral equivalent of the $217 \mathrm{~m}$ tuffaceous, carbonaceous mudstone exposed in Waiatai Valley between the LAD of Cibicides molestus and FAD of Globorotalia crassula and using strike correlations fill the sampling gap between WA17 and WA18 in the Waiatai Valley Section.

Radiolaria: Generally radiolaria are poorly preserved in these samples, none being suitable for statistical analysis. No definitive radiolarian age determinations can be made.

Reference: Hornibrook (1976b). 
Location: A composite column of strata exposed in the low hills to the south of the main highway opposite Tahaenui Station and at the entrance to Tahaenui Station plus roadcut localities up Kohukohu Road ( $4 \mathrm{~km}$ west of Nuhaka). See figure A.7.

Samples and Age: Nine Waipipian samples examined, seven of which contain Radiolaria and six were analysed in this thesis (TK01-TK06). The seventh sample (JAA444) is an approxiamate recollection of TK01. One Tongaporutuan? sample from immediately below the Whakapunake Limestone (at the northern end of Kohukohu Road) is barren.

Radiolaria: Of the six samples studied only one (TK05) warranted detailed investigation, the others containing only rare, recrystallised spongodiscids and the occasional member of the genus Thecosphaera. Even TK05 has a very poor fauna (NG=6, N=14, Q=4.84). No definitive zonal age could be determined but the presence of the thicker spined form of "Sphaerostylus" sp. aff. timmsi supports a post-Miocene age.

References: NZGS Micropaleontology Section unpublished stratigraphic column.

\section{A.15 CRICKLEWOOD ROAD SECTION}

Location: The valley slopes on either side of Huramua Stream beside the lower part of Cricklewood Road, about $2.5 \mathrm{~km}$ due west of Ohinepaka. See figure A.7.

Lithology and Age: The section is represented by tuffaceous mudstones which are poorly exposed and slumped in the neighbouring Waihua Valley Section. The Globorotalia crassula - dextral Globorotalia crassaformis overlap zone is recognised on the south side of the road (at least $5 \mathrm{~m}$ thick).

Samples: Samples range in age from Mangapanian to Nukumaruan. Six samples were examined (W19/f8659-8664), four of which contain Radiolaria and are used in this thesis (CR01-04).

Radiolaria: The two youngest radiolarian bearing samples are from above the dextral Globorotalia crassaformis - G. crassula overlap zone (CR01,02) and contain only rare spongodiscids and sample CR04, from below the overlap zone, contains relatively common spongodiscids and Thecosphaera sp., all three samples obviously affected by dissolution. Sample CR03 contains a poor assemblage ( $N G=12, \mathrm{~N}=21, \mathrm{Q}=5.05$ ), with post Miocene indicators such as Amphirhopalum cf. ypsilon and the thicker spined form of "Sphaerostylus" sp. aff. timmsi, but no zonal radiolarian fossils. The sample comes from the top of the overlap zone and is probably from the Lamprocyclas gamphonycha Zone.

References: Hornibrook (1981b), NZGS Micropaleontology Section unpublished stratigraphic column. 
FIGURE A19

WAIHUA VALLEY SECTION

Location: Figure A7

FORAMINIFERA AND

WH SAMPLES

RADIOLARIA:

G. truncatulinoides more abundant and typical upsection

- FAD G. crassula

- sinistral G.crassaformis Lamprocyrtis heteroporos

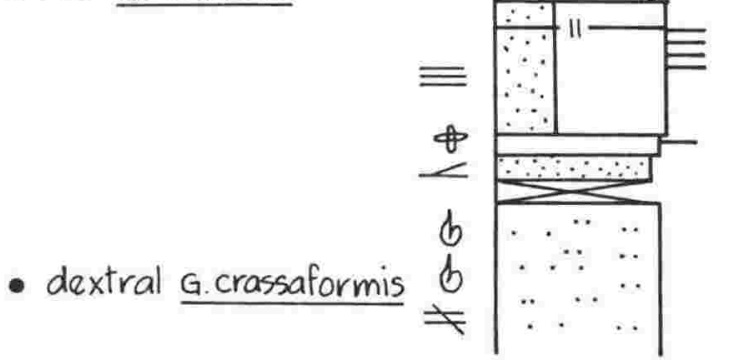

MUDSTONE: massive, occasional tuffs, scattered mollusca, poorly exposed, sandier towards top

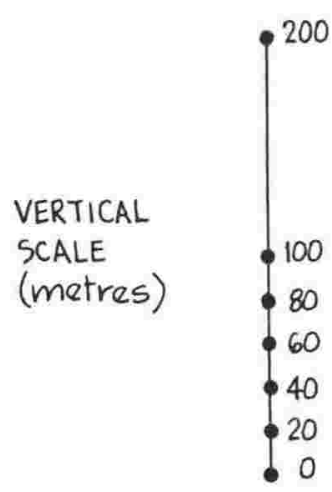

MUDSTONE/SANDSTONE: interbedded $(0.5$ to $3 \mathrm{~m})$, calcareous, thick mudstone at base

SANDSTONE; dk brn, sft $x$ bdd, non-calc SANDSTONE: fine to medium, grey, abundant mollusca 
Location: Roadcut and riverbank samples along the Waihua River Valley from the junction with Ngamahanga Stream to the Waihua River mouth. See figure A.7.

Stratigraphic column: Figure A.19.

Lithology and Age: The base of the section consists of a medium grey sandstone with abundant mollusca dated as Waitotaran by Marwick (1965). Foraminifera include abundant Notorotalia kingmai, rare, very small angular juveniles of Globorotalia truncatulinoides morphotypes and a small population of predominantly dextral Globorotalia crassaformis.

Overlying this is a $15 \mathrm{~m}$ weathered dark brown, non-calcareous soft sandstone.

Next in the sequence is a $10 \mathrm{~m}$ weathered mudstone containing dextral G. crassaformis.

The next unit is a distinctive interbedded sandstone-mudstone unit about $60 \mathrm{~m}$ thick which is a useful local marker unit.

Overlying is a thick (approximately $650 \mathrm{~m}$ ) interval of massive tuffaceous mudstone which in places is slumped and generally poorly exposed. A single specimen of G. crassula was found a few metres above the base of this unit (N115/f596) indicating a lower Nukumaruan age. One sample containing sinistral G. crassaformis was found near the middle of this unit (N115/f552). Consequently the Globorotalia crassula - dextral Globorotalia crassaformis overlap zone is difficult to define precisely in this section. In the upper part of the mudstone G. truncatulinoides becomes more abundant and typical.

Samples: Six samples from the Mangapanian part of the section (X19/f7, f10-14) are barren. Two Nukumaruan samples were examined from the same collection (NZ Geological Survey) of which only sample N115/f552 contains Radiolaria. Nine samples were collected from the Nukumaruan tuffaceous mudstone, six of which contained Radiolaria and are used in this thesis (WH01-05, WH07). Sample N115/f552 (WHO6) was also used in this thesis.

Radiolaria: Of the seven samples examined only samples WHO3 and WHO6 warranted statistical treatment, the other five generally containing poor faunas dominated by Spongotrochus glacialis. The two statistical samples have a low preservation and diversity typical of radiolarian faunas from Pleistocene samples ( $N G=22-23, N=23-26, Q=6.83-7.85)$. Sample WH03 lacks zonal radiolarians but contains post-Miocene indicators such as Actinomma leptodermum, the thicker spined form of "Sphaerostylus" sp. aff. timmsi and Amphirhopalum cf. ypsilon and is probably from the Lamprocyclas gamphonycha Zone. Sample WH06 contains Lamprocyrtis heteroporos but lacks Lamprocyclas gamphonycha which places the sample in the Lamprocyrtis heteroporos Zone.

References: Marwick (1965), Hornibrook (1981b), NZGS Micropaleontology Section unpublished stratigraphic column. 


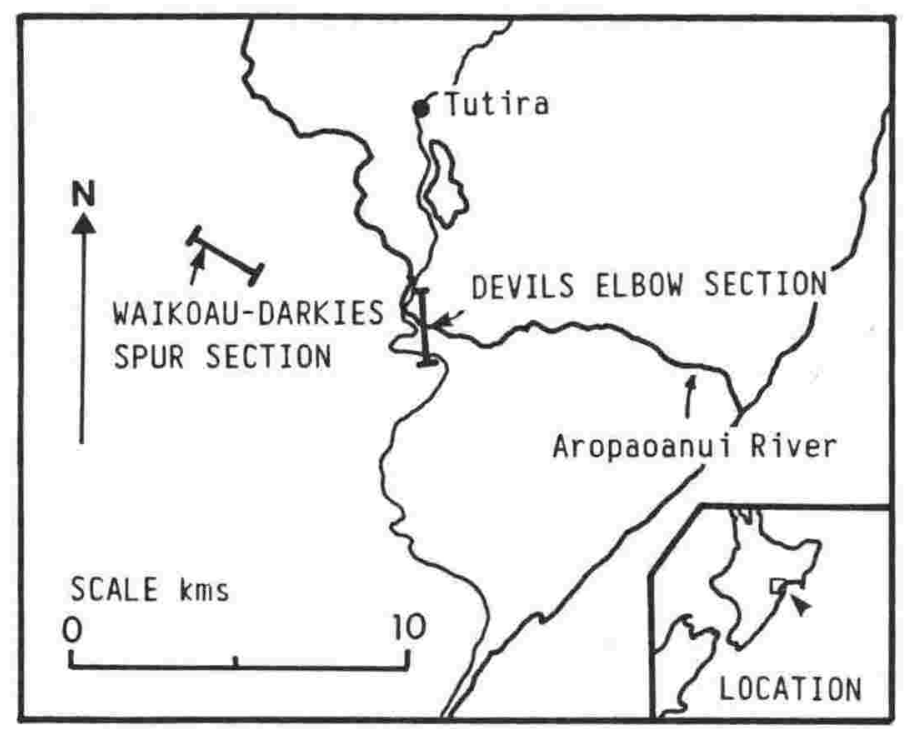

Figure A.20

Location of sections : Tutira area (central Hawke's Bay). 


\section{A.17 WAIKOAU-DARKIES SPUR SECTION}

Location: Western edge of a $350 \mathrm{~m}$ high limestone plateau above Waikoau, about $7 \mathrm{~km}$ due west of Lake Tutira which is on the Napier-Wairoa Highway. See figure A.20.

Samples: Three lower Nukumaruan samples (V20/f12-f14) were found to be barren.

References: Hornibrook (1981), NZGS Micropaleontology Section unpublished stratigraphic column.

\section{A.18 DEVILS ELBOW SECTION}

Location: Along the Napier-Wairoa Highway on the steep southern face of the Aropaoanui River Valley, about $4 \mathrm{~km}$ south of Lake Tutira. See figure A.20.

Samples: Two lower Nukumaruan samples (N124/f580, f583) were found to be barren.

References: Grant-Taylor and Hornibrook (1976), Hornibrook (1981), NZGS Micropaleontology Section unpublished stratigraphic column.

\section{A.19 ONEKAWA DRILLHOLE}

Samples: Four lower Nukumaruan samples from this drillhole near Napier (V21/436815 $40.5 \mathrm{~m}, 45.7 \mathrm{~m}, 62.1 \mathrm{~m}, 84.4 \mathrm{~m})$ contain very rare radiolarian specimens but were not examined in detail in this thesis.

Reference: Hornibrook (1981). 


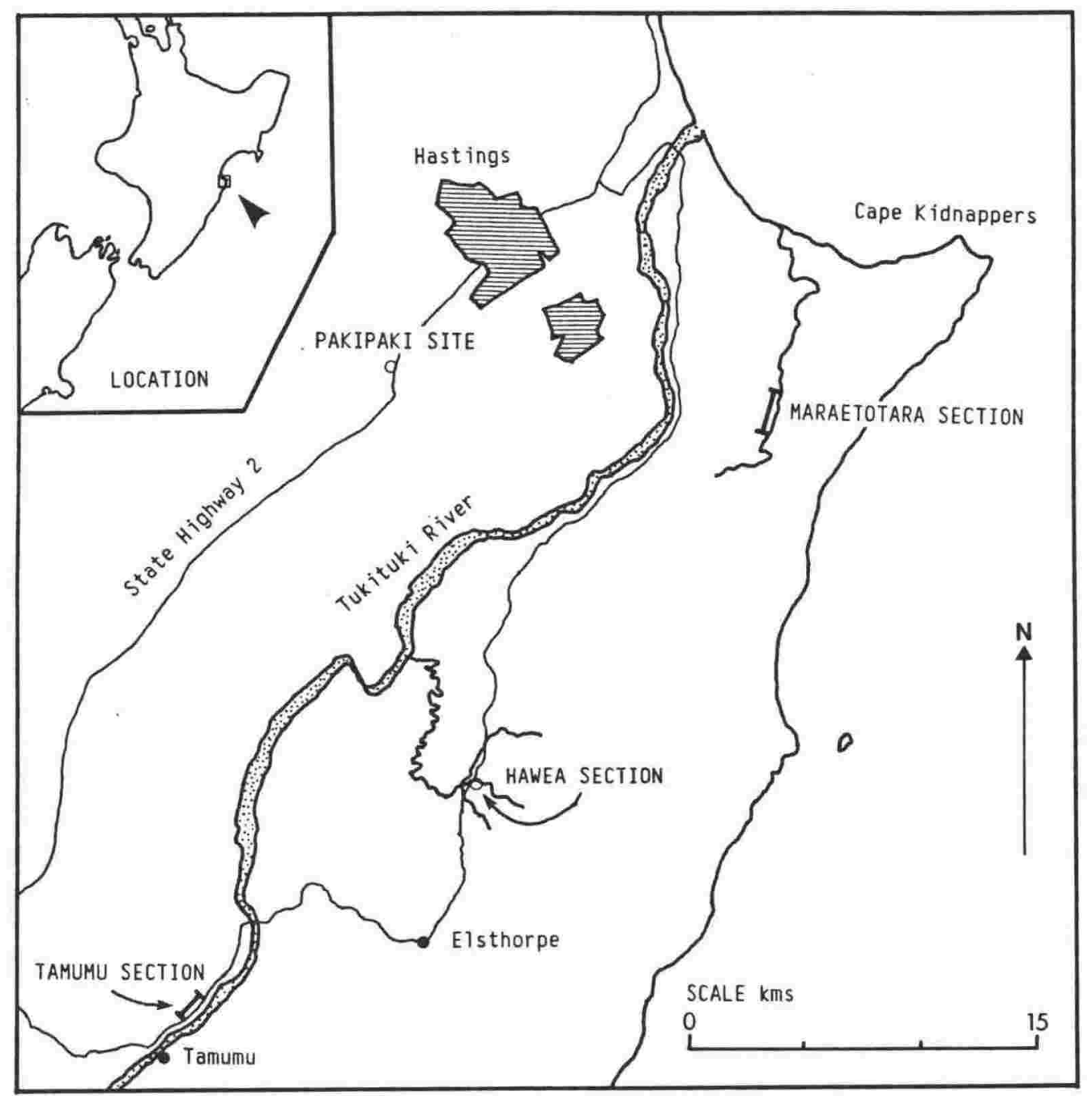

Figure A.21

Location of sections and site : Hastings area. 
Location: Along the middle reaches of the Maraetotara River, about $14 \mathrm{~km}$ southeast of Hastings. The section is moderately well exposed in a gorge immediately to the east of Maraetuna Homestead and in the entrenched river banks in younger strata to the north. Exposures are very poor in older strata to the south. See figure A.21.

Stratigraphic columns: Figures A.22 and A.23.

Lithology and Age: At least $880 \mathrm{~m}$ of massive moderately hard mudstone with rare macrofossils near the base and sandier facies in the upper $170 \mathrm{~m}$. No distinct tuff beds were found but glass shards are present in some of the residues and one sample contained pumiceous granules up to $5 \mathrm{~mm}$. The FAD of Bolivinita compressa was recorded by Kennett $580 \mathrm{~m}$ from the top of this unit (N135/f565). Although planktic foraminiferal faunas are generally poor there appears to be an abrupt change from five chambered Globorotalia miotumida to predominantly $4 / 4.5$ chambered forms about $44 \mathrm{~m}$ from the top of this unit.

Overlying is at least $40 \mathrm{~m}$ of interbedded hard $(5-10 \mathrm{~cm})$ and soft $(0.5-1 \mathrm{~m})$ muddy sandstone which gets more massive up-section. This unit contains Globorotalia crassaformis and G. puncticulata puncticulata.

Kennett (1966e) stated that the "contact between the Taranaki and Wanganui Series is not exposed, but no more than $150 \mathrm{ft}$ of strata is covered at this horizon" and he believed a disconformity was present between Opoitian and Tongaporutuan strata. In a small riverbank (W21/51986009) the unconformity is now exposed with a sharp contact between underiying biue-grey massive mudstone containing forms approaching Globorotalia conomiozea conomiozea (MT03) and a $5 \mathrm{~cm}$ shelly conglomerate which grades into the alternating hard and soft muddy sandstone unit. The first soft bed, about $10 \mathrm{~cm}$ above the sharp contact (MT02), contains rare G. puncticulata, G. crassaformis, and one specimen of G. conomiozea mons.

Samples: Two samples below the FAD of B. compressa are barren. Between the FAD of $B$. compressa and the unconformity, 18 samples were examined, 13 of which from the upper $150 \mathrm{~m}$ contained Radiolaria. Seven of these samples are examined in this thesis (MT04-MT10). Two samples from above the unconformity are barren of Radiolaria.

Radiolaria: Of the seven radiolarian bearing samples, five were suitable for statistical analysis. The three lower samples (MT08-10: $\mathrm{N}=34, \mathrm{Q}=7.82-8.60$ ) all contain Didymocyrtis laticonus with MT09 and possibly MT10 containing the large pored form of Heliodiscus asteriscus and MT18 Anthocyrtidium ehrenbergi pliocenica. This places these samples in the Heliodiscus asteriscus forma large pores Subzone. Diartus hughesi is possibly present in MT08 but not in any younger samples. The LAD of Didymocyrtis laticonus is in sample MT08 and between MT07 and MT08 there is an abrupt change from five to $4 / 4.5$ chambered Globorotalia miotumida. As forms very close to Globorotalia conomiozea conomiozea start appearing only $30 \mathrm{~m}$ above it is assumed that there is some time missing between MT07 and MT08 (possibly the Anthocyrtidium ehrenbergi pliocenica Subzone).

Reference: Kennett (1966e). 
FIGURE A22

MARAETOTARA SECTION (partially after Kennett 1966e)

Location: Figure A21

FORAMINIFERA:

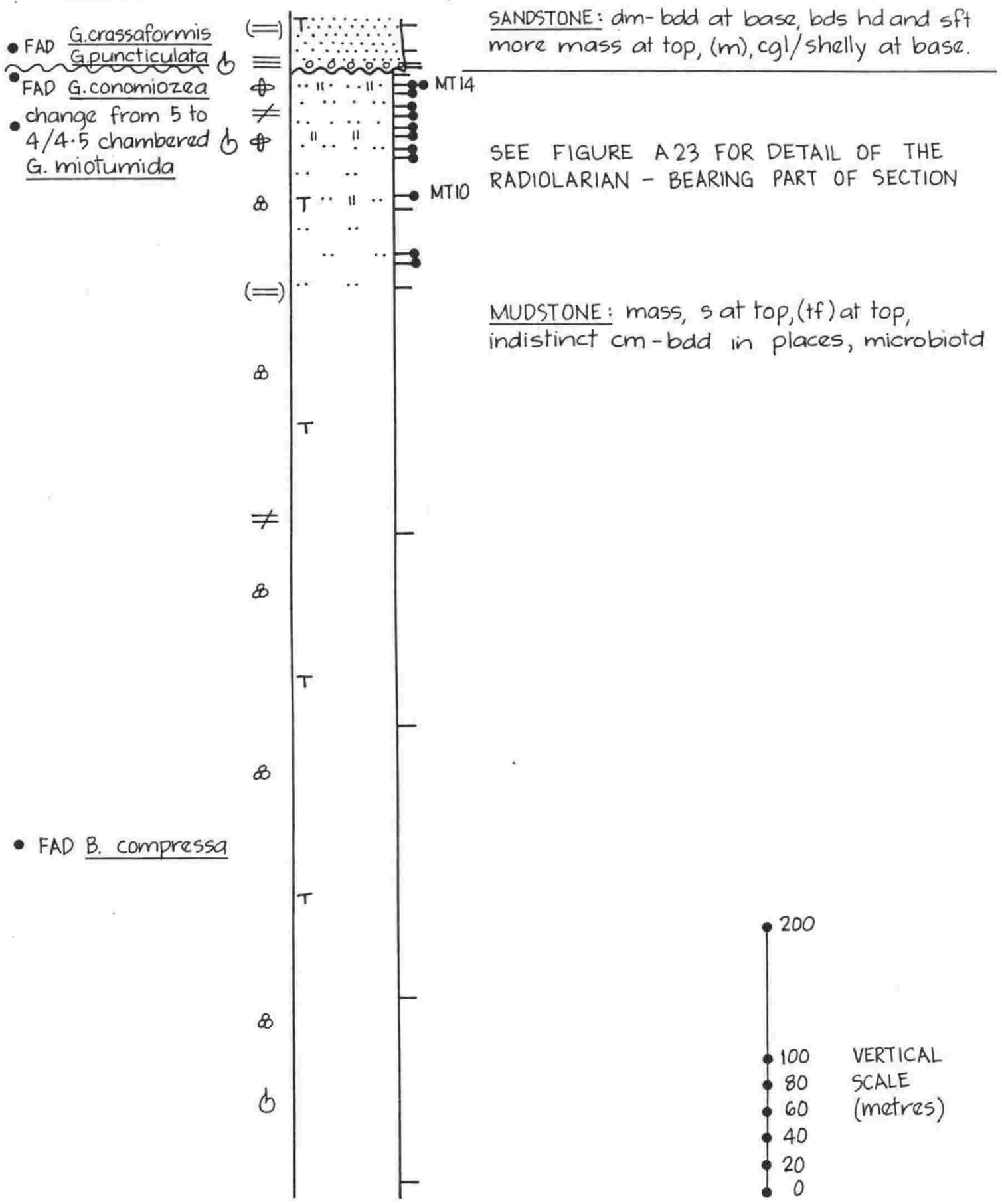


FIGURE A23

MARAETOTARA RIVER SECTION (detail of radiolarian bearing portion) Location: Figure A 21

FORAMINIFERA AND RADIOLARIA:

- FAD G.crassaformis, Guncticulata

- Fad g.conomiozea conomiozea s.l.

? Didymocyrtis antepenultima

- abrupt change from five to 4/4.5 chambered G. miotumida

- LAD D. laticonus

? Diartus hughesi: present

- Heliodiscus asteriscus forma large pores

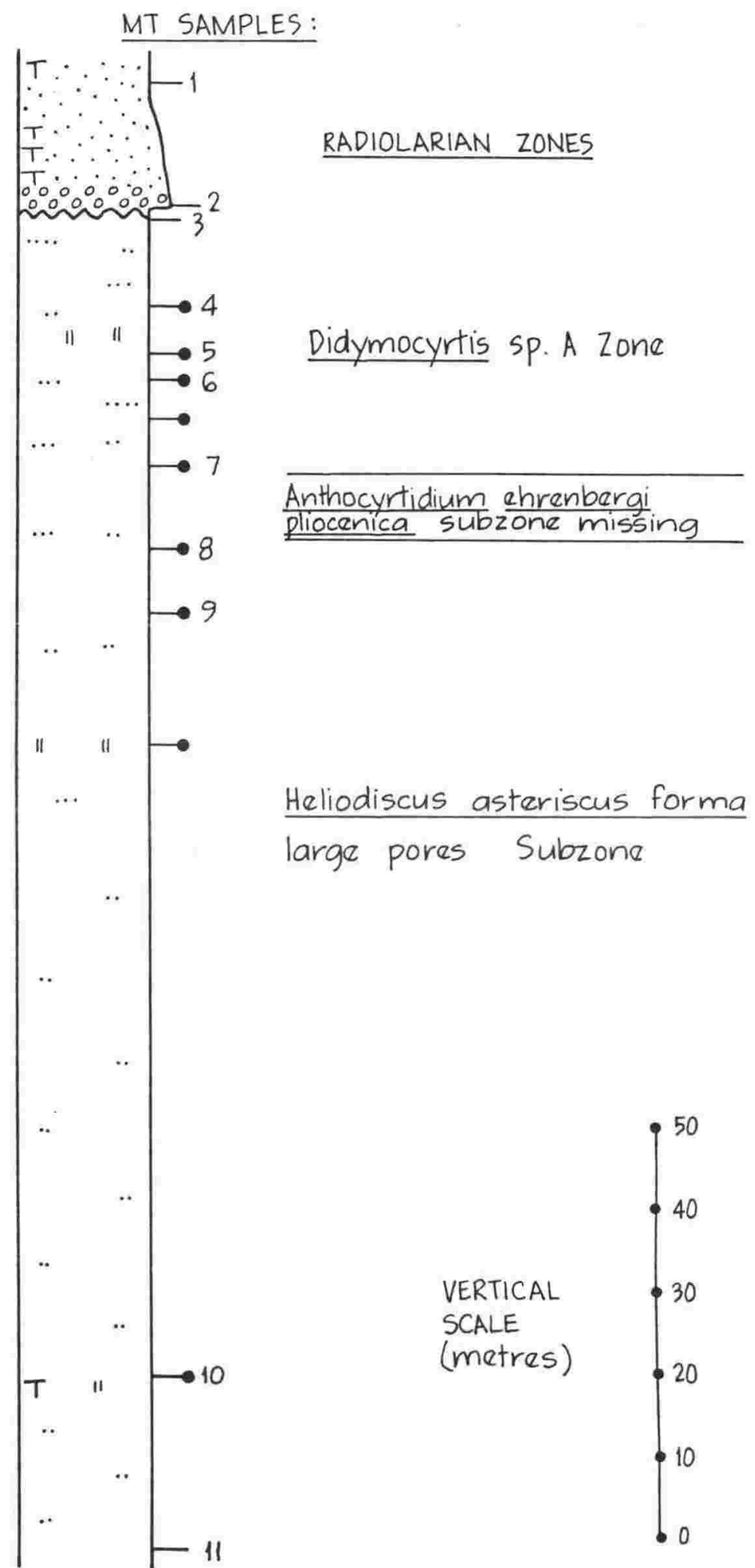




\section{A.21 HAWEA STREAM SECTION}

Location: Part of Hawea Stream, $0.4 \mathrm{~km}$ east of the Elsthorpe - Hastings Highway, $7 \mathrm{~km}$ north of Elsthorpe. See figure A.21.

Samples: Eight possible Southland Series samples (N141/f1402-f1409) were examined and two samples (f1408, f1409) contained rare, recrystallised Radiolaria and were not studied in this thesis.

References: Gibson (1963, 1967).

\section{A.22 TAMUMU SECTION}

Location: West bank of the Tukituki River, $2.8 \mathrm{~km}$ north of Tamumu Bridge. See figure A.21.

Samples: Five Waiauan to mid Tongaporutuan samples (N141/f1410, f1414-f1416, f1418) are barren.

References: Gibson (1963, 1967).

\section{A.23 PAKIPAKI SITE}

Location: Abandoned lime quarry at Pakipaki, $7 \mathrm{~km}$ south of Hastings. See figure A.21.

Samples: Two samples from the Globorotalia crassula - dextral Globorotalia crassaformis overlap zone (V21/f $7, \mathrm{f} 8$ ) were found to be barren.

Reference: Hornibrook (1981). 


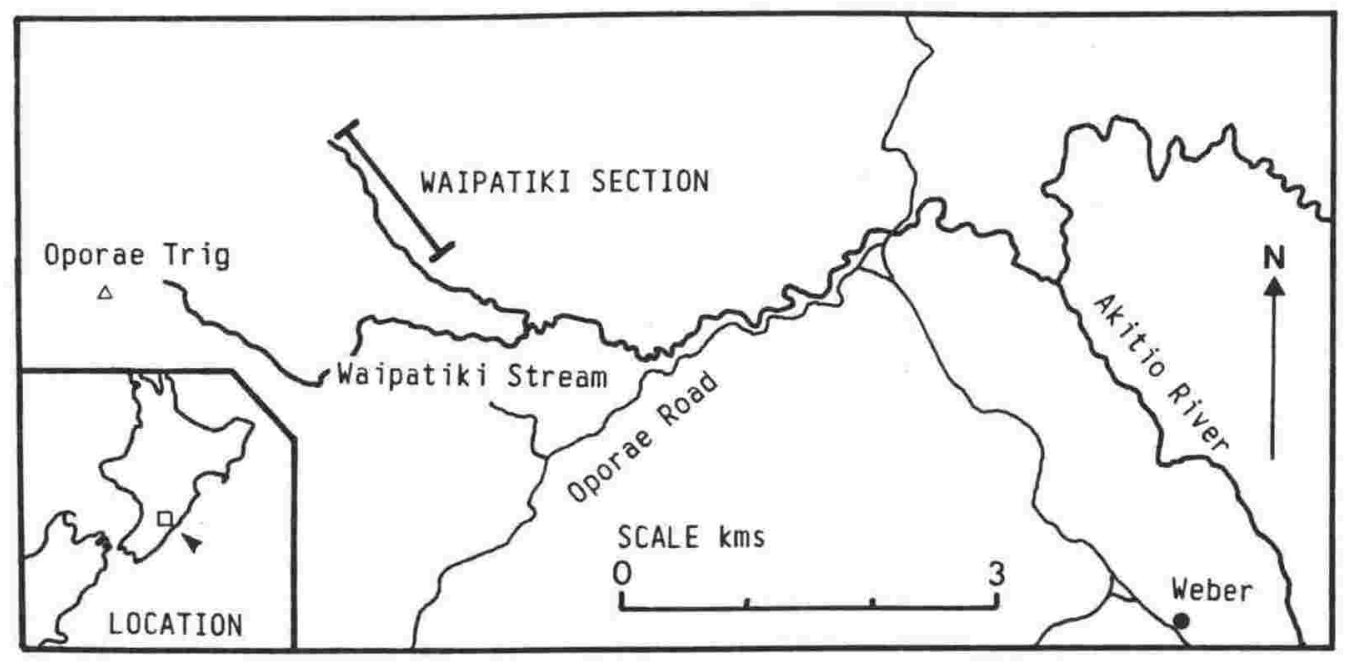

Figure A.24

Location of section : Waipatiki (northern Wairarapa).

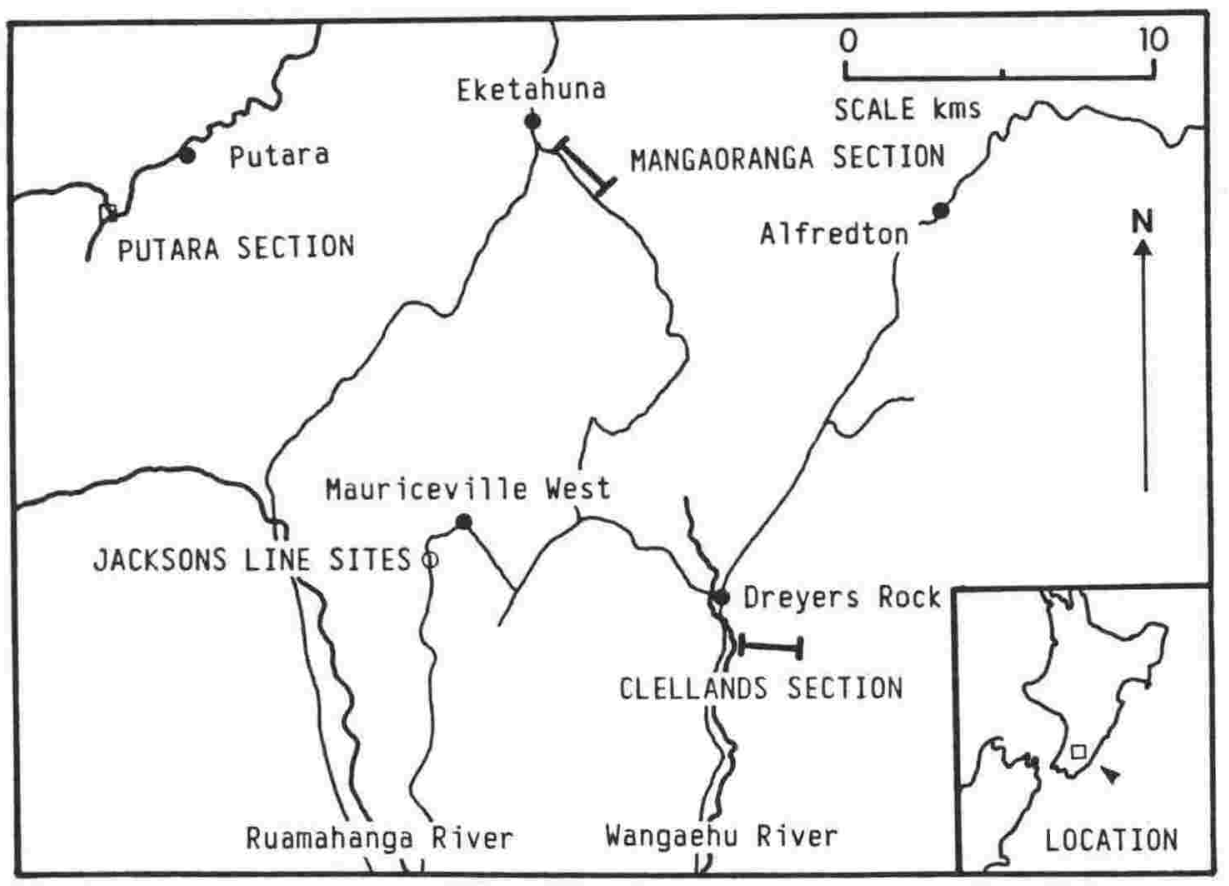

Figure A.25

Location of sections and sites : Mauriceville area (northern Wairarapa). 


\section{A.24 WAIPATIKI SECTION}

Location: Well exposed section in a tributary of the Waipatiki Stream, $2.4 \mathrm{~km}$ east of Oporae Trig and $7 \mathrm{~km}$ west-northwest of Weber. See figure A.24.

Samples: Three samples from the Kapitean part of the section (N150/f1032,1035,1038) and two from the lower Opoitian (N150/f1041,1042), all from massive silty mudstones are barren.

References: Laing (1964), Kennett (1966d).

\section{A.25 MANGAORANGA SECTION}

Location: Exposed in the banks of the Mangaoranga Stream from 1.4 to $3.2 \mathrm{~km}$ southeast of Eketahuna. See figure A.25.

Samples: Five samples were examined from Kennett's collection N153/f1172,1170 (Wo), f1165 (Tt/Tk), f1159,1160 (MTt), one of which (f1165) contained rare Radiolaria. A collection of 14 samples made by G. Scott and H. Morgans of the Geological Survey was then examined and two samples $(\mathrm{T} 25 / \mathrm{f} 14,15)$ contained rare, pyritised Radiolaria from sediments containing Bolivinita pliozea, Globorotalia miotumida (predominantly four chambered), and some conical forms approaching G. conomiozea conomiozea. The Radiolaria were considered to be too poorly preserved to be used in this thesis.

References: Kennett (1966d), Neef (1984).

\section{A.26 PUTARA SECTION}

Location: Moderately well exposed in cliffs cut by the Mangatainoka River immediately north of Putara and for $2.4 \mathrm{~km}$ northwest up a stream that flows into the Mangatainoka River. About $10 \mathrm{~km}$ due east of Eketahuna. See figure A.25.

Samples: One sample examined from Kennett's collection (N153/f1153 - Opoitian mudstone) is barren.

Reference: Kennett (1966d). 


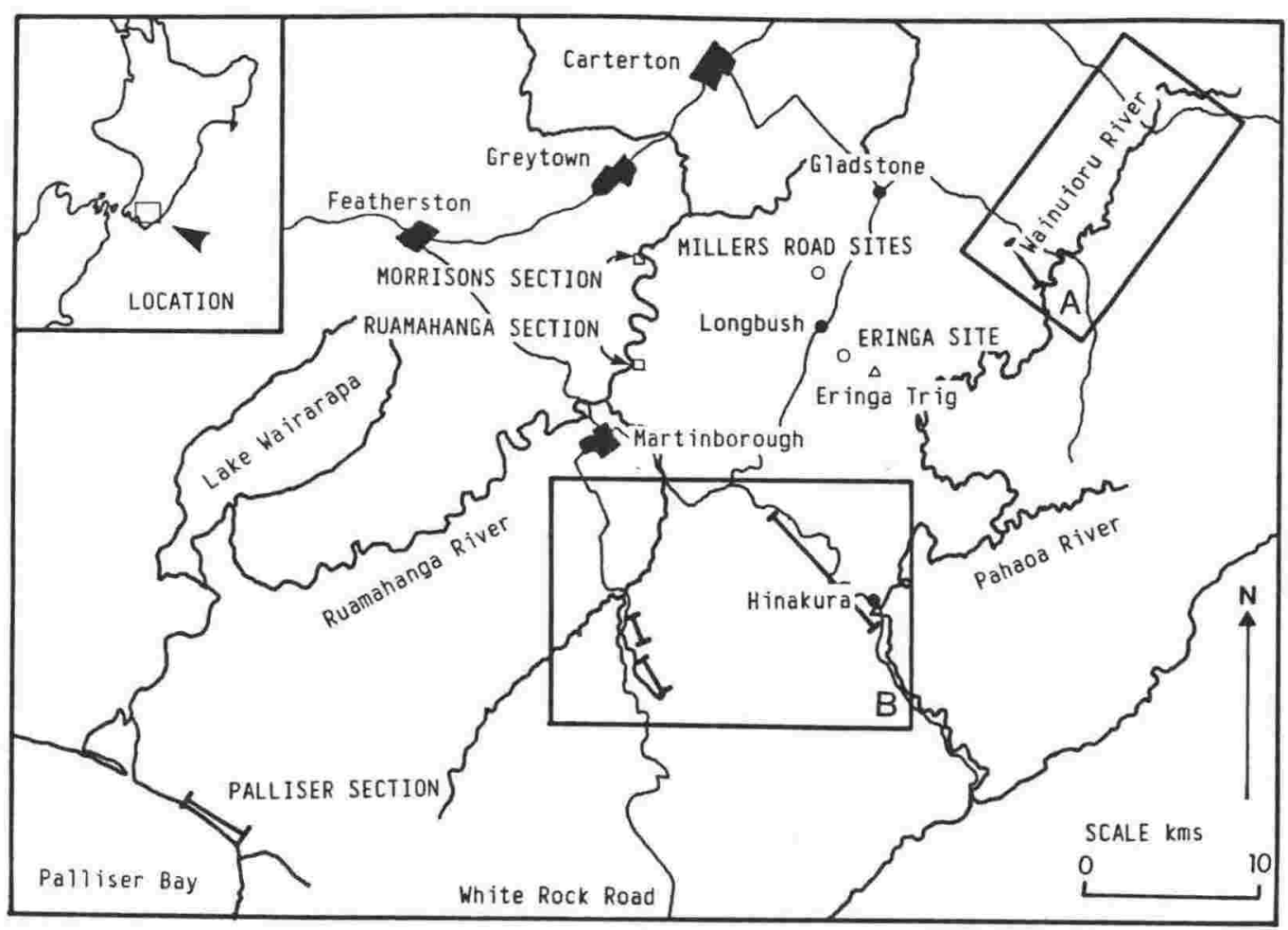

Figure A.26

Location of sections and sites : southern Wairarapa.

Inset A corresponds to figure A.27.

Inset B corresponds to figure A.28.

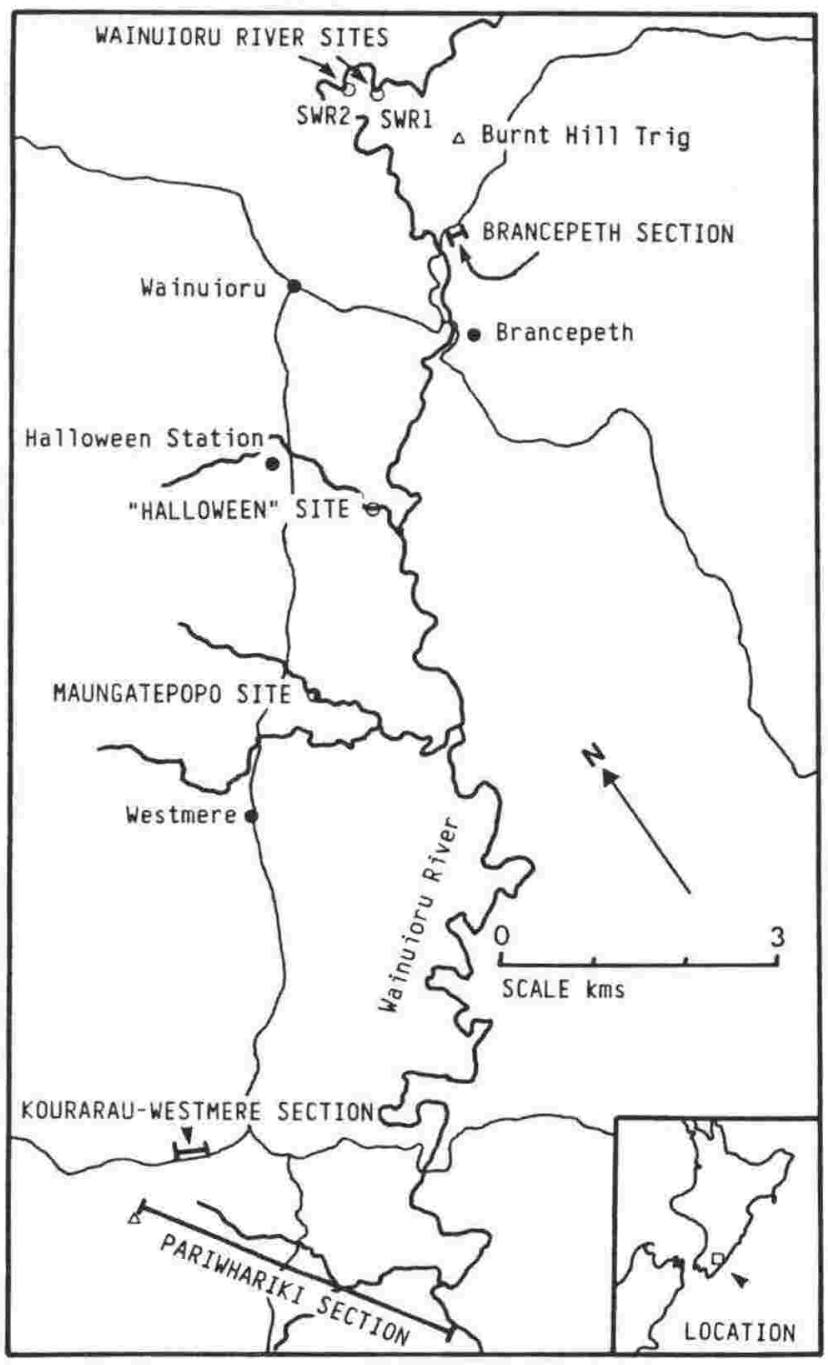

Figure A.27

Location of sections and sites :

Wainuioru Valley area. 
Location: East of Forsberg Trig, in roadcuts on Jacksons Line, about $2 \mathrm{~km}$ southwest of Mauriceville West (T25/348447). See figure A.25.

Samples: Two Opoitian massive mudstone samples examined are barren.

\section{A.28 CLELLANDS ROAD SECTION}

Location: Samples from roadcuts on Clellands Road which runs west from the Masterton-Alfredton Road, $1.7 \mathrm{~km}$ south of Dreyers Rock. Samples taken from between grid references T25/446417 and T25/462417. See figure A.25.

Samples: Eleven Kapitean to Opoitian samples were examined from this section. Two samples immediately above and below a tuff (T25/453416) contain poorly preserved, recrystallised Radiolaria which were not examined in this thesis. The tuff is believed to be an equivalent of the Hikawera tuff (Ford, 1975).

References: Orbell (1962), Vella (1963a, 1963b), Ford (1975).

\section{A.29 BRANCEPETH SECTION}

Location: Roadcut in the Masterton-Stronvar Road, $1 \mathrm{~km}$ northeast of the entrance to Brancepeth Station. See figure A.27.

Comment: This section contains the lithostratotype of the Cannonball Sandstone and Brancepeth Tuff (Crundwell, in prep.)

Samples and Age: Six samples from this roadcut (T26/f267-270, 229, 230) are all within Crundwell's Neogloboquadrina pachyderma Zone (upper Tt - lower Tk).

Twenty-nine samples were examined from this section, two contain Radiolaria and one sample (SWR5), $3.5 \mathrm{~m}$ above the Brancepeth Tuff is used in this thesis.

Radiolaria: Although moderate numbers of Radiolaria are present in this sample, only etched spongodiscids are represented. No age diagnostic radiolarians could be found.

\section{A.30 WAINUIORU RIVER SITES}

Location: River bank approximately $1.5 \mathrm{~km}$ northwest of Burnt Hill Trig. See figure A.27.

Samples and Age: Two radiolarian bearing samples from the uppermost part of the Wainuioru River Section (Crundwell, in prep.) are used in this thesis (SWR1, SWR2). The samples contain Globorotalia crassaformis and G. conomiozea mons (basal Opoitian).

Radiolaria: Although both samples have a relatively poor preservation and diversity $(\mathrm{N}=23,29: \mathrm{Q}=3.71,7.08)$ this is typical of lower Pliocene samples (average $\mathrm{N}=27.33, \mathrm{Q}=5.90$ ). Both samples contain Didymocyrtis tetrathalmus tetrathalmus although one only tentatively (SWR2). Both contain Lychnocanium sp. aff. grande placing the samples in the Lychnocanium sp. aff. grande Subzone. 
Location: Approximately $1.4 \mathrm{~km}$ northeast of Westmere in a tributary of the Maungatepopo Stream. See figure A.27.

Sample and Age: Sample T26/f132 from the basal Opoitian (Globorotalia crassaformis, G. pliozea) contains Radiolaria and is used in this thesis (SWR3). This sample is $40 \mathrm{~m}$ above T26/f133 which contains G. sphericomiozea.

Radiolaria: This sample has moderate preservation and diversity $(\mathrm{N}=26, \mathrm{Q}=5.40)$ but lacks age diagnostic radiolarians but foraminiferal faunas suggest an age within the Lychnocanium sp. aff. grande Subzone.

\section{A.32 "HALLOWEEN" STREAM SITE}

Location: In an unnamed stream $0.7 \mathrm{~km}$ east of the Westmere Road, $2.5 \mathrm{~km}$ south of Wainuioru in the stream bank. See figure A.27.

Sample and Age: One sample from lower Tongaporutuan mudstone (T26/f142), 0.1m below a tuff. This radiolarian bearing sample is below the LAD of Globoquadrina dehiscens and contains predominantly five chambered Globorotalia miotumida and is used in this thesis (SWR4).

Radiolaria: This sample has moderate preservation $(\mathrm{N}=35)$ but low diversity $(\mathrm{Q}=6.66)$. The tentative identification of Didymocyrtis laticonus and no accompanying Anthocyrtidium ehrenbergi pliocenica or large pored Heliodiscus asteriscus or Heliodiscus umbonatum places the sample within the Didymocyrtis laticonus Subzone which agrees with the sample being below the LAD of Globoquadrina dehiscens.

\section{A.33 KOURARAU-WESTMERE ROAD SECTION}

Location: In a road cut $1 \mathrm{~km}$ east of Pariwhariki Trig on the Kourarau-Westmere Road. See figure A.27.

Samples and Age: Six samples examined from upper Waipipian and lower Mangapanian strata, the youngest five of which contain Radiolaria and are studied in this thesis. In the section the incoming of Globorotalia crassula has been recorded in sample T27/f254, $155 \mathrm{~m}$ above the youngest radiolarian bearing sample. The samples containing Radiolaria (KW01-05) lack Cibicides molestus but a sample (Station 18 of Berry, 1972), which is about $15 \mathrm{~m}$ below the oldest radiolarian-bearing sample has C. molestus.

Radiolaria: All of the five radiolarian bearing samples were analysed and although numbers are reasonable, spongodiscids and cenosphaerids dominate the faunas with no nassellarians or age diagnostic radiolarians present.

References: Berry (1972), Crundwell (in prep.). 


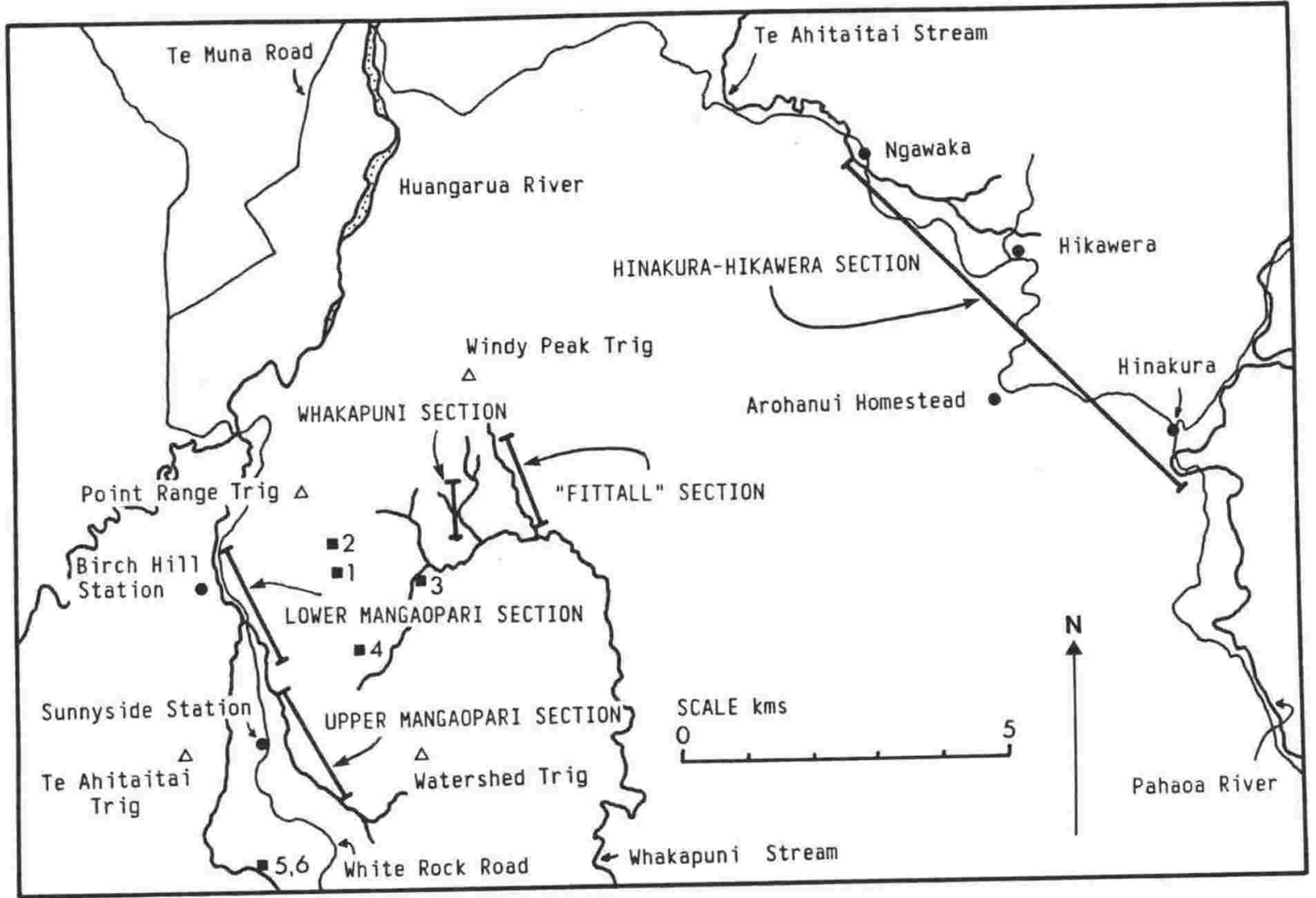

Figure A.28

Location of sections and sites : Mangaopari area.

SMA samples (Point Range sites and Mangaopari-Whakapuni Stream area sites) are shown as numbered solid boxes. 
Location: Well exposed in Wainuioru River, Pahuri Stream, Mangoariki Stream, Manga-a-whanaki Stream and a bluff under Pariwhariki Trig. The top of the section is $1 \mathrm{~km}$ south of the Kourarau-Westmere Road Section. See figure A.27.

Lithology and Age: The section extends from lower Tongaporutuan massive mudstone to lower Nukumaruan coquina limestone.

Samples: One lower Tongaporutuan sample (N162/f870), one mid Tongaporutuan sample (f872), two upper Tongaporutuan samples (f874, f876), and one Opoitian sample (f866) are all barren.

References: Bunopas (1966), Crundwell (in prep.).

\section{A.35 MILLERS ROAD SITES}

Location: An area south of Gladstone was mapped during the course of completing my BSc Honours degree (Ashby, 1978). This 9.25 sq. $\mathrm{km}$. area lies almost entirely within NZMS 270, Sheet S27B, the northeastern corner extending into Sheet T27A. Millers Road, connecting the main Wairarapa Valley with the Longbush Road, intersects the area. See figure A.26.

Comment: One formation exposed in this area, Mangaopari Mudstone, contains in places, Radiolaria. Many of the samples are weathered, the foraminifera having been dissolved, but the Radiolaria preserved.

Samples: Twenty-one Opoitian to Waipipian samples were examined, 17 contain Radiolaria and two (SMR1, SMR2) are used in this thesis. Sample SMR1 contains Globorotalia puncticulata puncticulata and forms approaching Globorotalia inflata and SMR2 is barren of foraminifera.

Radiolaria: Of the two samples, only SMR1 is suitable for statistical work $(\mathrm{N}=31, \mathrm{Q}=6.24)$. Both samples contain Didymocyrtis tetrathalmus tetrathalmus with SMR1 also containing Didymocyrtis sp. A and Lychnocanium sp. aff. grande present in SMR2 (tentative identification in SMR1). This indicates a Lychnocanium sp. aff. grande Subzone age for both samples.

Reference: Ashby (1978).

\section{A.36 ERINGA SITE}

Location: In the valley west of Eringa Trig (N162/118358). See figure A.26.

Sample: One Opoitian sample examined is barren. 
FIGURE A 29

MORRISON'S SECTION

Location: Figure A26

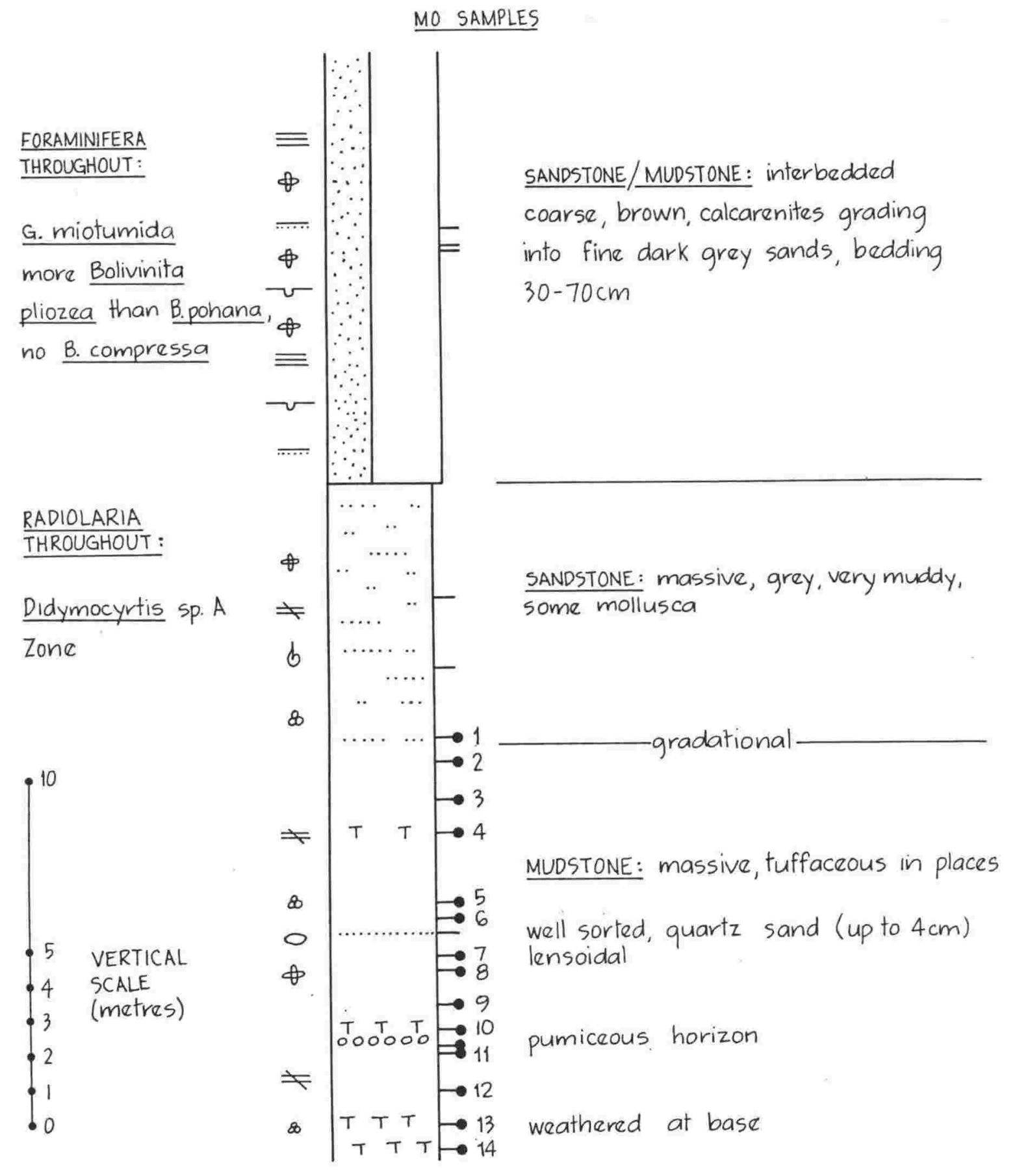




\section{A.37 MORRISONS SECTION}

Location: Southern banks of the Ruamahanga River, $0.6 \mathrm{~km}$ north of Glenmorven Homestead. See figure A.26.

Stratigraphic column: Figure A.29.

Lithology: At least $12 \mathrm{~m}$ of massive mudstone with two tephric horizons, sandy layers, and rare mollusca which grades into a $6 \mathrm{~m}$ massive muddy sandstone with some-mollusca. This is overlain by at least $13 \mathrm{~m}$ of regularly bedded $(30-70 \mathrm{~cm})$ coarse calcareous sands grading into fine sands.

Age: Planktic foraminiferal faunas are poor, the few specimens of Globorotalia miotumida tend to be dominated by five chambered forms. The Bolivinita fauna is dominated by $B$. pliozea with some B. cf. pohana. No B. compressa was found.

Samples: Three samples from the bedded unit and 18 from the sandstone and mudstone units were examined. 14 samples from the mudstone and the lowermost sample from the muddy sandstone contained radiolarian faunas and are used in this thesis (MO01-MO14).

Radiolaria: The radiolarian faunas from this short sectionare very good. Of the 14 radiolarian bearing samples studied, nine were considered good enough for statistical work and of these NG varied from 292 to $1112, \mathrm{~N}$ from 31 to 42 , and $\mathrm{Q}$ from 8.67 to 13.74 . The samples lack Diartus hughesi and Didymocyrtis laticonus, but Didymocyrtis sp. A is well represented. These samples are assigned to the Didymocyrtis sp. A Zone. 
FIGURE $A 30$

RUAMAHANGA RIVER SECTION

Location: Figure A 26

RM SAMPLES:

FORAMINIFERA THROUGHOUT:

$25 \%$ to $90 \%$ five chambered

G miotumida, Bolivinita pohana

B. ef pliozea, no B compressa

RADIOLARIAN DATUMS:

- LAD Diartus hughesi

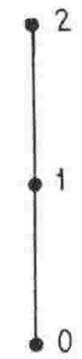

VERTICAL SCALE

(metres)

8

$\mid \begin{aligned} & T \\ & \cdots\end{aligned}$

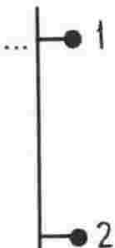

MUDSTONE: massive, sandy to slightly sandy, microbioturbated, light greengrey, slightly carbonaceous in places

gradational

MUDSTONE: Massive, microbioturbated light green-grey, slightly glauconitic at top. 


\section{A.38 RUAMAHANGA RIVER SECTION}

Location: In the cliffs on the east side of the Ruamahanga River at Riverside, $4.5 \mathrm{~km}$ north of Martinborough. See figure A.26.

Stratigraphic column: Figure A.30.

Samples and Lithology: The lower five samples examined contain abundant, well preserved Radiolaria in sediments ranging from massive mudstone to massive sandy mudstone (RM03-RM07) and the upper two samples from a sandier lithology contain rare Radiolaria (RM01-RM02).

Age: Generally planktic foraminifera are poor in the samples examined but those with reasonable populations of Globorotalia miotumida contain faunas ranging from $25 \%$ to $90 \%$ five chambered forms. Both Bolivinita pohana and $B$. cf. pliozea are present but the samples lack B. compressa.

Radiolaria: Of the seven radiolarian bearing samples the lower five (RM03-07) contained faunas suitable for statistical work with $\mathrm{N}$ varying from 31 to 41 and $\mathrm{Q}$ varying from 6.47 to 17.30 (Note: this is the highest $Q$ value of all the samples studied). Didymocyrtis laticonus is lacking but identifications of Diartus hughesi in RM05 indicates that at least the three oldest samples all lie within the Anthocyrtidium ehrenbergi pliocenica Subzone. Samples RM01-RM04, lack both Didymocyrtis laticonus and Diartus hughesi belong in the Didymocyrtis sp. A Zone. The LAD of Diartus hughesi coincides with a slightly glauconitic interval which may represent a period of slow deposition. 
FIGURE A 31

HINAKURA - HIKAWERA SECTION (partially after Vella e Collen 1984, Choong, Location: Figure A28

FORAMINIFERA:

AND RADIOLARIA

- LAD C.molestus

- FAD G inflata

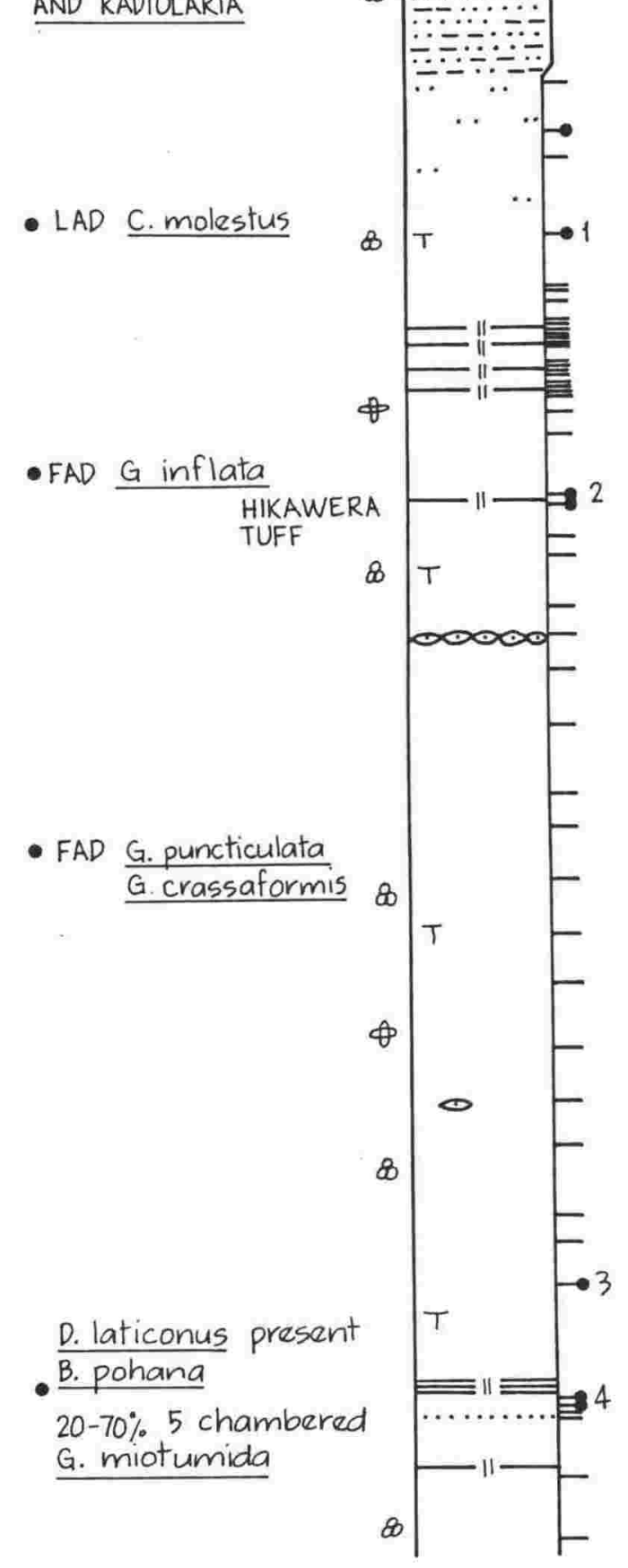

LIMESTONE: coquina

SANDSTONE: M

MUDSTONE: mass, $s-(s)$ near top, tfc in places, coner in places
VERTICAL SCALE (metres)

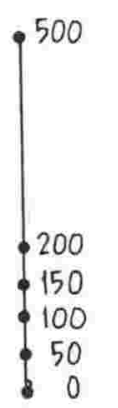




\section{A.39 HINAKURA-HIKA WERA SECTION}

Location: Poorly to moderately well exposed in the headwaters of Te Ahitaitai Stream from Ngawaka Homestead to Hikawera; on ridge top roadcuts between Hikawera and Arohanui Homestead; from Arohanui Homestead to Hinakura in the east flowing stream next to Hinakura Road ; and in the banks of the Pahaoa River, $0.5 \mathrm{~km}$ south of Hinakura. See figure A.28.

Stratigraphic column: Figure A.31.

Lithology: The section comprises of approximately $2500 \mathrm{~m}$ of massive mudstone with occasional tuff bands, concretionary, and sandy layers. At the top of the section the sequence grades through muddy sandstone into the Pukenui Limestone. The mudstones range in age from Tongaporutuan to Hautawan.

Samples: Fifty-one mudstone samples were examined at regular intervals throughout the section (with a concentration of sampling in the upper Opoitian), six contained Radiolaria and the following four are used in this thesis.

HHO1 - near the top of the range of Cibicides molestus.

HHO2 - immediately above the Hikawera Tuff (paleomagnetic age $3.29 \pm 0.10 \mathrm{Ma}$. This sample is $50 \mathrm{~m}$ below the FAD of Globorotalia inflata and $325 \mathrm{~m}$ above the joint FAD's of Globorotalia puncticulata and G. crassaformis.

HHO3 and HHO4 - near the base of the section. The samples contain typical Bolivinita pohana and Globorotalia miotumida with 26 to $66 \%$ five chambered forms and lack $B$. compressa and Globoquadrina dehiscens.

Radiolaria: The radiolarian faunas from this section are particularly poor, the only sample containing any age diagnostic radiolarians being $\mathrm{HHO4}$ which contains Didymocyrtis laticonus. This sample either belongs to the Didymocyrtis laticonus Subzone or could belong to the Heliodiscus asteriscus forma large pores Subzone with the large pored form of Heliodiscus asteriscus and Anthocyrtidium ehrenbergi pliocenica not represented because of dissolution. The latter situation is the preferred case as the samples lack Globoquadrina dehiscens.

References: Lienert, Christoffel and Vella (1972), Collen and Vella (1973), Choong (1983), Vella and Collen (1984). 


\section{A.40 POINT RANGE SITES}

Location: Two sites collected in farm track cuttings about $1.2 \mathrm{~km}$ southeast of Point Range Trig and $3.2 \mathrm{~km}$ north of the Mangaopari Stream Section. See figure A.28.

Comment: These samples were taken from near the axis of an anticline, the structure being defined by a greensand bed a few thin tephric beds in otherwise massive mudstone (P. Vella, pers. comm.).

Samples: Both samples contain good radiolarian faunas and are used in this thesis (SMA1, SMA2). Both samples have a poor planktic foraminiferal faunas but contain specimens of mainly four chambered Globorotalia miotumida. The added presence of abundant Bolivinita pliozea and B. compressa morphotypes indicates an upper Tongaporutuan age.

Radiolaria: Of the two radiolarian bearing samples, one (SMA1) was diverse enough for statistical work $(\mathrm{N}=26, \mathrm{Q}=7.76)$ and contains Didymocyrtis antepenultima but lacks Didymocyrtis laticonus and Diartus hughesi indicating a Didymocyrtis sp. A Zone age. Sample SMA2 contains mainly resistent spongodiscids, stylosphaerids, and a few nassellarians.

Reference: Geological Map of Sheet S27 (P. Vella and J. Collen, Victoria University, in prep.). 
FIGURE A 32

WHAKAPUNI TRIBUTARY SECTION

Location: Figure A28 Samples projected from the East Fork are marked.

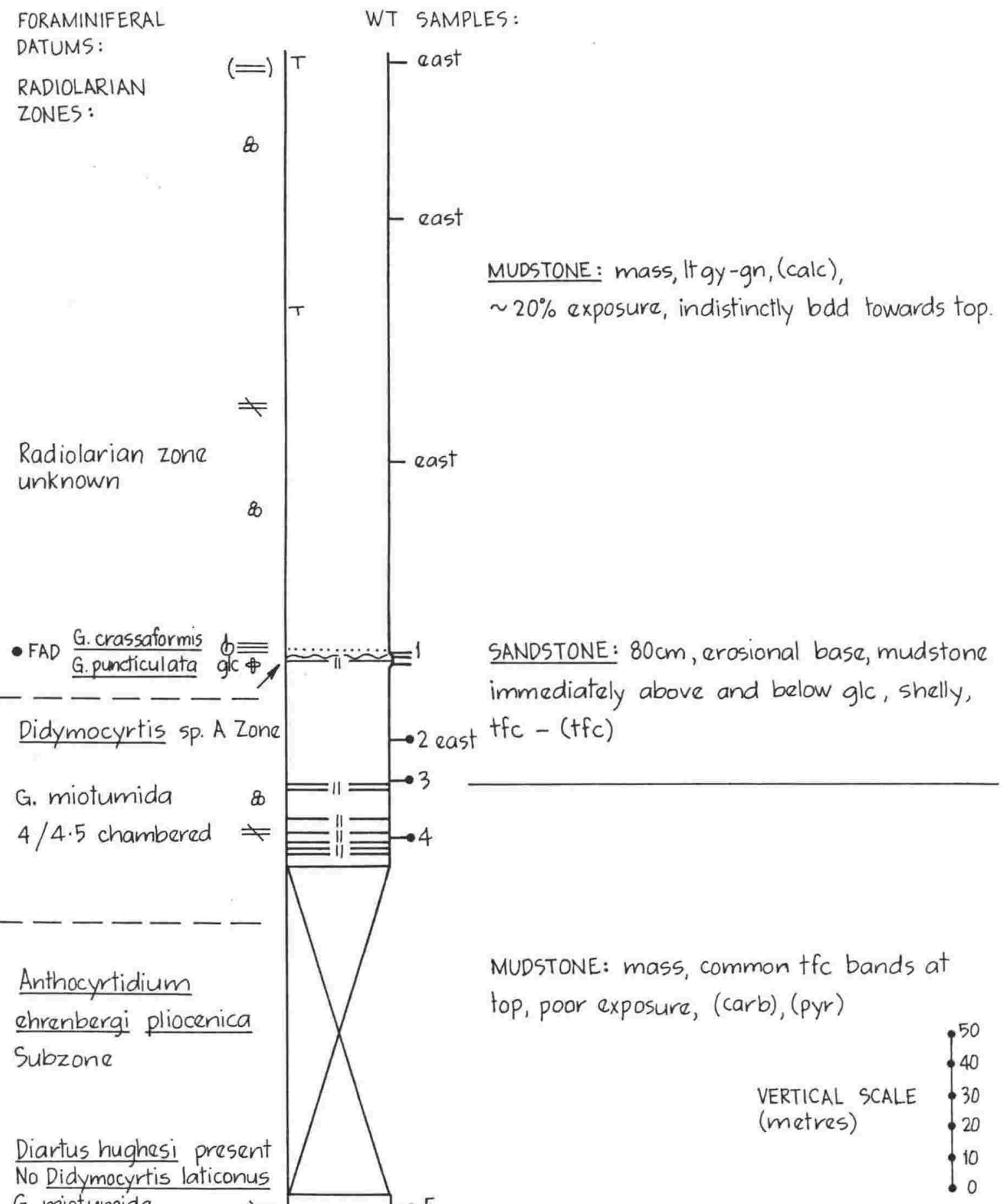


Location: Poorly exposed section in a south flowing tributary stream of Whakapuni Stream, due south of Windy Peak Trig. The section is a composite of exposures in two forks of this tributary. See figure A.28.

Stratigraphic column: Figure A.32.

Lithology and samples: The section consists of $370 \mathrm{~m}$ of massive mudstone, indistinctly bedded towards the top, with common tuff beds near the middle of the section. An $80 \mathrm{~cm}$ sandstone bed (exposed in the western fork: S27/20498595) with an erosional base, that grades upwards into a glauconitic mudstone, represents a probable time break and slow period of deposition. The sandstone is at the top of the radiolarian bearing portion of the section. Below the sandstone bed five samples were examined, four of which contain Radiolaria (WT02-05). Foraminifera from these samples included small populations of Globorotalia miotumida (moderately conical forms are present immediately below the sandstone). Members of the genus Bolivinita are very rare.

Immediately overlying the sandstone, sample WT01 contains Globorotalia crassaformis, G. puncticulata, and rare G. conomiozea mons. This and three other samples above the sandstone are barren.

Radiolaria: Of the four radiolarian bearing samples (WT02-05) two were considered suitable for statistical work. Sample WT03 contains a reasonable fauna $(\mathrm{N}=28, \mathrm{Q}=5.33$ ) and WT05 a diverse fauna $(\mathrm{N}=38, \mathrm{Q}=9.15)$. The latter sample contains Diartus hughesi but lacks Didymocyrtis laticonus and belongs to the Anthocyrtidium ehrenbergi pliocenica Subzone. The upper three samples (WT02-04) lack Diartus hughesi and belong to the Didymocyrtis sp. A Zone.

Reference: Fittall (1979).

\section{A.42 "FITTALL" STREAM SECTION}

Location: Tributary of Whakapuni Stream (herein named after the collector of the samples), about $1 \mathrm{~km}$ east of the radiolarian bearing Whakapuni Tributary Section. See figure A.28.

Comment: The sediments in this section represent the upper part of the Whakapuni Tributary Section and younger strata.

Lithology: Massive mudstone with three thin tuff bands exposed which are thought to correspond to the Seddelbahr, Missing, and Hikawera Tuff of Vella and Collen (1984).

Samples and Age: Seven Opoitian samples examined (S27/f206-211, f219) are all barren.

Reference: Fittall (1979). 


\section{A.43 MANGAOPARI-WHAKAPUNI STREAM AREA SITES}

One sample from a farm track in Whakapuni Stream Valley (about $1.1 \mathrm{~km}$ southwest of the Whakapuni Tributary Section) contained rare Globorotalia miotumida, Bolivinita pohana and some forms approaching B. compressa s.s., and common Radiolaria and is used in this thesis (SMA3). The absence of Diartus hughesi and Didymocyrtis tetrathalmus tetrathalmus and tentative presence of Didymocyrtis antepenultima indicates an age within the Didymocyrtis sp. A Zone.

One sample of weathered mudstone from a farm track overlooking the headwaters of the Whakapuni Stream, about halfway between the Whakapuni Tributary and Upper Mangaopari Stream Sections, is barren of foraminifera but contains abundant Radiolaria and is used in this thesis (SMA4). This sample contains Diartus hughesi but lacks Didymocyrtis laticonus and therefore belongs in the Anthocyrtidium ehrenbergi pliocenica Subzone.

Two samples in a west flowing creek approximately $2 \mathrm{~km}$ south of Sunnyside Station contain G. miotumida (20\% five chambered forms), B. compressa, and Radiolaria and are used in this thesis (SMA5, SMA6). The radiolarian faunas are not diverse $(Q=4.58-5.26)$ but SMA5 contains Didymocyrtis laticonus and the large pored form of Heliodiscus asteriscus indicating an age from the Heliodiscus asteriscus forma large pores Subzone. The foraminiferal fauna suggests an age slightly younger in the Tongaporutuan.

\section{A.44 LOWER MANGAOPARI STREAM SECTION}

Location: Mangaopari Stream Valley from the bluffs $0.6 \mathrm{~km}$ north of Birch Hill Station upstream to Mesozoic basement outcropping at grid reference $527 / 177835$, about $0.15 \mathrm{~km}$ east of the White Rock Road. See figure A.28.

Comment: This section has been described in detail (Devereux, Hendy and Vella, 1970; Vella and Briggs, 1971; Hornibrook, 1981).

Samples: Three samples from between $10 \mathrm{~cm}$ above and $1 \mathrm{~m}$ below the Spooner Tuff (S27/173843) and three samples from between $5 \mathrm{~cm}$ above and $5 \mathrm{~m}$ below a paired tuff in the Bridge Sandstone Member (S27/175842) were investigated. All six Opoitian samples are barren. The Bells Creek Mudstone outcropping in lower Mangaopari Stream was not sampled because of the detailed sampling of this part of the column in the upper reaches of Mangaopari Stream. 


\section{FIGURE A33}

UPPER MANGAOPARI STREAM SECTION (partially after Eggo 1979) Location: Figure A28

FORAMINIFERAL

DATUMS

- FAD G. inflata

- FAD $\frac{\text { G. crassaformis }}{\text { G. puncticulata }}$

- FAD G. sphericomiozea

- FAD G. conomiozea

Approximate transition

- to less than $20 \%$

five chambered forms of G. miotumida

- LAD G. dehiscens
MS SAMPLES:

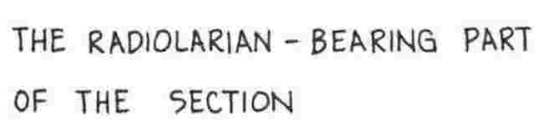

VERTICAL SCALE (metres)

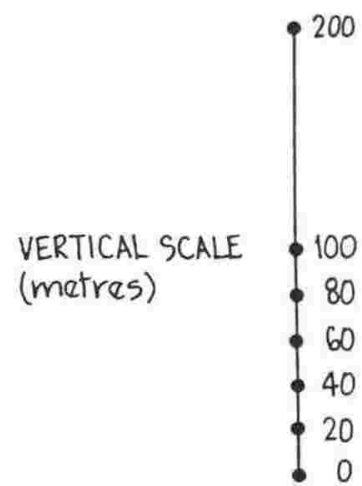

MUDSTONE: mass, tfe in places, s-(s) at top and base, (carb) in places, pyr microbiotd in places
\&

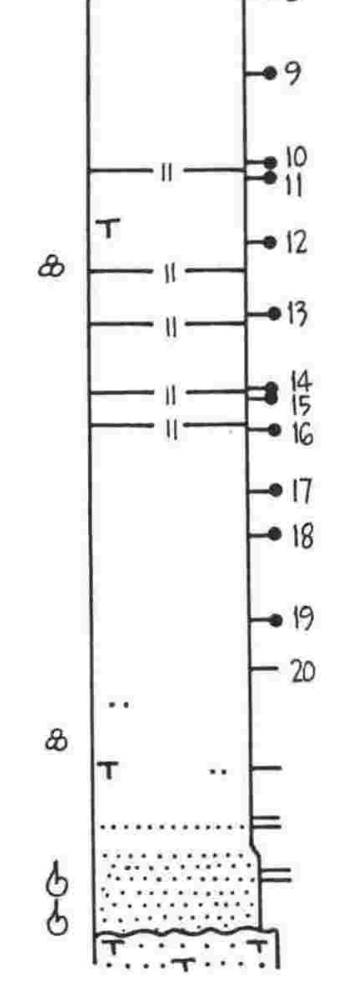

ms

gradational

SANDSTONE: mass, med, crs at base, abnd molc in places

GREYWACKE: med-crs $s$, hd 
Location: Mangaopari Stream, generally between Sunnyside Station and Watershed Trig, from the point where the Mangaopari Fault intersects Mangaopari Stream (S27/178831) to the headwaters of the stream (S27/188815). See figure A.28.

Stratigraphic columns: Figures A.33 and A.34.

Lithology: The basal unit comprises approximately $35 \mathrm{~m}$ of massive medium sandstone with abundant mollusca in places. This unit has a coarse sandstone base resting on an irregular greywacke surface and grades into $730 \mathrm{~m}$ of massive mudstone with occasional tuff layers and rare mollusca. The upper $90 \mathrm{~m}$ of the mudstone is slightly sandy.

Samples and Age: Twenty-nine samples at regular intervals throughout the section were examined for Radiolaria. Eighteen samples contained Radiolaria and are used in this thesis (MSO2-MS19).

The oldest radiolarian bearing sample (MS19) marks the LAD of Globoquadrina dehiscens (rare in this sample) in the section.

Sample MS01, which is $21 \mathrm{~m}$ above the youngest radiolarian bearing sample (MSO2), contains G. conomiozea conomiozea and a good population of G. miotumida (10\% five chambered forms). Within the radiolarian bearing zone the Bolivinita population is dominated by $B$. pohana, with $B$. cf. pliozea in the uppermost samples. Rare $B$. compressa morphotypes start appearing about $120 \mathrm{~m}$ from the top of the radiolarian bearing horizon (MS07) and although populations of G. miotumida are generally poor this is about the level of transition from $>20 \%$ to $<20 \%$ five chambered forms.

The top of the radiolarian bearing zone is about $47 \mathrm{~m}$ below the FAD of $G$. sphericomiozea, $100 \mathrm{~m}$ below the joint FAD's of G. crassaformis and G. puncticulata, and about $165 \mathrm{~m}$ below the FAD of G. inflata (after Eggo, 1979).

Radiolaria: Of the 18 radiolarian bearing samples, 16 proved to be suitable for statistical analysis. Sample MSO2 contains a poorly preserved fauna of mainly robust spongodiscids and some nassellarians and MS17 contains a very poor spongodiscid fauna. Of the other samples radiolarian preservation and diversity is generally high ( $N$ varies from 22 to 43 and $Q$ from 5.08 to 14.13) with seven samples having a $Q$ value $>10$ and nine having an $N$ value $>35$. One sample $\mathrm{MS} 16(\mathrm{~N}=23, \mathrm{Q}=3.76)$ occurs in the part of the section with poor preservation (near MS17). The radiolarian faunas indicate all the late Tongaporutuan radiolarian zones are present. Samples MS18 and MS19 contain Didymocyrtis laticonus before the FAD of Anthocyrtidium ehrenbergi pliocenica and the large pored form of Heliodiscus asteriscus indicating the Didymocyrtis laticonus Subzone. Sample MS16 marks the FAD of Heliodiscus asteriscus forma large pores and MS14 the FAD of Anthocyrtidium ehrenbergi pliocenica (although a tentative identification exists in MS15). From MS16 to MS12 (the LAD of Didymocyrtis laticonus) defines the Heliodiscus asteriscus forma large pores Subzone. The LAD of members of the Diartus hughesi group occurs in MS08 marking the top of the Anthocyrtidium ehrenbergi pliocenica Subzone. Above this samples MSO2 to MSO7 belong in the Didymocyrtis sp. A Zone.

References: Eggo (1979), Gosson (in prep.). 


\section{FIGURE A 34}

UPPER MANGAOPARI STREAM SECTION (detail of radiolarian bearing

MS SAMPLES:

\section{- FAD G. conomiozea conomiozea}

- transition from 5 to $4 / 4.5$ chambered G. miotumida

- LAD D. hughesi

- LAD B. pohana

- LAD D. laticonus

- FAD B. pliozea

- FAD Anthocyrtidium ehrenbergi

- FAD Heliodiscus asteriscus forma large pores

- LAD G. dehiscens

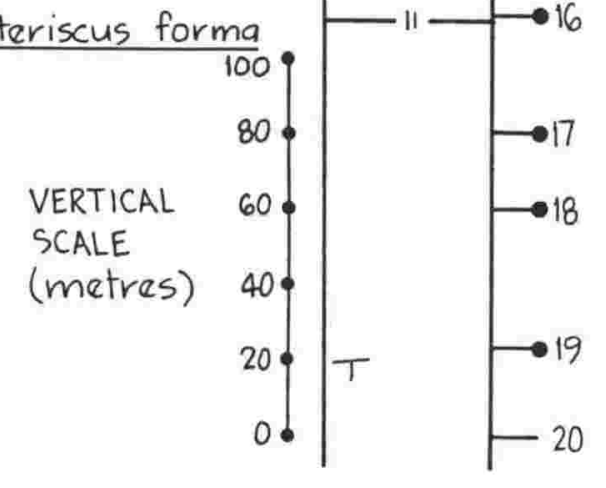

RADIOLARIAN ZONES:

Didymocyrtis sp. A Zone

Anthocyrtidium ehrenbergi pliocenica Subzone

Heliodiscus asteriscus forma large pores Subzone

Didymocyrtis laticonus Subzone 


\section{FIGURE A35}

PALLISER BAY SECTION

Location: Figure A 26

FORAMINIFERAL DATUMS

PB SAMPLES:

AND AGES

Nukumaruan

$\longrightarrow$ ?

Mangapanian

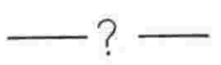

Waipipian

- ? -

\section{FAD G. puncticulata}

- FAD G. crassaformis

- FAD G. sphericomiozea

\section{- FAD G. conomiozea} conomiozea

- FAD B. pliozea

- rare B. pohana

- FAD B quadrilatera

SW?

$b$
8
+
$b$

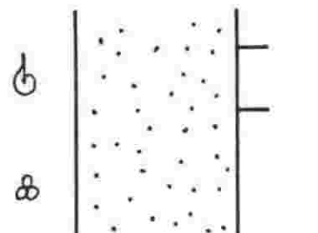

MUDSTONE : massive, sandy and shelly at top and base.

SEE FIGURE A 36 FOR DETAIL OF THE RADIOLARIAN BEARING PORTION OF THE SECTION

TUFF: $7 \cdot 27 \pm 1 \cdot 28 \mathrm{Ma}$ bored surface

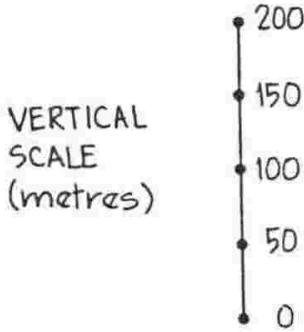

SANDSTONE, coarse, xbdd and conglomeratic at base 
Location: At the northeastern end of Palliser Bay in coastal cliffs between Whangimoana and the mouth of Hurupi Stream. See figure A.26.

Stratigraphic columns: Figures A.35 and A.36.

Lithology and Age: The base of the section is marked by a $2.5 \mathrm{~m}$ conglomeratic bed resting on an irregular greywacke surface. This is overlain by a $10 \mathrm{~m}$ of gritty sandstone with shell fragments and thin conglomerate lenses.

Overlying this is a $1130 \mathrm{~m}$ sequence of massive mudstone which is sandier in the lower and upper thirds of the unit. Rare macrofossils and concretionary layers are present and one $10 \mathrm{~cm}$ tuff is exposed near the middle of the mudstone.

The basal part of the section is probably Waiauan, the FAD of Bolivinita quadrilatera being recorded by Gibson (1963) approximately $170 \mathrm{~m}$ above the greywacke (N165/f693). Bolivinita pohana occurs approximately $50 \mathrm{~m}$ above in sample $\mathrm{N} 165 / \mathrm{f} 693$. The top of the section (S28/f74) is Nukumaruan. The section appears to be continuous but is subject to slumping and some portions are poorly exposed.

Samples: Twenty-six samples at regular intervals (with a concentration of samples in the upper Tongaporutuan part of the section) were examined from throughout the section. Eleven samples contained Radiolaria and ten are used in this thesis (PB02-PB11). The age of the radiolarian bearing horizon is hard to determine because planktic foraminifera are generally rare in this section but the horizon encompasses a tuff dated at $7.27 \pm 1.28$ Ma (Dr. D. Seward, pers. comm.). Sample PB01, 25m above the youngest radiolarian bearing sample, contains a good population of Globorotalia miotumida with $13 \%$ being five chambered forms, and some conical forms are very close to Globorotalia conomiozea conomiozea. The only other sample with a good population of G. miotumida is PB05, from near the middle of the radiolarian bearing horizon, contains $33 \%$ five chambered forms. The FAD of Bolivinita pliozea occurs in sample PB04 (36m above the tuff) which is in good agreement with Scott (1982b) who shows the position of this datum to be $50 \mathrm{~m}$ above the tuff. Globorotalia sphericomiozea first appears (in S28/f59) about $190 \mathrm{~m}$ above the youngest radiolarian bearing sample and the joint FAD's of Globorotalia puncticulata and G. crassaformis occurs approximately $50 \mathrm{~m}$ above this in sample $\mathrm{S} 28 / \mathrm{f} 62$. The FAD of Bolivinita compressa occurs in sample PB06. The oldest radiolarian-bearing sample (PB11) has a poor foraminiferal fauna but some specimens of Bolivinita pohana and B. cf. pohana are present. Globoquadrina dehiscens has not been recorded and could not be found in this section.

Radiolaria: Of the ten radiolarian bearing samples examined six were considered suitable for statistical analysis and generally have good preservation ( $N=22-35$ with five in the range 28-35) and good diversities $(\mathrm{Q}=6.14-10.56)$. Members of the Diartus hughesi group are positively identified in PB03 and tentatively identified in PB04,06,09. With only a tentative identification of Didymocyrtis laticonus in the oldest radiolarian bearing sample in the section (PB11), samples PB03-11 are placed in the Anthocyrtidium ehrenbergi pliocenica Subzone, PB11 being close to the base of this zone. There is an unknown amount of time missing represented by a bored surface between PB10 and PB11. Sample PB02 is placed in the Didymocyrtis sp. A Zone because of the lack of members of the Diartus hughesi group 
FIGURE A 36

PALLISER BAY SECTION (radiolarian bearing portion)

Location: Figure A 26

FORAMINIFERAL AND RADIOLARIAN DATUMS

- FAD $\frac{\text { G. conomiozea }}{\text { conomiozea }}$

- LAD D. hughesi

- FAD B. pliozea

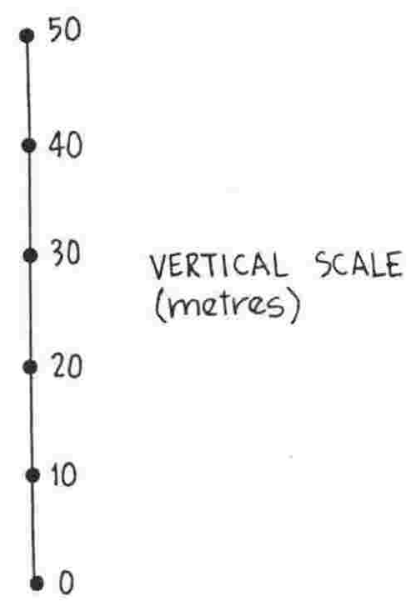

-? D. laticonus present

\section{PB SAMPLES}

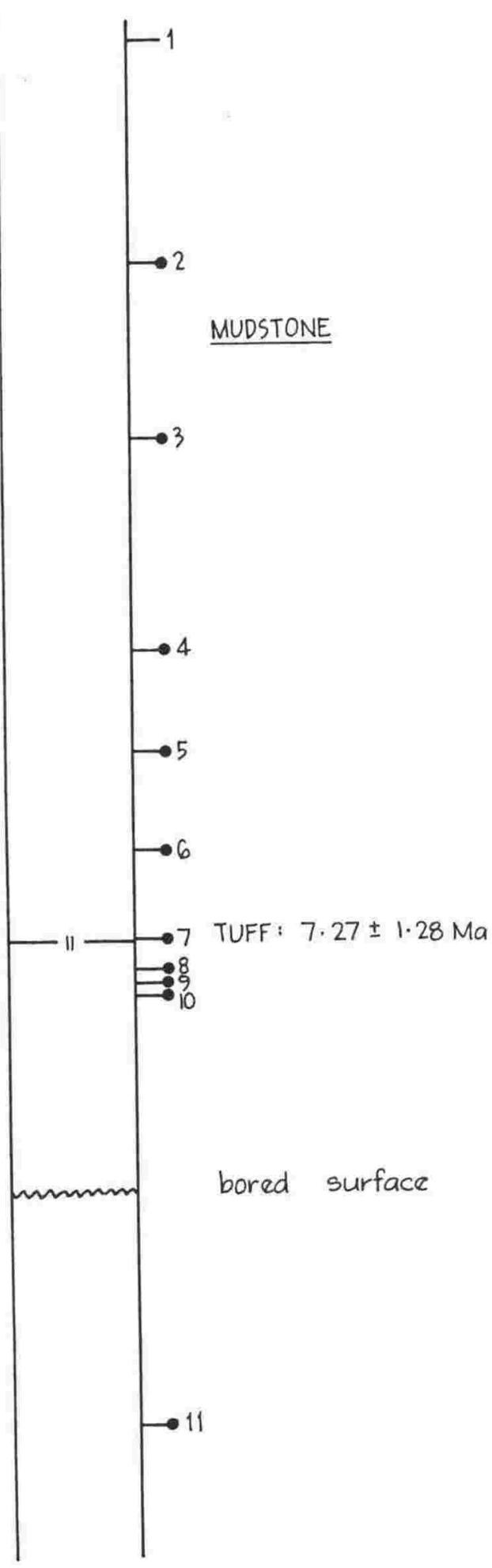


but this absence may be due to the sample having a low preservation $(\mathrm{N}=22)$.

References: Kennett (1966d), Bates (1967), Scott (1982b),

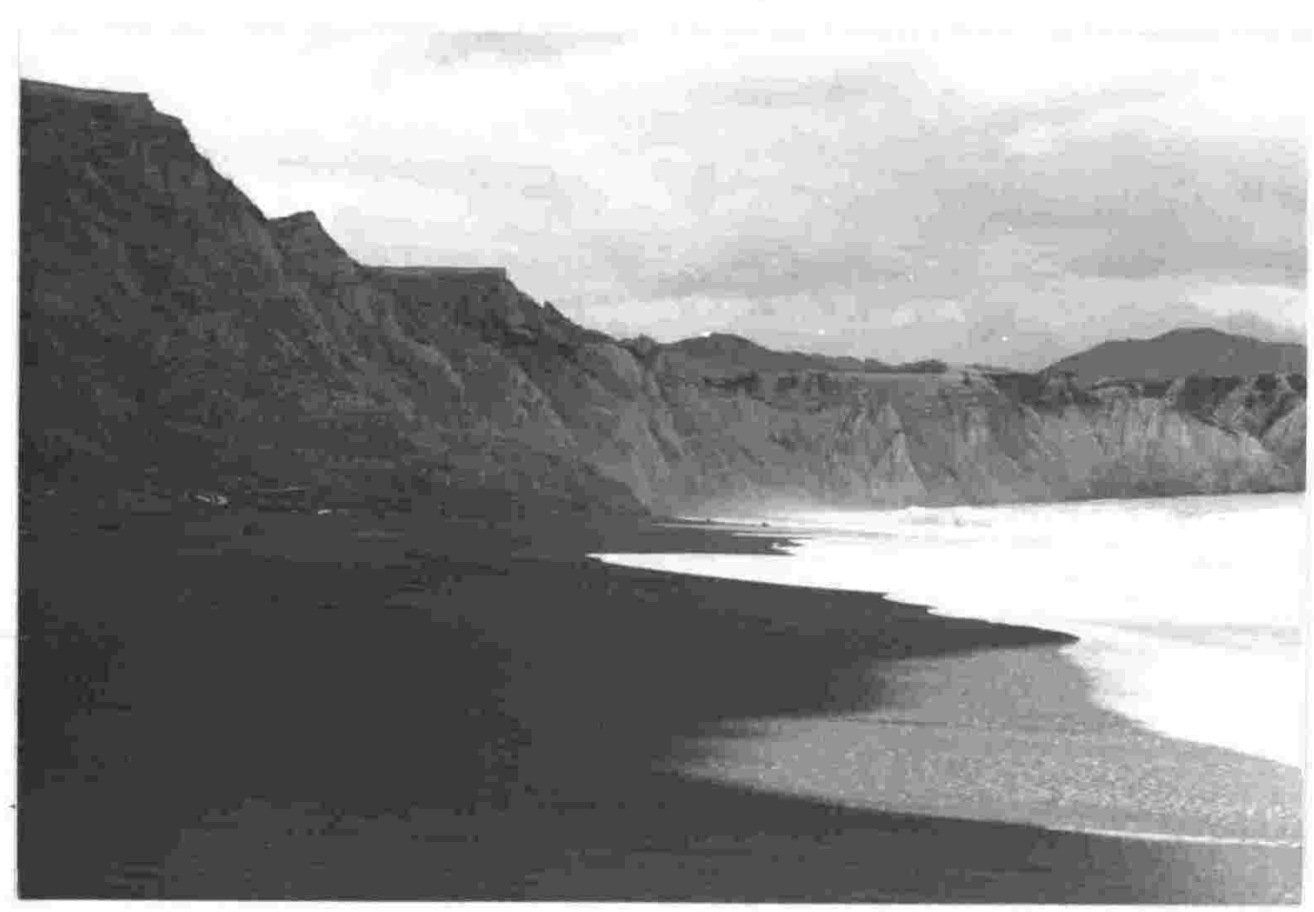

Plate A1.6

Palliser Bay Section : view looking east from slumped Kapitean massive mudstone to cliff-forming Tongaporutuan massive sandy mudstone. 


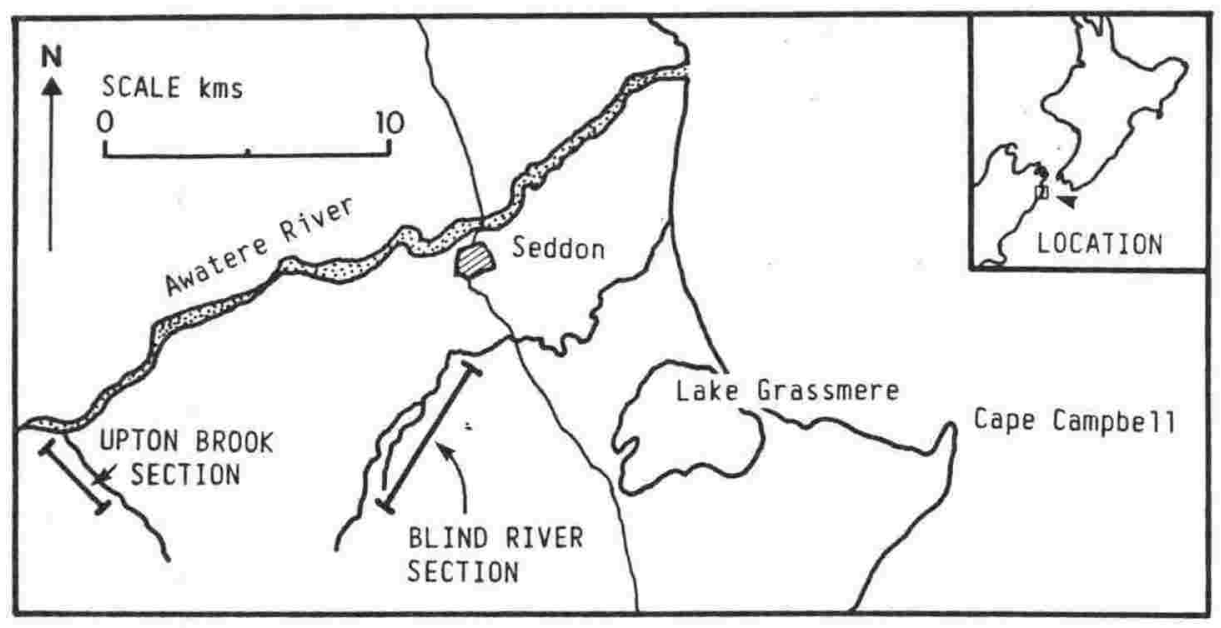

Figure A.37

Location of sections : Marlborough area.

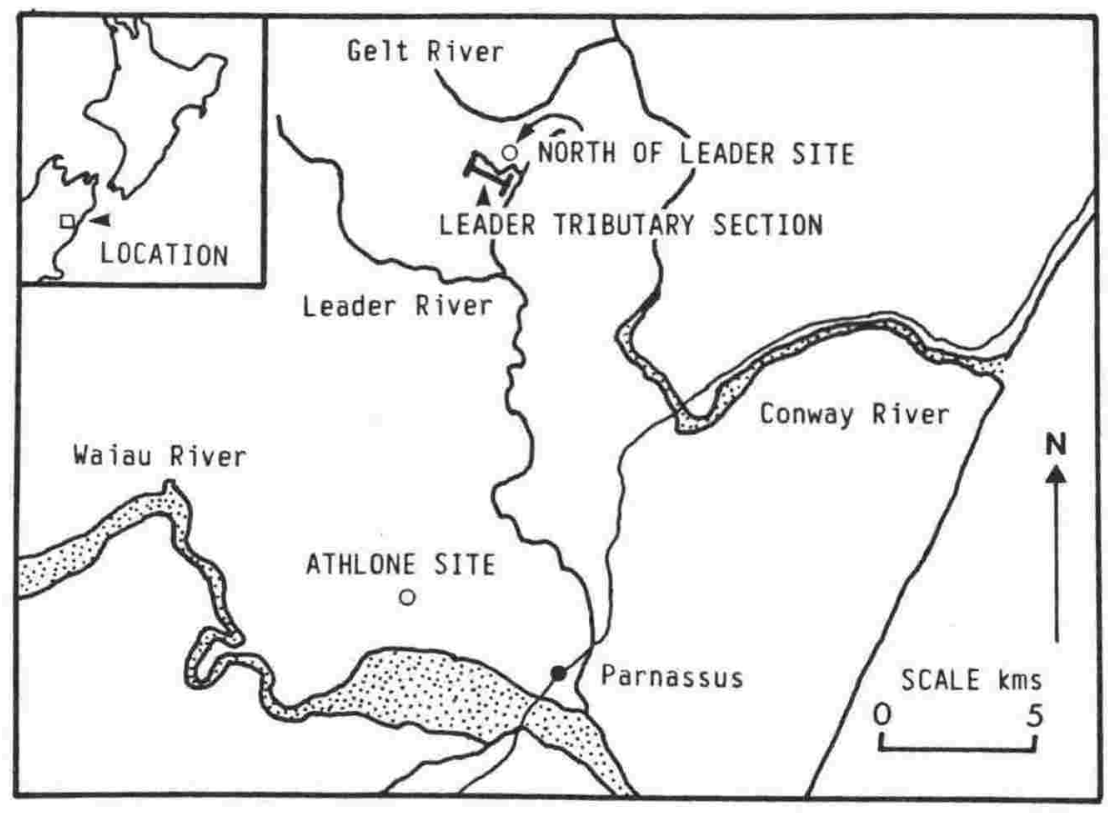

Figure A.38

Location of section and sites : northern Canterbury area. 


\section{A.47 BLIND RIVER SECTION}

Location: In north east Marlborough, approximately $7 \mathrm{~km}$ south of Seddon. See figure A.37.

Comment: The section has been investigated in detail for biostratigraphy (Kennett, 1966a, 1966b, 1966c; Scott, 1979, 1982b; Mildenhall, 1979), magnetostratigraphy (Kennett and Watkins, 1974), and paleoclimatology (Loutit and Kennett, 1979). A summary of the previous work and an integration of the bio-lithostratigraphy is given by Morgans (1980).

Lithology and Age: The base of this $2800 \mathrm{~m}$ sequence consists of coarse conglomerate and sandstone resting unconformably on Mesozoic greywacke. Overlying this is a moderately exposed, conformable sequence of Tongaporutuan to Opoitian mudstones and fine sandstones with occasional concretionary layers.

Kennett (1965) noted the occurrence of Globoquadrina dehiscens in samples $\mathrm{S} 2 \mathrm{~g} / \mathrm{f} 603$ and f635. Exhaustive searches of Kennett's slides and other samples has failed to confirm its presence in this section. The FAD of Bolivinita compressa occurs at about $6.52 \mathrm{Ma}$ (sample P29/f20) if the paleomagnetic interpretation of Loutit and Kennett (1979) is used.

Samples: Fifteen samples at regular intervals in the lower $75 \%$ of the Tongaporutuan strata, including Kennett's S29/f618, f635-f637 and Scott's P29/f23-f 29 are barren, as is one sample of Kennett's ( $\mathrm{S} 29 / \mathrm{f} 656$ ) from near the top of the Kapitean.

\section{A.48 UPTON BROOK SECTION}

Location: From near the junction of Upton Brook and Awatere River to about halfway up Upton Brook. Approximately $14.5 \mathrm{~km}$ southwest of Seddon. See figure A.37.

Lithology, Age, and Samples: Two samples from the upper Tongaporutuan (massive silty mudstones with occasional thin sandstone beds, concretionary layers, and conglomerate beds S28/f566, f567) and two samples from the Opoitian (poorly bedded siltstones - S28/f577, f580) are barren.

Reference: Kennett (1966c). 


\section{FIGURE A 39 \\ LEADER TRIBUTARY SECTION}

\section{Location: Figure A 38}

FORAMINIFERAL AGES

AND DATUMS:

LT SAMPLES:

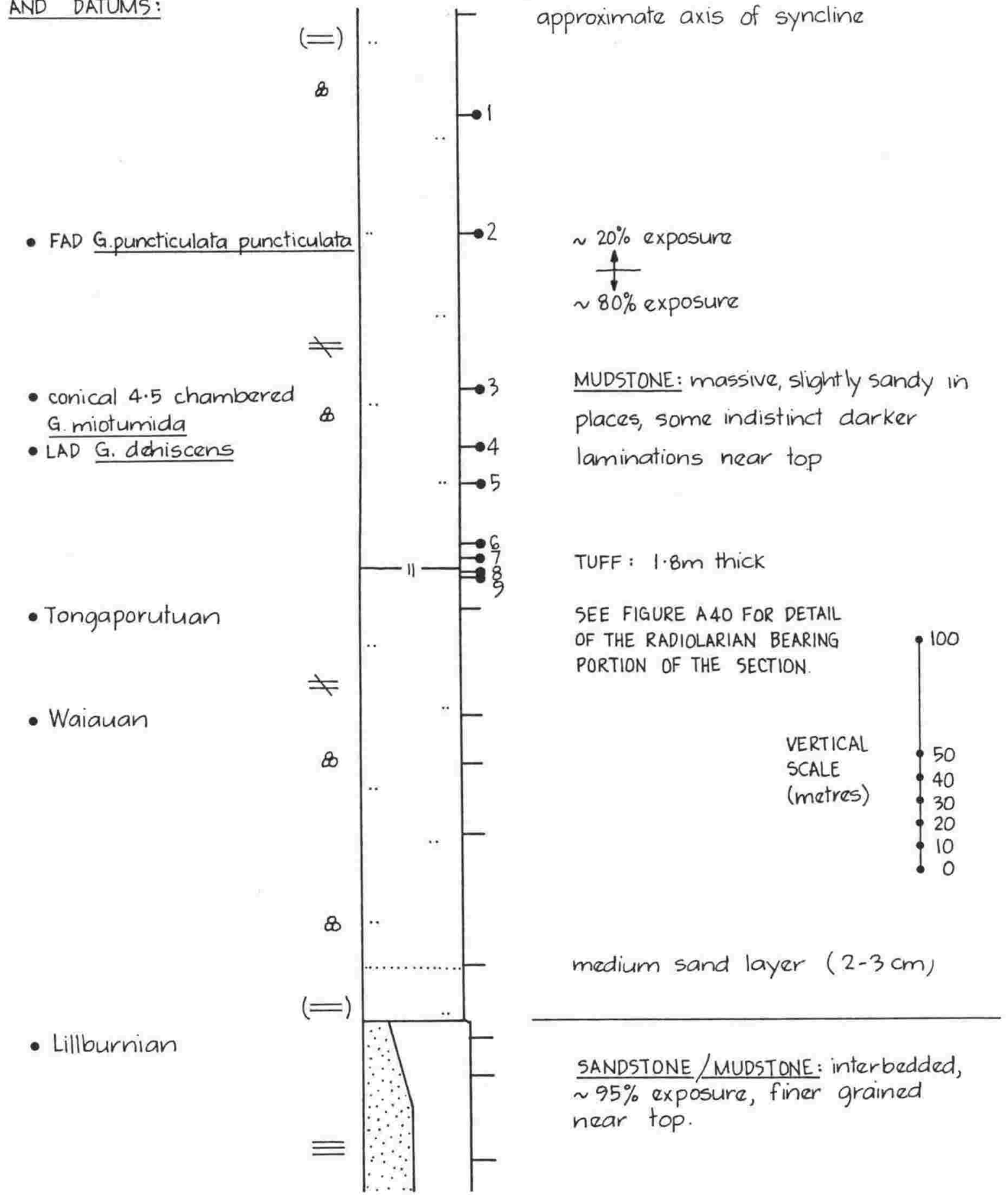




\section{A.49 LEADER TRIBUTARY SECTION}

Location: Eighteen kilometres north of Parnassus in the headwaters of a northern tributary of the Leader River. See figure A.38.

Stratigraphic columns: Figures A.39 and A.40.

Comment: The exposure is moderate to good. This section is in the southernmost extension of the East Coast Deformed Belt.

Lithology: The basal $67 \mathrm{~m}$ of this section consists of interbedded sandstones and mudstones which grade into approximately $300 \mathrm{~m}$ of massive mudstone with some sandy layers and a $1.8 \mathrm{~m}$ tuff bed near the middle. In the upper $140 \mathrm{~m}$ the massive mudstone becomes sandier.

Age: A sample near the top of the interbedded unit $(032 / f 78)$ yielded a Lillburnian foraminiferal fauna. The lower half of the massive mudstone is probably Waiauan with sample $032 / f 77$ ( $133 \mathrm{~m}$ from the base of this unit) containing a Waiauan foraminiferal fauna. Sample $032 / f 76$ ( $46 \mathrm{~m}$ above $\mathrm{f} 77$ and $16.5 \mathrm{~m}$ below the tuff) is Tongaporutuan in age. Sample O32/f70 (LT04) marks the LAD of Globoquadrina dehiscens in this section and is $53 \mathrm{~m}$ above the tuff. The next sample in the section (O32/f69: LT03) appears to be near the top of the Tongaporutuan with conical 4.5 chambered forms of Globorotalia miotumida present. This sample is only $25 \mathrm{~m}$ above the $\mathrm{LAD}$ of $G$. dehiscens and there is a distinct probability that part of the upper Tongaporutuan is missing between the two sites. A sample from the base of the sandy mudstone (O32/f68: LT02) contains G. puncticulata puncticulata (Opoitian). The Kapitean is either missing or not sampled between sites LT02 and LTO3.

Eighteen samples at subregular intervals throughout the section were examined with eight samples containing Radiolaria (LT01-03,05-09) ranging in position from just below the tuff ( $\mathrm{LTt}$ ) to within the sandy mudstone (Wo).

Radiolaria: Of the eight radiolarian bearing samples, five were considered suitable for statistical analysis. Of the four statistical Miocene samples (LT05,06,08,09) the NG values are very high (727-1188) with $\mathrm{N}$ varying from 28 to 38 and $\mathrm{Q}$ from 5.21 to 13.71 . The Pliocene sample (LT01) has a much lower abundance ( $N G=74, \mathrm{~N}=28$ ) but a comparable diversity (8.61). Sample LT09 marks the LAD of Heliodiscus umbonatum and is placed in the Heliodiscus umbonatum Subzone. Above this, samples LT08-05 contain Didymocyrtis laticonus but lack Anthocyrtidium ehrenbergi pliocenica or the large pored form of Heliodiscus asteriscus indicating the Didymocyrtis laticonus Subzone. The LAD of members of the Diartus hughesi group is in LT06 (possibly in LT05) indicating that LT03 is possibly from the Didymocyrtis sp. A Zone although this sample has poor preservation and Diartus hughesi may be missing for that reason. If LTO3 is in the Didymocyrtis sp. A Zone then all of the Heliodiscus asteriscus forma large pores Subzone and Anthocyrtidium ehrenbergi pliocenica Subzone is missing between LT05 and LT03 (LT04 lacks radiolarians). This correlates with the projected gap as determined from the Globorotalia miotumida populations. Sample LT01 contains Didymocyrtis tetrathalmus tetrathalmus and lacks Anthocyrtidium ehrenbergi pliocenica and Didymocyrtis sp. A and is placed in the Lamprocyrtis hannai Subzone.

References: Gosson (in prep.), G. Warren, NZ Geological Survey is regionally mapping this area. 


\section{FIGURE A40}

LEADER TRIBUTARY SECTION (detail of the radiolarian

bearing portion)

LT SAMPLES:

- Lamprocyrtis hannai Subzone

- FAD G. puncticulata puncticulata

- conical 4.5 chambered G. miotumida Didymocyrtis sp. A zone

- LAD G. dehiscens

- Didymocyrtis laticonus Subzone

- Didymocyrtis laticonus subzone

- Heliodiscus umbonatum subzone

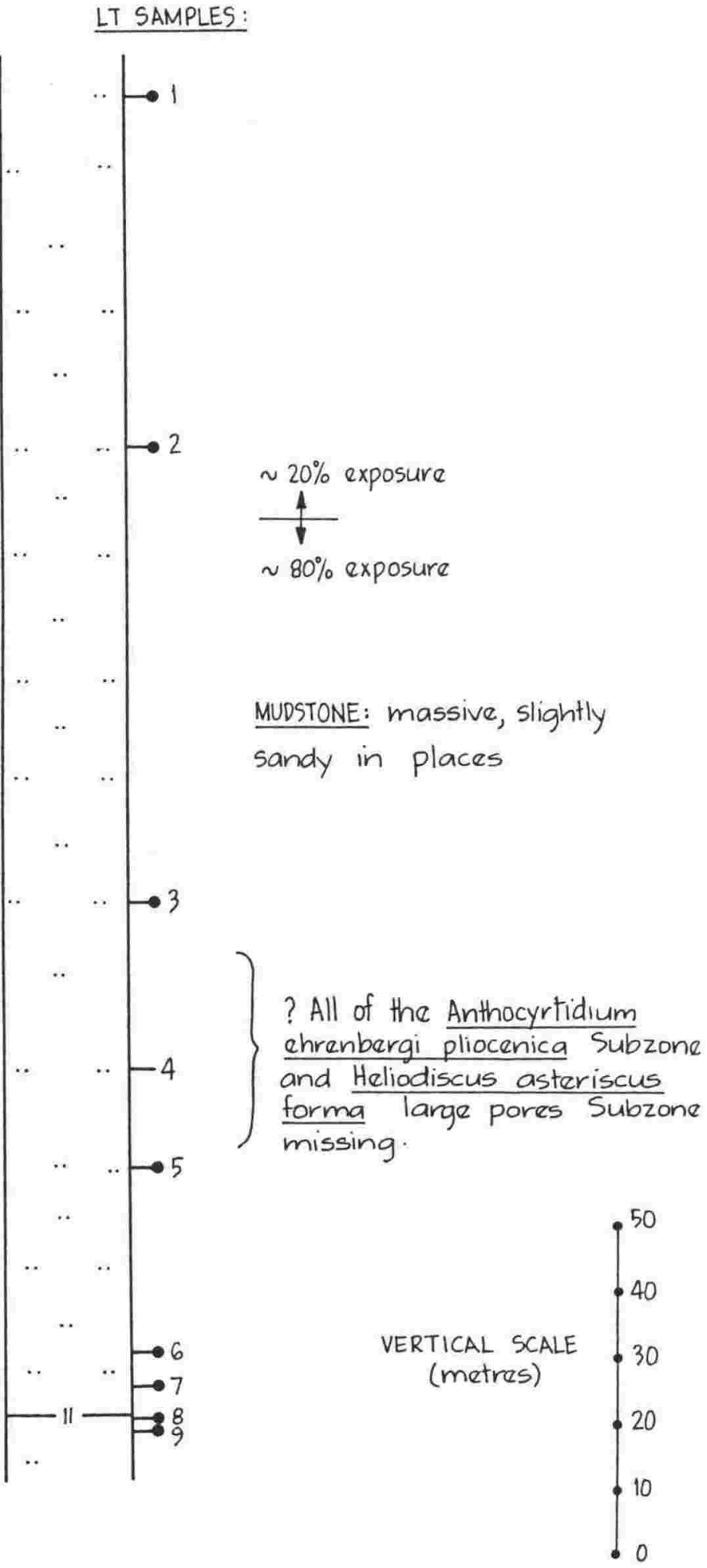




\section{A.50}

NORTH OF LEADER TRIBUTARY SITE

Samples: Two samples from $20 \mathrm{~cm}$ above and immediately below a tuff outcropping in a tributary north of the Leader Tributary Section were examined for Radiolaria. The sample immediately below (SPA1) contains Radiolaria and is used in this thesis. The tuff outcrop is only $500 \mathrm{~m}$ along strike from the tuff in the Leader Tributary Section and is geochemically identical (G. Gosson, pers. comm.). See figure A.38.

Radiolaria: The possible identification of Didymocyrtis laticonus in this sample lacking the large pored form of Heliodiscus asteriscus and Anthocyrtidium ehrenbergi pliocenica and Heliodiscus umbonatum indicates an age in the Didymocyrtis laticonus Subzone. The diversity is moderate for this sample $(Q=6.42)$ but it is interesting to note that this value of $Q$ agrees well with LT08 $(Q=5.20)$ from immediately below the tuff in the Leader River Tributary Section. Sample LT08 is in a section where Q values are generally alot higher $(>8.50)$.

\section{A.51 ATHLONE STREAM SITE}

This site is located $6 \mathrm{~km}$ northwest of Parnassus on the south side of Athlone Stream Valley in ?mid?-upper Tongaporutuan strata. Samples $5 \mathrm{~m}$ above, immediately below, and $0.5 \mathrm{~m}$ below a $50 \mathrm{~cm}$ thick tuff were examined for Radiolaria. The sample above was barren and the samples below contained rare Radiolaria but were not used in this thesis. See figure A.38. 


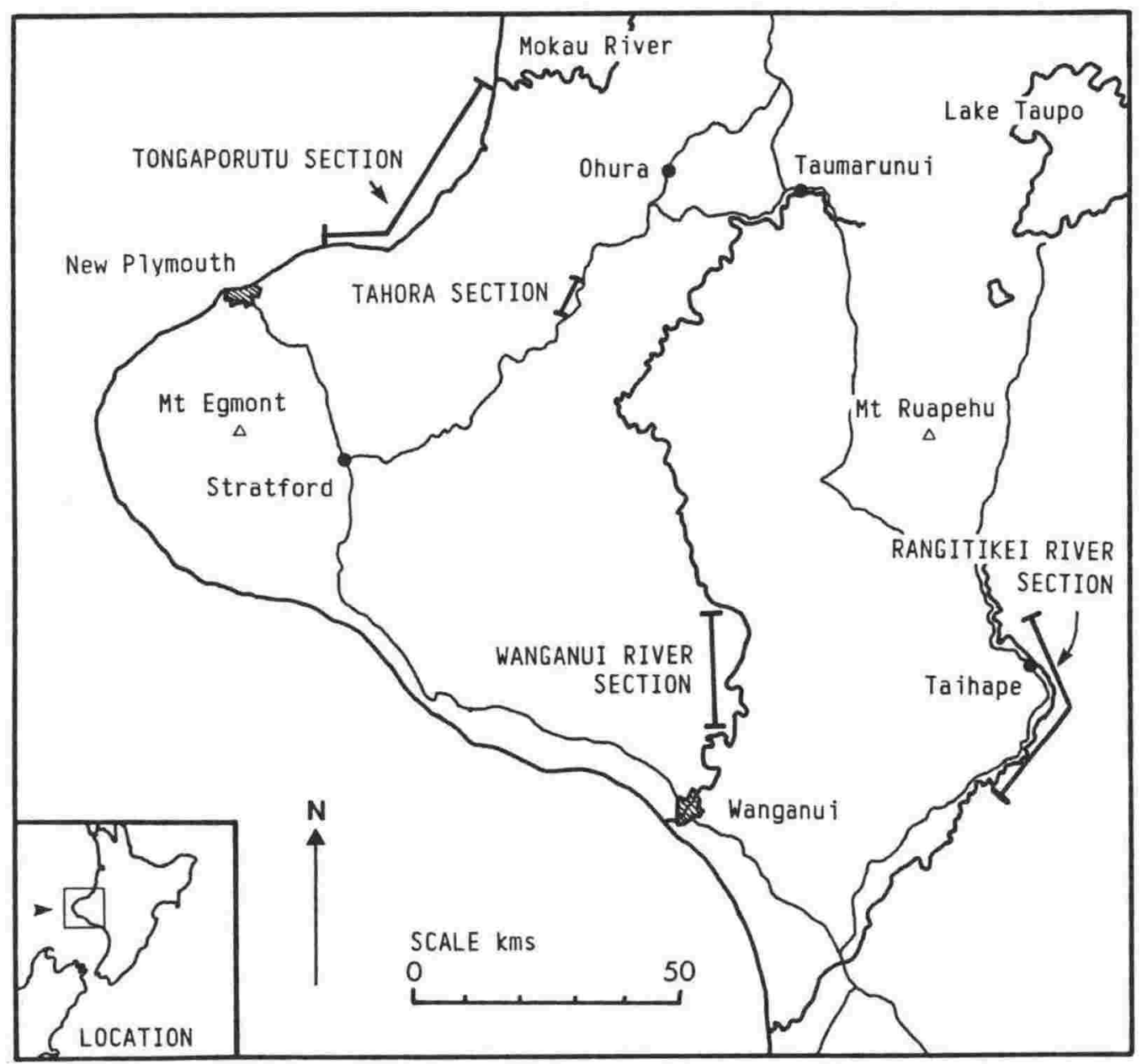

Figure A.41

Location of sections : West Coast, North Island. 
Location: Between Waitara and Mokau on the north Taranaki Coast. Forty kilometres of coastal cliffs providing excellent exposure of the Tongaporutuan holostratotype. See figure A.41.

Comment: The section straddles a deep-seated structural feature, the Patea-Tongaporutu High, which separates the Taranaki and Wanganui Basins (Hunt, 1980).

Lithology: The predominant lithologies are well-bedded mudstone, siltstone, and fine sandstone with occasional submarine channels infilled with quartz pebbles and sandstone clasts.

Age: Basal Tongaporutuan beds occur at N100/f547 and the LAD of Globoquadrina dehiscens at $\mathrm{N} 99 / \mathrm{f} 514$ (which approximates the FAD of Bolivinita compressa in this section (G. Scott pers. comm.). Above the LAD of G. dehiscens the section continues to an unconformable contact with the Pouakai Volcanic Group between Waitara and Urenui. The youngest samples in the section contain specimens close to Bolivinita pliozea (G. Scott, pers. comm.).

Samples: Twenty-three samples collected at regular intervals from the finest grained sediments in the section by G. Gosson and one sample of Gibson's (N99/f573) are barren.

References: Gibson (1963, 1967), Gosson (in prep.).

\section{A.53 TAHORA SECTION}

Location: Between Tahora and Kahuratahi on the Stratford-Ohura Highway. See figure A.41.

Samples: Six lower to mid Tongaporutuan samples (N110/f38-f43) are barren.

References: Gibson (1963, 1967).

\section{A.54 WANGANUI RIVER SECTION}

Location: On the banks of the Wanganui River between Ranana and Parikino. The samples examined were collected by J.D. Collen of Victoria University at the same time as N.D. Watkins and J.P. Kennett collected paleomagnetic samples (ZM series). See figure A.41.

Samples: Forty-four samples were examined, the oldest being N131/f515 (Wo) and the youngest N138/f551 (Wm). Radiolaria were found to be present in ten samples: N131/f524, f525, f528-f532 (Taihape Mudstone - Wo): N131/f535 (Koroniti Sandstone - Wo/Wp): N131/f537, f538 (lower Raumati Sandstone and upper Koroniti Sandstone - Wp). Faunas are generally impoverished.

Reference: Collen (1972b). 


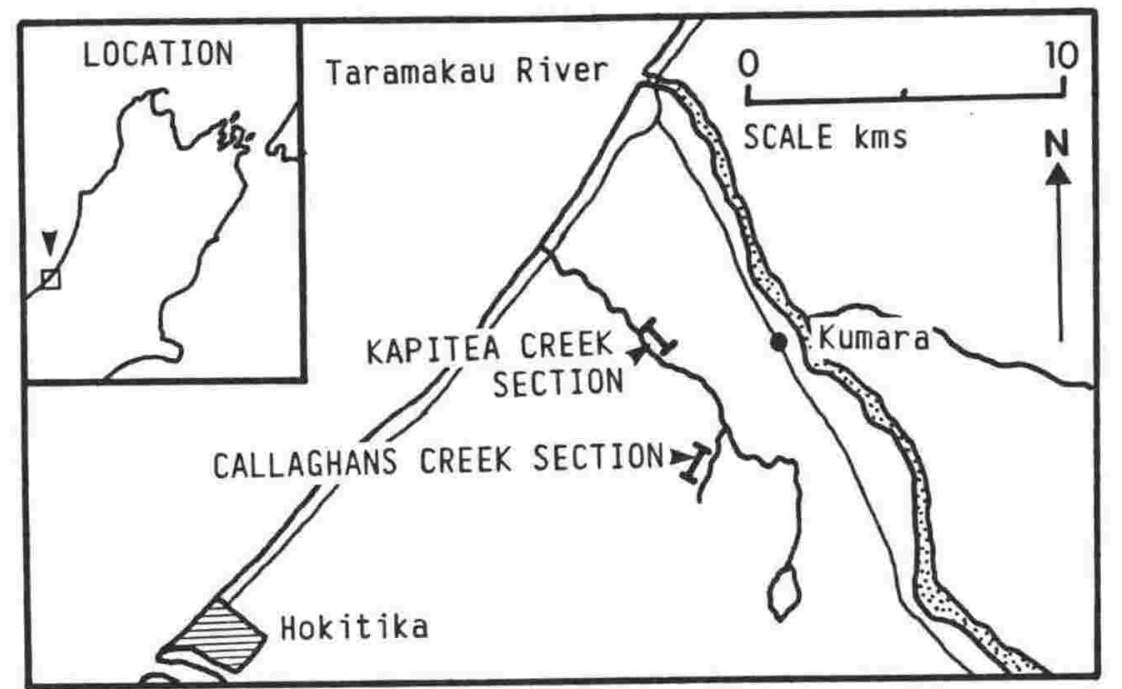

Figure A.42

Location of sections : West Coast, South Island. 


\section{A.55 RANGITIKEI RIVER SECTION}

Location: Samples collected from roadcuts on State Highway One up to $12 \mathrm{~km}$ north of Taihape, on the Napier-Taihape road between Moawhango and Taihape, and on State Highway One between Ohingaiti and Taihape; in the Rangitikei River Valley. See figure A.41.

Samples: Thirteen samples examined.

$\begin{array}{lcc}\text { Register Numbers } & \text { Fossil Record Numbers } & \text { Age } \\ \text { JAA289 } & \text { N132/f507 (projected) } & \text { Wo } \\ \text { JAA274 } & \text { N132/f509 } & \text { Wo } \\ \text { JAA272 } & \text { N132/f510 (projected) } & \text { Wo } \\ \text { JAA273 } & \text { N132/f510-f511 (projected) } & \text { Wo } \\ \text { JAA275 } & \text { N132/f511 } & \text { Wo } \\ \text { JAA276 } & \text { N132/f512 } & \text { Wo } \\ \text { JAA277 } & \text { N132/f514 } & \text { Wp } \\ \text { JAA278 } & \text { N139/f539 } & \text { Wp } \\ \text { JAA653 } & \text { N139/f540 } & \text { Wp } \\ \text { JAA652 } & \text { between N139/f539-f540 } & \text { Wp } \\ \text { JAA279 } & \text { between N139/f541-f542 } & \text { Wm } \\ \text { JAA651 } & \text { between N139/f542-f543 } & \text { Wm } \\ \text { JAA280 } & \text { N139/f544 } & \text { Wm }\end{array}$

Only two of the samples, JAA279 and JAA651 from the Mangapanian portion of the Mangaweka Mudstone, contain Radiolaria and these were only impoverished faunas containing mainly unrecognisable recrystallised forms.

Reference: Collen (1972b).

\section{A.56 KAPITEA CREEK SECTION}

Location: In low bluffs extending about $1.5 \mathrm{~km}$ down Kapitea Creek from its junction with Maori Gully; about $4.5 \mathrm{~km}$ west of Kumara. See figure A.42.

Comment: Holostratotype Kapitean.

Lithology, Age, and Samples: Six samples examined from massive medium blue-grey mudstones (S51/f642, f644-f648). All the samples are Kapitean except one Waiauan sample (f642) and all are barren of Radiolaria.

References: Kennett (1966a, 1966b), Jenkins (1971), Scott (1980b, 1982b).

\section{A.57 CALLAGHANS CREEK SECTION}

Location: This section is $3.2 \mathrm{~km}$ southeast of the Kapitea Creek Section in an artificial sludge channel constructed during the late 19th century to drain gold-sluicing claims. See figure A.42.

Samples: Two lower Tongaporutuan samples (S51/f652, f653) are barren.

References: Kennett (1966a, 1966b). 


\section{Appendix B \\ SAMPLE DESCRIPTIONS}

\section{B.1 INTRODUCTION}

This appendix describes the samples selected for study in this thesis. The order of presentation is by sections (arranged consecutively north to south) then sample descriptions from sites (sites prefixed by an S : e.g. SWR1) again arranged north to south. To save space the terms foraminifera and Radiolaria have been abbreviated to forams and rads.

To explain the layout of each description the first sample breaks down as follows:

EC01 : Thesis sample number as quoted in text and figures. The first two letters define the section (in this case East Cape) and the numerals the sample number in that section with 01 being the youngest sample discussed and samples getting progressively older as numbers get higher. With sites the sample number is prefixed by "S".

Z14/f46 : New Zealand Fossil Record File number.

Z14/96907135: Metric grid reference for NZMS 260 maps. Eight digit references indicate that a small scale base map for the section or site was drawn during the course of this study.

N72/91604965 : Imperial grid reference for NZMS 1 maps.

JAA814 : Personal sample register as lodged at Victoria University.

E589 : Field collection number.

PRM : Collector. Abbreviations for the various collectors are as follows:

$\begin{array}{ll}\text { DAH } & \text { David Heath, Victoria University of Wellington } \\ \text { GHS } & \text { George Scott, New Zealand Geological Survey, Lower Hutt } \\ \text { GJG } & \text { Greg Gosson, Victoria University of Wellington } \\ \text { GWG } & \text { Graham Gibson, Victoria University of Wellington } \\ \text { JDC } & \text { John Collen, Victoria University of Wellington } \\ \text { JNA } & \text { Jeff Ashby, Victoria University of Wellington } \\ \text { MEF } & \text { Mike Fittall, Victoria University of Wellington } \\ \text { MPC } & \text { Martin Crundwell, Victoria University of Wellington } \\ \text { NBH } & \text { Norcott Hornibrook, New Zealand Geological Survey, Lower Hutt } \\ \text { PPV } & \text { Paul Vella, Victoria University of Wellington } \\ \text { PRM } & \text { Phil Moore, New Zealand Geological Survey, Lower Hutt }\end{array}$

29-04-80 : Date of sample collection.

Next in the description is a brief account of the lithology of the sample including (in brackets) the percentage of the sample that is coarser than $54 \mu$, presence of microfossil groups, and any pertinent remark about the sample. Occasionally in the remarks the position of the sample in relation to a tuff will be given, the tuff being designated a " $G$ " number. This " $G$ " number is the number of the tuff as designated by Gosson (in prep.).

Finally there is an account of how the microfossils from the sample are stored. Two abbreviations are used here:

TL : transmitted light, and

SEM : scanning electron microscope 


\section{B.2 EAST CAPE SECTION}

$\begin{array}{lllllll}\text { EC01 Z14/f46 Z14/96907135 N72/91604965 JAA814 } & \text { E589 } & \text { PRM 29-04-80 }\end{array}$

Indurated, light grey-green mudstone $(6.0 \%)$, black carbonaceous specks, forams present, abundant spicules, glass shards present. In alternating fine sandstone, mudstone, tuff sequence, bedding approximately $40 \mathrm{~cm}$. Youngest rad-bearing sample in the section.

Rads - SEM stub. Forams - mounted slide.

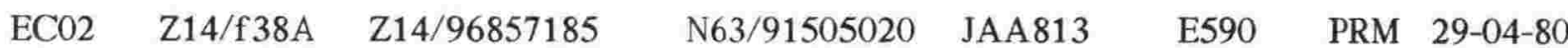
Grey-green mudstone $(7.8 \%)$, bioturbation picked out by concentration of white specks, oxidation halos where the specks are concentrated, common forams, abundant spicules, glass shards present. In alternating fine sandstone, mudstone, tuff sequence bedding approximately $40 \mathrm{~cm}$.

Rads - TL slide. Forams - mounted slide.

$\begin{array}{lllllll}\text { EC03 } & \text { Z14/f113 } & \text { Z14/981736 } & \text { N63/928522 JAA763 } & \text { EAST1 } & \text { GJG } & \text { 12-02-82 }\end{array}$

Massive, grey-green mudstone ( $8.5 \%$ ), some black carbonaceous fragments up to $2 \mathrm{~mm}$, forams present, spicules present, glass shards present.

Rads - SEM stub. Forams - mounted slide.

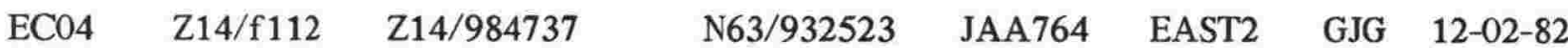

Massive, grey-green mudstone (10.2\%), pumiceous? fragments up to $3 \mathrm{~mm}$, common forams, spicules present, glass shards present. Oldest rad-bearing sample in the section but rads are recrystallised. Seems to be the shallowest sample in the section as the benthic/planktic foraminifera ratio is high.

Rads - TL slide. Forams - mounted slide.

\section{B.3 KAITI BEACH SECTION}

$\begin{array}{lllllll}\text { KB01 } & \text { Y18/f92 } & \text { Y18/470685 N98/403357 JAA530 K13 } & \text { GHS 08-03-81 }\end{array}$ Massive, grey-green mudstone $(1.8 \%), \mathrm{mm}$-scale bioturbation picked out by black oxidised burrows, abundant forams, spicules present, glass shards present. Youngest rad-bearing sample from the section.

Rads - TL slide, SEM stub. Forams - mounted slide.

KB02 Y18/f209 Y18/471682 N98/403353 JAA800 KAI4 GJG 13-02-82

Weakly bedded to massive, grey-green mudstone (2.1\%), indurated, black carbonaceous specks, forams present, common spicules, rads recrystallised.

Rads - SEM stub. Forams - mounted slide.

KB03 Y18/f94 Y18/473682 N98/405352 JAA528 K10 GHS 08-03-81 Massive, grey-green mudstone (1.4\%), thin black carbonaceous fragments, forams present, glass shards present, rads recrystallised.

Rads - SEM stub. Forams - mounted slide.

$\begin{array}{llllllll}\text { KB04 Y18/f100 } & \text { Y18/476677 N98/409348 JAA522 } & \text { K4 } & \text { GHS } & \text { 08-03-81 }\end{array}$ Massive, grey-green mudstone $(4.6 \%)$, black and white speckled, common forams, common spicules, glass shards present, diatoms present, rads recrystallised. Oldest rad-bearing sample in the section.

Rads - SEM stub. Forams - mounted slide. 
$\begin{array}{lllllll}\text { HR01 X18/f8 } & \text { X18/103658 } & \text { N97/001316 JAA578 } & \text { H2 } & \text { GHS } & \text { 07-03-81 }\end{array}$ Indistinctly bedded to massive, grey-green mudstone (5.8\%), brown carbonaceous specks, bioturbated (up to $8 \mathrm{~mm}$ diameter with $3 \mathrm{~mm}$ oxidation halos), common forams, common spicules, tuffaceous, diatoms present. Youngest rad bearing sample in section. $5-10 \mathrm{~cm}$ below a fine sandstone unit. In the top of the Mapiri Formation?

Rads - SEM stub. Forams - mounted slide.

HR02 X18/f9 X18/104659 N97/002317 JAA579 H3 GHS 07-03-81 Indurated, indistinctly bedded $(0.5 \mathrm{~m})$ grey-green mudstone $(2.9 \%)$, minor black carbonaceous specks, abundant spicules, forams present, glass shards present, diatoms present. Immediately above a tuff (G143).

Rads - TL slide, SEM stub. Forams - mounted slide.

$\begin{array}{lllllll}\text { HR03 X18/f10 X18/105659 N97/003317 JAA580 H4 } & \text { GHS } & \text { 07-03-81 }\end{array}$ Indistinctly bedded to massive, grey-green mudstone (3.6\%), shell fragments, tuffaceous, forams present, abundant spicules. Immediately above a tuff (G144).

Rads and forams - mounted slide.

HR04 X18/f11 X18/106662 N97/004320 JAA581 H5 GHS 07-03-81 Indistinctly bedded to massive, grey-green mudstone (3.6\%), black carbonaceous specks, abundant spicules, glass shards present, common forams.

Rads - TL slide, SEM stub. Forams - mounted slide.

HR05 X18/f12 X18/106663 N97/004321 JAA582 H6 GHS 07-03-81 Massive, grey-green mudstone (3.3\%), black and brown carbonaceous specks, abundant spicules, tuffaceous, common forams.

Rads - TL slide, SEM stub. Forams - mounted slide.

HR06 X18/f13 X18/112665 N97/011324 JAA583 H7 GHS 07-03-81 Massive, grey-green mudstone (3.9\%), abundant spicules, common forams, glauconite common, shell fragments, glass shards present.

Rads - TL slide. Forams - mounted slide.

$\begin{array}{lllllll}\text { HR07 X18/f14 X18/116668 N97/015327 JAA584 H8 } & \text { GHS 07-03-81 }\end{array}$ Massive, grey-green mudstone $(7.4 \%)$, white specks up to $1 \mathrm{~mm}$ concentrated in patches, abundant forams, abundant spicules, rads rare and recrystallised. Oldest rad bearing sample in the upper part of the section. Immediately below a 15-20 cm tuff (G146).

Forams - mounted slide.

\section{B.5 RUAKITURI RIVER SECTION}

$\begin{array}{lllllll}\text { RK01 X18/f29 X18/955580 N106/842226 JAA538 } & \text { R7 } & \text { GHS } & \text { 06-03-81 }\end{array}$ Massive, grey-green mudstone $(8.1 \%)$, some $2 \mathrm{~mm}$ tuffaceous fragments, common forams, abundant spicules, rads rare, diatoms present. $19 \mathrm{~m}$ above a tuff (G140). $80 \mathrm{~cm}$ above a smaller tuff. $5 \mathrm{~m}$ below alternating massive sands $(2 \mathrm{~m})$ and massive silts $(1.5 \mathrm{~m})$. Youngest rad bearing sample in section.

Forams - mounted slide. 
Massive, grey-green mudstone (1.9\%), tuffaceous, common rads, common forams (recrystallised), common spicules. Occasional thin $(1-2 \mathrm{~cm})$ sandstone beds. $1.5 \mathrm{~m}$ above a reworked tuff $(70 \mathrm{~cm}$ thick).

Rads - TL slide. Forams - mounted slide.

$\begin{array}{llllll}\text { RK03 X18/f27 X18/952583 N106/839229 JAA536 R6 } & \text { GHS 06-03-81 }\end{array}$ Grey-green mudstone (2.6\%) from interbedded mudstones $(20 \mathrm{~cm})$ and sandstones $(5-8 \mathrm{~cm})$, white tuffaceous specks, forams present, common rads (recrystallised), forams present, abundant spicules, glass shards present.

Rads - TL slide. Forams - mounted slide.

RK04 X18/f26 X18/951585 N106/838231 JAA535 R5 GHS 06-03-81 Indurated, grey-green mudstone $(1.6 \%)$ from interbedded mudstones $(1 \mathrm{~cm})$ and sandstones $(5-7 \mathrm{~cm})$, shell fragments, minor black carbonaceous specks, common forams, common spicules, common rads, diatoms present.

Rads - TL slide, SEM stub. Forams - mounted slide.

\section{RK05 X18/f25 X18/951586 N106/837232 JAA534 R4 GHS 06-03-81}

Massive, grey-green mudstone (13.8\%), black carbonaceous specks, iron-stained along joints, abundant forams, glass shards present, common spicules (etched), rads present (recrystallised), sterrasters common.

Forams - mounted slide.

\section{B.6 MANGAPOIKE RIVER SECTION}

$\begin{array}{llllllll}\text { TM01 X19/f9 } & \text { X19/012471 N106/908109 } & \text { JAA128 } & 16 & \text { NBH } & \text { 14-03-78 }\end{array}$

Massive, grey-brown sandy mudstone (17.6\%), brown carbonaceous specks, scattered mollusca and shell fragments, common spicules, forams present, very rare rads. Youngest rad bearing sample in section.

Forams - mounted slide.

TM02 X19/f8 X19/012471 N106/908109 JAA129 $15 \quad$ NBH 14-03-78

Massive, grey-green sandy mudstone (17.7\%), brown carbonaceous specks, tuffaceous, rare forams, common spicules, diatoms present, very rare rads, common sterrasters.

Forams - mounted slide.

$\begin{array}{llllllll}\text { TM03 X19/f6 } & \text { X19/020473 N106/916111 JAA131 } & 12 & \text { NBH } & \text { 14-03-78 }\end{array}$ Massive, grey-green sandy mudstone $(29.1 \%)$, forams present, rads rare. $25 \mathrm{~m}$ above Whakapunake Limestone. $2 \mathrm{~m}$ below the base of a $1 \mathrm{~m}$ tuff.

Forams - mounted slide.

TM04 X19/f7761B X19/04854619 N106/94790998 JAA629 POIKE43 JNA 08-03-81 Massive, grey-green sandy mudstone $(41.1 \%)$, sterrasters common, abundant spicules, glass shards present, forams present, rads rare, some mollusca. Occasional brown-white speckled, coarse, $20 \mathrm{~cm}$ thick calcarenites.

Forams - mounted slide. 
Massive, grey-green sandy mudstone (17.3\%), tuffaceous, diatoms present, common forams, common spicules, rads rare, ostracods present.

Forams - mounted slide.

TM06 X19/f7759B X19/05174653 N106/95131036 JAA627 POIKE45 JNA 08-03-81 Massive, grey-green sandy mudstone (24.0\%), common forams, tuffaceous, common rads, common spicules, diatoms present.

Rads - TL slide, SEM stub. Forams - mounted slide.

TM07 X19/f7758B X19/05134622 N106/95091002 JAA626 POIKE46 JNA 08-03-81 Massive, grey-green sandy mudstone (22.2\%), abundant forams, tuffaceous, common spicules, sterrasters common, rads present, diatoms present, rare ostracods. Occasional indurated sandier layers.

Rads - SEM stub. Forams - mounted slide.

TM08 X19/f7757B X19/05344594 N106/95330972 JAA625 POIKE47 JNA 08-03-81 Massive, grey-green sandy mudstone (18.9\%), bioturbated (mm-scale), common spicules, sterrasters common, rare forams, glass shards present, rads rare, ostracods present.

Forams - mounted slide.

TM09 X19/f7756B X19/05444587 N106/95440965 JAA624 POIKE48 JNA 08-03-81 Massive, grey-green mudstone (14.6\%), pumiceous fragments up to $3 \mathrm{~mm}$, common spicules, sterrasters common, ostracods present, rare forams, rads rare. $3 \mathrm{~m}$ below a tuff $(10 \mathrm{~cm}$, fining upwards, coarse base then $15 \mathrm{~cm}$ coarse layer then $55 \mathrm{~cm}$ of tephric mudstone).

Forams - mounted slide.

TM10 X19/f7755A X19/05594576 N106/95610953 JAA623 POIKE49 JNA 08-03-81 Massive, grey-green sandy mudstone (23.0\%), rare mollusca, common spicules, sterrasters common, common forams, glass shards present, rads rare. Occasional thin $(1 \mathrm{~cm})$ sandier layers.

Forams - mounted slide.

TM11 X19/f78 X19/05724553 N106/95760928 JAA622 POIKE50 JNA 08-03-81 Massive, grey-green sandy mudstone (31.3\%), black carbonaceous specks, rads rare, common spicules, glass shards present, common forams, sterrasters common, some mollusca. Occasional thin iron-stained sandier layers.

Forams - mounted slide.

TM12 X19/f7752B X19/05884559 N106/95930935 JAA621 POIKE51 JNA 08-03-81 Massive, grey-green sandy mudstone (41.3\%), black carbonaceous specks, patches of $0.5-1 \mathrm{~mm}$ tuffaceous burrows, shell fragments, rads present, common spicules, common forams, sparse mollusca, pumiceous fragments from 1 to $8 \mathrm{~mm}$.

Rads - SEM stub. Forams - mounted slide.

$\begin{array}{llllllll}\text { TM13 X19/f7834 } & \text { X19/06714502 } & \text { N106/96840877 } & \text { JAA134 } & 16 & \text { NBH } & 21-09-75\end{array}$ Massive, grey-green sandy mudstone (18.1\%), common forams, spicules present, rads rare (recrystallised), ostracods present. Above road-cut unconformity.

Forams - mounted slide. 
TM14 X19/f7738B X19/06734542 N106/96870919 JAA614 POIKE58 JNA 08-03-81 Massive, grey-green mudstone (3.0\%), black carbonaceous specks, abundant rads, abundant spicules, common forams. Stratigraphically below the roadcut unconformity equivalent.

Rads - TL slide, SEM stub. Forams - mounted slide.

TM15 X19/f75 X19/06754502 N106/96880876 JAA412 POIKE4 JNA 11-08-80 Massive, grey-green mudstone $(2.2 \%)$, abundant spicules, abundant rads, abundant forams. $0.5 \mathrm{~m}$ above a sandy ?tuffaceous? layer. Below road-cut unconformity.

Rads - TL slide, SEM stub. Forams - mounted slide.

$\begin{array}{lllllll}\text { TM16 X19/f7830 } & \text { X19/06754502 N106/96880876 JAA137 } & 17 & \text { NBH } & \text { 21-09-75 }\end{array}$ Massive, grey-green mudstone (0.9\%), abundant rads, common forams, abundant spicules, glass shards present. Between two $10 \mathrm{~cm}$ tuffs.

Rads - TL slide, SEM stub. Forams - mounted slide.

TM17 X19/f76 X19/06754502 N106/96880876 JAA417 POIKE9 JNA 11-08-80 Massive, grey-brown sandy mudstone (18.6\%), black carbonaceous specks, abundant spicules (etched), sterrasters abundant, rads rare, rare forams. Sandier layer within mudstone.

Rads - SEM stub. Forams - mounted slide.

TM18 X19/f63 X19/06794501 N106/96940875 JAA833 T26 GHS 06-03-81 Massive, grey-green mudstone $(3.6 \%)$, bioturbated (mm-scale), sterrasters present, rads present, forams present (recrystallised), abundant spicules, carbonaceous.

Rads - SEM stub. Forams - mounted slide.

TM19 X19/f62 X19/06934496 N106/97100870 JAA836 T25 $\quad$ GHS 06-03-81 Massive, grey-green mudstone $(1.9 \%)$, abundant spicules, tuffaceous, common rads, forams present, abundant diatoms. At base of a turbidite packet.

Rads - TL slide, SEM stub. Forams - mounted slide.

$\begin{array}{lllllll}\text { TM20 X19/f61 X19/07024504 N106/97200879 JAA834 } & \text { T24 } & \text { GHS } & \text { 06-03-81 }\end{array}$ Massive, grey-green mudstone $(2.1 \%)$, abundant spicules, tuffaceous, abundant rads, common forams, diatoms present. $2 \mathrm{~m}$ below a layer of irregularly shaped concretions.

Rads - TL slide, SEM stub. Forams - mounted slide.

TM21 X19/f74 X19/07224496 N106/97420871 JAA611 POIKE34 JNA 06-03-81 Massive, grey-green mudstone $(0.5 \%)$, abundant spicules, abundant rads, rare forams, abundant diatoms. $4 \mathrm{~m}$ above top of a tuff (G79).

Rads - TL slide, SEM stub. Forams - mounted slide.

$\begin{array}{lllllll}\text { TM22 } & \text { X19/f60 } & \text { X19/07334494 N106/97540869 JAA831 } & \text { T23 } & \text { GHS } & \text { 06-03-81 }\end{array}$ Massive, grey-green mudstone $(0.3 \%)$, abundant rads, abundant forams, abundant spicules (some etched), diatoms present, glass shards present.

Rads - TL slide, SEM stub. Forams - mounted slide.

$\begin{array}{lllllll}\text { TM23 X19/f59 X19/07594487 N106/97820862 JAA832 T22 } & \text { GHS 06-03-81 }\end{array}$ Indurated, massive, grey-green mudstone $(0.4 \%$ ), tuffaceous burrows (mm scale) with oxidation halos, abundant rads, abundant spicules, forams present, glass shards present, diatoms present. Oldest rad bearing sample in section.

Rads - TL slide, SEM stub. Forams - mounted slide. 


\section{B.7 WAIATAI VALLEY SECTION}

WA01 X19/f65 X19/941326 N116/835949 JAA575 TEUHI5 JNA 03-03-81 Massive, light brown-yellow-grey mudstone (0.1\%), some black carbonaceous specks, glass shards present, abundant rads, common spicules, rare forams. Youngest sample in section. Immediately below a weathered tuff?

Rads - TL slide.

WA02 X19/f66 X19/942327 N116/836949 JAA576 TEUHI6 JNA 03-03-81 Massive, light grey-green mudstone (1.5\%), black carbonaceous specks, abundant rads, tuffaceous, common spicules, rare forams, rare diatoms.

Rads - TL slide, SEM stub.

WA03 X19/f67 X19/942327 N116/837949 JAA574 TEUHI4 JNA 03-03-81 Massive, light grey-brown mottled mudstone (1.2\%), tuffaceous, abundant rads, common spicules, rare forams.

Rads - TL slide, SEM stub.

WA04 X19/f68 X19/943328 N116/838950 JAA573 TEUHI3 JNA 03-03-81 Massive, light grey mudstone $(0.7 \%)$, brown carbonaceous specks, tuffaceous, abundant rads, rare forams, spicules present.

Rads - SEM stub, mounted slide.

WA05 X19/f69 X19/943331 N116/838953 JAA571 TEUHI JNA 03-03-81 Massive, light grey-brown mudstone ( $8.6 \%$ ), brown carbonaceous specks, tuffaceous fragments up to $1 \mathrm{~mm}$, abundant rads, common forams, spicules present, mollusca present. Immediately above a $30 \mathrm{~cm}$ tuff with a $15 \mathrm{~cm}$, laminated, coarse base and a $15 \mathrm{~cm}$, bioturbated, medium-sand top.

Rads and forams - mounted slide.

WA06 X19/f9569 X19/95063276 N116/84509499 JAA206 $47 \quad$ NBH $24-09-75$ Massive, grey-green mudstone (2.3\%), minor brown carbonaceous specks, tuffaceous, common spicules, common rads, abundant forams.

Rads and forams - mounted slide.

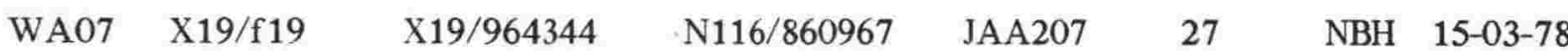
Massive, grey-green mudstone $(2.4 \%)$, black carbonaceous specks, tuffaceous, abundant rads, abundant forams, abundant spicules. Occasional thin, graded, sandstone beds in outcrop. Rads - TL slide, SEM stub. Forams - mounted slide.

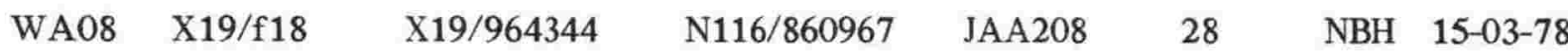
Massive, grey-green mudstone (3.0\%), tuffaceous, common forams, common rads, common spicules. Occasional thin, graded, sandstone beds in outcrop.

Rads - SEM stub. Rads and forams - mounted slide.

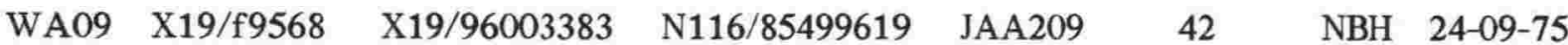
Massive, grey-green mudstone (6.9\%), brown carbonaceous specks up to $1 \mathrm{~mm}$, shell fragments, glass shards present, rads present, spicules present, common forams. Top of a graded bed unit.

Forams - mounted slide. 
$\begin{array}{lllllll}\text { WA10 X19/f30 N19/967341 N116/863965 JAA210 } & \text { X } & \text { NBH } & \text { 20-09-78 }\end{array}$

Massive, grey-green mudstone ( $4.0 \%$ ), tuffaceous specks up to $0.5 \mathrm{~mm}$, abundant forams, abundant rads, glass shards present, common spicules (some etched). $10 \mathrm{~m}$ below top of an alternating mudstone and graded, soft, brown sandstone unit.

Rads - TL slide, SEM stub. Forams and rads - mounted slide.

WA11 X19/f70 X19/971341 N116/867965 JAA211 $11 \quad$ NBH 20-09-78 Massive, grey-green mudstone (4.1\%), black carbonaceous specks, tuffaceous, rads present, spicules present. $40 \mathrm{~m}$ below top of an alternating mudstone and graded, soft, brown sandstone unit. Sample from a $2 \mathrm{~m}$ thick mudstone.

Rads - SEM stub, mounted slide.

$\begin{array}{llllllll}\text { WA12 } & \mathrm{X} 19 / \mathrm{f} 29 & \mathrm{X} 19 / 978342 & \mathrm{~N} 116 / 874967 & \mathrm{JAA} 212 & 12 & \mathrm{NBH} & \text { 20-09-78 }\end{array}$

Massive, grey-green mudstone (1.6\%), shell fragments, abundant forams, common spicules, common rads.

Rads - SEM stub. Rads and forams - mounted slide.

WA13 X19/f9567 X19/98603495 N116/88309750 JAA213 $40 \quad$ NBH $\quad$ 24-09-75

Massive, grey-green mudstone (1.4\%), abundant rads, tuffaceous, abundant forams, abundant spicules. Near the top of a $15-20 \mathrm{~m}$ mudstone within the alternating unit.

Rads - TL slide, SEM stub. Forams - mounted slide.

$\begin{array}{lllllll}\text { WA14 X19/f9564 X19/99893537 N116/89709799 JAA215 } & 37 & \text { NBH } & \text { 23-09-75 }\end{array}$

Massive grey-brown sandy mudstone (19.8\%), black carbonaceous specks, tuffaceous, forams present, rads present, spicules present.

Rads and forams - mounted slide.

WA15 X19/f9562 X19/00073527 N116/89909789 JAA217 $35 \quad$ NBH $\quad 23-09-75$

Massive, grey-green mudstone (3.5\%), tuffaceous, common rads, common forams, common spicules, diatoms present.

Rads - TL slide, SEM stub. Forams - mounted slide.

WA16 X19/f9561 X19/00073527 N116/89909789 JAA218 $34 \quad$ NBH $\quad 23-09-75$

Massive, grey-green mudstone (1.5\%), tuffaceous, rads present, common forams, common spicules, diatoms present.

Rads - TL slide, SEM stub. Forams - mounted slide.

$\begin{array}{lllllll}\text { WA17 X19/f9560 X19/00073527 N116/89909789 JAA219 } & \text { N3 } & \text { NBH } & \text { 23-09-75 }\end{array}$

Massive, grey-green mudstone $(3.3 \%)$, tuffaceous, common rads, common forams, abundant spicules, diatoms present.

Rads - TL slide, SEM stub. Forams - mounted slide.

$\begin{array}{lllllll}\text { WA18 } & \text { X19/f9534 } & \text { X19/00813553 N116/90709820 } & \text { JAA197 } & 2 & \text { NBH } & \text { 30-10-72 }\end{array}$

Massive, grey-green sandy mudstone (13.5\%), forams present, spicules present, rads rare, diatoms present, sterrasters common.

Rads and forams - mounted slide. 
$\begin{array}{lllllll}\text { WA19 } & \text { X19/f9535 } & \text { X19/02583694 N116/92599979 } & \text { JAA198 } & 10 & \text { NBH } & \text { 31-10-72 }\end{array}$

Massive, grey-green sandy mudstone (14.7\%), glass shards present, diatoms present, black carbonaceous specks, spicules present, rads rare, common forams.

Rads - TL slide. Forams and rads - mounted slide.

$\begin{array}{lllllll}\text { WA20 } & \text { X19/f9536 X19/02493685 N116/92499969 JAA199 } & \text { J1 } & \text { NBH } & \text { 31-10-72 }\end{array}$

Massive, grey-green mudstone $(2.2 \%)$, tuffaceous, abundant forams, common spicules, rads rare.

Forams - mounted slide.

$\begin{array}{lllllll}\text { WA21 X19/f9537 } & \text { X19/02493685 N116/92499969 } & \text { JAA200 } & 12 & \text { NBH } & \text { 31-10-72 }\end{array}$ Massive, grey-green mudstone (1.8\%), tuffaceous, abundant forams, abundant spicules, rads rare, sterrasters common.

Forams - mounted slide.

WA22 X19/f9538 X19/02493667 N116/92509950 JAA201 $13 \quad$ NBH $31-10-72$ Massive, grey-green mudstone (1.6\%), tuffaceous, common forams, abundant spicules, rads rare, sterrasters common.

Rads and forams - mounted slide.

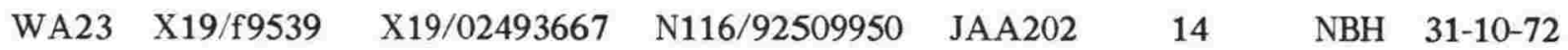
Massive, grey-green mudstone (2.6\%), abundant forams, diatoms present, common rads, spicules present.

Rads - TL slide. Forams - mounted slide.

WA24 X19/f9540 X19/02303649 N116/92309929 JAA203 $\quad 15 \quad$ NBH $\quad 31-10-72$ Massive, grey-green mudstone (2.9\%), shell fragments, common forams, common spicules, rads rare, sterrasters common.

Forams - mounted slide.

$\begin{array}{lllllll}\text { WA25 X19/f9541 X19/02303640 N116/92309919 JAA204 } & \text { J6 } & \text { NBH } & \text { 31-10-72 }\end{array}$ Massive, grey-green mudstone $(4.4 \%)$, abundant forams, diatoms present, abundant spicules, rads rare, sterrasters common.

Forams - mounted slide.

WA26 X19/f9542 X19/02293622 N116/92299900 JAA205 $17 \quad$ NBH $\quad$ 31-10-72 Massive, grey-green mudstone (6.3\%), abundant forams, diatoms present, common spicules, rads rare. Oldest sample in section.

Rads - TL slide. Forams - mounted slide.

\section{B.8 TAHAENUI-KOHUKOHU ROAD SECTION}

$\begin{array}{lllllll}\text { TK01 X19/f15 X19/163308 N116/078935 JAA140 } & \text { N4 } & \text { NBH } & \text { 15-03-78 }\end{array}$ Massive, grey-green sandy mudstone (17.3\%), abundant forams, abundant spicules, rads rare, sterrasters abundant, diatoms present. $1 \mathrm{~m}$ below base of a $6 \mathrm{~m}$ tuff. Youngest sample in section.

Forams - mounted slide. 
$\begin{array}{lllllll}\text { TK02 X19/f14 } & \text { X19/150295 N116/065920 } & \text { JAA141 } & 22 & \text { NBH } & 15-03-78\end{array}$

Massive, grey-green sandy mudstone (21.7\%), common forams, abundant spicules (etched), rads rare.

Forams - mounted slide.

TK03 X19/f9493 X19/15182945 N116/06609199 JAA142 $\quad$ NBH $30-10-72$

Massive, grey-green sandy mudstone (21.5\%), common forams, abundant spicules, rads rare, sterrasters abundant. Forams - mounted slide.

$\begin{array}{lllllll}\text { TK04 X19/f13 X19/158293 N116/073919 JAA143 } & \text { N } 20 & \text { NBH } & \text { 15-03-78 }\end{array}$

Massive, grey-green sandy mudstone (12.3\%), rare forams, diatoms present, abundant spicules, rads rare, sterrasters abundant.

Forams - mounted slide.

$\begin{array}{lllllll}\text { TK05 X19/f12 X19/158292 N116/073917 JAA144 } & 18 & \text { NBH } & \text { 15-03-78 }\end{array}$

Massive, grey-brown sandy mudstone (15.5\%), scattered mollusca, rare forams, abundant spicules, common rads, sterrasters common. $1 \mathrm{~m}$ below base of a $1 \mathrm{~m}$ tuff.

Rads - TL slide, SEM stub. Forams - mounted slide.

$\begin{array}{llllllll}\text { TK06 X19/f11 X19/158292 N116/073917 JAA145 } & 17 & \text { NBH } & \text { 15-03-78 }\end{array}$

Massive, grey-green mudstone (10.2\%), scattered mollusca, common forams, spicules present, rare rads. $20 \mathrm{~m}$ above the top of the Whakapunake Limestone.

Forams - mounted slide.

\section{B.9 CRICKLEWOOD ROAD SECTION}

$\begin{array}{lllllll}\text { CR01 W19/f8664 W19/833337 N115/717957 JAA107 } & \text { N1 } & \text { NBH } & \text { 23-09-75 }\end{array}$

Massive, grey-green sandy mudstone (12.7\%), black carbonaceous specks, common forams, spicules present, rads rare, diatoms present, sterrasters present. Youngest rad bearing sample in section. Immediately underlies a $2 \mathrm{~m}$ white tuff.

Forams - mounted slide.

$\begin{array}{lllllll}\text { CR02 W19/f8662 W19/834341 N115/717962 JAA109 } & 29 & \text { NBH } & \text { 23-09-75 }\end{array}$ Massive, grey-green-brown sandy mudstone (16.4\%), black carbonaceous specks, forams present, rads present, spicules present, glass shards present, sterrasters present.

Forams - mounted slide.

$\begin{array}{lllllll}\text { CR03 W19/f8661 W19/834341 N115/717962 JAA110 } & 28 & \text { NBH } & \text { 23-09-75 }\end{array}$ Massive, light grey-brown mudstone (3.0\%), brown carbonaceous specks, abundant forams, tuffaceous, rads rare, scattered small mollusca.

Rads - TL slide, SEM stub. Forams - mounted slide.

$\begin{array}{lllllll}\text { CR04 W19/f8659 W19/834347 N115/717967 JAA112 } & \text { W } & \text { NBH } & \text { 23-09-75 }\end{array}$ Massive, light grey-green mudstone $(0.7 \%)$, tuffaceous, common spicules, rads present, common forams, abundant small mollusca. Oldest rad bearing sample in section.

Rads - SEM stub. Forams - mounted slide. 


\section{B.10 WAIHUA VALLEY SECTION}

WH01 W19/f42 W19/820284 N115/703898 JAA570 WAIHUA8 JNA 03-03-81 Massive, grey-green sandy mudstone (44.4\%), black carbonaceous specks, micaceous, common forams, common spicules, sterrasters common, glass shards present, rads rare, some mollusca, ostracods present. Youngest rad bearing sample in section.

Rads and forams - mounted slide.

WH02 W19/f43 W19/800288 N115/681902 JAA568 WAIHUA6 JNA 03-03-81 Massive, light grey-green mudstone (7.8\%), some black tephric burrows up to $2 \mathrm{~cm}$ with yellow oxidation halos, common spicules, sterrasters common, common forams, rads present, glass shards present, diatoms present.

Rads and forams - mounted slide.

WH03 W19/f44 W19/798289 N115/679903 JAA567 WAIHUA5 JNA 03-03-81 Massive, light grey-green mudstone $(2.7 \%)$, common thin black carbonaceous fragments up to $5 \mathrm{~mm}$ long, rare small mollusca, sterrasters common, common spicules, abundant forams, rads present, diatoms present.

Rads - TL slide. Rads and forams - mounted slide.

WH04 W19/f45 W19/791288 N115/672902 JAA566 WAIHUA4 JNA 03-03-81 Indurated, massive, light grey-green mudstone (5.9\%), common forams, common spicules, sterrasters common, glass shards present, rads rare.

Rads - SEM stub. Rads and forams - mounted slide.

WH05 W19/f46 W19/790292 N115/670906 JAA565 WAIHUA3 JNA 03-03-81 Massive, grey-green sandy mudstone $(12.7 \%)$, minor black carbonaceous specks, some mollusca up to $2 \mathrm{~cm}$, abundant forams, common spicules (etched), sterrasters common, rads rare, glass shards present, ostracods present.

Rads and forams - mounted slide.

$\begin{array}{llllll}\text { WH06 W19/f8552 W19/784304 N115/663919 JAA120 } & \text { W } & \text { NBH } & \text { 19-11-69 }\end{array}$

Massive, light grey-green mudstone (2.0\%), common forams, rads present, spicules present, scattered mollusca, glass shards present.

Rads - TL slide. Forams - mounted slide.

WH07 W19/f47 W19/773303 N115/652918 JAA564 WAIHUA2 JNA 03-03-81 Massive, grey-green mudstone $(11.8 \%)$, black carbonaceous specks, common spicules, common forams, glass shards present, rads present, scattered mollusca. Oldest rad bearing sample in section. $130 \mathrm{~m}$ above top of graded bed unit.

Rads and forams - mounted slide.

\section{B.11 MARAETOTARA RIVER SECTION}

MT01 W21/f45 W21/51996016 N135/39631428 JAA440 MARAE15 JNA 10-08-80 Massive, grey-green muddy sandstone (68.2\%), brown-white-black speckled, shell fragments common, forams present (recrystallised), rare spicules (etched), ostracods abundant. Above $\mathrm{Wo} / \mathrm{Tt}$ unconformity.

Forams - mounted slide. 
MT02 W21/f44 W21/51986009 N135/39631420 JAA439 MARAE14 JNA 10-08-80

Grey muddy sandstone $(70.9 \%)$ in an alternating sequence of indurated $(5-10 \mathrm{~cm})$ and non-indurated $(0.5-1 \mathrm{~m})$ layers, white-black speckled, abundant ostracods, forams present. Sample from the first non-indurated layer immediately above a $5 \mathrm{~cm}$ pebbly, shelly sandstone. Immediately above the Wo/Tt unconformity.

Forams - mounted slide.

MT03 W21/f43 W21/51986009 N135/39631420 JAA437 MARAE12 JNA 10-08-80 Massive, grey-green sandy mudstone $(20.8 \%)$ with grey-black-brown-white-green speckled patches, shell fragments, rare forams. Grades into a $5 \mathrm{~cm}$ pebbly, shelly sandstone. Immediately below the $\mathrm{Wo} / \mathrm{Tt}$ unconformity.

Forams - mounted slide.

MT04 W21/f42 W21/51986004 N135/39631415 JAA436 MARAE11 JNA 10-08-80 Indurated massive, grey-green sandy mudstone (16.2\%), bioturbation (1mm) picked out by lighter material, some rounded pumiceous fragments up to $0.5 \mathrm{~cm}$, glass shards present, common rads, spicules present, rare forams. Youngest rad bearing sample in section.

Rads - TL slide, SEM stub. Forams - mounted slide.

MT05 W21/f41 W21/51996001 N135/39641412 JAA435 MARAE10 JNA 10-08-80 Indurated, massive, grey-green sandy mudstone (19.4\%), some brown and black carbonaceous specks, shell fragments, common spicules, common rads, forams present.

Rads - SEM stub. Rads and forams - mounted slide.

MT06 W21/f40 W21/52006001 N135/39651411 JAA434 MARAE9 JNA 10-08-80 Indurated, massive, grey-green sandy mudstone (28.7\%), spicules present (etched), forams present (recrystallised), rads present, glass shards present.

Rads - SEM stub. Rads and forams - mounted slide.

MT07 W22/f51 W22/52035997 N135/39681407 JAA432 MARAE7 JNA 10-08-80 Massive, grey-green sandy mudstone (13.9\%), tuffaceous, spicules present, rads present, forams present.

Rads - TL slide, SEM stub. Forams - mounted slide.

MT08 W22/f50 W22/52045993 N135/39701403 JAA431 MARAE6 JNA 10-08-80 Indurated, massive, grey-green mudstone (11.9\%), black carbonaceous specks, common spicules, rads present, forams present, glass shards present.

Rads - TL slide, SEM stub. Forams - mounted slide.

MT09 W22/f49 W22/52055989 N135/39711399 JAA430 MARAE5 JNA 10-08-80 Indurated, massive, grey-green mudstone $(10.5 \%)$, glass shards present, some mollusca, common spicules, rads present, forams present.

Rads - TL slide, SEM stub. Forams - mounted slide.

MT10 W22/f48 W22/51925955 N135/39581361 JAA427 MARAE2 JNA 10-08-80

Massive, grey-green sandy mudstone (12.9\%), slight brown mottling in places, common spicules (etched), common forams, rads rare. Oldest rad bearing sample in section.

Rads - TL slide, SEM stub. Forams - mounted slide. 
MT11 W22/f47 W22/51835946 N135/39481351 JAA426 MARAE1 JNA 10-08-80

Massive grey-brown mottled sandy mudstone (16.2\%), brown carbonaceous specks, rare spicules, rare forams, weathering picks out indistinct $3-5 \mathrm{~cm}$ bedding.

Forams - mounted slide.

\section{B.12 KOURARAU-WESTMERE ROAD SECTION}

$\begin{array}{lllllll}\text { KW01 T27/f207 } & \text { T27/39660810 N162/21544457 JAA749 } & \text { KW1 JNA } 23-02-81\end{array}$

Massive, grey-green mudstone $(1.6 \%)$, scattered rare mollusca, micaceous, bioturbated (mm-scale), rads present, diatoms present, common forams, abundant spicules, glass shards present. Youngest rad bearing sample in section.

Rads and forams - mounted slide.

KW02 T27/f206 T27/39720808 N162/21604455 JAA750 KW2 JNA 23-02-81 Massive, grey-green mudstone (3.7\%), bioturbated (mm-scale), tuffaceous, abundant spicules, rare forams, rads rare.

Rads and forams - mounted slide.

$\begin{array}{lllllll}\text { KW03 T27/f205 } & \text { T27/39760807 N162/21654454 JAA751 KW3 JNA 23-02-81 }\end{array}$ Massive, grey-green sandy mudstone (13.3\%), black carbonaceous specks, common spicules (etched), common forams, diatoms present, shell fragments, bioturbated (mm-scale), abundant mollusca.

Rads and forams - mounted slide.

$\begin{array}{lllllll}\text { KW04 T27/f204 T27/39810806 N162/21704453 JAA752 } & \text { KW4 JNA } 23-02-81\end{array}$ Massive, grey-green mudstone $(10.1 \%)$, scattered rare mollusca, common spicules, sterrasters common, glauconitic, common forams, rads rare, diatoms present.

Rads and forams - mounted slide.

KW05 T27/f203 T27/39890798 N162/21794445 JAA753 KW5 JNA 23-02-81 Massive, grey-green mudstone (4.0\%), shell fragments, rads rare, abundant spicules (some etched), forams present, diatoms present. Oldest rad bearing sample in section.

Rads and forams - mounted slide.

\section{B.13 MORRISON'S SECTION}

$\begin{array}{lllllll}\text { MO01 S27/f488 S27/17680416 N161/97633958 JAA367 MOR6 JNA 05-04-80 } & \text { SA }\end{array}$ Massive, grey-green sandy mudstone $(39.2 \%)$, black carbonaceous specks in patches with oxidation halos up to $1 \mathrm{~cm}$, common forams, common spicules, rads present (some etched). Youngest rad bearing sample in section. $6 \mathrm{~m}$ below interbedded $20-60 \mathrm{~cm}$, grey-green, fine to medium sands and $10 \mathrm{~cm}$, commonly bioturbated, coarse calcarenites.

Rads and forams - mounted slide.

MO02 S27/f489 S27/17670415 N161/97623957 JAA368 $\quad$ MOR7 JNA 05-04-80 Massive grey-green-black mudstone (11.8\%), some black speckled burrows up to $2 \mathrm{~mm}$ in diameter, common rads, abundant forams, common spicules, carbonaceous fragments common. Rads - TL slide, SEM stub. Forams - mounted slide. 
MO03 S27/f490 S27/17670415 N161/97623957 JAA369 MOR8 JNA 05-04-80

Massive grey-green-brown mudstone (3.6\%), common forams, pyritised burrows, common rads, common spicules.

Rads - TL slide. Forams - mounted slide.

MO04 S27/f491 S27/17660414 N161/97613956 JAA370 MOR9A JNA 05-04-80 Massive, grey-green mudstone (8.9\%), abundant spicules, common forams, common rads, glass shards present.

Rads - SEM stub. Rads and forams - mounted slide.

MO05 S27/f492 S27/17660414 N161/97613956 JAA371 MOR9 JNA 05-04-80 Massive, grey-green mudstone $(5.8 \%)$, common forams, common rads, common spicules.

Rads - TL slide. Forams - mounted slide.

MO06 S27/f493 S27/17650413 N161/97603955 JAA372 MOR10 JNA 05-04-80 Massive grey-green-brown mudstone (10.2\%), with white speckled patches, abundant forams, abundant rads, abundant spicules. $0.5 \mathrm{~m}$ above a lensoidal (up to $4 \mathrm{~cm}$ thick), yellow stained, well sorted quartz sand.

Rads - TL slide, SEM stub. Forams - mounted slide.

M007 S27/f494 S27/17640411 N161/97593952 JAA374 MOR12 JNA $05-04-80$ Massive, light grey-brown mudstone $(5.2 \%)$, minor black carbonaceous specks, glauconitic, abundant forams, abundant rads, abundant spicules. $0.5 \mathrm{~m}$ below a lensoidal (up to $4 \mathrm{~cm}$ thick), yellow stained, well sorted quartz sand.

Rads - TL slide, SEM stub. Forams - mounted slide.

MO08 S27/f495 S27/17640411 N161/97593952 JAA375 MOR13 JNA 05-04-80 Massive, grey-brown mudstone (5.5\%), minor black carbonaceous specks, common spicules, common forams, common rads.

Rads - SEM stub. Rads and forams - mounted slide.

MO09 S27/f496 S27/17630410 N161/97583951 JAA376 MOR14 JNA 05-04-80 Massive, grey-green mudstone $(4.4 \%)$, white specks, common rads, common forams, common spicules.

Rads - SEM stub. Rads and forams - mounted slide.

$\begin{array}{lllllll}\text { MO10 S27/f497 S27/17630410 N161/97583951 JAA377 MOR15 JNA } & \text { 05-04-80 }\end{array}$ Massive, grey-green mudstone (3.6\%), black carbonaceous specks, abundant rads, spicules present, glass shards present, common forams. $35 \mathrm{~cm}$ above a horizon containing rounded pumice blocks up to $2 \mathrm{~cm}$ in diameter.

Rads - TL slide, SEM stub. Forams - mounted slide.

MO11 S27/f498 S27/17620409 N161/97573950 JAA378 MOR16 JNA 05-04-80 Massive, grey-green mudstone (3.0\%), abundant rads, common spicules, glass shards present, rare forams. $35 \mathrm{~cm}$ below a horizon containing rounded pumice blocks up to $2 \mathrm{~cm}$ in diameter.

Rads - TL slide. Forams - mounted slide. 
Massive, grey-green mudstone $(6.1 \%)$, black carbonaceous specks, common spicules, common rads, common forams.

Rads and forams - mounted slide.

$\begin{array}{lllllll}\text { MO13 S27/f500 S27/17610408 N161/97563949 JAA380 MOR18 JNA } & \text { 05-04-80 }\end{array}$ Massive, grey-green mudstone (3.6\%), black carbonaceous specks concentrated in burrows $7 \mathrm{~mm}$ across, abundant rads, glass shards present, common forams, common spicules, mollusca present.

Rads - TL slide, SEM stub. Forams - mounted slide.

M014 S27/f501 S27/17600407 N161/97553948 JAA381 MOR19 JNA 05-04-80 Massive green-grey-brown mudstone $(3.5 \%)$, abundant rads, glass shards present, common spicules, no forams. Oldest sample in section.

Rads - TL slide.

\section{B.14 RUAMAHANGA RIVER SECTION}

$\begin{array}{llllllll}\text { RM01 S27/f18 } & \text { S27/17840030 N161/97933537 JAA196 } & 18 & \text { PPV } & \text { 04-07-76 }\end{array}$ Massive, dark grey-green mottled sandy mudstone (26.1\%), abundant forams, rads rare, spicules present. Youngest rad bearing sample in section.

Rads - SEM stub. Forams - mounted slide.

$\begin{array}{llllllll}\text { RM02 S27/f17 } & \text { S27/17840032 N161/97933539 JAA195 } & 17 & \text { PPV } & \text { 04-07-76 }\end{array}$ Massive, grey-black speckled sandy mudstone $(33.8 \%)$, spicules present, rads present, forams present.

Rads - SEM stub. Rads and forams - mounted slide.

$\begin{array}{lllllll}\text { RM03 S27/f15 } & \text { S27/17850034 N161/97943541 } & \text { JAA194 } & 15 & \text { PPV } & \text { 04-07-76 }\end{array}$ Massive, grey-green sandy mudstone $(21.4 \%)$, black carbonaceous specks, abundant spicules, abundant forams, common rads.

Rads - TL slide, SEM stub. Forams - mounted slide.

$\begin{array}{llllllll}\text { RM04 } & \text { S27/f7 } & \text { S27/17860040 N161/97953548 } & \text { JAA193 } & 7 & \text { PPV } & \text { 04-07-76 }\end{array}$ Massive, grey-black speckled sandy mudstone (13.8\%), common rads, common forams, common spicules, diatoms present.

Rads - TL slide, SEM stub. Forams - mounted slide.

$\begin{array}{lllllll}\text { RM05 } & \text { S27/f4 } & \text { S27/17870042 N161/97963550 } & \text { JAA192 } & 4 & \text { PPV } & \text { 04-07-76 }\end{array}$ Massive, grey-green mudstone (9.9\%), abundant rads, glauconitic, common forams, abundant spicules, diatoms present.

Rads - TL slide, SEM stub. Forams - mounted slide.

$\begin{array}{llllllll}\text { RM06 } & \text { S27/f8 } & \text { S27/17870043 N161/97963551 } & \text { JAA191 } & 8 & \text { PPV } & \text { 04-07-76 }\end{array}$ Massive, grey-brown mudstone (6.3\%), minor black carbonaceous specks, diatoms present, abundant rads (etched), common spicules (some etched), common forams. Rads - TL slide, SEM stub. Forams - mounted slide. 
Massive, light grey-green mudstone (5.4\%), brown carbonaceous specks, common rads, abundant forams, common spicules, diatoms present. Oldest rad bearing sample in section. Rads - TL slide, SEM stub. Forams - mounted slide.

\section{B.15 HINAKURA-HIKA WERA SECTION}

HH01 S27/f9917 S27/270909 N166/082254 JAA456 HK17A PPV 11-11-69 Massive, grey-green mudstone (4.1\%), abundant spicules (etched), common forams, rads present. Youngest rad bearing sample in section.

Rads and forams - mounted slide.

HH02 S27/f565 S27/29238955 N166/10712397 JAA655 ABOVEHK JNA 30-09-80 Massive grey-green-brown mottled mudstone (3.5\%), bioturbation ( $\mathrm{mm}$-scale) picked out by tuffaceous material in burrows especially on weathered surfaces, tuffaceous, common spicules, forams very rare, rads present. Immediately above the Hikawera Tuff.

Rads - mounted slide.

\section{HH03 T27/f233 T27/31498730 N166/13252158 JAA759 HINK5 JNA 25-02-82} Indurated massive, grey-green mudstone (1.0\%), carbonaceous, rads rare, forams present. Forams - mounted slide.

HH04 T27/f8899 T27/319869 N166/137212 JAA481 HK26 PPV 11-11-69 Massive, grey-green mudstone $(1.1 \%)$, minor black carbonaceous specks up to $1 \mathrm{~mm}$ with $0.5 \mathrm{~mm}$ oxidation halos, tephric burrows $(0.5 \mathrm{~mm})$, abundant forams (recrystallised), rads present (recrystallised), rare spicules (etched). Oldest rad bearing sample in section. Associated tuffs in the outcrop.

Rads and forams - mounted slide.

\section{B.16 WHAKAPUNI TRIBUTARY SECTION}

WT01 S27/f570 S27/20498595 N166/01271976 JAA561 TWHAK8 JNA 23-02-81 Massive, grey-green mudstone (5.3\%), black carbonaceous specks, white tephric burrows $(1 \mathrm{~mm})$, abundant forams, glass shards present, glauconitic, small mollusca up to $3 \mathrm{~mm}$. $2 \mathrm{~m}$ above a tuff (G105).

Forams - mounted slide.

WT02 S27/f569 S27/20668589 N166/01461970 JAA557 TWHAK4 JNA 23-02-81 Massive, grey-green mudstone $(1.7 \%)$, brown and black carbonaceous specks, bifurcating thin black bands throughout the sample, glass shards present, pyritic, forams present (pyritic infillings), spicules present (etched), sterrasters common, rads present (etched). Youngest rad bearing sample in section.

Rads - mounted slide.

WT03 S27/f568 S27/20568585 N166/01351966 JAA559 TWHAK6 JNA 23-02-81 Massive grey-green-brown mudstone (3.8\%), black carbonaceous specks with oxidation halos up to $4 \mathrm{~mm}$, common forams, common rads, abundant spicules (etched), sterrasters common. $2 \mathrm{~m}$ above a tuff (G104).

Rads - TL slide, SEM stub. Forams - mounted slide. 
Light grey-brown massive mudstone (2.4\%), mottled yellow in places, tiny black carbonaceous specks with $2 \mathrm{~mm}$ oxidation halos, a couple of thin black bands in sample, forams present, rads present, common spicules (etched). Between two tuffs (G100 and G101).

Rads and forams - mounted slide.

WT05 S27/f566 S27/20778559 N166/01661925 JAA562 TWHAK10 JNA 23-02-81 Light grey-brown massive mudstone (3.1\%), brown carbonaceous specks, common forams, common rads (recrystallised), rare spicules (etched). Oldest sample in section.

Rads - TL slide, SEM stub. Forams - mounted slide.

\section{B.17 UPPER MANGAOPARI STREAM SECTION}

$\begin{array}{lllllll}\text { MS01 S27/f502 } & \text { S27/18018221 N165/98681560 JAA326 MANG36 JNA } & \text { 06-04-80 }\end{array}$ Massive, grey-green mudstone (6.7\%), black carbonaceous specks, common forams, common spicules (etched), no shards, no rads, rare mollusca.

Forams - mounted slide.

$\begin{array}{lllllll}\text { MS02 S27/f503 S27/18038217 N165/98701555 JAA327 MANG33 JNA 06-04-80 } & \text { S27 }\end{array}$ Massive, grey-green mudstone (7.1\%), burrows with admixed tephra and mud up to $8 \mathrm{~mm}$, forams present, common spicules, large pumiceous shards up to $3 \mathrm{~mm}$, common rads (poor preservation). Youngest rad bearing sample in section. Between two tuffs (G113 and G111).

Rads - SEM stub. Rads and forams - mounted slide.

MS03 S27/f504 S27/18038217 N165/98701555 JAA331 MANG31 JNA 06-04-80 Massive, grey-green mudstone (2.9\%), black carbonaceous specks, diatoms present, forams present, abundant spicules, glass shards present, abundant rads. $1 \mathrm{~m}$ below a tuff (G111).

Rads - TL slide, SEM stub. Forams - mounted slide.

$\begin{array}{lllllll}\text { MS04 S27/f505 } & \text { S27/18058209 N165/97731547 JAA335 } & \text { MANG27 JNA } & \text { 06-04-80 }\end{array}$ Massive, grey-green mudstone (3.2\%), white tuffaceous burrows (1mm), common forams, common spicules, glass shards present, common rads, diatoms present.

Rads - TL slide, SEM stub. Forams - mounted slide.

MS05 S27/f506 S27/18108205 N165/98781543 JAA336 MANG26 JNA 06-04-80 Massive, grey-green mudstone ( $3.0 \%$ ), black carbonaceous specks up to $1 \mathrm{~mm}$ with $2 \mathrm{~mm}$ oxidation halos, common forams, spicules present, glass shards present, common rads. Rads - TL slide, SEM stub. Forams - mounted slide.

$\begin{array}{lllllll}\text { MS06 S27/f507 S27/18138200 N165/98821537 JAA337 MANG25 JNA } & \text { 06-04-80 }\end{array}$ Massive, grey-green mudstone $(2.2 \%)$, black carbonaceous specks, diatoms present, common forams, spicules present (slightly etched), rads present.

Rads - TL slide, SEM stub. Forams - mounted slide. 
MS07 S27/f508 S27/18198198 N165/98881535 JAA338 MANG24 JNA 06-04-80 Massive, light grey-green mudstone (3.4\%), some black carbonaceous specks concentrated in patches $5 \mathrm{~mm}$ across, abundant spicules, forams present, glass shards present, abundant rads. Rads - TL slide. Forams - mounted slide.

$\begin{array}{lllllll}\text { MS08 } & \text { S27/f509 } & \text { S27/18238190 N165/98931527 JAA339 } & \text { MANG23 JNA } & \text { 06-04-80 }\end{array}$ Massive, grey-green mudstone (2.3\%), black carbonaceous fragments up to $10 \mathrm{~mm}$ long, common forams, common spicules, common rads.

Rads - TL slide. Forams - mounted slide.

MS09 S27/f510 S27/18318188 N165/99021525 JAA340 MANG22 JNA 06-04-80 Massive, grey-green mudstone $(1.8 \%)$, some brown mottling, abundant forams, common rads, common spicules.

Rads - TL slide, SEM stub. Forams - mounted slide.

MS10 S27/f511 S27/18388184 N165/99091520 JAA341 MANG21 JNA 06-04-80 Massive, grey-green mudstone $(1.7 \%)$, black carbonaceous fragments up to $8 \mathrm{~mm}$ long, white tuffaceous burrows $(1 \mathrm{~mm})$, abundant forams, glass shards present, common spicules, rads present (minor dissolution). $2 \mathrm{~m}$ above a thin lensoidal tuff.

Rads - TL slide. Forams - mounted slide.

MS11 S27/f512 S27/18388184 N165/99091520 JAA343 MANG19 JNA 06-04-80 Massive, grey-green mudstone $(1.7 \%)$, black carbonaceous specks, pyritic burrows, common forams, common spicules, common rads, glass shards present.

Rads - TL slide. Forams - mounted slide.

MS12 S27/f513 S27/18448183 N165/99161520 JAA344 MANG18 JNA 06-04-80 Massive, grey-green mudstone $(4.6 \%)$, black carbonaceous specks, abundant forams, abundant rads, abundant spicules.

Rads - TL slide, SEM stub. Forams - mounted slide.

MS13 S27/f514 S27/18468175 N165/99181511 JAA345 MANG17 JNA 06-04-80 Massive, grey-green mudstone $(2.1 \%)$, abundant forams, abundant spicules, abundant rads. $1 \mathrm{~m}$ above a tuff (G109).

Rads - TL slide. Forams - mounted slide.

MS14 S27/f515 S27/18518173 N165/99241509 JAA346 MANG16 JNA 06-04-80 Massive, grey-green mudstone (2.2\%), black carbonaceous specks, 3-4mm burrows with white tuffaceous material and thin dark oxidation halos, abundant forams, abundant spicules, abundant rads. $1 \mathrm{~m}$ above a tuff (G108).

Rads - TL slide. Forams - mounted slide.

MS15 S27/f516 S27/18518173 N165/99241509 JAA348 MANG14 JNA 06-04-80 Massive, grey-green mudstone (2.2\%), black carbonaceous specks, abundant forams, abundant rads, abundant spicules, glass shards present. Between two tuffs (G108 and G107).

Rads - TL slide, SEM stub. Forams - mounted slide. 
$\begin{array}{lllllll}\text { MS16 S27/f517 S27/18518167 N165/99241502 JAA352 MANG13 JNA 06-04-80 } & \text { J }\end{array}$ Massive, grey-green mudstone $(1.8 \%)$, black carbonaceous specks, thin carbonaceous fragments up to $7 \mathrm{~mm}$ long, common rads, common forams, abundant spicules, glass shards present. $1 \mathrm{~m}$ below a tuff (G107).

Rads - TL slide, SEM stub. Forams - mounted slide.

MS17 S27/f518 S27/18558164 N165/99291499 JAA353 MANG9 JNA 06-04-80 Massive, grey-green mudstone $(1.8 \%$ ), abundant forams, common spicules, rads rare (etched). Forams - mounted slide.

MS18 S27/f519 S27/18608164 N165/99341499 JAA354 MANG8 JNA 06-04-80 Massive, grey-green mudstone (1.6\%) mottled brown-yellow in patches, black carbonaceous specks up to $3 \mathrm{~mm}$ long, common rads (etched), common forams, common spicules.

Rads - TL slide, SEM stub. Forams - mounted slide.

MS19 S27/f520 S27/18648159 N165/99391494 JAA355 MANG7 JNA 06-04-80 Massive, light grey-green mudstone (3.4\%), brown and black carbonaceous specks, spicules present, forams present, rads present. Oldest rad bearing sample in section.

Rads - TL slide, SEM stub. Forams - mounted slide.

$\begin{array}{llllll}\text { MS20 S27/f521 S27/18728161 N165/99471496 JAA356 MANG6 JNA 06-04-80 } & \text { S }\end{array}$ Massive, grey-green mudstone (3.1\%), black carbonaceous specks, brown oxidation patches up to $2 \mathrm{~mm}$, common forams, spicules present, no rads.

Forams - mounted slide.

\section{B.18 PALLISER BAY SECTION}

PB01 S28/f75 S28/94037383 N165/72590572 JAA155 PB1 $\quad$ JNA $10-05-79$ Massive, grey-green mudstone $(9.2 \%)$, common forams, no rads.

Forams - mounted slide.

$\begin{array}{lllllll}\text { PB02 S28/f76 S28/94107377 N165/72670565 JAA156 } & \text { PB2 } & \text { JNA } & \text { 10-05-79 }\end{array}$ Massive, grey-green mudstone $(2.1 \%)$, black carbonaceous specks up to $0.5 \mathrm{~mm}$, abundant forams, abundant spicules, glass shards present. Youngest sample in rad horizon.

Rads - TL slide, SEM stub. Forams - mounted slide.

PB03 S28/f77 S28/94167371 N165/72730560 JAA157 $\quad$ PB3 $\quad$ JNA 10-05-79 Massive, grey-green mudstone $(2.9 \%)$, abundant forams common spicules, glass shards present. Rads - SEM stub. Forams - mounted slide.

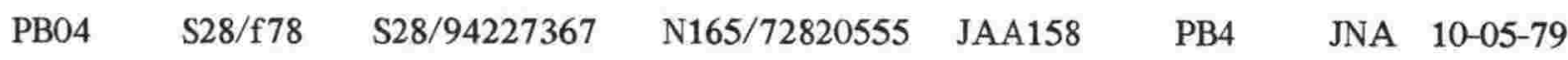
Massive, grey-green mudstone $(2.2 \%)$, black carbonaceous specks, common forams, spicules present, glass shards present.

Rads - TL slide, SEM stub. Forams - mounted slide.

PB05 S28/f79 S28/94257362 N165/72860550 JAA159 PB5 JNA 10-05-79 Massive, grey-green mudstone $(2.7 \%)$, black carbonaceous specks, abundant forams, common spicules, glass shards present.

Rads - TL slide, SEM stub. Forams - mounted slide. 
Massive, grey-green mudstone $(2.2 \%)$, black carbonaceous specks, abundant forams, abundant spicules, glass shards present.

Rads - TL slide, SEM stub. Forams - mounted slide.

PB07 S28/f81 S28/94317357 N165/72930545 JAA161 PB7A JNA 10-05-79 Massive, light grey-green mudstone (2.2\%), abundant forams, abundant spicules, glass shards present. $3 \mathrm{~m}$ above base of tuff dated at $7.27 \pm 1.28 \mathrm{Ma}$ (D. Seward, pers. comm.).

Rads - SEM stub. Forams - mounted slide.

PB08 S28/f82 S28/94317357 N165/72930545 JAA164 PB7D JNA 10-05-79

Massive, light grey-green mudstone (2.2\%), abundant forams, abundant spicules, glass shards present. $10 \mathrm{~cm}$ below base of dated tuff.

Rads - SEM stub. Forams - mounted slide.

PB09 S28/f115 S28/94317357 N165/72930545 JAA165 PB7E JNA 10-05-79

Massive, grey-green mudstone $(2.1 \%)$, abundant forams, diatoms present, black carbonaceous specks some with oxidation halos up to $5 \mathrm{~mm}$, spicules present, glass shards present. $1 \mathrm{~m}$ below base of dated tuff.

Rads - TL slide.

PB10 S28/f83 S28/94317357 N165/72930545 JAA166 PB7F JNA 10-05-79 Massive, grey-green mudstone (4.2)\%, brown carbonaceous specks, some tuffaceous burrows up to $5 \mathrm{~mm}$ diameter and $2 \mathrm{~cm}$ long, common forams, common spicules. $3 \mathrm{~m}$ below base of dated tuff.

Rads - SEM stub. Forams - mounted slide.

$\begin{array}{lllllll}\text { PB11 S28/f84 } & \text { S28/94457347 N165/73110536 JAA167 } & \text { PB8 } & \text { JNA } & \text { 10-05-79 }\end{array}$

Massive, grey-green mudstone (5.5\%), black carbonaceous specks, tuffaceous, common forams, common spicules. Oldest rad bearing sample in the section.

Rads - TL slide, SEM stub. Forams - mounted slide.

\section{B.19 LEADER RIVER TRIBUTARY SECTION}

LT01 O32/f67 032/31645006 S55/58377354 JAA508 LEAD9 JNA 04-01-81 Massive, grey-green mudstone (11.6\%), micaceous, forams present, rads present, common spicules. Youngest rad bearing sample in section.

Rads - TL slide, SEM stub. Forams - mounted slide.

LT02 O32/f68 O32/31694997 S55/58437344 JAA507 LEAD10 JNA 04-01-81 Massive, grey-green sandy mudstone (14.3\%), minor brown carbonaceous specks, glass shards present, common diatoms, rads rare (etched), rare forams, common spicules.

Forams - mounted slide.

LT03 O32/f69 032/31794992 S55/58547338 JAA506 LEAD11 JNA 04-01-81 Massive, grey-green sandy mudstone (32.3\%), rare forams, rads present (etched), glass shards present, common spicules, diatoms present.

Rads - SEM stub. Rads and forams - mounted slide. 
LT04 O32/f70 O32/31834992 S55/58587338 JAA505 LEAD12 JNA 04-01-81 Massive, grey-green sandy mudstone (18.5\%), thin carbonaceous fragments, forams present, rare spicules.

Forams - mounted slide.

LT05 O32/f71 O32/31864991 S55/58617337 JAA504 LEAD13 JNA 04-01-81 Massive, light grey-green mudstone $(7.1 \%)$, brown carbonaceous specks, tuffaceous, common forams (iron stained), common rads, common spicules.

Rads - TL slide, SEM stub. Forams - mounted slide.

$\begin{array}{lllllll}\text { LT06 } & \text { O32/f72 } & \text { O32/31904990 } & \text { S55/58657336 JAA503 } & \text { LEAD14 JNA } & \text { 04-01-81 }\end{array}$ Massive, light grey-green mudstone $(9.3 \%)$, glass shards present, common forams, common rads, common spicules.

Rads - TL slide, SEM stub. Forams - mounted slide.

LT07 O32/f73 O32/31914990 S55/58677336 JAA502 LEAD3 JNA 04-01-81 Massive, light grey-green mudstone $(10.8 \%)$, some oxidation halos up to $3 \mathrm{~mm}$, glass shards present, forams present, rads rare, common spicules. $3 \mathrm{~m}$ above a tuff (G20).

Rads - SEM stub. Rads and forams - mounted slide.

$\begin{array}{lllllll}\text { LT08 O32/f74 O32/31914990 S55/58677336 JAA501 LEAD2 JNA 04-01-81 } & \text { O }\end{array}$ Massive, light grey-green sandy mudstone (19.4\%), rare black carbonaceous specks, glass shards present, abundant forams, abundant spicules, common rads. Immediately below a tuff (G20).

Rads - TL slide, SEM stub. Forams - mounted slide.

LT09 O32/f75 O32/31914990 S55/58677336 JAA500 LEAD1 JNA 04-01-81 Massive, grey-green mudstone $(9.4 \%)$, carbonaceous streaks with oxidation halos, abundant forams, common spicules, common rads. $2 \mathrm{~m}$ below a $1.8 \mathrm{~m}$ thick tuff (G20). Oldest rad bearing sample in section.

Rads - TL slide, SEM stub. Forams - mounted slide.

\section{B.20 WAIMATA VALLEY SITE}

SWM1 Y17/f29 Y17/487830 N98/416516 JAA796 WAIM1 GJG 10-02-82 Indurated, massive, grey-green mudstone $(4.0 \%)$, white speckled patches $(1-2 \mathrm{~cm})$, some mollusca, common forams, common spicules, rads present, sterrasters common. $0.5 \mathrm{~m}$ above a $2-3 \mathrm{~cm}$ tuff.

Rads - TL slide. Forams - mounted slide.

\section{B.21 CAVES ROAD SITE}

$\begin{array}{lllllll}\text { SCV1 } & \text { Y18/f169 } 189 / 497739 & \text { N98/430417 JAA824 } & \text { C7 } & \text { GHS } & 18-02-82\end{array}$ Massive, grey-green mudstone $(3.8 \%)$, common spicules, common rads, forams present (recrystallised), glass shards present.

Rads - TL slide, SEM stub. Forams - mounted slide. 


\section{B.22}

WAIROA - NUHAKA ROAD SITES

$\begin{array}{lllllll}\text { SWN1 X19/f73 } & \mathrm{X} 19 / 030311 & \mathrm{~N} 116 / 932934 & \text { JAA448 } & \text { K8 } & \text { JNA } & 11-08-80\end{array}$

Massive, grey-green mudstone $(2.7 \%)$, iron-stained along joints, glass shards present, common spicules, abundant forams, rads present, diatoms present. $0.5 \mathrm{~m}$ above a $2-4 \mathrm{~cm}$ tuff.

Rads and forams - mounted slide.

SWN2 X19/f72 X19/037309 N116/940932 JAA446 K6 JNA 11-08-80

Massive, grey-green mudstone $(2.8 \%)$, minor black carbonaceous specks, abundant forams, glass shards present, common spicules, diatoms present, rads present. $0.2 \mathrm{~m}$ below a $1-10 \mathrm{~cm}$ tuff.

Rads - SEM stub. Rads and forams - mounted slide.

SWN3 X19/f71 X19/048304 N116/952927 JAA654 K5 JNA 11-08-80

Massive, grey-green mudstone $(5.6 \%)$, common forams, common rads, spicules present, diatoms present, carbonaceous.

Rads - SEM stub. Rads and forams - mounted slide.

\section{B.23 MAHIA PENINSULA SITE}

$\begin{array}{llllllll}\text { SMH1 } 1 & \text { Y19/f27 } & \text { Y19/307238 N116/237862 } & \text { JAA270 } & 2 & \text { NBH } & \text { 03-02-80 }\end{array}$

Massive, grey-green mudstone (3.0\%), tuffaceous, abundant rads, abundant forams, common spicules. $3.0 \mathrm{~m}$ below a tuff dated at $6.39 \pm 1.14 \mathrm{Ma}$ (D. Seward, pers. comm.).

Rads - TL slide. Forams - mounted slide.

\section{B.24 WAINUIORU VALLEY SITES}

$\begin{array}{lllllll}\text { SWR1 T26/f167 T26/48091639 N162/30495390 JAA811 } & 147 \quad \text { MPC 29-10-81 }\end{array}$

Massive, grey-green mudstone $(0.7 \%)$, black carbonaceous specks, pyritic, common rads, abundant forams, common spicules.

Rads - TL slide. Forams - mounted slide.

$\begin{array}{lllllll}\text { SWR2 T26/f168 T26/47851662 N162/30225414 JAA812 } & 148 \quad \text { MPC 29-10-81 }\end{array}$

Massive, grey-green mudstone $(0.8 \%)$, black carbonaceous specks, micaceous, glauconitic, tuffaceous, abundant forams, diatoms present, spicules present, rads present.

Rads - TL slide. Forams - mounted slide.

$\begin{array}{lllllll}\text { SWR3 T26/f132 T26/43841133 N162/26004823 JAA809 } & 112 \quad \text { MPC } & \text { 18-09-81 }\end{array}$

Massive, grey-green mudstone $(0.5 \%)$, black carbonaceous specks, pyritic, abundant forams, abundant rads (some etched), common spicules. $1.3 \mathrm{~m}$ below the base of a tuff.

Rads - TL slide. Forams - mounted slide.

$\begin{array}{lllllll}\text { SWR4 T26/f142 } & \text { T26/45501267 N162/27784975 JAA810 } & 122 & \text { MPC } & \text { 22-09-81 }\end{array}$ Massive, grey-green mudstone $(2.1 \%)$, glauconitic, rare ostracods, abundant forams, common spicules (some etched), common rads.

Rads - TL slide, SEM stub. Forams - mounted slide. 
$\begin{array}{lllllll}\text { SWR5 T26/f230 T26/479147 N162/304521 JAA302 } & \text { STRON20 JNA } & \text { 06-04-80 }\end{array}$ Massive, grey-green mudstone (3.9\%), minor brown carbonaceous specks, common forams, rads rare (etched), carbonaceous. $3.5 \mathrm{~m}$ above the Brancepeth Tuff. Top of a graded bed in a sequence of slightly graded beds (1-2m thick).

Rads and forams - mounted slide.

\section{B.25 MILLERS ROAD SITES}

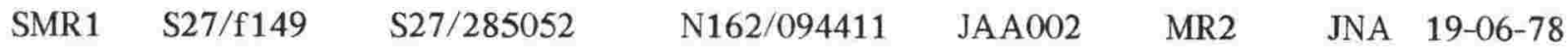

Massive, grey-green mudstone $(0.6 \%)$, common spicules, common forams, rads present.

Rads - TL slide, SEM stub. Forams - mounted slide.

$\begin{array}{lllllll}\text { SMR2 S27/f153 S27/285053 N162/094412 JAA006 } & \text { H1 } & \text { JNA } & \text { 09-05-78 }\end{array}$

Massive, grey-brown-yellow mottled mudstone $(0.7 \%)$, common rads, spicules present, no forams.

Rads - SEM stub.

\section{B.26 MANGAOPARI-WHAKAPUNI AREA SITES}

SMA1 S27/f557 S27/188850 N165/995187 JAA761 $\quad$ FT1 JNA 26-02-82 Indurated, massive, grey-brown mudstone $(7.6 \%)$, bioturbated (mm-scale), tuffaceous, common forams, common spicules, common rads. $50 \mathrm{~cm}$ above a thin tuff.

Rads - TL slide, SEM stub. Forams - mounted slide.

SMA2 S27/f558 S27/187854 N165/993191 JAA762 FT2 JNA 26-02-82

Massive, grey-green mudstone (5.8\%), abundant rads, glass shards present (some etched), abundant forams, abundant spicules. Occasional thin layers of glauconitic sandstone. $1 \mathrm{~m}$ below a tuff.

Rads - SEM stub. Rads and forams - mounted slide.

$\begin{array}{lllllll}\text { SMA3 S27/f196 S27/200849 N166/008186 JAA078 MF9 MEF 10-03-79 } & \text { S }\end{array}$ Massive, grey-green mudstone (5.9\%), common forams, common rads.

Rads - TL slide, SEM stub. Forams - mounted slide.

$\begin{array}{lllllll}\text { SMA4 S27/f98 S27/191838 N165/998174 JAA096 } & \text { 3/16 } & \text { DAH } & \text { 11-03-78 }\end{array}$

Massive grey-brown mudstone $(2.3 \%)$, brown carbonaceous specks, pyritic, abundant rads.

Rads - TL slide, SEM stub.

$\begin{array}{llllllll}\text { SMA5 } & \text { S27/f111 } & \text { S27/174805 N165/981137 } & \text { JAA098 } & \text { X2 } & \text { JDC } & \text { 18-03-78 }\end{array}$

Massive, grey-green mudstone $(1.6 \%)$, black carbonaceous specks up to $2 \mathrm{~mm}$ with $5 \mathrm{~mm}$ oxidation halos, abundant forams, common spicules, rads present.

Rads - TL slide, SEM stub. Forams - mounted slide.

$\begin{array}{llllll}\text { SMA6 } & \text { S27/f112 } & \text { S27/175804 N165/982136 JAA099 } & \text { JDC } & \text { 18-03-78 }\end{array}$

Massive, grey-green mudstone $(4.3 \%)$, black carbonaceous specks up to $2 \mathrm{~mm}$ with $5 \mathrm{~mm}$ oxidation halos, rads present, spicules present, common forams.

Rads - TL slide. Forams - mounted slide. 


\section{B.27 NORTH OF LEADER SITE}

SPA1 O32/f79 O32/322505 S55/590740 JAA517 NLEAD2 GJG 04-01-81

Massive, grey-brown-yellow mottled sandy mudstone (15.5\%), black carbonaceous specks up to $2 \mathrm{~mm}$, tuffaceous, forams present, rads present, abundant spicules. Immediately below a tuff (G21).

Rads - TL slide. Forams - mounted slide. 
Appendix C

TECHNIQUES PAPER

The following paper entitled:

\section{Improvements in the technique for the extraction and statistical faunal analysis of radiolarians from Neogene mudstones.}

was published in Micropaleontology 29 (4) : 146-149 in 1983.

Parts of this paper have been reproduced within Chapter Two to enhance the readability of that chapter. 


\section{J. N. Ashby}

Department of Geology

Victoria University of Wellington

New Zealand

\section{Improvements in the technique for the extraction and statistical faunal analysis of radiolarians from Neogene mudstones}

\section{INTRODUCTION}

Upper Miocene and Pliocene tuffaceous mudstones that crop out east of the main axial ranges of the North Island, New Zealand contain, in places, abundant fossil Radiolaria. I have used previously described methods for washing and mounting specimens (e.g., Riedel and Sanfilippo, 1977), with additional procedures for preventing contamination, for concentration and for making mounts of randomly dispersed specimens.

\section{WET SIEVING}

Wet sieving over brass or stainless steel meshes is preferred by most laboratories. At Scripps Institute of Oceanography, the meshes are cleaned after each use by washing in strong jets of water and rubbing vigorously with a paper towel to break and dislodge skeletons. The sieves have to be repaired fairly often (Riedel, personal communication). Furthermore, the composition and open pore structure of many radiolarian skeletons renders ineffective the common staining techniques used to detect contamination, such as dipping the mesh in methylene blue.

Baker (1951) described a technique by which cloth (organdy and silk) sieves were used for separating microfossils from muddy matrix. The advantages are reduction of damage owing to the cushioning effect of the cloth, and the ease of cleaning fabrics.

The technique described in the present paper involves the use of monolen mesh held taut in a PVC frame. Monolen is a polyester and nylon combination resistant to $40 \%$ hydrofluoric acid. In order to avoid contamination, the mesh is immersed in $20 \%$ aqueous hydrofluoric acid after each preparation, dissolving attached siliceous skeletons, then neutralized in a sodium bicarbonate solution. Monolen is very durable.

\section{DENSITY SEPARATION USING ZINC BROMIIDE SOLUTION}

Residues of New Zealand Neogene mudstones almost always contain sand-sized inorganic mineral grains. In most cases the siliceous biogenic component is small, requiring concentration by density separation. As quantitative data on the radiolarians are required, the separate must be representative of the assemblage in the sample. Density separation, using a heavy liquid, is the usual method of concentration. Carbon tetrachloride has a maximum specific gravity of 1.6 at $20^{\circ} \mathrm{C}$, which is insufficient for good specific gravity separations. Solutions of bromoform (tribromoethane) adjusted to a density of 2.2 to 2.4 are suitable for separating foraminiferal specimens (Gibson and Walker, 1967). 
To concentrate radiolarian samples for quantitative analysis, flotation in aqueous solutions of zinc bromide has been found to be effective. Zinc bromide solution is commonly used in palynology, and Brady (1977) described its use for the flotation of diatom frustules. The maximum specific gravity obtainable at $18^{\circ} \mathrm{C}$ is 2.64 . Its advantages over bromoform is that it is miscible in water, relatively non-toxic and more viscous, allowing for slower and therefore more accurate separation. Zinc bromide solutions are made up using 10\% hydrochloric acid to prevent the precipitation of zinc hydroxide and discoloration of the solution by ferric ions from the residues. Hydrogen ions in the acid solutions transform ferric complexes into ferrous chloride, which is almost colorless (a slight yellow tinge may develop with use). The acid in the heavy liquid makes it unusable for foraminiferal flotation. The specific gravity of the zinc bromide solution is adjusted by evaporating or adding water.

A split for radiolarian analysis is washed in dilute hydrochloric acid, then rinsed and dried. A separating funnel is used in a way similar to that described by Hecht (1933) (text-fig. 1). The separating funnel is filled with zinc bromide solution (specific gravity 2.3 ) and the acid-washed residue sprinkled onto the surface of the liquid, using a slow-feed device similar to that described by Faul and Davis (1959). The residue must be fed slowly into the heavy liquid to prevent radiolarians from being pushed to the bottom of the separating funnel. After separation is complete, the stopcock is opened and the heavy fraction is allowed to run off into a sintered glass filter placed on top of a vacuum flask. The zinc bromide solution is then vacuumed into the flask. Next, the heavy fraction is washed off the sintered glass filter with a jet of water. The filter is rinsed in acetone and dried. The light fraction that contains most of the radiolarians is then allowed to run off onto the glass filter, and the zinc bromide solution is vacuumed into the flask as before. The use of the vacuum flask enables approximately $99 \%$ of the heavy liquid to be retained without change in its specific gravity. The sintered glass filter that contains most of the light fraction is then placed on a different vacuum flask, and the rest of the light fraction left clinging to the sides of the funnel is washed through onto the filter with water from a wash bottle. The filtrant is returned to the wash bottle, and the filtrate is washed into a beaker with a jet of water. Filter paper cannot be used with zinc bromide solutions because the paper fibers swell and burst. In any case, filter papers should not be used to collect radiolarian residues, as the specimens tend to stick to the paper (Burma, 1965). Contamination from the sintered glass filter is eliminated by scrubbing the filter with a stiff $1-\mathrm{cm}$ paintbrush and rinsing thoroughly after each sample treatment.

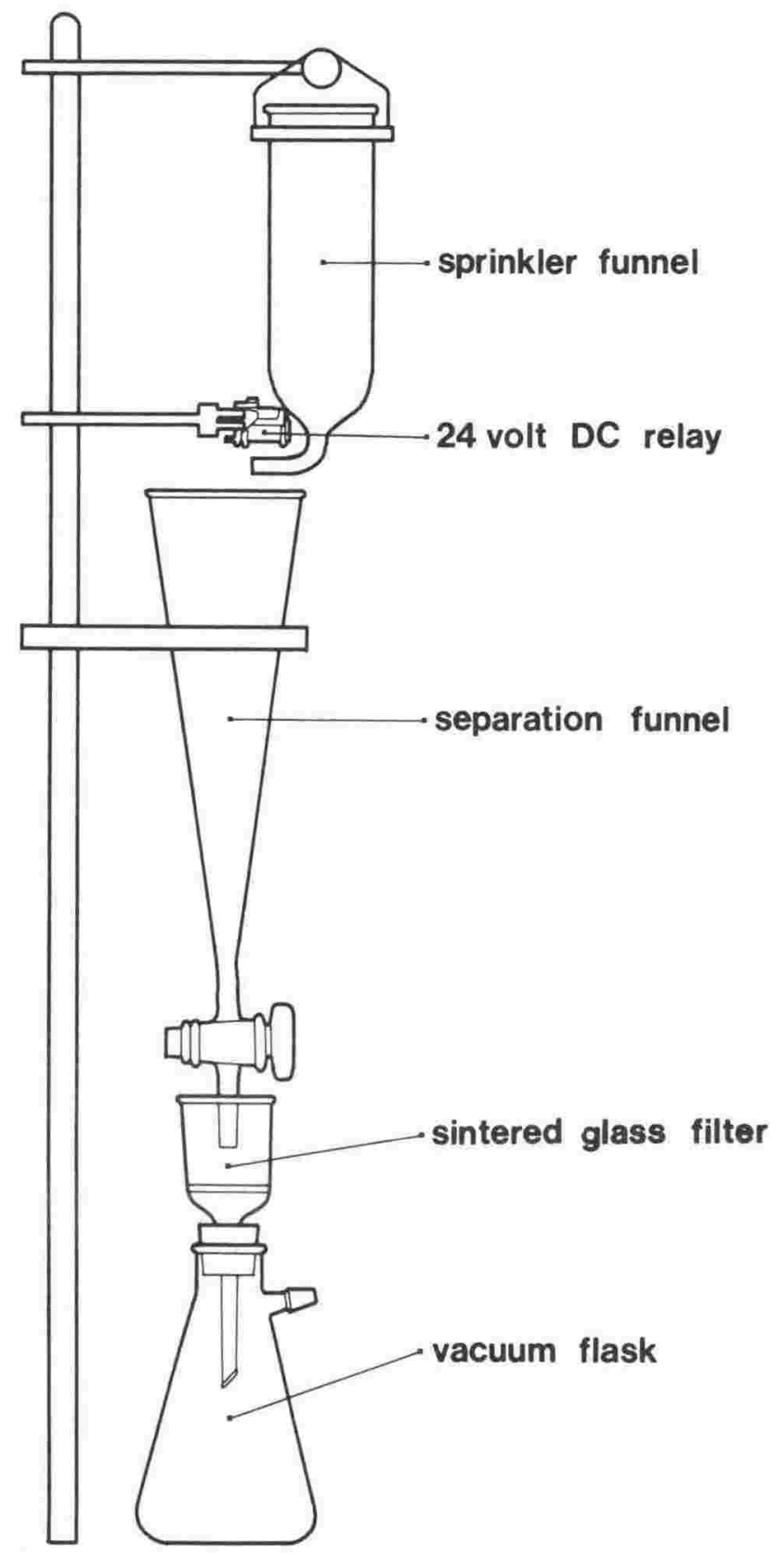

TEXT-FIGURE 1

Apparatus for heavy liquid separation.

\section{MOUNTING TECHNIQUE}

For quantitative work, the radiolarian residues are mounted in Caedex. The following method works equally well using Canada Balsam, but it is advisable to cook the balsam at a slightly lower temperature $\left(85-90^{\circ} \mathrm{C}\right)$ than normal $\left(100-110^{\circ} \mathrm{C}\right)$ and for a longer time. At the lower temperature the balsam remains slightly more fluid, making it easier to cover the slide without enclosing air bubbles. 


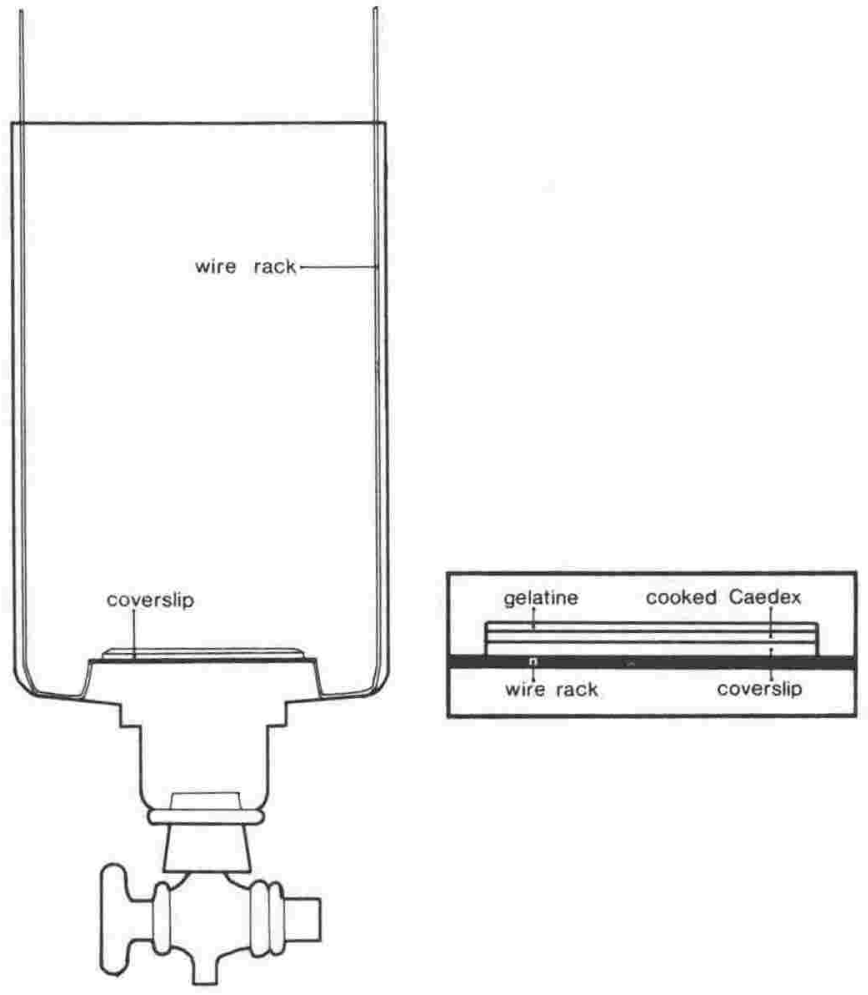

TEXT-FIGURE 2

Cross section of settling container, showing positioning of coverslip.

A common method is to pipette a drop of radiolarian skeletons in suspension in water onto a glass slide. However, the heavy skeletons sink to the bottom of the drop and remain at the center when the drop is placed on the slide, while delicate forms are carried to the sides. The distribution of skeletons on the slide cannot be randomized by stirring with a probe (Moore, 1973).

Radiolarian skeletons are too large for the spraying method of Mclntyre et al. (1967). Moore (1973) described a more reliable method of achieving a random distribution of species, by settling the radiolarian skeletons onto a microscope slide from a water suspension. Moore's technique is as follows. A gelatin-coated slide is placed at the bottom of a container filled with water. The residue is placed in the water, which is then stirred with a vertical motion. The radiolarians are allowed to settle. Then all but $1 \mathrm{~cm}$ of water is siphoned out of the container, and the rest is dried under an infra-red lamp. When the surface of the slide is dry (in about two hours), the coverslip can be mounted using the preferred medium.

My modifications to the formerly developed technique include the use of a coverslip instead of a glass slide at the bottom of the settling container, the added presence of a thin film of cooked Caedex between the gelatin and the coverslip, the use of a settling container with a stopcock at its base (text-fig. 2) and the use of a wire rack in the settling container.

The coverslip is prepared by smearing about five drops of a 1:10 Caedex to xylene mixture onto the coverslip and placing it on a hotplate. After the Caedex has been cooked and cooled, the surface is scored with fine emery paper, and a thin film of gelatin solution (10$20 \mathrm{mg}$ in $50 \mathrm{ml}$ of water) is brushed onto the Caedex. The gelatin solution is left to dry on the Caedex-coated coverslip, after which it is placed on the wire rack in the settling container. The container is then filled with water and the residue is added. The water is stirred with a vertical motion as recommended by Moore. After the specimens have settled onto the coverslip, the stopcock is opened and the container is emptied. No undue turbulence is created if the container is emptied slowly and the stopcock is closed to a drip as the falling water level reaches the surface of the coverslip, in order to avoid runoff carrying specimens off the slide. By releasing the water in this way specimens which have not sunk, owing to entrapment of air, are

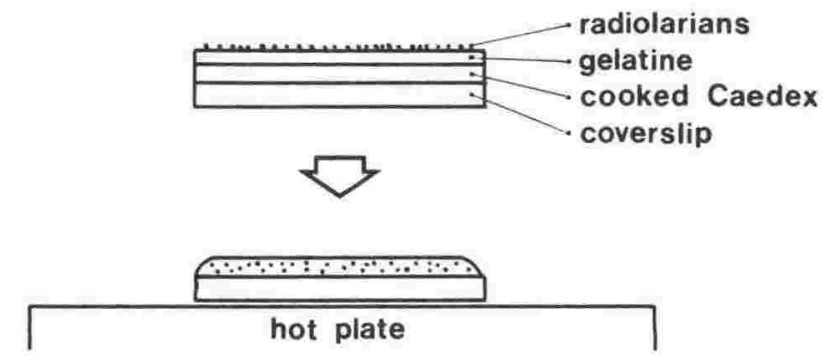

The coverslip is placed on a hotplate, melting the Caedex which embeds the radiolarians.

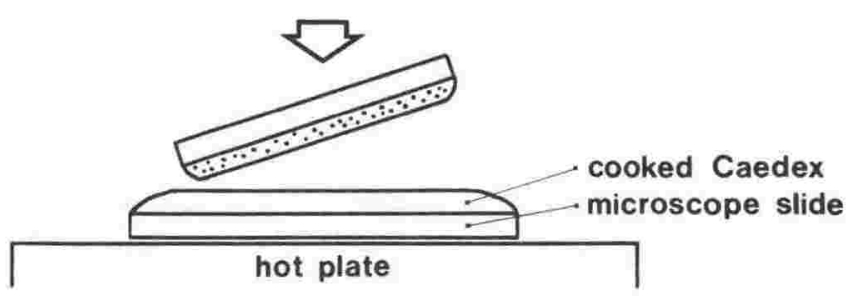

The coverslip is then inverted and lowered onto a Caedex coated microscope slide.

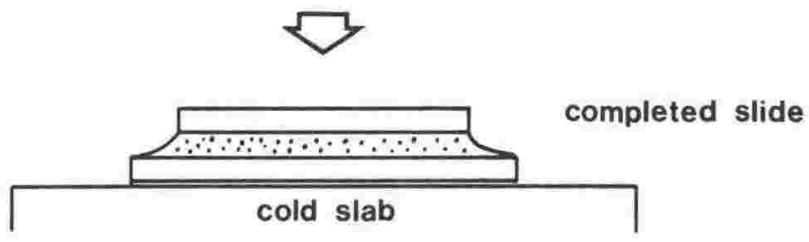

TEXT-FIGURE 3

Diagram showing four stages involved in mounting coverslip onto glass slide. 
deposited randomly on the coverslip. The wire rack is used to ease emplacement and removal of the coverslip from the bottom of the container.

After the water has been emptied from the container, the coverslip is removed and dried. The specimens are then glued to the gelatin. The coverslip is placed on a hot plate (text-fig. 3 ) and the skeletons drop into the melted Caedex. The coverslip can then be inverted without losing specimens. A slide is prepared with Caedex and the inverted coverslip lowered slowly onto it. Duplicate slides can be prepared either by splitting the radiolarian float or collecting and re-suspending the specimens that do not collect on the coverslip.

\section{ACKNOWLEDGMENTS}

Dr. N. deB. Hornibrook and Professor P. Vella reviewed the manuscript. The research was supported by DSIR Research Contract No. UV-6/28 and the Victoria University Internal Research Committee. Thanks are due to fellow students for their constructive criticism.

\section{REFERENCES}

BAKER, W. H. V., 1951. A simple technique for extracting microfossils. Micropaleontologist, 5(4):39-40.
BRADY, H. T., 1977. Extraction of diatoms from glacial sediments. Antarctic Jour. U.S., 12(4):123-124.

BURMA, B. H., 1965. Radiolarians. In: Kummel, B., and Raup, D., Eds., Handbook of paleontological techniques. San Francisco: W. H. Freeman, 7-14.

FAUL, H., and DAVIS, G. L., 1959. Mineral separation with asymmetric vibrators. Amer. Mineral., 44(10): 1076-1082.

GIBSON, T. G., and WALKER, W. M., 1967. Flotation methods for obtaining foraminifera from sediment samples. Jour. Pal., 41(5): 1294-1297.

HECHT, F., 1933. Arbeitsweisen der Mikropaläontologie. Senckenbergiana, 15(6):346-362.

MCINTYRE, A., BE, A. W. H., and PREIKSTAS, R., 1967. Coccoliths and the Pliocene-Pleistocene boundary. In: Sears, M., Ed., The Quaternary history of the ocean basins (Progress in oceanography, Vol. 4). New York: Pergamon Press, 3-25.

MOORE, T. C., 1973. Method of randomly distributing grains for microscopic examination. Jour. Sediment. Petrol., 43(3):904-906.

RIEDEL, W. R., and SANFILIPPO, A., 1977. Cainozoic Radiolaria. In: Ramsay, A. T. S., Ed., Oceanic micropaleontology. London; Academic Press, 847-912.

Manuscript received January 22, 1982.

Revised manuscript accepted October 20, 1982. 


\section{Appendix D \\ PRESENCE AND ABSENCE DATA}

This appendix tabulates the presence or absence of radiolarian species and varieties in the samples studied. Absence is indicated by a '. ' and presence is indicated in two categories. A closed square ' $\square$ ' indicates positive occurrence and an open square ' $\square$ ' tentative occurrence in that the identification may be based on a fragment or on badly corroded or recrystallised specimens.

The samples are arranged with sections and sites in north to south geographical order :

$\begin{array}{ll}\text { A73 - A79 } & \text { East Cape, Waimata, Caves, Kaiti, Hangaroa } \\ \text { A80 - A86 } & \text { Ruakituri, Mangapoike, Mahia } \\ \text { A87 - A93 } & \text { Waiatai } \\ \text { A94 - A100 } & \text { Wairoa-Nuhaka, Tahaenui, Waihua, Cricklewood } \\ \text { A101 - A107 } & \text { Maraetotara, Wainuioru, Kourarau-Westmere } \\ \text { A108 - A114 } & \text { Millers, Morrisons, Hinakura-Hikawera } \\ \text { A115 - A121 } & \text { Ruamahanga, Whakapuni, Mangaopari sites } \\ \text { A122 - A128 } & \text { Upper Mangaopari } \\ \text { A129 - A135 } & \text { Palliser, north Leader, Leader }\end{array}$


Suborder SPUMELLARIA

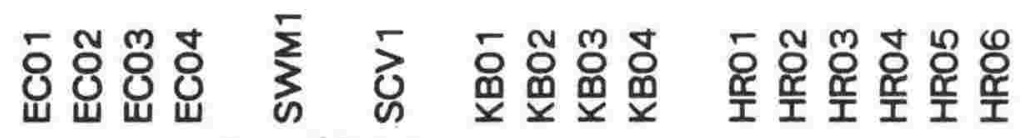

Family OROSPHAERIDAE

Genus OROPELEX

? Oropelex sp.

Family COLLOSPHAERIDAE

Genus COLLOSPHAERA

C. cf. polygona

C. sp. aff. huxleyi

Collosphaera sp. A

Genus ACROSPHAERA
A. spinosa echinoides
A. spinosa spinosa

Genus SIPHONOSPHAERA

$S$. polysiphonia

Genus OTOSPHAERA

O. polymor pha

Family ACTINOMMIDAE

Genus ACTINOMMA
A. antarcticum
A. cf. medianum
A. leptodermum
A. cf. leptodermum
A. polycanthum group

Genus CLADOCOCCUS

C. dentata

C. stalactites

\section{Genus CENOSPHAERA}

C. cristata

Cenosphaera sp. A

Cenosphaera sp. B

Cenosphaera sp. C

Cenosphaera sp. D

Genus ACANT HOSPHAERA

A. dodecastyla

A. sp. A : few spines

A. sp. A : many spines

Acanthos phaera sp. B

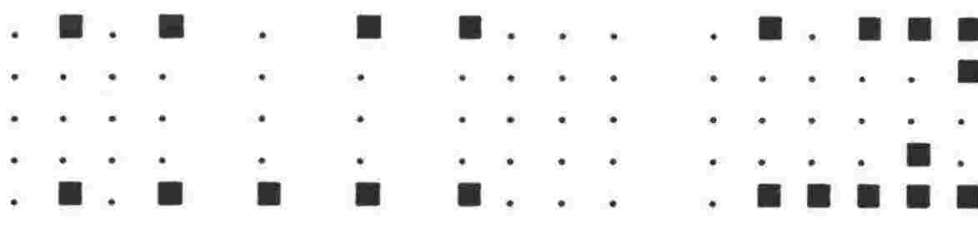


Genus HEXACONTIUM

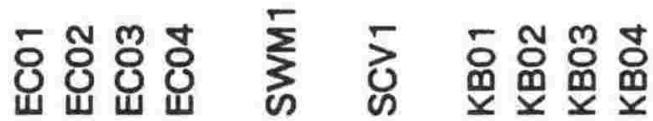

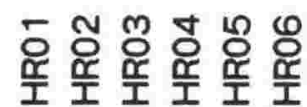

$H$. enthacanthum sensu stricto

$H$. enthacanthum : oval form

$H$. enthacanthum : quadrate form

$H$. enthacanthum X laevigatum

$H$. laevigatum sensu stricto

$H$. laevigatum : oval form

$H$. laevigatum : quadrate form

$H$. laevigatum : long spined

Genus THECOSPHAERA

$T$. cf. akitaensis

T. grecoi group

Genus PRUNULUM

Prunulum spp.

Genus STYPTOSPHAERA

S. stupacea

S. spumacea

Genus 'STYLATRACTUS'

' $S$ '. neptunus forma. large pores

'S. universus : small pores

'S'. universus : large pores

Genus 'SPHAEROSTYLUS'

'S. sp. aff. timmsi : sensu Campbell

'S'. sp. aff. timmsi : symmetrical

Genus ' $X I P H A T R A C T U S$ '

'Xiphatractus' sp. A

Genus PRUNOPYLE

? $P$. antarctica

Prunopyle sp. A

Genus SPONGURUS

$S$. pylomaticus

Spongurus sp. A

Genus SPONGOCORE

$S$. puella

Spongacore sp. A

Family PHACODISCIDAE

Genus HELIODISCUS

$H$. asteriscus : large pores

$H$. asteriscus : small pores

$H$. asteriscus : long spines

$H$. cf. echiniscus

$H$. umbonatum

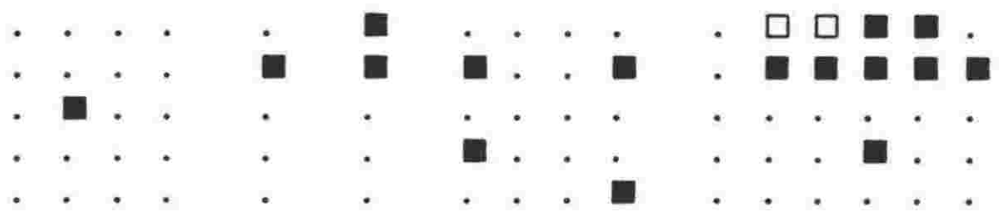


Family COCCODISCIDAE

\section{Genus DIDYMOCYRTIS}

D. antepenultima

D. antepenultima $\mathrm{X}$ laticonus

D. laticonus

D. virgineum : non-constricted

D. virgineum : constricted

D. virgineum : tuberculate

D. sp. A : non-constricted

D. sp. A : constricted

D. sp. A : spherical

D. sp. A : narrow

D. tetrathalmus tetrathalmus

Genus DIARTUS

$D$. hughesi group

Family SPONGODISCIDAE

Genus AMPHIRHOPALUM

A. cf. ypsilon

Genus DICTYOCORYNE

D. profunda

Genus HYMENIAST RUM $H$. euclidis

Genus SPONGASTER

$S$. pentas

Genus STYLODICTYA

S. validispina sensu stricto

$S$. validispina : spinose form

$S$. validispina : quadrate form

S. cornuspira

Genus PORODISCUS

Porodiscus sp. A : normal form

Porodiscus sp. A : spiral form

Porodiscus sp. B

Genus STYLOCHLAMYDIUM

$S$. asteriscus

Genus SPONGOTROCHUS

$S$. glacialis

Family PYLONIIDAE

Genus HEXAPYLE

$H$. cf. dodecantha

Genus TETRAPYLE

$T$. actacantha group

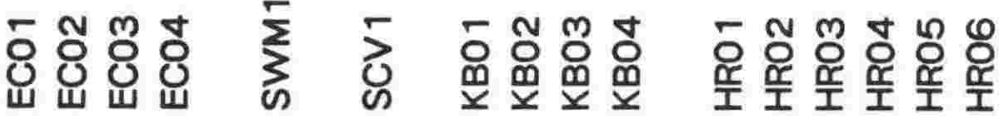

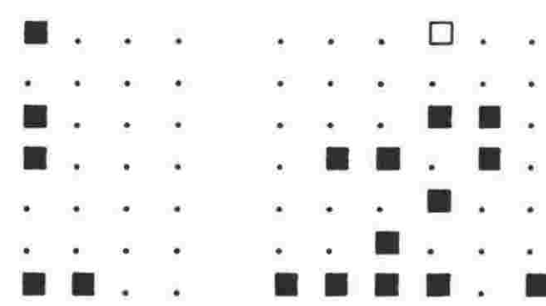


Family LARNACIDAE

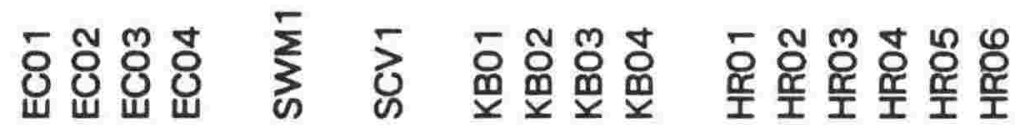

Genus LARN ACILLA

L. typus

Family THOLONIIDAE

Genus CUBOTHOLUS

C. rhombicus

Family LITHELIIDAE

Genus LITHELIUS

L. minor

L. nautiloides

Lithelius sp. A

Lithelius sp. B

Genus PYLOSPIRA

$P$. octopyle

Suborder NASSELLARIA

Family PLAGONIIDAE

Genus ANT ARCT ISSA

A. antedenticulata

A. conradae

A. longa

A. strelkovi

Genus LITHOMELISSA

(?) L. setosa sensu stricto

(?) L. setosa : tri-legged

Genus LOPHOPHAENA

L. macrencephala group

Family ACANTHODESMIIDAE

Genus DESMOSPYRIS

$D$. rhodospyroides

D. sp. aff. rhodospyroides

Desmospyris (?) sp. A.

Genus GORGOSPYRIS

G. sp. aff. perizostra

Genus PHORMOSPYRIS

$P$. stabilis antarctica group

$P$. stabilis scaphipes group 


\section{Family CARPOCANIIDAE}

\section{Genus CARPOCAN ARIUM}

C. papillosum

Carpocanarium sp. A

Genus CARPOCANIST RUM

C. sp. A : with terminal teeth

C. sp. A : toothless

C. sp. A : very constricted

Genus CYSTOPHORMIS

C. sp. A : with terminal teeth

C. sp. A : toothless

Cystophormis sp. B

Family THEOPERIDAE

Genus CORNUTELLA

C. profunda : three pores

C. profunda : six pores

Genus PLECTOPYRAMIS

$P$. dodecomma

Genus PERIPYRAMIS

$P$. cf. circumtexta

Genus DICTYOPHIMUS

$D$. hirundo group

Genus PSEUDODICTYOPHIMUS

$P$. gracilipes

\section{Genus LYCHNOCANIUM}

$L$. sp. aff. grande : vertical feet

$L$. sp. aff. grande : divergent feet

Genus LYCHNOCANELLA

L. conicum

\section{Genus ARCHIPILIUM}

\section{A. macropus}

Genus CYRTOCAPSELLA

C. japonica : inflated abdomen

C. japonica : rounded abdomen

C. tetrapera

Genus CYRTOLAGENA

C. laguncula sensu stricto

C. laguncula : spiralling form

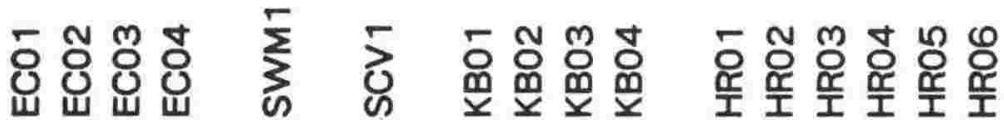


Genus THEOCALY PTRA

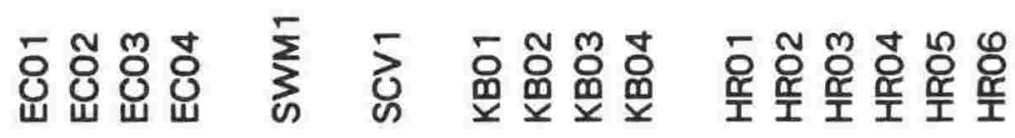

$T$. bicornis

T. davisiana davisiana

Genus LAMPROMITRA

L. butschlii

L. erosa

L. tiara : flaring

L. tiara : U-shaped

Genus THEOCAMPE

? T. cf. mongolfieri

Genus EUCYRTIDIUM

E. acuminatum

E. cienkowskii

E. hexagonatum

E. calvertense

$E$. calvertense $\mathrm{X}$ inflatum

E. inflatum

E. punctatum

E. cf. montiparum

Eucyrtidium sp. A

$E$. vincentense : small pores

$E$. vincentense : large pores

Genus STICHOCORYS

S. peregrina

$S$. peregrina $\mathrm{X}$ delmontensis

$S$. delmontensis

Stichocorys sp. A

Genus GONDW ANARIA

G. dogeli group

Genus 'ARTOSTROBUS'

'A.' pretabulatus

Family PTEROCORYTHIDAE

Genus ANT HOCY RT IDIUM

A. ehrenbergi pliocenica

? Anthocyrtidium sp. A

A. zanguebaricum

Genus LAMPROCYCLAS

L. gamphonycha

L. maritalis sensu stricto

L. cf. maritalis

Lamprocyclas (?) sp. A

Lamprocyclas sp. B

Lamprocyclas sp. C

Lamprocyclas sp. C X D

Lamprocyclas sp. D

Lamprocyclas sp. E 
Genus LAMPROCY RTIS

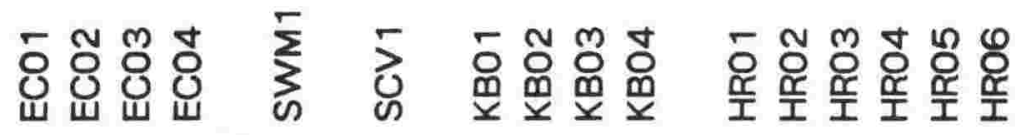

L. (?) apollinis

L. hannai

L. heteroporos

L. (?) junonis

L. (?) cf. junonis

Family ARTOSTROBIIDAE

Genus BOT RYOSTROBUS

$B$. aquilonaris

$B$. auritus-australis group

B. bramlettei

Genus PHORMOSTICHOARTUS

$P$. fistula

Phormostichoartus sp. A

Genus SIPHOCAMPE

$S$. arachnea group

S. lineata : strictured

$S$. lineata : smooth

$S$. nodosaria

Genus SIPHOST ICH ARTUS

S. corona

Genus SPIROCYRTIS

S. subscalaris

Family CANNOBOTRYIDAE

Genus BOT RYOPYLE

$B$. dictyocephalus sensu stricto

$B$. dictyocephalus : large lobe 
Suborder SPUMELLARIA

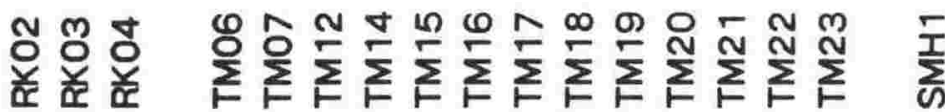

Family OROSPHAERIDAE

Genus OROPELEX

? Oropelex sp.

Family COLLOSPHAERIDAE

Genus COLLOSPHAERA

C. cf. polygona

C. sp. aff. huxleyi

Collosphaera sp. A

Genus ACROSPHAERA

A. spinosa echinoides

A. spinosa spinosa

Genus SIPHONOSPHAERA

S. polysiphonia

Genus OTOSPHAERA

O. polymorpha

Family ACTINOMMIDAE

Genus ACTINOMMA

A. antarcticum

A. cf. medianum

A. leptodermum

A. cf. leptodermum

A. polycanthum group

Genus CLADOCOCCUS

C. dentata

C. stalactites

Genus CENOSPHAERA

C. cristata

Cenosphaera sp. A

Cenosphaera sp. B

Cenosphaera sp. C

Cenosphaera sp. D

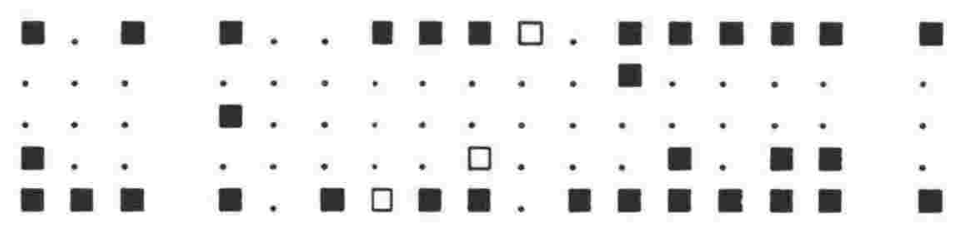

Genus ACANT HOSPHAERA

A. dodecastyla

A. sp. A : few spines

$A$. sp. A : many spines

Acanthosphaera sp. B

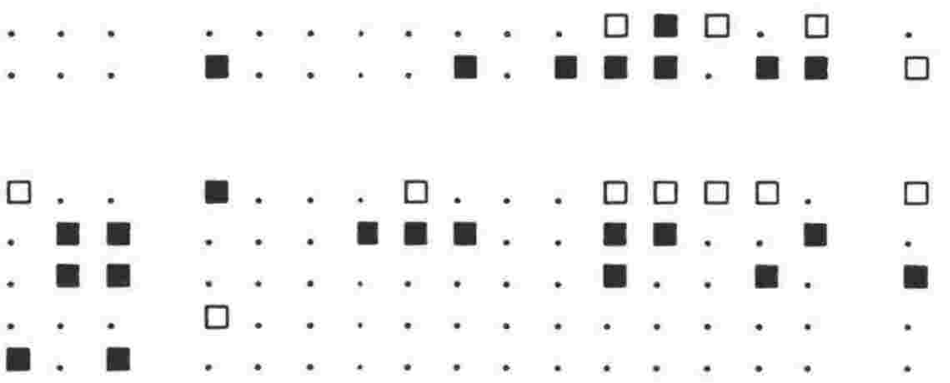


Genus HEXACONTIUM

$H$. enthacanthum sensu stricto

$H$. enthacanthum : oval form

$H$. enthacanthum : quadrate form

$H$. enthacanthum X laevigatum

$H$. laevigatum sensu stricto

$H$. laevigatum : oval form

$H$. laevigatum : quadrate form

$H$. laevigatum : long spined

Genus THECOSPHAERA

$T$. cf. akitaensis

T. grecoi group

Genus PRUNULUM

Prunulum spp.

Genus STYPTOSPHAERA

S. stupacea

S. spumacea

Genus 'STYLATRACTUS'

'S'. neptunus forma. large pores

' $S$ '. universus : small pores

'S'. universus : large pores

Genus 'SPHAEROSTYLUS'

'S'. sp. aff. timmsi : sensu Campbell

'S'. sp. aff. timmsi : symmetrical

Genus ' $X I P H A T R A C T U S '$

'Xiphatractus' sp. A

Genus PRUNOPYLE

? P. antarctica

Prunopyle sp. A

Genus SPONGURUS

$S$. pylomaticus

Spongurus sp. A

Genus SPONGOCORE

$S$. puella

Spongocore sp. A

Family PHACODISCIDAE

Genus HELIODISCUS

$H$. asteriscus : large pores

$H$. asteriscus : small pores

$H$. asteriscus : long spines

$H$. cf. echiniscus

$H$. umbonatum

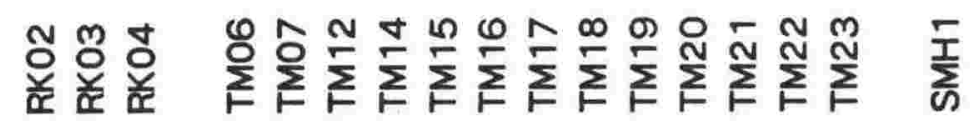

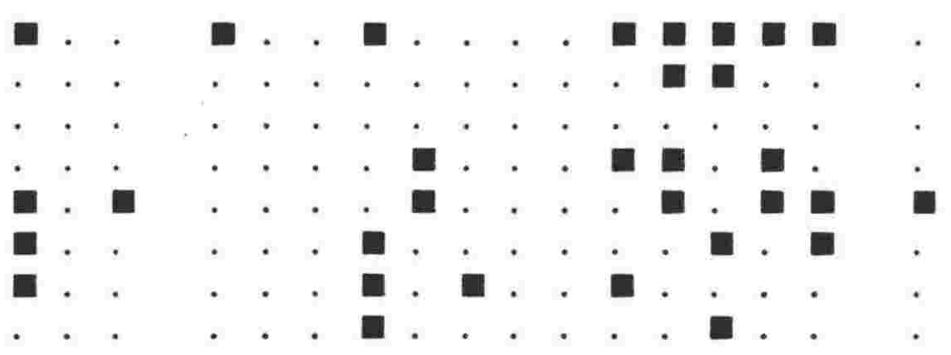

घ घ

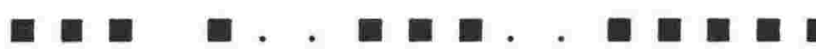
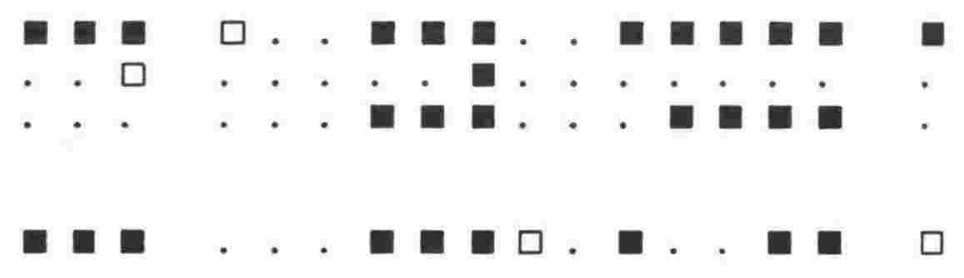

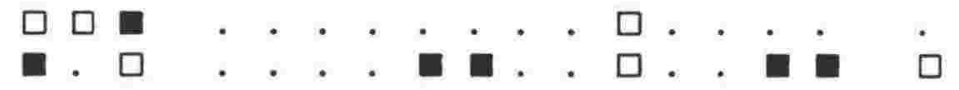

घ

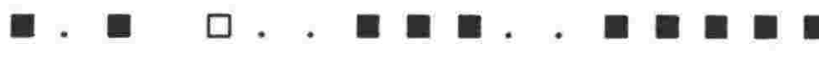


Family COCCODISCIDAE

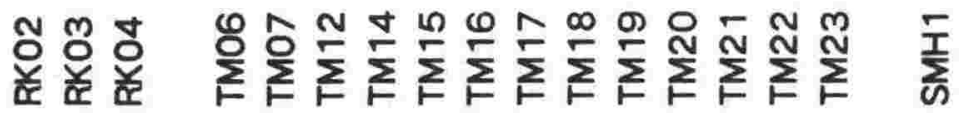

Genus DIDYMOCY RTIS

$D$. antepenultima

D. antepenultima $\mathrm{X}$ laticonus

D. laticonus

D. virgineum : non-constricted

D. virgineum : constricted

D. virgineum : tuberculate

D. sp. A : non-constricted

D. sp. A : constricted

D. sp. A : spherical

$D$. sp. A : narrow

D. tetrathalmus tetrathalmus

Genus DIARTUS

$D$. hughesi group

Family SPONGODISCIDAE

Genus AMPHIRHOPALUM

A. cf. ypsilon

Genus DICTYOCORYNE

D. profunda

Genus HYMENIAST RUM

$H$. euclidis

Genus SPONGASTER

$S$. pentas

Genus STYLODICTY A

S. validispina sensu stricto

$S$. validispina : spinose form

$S$. validispina : quadrate form

$S$. cornuspira

Genus PORODISCUS

Porodiscus sp. A : normal form

Porodiscus sp. A : spiral form

Porodiscus sp. B

Genus STYLOCHLAMY DIUM

S. asteriscus

Genus SPONGOT ROCHUS

$S$. glacialis

Family PYLONIIDAE

Genus HEXAPYLE

$H$. cf. dodecantha

Genus TET RAPYLE

$T$. octacantha group

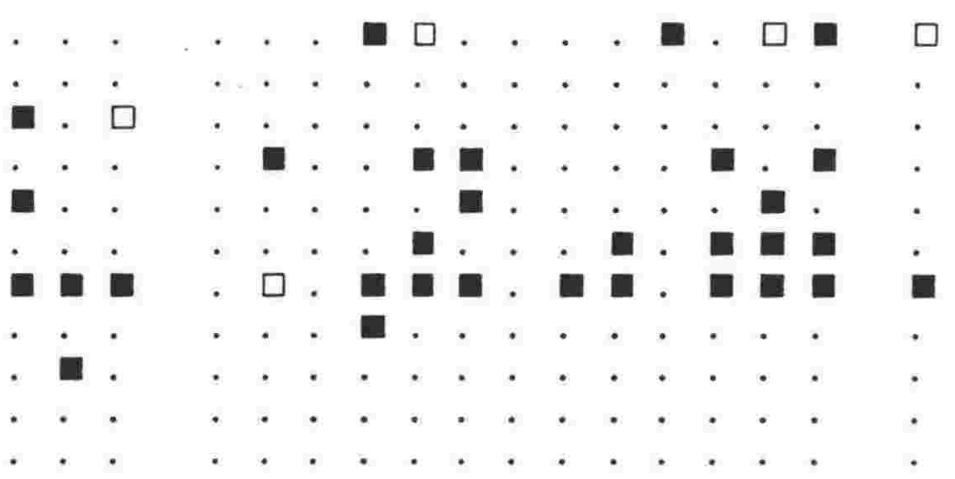

-

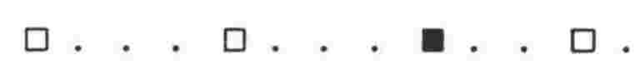

a

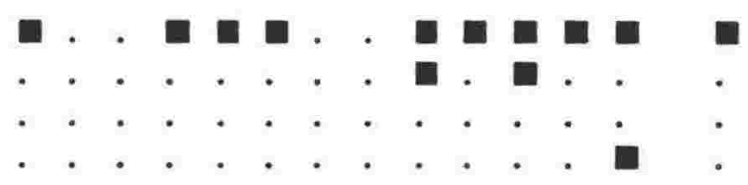

-1.

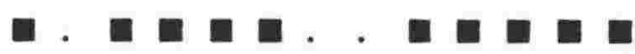

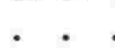

$\cdot \cdot \cdot$ 
Family LARNACIDAE

Genus LARNACILLA

L. typus

Family THOLONIIDAE

Genus CUBOT HOLUS

C. rhombicus

Family LITHELIIDAE

Genus LITHELIUS

L. minor

L. nautiloides

Lithelius sp. A

Lithelius sp. B

Genus PYLOSPIRA

$P$. octopyle

Suborder NASSELLARIA

Family PLAGONIIDAE

Genus ANT ARCTISSA

A. antedenticulata

A. conradae

A. longa

A. strelkovi

Genus LIT HOMELISSA

(?) L. setosa sensu stricto

(?) L. setosa : tri-legged

Genus LOPHOPHAENA

L. macrencephala group

Family ACANTHODESMIIDAE

Genus DESMOSPYRIS

D. rhodospyroides

D. sp. aff. rhodospyroides

Desmospyris (?) sp. A.

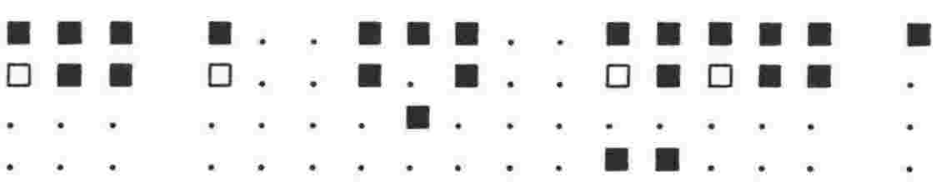

Genus GORGOSPYRIS

G. sp. aff. perizostra

Genus PHORMOSPYRIS

$P$. stabilis antarctica group

P. stabilis scaphipes group 
Family CARPOCANIIDAE

Genus CARPOCANARIUM

C. papillosum

Carpocanarium sp. A

Genus CARPOCANIST RUM

C. sp. A : with terminal teeth

C. sp. A : toothless

C. sp. A : very constricted

Genus CYSTOPHORMIS

C. sp. A : with terminal teeth

C. sp. A : toothless

Cystophormis sp. B

Family THEOPERIDAE

Genus CORNUTELLA

C. profunda : three pores

C. profunda : six pores

Genus PLECTOPYRAMIS

$P$. dodecomma

Genus PERIPYRAMIS

$P$. cf. circumtexta

Genus DICTYOPHIMUS

$D$. hirundo group

Genus PSEUDODICTYOPHIMUS

$P$. gracilipes

Genus LYCHNOCANIUM

$L$. sp. aff. grande : vertical feet

$L$. sp. aff. grande : divergent feet

Genus LYCHNOCANELLA

L. conicum

Genus ARCHIPILIUM

A. macropus

Genus CYRTOCAPSELLA

C. japonica : inflated abdomen

C. japonica : rounded abdomen

C. tetrapera

Genus CYRTOLAGENA

C. laguncula sensu stricto

C. laguncula : spiralling form

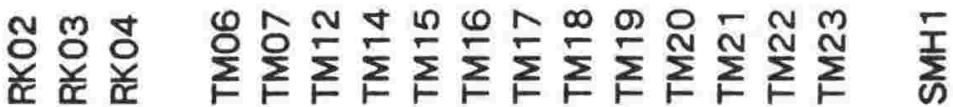

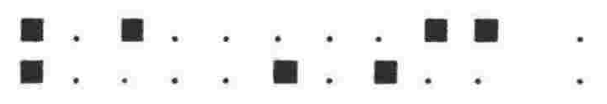

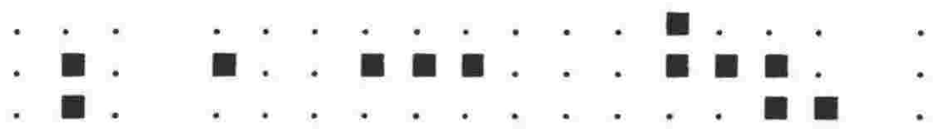

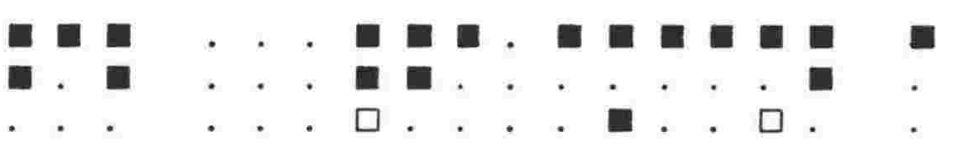

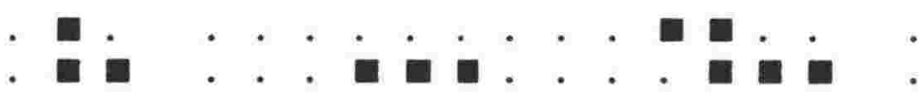

$\square . . \square . \quad \square \square \square . . \square \square \square \square$

Genus STICHOPHORMIS

$S$. cornutella 
Genus THEOCALY PTRA

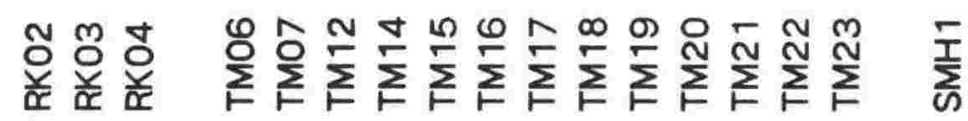

T. bicornis

$T$. davisiana davisiana

Genus LAMPROMITRA

L. butschlii

L. erosa

L. tiara : flaring

L. tiara : U-shaped

Genus THEOCAMPE

? T. cf. mongolfieri

Genus EUCYRTIDIUM

E. acuminatum

E. cienkowskii

E. hexagonatum

E. calvertense

$E$. calvertense $\mathrm{X}$ inflatum

E. in flatum

E. punctatum

E. cf. montiparum

Eucyrtidium sp. A

E. vincentense : small pores

E. vincentense : large pores

Genus STICHOCORYS

$S$. peregrina

$S$. peregrina $\mathrm{X}$ delmontensis

$S$. delmontensis

Stichocorys sp. A

Genus GONDW AN ARI A

G. dogeli group

Genus 'ARTOST ROBUS'

'A.' pretabulatus

Family PTEROCORYTHIDAE

Genus ANTHOCY RTIDIUM

A. ehrenbergi pliocenica

? Anthocyrtidium sp. A

A. zanguebaricum

Genus LAMPROCYCLAS

L. gamphonycha

L. maritalis sensu stricto

L. cf. maritalis

Lamprocyclas (?) sp. A

Lamprocyclas sp. B

Lamprocyclas $\mathrm{sp}$. C

Lamprocyclas sp. C X D

Lamprocyclas sp. D
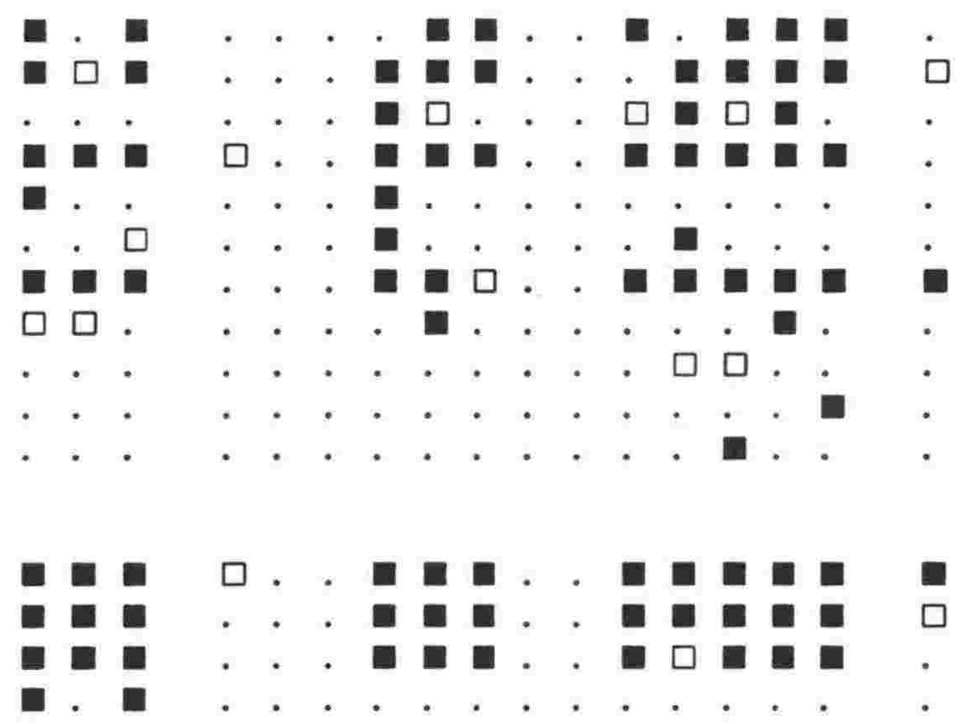

Lamprocyclas sp. E 
Genus LAMPROCY RTIS

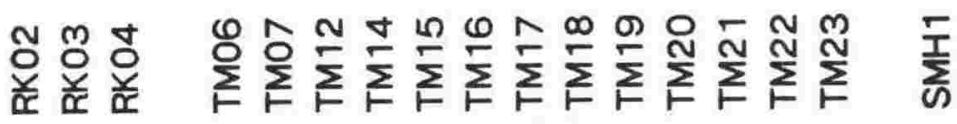

L. (?) apollinis

L. hannai

L. heteroporos

L. (?) junonis

L. (?) cf. junonis

Family ARTOSTROBIIDAE

Genus BOT RYOST ROBUS

$B$. aquilonaris

$B$. auritus-australis group

B. bramlettei

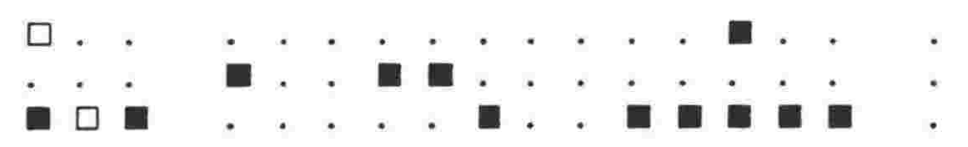

Genus PHORMOSTICHOARTUS

$P$. fistula

Phormostichoartus sp. A

Genus SIPHOCAMPE
$S$. arachnea group
$S$. lineata : strictured
$S$. lineata : smooth
S. nodosaria

Genus SIPHOSTICHARTUS

$S$. corona

Genus SPIROCYRTIS

S. subscalaris

Family CANNOBOTRYIDAE

Genus BOT RYOPYLE

$B$. dictyocephalus sensu stricto

B. dictyocephalus : large lobe
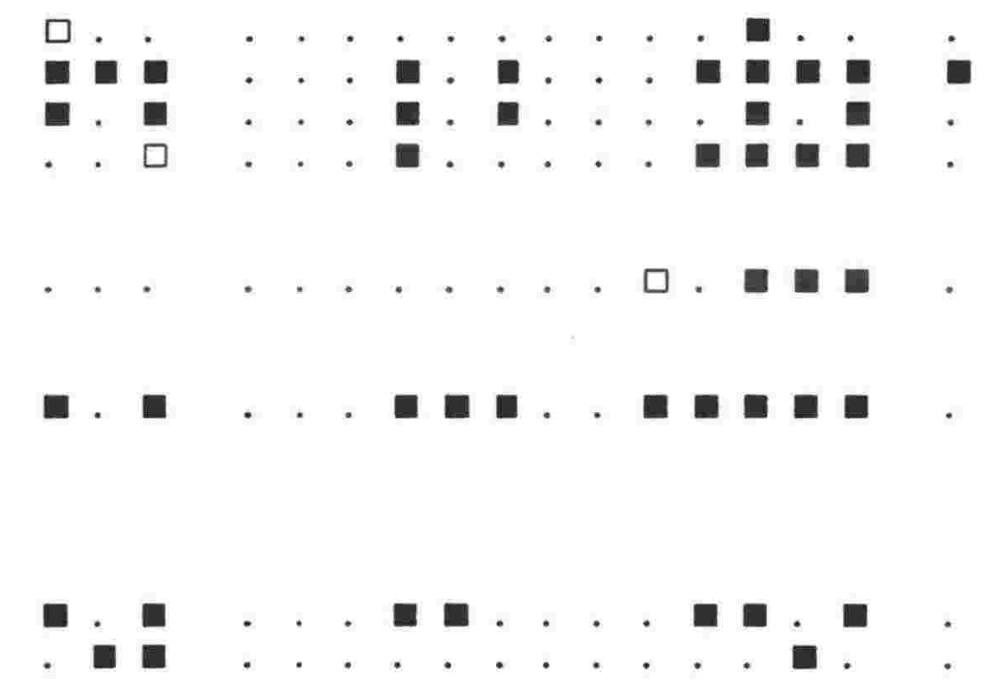
Suborder SPUMELLARIA

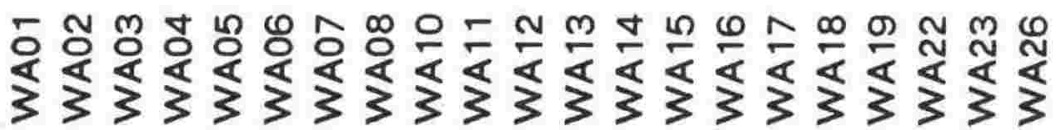

Family OROSPHAERIDAE

Genus OROPELEX

? Oropelex sp.

Family COLLOSPHAERIDAE

Genus COLLOSPHAERA

C. cf. polygona

C. sp. aff. huxleyi

Collosphaera sp. A

Genus ACROSPHAERA

A. spinosa echinoides

A. spinosa spinosa

Genus SIPHONOSPHAERA

S. polysiphonia

Genus OTOSPHAERA

O. polymor pha

Family ACTINOMMIDAE

Genus ACTINOMMA
A. antarcticum
A. cf. medianum
A. leptodermum
A. cf. leptodermum
A. polycanthum group

Genus CLADOCOCCUS

C. dentata

C. stalactites

Genus CENOSPHAERA

C. cristata

Cenosphaera sp. A

Cenosphaera sp. B

Cenosphaera sp. C

Cenosphaera sp. D

Genus ACANT HOSPHAERA

A. dodecastyla

A. sp. A : few spines

A. sp. A : many spines

Acanthosphaera sp. B
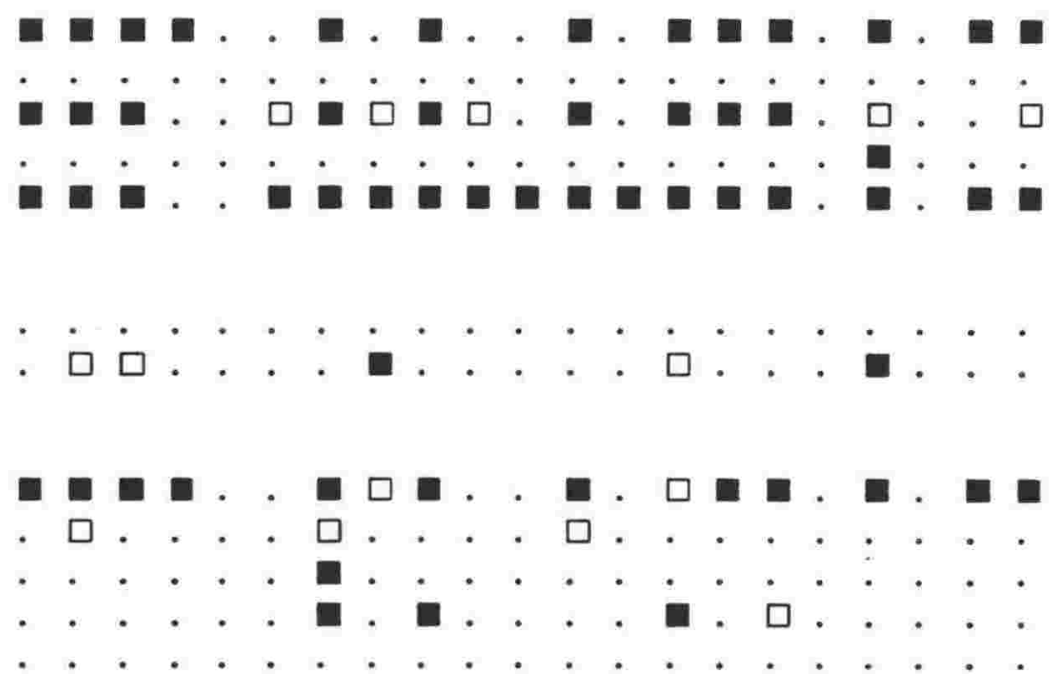
Genus HEX ACONTIUM

$H$. enthacanthum sensu stricto

$H$. enthacanthum : oval form

$H$. enthacanthum : quadrate form

$H$. enthacanthum X laevigatum

$H$. laevigatum sensu stricto

$H$. laevigatum : oval form

$H$. laevigatum : quadrate form

$H$. laevigatum : long spined

Genus THECOSPHAERA

$T$. cf. akitaensis

T. grecoi group

Genus PRUNULUM

Prunulum spp.

Genus STYPTOSPHAERA

S. stupacea

S. spumacea

Genus 'STYLATRACTUS'

'S. neptunus forma. large pores

'S'. universus : small pores

'S. universus : large pores

Genus 'SPHAEROSTYLUS'

'S. sp. aff. timmsi : sensu Campbell

'S'. sp. aff. timmsi : symmetrical

Genus 'XIPHATRACTUS'

'Xiphatractus' sp. A

Genus PRUNOPYLE

? P. antarctica

Prunopyle sp. A

Genus SPONGURUS

$S$. pylomaticus

Spongurus sp. A

Genus SPONGOCORE

$S$. puella

Spongocore sp. A

Family PHACODISCIDAE

Genus HELIODISCUS

$H$. asteriscus : large pores

$H$. asteriscus : small pores

$H$. asteriscus : long spines

$H$. cf. echiniscus

H. umbonatum
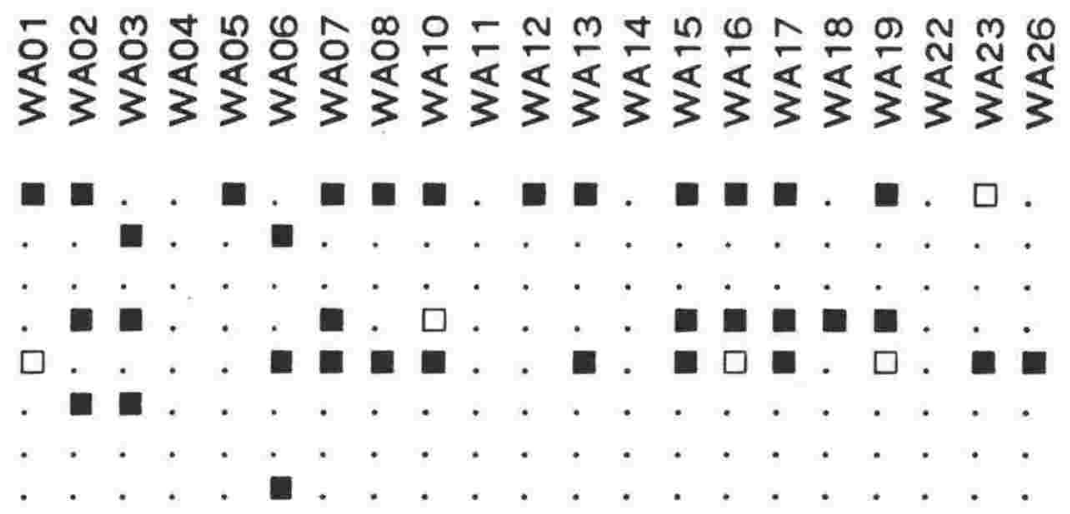

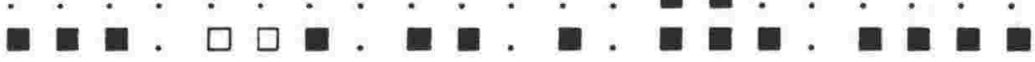

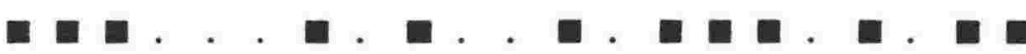

ㅁ.

밈

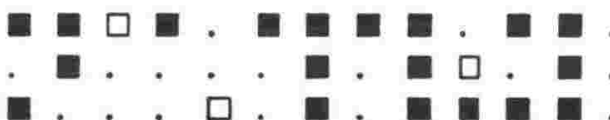

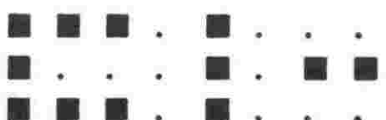

.

- $\square$.

. $\square$ घ. घ曰.

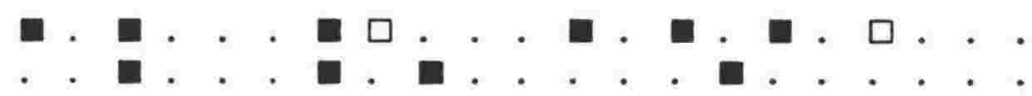


Family COCCODISCIDAE

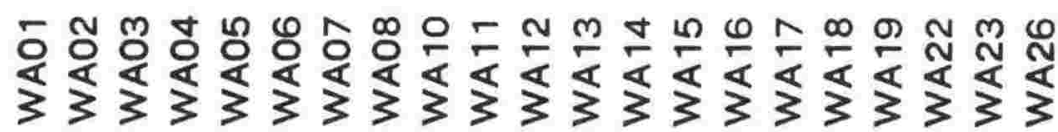

Genus DIDY MOCY RTIS

D. antepenultima

D. antepenultima $\mathrm{X}$ laticonus

D. laticonus

D. virgineum : non-constricted

D. virgineum : constricted

D. virgineum : tuberculate

D. sp. A : non-constricted

D. sp. A : constricted

D. sp. A : spherical

D. sp. A : narrow

D. tetrathalmus tetrathalmus

Genus DIARTUS

$D$. hughesi group

Family SPONGODISCIDAE

Genus AMPHIRHOPALUM

A. cf. ypsilon

Genus DICTYOCORYNE

D. profunda

Genus HYMENIAST RUM

H. euclidis

Genus SPONGASTER

$S$. pentas

Genus STYLODICTYA

$S$. validispina sensu stricto

$S$. validispina : spinose form

$S$. validispina : quadrate form

$S$. cornuspira

Genus PORODISCUS

Porodiscus sp. A : normal form

Porodiscus sp. A : spiral form

Porodiscus sp. B

Genus STYLOCHLAMY DIUM

S. asteriscus

Genus SPONGOTROCHUS

S. glacialis

Family PYLONIIDAE

Genus HEX APY LE

$H$. cf. dodecantha

Genus TETRAPYLE

$T$. octacantha group
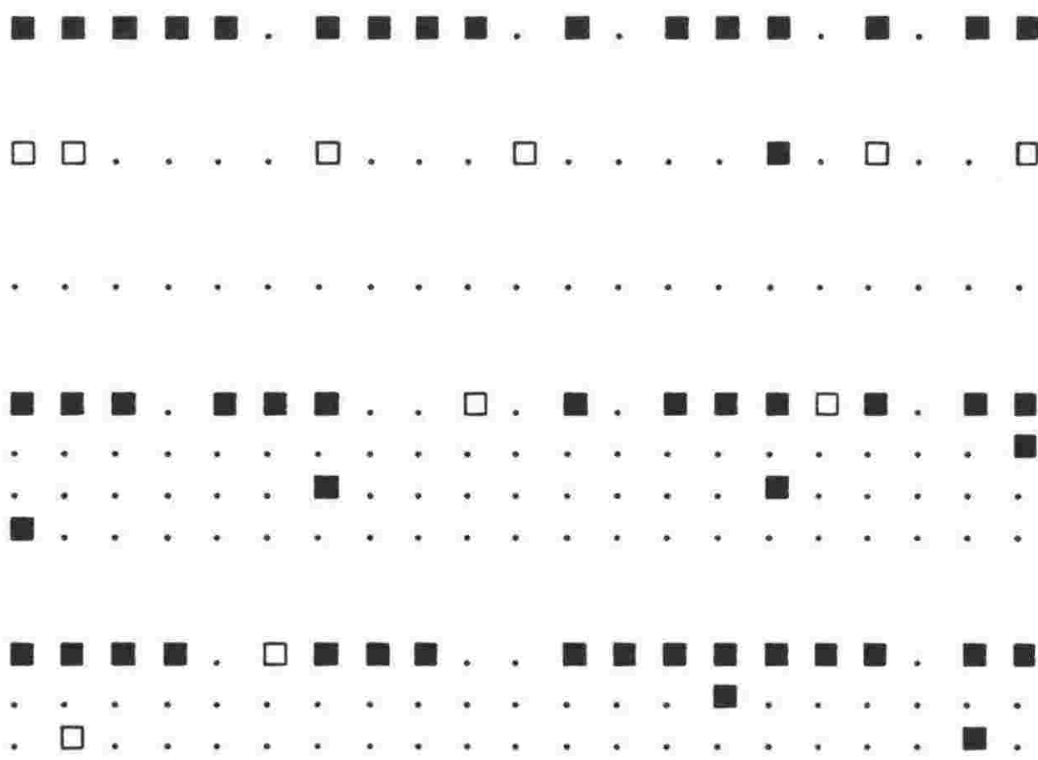
Family LARNACIDAE

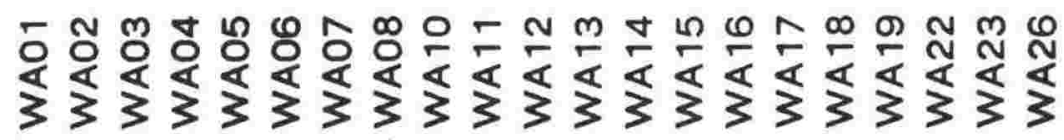

Genus LARNACILLA

L. typus

Family THOLONIIDAE

Genus CUBOTHOLUS

C. rhombicus

Family LITHELIIDAE

Genus LITHELIUS

L. minor

L. nautiloides

Lithelius sp. A

Lithelius sp. B

Genus PYLOSPIRA

P. octopyle

Suborder NASSELLARIA

Family PLAGONIIDAE

Genus ANT ARCTISSA

A. antedenticulata

A. conradae

A. longa

A. strelkovi

Genus LITHOMELISSA

(?) L. setosa sensu stricto

(?) L. setosa : tri-legged

Genus LOPHOPHAENA

$L$. macrencephala group

Family ACANTHODESMIIDAE

Genus DESMOSPYRIS

$D$. rhodospyroides

D. sp. aff. rhodospyroides

Desmospyris (?) sp. A.

Genus GORGOSPYRIS

G. sp. aff. perizostra

Genus PHORMOSPYRIS

$P$. stabilis antarctica group

$P$. stabilis scaphipes group 


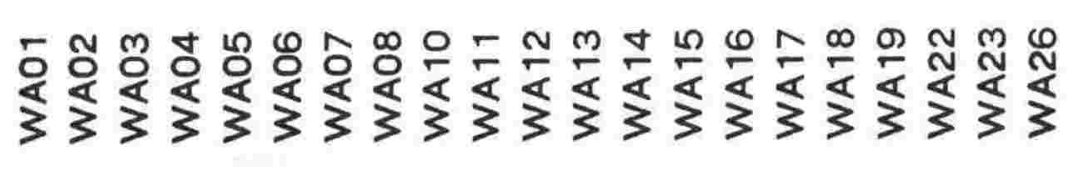


Genus THEOCALYPTRA

T. bicornis

$T$. davisiana davisiana

Genus LAMPROMITRA

L. butschlii

L. erosa

L. tiara : flaring

L. tiara : U-shaped

Genus THEOCAMPE

? $T$. cf. mongolfieri

Genus EUCYRTIDIUM

E. acuminatum

E. cienkowskii

$E$. hexagonatum

$E$. calvertense

$E$. calvertense $\mathrm{X}$ inflatum

$E$. inflatum

E. punctatum

E. cf. montiparum

Eucyrtidium sp. A

$E$. vincentense : small pores

$E$. vincentense : large pores

\section{Genus STICHOCORYS}

$S$. peregrina

$S$. peregrina $\mathrm{X}$ delmontensis

$S$. delmontensis

Stichocorys sp. A

Genus GONDW ANARIA

G. dogeli group

Genus 'ARTOSTROBUS'

'A.' pretabulatus

Family PTEROCORYTHIDAE

Genus ANT HOCY RTIDIUM

A. ehrenbergi pliocenica

? Anthocyrtidium sp. A

A. zanguebaricum

Genus LAMPROCYCLAS

L. gamphonycha

L. maritalis sensu stricto

$L$. cf. maritalis

Lamprocyclas (?) sp. A

Lamprocyclas sp. B

Lamprocyclas sp. C

Lamprocyclas sp. C X D

Lamprocyclas sp. D

Lamprocyclas sp. E
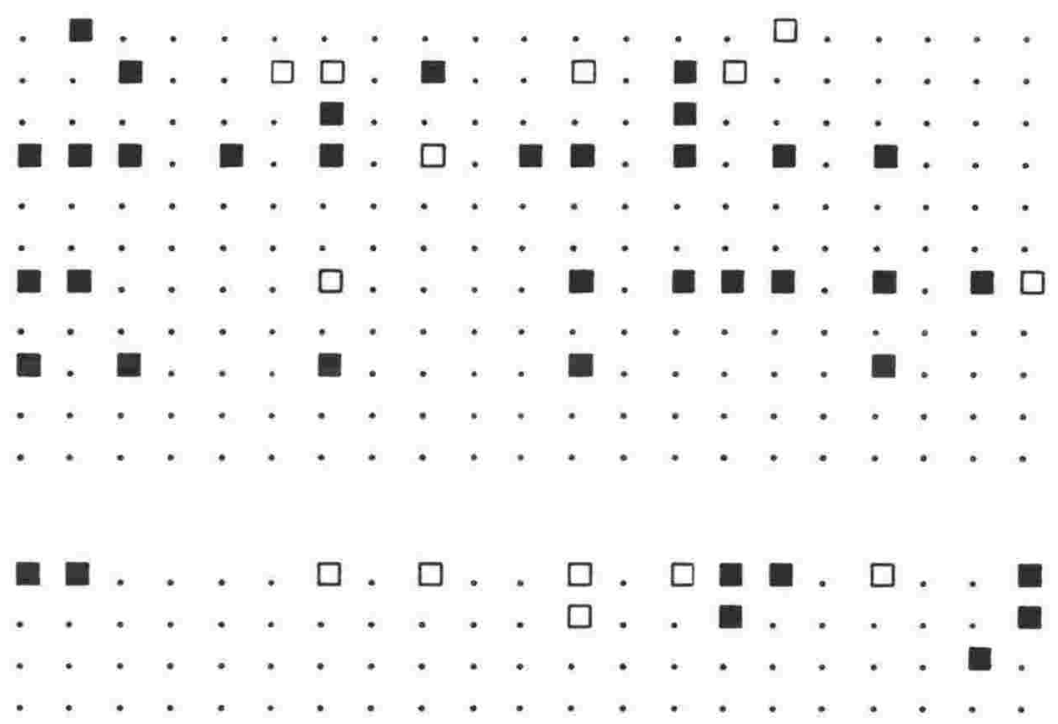
Genus LAMPROCYRTIS

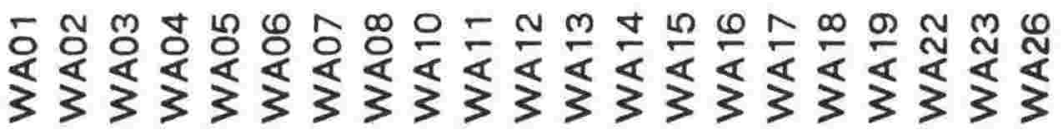

L. (?) apollinis

L. hannai

L. heteroporos

L. (?) junonis

L. (?) cf. junonis

Family ARTOSTROBIIDAE

Genus BOT RYOST ROBUS

$B$. aquilonaris

B. auritus-australis group

B. bramlettei

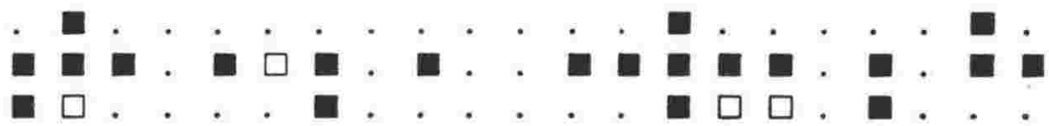

Genus PHORMOSTICHOARTUS

$P$. fistula

Phormostichoartus sp. A

Genus SIPHOCAMPE

$S$. arachnea group

$S$. lineata : strictured

$S$. lineata : smooth

$S$. nodosaria

Genus SIPHOSTICHARTUS

S. corona

Genus SPIROCYRTIS

S. subscalaris

Family CANNOBOTRYIDAE

Genus BOT RYOPYLE

$B$. dictyocephalus sensu stricto

$B$. dictyocephalus : large lobe 
Suborder SPUMELLARIA

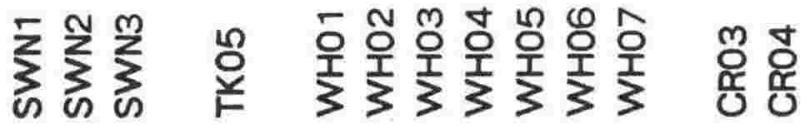

Family OROSPHAERIDAE

Genus OROPELEX

? Oropelex sp.

Family COLLOSPHAERIDAE

Genus COLLOSPHAERA

C. cf. polygona

C. sp. aff. huxleyi

Collosphaera sp. A

Genus ACROSPHAERA

A. spinosa echinoides

A. spinosa spinosa

Genus SIPHONOSPHAERA

$S$. polysiphonia

Genus OTOSPHAERA

O. polymorpha

Family ACTINOMMIDAE

Genus ACTINOMMA

A. antarcticum

A. cf. medianum

A. leptodermum

A. cf. leptodermum

A. polycanthum group

Genus CLADOCOCCUS

C. dentata

C. stalactites

Genus CENOSPHAERA

C. cristata

Cenosphaera sp. A

Cenosphaera sp. B

Cenosphaera sp. C

Cenosphaera sp. D

Genus ACANT HOSPHAERA

A. dodecastyla

A. sp. A : few spines

A. sp. A : many spines

Acanthosphaera sp. B 
Genus HEX ACONTIUM

$H$. enthacanthum sensu stricto

$H$. enthacanthum : oval form

$H$. enthacanthum : quadrate form

$H$. enthacanthum X laevigatum

$H$. laevigatum sensu stricto

$H$. laevigatum : oval form

$H$. laevigatum : quadrate form

$H$. laevigatum : long spined

Genus THECOSPHAERA

$T$. cf. akitaensis

$T$. grecoi group

Genus PRUNULUM

Prunulum spp.

Genus STYPTOSPHAERA

S. stupacea

S. spumacea

Genus 'STYLATRACTUS'

' $S$ '. neptunus forma. large pores

'S'. universus : small pores

'S'. universus : large pores

Genus 'SPHAEROSTYLUS'

'S. sp. aff. timmsi : sensu Campbell

'S. sp. aff. timmsi : symmetrical

Genus 'XIPH ATRACTUS'

'Xiphatractus' sp. A

Genus PRUNOPYLE

? P. antarctica

Prunopyle sp. A

Genus SPONGURUS

$S$. pylomaticus

Spongurus sp. A

Genus SPONGOCORE

$S$. puella

Spongocore sp. A

Family PHACODISCIDAE

Genus HELIODISCUS

$H$. asteriscus : large pores

$H$. asteriscus : small pores

$H$. asteriscus : long spines

$H$. cf. echiniscus

H. umbonatum
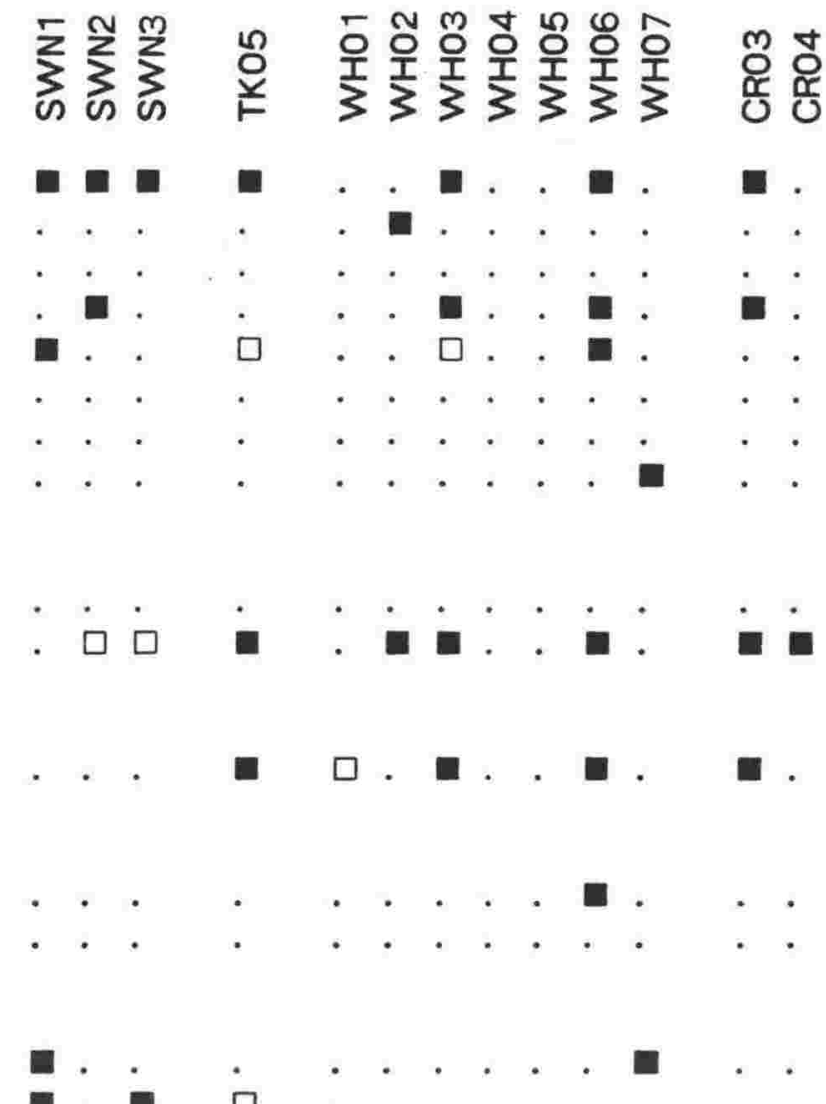

$\square$ 
Family COCCODISCIDAE

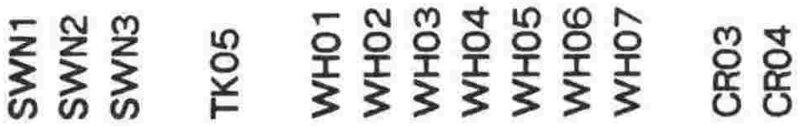

Genus DIDY MOCY RTIS

D. antepenultima

D. antepenultima $\mathrm{X}$ laticonus

D. laticonus

D. virgineum : non-constricted

D. virgineum : constricted

D. virgineum : tuberculate

D. sp. A : non-constricted

D. sp. A : constricted

D. sp. A : spherical

D. sp. A : narrow

D. tetrathalmus tetrathalmus

Genus DIARTUS

$D$. hughesi group

Family SPONGODISCIDAE

Genus AMPHIRHOPALUM

A. cf. ypsilon

Genus DICTYOCORYNE

D. profunda

Genus HYMENIAST RUM

H. euclidis

Genus SPONGASTER

$S$. pentas

Genus STYLODICTYA

$S$. validispina sensu stricto

$S$. validispina : spinose form

$S$. validispina : quadrate form

$S$. cornuspira

Genus PORODISCUS

Porodiscus sp. A : normal form

Porodiscus sp. A : spiral form

Porodiscus sp. B

Genus STYLOCHLAMYDIUM

$S$. asteriscus

Genus SPONGOT ROCHUS

$S$. glacialis

Family PYLONIIDAE

Genus HEXAPYLE

$H$. cf. dodecantha

Genus TETRAPYLE

$T$. octacantha group 
Family LARNACIDAE

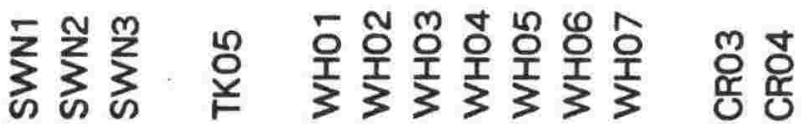

Genus LARNACILLA

L. typus

Family THOLONIIDAE

Genus CUBOT HOLUS

C. rhombicus

Family LITHELIIDAE

Genus LIT HELIUS

L. minor

$L$. nautiloides

Lithelius sp. A

Lithelius sp. B

Genus PYLOSPIRA

$P$. octopyle

Suborder NASSELLARIA

Family PLAGONIIDAE

Genus ANT ARCT ISSA

A. antedenticulata

A. conradae

A. longa

A. strelkovi

Genus LIT HOMELISSA

(?) L. setosa sensu stricto

(?) L. setosa : tri-legged

Genus LOPHOPHAENA

L. macrencephala group

Family ACANTHODESMIIDAE

Genus DESMOSPYRIS

$D$. rhodospyroides

$D$. sp. aff. rhodospyroides

Desmospyris (?) sp. A.

Genus GORGOSPYRIS

$G$. sp. aff. perizostra

Genus PHORMOSPYRIS

$P$. stabilis antarctica group

$P$. stabilis scaphipes group 
Family CARPOCANIIDAE

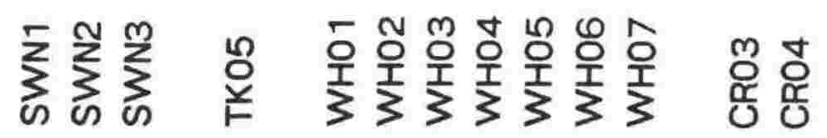

Genus CARPOCANARIUM

C. papillosum

Carpocanarium sp. A

Genus CARPOCANIST RUM

C. sp. A : with terminal teeth

C. sp. A : toothless

C. sp. A : very constricted

Genus CYSTOPHORMIS

C. sp. A : with terminal teeth

C. sp. A : toothless

Cystophormis sp. B

Family THEOPERIDAE

Genus CORNUTELLA

C. profunda : three pores

C. profunda: six pores

Genus PLECTOPY RAMIS

$P$. dodecomma

Genus PERIPYRAMIS

$P$. cf. circumtexta

Genus DICTYOPHIMUS

$D$. hirundo group

Genus PSEUDODICTYOPHIMUS

$P$. gracilipes

Genus LYCHNOCANIUM

$L$. sp. aff. grande : vertical feet

$L$. sp. aff. grande : divergent feet

Genus LYCHNOCANELLA

L. conicum

Genus ARCHIPILIUM

A. macropus

Genus CYRTOCAPSELLA

C. japonica : inflated abdomen

C. japonica : rounded abdomen

C. tetrapera

Genus CY RTOLAGENA

C. laguncula sensu stricto

C. laguncula : spiralling form

Genus STICHOPHORMIS

$S$. cornutella 
Genus THEOCALY PTRA

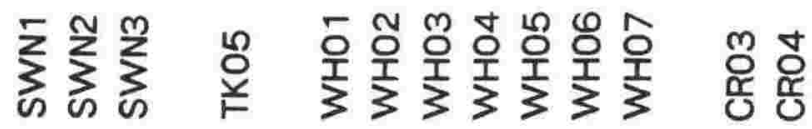

T. bicornis

T. davisiana davisiana

Genus LAMPROMITRA

L. butschlii

L. erosa

L. tiara : flaring

L. tiara : U-shaped

Genus THEOCAMPE

? T. cf. mongolfieri

Genus EUCY RTIDIUM

E. acuminatum

E. cienkowskii

$E$. hexagonatum

E. calvertense

E. calvertense $\mathrm{X}$ inflatum

E. in flatum

E. punctatum

$E$. cf. montiparum

Eucyrtidium sp. A

$E$. vincentense : small pores

$E$. vincentense : large pores

Genus STICHOCORYS

S. peregrina

$S$. peregrina $\mathrm{X}$ delmontensis

$S$. delmontensis

Stichocorys sp. A

Genus GONDW ANARIA

G. dogeli group

Genus 'ARTOSTROBUS'

'A.' pretabulatus

Family PTEROCORYTHIDAE

Genus ANT HOCY RTIDIUM

A. ehrenbergi pliocenica

? Anthocyrtidium sp. A

A. zanguebaricum

Genus LAMPROCYCLAS

L. gamphonycha

L. maritalis sensu stricto

L. cf. maritalis

Lamprocyclas (?) sp. A

Lamprocyclas sp. B

Lamprocyclas sp. C

Lamprocyclas sp. C X D

Lamprocyclas sp. D

Lamprocyclas sp. E 
Genus LAMPROCY RTIS

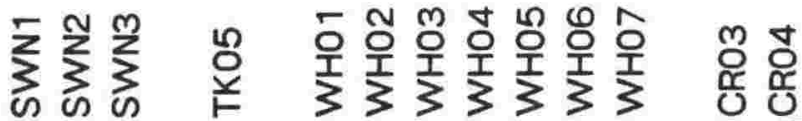

L. (?) apollinis

L. hannai

L. heteroporos

L. (?) junonis

L. (?) cf. junonis

Family ARTOSTROBIIDAE

Genus BOT RYOST ROBUS

$B$. aquilonaris

$B$. auritus-australis group

B. bramlettei

Genus PHORMOSTICHOARTUS

$P$. fistula

Phormostichoartus sp. A

Genus SIPHOCAMPE

$S$. arachnea group

$S$. lineata : strictured

$S$. lineata : smooth

$S$. nodosaria

Genus SIPHOSTICHARTUS

$S$. corona

Genus SPIROCYRTIS

S. subscalaris

Family CANNOBOTRYIDAE

Genus BOT RYOPYLE

$B$. dictyocephalus sensu stricto

$B$. dictyocephalus : large lobe 
Suborder SPUMELLARIA

Family OROSPHAERIDAE

Genus OROPELEX

? Oropelex sp.

Family COLLOSPHAERIDAE

Genus COLLOSPHAERA

C. cf. polygona

C. sp. aff. huxleyi

Collosphaera sp. A

Genus ACROSPHAERA

A. spinosa echinoides

A. spinosa spinosa

Genus SIPHONOSPHAERA

$S$. polysiphonia

Genus OTOSPHAERA

O. polymor pha

Family ACTINOMMIDAE

Genus ACT INOMMA

A. antarcticum

A. cf. medianum

A. leptodermum

A. cf. leptodermum

A. polycanthum group

Genus CLADOCOCCUS

C. dentata

C. stalactites

Genus CENOSPHAERA

C. cristata

Cenosphaera sp. A

Cenosphaera sp. B

Cenosphaera sp. C

Cenosphaera sp. D

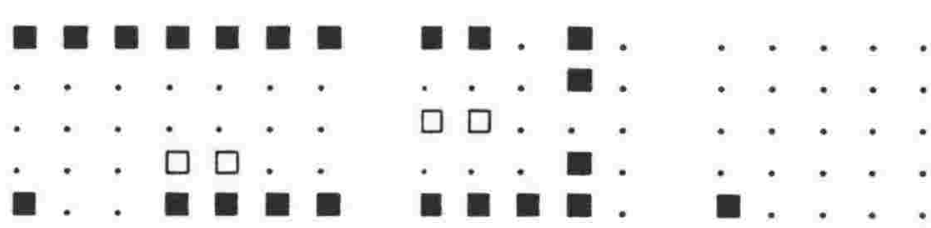

Genus ACANT HOSPH AERA

A. dodecastyla

A. sp. A : few spines

A. sp. A : many spines

Acanthosphaera sp. B 
Genus HEXACONTIUM

$H$. enthacanthum sensu stricto

$H$. enthacanthum : oval form

$H$. enthacanthum : quadrate form

$H$. enthacanthum X laevigatum

$H$. laevigatum sensu stricto

$H$. laevigatum : oval form

$H$. laevigatum : quadrate form

$H$. laevigatum : long spined

Genus THECOSPHAERA

$T$. cf. akitaensis

$T$. grecoi group

Genus PRUNULUM

Prunulum spp.

Genus STYPTOSPHAERA
$S$. stupacea
S. spumacea

Genus 'STYLATRACTUS'

' $S$ '. neptunus forma. large pores

'S'. universus : small pores

'S'. universus : large pores

Genus 'SPHAEROSTYUUS'

'S. sp. aff. timmsi : sensu Campbell

' $S$ '. sp. aff. timmsi : symmetrical

Genus 'XIPHAT RACTUS'

'Xiphatractus' sp. A

Genus PRUNOPYLE

? $P$. antarctica

Prunopyle sp. A

Genus SPONGURUS

$S$. pylomaticus

Spongurus sp. A

Genus SPONGOCORE

$S$. puella

Spongocore sp. A

Family PHACODISCIDAE

Genus HELIODISCUS

$H$. asteriscus : large pores

$H$. asteriscus : small pores

$H$. asteriscus : long spines

$H$. cf. echiniscus

H. umbonatum
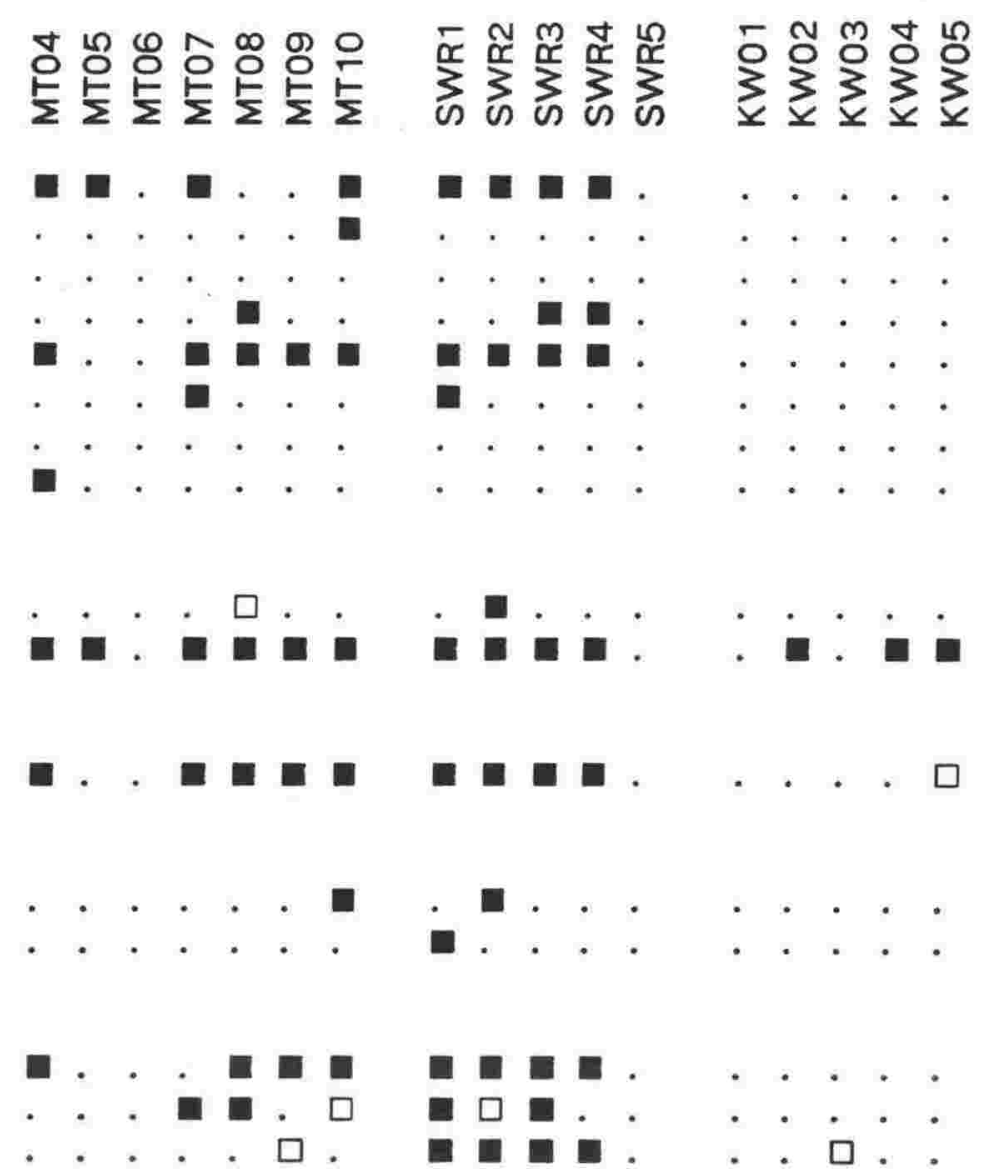
Family COCCODISCIDAE
Genus DIDY MOCY RT IS
D. antepenultima
D. antepenultima $\mathrm{X}$ laticonus
D. laticonus
D. virgineum : non-constricted
D. virgineum : constricted
D. virgineum : tuberculate
D. sp. A : non-constricted
D. sp. A : constricted
D. sp. A : spherical
D. sp. A : narrow
D. tetrathalmus tetrathalmus

Genus DIARTUS

$D$. hughesi group

Family SPONGODISCIDAE

Genus AMPHIRHOPALUM

A. cf. ypsilon

Genus DICTYOCORYNE

D. profunda

Genus HYMENIAST RUM

$H$. euclidis

Genus SPONGASTER

$S$. pentas

Genus STYLODICTYA

S. validispina sensu stricto

$S$. validispina : spinose form

S. validispina : quadrate form

$S$. cornuspira

Genus PORODISCUS

Porodiscus sp. A : normal form Porodiscus sp. A : spiral form

Porodiscus sp. B

Genus STYLOCHLAMYDIUM

$S$. asteriscus

Genus SPONGOTROCHUS

$S$. glacialis

Family PYLONIIDAE

Genus HEXAPYLE

$H$. cf. dodecantha

Genus TETRAPYLE

$T$. octacantha group

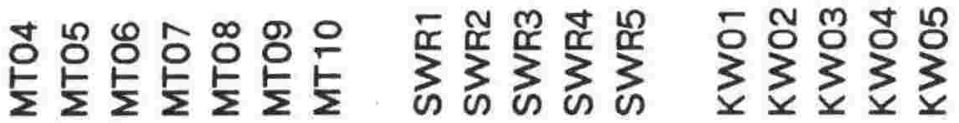
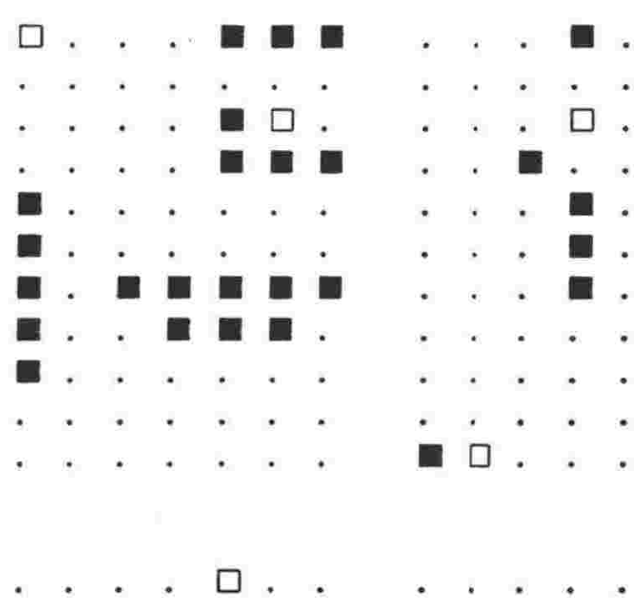

(n)


Family LARNACIDAE

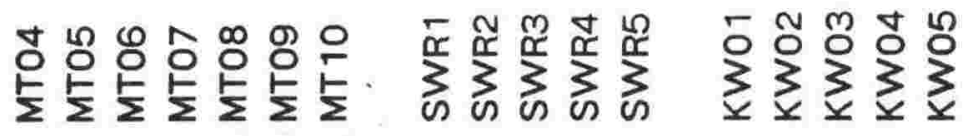

Genus LARNACILLA

L. typus

Family THOLONIIDAE

Genus CUBOT HOLUS

C. rhombicus

Family LITHELIIDAE

Genus LIT HELIUS

L. minor

L. nautiloides

Lithelius sp. A

Lithelius sp. B

Genus PYLOSPIRA

$P$. octopyle

Suborder NASSELLARIA

Family PLAGONIIDAE

Genus ANT ARCTISSA
A. antedenticulata
A. conradae
A. longa
A. strelkovi

Genus LITHOMELISSA

(?) L. setosa sensu stricto

(?) L. setosa : tri-legged

Genus LOPHOPHAENA

L. macrencephala group

Family ACANTHODESMIIDAE

Genus DESMOSPYRIS

$D$. rhodospyroides

$D$. sp. aff. rhodospyroides

Desmospyris (?) sp. A.

Genus GORGOSPYRIS

G. sp. aff. perizostra

Genus PHORMOSPYRIS

$P$. stabilis antarctica group

$P$. stabilis scaphipes group 
Family CARPOCANIIDAE

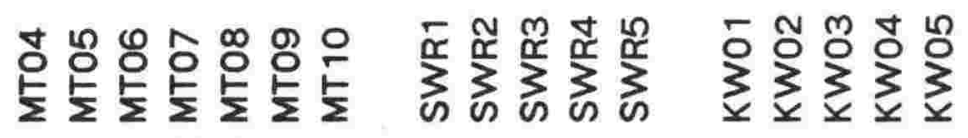

Genus CARPOCANARIUM

C. papillosum

Carpocanarium sp. A

Genus CARPOCANIST RUM

C. sp. A : with terminal teeth

C. sp. A : toothless

C. sp. A : very constricted

Genus CYSTOPHORMIS

C. sp. A : with terminal teeth

C. sp. A : toothless

Cystophormis sp. B

Family THEOPERIDAE

Genus CORNUTELLA

C. profunda : three pores

C. profunda : six pores

Genus PLECTOPYRAMIS

$P$. dodecomma

Genus PERIPYRAMIS

$P$. cf. circumtexta

Genus DICTYOPHIMUS

$D$. hirundo group

Genus PSEUDODICTYOPHIMUS

$P$. gracilipes

Genus LYCHNOCANIUM

$L$. sp. aff. grande : vertical feet

$L$. sp. aff. grande : divergent feet

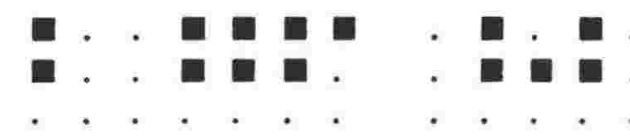

Genus $L Y C H N O C A N E L L A$

L. conicum

Genus ARCHIPILIUM

A. macropus

Genus CYRTOCAPSELLA

C. japonica : inflated abdomen

C. japonica : rounded abdomen

C. tetrapera

Genus CYRTOLAGENA

C. Laguncula sensu stricto

C. laguncula : spiralling form

Genus STICHOPHORMIS

$S$. cornutella 
Genus THEOCALYPTRA

T. bicornis

T. davisiana davisiana

Genus LAMPROMITRA

L. butschlii

L. erosa

L. tiara : flaring

L. tiara : U-shaped

Genus THEOCAMPE

? T. cf. mongolfieri

Genus EUCYRTIDIUM

E. acuminatum

E. cienkowskii

$E$. hexagonatum

$E$. calvertense

$E$. calvertense $\mathrm{X}$ inflatum

E. inflatum

E. punctatum

E. cf. montiparum

Eucyrtidium sp. A

$E$. vincentense : small pores

$E$. vincentense : large pores

\section{Genus STICHOCORYS}

$S$. peregrina

S. peregrina $\mathrm{X}$ delmontensis

$S$. delmontensis

Stichocorys sp. A

Genus GONDWANARIA

G. dogeli group

Genus 'ARTOST ROBUS'

'A.' pretabulatus

Family PTEROCORYTHIDAE

Genus ANT HOCY RTIDIUM

A. ehrenbergi pliocenica

? Anthocyrtidium sp. A

A. zanguebaricum

Genus LAMPROCYCLAS

L. gamphonycha

L. maritalis sensu stricto

$L$. cf. maritalis

Lamprocyclas (?) sp. A

Lamprocyclas sp. B

Lamprocyclas sp. C

Lamprocyclas sp. C X D

Lamprocyclas sp. D
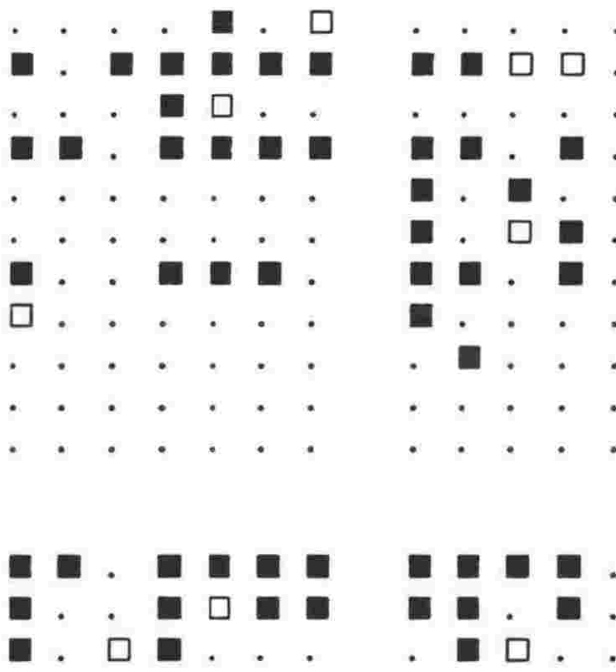

Lamprocyclas sp. E 
Genus LAMPROCY RTIS

L. (?) apollinis

L. hannai

L. heteroporos

L. (?) junonis

L. (?) cf. junonis

Family ARTOSTROBIIDAE

Genus BOT RYOST ROBUS

$B$. aquilonaris

$B$. auritus-australis group

B. bramlettei

Genus PHORMOSTICHOARTUS

$P$. fistula

Phormostichoartus sp. A

Genus SIPHOCAMPE

$S$. arachnea group

S. lineata : strictured

$S$. lineata : smooth

$S$. nodosaria

Genus SIPHOSTICHARTUS

$S$. corona

Genus SPIROCY RTIS

$S$. subscalaris

Family CANNOBOTRYIDAE

Genus BOT RYOPYLE

$B$. dictyocephalus sensu stricto

$B$. dictyocephalus : large lobe

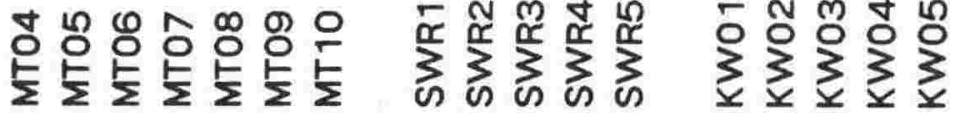

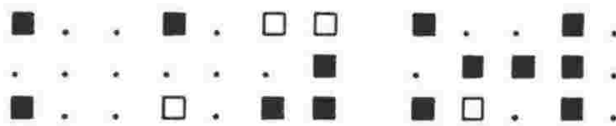
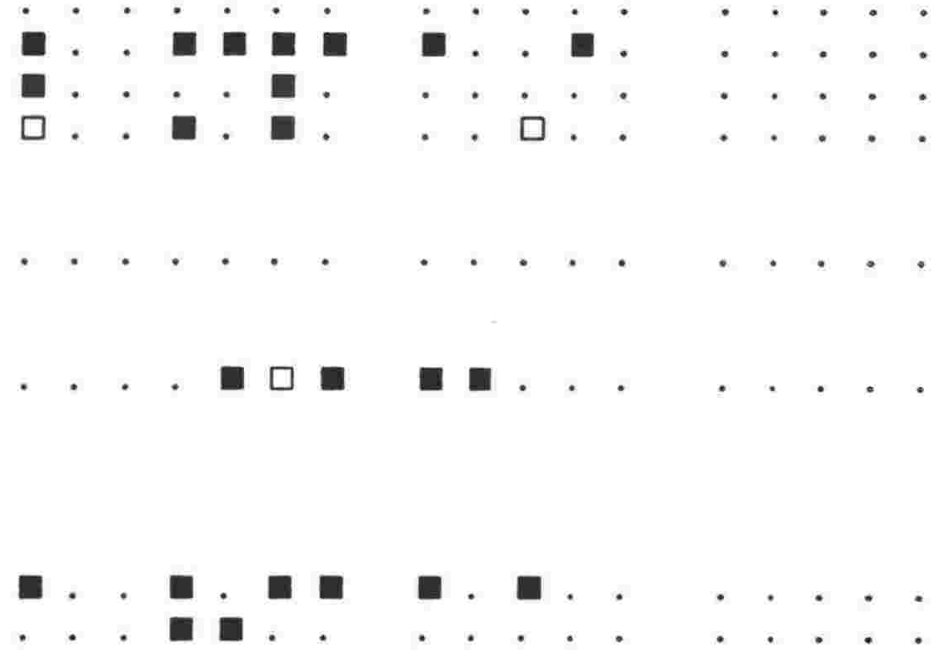
Suborder SPUMELLARIA
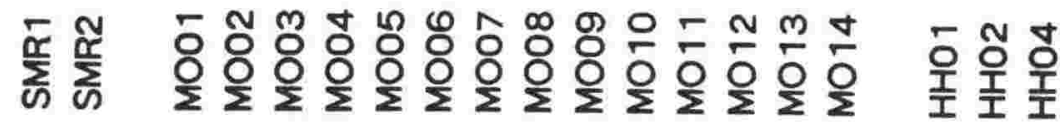

Family OROSPHAERIDAE

Genus OROPELEX

? Oropelex sp.

Family COLLOSPHAERIDAE

Genus COLLOSPHAERA

C. cf. polygona

C. sp. aff. huxleyi

Collosphaera sp. A

Genus ACROSPHAERA

A. spinosa echinoides

A. spinosa spinosa

Genus SIPHONOSPHAERA

$S$. polysiphonia

Genus OTOSPHAERA

O. polymor pha

Family ACTINOMMIDAE

Genus ACTINOMMA
A. antarcticum
A. cf. medianum
A. leptodermum
A. cf. leptodermum
A. polycanthum group

Genus CLADOCOCCUS

C. dentata

C. stalactites

Genus CENOSPHAERA

C. cristata

Cenosphaera sp. A

Cenosphaera sp. B

Cenosphaera sp. C

Cenosphaera sp. D

Genus ACANTHOSPHAERA

A. dodecastyla

A. sp. A : few spines

A. sp. A : many spines

Acanthosphaera sp. B
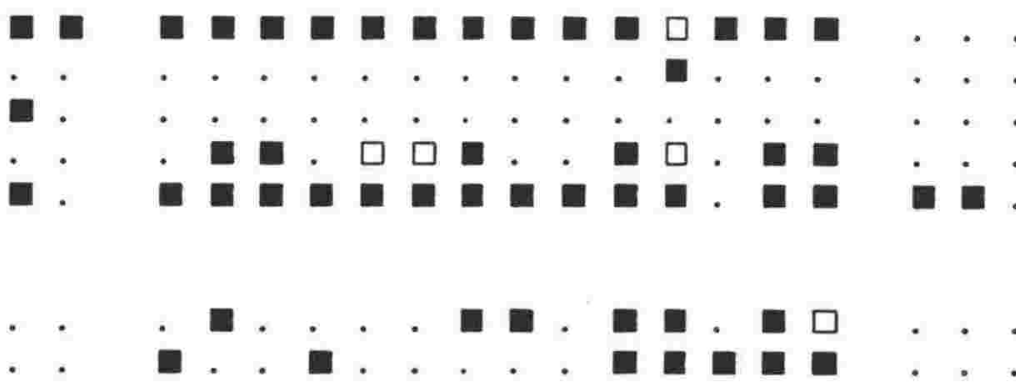
Genus $H E X A C O N T I U M$

$H$. enthacanthum sensu stricto

$H$. enthacanthum : oval form

$H$. enthacanthum : quadrate form

$H$. enthacanthum X laevigatum

$H$. laevigatum sensu stricto

$H$. laevigatum : oval form

$H$. laevigatum : quadrate form

$H$. laevigatum : long spined

Genus THECOSPHAERA

$T$. cf. akitaensis

T. grecoi group

Genus PRUNULUM

Prunulum spp.

Genus STYPTOSPHAERA

$S$. stupacea

S. spumacea

Genus 'STYLATRACTUS'

' $S$ '. neptunus forma. large pores

' $S$ '. universus : small pores

'S'. universus : large pores

Genus 'SPHAEROSTYLUS'

'S". sp. aff. timmsi : sensu Campbell

'S'. sp. aff. timmsi : symmetrical

Genus 'XIPH AT RACTUS'

'Xiphatractus' sp. A

Genus PRUNOPYLE

? P. antarctica

Prunopyle sp. A

Genus SPONGURUS

$S$. pylomaticus

Spongurus sp. A

Genus SPONGOCORE

$S$. puella

Spongocore sp. A

Family PHACODISCIDAE

Genus HELIODISCUS

$H$. asteriscus : large pores

$H$. asteriscus : small pores

$H$. asteriscus : long spines

$H$. cf. echiniscus

H. umbonatum

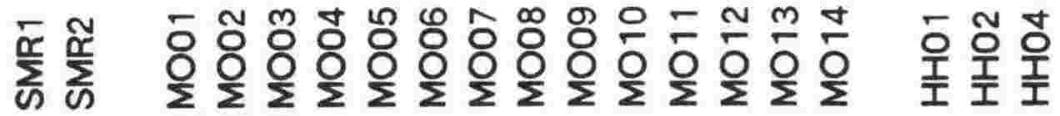

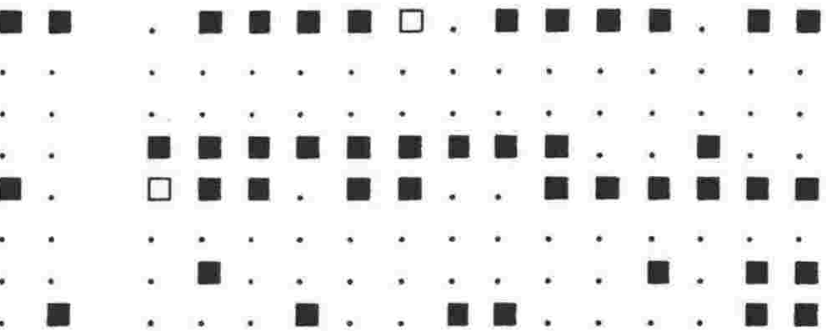

- 뭏.

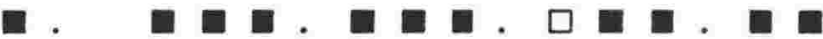
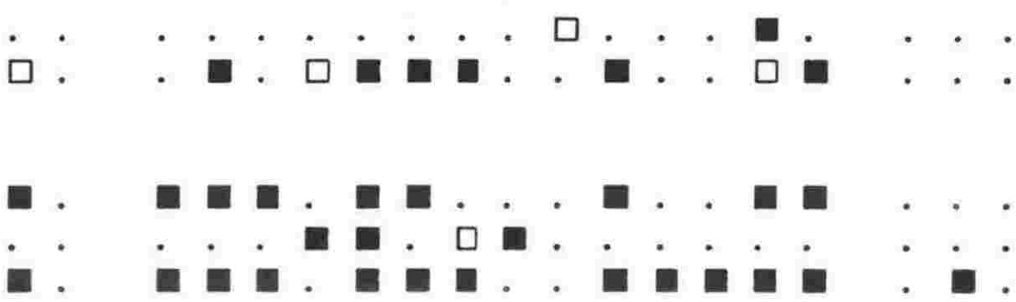
Family COCCODISCIDAE

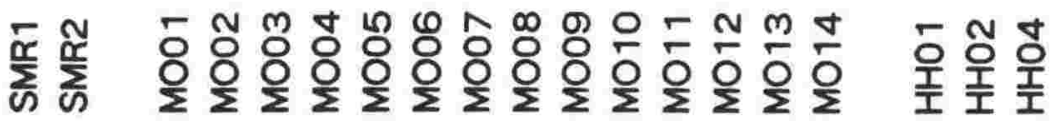

Genus DIDYMOCY RTIS

D. antepenultima

D. antepenultima $\mathrm{X}$ laticonus

D. laticonus

D. virgineum : non-constricted

D. virgineum : constricted

D. virgineum : tuberculate

D. sp. A : non-constricted

D. sp. A : constricted

D. sp. A : spherical

D. sp. A : narrow

D. tetrathalmus tetrathalmus

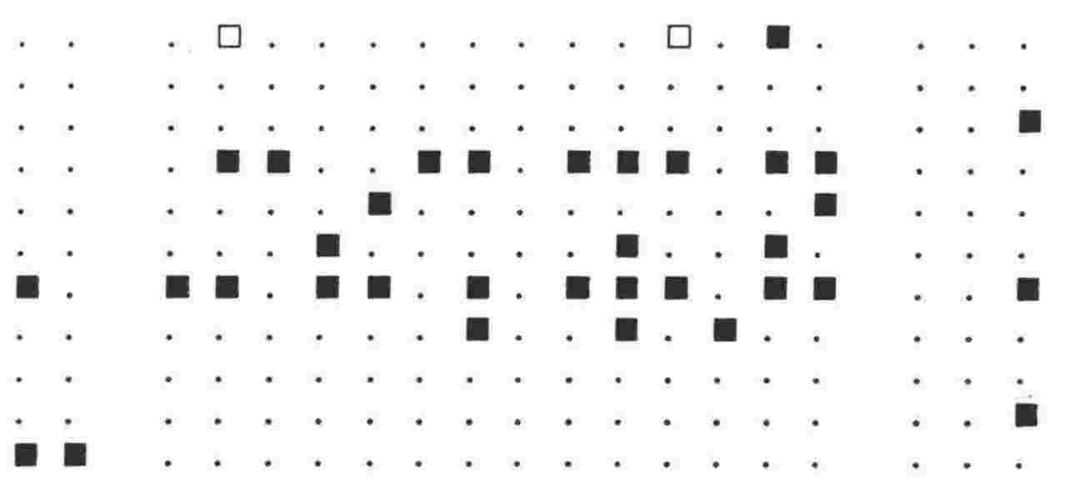

Genus DIARTUS

D. hughesi group

Family SPONGODISCIDAE

Genus AMPHIRHOPALUM

A. cf. ypsilon

Genus DICTYOCORYNE

D. profunda

Genus HYMENIAST RUM

H. euclidis

Genus SPONGASTER

$S$. pentas

Genus STYLODICTY A

$S$. validispina sensu stricto

$S$. validispina : spinose form

S. validispina : quadrate form

S. cornuspira

Genus PORODISCUS

Porodiscus sp. A : normal form Porodiscus sp. A : spiral form Porodiscus sp. B

Genus STYLOCHLAMYDIUM

$S$. asteriscus

Genus SPONGOTROCHUS

$S$. glacialis

Family PYLONIIDAE

Genus HEX APYLE

$H$. cf. dodecantha

Genus TETRAPYLE

$T$. octacantha group 
Family LARNACIDAE

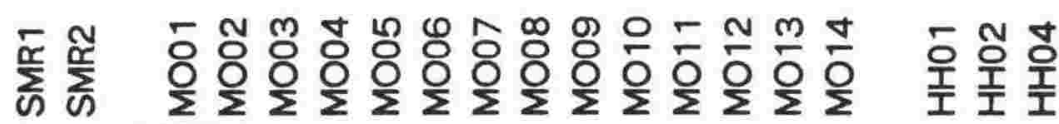

Genus LARNACILLA

L. typus

Family THOLONIIDAE

Genus CUBOTHOLUS

C. rhombicus

Family LITHELIIDAE

Genus LITHELIUS

L. minor

L. nautiloides

Lithelius sp. A

Lithelius sp. B

Genus PYLOSPIRA

P. octopyle

Suborder NASSELLARIA

Family PLAGONIIDAE

Genus ANT ARCT ISSA
A. antedenticulata
A. conradae
A. longa
A. strelkovi

Genus LITHOMELISSA

(?) L. setosa sensu stricto

(?) L. setosa : tri-legged

Genus LOPHOPHAENA

L. macrencephala group

Family ACANTHODESMIIDAE

Genus DESMOSPYRIS

$D$. rhodospyroides

$D$. sp. aff. rhodospyroides

Desmospyris (?) sp. A.

Genus GORGOSPYRIS

G. sp. aff. perizostra

Genus PHORMOSPYRIS

$P$. stabilis antarctica group

$P$. stabilis scaphipes group 
Family CARPOCANIIDAE

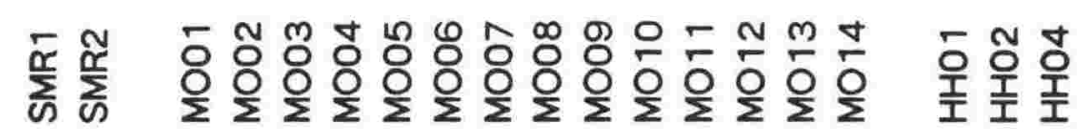

Genus CARPOCANARIUM

C. papillosum

Carpocanarium sp. A

Genus CARPOCANIST RUM

C. sp. A : with terminal teeth

C. sp. A : toothless

C. sp. A : very constricted

Genus CYSTOPHORMIS

C. sp. A : with terminal teeth

C. sp. A : toothless

Cystophormis sp. B

Family THEOPERIDAE

Genus CORNUTELLA

C. profunda : three pores

C. profunda : six pores

Genus PLECTOPY RAMIS

P. dodecomma

Genus PERIPYRAMIS

$P$. cf. circumtexta

Genus DICTYOPHIMUS

$D$. hirundo group

Genus PSEUDODICTYOPHIMUS

$P$. gracilipes

Genus LYCHNOCANIUM

$L$. sp. aff. grande : vertical feet

$L$. sp. aff. grande : divergent feet

Genus LYCHNOCANELLA

L. conicum

Genus ARCHIPILIUM

A. macropus

Genus CYRTOCAPSELLA

C. japonica : inflated abdomen

C. japonica : rounded abdomen

C. tetrapera

Genus CYRTOLAGENA

C. laguncula sensu stricto

C. laguncula : spiralling form

Genus STICHOPHORMIS

$S$. cornutella 
Genus THEOCALY PT RA

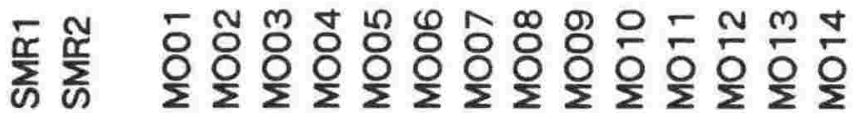

T. bicornis

T. davisiana davisiana

Genus LAMPROMITRA

L. butschlii

L. erosa

L. tiara : flaring

L. tiara : U-shaped

Genus THEOCAMPE

? T. cf. mongolfieri

Genus EUCY RTIDIUM

E. acuminatum

E. cienkowskii

$E$. hexagonatum

E. calvertense

$E$. calvertense $\mathrm{X}$ inflatum

$E$. inflatum

E. punctatum

E. cf. montiparum

Eucyrtidium sp. A

$E$. vincentense : small pores

E. vincentense : large pores

Genus STICHOCORYS

$S$. peregrina

S. peregrina $\mathrm{X}$ delmontensis

$S$. delmontensis

Stichocorys sp. A

Genus GONDW ANARIA

G. dogeli group

Genus 'ARTOSTROBUS'

'A.' pretabulatus

Family PTEROCORYTHIDAE

Genus ANTHOCY RTIDIUM A. ehrenbergi pliocenica ? Anthocyrtidium sp. A

A. zanguebaricum

Genus LAMPROCYCLAS

L. gamphonycha

L. maritalis sensu stricto

L. cf. maritalis

Lamprocyclas (?) sp. A

Lamprocyclas sp. B

Lamprocyclas sp. C

Lamprocyclas sp. C X D

Lamprocyclas sp. D

Lamprocyclas sp. E 
Genus LAMPROCY RTIS

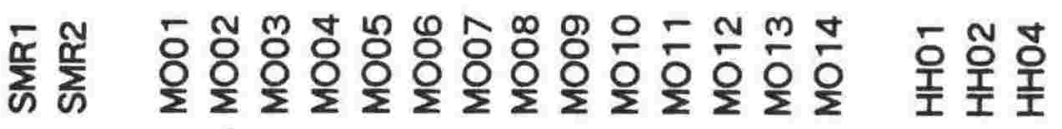

L. (?) apollinis

L. hannai.

L. heteroporos

L. (?) junonis

L. (?) cf. junonis

Family ARTOSTROBIIDAE

Genus BOT RYOST ROBUS

$B$. aquilonaris

B. auritus-australis group

B. bramlettei

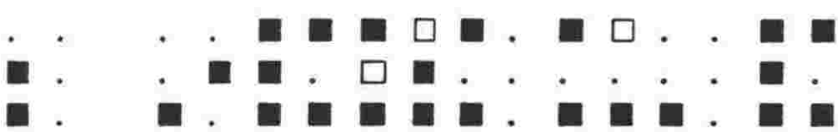

Genus PHORMOSTICHOARTUS

$P$. fistula

Phormostichoartus sp. A

Genus SIPHOCAMPE

$S$. arachnea group

$S$. lineata : strictured

$S$. lineata : smooth

$S$. nodosaria

Genus SIPHOSTICHARTUS

S. corona

Genus SPIROCYRTIS

S. subscalaris

Family CANNOBOTRYIDAE

Genus BOT RYOPYLE

$B$. dictyocephalus sensu stricto

$B$. dictyocephalus : large lobe 
Suborder SPUMELLARIA

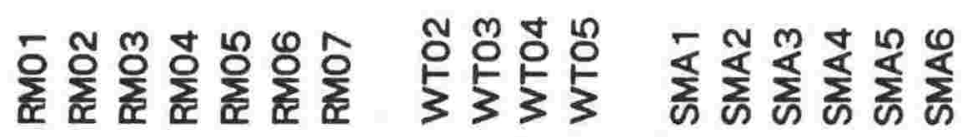

Family OROSPHAERIDAE

Genus OROPELEX

? Oropelex sp.

Family COLLOSPHAERIDAE

Genus COLLOSPHAERA

C. cf. polygona

C. sp. aff. huxleyi

Collosphaera sp. A

Genus ACROSPHAERA

A. spinosa echinoides

A. spinosa spinosa

Genus SIPHONOSPHAERA

$S$. polysiphonia

Genus OTOSPHAERA

O. polymorpha

Family ACTINOMMIDAE

Genus ACT INOMMA

A. antarcticum

A. cf. medianum

A. leptodermum

A. cf. leptodermum

A. polycanthum group

Genus CLADOCOCCUS

C. dentata

C. stalactites

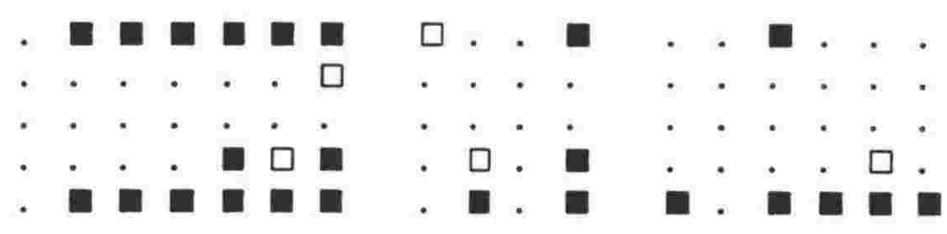

Genus CENOSPHAERA

C. cristata

Cenosphaera sp. A

Cenosphaera sp. B

Cenosphaera sp. C

Cenosphaera sp. D

Genus ACANTHOSPHAERA

A. dodecastyla

A. sp. A : few spines

A. sp. A : many spines

Acanthosphaera sp. B 
Genus HEXACONTIUM

$H$. enthacanthum sensu stricto

$H$. enthacanthum : oval form

$H$. enthacanthum : quadrate form

$H$. enthacanthum $X$ laevigatum

$H$. laevigatum sensu stricto

$H$. laevigatum : oval form

$H$. laevigatum : quadrate form

$H$. laevigatum : long spined

Genus THECOSPHAERA

T. cf. akitaensis

T. grecoi group

Genus PRUNULUM

Prunulum spp.

Genus STYPTOSPHAERA

S. stupacea

S. spumacea

Genus 'STYLATRACTUS'

'S. neptunus forma. large pores

'S. universus : small pores

'S'. universus : large pores

Genus 'SPHAEROSTYLUS'

'S. sp. aff. timmsi : sensu Campbell

'S'. sp. aff. timmsi : symmetrical

Genus 'XIPH ATRACTUS'

'Xiphatractus' sp. A

Genus PRUNOPYLE

? P. antarctica

Prunopyle sp. A

Genus SPONGURUS

$S$. pylomaticus

Spongurus sp. A

Genus SPONGOCORE

$S$. puella

Spongocore sp. A

Family PHACODISCIDAE

Genus HELIODISCUS

$H$. asteriscus : large pores

$H$. asteriscus : small pores

$H$. asteriscus : long spines

$H$. cf. echiniscus

$H$. umbonatum
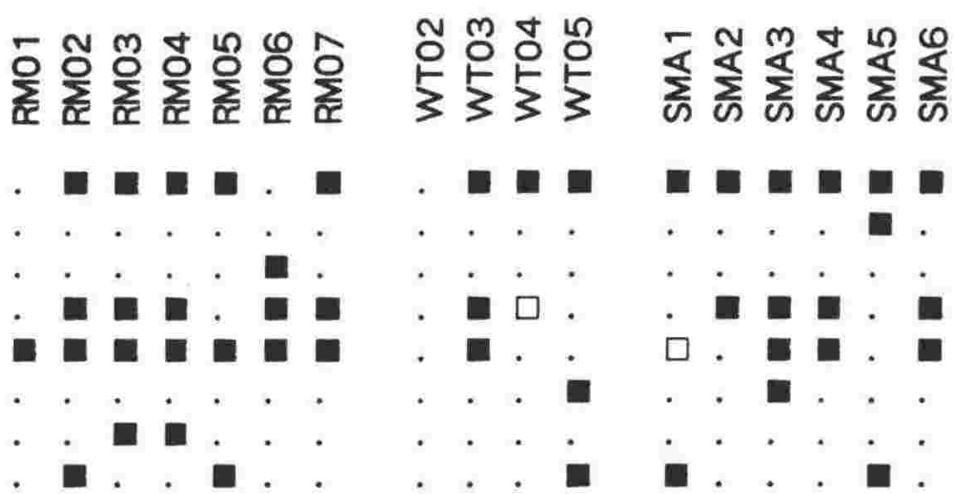

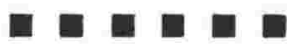

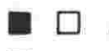

i

므.

….
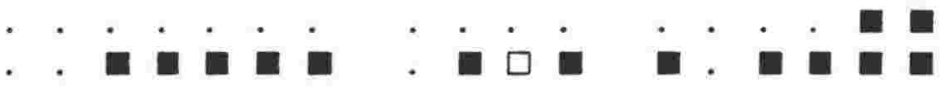

. $\square \square \square \square$
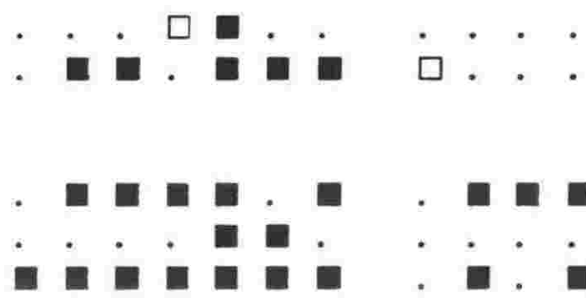
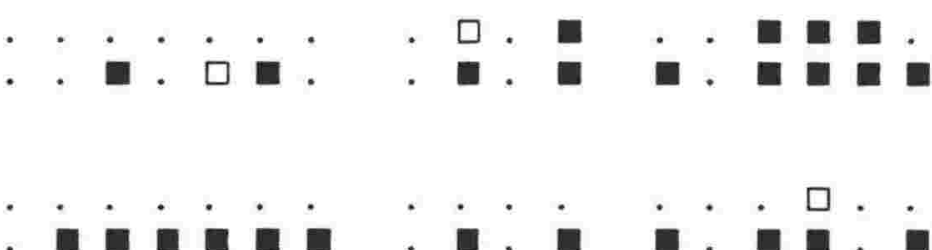

․

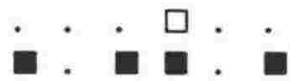


Family COCCODISCIDAE

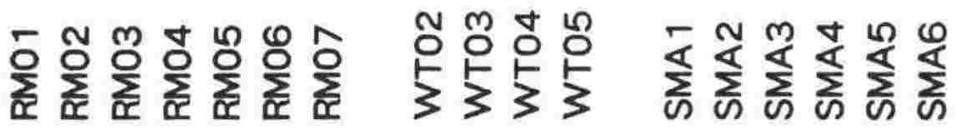

Genus DIDYMOCY RTIS

D. antepenultima

D. antepenultima $\mathrm{X}$ laticonus

D. laticonus

D. virgineum : non-constricted

D. virgineum : constricted

D. virgineum : tuberculate

D. sp. A : non-constricted

D. sp. A : constricted

D. sp. A : spherical

D. sp. A : narrow

D. tetrathalmus tetrathalmus

Genus DIARTUS

$D$. hughesi group

Family SPONGODISCIDAE

Genus AMPHIRHOPALUM

A. cf. ypsilon

Genus DICTYOCORYNE

D. profunda

Genus HYMENIASTRUM

$H$. euclidis

Genus SPONGASTER

$S$. pentas

Genus STYLODICTYA

$S$. validispina sensu stricto

$S$. validispina : spinose form

$S$. validispina : quadrate form

S. cornuspira

Genus PORODISCUS

Porodiscus sp. A : normal form

Porodiscus sp. A : spiral form

Porodiscus sp. B

Genus STYLOCHLAMY DIUM

$S$. asteriscus

Genus SPONGOT ROCHUS

$S$. glacialis

Family PYLONIIDAE

Genus HEXAPYLE

$H$. cf. dodecantha

Genus TETRAPYLE

$T$. octacantha group
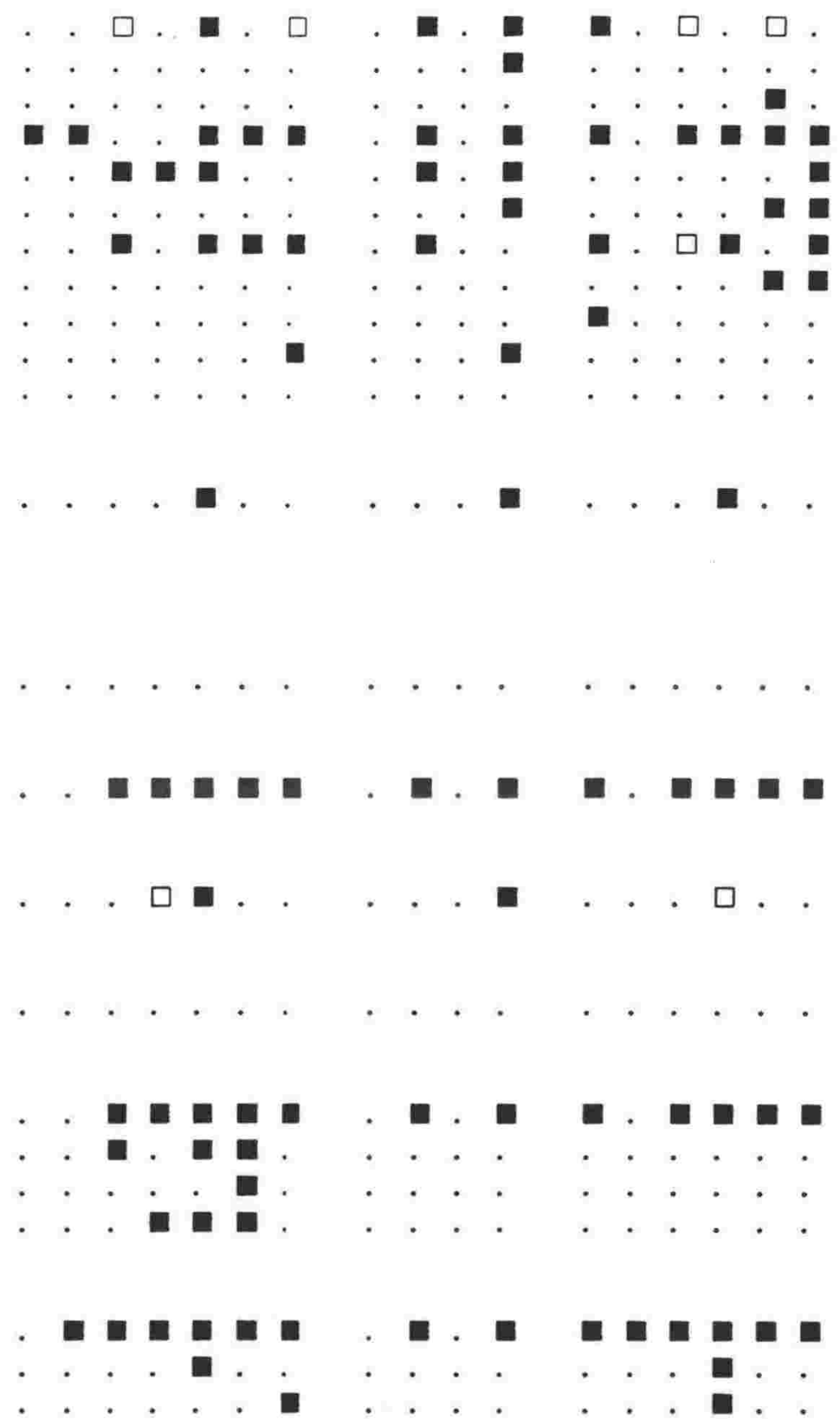

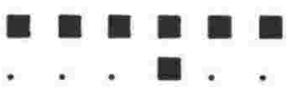

・,$\quad$. 
Family LARNACIDAE

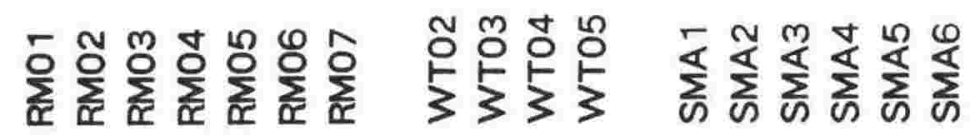

Genus LARNACILLA

L. typus

Family THOLONIIDAE

Genus CUBOT HOLUS

C. rhombicus

Family LITHELIIDAE

Genus LITHELIUS

L. minor

L. nautiloides

Lithelius sp. A

Lithelius sp. B

Genus PYLOSPIRA

$P$. octopyle

Suborder NASSELLARIA

Family PLAGONIIDAE

Genus ANT ARCTISSA

A. antedenticulata

A. conradae

A. longa

A. strelkovi

Genus LIT HOMELISSA

(?) L. setosa sensu stricto

(?) L. setosa : tri-legged

Genus LOPHOPHAENA

L. macrencephala group

Family ACANTHODESMIIDAE

Genus DESMOSPYRIS

$D$. rhodospyroides

$D$. sp. aff. rhodospyroides

Desmospyris (?) sp. A.

Genus GORGOSPYRIS

G. sp. aff. perizostra

Genus PHORMOSPYRIS

$P$. stabilis antarctica group

$P$. stabilis scaphipes group 
Family CARPOCANIIDAE

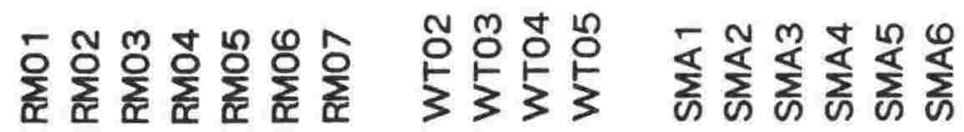

Genus CARPOCANARIUM

C. papillosum

Carpocanarium sp. A

Genus CARPOCANIST RUM

C. sp. A : with terminal teeth

C. sp. A : toothless

C. sp. A : very constricted

Genus CYSTOPHORMIS

C. sp. A : with terminal teeth

C. sp. A : toothless

Cystophormis sp. B

Family THEOPERIDAE

Genus CORNUTELLA

C. profunda: three spines

C. profunda : six spines

Genus PLECTOPYRAMIS

$P$. dodecomma

Genus PERIPYRAMIS

$P$. cf. circumtexta

Genus DICTYOPHIMUS

$D$. hirundo group

Genus PSEUDODICTYOPHIMUS

$P$. gracilipes

Genus LYCHNOCANIUM

$L$. sp. aff. grande : vertical feet

$L$. sp. aff. grande : divergent feet

Genus LYCHNOCANELLA

L. conicum

Genus ARCHIPILIUM

A. macropus

Genus CY RTOCAPSELLA

C. japonica : inflated abdomen

C. japonica : rounded abdomen

C. tetrapera

Genus CY RTOLAGENA

C. laguncula sensu stricto

C. laguncula : spiralling form

Genus STICHOPHORMIS

$S$. cornutella 
Genus THEOCALYPTRA

T. bicornis

T. davisiana davisiana

Genus LAMPROMITRA

L. butschlii

L. erosa

L. tiara : flaring

L. tiara : U-shaped

Genus THEOCAMPE

? T. cf. mongolfieri

\section{Genus EUCY RTIDIUM}

E. acuminatum

E. cienkowskii

$E$. hexagonatum

$E$. calvertense

$E$. calvertense $\mathrm{X}$ inflatum

$E$. inflatum

E. punctatum

E. cf. montiparum

Eucyrtidium sp. A

$E$. vincentense : small pores

E. vincentense : large pores

Genus STICHOCORYS

$S$. peregrina

$S$. peregrina $\mathrm{X}$ delmontensis

$S$. delmontensis

Stichocorys sp. A

Genus GONDW ANARIA

G. dogeli group

Genus 'ARTOST ROBUS'

'A.' pretabulatus

Family PTEROCORYTHIDAE

Genus ANTHOCY RTIDIUM

A. ehrenbergi pliocenica

? Anthocyrtidium sp. A

A. zanguebaricum

Genus LAMPROCYCLAS

L. gamphonycha

L. maritalis sensu stricto

$L$. cf. maritalis

Lamprocyclas (?) sp. A

Lamprocyclas sp. B

Lamprocyclas sp. C

Lamprocyclas sp. C X D

Lamprocyclas sp. D

Lamprocyclas $\mathrm{sp}$. E
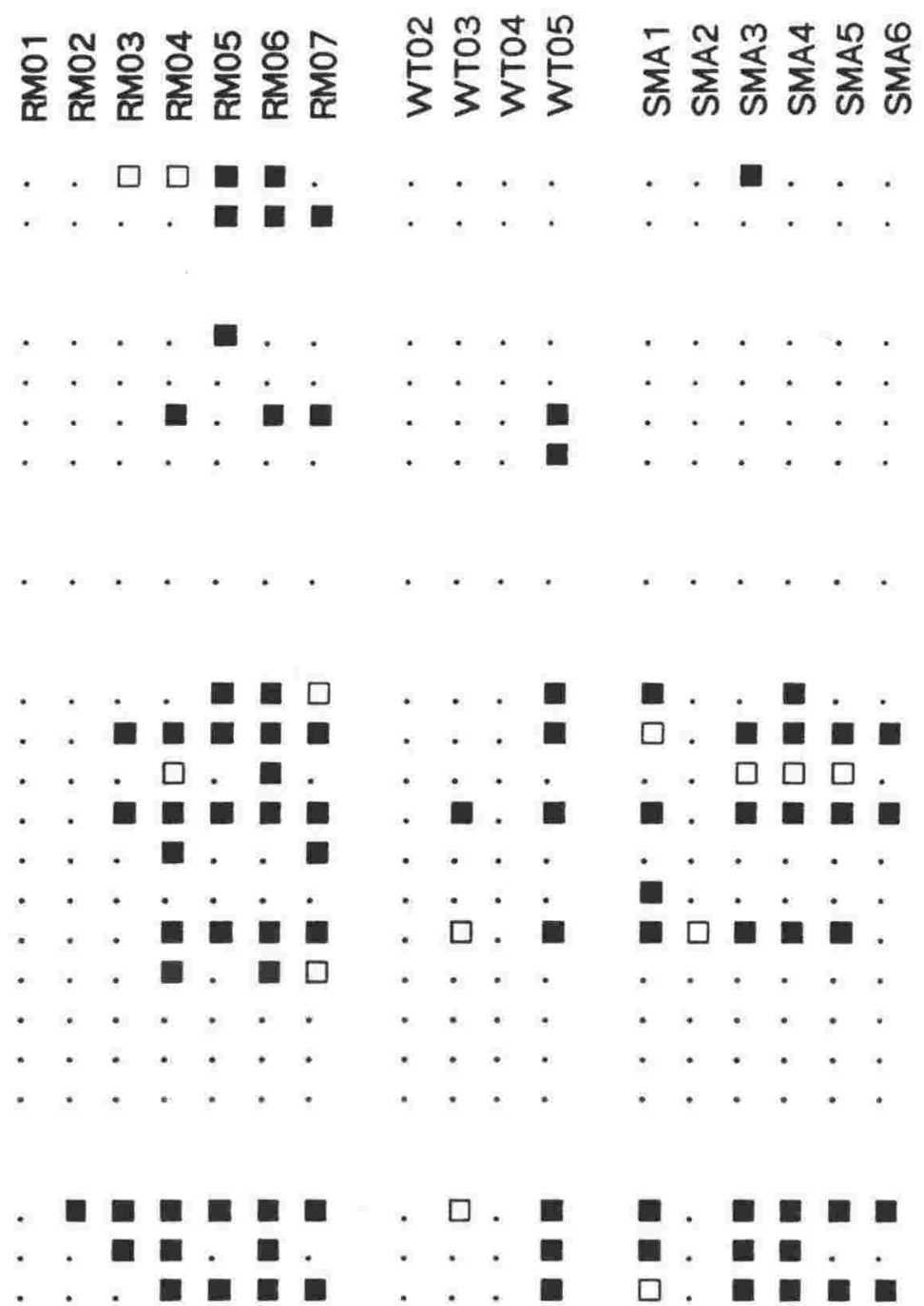

.

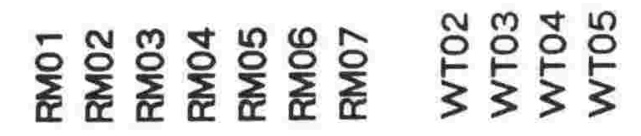

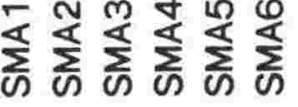


Genus LAMPROCY RTIS

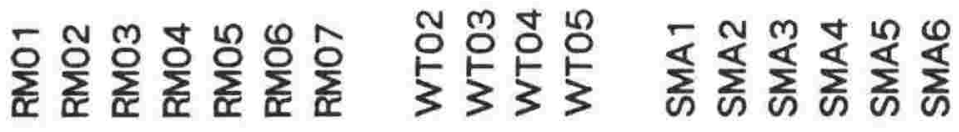

L. (?) apollinis

L. hannai

L. heteroporos

L. (?) junonis

L. (?) cf. junonis

Family ARTOSTROBIIDAE

Genus BOT RYOST ROBUS

$B$. aquilonaris

$B$. auritus-australis group

B. bramlettei

Genus PHORMOSTICHOARTUS

$P$. fistula

Phormostichoartus sp. A

Genus SIPHOCAMPE

$S$. arachnea group

$S$. lineata : strictured

S. lineata : smooth

$S$. nodosaria

Genus SIPHOSTICH ARTUS

$S$. corona

Genus SPIROCYRTIS

S. subscalaris

Family CANNOBOTRYIDAE

Genus BOT RYOPYLE

$B$. dictyocephalus sensu stricto

$B$. dictyocephalus : large lobe 
Suborder SPUMELLARIA

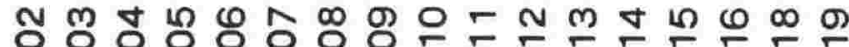

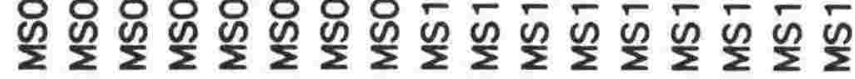

Family OROSPHAERIDAE

Genus OROPELEX

? Oropelex sp.

Family COLLOSPHAERIDAE

Genus COLLOSPHAERA

C. cf. polygona

C. sp. aff. huxleyi

Collosphaera sp. A

Genus ACROSPHAERA

A. spinosa echinoides

A. spinosa spinosa

Genus SIPHONOSPHAERA

$S$. polysiphonia

Genus OTOSPHAERA

$O$. polymor pha

Family ACTINOMMIDAE

Genus ACTINOMMA

A. antarcticum

A. cf. medianum

A. leptodermum

A. cf. leptodermum

A. polycanthum group

Genus CLADOCOCCUS

C. dentata

C. stalactites

Genus CENOSPHAERA

C. cristata

Cenosphaera sp. A

Cenosphaera sp. B

Cenosphaera sp. C

Cenosphaera sp. D

Genus ACANTHOSPHAERA

A. dodecastyla

A. sp. A : few spines

A. sp. A : many spines Acanthosphaera sp. B
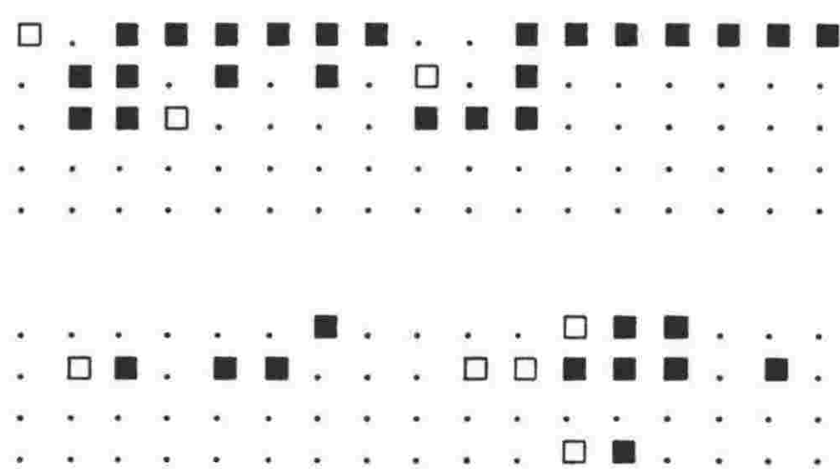
Genus $H E X A C O N T I U M$

$H$. enthacanthum sensu stricto

$H$. enthacanthum : oval form

$H$. enthacanthum : quadrate form

$H$. enthacanthum X laevigatum

$H$. laevigatum sensu stricto

$H$. laevigatum : oval form

$H$. laevigatum : quadrate form

$H$. laevigatum : long spined

Genus THECOSPHAERA

$T$. cf. akitaensis

T. grecoi group

\section{Genus PRUNULUM}

Prunulum spp.

\section{Genus STYPTOSPHAERA}

S. stupacea

S. spumacea

Genus 'STYLATRACTUS'

' $S$ '. neptunus forma. large pores

' $S$ '. universus : small pores

'S'. universus : large pores

Genus 'SPHAEROSTYLUS'

'S". sp. aff. timmsi : sensu Campbell

'S. sp. aff. timmsi : symmetrical

Genus 'XIPHATRACTUS'

'Xiphatractus' sp. A

Genus PRUNOPYLE

? P. antarctica

Prunopyle sp. A

Genus SPONGURUS

$S$. pylomaticus

Spongurus sp. A

Genus SPONGOCORE

$S$. puella

Spongocore sp. A

Family PHACODISCIDAE

Genus HELIODISCUS

$H$. asteriscus : large pores

$H$. asteriscus : small pores

$H$. asteriscus : long spines

$H$. cf. echiniscus

$H$. umbonatum
₹

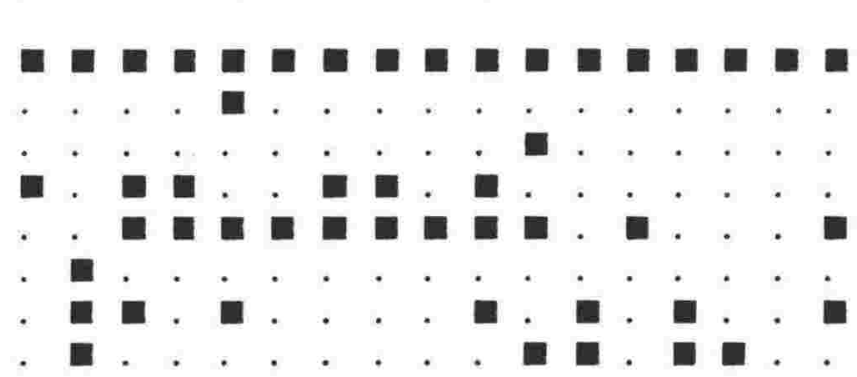

a

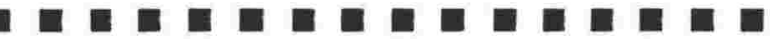

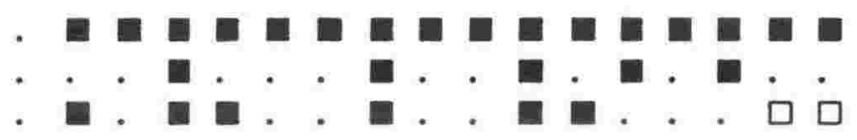

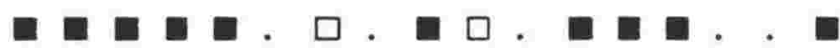

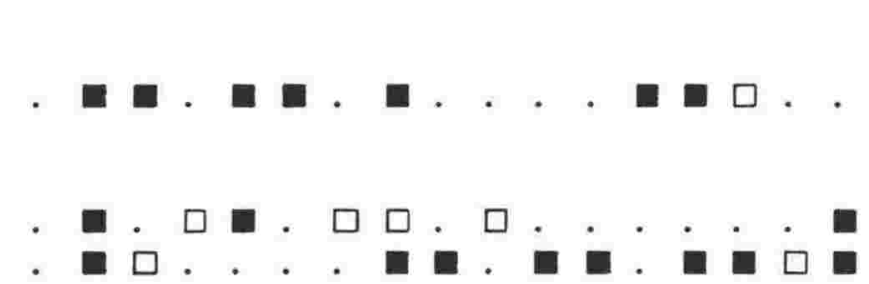

.

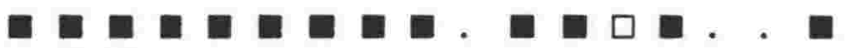

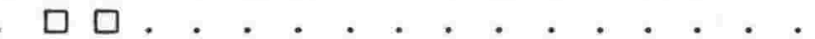


Family COCCODISCIDAE

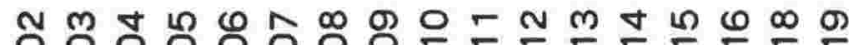

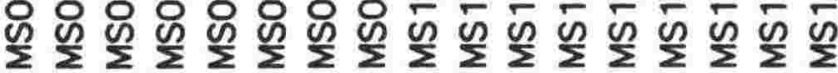

Genus DIDY MOCY RT IS

D. antepenultima

D. antepenultima $\mathrm{X}$ laticonus

D. laticonus

D. virgineum : non-constricted

D. virgineum : constricted

D. virgineum : tuberculate

D. sp. A : non-constricted

D. sp. A : constricted

D. sp. A : spherical

D. sp. A : narrow

D. tetrathalmus tetrathalmus

Genus DIARTUS

$D$. hughesi group

Family SPONGODISCIDAE

Genus AMPHIRHOPALUM

A. cf. ypsilon

Genus DICTYOCORYNE

D. profunda

Genus HYMENI AST RUM

$H$. euclidis

Genus SPONGASTER

$S$. pentas

Genus STYLODICTY A

S. validispina sensu stricto

$S$. validispina : spinose form

$S$. validispina : quadrate form

$S$. cornuspira

Genus PORODISCUS

Porodiscus sp. A : normal form

Porodiscus sp. A : spiral form

Porodiscus sp. B

Genus STYLOCHLAMY DIUM

$S$. asteriscus

Genus SPONGOT ROCHUS

$S$. glacialis

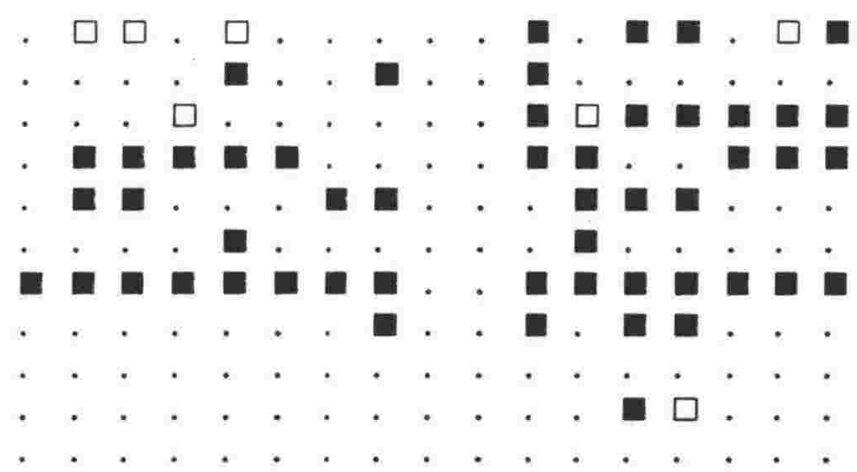

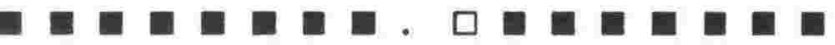

Family PYLONIIDAE

Genus HEXAPYLE

$H$. cf. dodecantha

Genus TETRAPYLE

T. octacantha group
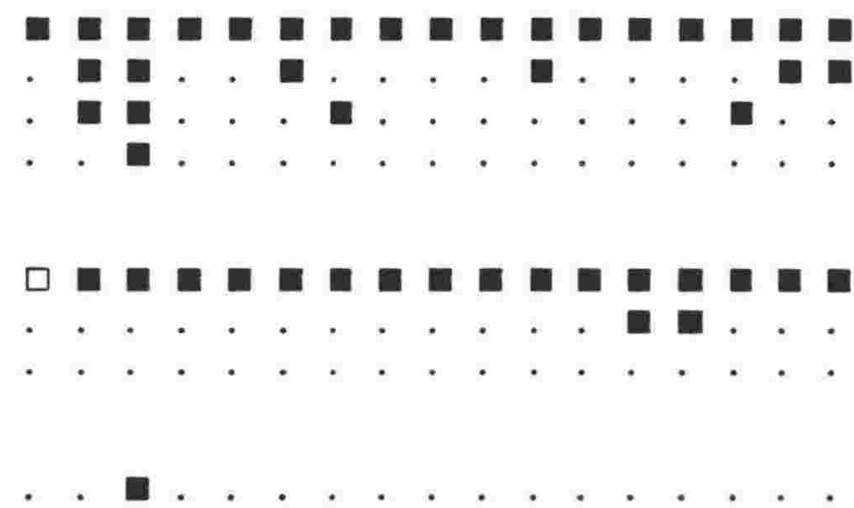

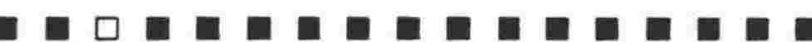


Family LARNACIDAE

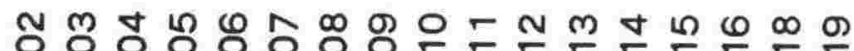
$\sum \sum \sum \sum \sum \sum \sum \sum \sum \sum \sum \sum \sum \sum \sum \sum \sum \sum \frac{W}{\Sigma} \sum \sum$

Genus LARNACILLA

L. typus

Family THOLONIIDAE

Genus CUBOT HOLUS

C. rhombicus

Family LITHELIIDAE

Genus LITHELIUS

L. minor

L. nautiloides

Lithelius sp. A

Lithelius sp. B

Genus PYLOSPIRA

$P$. octopyle

Suborder NASSELLARIA

Family PLAGONIIDAE

Genus ANT ARCTISSA

$A$. antedenticulata

A. conradae

A. longa

A. strelkovi

Genus LITHOMELISSA

(?) L. setosa sensu stricto

(?) L. setosa : tri-legged

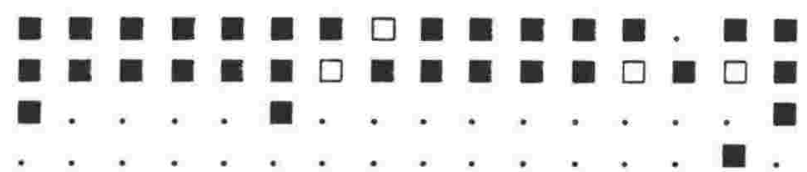

Genus LOPHOPHAENA

L. macrencephala group

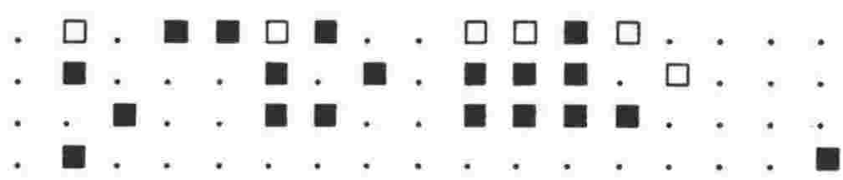

Family ACANTHODESMIIDAE

Genus DESMOSPYRIS

$D$. rhodospyroides

D. sp. aff. rhodospyroides

Desmospyris (?) sp. A.

Genus GORGOSPYRIS

G. sp. aff. perizostra

Genus PHORMOSPYRIS

$P$. stabilis antarctica group

$P$. stabilis scaphipes group

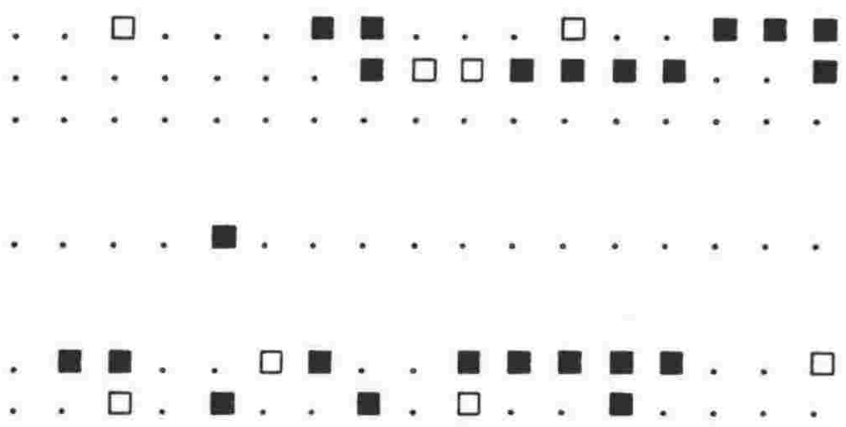


Family CARPOCANIIDAE

Genus CARPOCANARIUM

C. papillosum

Carpocanarium sp. A

Genus CARPOCANIST RUM

C. sp. A : with terminal teeth

C. sp. A : toothless

C. sp. A : very constricted

\section{Genus CYSTOPHORMIS}

C. sp. A : with terminal teeth

C. sp. A : toothless

Cystophormis sp. B

Family THEOPERIDAE

Genus CORNUTELLA

C. profunda: three spines

C. profunda : six spines

Genus PLECTOPY RAMIS

$P$. dodecomma

Genus PERIPYRAMIS

$P$. cf. circumtexta

Genus DICTYOPHIMUS

$D$. hirundo group

Genus PSEUDODICTYOPHIMUS

$P$. gracilipes

Genus LYCHNOCANIUM

$L$. sp. aff. grande : vertical feet

$L$. sp. aff. grande : divergent feet

Genus LYCHNOCANELLA

L. conicum

Genus ARCHIPILIUM

A. macropus

Genus CYRTOCAPSELLA

C. japonica : inflated abdomen

C. japonica : rounded abdomen

C. tetrapera

Genus CY RTOLAGENA

C. laguncula sensu stricto

C. laguncula : spiralling form

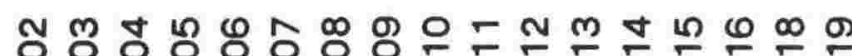

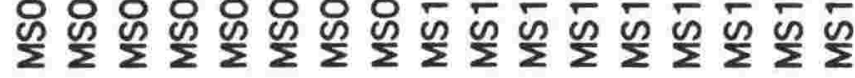

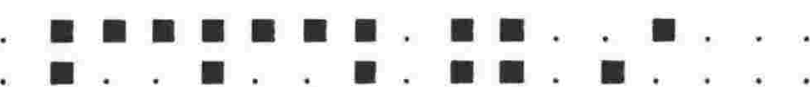
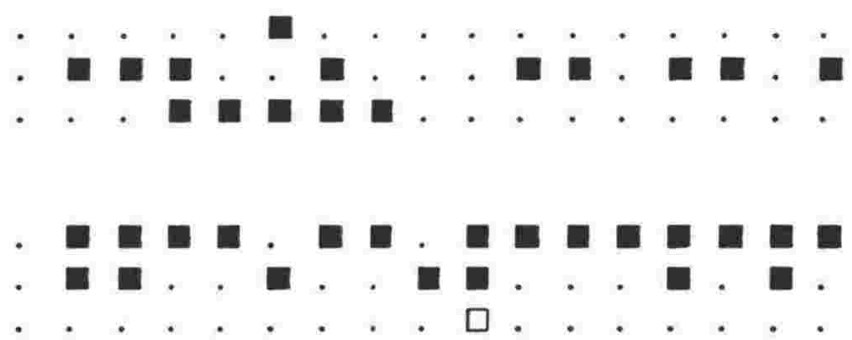
Genus THEOCALYPTRA

$T$. bicornis

T. davisiana davisiana

Genus LAMPROMITRA

L. butschlii

L. erosa

L. tiara : flaring

L. tiara : U-shaped

Genus THEOCAMPE

? T. cf. mongolfieri

Genus EUCYRTIDTUM

E. acuminatum

E. cienkowskii

$E$. hexagonatum

E. calvertense

$E$. calvertense $\mathrm{X}$ inflatum

E. inflatum

$E$. punctatum

E. cf. montiparum

Eucyrtidium sp. A

$E$. vincentense : small pores

$E$. vincentense : large pores

Genus STICHOCORYS

$S$. peregrina

$S$. peregrina $\mathrm{X}$ delmontensis

$S$. delmontensis

Stichocorys sp. A

Genus GONDWANARIA

G. dogeli group

Genus 'ARTOSTROBUS'

'A.' pretabulatus

Family PTEROCORYTHIDAE

Genus ANTHOCY RTIDIUM

A. ehrenbergi pliocenica

? Anthocyrtidium sp. A

A. zanguebaricum

Genus LAMPROCYCLAS

L. gamphonycha

L. maritalis sensu stricto

L. cf. maritalis

Lamprocyclas (?) sp. A

Lamprocyclas sp. B

Lamprocyclas sp. C

Lamprocyclas sp. C X D

Lamprocyclas sp. D

Lamprocyclas sp. E

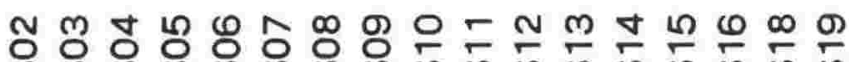

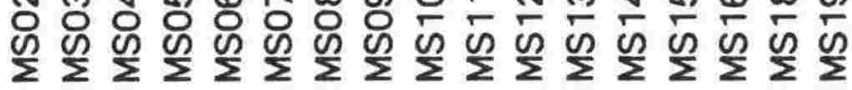

$\square \square$
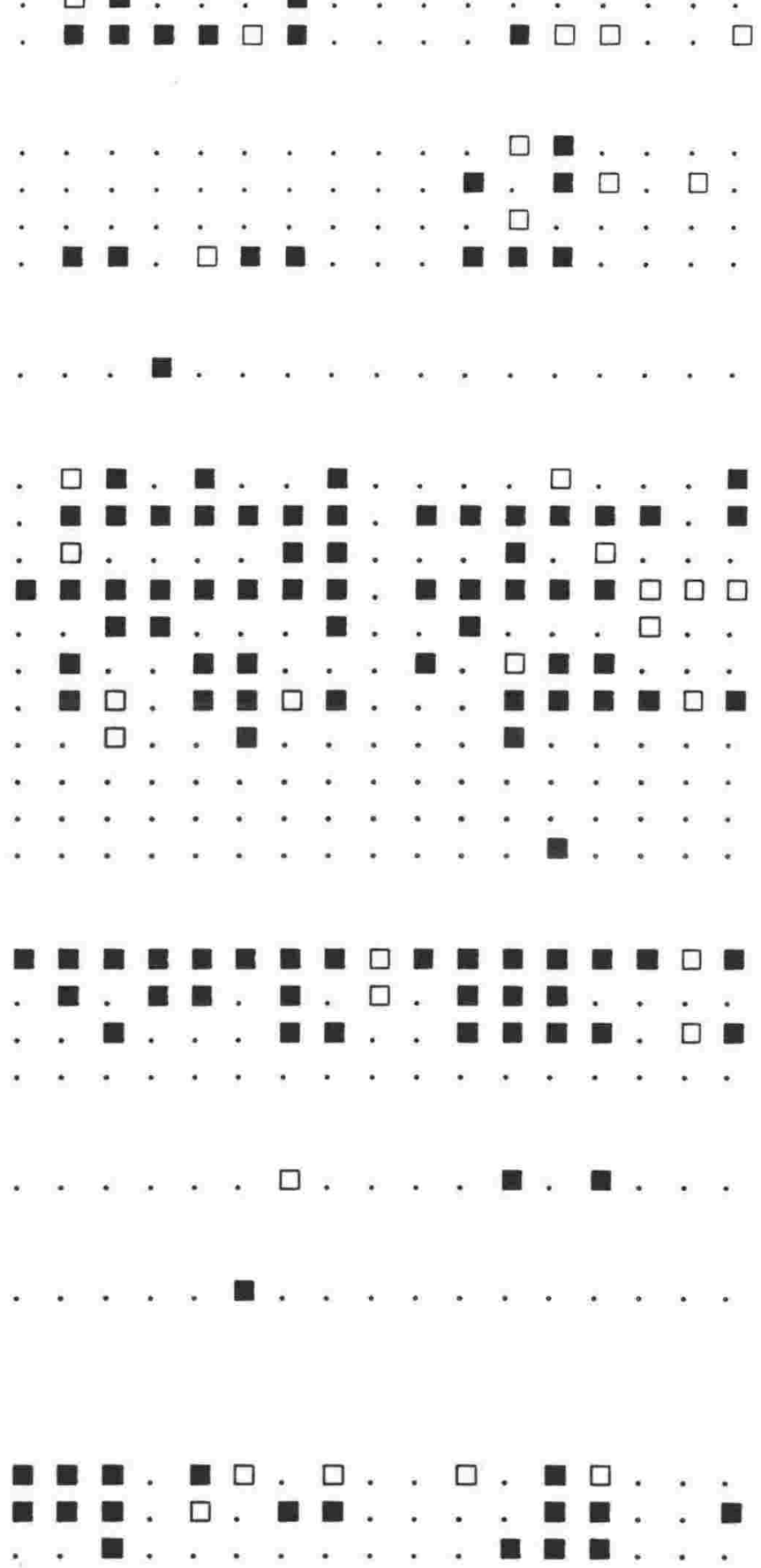
Genus LAMPROCYRTIS

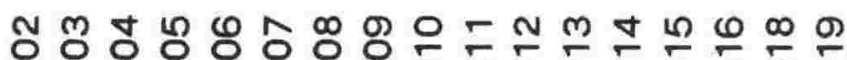

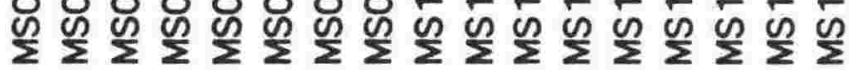

L. (?) apollinis

L. hannai

L. heteroporos

L. (?) junonis

L. (?) cf. junonis

Family ARTOSTROBIIDAE

Genus BOT RYOST ROBUS

$B$. aquilonaris

$B$. auritus-australis group

B. bramlettei

Genus PHORMOSTICHOARTUS

$P$. fistula

Phormostichoartus sp. A

Genus SIPHOCAMPE

$S$. arachnea group

$S$. lineata : strictured

$S$. lineata : smooth

$S$. nodosaria

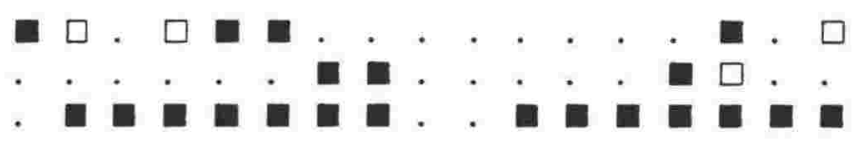

Genus SIPHOSTICHARTUS

$S$. corona

Genus SPIROCYRTIS

S. subscalaris

Family CANNOBOTRYIDAE

Genus BOTRYOPYLE

B. dictyocephalus sensu stricto

$B$. dictyocephalus : large lobe
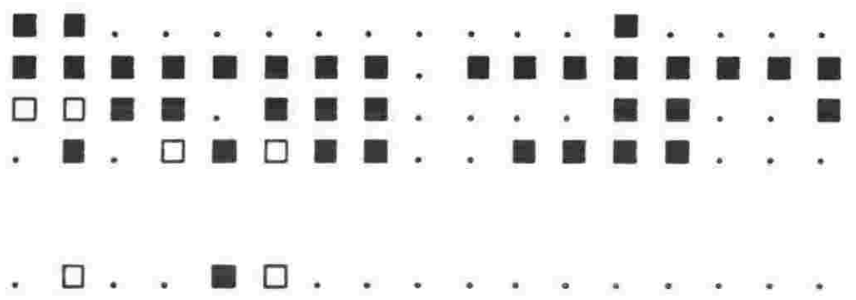
Suborder SPUMELLARIA

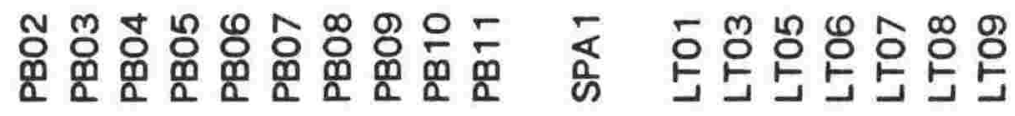

Family OROSPHAERIDAE

Genus OROPELEX

? Oropelex sp.

Family COLLOSPHAERIDAE

Genus COLLOSPHAERA

C. cf. polygona

C. sp. aff. huxleyi

Collosphaera sp. A

Genus ACROSPHAERA

A. spinosa echinoides

A. spinosa spinosa

Genus SIPHONOSPHAERA

S. polysiphonia

Genus OTOSPHAERA

$O$. polymor pha

Family ACTINOMMIDAE

Genus ACTINOMMA

A. antarcticum

A. cf. medianum

A. leptodermum

A. cf. leptodermum

A. polycanthum group

Genus CLADOCOCCUS

C. dentata

C. stalactites

Genus CENOSPHAERA

C. cristata

Cenosphaera sp. A

Cenosphaera sp. B

Cenosphaera sp. C

Cenosphaera sp. D

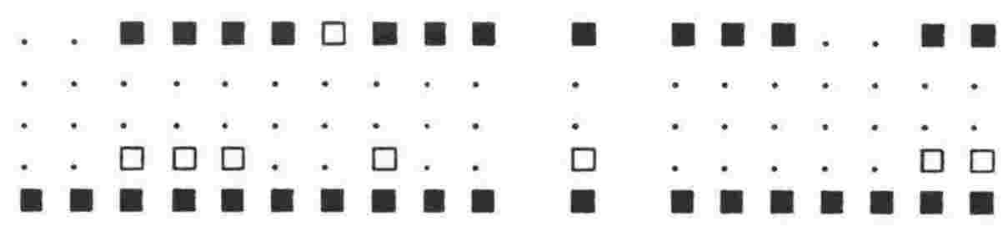

Genus ACANTHOSPHAERA

A. dodecastyla

A. sp. $A$ : few spines

A. sp. A : many spines

Acanthosphaera sp. B 
Genus HEXACONTIUM

$H$. enthacanthum sensu stricto

$H$. enthacanthum : oval form

$H$. enthacanthum : quadrate form

$H$. enthacanthum X laevigatum

$H$. laevigatum sensu stricto

$H$. laevigatum : oval form

$H$. laevigatum : quadrate form

$H$. laevigatum : long spined

Genus THECOSPHAERA

$T$. cf. akitaensis

T. grecoi group

\section{Genus PRUNULUM}

Prunulum spp.

Genus STYPTOSPHAERA

S. stupacea

S. spumacea

\section{Genus 'STYLATRACTUS'}

'S. neptunus forma. large pores

'S', universus : small pores

' $S$ '. universus : large pores

Genus 'SPHAEROSTYLUS'

'S. sp. aff. timmsi : sensu Campbell

'S'. sp. aff. timmsi : symmetrical

Genus 'XIPHATRACTUS'

'Xiphatractus' sp. A

Genus PRUNOPYLE

? P. antarctica

Prunopyle sp. A

Genus SPONGURUS

$S$. pylomaticus

Spongurus sp. A

Genus SPONGOCORE

$S$. puella

Spongocore sp. A

Family PHACODISCIDAE

Genus HELIODISCUS

$H$. asteriscus : large pores

$H$. asteriscus : small pores

$H$. asteriscus : long spines

$H$. cf. echiniscus

H. umbonatum

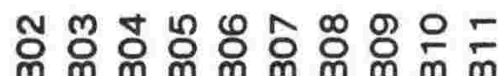

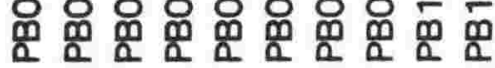

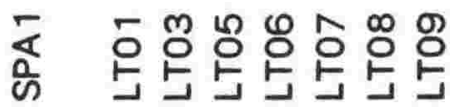
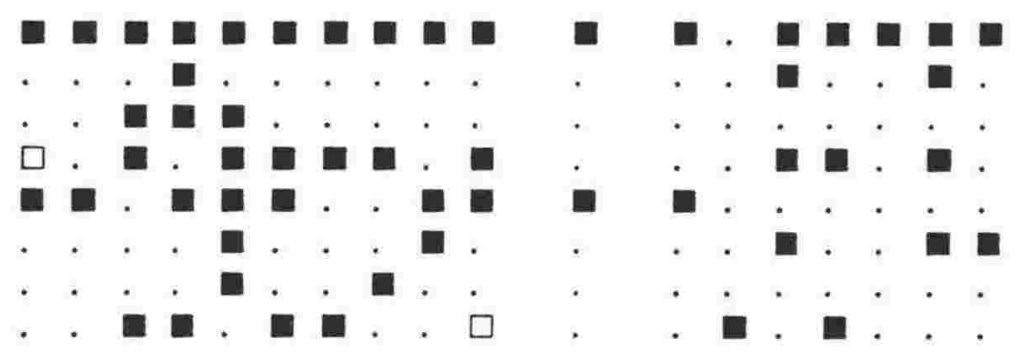

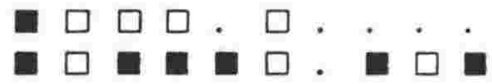

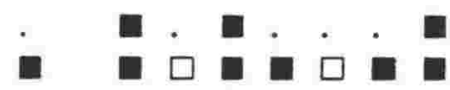

- $\square$ घ
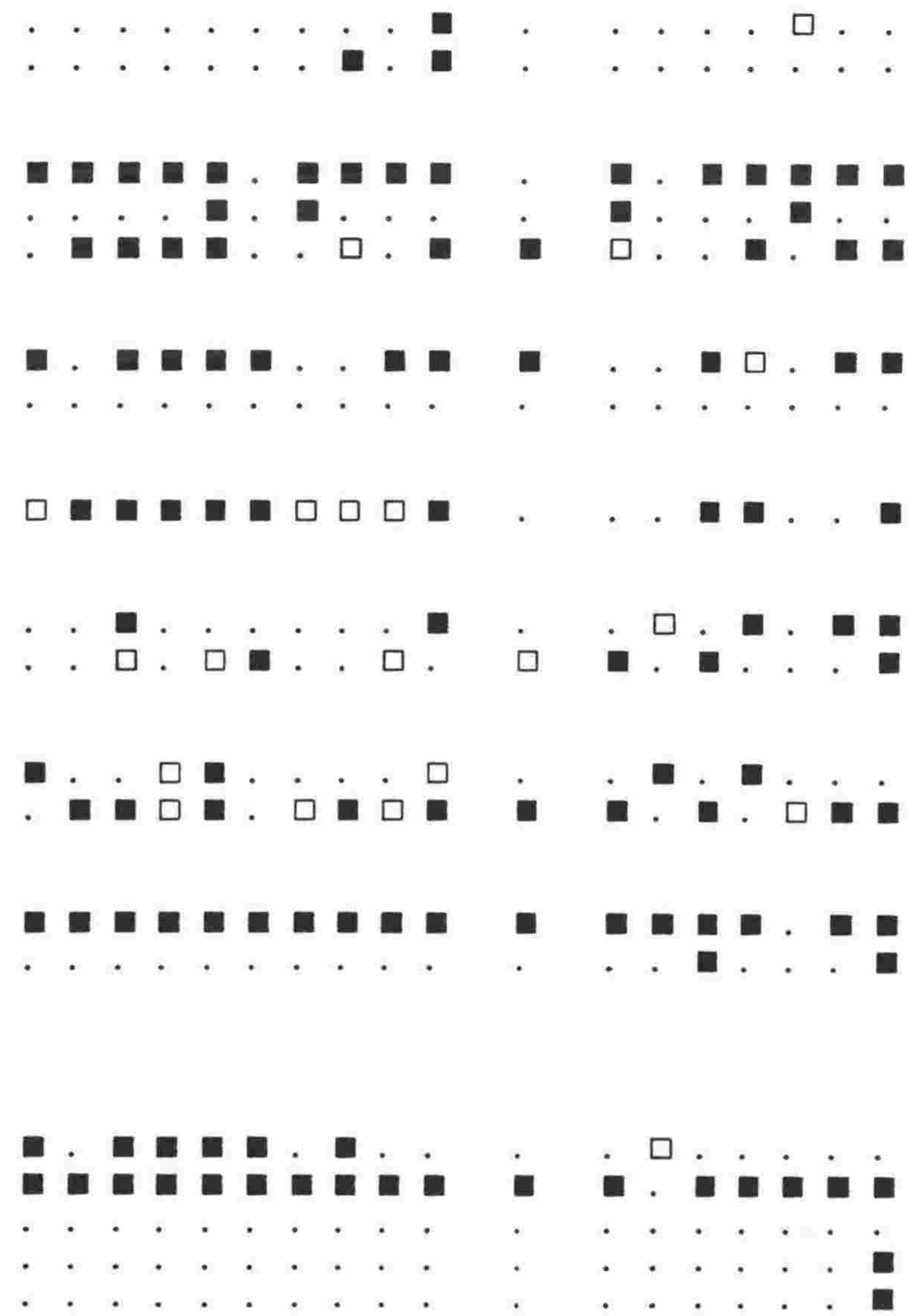
Family COCCODISCIDAE

Genus DIDYMOCYRTIS
$D$. antepenultima
D. antepenultima $\mathrm{X}$ laticonus
D. laticonus
D. virgineum : non-constricted
D. virgineum : constricted
D. virgineum : tuberculate
D. sp. A : non-constricted
D. sp. A : constricted
D. sp. A : spherical
$D$. sp. A : narrow
D. tetrathalmus tetrathalmus

\section{Genus DIARTUS}

D. hughesi group

Family SPONGODISCIDAE

Genus AMPHIRHOPALUM

A. cf. ypsilon

\section{Genus DICTYOCORYNE}

D. profunda

Genus HYMENIASTRUM $H$. euclidis

\section{Genus SPONGASTER}

\section{$S$. pentas}

\section{Genus STYLODICTYA}

S. validispina sensu stricto

$S$. validispina : spinose form

S. validispina : quadrate form

$S$. cornuspira

\section{Genus PORODISCUS}

Porodiscus sp. A : normal form Porodiscus sp. A : spiral form

Porodiscus sp. B
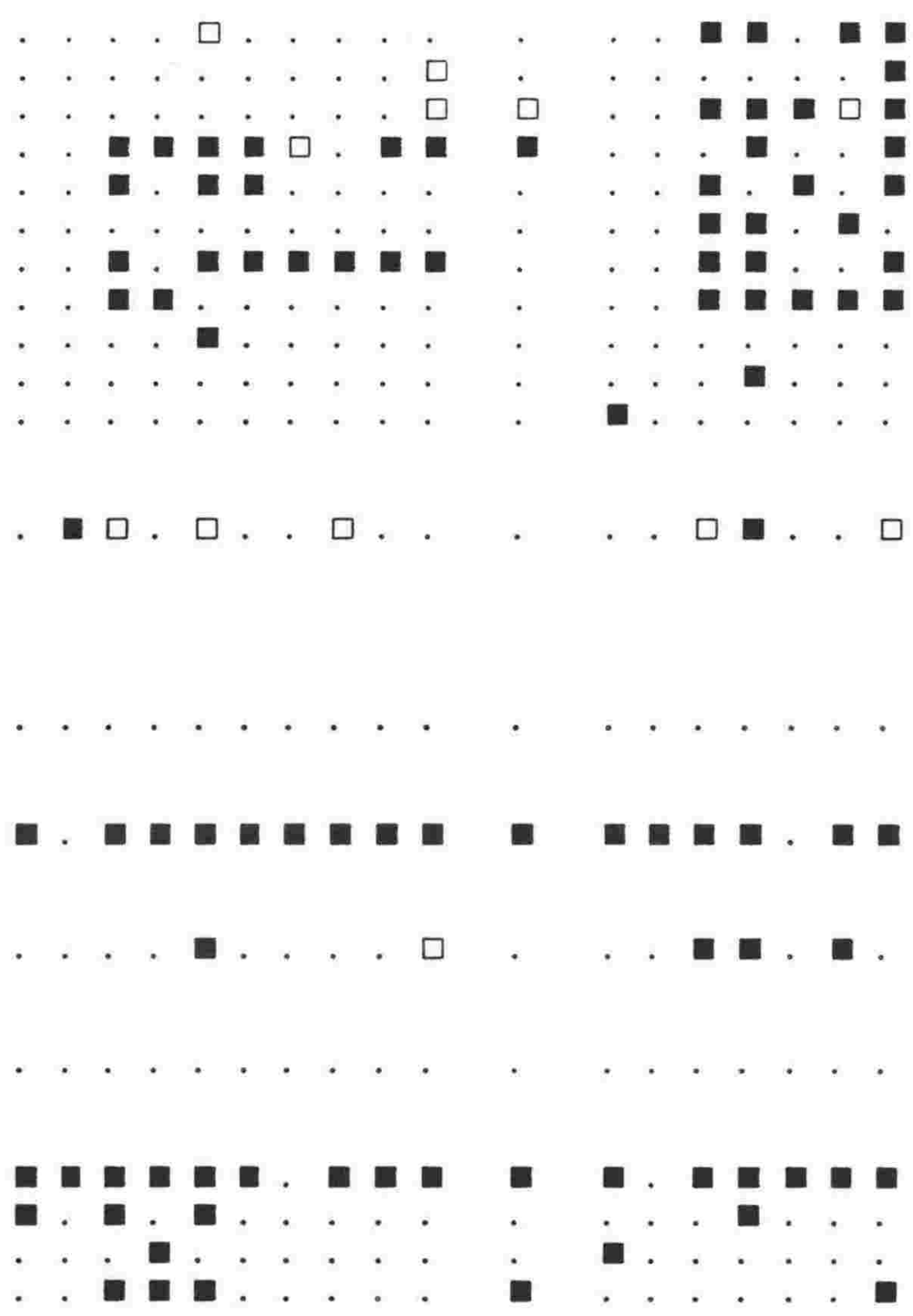

\section{Genus STYLOCHLAMYDIUM}

S. asteriscus

Genus SPONGOTROCHUS

S. glacialis

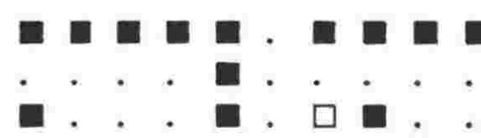

Family PYLONIIDAE

Genus HEXAPYLE

$H$. cf. dodecantha

Genus TETRAPYLE

$T$. octacantha group 
Family LARNACIDAE

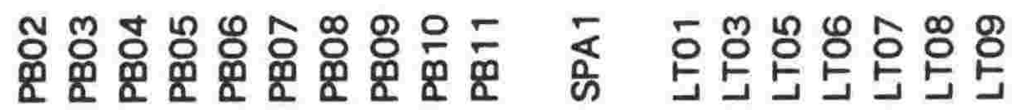

Genus LARNACILLA

L. typus

Family THOLONIIDAE

Genus CUBOTHOLUS

C. rhombicus

Family LITHELIIDAE

Genus LIT HELIUS

L. minor

L. nautiloides

Lithelius sp. A

Lithelius sp. B

Genus PYLOSPIRA

$P$. octopyle

Suborder NASSELLARIA

Family PLAGONIIDAE

Genus ANT ARCT ISSA

$A$. antedenticulata

A. conradae

A. longa

A. strelkovi

Genus LIT HOMELISSA

(?) L. setosa sensu stricto

(?) L. setosa : tri-legged

Genus LOPHOPHAENA

$L$. macrencephala group

Family ACANTHODESMIIDAE

Genus DESMOSPYRIS

$D$. rhodospyroides

D. sp. aff. rhodospyroides

Desmospyris (?) sp. A.

Genus GORGOSPYRIS

G. sp. aff. perizostra

Genus PHORMOSPYRIS

$P$. stabilis antarctica group

$P$. stabilis scaphipes group

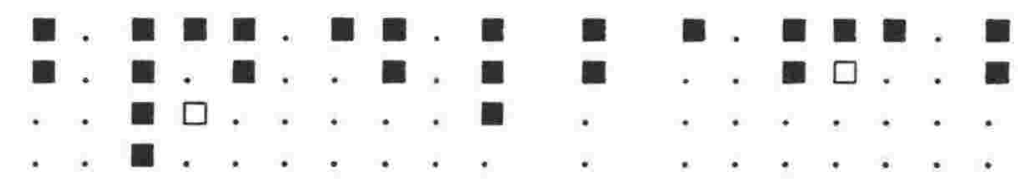


Family CARPOCANIIDAE

Genus CARPOCANARIUM

C. papillosum

Carpocanarium sp. A

Genus CARPOCANIST RUM

C. sp. A : with terminal teeth

C. sp. A : toothless

C. sp. A : very constricted

Genus CYSTOPHORMIS

C. sp. A : with terminal teeth

C. sp. A : toothless

Cystophormis sp. B

Family THEOPERIDAE

Genus CORNUTELLA

C. profunda : three spines

C. profunda : six spines

Genus PLECTOPYRAMIS

$P$. dodecomma

Genus PERIPYRAMIS

$P$. cf. circumtexta

Genus DICTYOPHIMUS

$D$. hirundo group

Genus PSEUDODICTYOPHIMUS

$P$. gracilipes

Genus LYCHNOCANIUM

L. sp. aff. grande : vertical feet

$L$. sp. aff. grande : divergent feet

Genus LYCHNOCANELLA

L. conicum

Genus ARCHIPILIUM

A. macropus

Genus CYRTOCAPSELLA

C. japonica : inflated abdomen

C. japonica : rounded abdomen

C. tetrapera

Genus CYRTOLAGENA

C. laguncula sensu stricto

C. laguncula : spiralling form

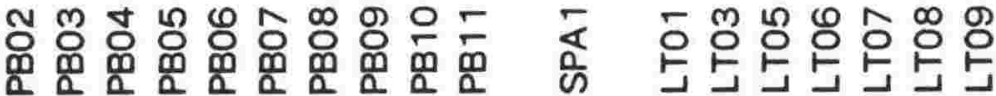

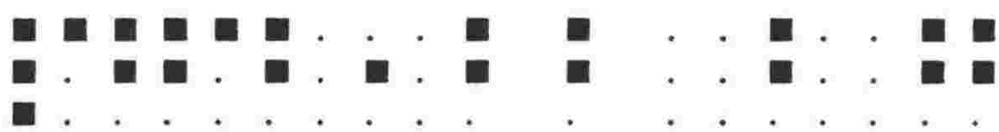

Genus STICHOPHORMIS

S. cornutella 
Genus THEOCALYPTRA

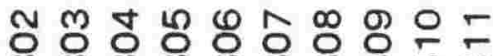

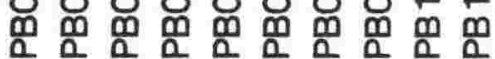

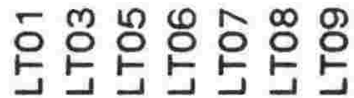

T. bicornis

T. davisiana davisiana

Genus LAMPROMITRA

L. butschlii

L. erosa

L. tiara : flaring

L. tiara : U-shaped

Genus THEOCAMPE

? T. cf. mongolfieri

Genus EUCYRTIDIUM

E. acuminatum

E. cienkowskii

$E$. hexagonatum

E. calvertense

$E$. calvertense $\mathrm{X}$ inflatum

E. inflatum

E. punctatum

$E$. cf. montiparum

Eucyrtidium sp. A

$E$. vincentense : small pores

$E$. vincentense : large pores

Genus STICHOCORYS

$S$. peregrina

$S$. peregrina $\mathrm{X}$ delmontensis

$S$. delmontensis

Stichocorys sp. A

Genus GONDW AN ARI A

$G$. dogeli group

Genus 'ARTOSTROBUS'

'A.' pretabulatus

Family PTEROCORYTHIDAE

Genus ANTHOCY RTIDIUM

A. ehrenbergi pliocenica

? Anthocyrtidium sp. A

A. zanguebaricum
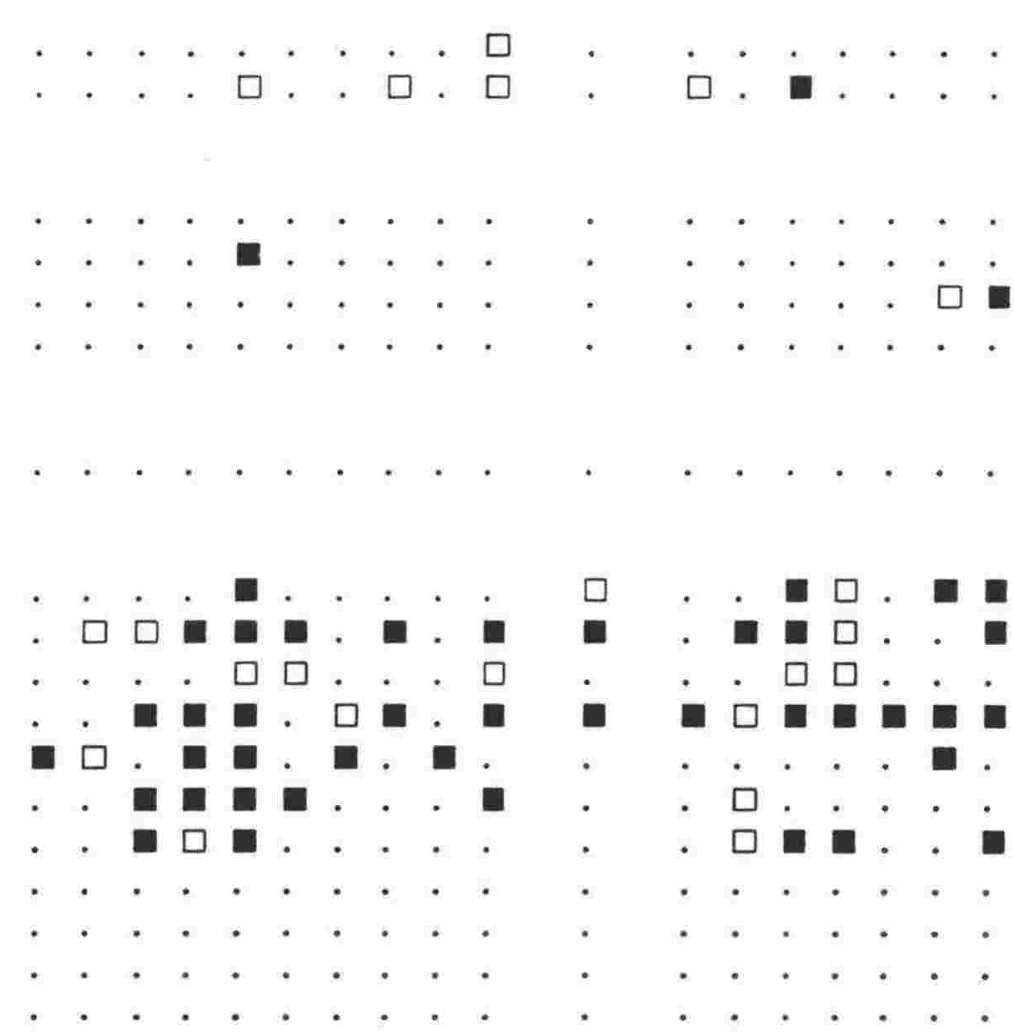
Genus LAMPROCY RTIS

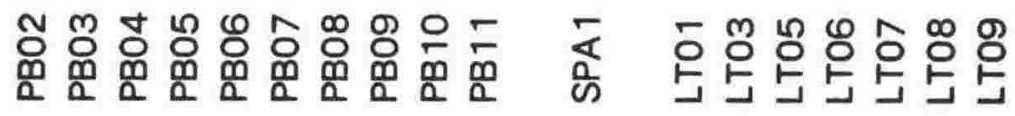

L. (?) apollinis

L. hannai

L. heteroporos

L. (?) junonis

L. (?) cf. junonis

Family ARTOSTROBIIDAE

Genus BOT RYOST ROBUS

$B$. aquilonaris

$B$. auritus-australis group

B. bramlettei

Genus PHORMOSTICHOARTUS

$P$. fistula

Phormostichoartus sp. A

Genus SIPHOCAMPE

$S$. arachnea group

$S$. lineata : strictured

$S$. lineata : smooth

$S$. nodosaria

Genus SIPHOSTICHARTUS

S. corona

Genus SPIROCY RTIS

$S$. subscalaris

Family CANNOBOTRYIDAE

Genus BOT RYOPYLE

$B$. dictyocephalus sensu stricto

$B$. dictyocephalus : large lobe 
Appendix E

RAW AND REDUCED DATA SETS

\section{E.1 INTRODUCTION}

This appendix contains all the raw and reduced data sets that are used in this thesis. The data originates from counts made on transmitted light slides on samples with reasonable radiolarian faunal preservation.

\section{E.2 RAW COUNTING DATA}

This section tabulates the original counts made on the transmitted light slides. Samples (97) are listed in the alphabetical order of their thesis numbers. The variables listed are indexed on the facing page.

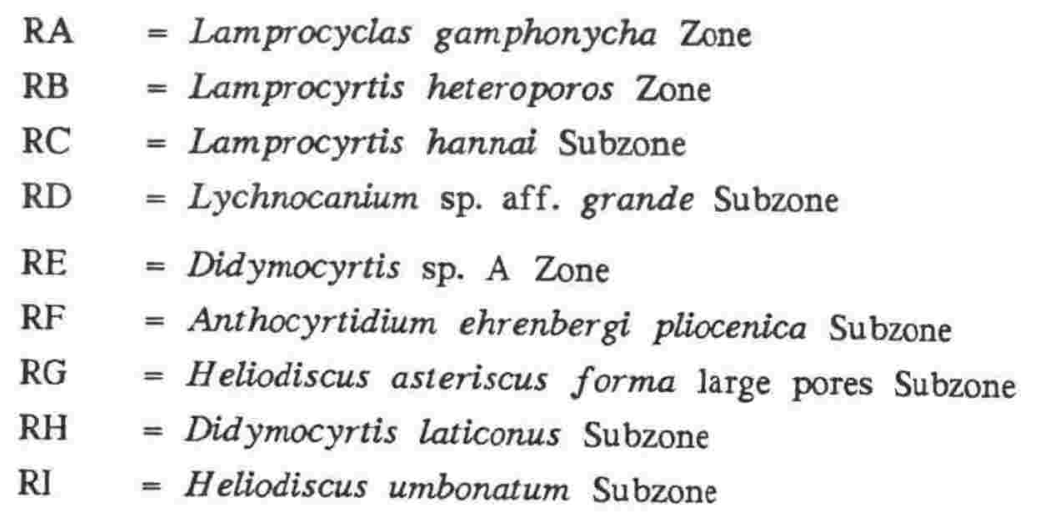


SAM : thesis sample number

AGE : New Zealand Stage

ZN : Radiolarian zone

1 : Collosphaera spp.

2: Acrosphaera spp.

3 : Actinomma antarcticum

4 : Actinomma leptodermum

5 : Actinomma polycanthum group

6 : Cladococcus spp.

7 : Cenosphaera spp.

8: Acanthosphaera spp.

9 : Hexacontium enthacanthum

10 : Hexacontium laevigatum

11 : Thecosphaera spp.

12 : Prunulum spp.

13 : Styptosphaera spp.

14 : "Stylatractus" spp.

15 : "Sphaerostylus" sp. aff. timmsi 
$\begin{array}{llllllllllllllllll}\mathrm{SAM} & \mathrm{AGE} & \mathrm{ZN} & 1 & 2 & 3 & 4 & 5 & 6 & 7 & 8 & 9 & 10 & 11 & 12 & 13 & 14 & 15\end{array}$

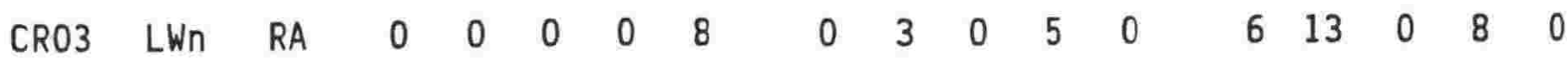

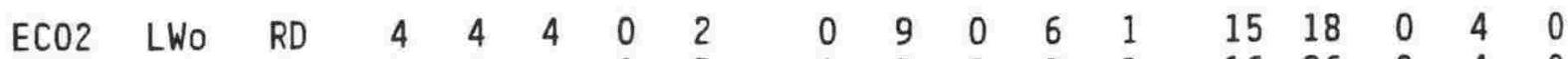

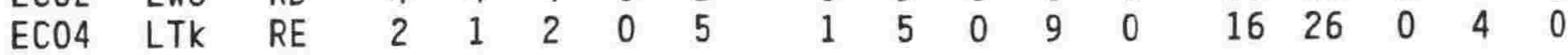
$\begin{array}{lllllllllllllllll}\text { HRO2 } & \text { UTt RF } & 1 & 0 & 4 & 0 & 2 & 0 & 4 & 0 & 5 & 3 & 10 & 13 & 0 & 9 & 4\end{array}$ $\begin{array}{lllllllllllllllll}\text { HRO4 UTt RG } & 2 & 3 & 3 & 0 & 0 & 0 & 1 & 2 & 2 & 3 & 18 & 19 & 0 & 4 & 1\end{array}$ $\begin{array}{llllllllllllllllll}\text { HRO5 } & \text { UTt } & \text { RG } & 1 & 0 & 1 & 1 & 2 & 0 & 0 & 0 & 5 & 2 & 5 & 17 & 0 & 9 & 1 \\ \text { HRO6 } & \text { UTt } & \text { RH } & 1 & 0 & 1 & 0 & 6 & 0 & 2 & 0 & 4 & 0 & 7 & 27 & 0 & 11 & 2\end{array}$

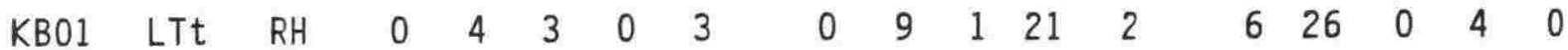

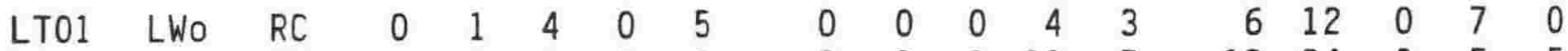

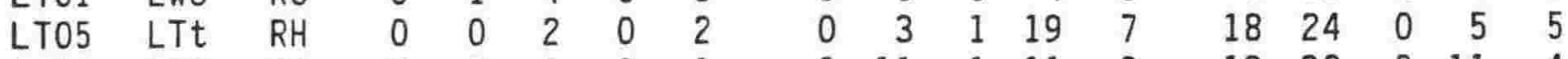
$\begin{array}{lllllllllllllllll}\text { LT06 LTt } & \text { RH } & 0 & 0 & 0 & 0 & 1 & 0 & 11 & 1 & 11 & 3 & 19 & 32 & 0 & 11 & 4\end{array}$ $\begin{array}{llllllllllllllllll}\text { LT08 } & \text { LTt } & \text { RH } & 0 & 0 & 2 & 1 & 5 & 0 & 16 & 0 & 14 & 2 & 13 & 22 & 0 & 15 & 0 \\ \text { LT09 } & \text { LTt } & \text { RI } & 0 & 0 & 4 & 1 & 4 & 0 & 14 & 1 & 14 & 3 & 14 & 30 & 0 & 18 & 1\end{array}$ $\begin{array}{lllllllllllllllll}\text { M002 UTt RE } & 1 & 0 & 2 & 3 & 19 & 0 & 4 & 0 & 3 & 6 & 11 & 25 & 0 & 8 & 1\end{array}$ $\begin{array}{lllllllllllllllll}\text { MO03 UTt RE } & 1 & 0 & 1 & 2 & 11 & 0 & 9 & 0 & 10 & 3 & 6 & 42 & 0 & 14 & 8\end{array}$ $\begin{array}{lllllllllllllllll}\text { MO05 UTt RE } & 0 & 0 & 2 & 1 & 6 & 0 & 5 & 0 & 3 & 1 & 7 & 22 & 0 & 4 & 2\end{array}$ $\begin{array}{lllllllllllllllll}\text { MO06 UTt RE } & 1 & 0 & 2 & 2 & 4 & 0 & 5 & 0 & 4 & 1 & 6 & 30 & 0 & 4 & 7\end{array}$ $\begin{array}{lllllllllllllllll}\text { MO07 UTt RE } & 0 & 0 & 1 & 3 & 6 & 0 & 0 & 1 & 1 & 10 & 8 & 14 & 0 & 7 & 5\end{array}$

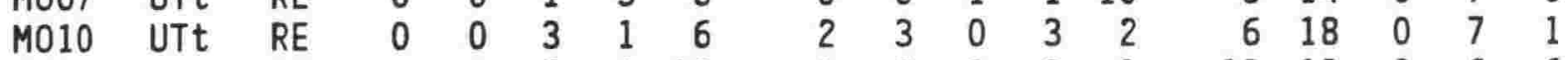

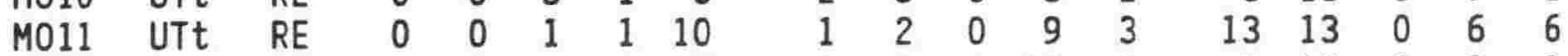
$\begin{array}{lllllllllllllllll}\text { M013 UTt RE } & 0 & 2 & 3 & 2 & 5 & 3 & 3 & 0 & 13 & 2 & 9 & 12 & 0 & 9 & 0\end{array}$

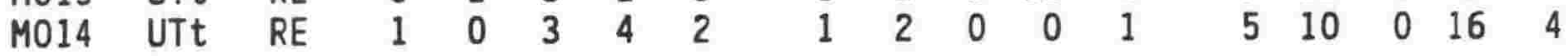

$\begin{array}{llllllllllllllllll}\text { MSO3 UTt RE } & 0 & 0 & 0 & 4 & 4 & 0 & 5 & 2 & 2 & 2 & 6 & 19 & 0 & 5 & 3\end{array}$ $\begin{array}{llllllllllllllllll}\text { MSO4 UTt RE } & 1 & 2 & 4 & 1 & 7 & 0 & 1 & 4 & 17 & 7 & 8 & 9 & 0 & 10 & 3\end{array}$ $\begin{array}{lllllllllllllllll}\text { MSO5 UTt RE } & 0 & 0 & 1 & 2 & 3 & 0 & 7 & 0 & 6 & 1 & 6 & 27 & 0 & 14 & 1\end{array}$

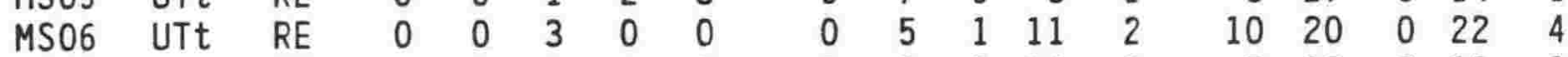

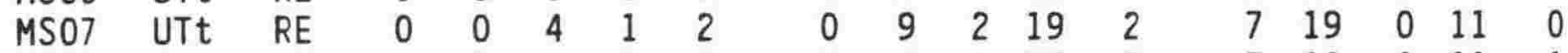

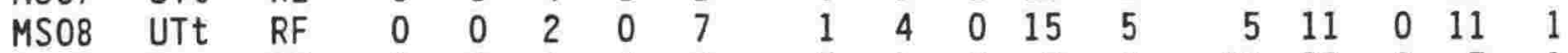

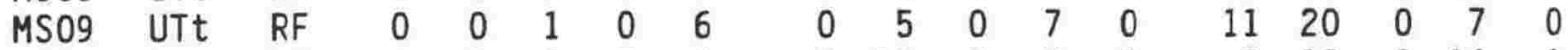
MS10 UTt RF $0 \begin{array}{lllllllllllllll} & 0 & 0 & 2 & 6 & 0 & 11 & 0 & 5 & 2 & 8 & 12 & 0 & 14 & 1\end{array}$

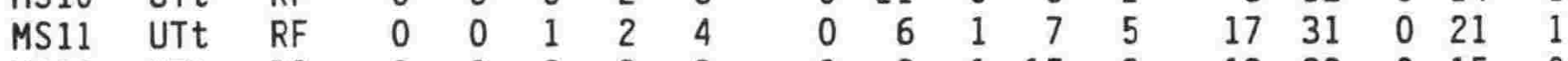
MS12 UTt RG $0 \begin{array}{lllllllllllllll} & 0 & 2 & 2 & 9 & 0 & 2 & 1 & 15 & 8 & 13 & 23 & 0 & 15 & 0\end{array}$

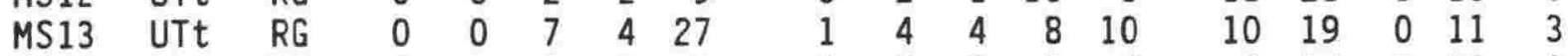

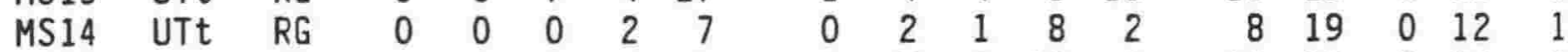
MS15 UTt RG $0 \begin{array}{lllllllllllllll} & 0 & 3 & 0 & 7 & 0 & 5 & 1 & 19 & 1 & 11 & 19 & 0 & 11 & 0\end{array}$

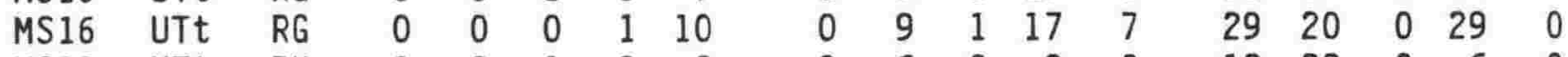
$\begin{array}{lllllllllllllrllll}\text { MS18 } & \text { UTt } & \text { RH } & 1 & 0 & 1 & 0 & 2 & 0 & 6 & 0 & 9 & 0 & 18 & 28 & 0 & 6 & 0 \\ \text { MS19 } & \text { LTt } & \text { RH } & 0 & 0 & 0 & 0 & 5 & 0 & 2 & 0 & 5 & 4 & 8 & 15 & 0 & 8 & 1\end{array}$ $\begin{array}{llllllllllllllllll}\text { MS19 LTt } & \text { RH } & 0 & 0 & 0 & 0 & 5 & 0 & 2 & 0 & 5 & 4 & 8 & 15 & 0 & 8 & 1\end{array}$

$\begin{array}{lllllllllllllllll}\text { MT04 UTt RE } & 1 & 0 & 2 & 0 & 6 & 0 & 4 & 0 & 2 & 3 & 15 & 15 & 0 & 6 & 0\end{array}$ $\begin{array}{lllllllllllllllll}\text { MTO7 UTt RE } & 0 & 0 & 2 & 2 & 2 & 0 & 1 & 0 & 6 & 4 & 17 & 14 & 0 & 5 & 1\end{array}$ $\begin{array}{lllllllllllllllll}\text { MTOB UTt RG } & 1 & 0 & 0 & 1 & 4 & 0 & 4 & 0 & 3 & 2 & 6 & 21 & 0 & 8 & 4\end{array}$ $\begin{array}{lllllllllllllllll}\text { MT09 UTt RG } & 0 & 1 & 2 & 0 & 3 & 0 & 8 & 0 & 8 & 2 & 11 & 19 & 0 & 6 & 2\end{array}$ $\begin{array}{lllllllllllllllll}\text { MT10 UTt RG } & 1 & 0 & 0 & 0 & 4 & 0 & 0 & 1 & 4 & 1 & 11 & 32 & 0 & 3 & 1\end{array}$

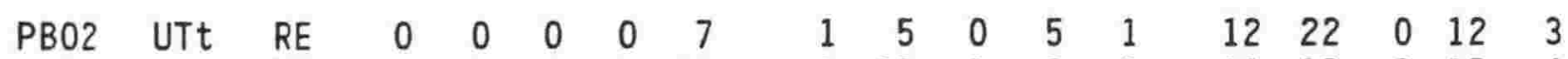
$\begin{array}{lllllllllllllllll}\text { PBO4 UTt } & \text { RF } & 2 & 1 & 4 & 1 & 18 & 0 & 13 & 1 & 8 & 3 & 11 & 19 & 0 & 18 & 4\end{array}$

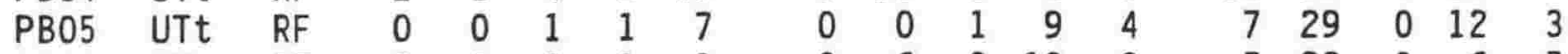
$\begin{array}{lllllllllllllllll}\text { PBO6 UTt RF } & 0 & 0 & 2 & 1 & 9 & 0 & 6 & 0 & 10 & 2 & 5 & 22 & 0 & 6 & 7\end{array}$ $\begin{array}{llllllllllllllllll}\text { PB09 } & \text { UTt } & \text { RF } & 0 & 0 & 0 & 1 & 4 & 1 & 2 & 2 & 15 & 0 & 7 & 24 & 0 & 4 & 0 \\ \text { PB11 } & \text { UTt } & \text { RF } & 2 & 0 & 3 & 0 & 6 & 0 & 9 & 3 & 10 & 5 & 4 & 31 & 0 & 8 & 2\end{array}$ 
SAM : thesis sample number

AGE : New Zealand Stage

$\mathrm{ZN}$ : Radiolarian zone

1: Collosphaera spp.

2 : Acrosphaera spp.

3: Actinomma antarcticum

4 : Actinomma leptodermum

5: Actinomma polycanthum group

6 : Cladococcus spp.

7 : Cenosphaera spp.

8: Acanthosphaera spp.

9 : Hexacontium enthacanthum

10 : Hexacontium laevigatum

11 : Thecosphaera spp.

12 : Prunulum spp.

13 : Styptosphaera spp.

14 : "Stylatractus" spp.

15 : "Sphaerostylus" sp. aff. timmsi 
$\begin{array}{lllllllllllllllllll}\text { SAM } & \mathrm{AGE} & \mathrm{ZN} & 1 & 2 & 3 & 4 & 5 & 6 & 7 & 8 & 9 & 10 & 11 & 12 & 13 & 14 & 15\end{array}$

$\begin{array}{llllllllllllllllll}\text { RKO2 UTt } & \text { RH } & 0 & 0 & 1 & 1 & 8 & 0 & 5 & 1 & 8 & 2 & & 4 & 29 & 0 & 5 & 1\end{array}$ $\begin{array}{lllllllllllrllllll}\text { RKO3 } & \text { UTt } & \text { RH } & 0 & 0 & 0 & 0 & 0 & 0 & 7 & 0 & 12 & 0 & 10 & 16 & 0 & 5 & 0 \\ \text { RKO4 } & \text { LTt } & \text { RH } & 0 & 0 & 2 & 0 & 5 & 0 & 3 & 1 & 2 & 6 & 10 & 23 & 0 & 9 & 0\end{array}$

$\begin{array}{llllllllllllllllll}\mathrm{RMO} 3 & \mathrm{UTt} & \mathrm{RE} & 3 & 0 & 1 & 0 & 10 & 1 & 17 & 1 & 8 & 3 & 3 & 21 & 0 & 14 & 5\end{array}$

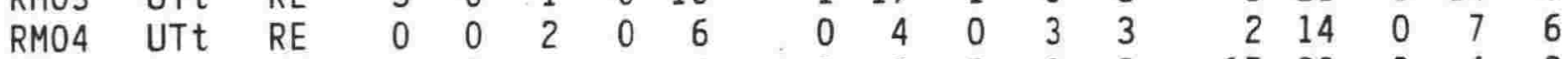
$\begin{array}{lllllllllllllllll}\text { RM05 UTt RF } & 0 & 0 & 1 & 2 & 6 & 0 & 2 & 0 & 2 & 2 & 15 & 20 & 0 & 4 & 2\end{array}$

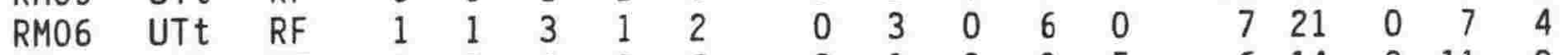

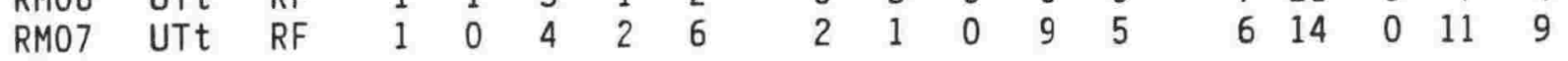

$\begin{array}{lllllllllllllllllll}\text { SCV1 UTt RG } & 2 & 2 & 1 & 0 & 3 & 0 & 3 & 1 & 2 & 1 & 11 & 11 & 0 & 9 & 1\end{array}$

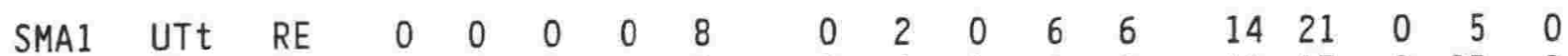
$\begin{array}{lllllllllllllllll}\text { SMA3 UTt RE } & 1 & 0 & 1 & 0 & 8 & 0 & 4 & 1 & 9 & 3 & 11 & 17 & 0 & 27 & 2\end{array}$ $\begin{array}{lllllllllllllllll}\text { SMA4 UTt RF } & 0 & 0 & 0 & 0 & 4 & 0 & 6 & 0 & 5 & 4 & 10 & 17 & 0 & 17 & 0\end{array}$ $\begin{array}{llllllllllllllllll}\text { SMA5 UTt RG } & 0 & 0 & 0 & 1 & 22 & 0 & 3 & 1 & 17 & 5 & 12 & 19 & 0 & 14 & 0\end{array}$

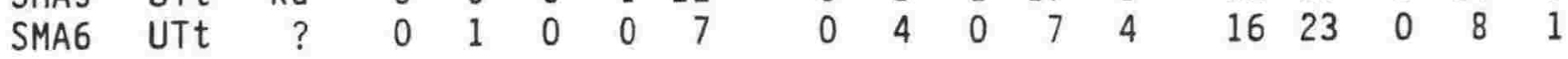

$\begin{array}{llllllllllllllllll}\text { SMH1 UTt } & \text { RE } & 2 & 1 & 1 & 0 & 7 & 1 & 7 & 0 & 0 & 0 & 18 & 29 & 0 & 8 & 2\end{array}$

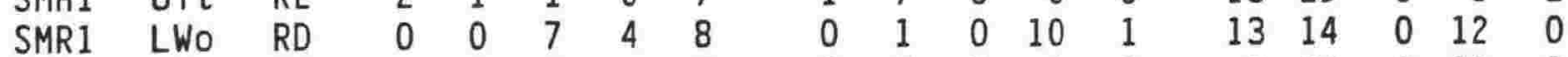

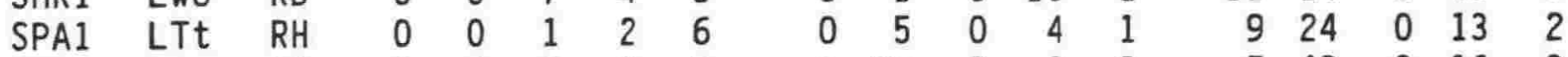

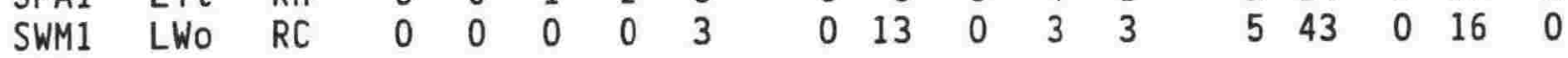

$\begin{array}{llllllllllllllllll}\text { SWR1 LWo } & \mathrm{RD} & 0 & 0 & 2 & 2 & 8 & 0 & 5 & 3 & 3 & 8 & 6 & 22 & 0 & 27 & 0\end{array}$

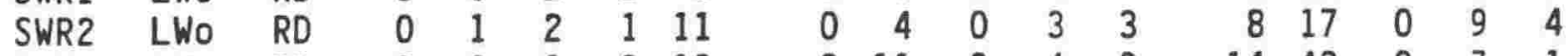
$\begin{array}{lllllllrlrlrrrrrrr}\text { SWR3 } & \text { LWo } & \text { RD } & 0 & 0 & 0 & 0 & 10 & 0 & 11 & 0 & 4 & 3 & 14 & 43 & 0 & 7 & 1 \\ \text { SWR4 } & \text { LTt } & \text { RH } & 1 & 0 & 1 & 4 & 5 & 0 & 7 & 1 & 21 & 5 & 21 & 26 & 0 & 14 & 2\end{array}$ $\begin{array}{llllllllllllllllll}\text { TKO5 Wop ? } & 0 & 0 & 0 & 0 & 1 & 0 & 3 & 0 & 0 & 1 & & 2 & 2 & 0 & 1 & 0\end{array}$

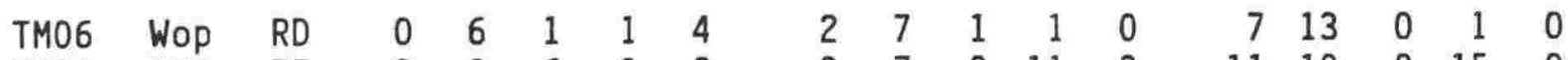

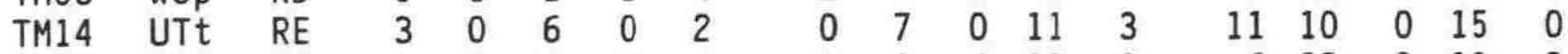
$\begin{array}{lllllllllllllllll}\text { TM15 UTt RE } & 4 & 0 & 3 & 0 & 6 & 0 & 8 & 4 & 13 & 0 & 6 & 28 & 0 & 10 & 3\end{array}$ TM16 UTt RE $0 \begin{array}{lllllllllllllll} & 0 & 2 & 2 & 9 & 0 & 4 & 2 & 18 & 5 & 9 & 13 & 0 & 10 & 4\end{array}$

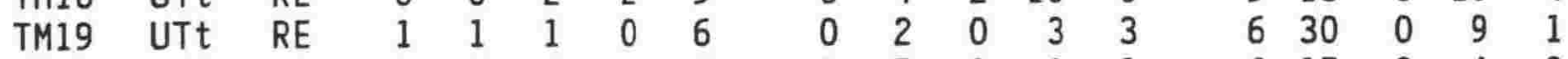
$\begin{array}{lllllllllllllllll}\text { TM20 UTt } & \text { RE } & 3 & 0 & 2 & 3 & 5 & 0 & 5 & 1 & 1 & 3 & 6 & 17 & 0 & 4 & 0\end{array}$ TM21 UTt RE $0 \begin{array}{lllllllllllllll} & 0 & 3 & 0 & 3 & 0 & 7 & 1 & 15 & 1 & 10 & 13 & 0 & 0 & 0\end{array}$ $\begin{array}{llllllllllrlrrrrr}\text { TM22 UTt } & \text { RE } & 1 & 0 & 1 & 1 & 3 & 0 & 2 & 1 & 10 & 1 & 4 & 14 & 0 & 17 & 2\end{array}$ $\begin{array}{lllllllllllllllll}\text { TM23 UTt RE } & 2 & 0 & 1 & 2 & 2 & 0 & 5 & 0 & 5 & 3 & & 4 & 9 & 2 & 9 & 2\end{array}$

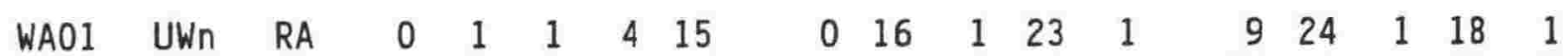
$\begin{array}{lllllllllllllllll}\text { WA02 UWn RA } & 1 & 3 & 7 & 7 & 6 & 0 & 9 & 2 & 10 & 2 & 12 & 9 & 0 & 42 & 0\end{array}$ $\begin{array}{llllllllllllllllll}\text { WA03 UWn } & \text { RA } & 0 & 0 & 5 & 17 & 8 & 1 & 6 & 0 & 3 & 2 & & 7 & 10 & 0 & 64 & 18\end{array}$

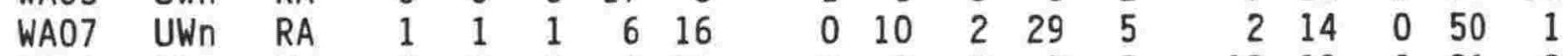
$\begin{array}{lllllllllllllllll}\text { WA10 LWn } & \text { RB } & 0 & 0 & 0 & 4 & 24 & 0 & 9 & 0 & 7 & 5 & 19 & 13 & 0 & 21 & 2\end{array}$ $\begin{array}{lllllllllllllllll}\text { WA13 Wm } & \text { RB } & 0 & 0 & 2 & 2 & 4 & 0 & 3 & 0 & 6 & 3 & 14 & 14 & 0 & 19 & 0\end{array}$ $\begin{array}{lllllllllllllllllll}\text { WA15 Wm } & \mathrm{RB} & 1 & 0 & 1 & 12 & 12 & 0 & 5 & 1 & 9 & 5 & 6 & 18 & 0 & 19 & 2\end{array}$ $\begin{array}{lllllllllllllllll}\text { WA16 Wm } & \mathrm{RB} & 1 & 1 & 3 & 4 & 13 & 0 & 4 & 0 & 9 & 1 & 8 & 33 & 0 & 13 & 1\end{array}$

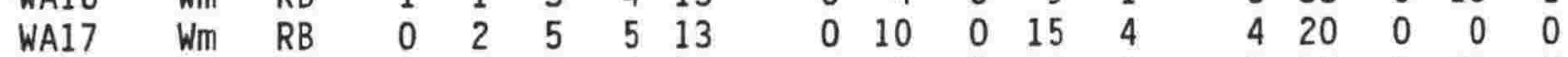

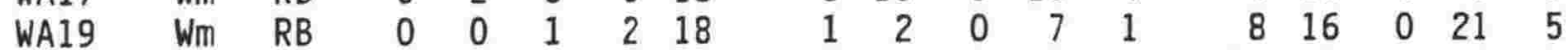

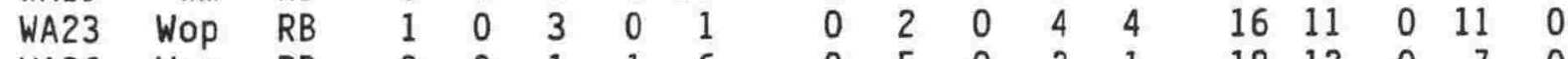
WA26 Wop RB $0 \begin{array}{lllllllllllllll} & 0 & 1 & 1 & 6 & 0 & 5 & 0 & 2 & 1 & 18 & 12 & 0 & 7 & 0\end{array}$ $\begin{array}{lllllllllllllllll}\text { WHO3 UWn RA } & 0 & 2 & 4 & 0 & 12 & 0 & 10 & 0 & 0 & 1 & 18 & 31 & 0 & 5 & 1\end{array}$

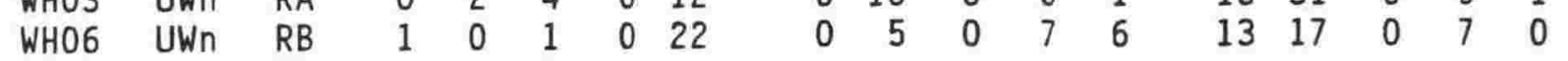

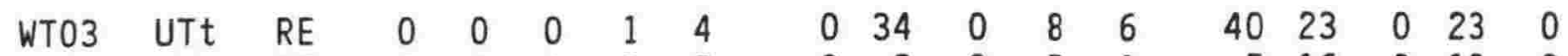
$\begin{array}{lllllllllllllllll}\text { WTO5 UTt RF } & 2 & 1 & 1 & 2 & 5 & 0 & 2 & 0 & 5 & 1 & & 5 & 16 & 0 & 18 & 0\end{array}$ 
SAM : thesis sample number

16 : Prunopyle and Spongurus spp.

17 : Spongocore puella

18: Heliodiscus spp.

19: Didymocyrtis antepenultima

20 : Didymocyrtis laticonus

21 : Didymocyrtis virgineum

22 : Didymocyrtis sp. A

23 : Didymocyrtis tetrathalmus tetrathalmus

24 : Diartus hughesi group

25 : Dictyocoryne and Hymeniastrum spp.

26 : Stylodictya spp.

27 : Porodiscus spp.

28 : Spongotrochus glacialis

29 : Tetrapyle octacantha group

30 : Cubotholus rhombicus 
SAM

CRO3

ECO2

ECO4

HRO2

HRO 4

HRO 5

HRO6

KBO1

LT01

LT05

LT06

LT08

LTO9

M002

$\mathrm{MOO3}$

M005

M006

M007

MO10

M011

M013

M014

$\mathrm{MSO} 3$

MSO4

MSO 5

MSO6

MSO 7

MSO8

MSO9

MS10

MS11

MS12

MS13

MS14

MS15

MS16

MS18

MS19

MTO4

MT07

MT08

MT09

MT10

$\mathrm{PBO} 2$

PBO 4

PB05

PB06

PB09

PB1 1 $\begin{array}{lllll}16 & 17 & 18 & 19 & 20\end{array}$

$\begin{array}{lllll}21 & 22 & 23 & 24 & 25\end{array}$

$\begin{array}{lllll}1 & 0 & 0 & 0 & 4\end{array}$

$\begin{array}{lllll}0 & 0 & 0 & 0 & 16\end{array}$ $\begin{array}{lllll}2 & 3 & 3 & 0 & 0 \\ 4 & 0 & 0 & 0 & 0\end{array}$

$\begin{array}{lllll}0 & 0 & 0 & 0 & 11\end{array}$

$\begin{array}{lllll}5 & 1 & 2 & 0 & 0\end{array}$

$\begin{array}{lllll}0 & 0 & 0 & 0 & 10\end{array}$

$\begin{array}{lllll}1 & 0 & 0 & 0 & 16\end{array}$

$\begin{array}{lllll}6 & 0 & 1 & 1 & 0 \\ 6 & 0 & 1 & 0 & 0\end{array}$

$\begin{array}{rrrrr}1 & 0 & 0 & 0 & 13 \\ 0 & 0 & 0 & 0 & 8\end{array}$

$\begin{array}{lllll}4 & 2 & 2 & 0 & 0\end{array}$

$\begin{array}{lllll}3 & 5 & 5 & 3 & 3\end{array}$

$\begin{array}{lllll}5 & 2 & 4 & 0 & 0\end{array}$

$\begin{array}{lllll}2 & 0 & 3 & 5 & 2\end{array}$

$\begin{array}{lllll}3 & 3 & 4 & 3 & 1\end{array}$

$\begin{array}{lllll}2 & 0 & 0 & 2 & 1\end{array}$

$\begin{array}{lllll}3 & 5 & 2 & 2\end{array}$

$\begin{array}{lllll}0 & 1 & 4 & 1 & 0 \\ 3 & 1 & 4 & 0 & 0\end{array}$

$\begin{array}{lllll}3 & 1 & 4 & 0 & 0 \\ 1 & 0 & 4 & 0 & 0\end{array}$

$\begin{array}{lllll}5 & 1 & 5 & 0 & 0\end{array}$

$\begin{array}{lllll}2 & 1 & 3 & 0 & 0\end{array}$

$$
\begin{array}{lllll}
12 & 2 & 3 & 0 & 0
\end{array}
$$

$\begin{array}{lllll}6 & 2 & 2 & 2 & 0\end{array}$

$\begin{array}{lllll}4 & 0 & 0 & 1 & 0 \\ 9 & 0 & 2 & 0 & 0\end{array}$

$\begin{array}{lllll}0 & 0 & 0 & 0 & 5\end{array}$

$\begin{array}{lllll}0 & 0 & 0 & 0 & 10\end{array}$

$\begin{array}{lllll}0 & 0 & 0 & 0 & 6\end{array}$

$\begin{array}{lllll}1 & 0 & 0 & 0 & 6 \\ 0 & 0 & 0 & 0 & 9\end{array}$

$\begin{array}{lllll}0 & 0 & 0 & 0 & 9 \\ 0 & 0 & 0 & 0 & 6\end{array}$

$\begin{array}{lllll}0 & 0 & 0 & 0 & 13\end{array}$

$\begin{array}{lllll}0 & 0 & 0 & 0 & 12\end{array}$

$\begin{array}{lllll}0 & 0 & 0 & 0 & 6\end{array}$

$\begin{array}{lllll}2 & 0 & 0 & 0 & 10\end{array}$

$\begin{array}{lllll}1 & 0 & 0 & 0 & 8\end{array}$

$\begin{array}{lllll}0 & 0 & 0 & 0 & 7\end{array}$

$\begin{array}{lllll}0 & 0 & 0 & 0 & 8\end{array}$

$\begin{array}{lllll}0 & 0 & 0 & 0 & 13\end{array}$

$\begin{array}{lllll}1 & 0 & 0 & 0 & 9\end{array}$

$\begin{array}{lllll}2 & 0 & 0 & 0 & 18\end{array}$

$\begin{array}{llllr}3 & 0 & 0 & 0 & 5\end{array}$

$\begin{array}{lllll}1 & 0 & 0 & 0 & 10\end{array}$

$\begin{array}{rrrrr}0 & 0 & 0 & 0 & 7 \\ 1 & 0 & 0 & 0 & 10\end{array}$

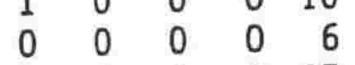

$\begin{array}{lllll}0 & 0 & 0 & 0 & 17\end{array}$

$\begin{array}{lllll}0 & 0 & 0 & 0 & 0\end{array}$

$\begin{array}{lllll}0 & 0 & 0 & 0 & 1 \\ 2 & 0 & 0 & 1 & 7\end{array}$

$\begin{array}{lllll}2 & 0 & 0 & 1 & 7 \\ 0 & 0 & 0 & 0 & 8\end{array}$

$\begin{array}{lllll}1 & 0 & 0 & 0 & 6\end{array}$

$\begin{array}{lllll}0 & 0 & 0 & 0 & 12\end{array}$

$\begin{array}{lllll}0 & 0 & 0 & 0 & 5\end{array}$

$\begin{array}{rrrrr}3 & 0 & 0 & 0 & 3 \\ 2 & 0 & 0 & 0 & 10\end{array}$

$\begin{array}{lllll}0 & 0 & 1 & 3 & 0\end{array}$

$\begin{array}{lllll}2 & 2 & 2 & 0 & 0 \\ 1 & 1 & 7 & 0 & 0 \\ 3 & 0 & 0 & 3 & 1 \\ 4 & 0 & 5 & 4 & 1 \\ 6 & 0 & 1 & 4 & 0\end{array}$

$\begin{array}{lllll}3 & 0 & 0 & 0 & 8\end{array}$

$\begin{array}{lllll}3 & 0 & 0 & 0 & 8 \\ 0 & 0 & 0 & 0 & 11\end{array}$

$\begin{array}{lllll}2 & 0 & 0 & 0 & 7\end{array}$

$\begin{array}{lllll}1 & 0 & 0 & 0 & 10 \\ 1 & 0 & 0 & 0 & 11\end{array}$

$\begin{array}{lllll}0 & 0 & 0 & 0 & 1\end{array}$

$\begin{array}{lllll}3 & 0 & 0 & 0 & 5\end{array}$

$\begin{array}{lllll}0 & 0 & 0 & 0 & 13\end{array}$

$\begin{array}{lllll}3 & 0 & 0 & 0 & 24\end{array}$

$\begin{array}{rrrrr}0 & 0 & 0 & 0 & 10 \\ 0 & 0 & 0 & 0 & 9\end{array}$ $\begin{array}{lllll}26 & 27 & 28 & 29 & 30\end{array}$

$\begin{array}{lllll}3 & 36 & 63 & 0 & 0\end{array}$

$\begin{array}{lllll}28 & 44 & 66 & 11 & 0\end{array}$ $\begin{array}{lllll}42 & 48 & 56 & 7 & 0\end{array}$

$\begin{array}{lllll}7 & 29 & 69 & 6 & 0\end{array}$ $\begin{array}{lllll}15 & 43 & 46 & 6 & 1\end{array}$ $\begin{array}{lllll}9 & 37 & 42 & 1 & 1\end{array}$ $\begin{array}{lllll}5 & 30 & 66 & 5 & 0\end{array}$ $\begin{array}{lllll}29 & 17 & 62 & 20 & 0\end{array}$ $\begin{array}{lllll}7 & 31 & 88 & 13 & 1\end{array}$ $\begin{array}{lllll}18 & 24 & 43 & 3 & 0\end{array}$ $\begin{array}{lllll}10 & 25 & 74 & 2 & 0\end{array}$ $\begin{array}{lllll}23 & 37 & 66 & 4 & 0\end{array}$ $\begin{array}{lllll}28 & 33 & 60 & 2 & 0\end{array}$

$\begin{array}{lllll}19 & 31 & 54 & 6 & 0\end{array}$ $\begin{array}{lllll}17 & 29 & 60 & 4 & 0\end{array}$ $\begin{array}{lllll}11 & 46 & 39 & 5 & 0\end{array}$ $\begin{array}{lllll}7 & 32 & 56 & 3 & 0\end{array}$ $\begin{array}{lllll}14 & 33 & 58 & 3 & 0\end{array}$ $\begin{array}{lllll}10 & 39 & 49 & 9 & 0\end{array}$ $\begin{array}{lllll}11 & 50 & 62 & 4 & 0\end{array}$ $\begin{array}{lllll}16 & 31 & 43 & 6 & 0\end{array}$

$\begin{array}{lllll}17 & 43 & 56 & 7 & 0\end{array}$ $\begin{array}{lllll}14 & 19 & 53 & 11 & 0\end{array}$ $\begin{array}{lllll}13 & 26 & 58 & 2 & 0\end{array}$ $\begin{array}{lllll}14 & 22 & 41 & 4 & 0\end{array}$ $\begin{array}{lllll}16 & 21 & 55 & 2 & 0\end{array}$ $\begin{array}{lllll}18 & 44 & 47 & 2 & 0\end{array}$ $\begin{array}{lllll}11 & 37 & 61 & 8 & 0\end{array}$ $\begin{array}{lllll}3 & 7 & 19 & 0 & 0\end{array}$ $\begin{array}{lllll}16 & 25 & 49 & 1 & 0\end{array}$ $\begin{array}{lllll}12 & 35 & 37 & 2 & 0\end{array}$ $\begin{array}{lllll}20 & 23 & 39 & 6 & 0\end{array}$ $\begin{array}{lllll}14 & 23 & 57 & 2 & 0\end{array}$ $\begin{array}{lllll}20 & 15 & 59 & 3 & 0\end{array}$ $\begin{array}{lllll}16 & 30 & 36 & 0 & 0\end{array}$ $\begin{array}{lllll}11 & 26 & 59 & 0 & 0\end{array}$ $\begin{array}{lllll}12 & 46 & 61 & 2 & 0\end{array}$ $\begin{array}{lllll}15 & 31 & 70 & 5 & 0\end{array}$ $\begin{array}{lllll}16 & 39 & 69 & 1 & 0\end{array}$ $\begin{array}{lllll}22 & 31 & 89 & 3 & 0\end{array}$ $\begin{array}{lllll}18 & 47 & 78 & 6 & 0\end{array}$ $\begin{array}{lllll}6 & 22 & 36 & 0 & 0\end{array}$ $\begin{array}{lllll}11 & 21 & 45 & 7 & 1\end{array}$ $\begin{array}{lllll}23 & 33 & 76 & 3 & 0\end{array}$ $\begin{array}{lllll}21 & 32 & 53 & 5 & 1\end{array}$ $\begin{array}{lllll}13 & 23 & 92 & 4 & 0\end{array}$ 
SAM : thesis sample number

16 : Prunopyle and Spongurus spp.

17 : Spongocore puella

18 : Heliodiscus spp.

19 : Didymocyrtis antepenultima

20 : Didymocyrtis laticonus

21: Didymocyrtis virgineum

22 : Didymocyrtis sp. A

23 : Didymocyrtis tetrathalmus tetrathalmus

24 : Diartus hughesi group

25 : Dictyocoryne and Hymeniastrum spp.

26 : Stylodictya spp.

27 : Porodiscus spp.

28 : Spongotrochus glacialis

29 : Tetrapyle octacantha group

30 : Cubotholus rhombicus 
RKO2

RKO3

RKO4

$\mathrm{RMO} 3$

RMO4

RM05

RMO6

RMO7

SCV1

SMA1

SMA3

SMA4

SMA5

SMA6

SMH1

SMR 1

SPA1

SWM1

SWR1

SWR2

SWR3

SWR4

TK05

TM06

TM14

TM15

TM16

TM19

TM20

TM21

TM22

TM23

WA01

WAO2

WAO3

WA07

WA10

WA13

WA15

WA16

WA17

WA19

WA23

WA26

WHO3

WHOG

$\begin{array}{lllll}3 & 0 & 1 & 0 & 0 \\ 4 & 0 & 2 & 0 & 0 \\ 2 & 3 & 0 & 0 & 0\end{array}$

$\begin{array}{lllll}1 & 1 & 4 & 1 & 0 \\ 2 & 2 & 2 & 0 & 0 \\ 1 & 0 & 2 & 1 & 0 \\ 0 & 1 & 0 & 0 & 0 \\ 2 & 0 & 2 & 1 & 0\end{array}$

$\begin{array}{lllll}3 & 1 & 2 & 1 & 0\end{array}$

$\begin{array}{lllll}2 & 0 & 1 & 4 & 0 \\ 4 & 2 & 1 & 2 & 0 \\ 3 & 2 & 1 & 0 & 0 \\ 8 & 1 & 4 & 1 & 3 \\ 2 & 0 & 2 & 0 & 0\end{array}$

$\begin{array}{lllll}3 & 0 & 5 & 2 & 0\end{array}$

$\begin{array}{lllll}1 & 0 & 1 & 0 & 0\end{array}$

$\begin{array}{lllll}2 & 1 & 1 & 0 & 0 \\ 1 & 2 & 1 & 0 & 0\end{array}$

$\begin{array}{lllll}0 & 4 & 2 & 0 & 0\end{array}$ $\begin{array}{lllll}0 & 3 & 0 & 0 & 0\end{array}$

$\begin{array}{lllll}1 & 1 & 3 & 0 & 0\end{array}$

$\begin{array}{lllll}2 & 0 & 1 & 3 & 0\end{array}$

$\begin{array}{lllll}3 & 0 & 0 & 0 & 0\end{array}$

$\begin{array}{lllll}0 & 1 & 3 & 0 & 0\end{array}$

$\begin{array}{lllll}2 & 0 & 3 & 0 & 0\end{array}$

$\begin{array}{lllll}6 & 1 & 2 & 2 & 0\end{array}$

$\begin{array}{lllll}0 & 0 & 5 & 0 & 0\end{array}$

$\begin{array}{lllll}5 & 0 & 1 & 0 & 0\end{array}$

$\begin{array}{lllll}8 & 3 & 1 & 1 & 0\end{array}$

$\begin{array}{lllll}4 & 3 & 0 & 0 & 0\end{array}$

$\begin{array}{lllll}5 & 2 & 0 & 1 & 0\end{array}$

$\begin{array}{lllll}7 & 1 & 0 & 0 & 0\end{array}$

$\begin{array}{lllll}2 & 2 & 0 & 0 & 0\end{array}$

$\begin{array}{lllll}0 & 1 & 1 & 0 & 0\end{array}$

$\begin{array}{lllll}3 & 0 & 0 & 0 & 0\end{array}$

$\begin{array}{lllll}2 & 1 & 0 & 0 & 0 \\ 1 & 0 & 0 & 0 & 0\end{array}$

$\begin{array}{lllll}0 & 3 & 2 & 0 & 0\end{array}$

$\begin{array}{lllll}5 & 3 & 0 & 0 & 0\end{array}$

$\begin{array}{lllll}0 & 3 & 0 & 0 & 0\end{array}$

$\begin{array}{lllll}1 & 5 & 0 & 0 & 0 \\ 4 & 4 & 1 & 0 & 0\end{array}$

$\begin{array}{lllll}4 & 2 & 1 & 0 & 0\end{array}$

$\begin{array}{lllll}1 & 0 & 0 & 0 & 0\end{array}$

$\begin{array}{lllll}4 & 3 & 2 & 0 & 0\end{array}$

$\begin{array}{lllll}1 & 0 & 0 & 0 & 0\end{array}$

WTO3

WT05 $\begin{array}{lllll}0 & 0 & 0 & 0 & 11 \\ 0 & 0 & 0 & 0 & 22\end{array}$

$\begin{array}{lllll}0 & 0 & 0 & 0 & 13\end{array}$

$\begin{array}{rrrrr}0 & 0 & 0 & 0 & 2 \\ 1 & 0 & 0 & 0 & 13\end{array}$

$\begin{array}{lllll}1 & 0 & 0 & 0 & 10\end{array}$

$\begin{array}{lllll}2 & 0 & 0 & 0 & 8\end{array}$

$\begin{array}{lllll}1 & 0 & 0 & 0 & 6\end{array}$

$\begin{array}{lllll}2 & 0 & 0 & 0 & 14\end{array}$

$\begin{array}{lllll}0 & 0 & 0 & 0 & 12\end{array}$

$\begin{array}{lllll}1 & 0 & 0 & 0 & 11\end{array}$

$\begin{array}{lllll}0 & 0 & 0 & 0 & 3\end{array}$

$\begin{array}{lllll}0 & 0 & 0 & 0 & 10\end{array}$

$\begin{array}{lllll}2 & 0 & 0 & 0 & 11\end{array}$

$\begin{array}{lllll}0 & 0 & 0 & 0 & 19\end{array}$

$\begin{array}{lllll}0 & 0 & 0 & 0 & 20\end{array}$

$\begin{array}{lllll}0 & 0 & 0 & 0 & 4\end{array}$

$\begin{array}{lllll}0 & 0 & 0 & 0 & 22\end{array}$

$\begin{array}{lllll}0 & 0 & 0 & 0 & 20\end{array}$

$\begin{array}{lllll}0 & 0 & 0 & 0 & 21\end{array}$

$\begin{array}{lllll}0 & 0 & 0 & 0 & 7\end{array}$

$\begin{array}{lllll}1 & 0 & 0 & 0 & 4\end{array}$

$\begin{array}{lllll}0 & 0 & 0 & 0 & 3\end{array}$

$\begin{array}{lllll}0 & 0 & 0 & 0 & 23\end{array}$

$\begin{array}{lllll}0 & 0 & 0 & 0 & 16\end{array}$

$\begin{array}{lllll}1 & 0 & 0 & 0 & 8\end{array}$

$\begin{array}{lllll}3 & 0 & 0 & 0 & 10\end{array}$

$\begin{array}{lllll}0 & 0 & 0 & 0 & 24\end{array}$

$\begin{array}{lllll}0 & 0 & 0 & 0 & 7\end{array}$

$\begin{array}{lllll}0 & 0 & 0 & 0 & 16\end{array}$

$\begin{array}{lllll}0 & 0 & 0 & 0 & 12\end{array}$

$\begin{array}{lllll}0 & 0 & 0 & 0 & 12\end{array}$

$\begin{array}{rrrrr}0 & 0 & 0 & 0 & 9 \\ 0 & 0 & 1 & 0 & 13\end{array}$

$\begin{array}{llllr}0 & 0 & 1 & 0 & 4\end{array}$

$\begin{array}{lllll}0 & 0 & 2 & 0 & 6\end{array}$

$\begin{array}{lllll}0 & 0 & 0 & 0 & 1\end{array}$

$\begin{array}{lllll}0 & 0 & 1 & 0 & 21\end{array}$

$\begin{array}{lllll}0 & 0 & 0 & 0 & 17\end{array}$

$\begin{array}{lllll}0 & 0 & 0 & 0 & 18\end{array}$

$\begin{array}{lllll}0 & 0 & 0 & 0 & 13\end{array}$

$\begin{array}{lllll}0 & 0 & 0 & 0 & 18\end{array}$

$\begin{array}{lllll}0 & 0 & 3 & 0 & 29\end{array}$

$\begin{array}{lllll}0 & 0 & 0 & 0 & 19\end{array}$

$\begin{array}{lllll}0 & 0 & 0 & 0 & 22\end{array}$

$\begin{array}{lllll}0 & 0 & 0 & 0 & 10\end{array}$

$\begin{array}{lllll}2 & 0 & 0 & 0 & 3 \\ 0 & 0 & 0 & 1 & 8\end{array}$ $\begin{array}{lllll}9 & 47 & 36 & 0 & 1\end{array}$

$\begin{array}{lllll}23 & 41 & 73 & 2 & 0\end{array}$

$\begin{array}{lllll}20 & 34 & 85 & 2 & 0\end{array}$

$\begin{array}{lllll}2 & 3 & 14 & 4 & 0\end{array}$

$\begin{array}{lllll}14 & 41 & 46 & 8 & 0\end{array}$

$\begin{array}{lllll}9 & 27 & 58 & 6 & 0\end{array}$

$\begin{array}{lllll}8 & 45 & 45 & 1 & 0\end{array}$

$\begin{array}{lllll}10 & 37 & 41 & 4 & 0\end{array}$

$\begin{array}{lllll}16 & 37 & 67 & 2 & 2\end{array}$

$\begin{array}{lllll}17 & 38 & 75 & 0 & 1\end{array}$

$\begin{array}{lllll}18 & 31 & 67 & 2 & 0\end{array}$

$\begin{array}{lllll}13 & 47 & 75 & 2 & 0\end{array}$

$\begin{array}{lllll}15 & 35 & 65 & 2 & 1\end{array}$

$\begin{array}{lllll}23 & 31 & 70 & 0 & 0\end{array}$

$\begin{array}{lllll}13 & 52 & 49 & 1 & 0\end{array}$

$\begin{array}{lllll}23 & 19 & 95 & 9 & 0\end{array}$

$\begin{array}{lllll}17 & 41 & 75 & 2 & 0\end{array}$

$\begin{array}{lllll}50 & 45 & 63 & 2 & 0\end{array}$

$\begin{array}{lllll}25 & 13 & 85 & 3 & 0\end{array}$

$\begin{array}{lllll}15 & 34 & 44 & 2 & 0\end{array}$

$\begin{array}{lllll}11 & 17 & 93 & 0 & 0\end{array}$

$\begin{array}{lllll}17 & 18 & 62 & 2 & 0\end{array}$

$\begin{array}{lllll}0 & 9 & 13 & 1 & 0\end{array}$

$\begin{array}{lllll}23 & 34 & 99 & 10 & 0\end{array}$

$\begin{array}{lllll}17 & 20 & 49 & 8 & 0\end{array}$

$\begin{array}{lllll}14 & 43 & 49 & 9 & 0\end{array}$

$\begin{array}{lllll}21 & 34 & 49 & 2 & 0\end{array}$

$\begin{array}{lllll}15 & 46 & 36 & 1 & 0\end{array}$

$\begin{array}{lllll}9 & 43 & 46 & 7 & 0\end{array}$

$\begin{array}{lllll}15 & 34 & 30 & 7 & 1\end{array}$

$\begin{array}{lllll}23 & 46 & 38 & 11 & 0\end{array}$

$\begin{array}{lllll}21 & 35 & 26 & 9 & 0\end{array}$

$\begin{array}{lllll}16 & 32 & 70 & 6 & 0\end{array}$

$\begin{array}{lllll}7 & 13 & 71 & 5 & 0\end{array}$

$\begin{array}{lllll}8 & 22 & 61 & 8 & 0\end{array}$

$\begin{array}{lllll}13 & 8 & 34 & 3 & 0\end{array}$

$\begin{array}{lllll}0 & 11 & 21 & 0 & 0\end{array}$

$\begin{array}{lllll}8 & 29 & 79 & 5 & 0\end{array}$

$\begin{array}{lllll}10 & 18 & 54 & 6 & 0\end{array}$

$\begin{array}{lllll}16 & 30 & 45 & 4 & 0\end{array}$

$\begin{array}{lllll}6 & 20 & 55 & 10 & 0\end{array}$

$\begin{array}{lllll}15 & 22 & 53 & 1 & 0\end{array}$

$\begin{array}{lllll}19 & 33 & 72 & 4 & 1\end{array}$

$\begin{array}{lllll}17 & 62 & 63 & 0 & 0\end{array}$

$\begin{array}{lllll}9 & 32 & 76 & 1 & 0\end{array}$

$\begin{array}{lllll}13 & 24 & 85 & 0 & 0\end{array}$

$\begin{array}{lllll}5 & 14 & 31 & 1 & 0\end{array}$

$\begin{array}{lllll}21 & 36 & 50 & 4 & 1\end{array}$ 
SAM : thesis sample number

31 : Lithelius minor

32 : Lithelius nautiloides

33 : other Spumellarians

34 : Antarctissa and Lithomelissa spp.

35 : Lophophaena spp.

36 : Desmospyris and Gorgospyris spp.

37 : Phormospyris spp.

38 : Carpocaniidae

39 : Cornutella profunda

40 : Plectopyramis dodecomma

41 : Dictyophimus hirundo group

42 : Lychnocanium and Lychnocanella spp.

43 : Cyrtocapsella japonica

44 : Cyrtocapsella tetrapera

45 : Theocalyptra spp.

46 : Lampromitra spp. 
SAM

$\begin{array}{llll}31 & 32 & 33 & 34\end{array}$

$\begin{array}{llll}35 & 36 & 37 & 38\end{array}$

$\begin{array}{llll}39 & 40 & 41 & 42\end{array}$

$\begin{array}{llll}43 & 44 & 45 & 46\end{array}$

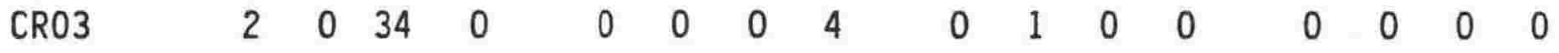

$\begin{array}{lllllllllllllllll}\mathrm{ECO} 2 & 2 & 0 & 34 & 0 & 0 & 0 & 0 & 5 & 0 & 0 & 0 & 0 & 0 & 0 & 0 & 0 \\ \mathrm{ECO} 4 & 3 & 1 & 37 & 0 & 0 & 0 & 0 & 7 & 1 & 1 & 0 & 0 & 0 & 0 & 0 & 0\end{array}$

HRO2

HRO 4

321

$\begin{array}{lll}0 & 0 & 6\end{array}$

HRO5

$4 \begin{array}{lll}4 & 1 & 15 \\ 0 & 4 & 23\end{array}$

$\begin{array}{llll}0 & 4 & 23 & 0\end{array}$

HROG

$\begin{array}{llll}0 & 0 & 32 & 1\end{array}$

KBO1

$\begin{array}{llll}3 & 6 & 62 & 0\end{array}$

$\begin{array}{llll}0 & 4 & 0 & 21\end{array}$

$\begin{array}{lll}1 & 0 & 0\end{array}$

$\begin{array}{llll}0 & 0 & 0 & 0\end{array}$

LTO1

$\begin{array}{llll}1 & 0 & 46 & 0\end{array}$

LT05 3325

LTO6

$\begin{array}{llll}3 & 1 & 25 & 0\end{array}$

LT08

$\begin{array}{llll}4 & 1 & 26 & 0\end{array}$

LTO9

$$
\begin{array}{llll}
6 & 1 & 29 & 0
\end{array}
$$

$\begin{array}{lll}3 & 0 & 1\end{array}$

$\begin{array}{llll}0 & 0 & 0 & 1\end{array}$

$\begin{array}{llll}0 & 1 & 1 & 1\end{array}$

M002

$\begin{array}{llll}3 & 1 & 52 & 0\end{array}$

$\mathrm{MOO3}$

$\begin{array}{llll}3 & 0 & 71 & 0\end{array}$

M005

M006

$\begin{array}{llll}3 & 1 & 54 & 0\end{array}$

M007

12510

M010

$\begin{array}{llll}2 & 4 & 42 & 0\end{array}$

M011

$\begin{array}{llll}1 & 3 & 66 & 1 \\ 1 & 0 & 42 & 0\end{array}$

M014

1145

$\mathrm{MSO} 3$

MSO4

MSO5

MSO6

MSO7

MS08

MSO9

MS10

MS11

MS12

MS13

MS14

MS15

MS16

MS18

MS19

MTO4

MT07

MT08

MT09

MT10

$\begin{array}{llll}1 & 2 & 41 & 0\end{array}$

$\begin{array}{llll}3 & 3 & 31 & 0\end{array}$

$\begin{array}{llll}2 & 1 & 49 & 0 \\ 2 & 1 & 25 & 0\end{array}$

$\begin{array}{llll}3 & 1 & 34 & 1\end{array}$

$\begin{array}{llll}2 & 0 & 30 & 0\end{array}$

$\begin{array}{llll}3 & 2 & 39 & 0\end{array}$

$\begin{array}{llll}2 & 0 & 0 & 0\end{array}$

$\begin{array}{llll}3 & 1 & 2 & 17\end{array}$

$\begin{array}{rrrr}0 & 1 & 1 & 9 \\ 0 & 1 & 0 & 12\end{array}$$$
\begin{array}{llll}
2 & 0 & 0 & 1
\end{array}
$$$$
\begin{array}{llll}
0 & 0 & 0 & 0
\end{array}
$$

$$
\begin{array}{llll}
0 & 3 & 1 & 14
\end{array}
$$

$\begin{array}{llll}3 & 0 & 0 & 0\end{array}$

$\begin{array}{llll}3 & 0 & 1 & 0\end{array}$

$\begin{array}{llll}2 & 2 & 0 & 1\end{array}$

$\begin{array}{llll}1 & 0 & 0 & 0\end{array}$

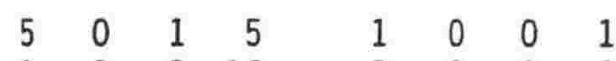

$\begin{array}{llll}1 & 0 & 0 & 1 \\ 0 & 0 & 0 & 0\end{array}$

$\begin{array}{llll}3 & 0 & 0 & 12\end{array}$

$\begin{array}{llll}0 & 0 & 0 & 0\end{array}$

$\begin{array}{llllllll}3 & 0 & 0 & 5 & 1 & 0 & 1 & 2\end{array}$

$\begin{array}{llllllll}4 & 0 & 0 & 7 & 2 & 0 & 0 & 3\end{array}$

$\begin{array}{llllllll}4 & 0 & 2 & 5 & 1 & 0 & 2 & 2\end{array}$

$\begin{array}{llll}10 & 0 & 2 & 5\end{array}$

$\begin{array}{llll}6 & 0 & 2 & 4 \\ 4 & 0 & 3 & 5\end{array}$

$\begin{array}{llll}2 & 0 & 2 & 2 \\ 2 & 0 & 0 & 3\end{array}$

$\begin{array}{llll}3 & 0 & 0 & 0\end{array}$

$\begin{array}{llll}1 & 1 & 14 & 0\end{array}$

$\begin{array}{llll}7 & 3 & 60 & 0\end{array}$

$\begin{array}{llll}4 & 2 & 51 & 0 \\ 2 & 1 & 36 & 0 \\ 3 & 3 & 48 & 1\end{array}$

$\begin{array}{llll}3 & 3 & 48 & 1\end{array}$

$\begin{array}{llll}4 & 5 & 34 & 0\end{array}$

$\begin{array}{lll}6 & 0 & 0 \\ 0 & 1 & 1 \\ 1 & 0 & 0\end{array}$

$\begin{array}{rrrr}1 & 0 & 0 & 8 \\ 6 & 0 & 1 & 10\end{array}$

$\begin{array}{llll}1 & 0 & 1 & 6 \\ 4 & 1 & 0 & 5\end{array}$

$\begin{array}{llll}2 & 0 & 0 & 3 \\ 1 & 1 & 0 & 1\end{array}$

$\begin{array}{llll}0 & 0 & 1 & 0\end{array}$

$\begin{array}{llll}0 & 0 & 0 & 0\end{array}$

$\begin{array}{llll}0 & 0 & 0 & 0\end{array}$

$\begin{array}{llll}0 & 0 & 0 & 0\end{array}$

$\begin{array}{llllllll}6 & 1 & 52 & 0 & 0 & 1 & 0 & 10\end{array}$

$\begin{array}{llllllll}5 & 1 & 42 & 0 & 0 & 1 & 1 & 8\end{array}$

$\mathrm{PBO} 2$

PBO 4

$\begin{array}{lll}0 & 0 & 35\end{array}$

$\begin{array}{llll}1 & 0 & 35 & 0\end{array}$

$\begin{array}{llll}1 & 0 & 1 & 13\end{array}$

$\begin{array}{llll}2 & 0 & 40 & 0\end{array}$

$\begin{array}{llll}3 & 0 & 38 & 0\end{array}$

$\begin{array}{llll}1 & 0 & 0 & 17 \\ 1 & 0 & 1 & 17\end{array}$

$\begin{array}{llllllll}0 & 0 & 1 & 1 & 0 & 0 & 1 & 0\end{array}$

$\begin{array}{llllllll}2 & 0 & 2 & 2 & 0 & 0 & 0 & 0\end{array}$

$\begin{array}{llllllll}2 & 1 & 2 & 2 & 0 & 0 & 0 & 0\end{array}$

$\begin{array}{llll}1 & 0 & 1 & 5\end{array}$

$\begin{array}{llll}8 & 0 & 1 & 3 \\ 0 & 0 & 5 & 3\end{array}$

$\begin{array}{llll}0 & 0 & 0 & 0\end{array}$

$\begin{array}{llll}0 & 0 & 0 & 2\end{array}$

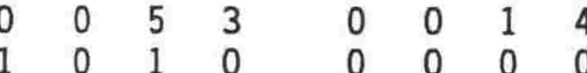

PB05

PB06

$\begin{array}{llll}1 & 0 & 41 & 0\end{array}$

$\begin{array}{llllllll}1 & 0 & 0 & 8 & 1 & 0 & 0 & 2\end{array}$

$\begin{array}{llll}0 & 0 & 0 & 0\end{array}$

$\begin{array}{llllllll}0 & 0 & 2 & 0 & 0 & 0 & 0 & 0\end{array}$

$\begin{array}{llllllll}2 & 0 & 0 & 0 & 0 & 0 & 0 & 0\end{array}$

$\begin{array}{llllllll}0 & 0 & 4 & 2 & 0 & 0 & 0 & 0\end{array}$

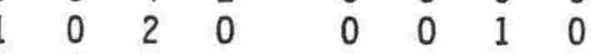

$\begin{array}{llllllll}1 & 0 & 1 & 2 & 1 & 0 & 3 & 0\end{array}$

$\begin{array}{llllllll}1 & 0 & 2 & 1 & 0 & 0 & 1 & 0 \\ 1 & 0 & 0 & 1 & 0 & 0 & 0 & 0\end{array}$

$\begin{array}{llllllll}0 & 0 & 3 & 0 & 0 & 0 & 0 & 0\end{array}$

PB09

$\begin{array}{lll}9 & 0 & 36\end{array}$

$\begin{array}{lllll}3 & 3 & 41 & 0\end{array}$

$\begin{array}{llll}2 & 0 & 2 & 4\end{array}$

$\begin{array}{llllllll}3 & 0 & 52 & 0 & 0 & 0 & 0 & 5\end{array}$

PB11

$\begin{array}{llllllll}6 & 3 & 41 & 0 & 0 & 0 & 0 & 4\end{array}$

$\begin{array}{llllllll}3 & 3 & 43 & 0 & 0 & 0 & 0 & 8\end{array}$

$\begin{array}{llll}3 & 2 & 37 & 0\end{array}$

$\begin{array}{llll}0 & 0 & 0 & 2\end{array}$

$\begin{array}{llll}1 & 0 & 0 & 4 \\ 2 & 0 & 0 & 0 \\ 1 & 0 & 0 & 2 \\ 1 & 0 & 0 & 0 \\ 1 & 0 & 0 & 0\end{array}$

$\begin{array}{llll}0 & 0 & 1 & 0\end{array}$ 
SAM : thesis sample number

31 : Lithelius minor

32 : Lithelius nautiloides

33 : other Spumellarians

34 : Antarctissa and Lithomelissa spp.

35 : Lophophaena spp.

36 : Desmospyris and Gorgospyris spp.

37 : Phormospyris spp.

38 : Carpocaniidae

39 : Cornutella profunda

40 : Plectopyramis dodecomma

41 : Dictyophimus hirundo group

42 : Lychnocanium and Lychnocanella spp.

43 : Cyrtocapsella japonica

44 : Cyrtocapsella tetrapera

45 : Theocalyptra spp.

46 : Lampromitra spp. 
SAM

$\begin{array}{llllllll}31 & 32 & 33 & 34 & 35 & 36 & 37 & 38\end{array}$

RKO2
RKO3

RKO4

RMO3

RMO4

RMO5

RM06

RM07

SCV1

SMA1

SMA3

SMA4

SMA5

SMA6

SMH1

SMR1

SPAI

SWMI

SWRI

SWR2

SWR3

SWR4

TK05

TMO6

TM14

TM15

TM16

TM19

TM20

TM21

TM22

TM23

WA01

WA02

WAO3

WA07

WA10

WA13

WA15

WA16

WA17

WA19

WA23

WA26

WHO3

WHOG

WT03

WT05 $\begin{array}{llll}4 & 1 & 28 & 0 \\ 1 & 0 & 24 & 0 \\ 3 & 0 & 29 & 0\end{array}$

$\begin{array}{llll}1 & 0 & 58 & 0\end{array}$

$\begin{array}{llll}3 & 0 & 43 & 0\end{array}$

$\begin{array}{llll}1 & 1 & 46 & 0\end{array}$

$\begin{array}{llll}2 & 1 & 54 & 0\end{array}$

$\begin{array}{llll}1 & 0 & 52 & 2\end{array}$

$\begin{array}{llll}5 & 0 & 26 & 0\end{array}$

$\begin{array}{llll}2 & 1 & 53 & 0\end{array}$

$\begin{array}{llll}5 & 1 & 45 & 0\end{array}$

$\begin{array}{llll}7 & 1 & 56 & 0\end{array}$

$\begin{array}{llll}4 & 0 & 48 & 0\end{array}$

$\begin{array}{lll}6 & 1 & 4\end{array}$

$\begin{array}{llll}7 & 0 & 43 & 0\end{array}$

$\begin{array}{llll}3 & 1 & 42 & 0\end{array}$

$\begin{array}{llll}3 & 1 & 45 & 0\end{array}$

$\begin{array}{llll}1 & 1 & 29 & 0\end{array}$

$\begin{array}{llll}3 & 2 & 33 & 0\end{array}$

$\begin{array}{llll}4 & 1 & 53 & 0\end{array}$

$\begin{array}{llll}3 & 1 & 52 & 1\end{array}$

$\begin{array}{llll}0 & 0 & 0 & 1 \\ 0 & 0 & 0 & 1\end{array}$

$\begin{array}{llll}0 & 2 & 0 & 10\end{array}$

$\begin{array}{llll}0 & 0 & 0 & 0\end{array}$

$\begin{array}{llll}0 & 0 & 0 & 3\end{array}$

$\begin{array}{llll}0 & 0 & 0 & 5 \\ 0 & 0 & 0 & 1\end{array}$

$\begin{array}{llll}0 & 0 & 0 & 16\end{array}$

$\begin{array}{llll}0 & 0 & 0 & 0\end{array}$

$\begin{array}{lll}3 & 1 & 33\end{array}$

$\begin{array}{llll}3 & 1 & 32 & 0\end{array}$

$\begin{array}{llll}2 & 0 & 32 & 1\end{array}$

$\begin{array}{llll}3 & 2 & 35 & 0\end{array}$

$\begin{array}{llll}2 & 1 & 43 & 0\end{array}$

$\begin{array}{llll}6 & 1 & 44 & 0\end{array}$

$\begin{array}{llll}5 & 1 & 33 & 1\end{array}$

$\begin{array}{llll}2 & 2 & 37 & 0 \\ 3 & 2 & 48 & 0\end{array}$

$\begin{array}{llll}1 & 0 & 0 & 1\end{array}$

$\begin{array}{llll}2 & 0 & 1 & 7 \\ 2 & 0 & 0 & 5\end{array}$

$\begin{array}{llll}2 & 0 & 0 & 5\end{array}$

$\begin{array}{llll}0 & 0 & 0 & 12\end{array}$

$\begin{array}{llll}1 & 0 & 0 & 10\end{array}$

$\begin{array}{llll}3 & 0 & 1 & 4\end{array}$

$\begin{array}{llll}10 & 2 & 0 & 12\end{array}$

$\begin{array}{llll}6 & 0 & 0 & 10\end{array}$

$\begin{array}{llll}6 & 1 & 47 & 0\end{array}$

$\begin{array}{llll}1 & 2 & 26 & 0\end{array}$

$\begin{array}{llll}0 & 0 & 0 & 3\end{array}$

$\begin{array}{llll}4 & 3 & 32 & 0\end{array}$

$\begin{array}{llll}10 & 2 & 0 & 0\end{array}$

$\begin{array}{llll}9 & 0 & 39 & 0\end{array}$

$\begin{array}{llll}3 & 1 & 17 & 0\end{array}$

$\begin{array}{llll}3 & 0 & 43 & 0\end{array}$

$\begin{array}{llll}4 & 1 & 68 & 2 \\ 5 & 2 & 55 & 0\end{array}$

$\begin{array}{llll}6 & 0 & 51 & 3\end{array}$

$\begin{array}{llll}6 & 0 & 58 & 0\end{array}$

$\begin{array}{llll}1 & 0 & 37 & 0\end{array}$

$\begin{array}{lll}0 & 0 & 0\end{array}$

$\begin{array}{llll}1 & 0 & 0 & 2\end{array}$

$\begin{array}{llll}1 & 1 & 1 & 4 \\ 2 & 0 & 1 & 2\end{array}$

$\begin{array}{llll}1 & 0 & 0 & 3\end{array}$

$\begin{array}{llll}5 & 0 & 1 & 2\end{array}$

$\begin{array}{llll}1 & 0 & 0 & 4\end{array}$

$\begin{array}{llll}9 & 0 & 1 & 2 \\ 3 & 0 & 0 & 2\end{array}$

$\begin{array}{llll}4 & 0 & 34 & 0\end{array}$

$\begin{array}{llll}0 & 0 & 0 & 2 \\ 3 & 0 & 2 & 5\end{array}$

$\begin{array}{llll}5 & 3 & 41 & 0\end{array}$

$\begin{array}{llll}9 & 0 & 53 & 0\end{array}$

$\begin{array}{llll}2 & 1 & 31 & 1\end{array}$ $\begin{array}{llll}0 & 0 & 1 & 2\end{array}$

$\begin{array}{llll}1 & 0 & 0 & 0\end{array}$ $\begin{array}{llllllll}0 & 0 & 0 & 0 & 2 & 0 & 0 & 0 \\ 1 & 0 & 0 & 0 & 1 & 1 & 0 & 0\end{array}$ $\begin{array}{llllllll}0 & 0 & 0 & 11 & 0 & 0 & 0 & 0\end{array}$ $\begin{array}{llllllll}0 & 0 & 0 & 3 & 0 & 0 & 1 & 0\end{array}$ $\begin{array}{llllllll}2 & 1 & 0 & 2 & 0 & 0 & 1 & 1\end{array}$ $\begin{array}{llllllll}0 & 0 & 4 & 2 & 0 & 0 & 1 & 0\end{array}$ $\begin{array}{llllllll}0 & 0 & 2 & 1 & 0 & 0 & 2 & 0\end{array}$ $\begin{array}{llllllll}0 & 0 & 0 & 4 & 0 & 0 & 0 & 0\end{array}$ $\begin{array}{llllllll}1 & 0 & 1 & 0 & 0 & 0 & 0 & 0\end{array}$ $\begin{array}{llll}1 & 0 & 0 & 0\end{array}$ $\begin{array}{llllllll}0 & 0 & 1 & 0 & 0 & 0 & 0 & 0\end{array}$ $\begin{array}{llllllll}0 & 1 & 1 & 0 & 1 & 0 & 0 & 0\end{array}$ $\begin{array}{llllllll}0 & 0 & 0 & 0 & 0 & 0 & 0 & 0\end{array}$ $\begin{array}{llllllll}0 & 0 & 0 & 0 & 0 & 0 & 0 & 0\end{array}$ $\begin{array}{llllllll}0 & 0 & 0 & 0 & 1 & 0 & 0 & 0\end{array}$ $\begin{array}{llllllll}0 & 0 & 0 & 0 & 0 & 0 & 0 & 0\end{array}$ $\begin{array}{llllllll}0 & 0 & 0 & 0 & 0 & 0 & 0 & 0\end{array}$ $\begin{array}{llllllll}0 & 0 & 0 & 1 & 0 & 0 & 0 & 0\end{array}$ $\begin{array}{llllllll}0 & 0 & 0 & 0 & 0 & 0 & 1 & 0 \\ 1 & 1 & 0 & 3 & 0 & 0 & 0 & 0\end{array}$ $\begin{array}{llllllll}0 & 0 & 0 & 0 & 0 & 0 & 0 & 0\end{array}$ $\begin{array}{llllllll}0 & 0 & 2 & 0 & 0 & 0 & 0 & 0\end{array}$ $\begin{array}{llllllll}0 & 1 & 1 & 2 & 0 & 2 & 0 & 0\end{array}$ $\begin{array}{llllllll}0 & 0 & 1 & 0 & 0 & 0 & 0 & 1\end{array}$ $\begin{array}{llllllll}0 & 0 & 1 & 1 & 0 & 0 & 0 & 0\end{array}$ $\begin{array}{llllllll}0 & 0 & 1 & 3 & 2 & 0 & 2 & 0\end{array}$ $\begin{array}{llllllll}1 & 0 & 1 & 1 & 0 & 0 & 2 & 0\end{array}$ $\begin{array}{llllllll}3 & 0 & 1 & 2 & 1 & 0 & 3 & 0\end{array}$ $\begin{array}{llllllll}1 & 1 & 3 & 3 & 0 & 0 & 0 & 0 \\ 1 & 0 & 1 & 0 & 1 & 0 & 0 & 0\end{array}$ $\begin{array}{llllllll}0 & 1 & 2 & 1 & 0 & 0 & 0 & 0\end{array}$ $\begin{array}{llllllll}0 & 0 & 6 & 0 & 0 & 0 & 0 & 0\end{array}$ $\begin{array}{llllllll}0 & 1 & 1 & 0 & 1 & 0 & 7 & 1\end{array}$ $\begin{array}{llllllll}1 & 1 & 4 & 0 & 0 & 0 & 3 & 0\end{array}$ $\begin{array}{llllllll}0 & 0 & 1 & 0 & 0 & 0 & 0 & 0\end{array}$ $\begin{array}{llllllll}0 & 0 & 1 & 1 & 0 & 0 & 0 & 0\end{array}$ $\begin{array}{llllllll}1 & 0 & 1 & 0 & 0 & 0 & 0 & 1\end{array}$ $\begin{array}{llllllll}2 & 2 & 0 & 0 & 0 & 0 & 0 & 0\end{array}$ $\begin{array}{llllllll}5 & 0 & 3 & 0 & 0 & 0 & 0 & 0\end{array}$ $\begin{array}{llllllll}0 & 1 & 0 & 0 & 0 & 0 & 1 & 3\end{array}$ $\begin{array}{llllllll}0 & 0 & 0 & 0 & 0 & 0 & 1 & 0\end{array}$ $\begin{array}{llllllll}0 & 0 & 3 & 0 & 0 & 0 & 0 & 0\end{array}$ $\begin{array}{llllllll}0 & 0 & 0 & 0 & 0 & 0 & 2 & 0 \\ 0 & 0 & 0 & 0 & 0 & 0 & 0 & 0\end{array}$ $\begin{array}{llllllll}0 & 1 & 0 & 14 & 1 & 0 & 0 & 0\end{array}$ $\begin{array}{llll}0 & 0 & 0 & 0\end{array}$ $\begin{array}{llllllllllll}8 & 1 & 0 & 12 & 6 & 0 & 2 & 0 & 0 & 0 & 0 & 0\end{array}$ 
SAM : thesis sample number

47 : E. acuminatum, E. cienkowskii group, and E. hexagonatum

$48:$ : . calvertense and $E$. inflatum

49: Eucyrtidium punctatum group

50 : Eucyrtidium sp. A and E. montiparum

51 : Stichocorys peregrina

52 : Stichocorys delmontensis

53 : Stichocorys spp. (transitionals)

54 : Anthocyrtidium spp.

55 : Lamprocyclas and Lamprocyrtis spp.

56 : Botryostrobus spp.

57 : Siphocampe spp.

58 : Spirocyrtis subscalaris

59 : Botryopyle dictyocephalus group

NG : number of radiolarians per gram of sediment

TOT : total number of radiolarians counted 
SAM

$\begin{array}{llll}47 & 48 & 49 & 50\end{array}$

$\begin{array}{lllll}51 & 52 & 53 & 54 & 55\end{array}$

$\begin{array}{llllll}56 & 57 & 58 & 59 & \text { NG } & \text { TOT }\end{array}$

CRO3

$\begin{array}{lll}0 & 0 & 1\end{array}$

$\begin{array}{lllll}1 & 1 & 0 & 0 & 2\end{array}$

$\begin{array}{llllll}3 & 0 & 0 & 0 & 12 & 200\end{array}$

$\mathrm{ECO} 2$

$\begin{array}{lll}1 & 0 & 1 \\ 0 & 0 & 0\end{array}$

$\begin{array}{lllll}5 & 4 & 0 & 0 & 3\end{array}$

$\begin{array}{llllll}0 & 0 & 0 & 2 & 130 & 297\end{array}$

$\mathrm{ECO} 4$

$\begin{array}{lllll}1 & 3 & 1 & 0 & 1\end{array}$

$\begin{array}{lllll}2 & 0 & 0 & 0 & 225\end{array}$

297

HRO2

$\begin{array}{llll}0 & 2 & 2 & 0\end{array}$

$\begin{array}{lllll}23 & 7 & 10 & 0 & 0\end{array}$

$\begin{array}{llllll}0 & 1 & 0 & 0 & 370 & 259\end{array}$

HRO 4

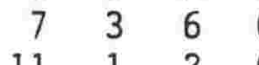

HRO5

HRO6

$\begin{array}{llll}11 & 1 & 2 & 0\end{array}$

$\begin{array}{llll}14 & 17 & 5 & 0\end{array}$

$\begin{array}{llllll}9 & 4 & 2 & 1 & 269 & 309\end{array}$

KBO1

$\begin{array}{lllll}23 & 29 & 5 & 1 & 2 \\ 21 & 31 & 6 & 1 & 5\end{array}$

$\begin{array}{llllll}6 & 1 & 0 & 1 & 535 & 275\end{array}$

$\mathrm{KBO}$

$\begin{array}{llll}5 & 1 & 1 & 0\end{array}$

$\begin{array}{lllll}0 & 0 & 1 & 0 & 3\end{array}$

$\begin{array}{lllll}3 & 7 & 1 & 2 & 568\end{array}$

357

LTO1

LTO5

$\begin{array}{lllllllll}0 & 0 & 0 & 0 & 16 & 5 & 5 & 0 & 5\end{array}$

$\begin{array}{llllll}0 & 17 & 0 & 2 & 74 & 306\end{array}$

LTO6 $\begin{array}{llll}2 & 1 & 1 & 0 \\ 1 & 1 & 2 & 0\end{array}$

LT08 $\begin{array}{llll}0 & 0 & 0 & 0\end{array}$

$\begin{array}{lllll}3 & 3 & 1 & 0 & 5\end{array}$

$\begin{array}{llllll}5 & 11 & 0 & 4 & 829 & 286\end{array}$

LTO9

$\begin{array}{lllllllll}3 & 3 & 0 & 0 & 0 & 1 & 1 & 0 & 5\end{array}$

$\begin{array}{llllll}3 & 8 & 0 & 1 & 1188 & 291\end{array}$

$\begin{array}{llllll}1 & 11 & 0 & 0 & 727 & 295\end{array}$

M002

M003

$\begin{array}{llll}1 & 2 & 1 & 0\end{array}$

M005

M006 $\begin{array}{llll}0 & 1 & 1 & 0\end{array}$

M007 $\begin{array}{llll}1 & 1 & 3 & 0\end{array}$

M010 $\begin{array}{llll}0 & 1 & 0 & 0\end{array}$

$\begin{array}{llll}0 & 2 & 1 & 0\end{array}$

M011

$\begin{array}{llll}4 & 1 & 2 & 0 \\ 0 & 3 & 3 & 0\end{array}$

M013

$\begin{array}{llll}5 & 0 & 1 & 0\end{array}$

M014

$\begin{array}{llll}1 & 2 & 2 & 0\end{array}$

$5 \quad 11$

610

$1187 \quad 336$

$\mathrm{MSO} 3$

$\begin{array}{llll}3 & 2 & 0 & 0\end{array}$

$16 \quad 12$

25

12

110

$\begin{array}{llll}0 & 551 & 301\end{array}$

$\begin{array}{rrrrrrrrrrr}13 & 8 & 1 & 1 & 2 & 16 & 1 & 0 & 1 & 532 & 302 \\ 10 & 16 & 2 & 1 & 5 & 11 & 5 & 0 & 1 & 648 & 303\end{array}$

$\begin{array}{lllllllllll}8 & 15 & 6 & 0 & 1 & 10 & 4 & 0 & 0 & 1112 & 298\end{array}$

MSO4

$\begin{array}{llll}7 & 1 & 0 & 1\end{array}$

$\begin{array}{lllll}14 & 20 & 2 & 5 & 2\end{array}$

28

$\begin{array}{llllll}2 & 4 & 2 & 5 & 789 & 296\end{array}$

$\begin{array}{llllll}3 & 8 & 0 & 0 & 735 & 285\end{array}$

MSO5

MSO6

$\begin{array}{llll}1 & 0 & 0 & 0 \\ 3 & 0 & 0 & 0\end{array}$

$\begin{array}{lllll}12 & 15 & 5 & 0 & 5\end{array}$

MSO7

$\begin{array}{llll}3 & 0 & 0 & 0 \\ 0 & 0 & 2 & 0\end{array}$

$\begin{array}{llll}11 & 8 & 9 & 2\end{array}$

24

$\begin{array}{lllll}2 & 23 & 5 & 2 & 3\end{array}$

$\begin{array}{ll}9 & 12\end{array}$

$\begin{array}{lll}2 & 715 & 293\end{array}$

MSO8

$\begin{array}{lllll}9 & 3 & 1 & 0 & 10\end{array}$

$\begin{array}{llll}5 & 1 & 0 & 0\end{array}$

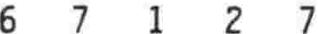

$\begin{array}{lllll}3 & 4 & 0 & 1 & 4\end{array}$

38

60

$12-4$

692302

MSO9

$\begin{array}{lllll}6 & 8 & 3 & 0 & 0\end{array}$

1213

4

$\begin{array}{ll}4 & 2\end{array}$

$\begin{array}{llll}0 & 0 & 0 & 1\end{array}$

$204 \quad 291$

MS10

$\begin{array}{llll}1 & 2 & 0 & 0 \\ 0 & 0 & 0 & 0\end{array}$

$\begin{array}{lllll}12 & 7 & 1 & 0 & 5\end{array}$

$\begin{array}{llll}0 & 0 & 0 & 0 \\ 0 & 3 & 0 & 0\end{array}$

$\begin{array}{lllll}5 & 0 & 0 & 0 & 2\end{array}$

MS 11

$\begin{array}{llll}0 & 3 & 0 & 0\end{array}$

$\begin{array}{lllll}4 & 1 & 0 & 0 & 2\end{array}$

MS13

$\begin{array}{llll}0 & 1 & 0 & 0 \\ 2 & 1 & 1 & 0\end{array}$

$\begin{array}{lllll}13 & 8 & 3 & 0 & 3\end{array}$

MS14

$\begin{array}{llll}1 & 1 & 1 & 0\end{array}$

$\begin{array}{lllll}1 & 8 & 4 & 1 & 3\end{array}$

MS15

MS16

$\begin{array}{lllll}10 & 7 & 2 & 1 & 3\end{array}$

$\begin{array}{llll}1 & 0 & 1 & 0\end{array}$

$\begin{array}{lllll}2 & 11 & 9 & 1 & 7\end{array}$

$\begin{array}{llll}0 & 0 & 61 & 121\end{array}$

MS18

MS19

$\begin{array}{lllll}5 & 0 & 0 & 0 & 3\end{array}$

$\begin{array}{llll}0 & 1 & 1 & 0\end{array}$

$\begin{array}{lllll}3 & 2 & 0 & 0 & 2\end{array}$

$\begin{array}{llllll}0 & 1 & 0 & 0 & 56 & 298\end{array}$

$\begin{array}{llllll}7 & 2 & 1 & 0 & 418 & 307\end{array}$

$\begin{array}{llllll}4 & 3 & 4 & 4 & 482 & 303\end{array}$

$\begin{array}{llllll}9 & 5 & 3 & 1 & 378 & 296\end{array}$

$\begin{array}{llllll}8 & 1 & 1 & 3 & 402 & 303\end{array}$

$\begin{array}{llllll}21 & 0 & 0 & 0 & 93 & 291\end{array}$

$\begin{array}{rrrrrr}1 & 1 & 0 & 0 & 50 & 261\end{array}$

$\begin{array}{llllllllllllllll}\text { MT04 } & 1 & 0 & 0 & 0 & 6 & 19 & 2 & 0 & 4 & 4 & 6 & 0 & 1 & 140 & 291\end{array}$

$\begin{array}{llllllllllllllll}\text { MT07 } & 0 & 0 & 0 & 0 & 3 & 6 & 2 & 0 & 6 & 3 & 9 & 0 & 0 & 111 & 290\end{array}$

$\begin{array}{llllllllllllllll}\text { MT08 } & 2 & 3 & 0 & 0 & 8 & 3 & 1 & 1 & 6 & 0 & 0 & 0 & 0 & 56 & 304\end{array}$

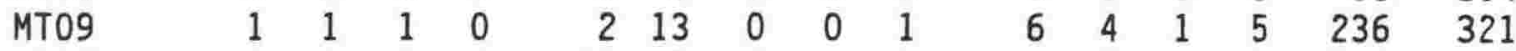

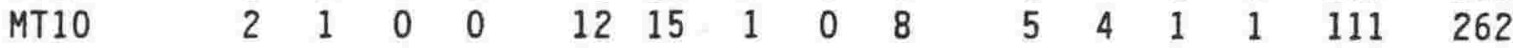

$\begin{array}{llllllllllllllll}\text { PBO2 } & 0 & 0 & 0 & 0 & 4 & 2 & 0 & 0 & 5 & 0 & 0 & 0 & 0 & 17 & 202\end{array}$

$\begin{array}{llllllllllllllll}\text { PBO4 } & 1 & 0 & 0 & 0 & 3 & 11 & 11 & 0 & 5 & 0 & 1 & 0 & 0 & 131 & 297\end{array}$

$\begin{array}{llllllllllllllll}\text { PBO5 } & 0 & 4 & 0 & 0 & 6 & 13 & 3 & 0 & 4 & 0 & 0 & 0 & 1 & 172 & 323\end{array}$

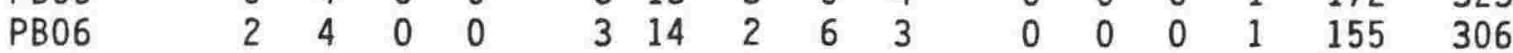

$\begin{array}{llllllllllllllll}\text { PBO9 } & 1 & 0 & 0 & 0 & 11 & 4 & 0 & 1 & 4 & 2 & 4 & 0 & 0 & 90 & 295\end{array}$

PB11

$1 \quad 0 \quad 000$

$\begin{array}{lllll}3 & 5 & 3 & 0 & 2\end{array}$

$0 \quad 10$

$617 \quad 286$ 
SAM : thesis sample number

47 : E. acuminatum, E. cienkowskii group, and E. hexagonatum

$48:$ E. calvertense and $E$. inflatum

49 : Eucyrtidium punctatum group

50 : Eucyrtidium sp. A and E. montiparum

51 : Stichocorys peregrina

52 : Stichocorys delmontensis

53 : Stichocorys spp. (transitionals)

54 : Anthocyrtidium spp.

55 : Lamprocyclas and Lamprocyrtis spp.

56 : Botryostrobus spp.

57 : Siphocampe spp.

58 : Spirocyrtis subscalaris

59 : Botryopyle dictyocephalus group

NG : number of radiolarians per gram of sediment

TOT : total number of radiolarians counted 
$\begin{array}{llllllllllllllll}\text { SAM } & 47 & 48 & 49 & 50 & 51 & 52 & 53 & 54 & 55 & 56 & 57 & 58 & 59 & \text { NG } & \text { TOT }\end{array}$

$\begin{array}{llllllrlllllllll}\text { RKO2 } & 4 & 3 & 4 & 2 & 0 & 26 & 6 & 0 & 8 & 3 & 5 & 0 & 3 & 211 & 284 \\ \text { RKO3 } & 1 & 2 & 3 & 2 & 7 & 7 & 0 & 0 & 1 & 0 & 3 & 0 & 0 & 223 & 279\end{array}$

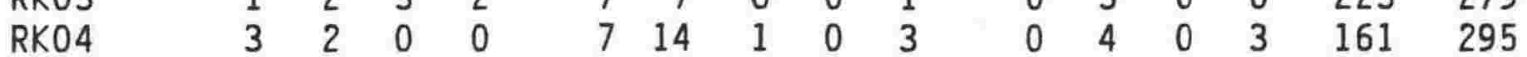

$\begin{array}{llllllllllllllll}\mathrm{RMO} 3 & 0 & 0 & 0 & 0 & 11 & 5 & 1 & 2 & 11 & 8 & 0 & 0 & 0 & 94 & 239\end{array}$

$\begin{array}{llllllllllllllll}\text { RMO4 } & 2 & 2 & 4 & 0 & 12 & 11 & 4 & 2 & 0 & 18 & 1 & 0 & 1 & 436 & 296\end{array}$

$\begin{array}{llllllllllllllll}\text { RMO5 } & 3 & 1 & 1 & 0 & 10 & 13 & 2 & 3 & 7 & 8 & 4 & 1 & 0 & 448 & 293\end{array}$

$\begin{array}{llllllllllllllll}\text { RMO6 } & 4 & 2 & 4 & 0 & 10 & 14 & 2 & 1 & 1 & 16 & 2 & 0 & 0 & 353 & 291\end{array}$

$\begin{array}{llllllllllllllll}\text { RMO7 } & 1 & 4 & 2 & 0 & 4 & 6 & 3 & 2 & 4 & 5 & 0 & 0 & 0 & 430 & 270\end{array}$

$\begin{array}{llllllllllllllll}\text { SCV1 } & 4 & 0 & 2 & 0 & 18 & 8 & 10 & 1 & 3 & 5 & 1 & 0 & 0 & 596 & 290\end{array}$

$\begin{array}{llllllllllllllll}\text { SMA1 } & 1 & 2 & 1 & 0 & 1 & 13 & 0 & 0 & 3 & 1 & 3 & 0 & 0 & 279 & 303\end{array}$

$\begin{array}{llllllllllllllll}\text { SMA3 } & 2 & 1 & 1 & 0 & 7 & 7 & 0 & 0 & 8 & 3 & 0 & 0 & 1 & 617 & 316\end{array}$

$\begin{array}{llllllllllllllll}\text { SMA4 } & 2 & 2 & 0 & 0 & 4 & 4 & 3 & 0 & 0 & 1 & 0 & 0 & 0 & 246 & 296\end{array}$

$\begin{array}{llllllllllllllll}\text { SMA5 } & 1 & 0 & 1 & 0 & 4 & 3 & 2 & 1 & 4 & 16 & 1 & 3 & 0 & 125 & 339\end{array}$

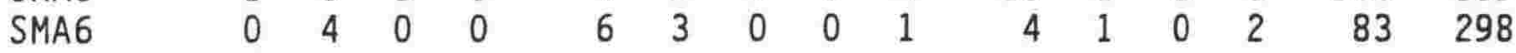

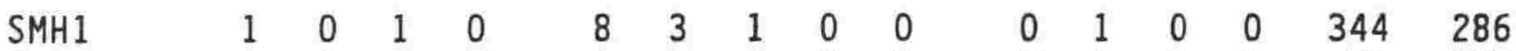

$\begin{array}{llllllllllllllll}\text { SMR1 } & 0 & 0 & 2 & 0 & 1 & 0 & 0 & 0 & 2 & 5 & 0 & 0 & 0 & 51 & 295\end{array}$

$\begin{array}{llllllllllllllll}\text { SPA1 } & 0 & 1 & 0 & 0 & 5 & 2 & 0 & 0 & 0 & 1 & 3 & 0 & 0 & 613 & 284\end{array}$

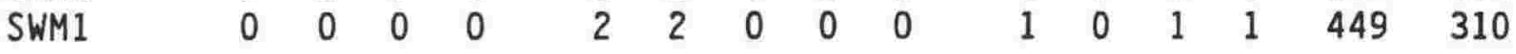

$\begin{array}{llllllllllllllll}\text { SWR1 } & 1 & 10 & 0 & 1 & 2 & 5 & 0 & 1 & 2 & 2 & 0 & 0 & 1 & 271 & 304\end{array}$

$\begin{array}{llllllllllllllrr}\text { SWR2 } & 0 & 1 & 0 & 0 & 16 & 17 & 5 & 0 & 5 & 3 & 0 & 1 & 0 & 91 & 274\end{array}$

$\begin{array}{llllllllllllllll}\text { SWR3 } & 1 & 0 & 0 & 0 & 5 & 4 & 2 & 0 & 1 & 1 & 0 & 0 & 0 & 104 & 300\end{array}$

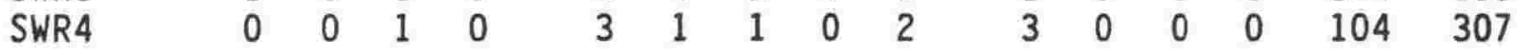

$\begin{array}{llllllllllllllll}\text { TK05 } & 0 & 0 & 0 & 0 & 0 & 2 & 0 & 0 & 0 & 0 & 0 & 0 & 0 & 6 & 50\end{array}$

$\begin{array}{llllllllllllllll}\text { TM06 } & 0 & 1 & 0 & 0 & 1 & 0 & 0 & 0 & 5 & 3 & 0 & 0 & 0 & 285 & 288\end{array}$

$\begin{array}{llllllllllllllll}\text { TM14 } & 4 & 1 & 0 & 0 & 4 & 27 & 17 & 3 & 3 & 2 & 3 & 0 & 1 & 662 & 300\end{array}$

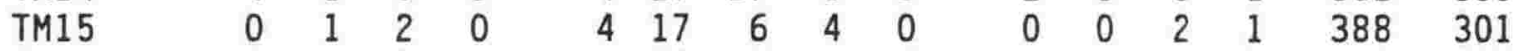

$\begin{array}{llllllllllllllll}\text { TM16 } & 4 & 0 & 1 & 0 & 2 & 24 & 4 & 0 & 4 & 1 & 1 & 0 & 0 & 223 & 297\end{array}$

$\begin{array}{llllllllllllllll}\text { TM19 } & 4 & 0 & 0 & 0 & 10 & 15 & 3 & 1 & 5 & 0 & 0 & 1 & 0 & 400 & 295\end{array}$

$\begin{array}{llllllllllllllll}\text { TM20 } & 3 & 4 & 3 & 0 & 11 & 10 & 2 & 1 & 14 & 2 & 0 & 1 & 3 & 275 & 293\end{array}$

$\begin{array}{llllllllllllllll}\text { TM21 } & 14 & 1 & 0 & 1 & 0 & 15 & 7 & 2 & 4 & 5 & 2 & 0 & 1 & 604 & 289\end{array}$

$\begin{array}{llllllllllllllll}\text { TM22 } & 6 & 1 & 2 & 0 & 2 & 27 & 9 & 2 & 4 & 7 & 3 & 3 & 0 & 321 & 326\end{array}$

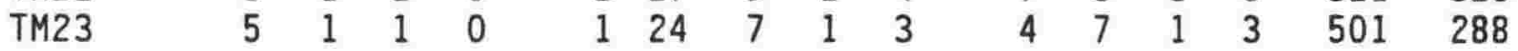

$\begin{array}{llllllllllllllll}\text { WAO1 } & 0 & 2 & 1 & 1 & 1 & 0 & 0 & 0 & 1 & 1 & 1 & 0 & 0 & 69 & 321\end{array}$

$\begin{array}{llllllllllllllll}\text { WAO2 } & 0 & 2 & 2 & 0 & 0 & 0 & 0 & 0 & 0 & 13 & 0 & 0 & 0 & 193 & 282\end{array}$

$\begin{array}{llllllllllllllll}\text { WAO3 } & 0 & 1 & 0 & 0 & 0 & 0 & 0 & 1 & 3 & 5 & 1 & 1 & 1 & 147 & 321\end{array}$

$\begin{array}{llllllllllllllll}\text { WA07 } & 0 & 3 & 0 & 1 & 0 & 1 & 0 & 0 & 0 & 6 & 0 & 2 & 0 & 129 & 279\end{array}$

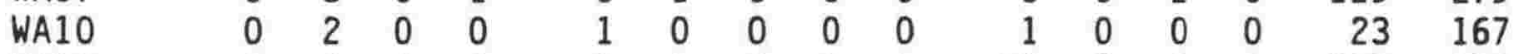

$\begin{array}{llllllllllllllll}\text { WA13 } & 1 & 1 & 4 & 1 & 2 & 1 & 1 & 0 & 2 & 12 & 1 & 0 & 0 & 202 & 296\end{array}$

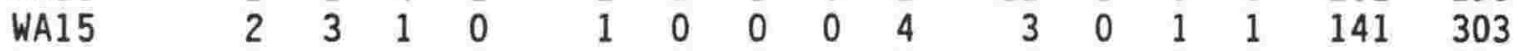

$\begin{array}{llllllllllllllll}\text { WA16 } & 1 & 0 & 2 & 0 & 0 & 2 & 0 & 0 & 1 & 6 & 1 & 0 & 0 & 97 & 290\end{array}$

$\begin{array}{llllllllllllllll}\text { WA17 } & 0 & 3 & 3 & 0 & 1 & 0 & 0 & 1 & 2 & 22 & 1 & 0 & 0 & 131 & 297\end{array}$

$\begin{array}{llllllllllllllll}\text { WA19 } & 0 & 5 & 2 & 1 & 1 & 0 & 0 & 0 & 4 & 6 & 0 & 1 & 0 & 144 & 294\end{array}$

$\begin{array}{llllllllllllllll}\text { WA23 } & 0 & 0 & 3 & 0 & 5 & 0 & 0 & 0 & 3 & 8 & 0 & 2 & 1 & 102 & 289\end{array}$

$\begin{array}{llllllllllllllll}\text { WA26 } & 0 & 0 & 1 & 0 & 2 & 0 & 0 & 0 & 1 & 13 & 1 & 0 & 1 & 142 & 295\end{array}$

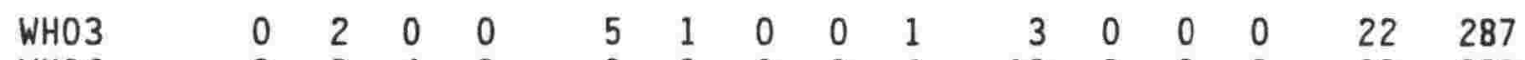

$\begin{array}{llllllllllllllll}\text { WHO6 } & 0 & 0 & 4 & 0 & 0 & 0 & 0 & 0 & 4 & 10 & 0 & 0 & 0 & 23 & 289\end{array}$

$\begin{array}{llllllllllllllll}\text { WT03 } & 0 & 2 & 2 & 0 & 3 & 1 & 0 & 0 & 3 & 0 & 0 & 0 & 1 & 65 & 289\end{array}$ $\begin{array}{llllllllllllllll}\text { WT05 } & 0 & 0 & 1 & 0 & 14 & 7 & 5 & 0 & 3 & 1 & 6 & 2 & 0 & 392 & 295\end{array}$ 


\section{E.3 LIST OF FACTORS FOR STATISTICAL SAMPLES}

This section contains the list of commonly quoted factors for the statistical samples. The samples are arranged in the alphabetical order of the thesis numbers (as in Appendix E.2). The factors listed are indexed as follows:

SAM : Thesis sample number

AGE : New Zealand Stage

ZN : Radiolarian zone or subzone code

Lamprocyclas gamphonycha Zone Code : RA

Lamprocyrtis heteroporos Zone Code : RB

Lamprocyrtis hannai Subzone Code : RC

Lychnocanium sp. aff. grande Subzone Code : RD

Didymocyrtis sp. A Zone Code : RE

Anthocyrtidium ehrenbergi pliocenica Subzone Code : RF

Heliodiscus asteriscus forma large pores Subzone Code : RG

Didymocyrtis laticonus Subzone Code : RH

Heliodiscus umbonatum Subzone Code : RI

NG : Number of radiolarians per gram of sediment

TOT : Total number of radiolarians counted

$\mathbf{N}$ : Number of counting groups filled

This factor gives an idea of the preservation of radiolarians in the sample, the higher the number indicating better preservation because more delicate forms are preserved. Low $\mathrm{N}$ values indicate only the more robust species are preserved in samples with low preservation.

Q : the diversity statistic $Q$ as defined by Kempton and Wedderburn (1978):

$Q=(N / 2) / \ln (Q 3 / Q 1)$, where $Q 3$ and $Q 1$ are the third and first quartiles of the series, $\mathrm{Pi}_{\mathrm{i}}$, where $i=1,2,3,4 \ldots \mathrm{N}$ (the proportional abundances of the radiolarian counting groups arranged in ascending order).

This diversity index emphasises the midrange values and deemphasises the extremes, which is advantageous for fossil assemblages in which extreme values could be a result of differential preservation (Riedel, Westberg-Smith and Budai, 1985).

On page A148 the samples are grouped by radiolarian zone and the means of NG, N, and $Q$ listed. 


\begin{tabular}{|c|c|c|c|c|c|c|}
\hline SAM & $\mathrm{AGE}$ & $\mathbf{Z N}$ & NG & TOT & $\mathrm{N}$ & C \\
\hline $\mathrm{CRO} 3$ & LWn & RA & 12 & 200 & 21 & 5.05 \\
\hline $\begin{array}{l}\mathrm{ECO} 2 \\
\mathrm{ECO} 4\end{array}$ & $\begin{array}{r}\text { LWo } \\
\text { LTk }\end{array}$ & $\begin{array}{l}\mathrm{RD} \\
\mathrm{RE}\end{array}$ & $\begin{array}{l}130 \\
225\end{array}$ & $\begin{array}{l}297 \\
297\end{array}$ & $\begin{array}{l}27 \\
27\end{array}$ & $\begin{array}{l}6.68 \\
5.66\end{array}$ \\
\hline $\begin{array}{l}\text { HRO2 } \\
\text { HRO4 } \\
\text { HRO5 } \\
\text { HRO6 }\end{array}$ & $\begin{array}{l}\text { UTt } \\
\text { UTt } \\
\text { UTt } \\
\text { UTt }\end{array}$ & $\begin{array}{l}\text { RF } \\
\text { RG } \\
\text { RG } \\
\text { RH }\end{array}$ & $\begin{array}{l}370 \\
269 \\
535 \\
285\end{array}$ & $\begin{array}{l}259 \\
309 \\
275 \\
300\end{array}$ & $\begin{array}{l}29 \\
44 \\
35 \\
31\end{array}$ & $\begin{array}{r}9.00 \\
10.23 \\
7.93 \\
11.21\end{array}$ \\
\hline KBO1 & LTt & $\mathrm{RH}$ & 568 & 357 & 37 & 15.91 \\
\hline $\begin{array}{l}\text { LT01 } \\
\text { LT05 } \\
\text { LT06 } \\
\text { LT08 } \\
\text { LT09 }\end{array}$ & $\begin{array}{l}\text { LWo } \\
\text { LTt } \\
\text { LTt } \\
\text { LTt } \\
\text { LTt }\end{array}$ & $\begin{array}{r}\mathrm{RC} \\
\mathrm{RH} \\
\mathrm{RH} \\
\mathrm{RH} \\
\mathrm{Rl}\end{array}$ & $\begin{array}{r}74 \\
829 \\
1188 \\
727 \\
1187\end{array}$ & $\begin{array}{l}306 \\
286 \\
291 \\
295 \\
336\end{array}$ & $\begin{array}{l}28 \\
38 \\
38 \\
28 \\
36\end{array}$ & $\begin{array}{r}8.61 \\
13.71 \\
8.50 \\
5.21 \\
9.30\end{array}$ \\
\hline $\begin{array}{l}\text { MO02 } \\
\text { MO03 } \\
\text { MO05 } \\
\text { MO06 } \\
\text { MO07 } \\
\text { MO10 } \\
\text { MO11 } \\
\text { MO13 } \\
\text { MO14 }\end{array}$ & $\begin{array}{l}\text { UTt } \\
\text { UTt } \\
\text { UTt } \\
\text { UTt } \\
\text { UTt } \\
\text { UTt } \\
\text { UTt } \\
\text { UTt } \\
\text { UTt }\end{array}$ & $\begin{array}{l}\text { RE } \\
R E \\
R E \\
R E \\
R E \\
R E \\
R E \\
R E \\
R E\end{array}$ & $\begin{array}{r}762 \\
292 \\
551 \\
532 \\
648 \\
1112 \\
568 \\
789 \\
735\end{array}$ & $\begin{array}{l}313 \\
358 \\
301 \\
302 \\
303 \\
298 \\
371 \\
296 \\
285\end{array}$ & $\begin{array}{l}38 \\
31 \\
33 \\
38 \\
36 \\
37 \\
42 \\
37 \\
39\end{array}$ & $\begin{array}{r}8.76 \\
8.67 \\
10.56 \\
9.74 \\
8.84 \\
12.78 \\
13.74 \\
11.19 \\
8.86\end{array}$ \\
\hline $\begin{array}{l}\text { MS03 } \\
\text { MS04 } \\
\text { MS05 } \\
\text { MS06 } \\
\text { MS07 } \\
\text { MS08 } \\
\text { MS09 } \\
\text { MS10 } \\
\text { MS11 } \\
\text { MS12 } \\
\text { MS13 } \\
\text { MS14 } \\
\text { MS15 } \\
\text { MS16 } \\
\text { MS18 } \\
\text { MS19 }\end{array}$ & $\begin{array}{l}\text { UTt } \\
\text { UTt } \\
\text { UTt } \\
\text { UTt } \\
\text { UTt } \\
\text { UTt } \\
\text { UTt } \\
\text { UTt } \\
\text { UTt } \\
\text { UTt } \\
\text { UTt } \\
\text { UTt } \\
\text { UTt } \\
\text { UTt } \\
\text { UTt } \\
\text { LTt }\end{array}$ & $\begin{array}{l}\text { RE } \\
\text { RE } \\
\text { RE } \\
\text { RE } \\
R E \\
\text { RF } \\
R F \\
R F \\
R F \\
R G \\
R G \\
R G \\
R G \\
R G \\
R H \\
R H\end{array}$ & $\begin{array}{r}715 \\
692 \\
204 \\
405 \\
395 \\
512 \\
303 \\
61 \\
56 \\
418 \\
482 \\
378 \\
402 \\
93 \\
50 \\
109\end{array}$ & $\begin{array}{l}293 \\
302 \\
291 \\
296 \\
285 \\
293 \\
294 \\
121 \\
298 \\
307 \\
303 \\
296 \\
303 \\
291 \\
261 \\
287\end{array}$ & $\begin{array}{l}34 \\
42 \\
35 \\
37 \\
39 \\
36 \\
32 \\
22 \\
31 \\
38 \\
40 \\
43 \\
38 \\
23 \\
28 \\
36\end{array}$ & $\begin{array}{r}13.18 \\
13.93 \\
7.93 \\
8.06 \\
12.94 \\
10.99 \\
6.67 \\
5.08 \\
5.90 \\
11.97 \\
14.43 \\
11.10 \\
7.92 \\
3.76 \\
6.12 \\
8.67\end{array}$ \\
\hline $\begin{array}{l}\text { MT04 } \\
\text { MT07 } \\
\text { MT08 } \\
\text { MT09 } \\
\text { MT10 }\end{array}$ & $\begin{array}{l}\text { UTt } \\
\text { UTt } \\
\text { UTt } \\
\text { UTt } \\
\text { UTt }\end{array}$ & $\begin{array}{l}\mathrm{RE} \\
\mathrm{RE} \\
\mathrm{RG} \\
\mathrm{RG} \\
\mathrm{RG}\end{array}$ & $\begin{array}{r}140 \\
111 \\
56 \\
236 \\
111\end{array}$ & $\begin{array}{l}291 \\
290 \\
304 \\
321 \\
262\end{array}$ & $\begin{array}{l}33 \\
30 \\
34 \\
34 \\
34\end{array}$ & $\begin{array}{l}9.97 \\
8.48 \\
8.60 \\
7.92 \\
7.82\end{array}$ \\
\hline $\begin{array}{l}\text { PBO2 } \\
\text { PB04 } \\
\text { PB05 } \\
\text { PB06 } \\
\text { PB09 } \\
\text { PB11 }\end{array}$ & $\begin{array}{l}\text { UTt } \\
\text { UTt } \\
\text { UTt } \\
\text { UTt } \\
\text { UTt } \\
\text { UTt }\end{array}$ & $\begin{array}{l}\text { RE } \\
\text { RF } \\
\text { RF } \\
\text { RF } \\
\text { RF } \\
\text { RF }\end{array}$ & $\begin{array}{r}17 \\
131 \\
172 \\
155 \\
90 \\
617\end{array}$ & $\begin{array}{l}202 \\
297 \\
323 \\
306 \\
295 \\
286\end{array}$ & $\begin{array}{l}22 \\
35 \\
28 \\
33 \\
29 \\
31\end{array}$ & $\begin{array}{r}6.14 \\
10.24 \\
6.51 \\
10.56 \\
8.76 \\
10.31\end{array}$ \\
\hline
\end{tabular}




\begin{tabular}{|c|c|c|c|c|c|c|}
\hline SAM & $\mathrm{AGE}$ & $\mathrm{ZN}$ & NG & TOT & $\mathbf{N}$ & $\mathbf{Q}$ \\
\hline RKO2 & UTt & $\mathrm{RH}$ & 211 & 284 & 36 & 9.71 \\
\hline RKO3 & UTt & $\mathrm{RH}$ & 223 & 279 & 25 & 6.44 \\
\hline RKO4 & LTt & $\mathrm{RH}$ & 161 & 295 & 31 & 9.65 \\
\hline RMO3 & UTt & $\mathrm{RE}$ & 94 & 239 & 31 & 6.48 \\
\hline RMO4 & UTt & $\mathrm{RE}$ & 436 & 296 & 34 & 9.88 \\
\hline RM05 & UTt & RF & 448 & 293 & 41 & 9.84 \\
\hline RM06 & UTt & $\mathrm{RF}$ & 353 & 291 & 36 & 8.75 \\
\hline RMO7 & UTt & RF & 430 & 270 & 38 & 17.30 \\
\hline SCV1 & UTt & $R G$ & 596 & 290 & 39 & 8.94 \\
\hline SMA 1 & UTt & $\mathrm{RE}$ & 279 & 303 & 26 & 7.76 \\
\hline SMA3 & UTt & $R E$ & 617 & 316 & 36 & 6.87 \\
\hline SMA4 & UTt & RF & 246 & 296 & 31 & 7.49 \\
\hline SMA5 & UTt & RG & 125 & 339 & 27 & 5.26 \\
\hline SMAG & UTt & $?$ & 83 & 298 & 24 & 4.58 \\
\hline SMH1 & UTt & $\mathrm{RE}$ & 344 & 286 & 37 & 8.69 \\
\hline SMR1 & LWo & $\mathrm{RD}$ & 51 & 295 & 31 & 6.24 \\
\hline SPA1 & LTt & $\mathrm{RH}$ & 613 & 284 & 29 & 6.42 \\
\hline SWM1 & LWo & $\mathrm{RC}$ & 449 & 310 & 30 & 8.93 \\
\hline SWR1 & LWo & RD & 271 & 304 & 23 & 3.71 \\
\hline SWR2 & LWo & RD & 91 & 274 & 29 & 7.08 \\
\hline SWR3 & LWo & $\mathrm{RD}$ & 104 & 300 & 26 & 5.40 \\
\hline SWR4 & LTt & RH & 104 & 307 & 35 & 6.66 \\
\hline TKO5 & Wop & $?$ & 6 & 50 & 14 & 4.84 \\
\hline TM06 & Wop & $\mathrm{RD}$ & 285 & 288 & 28 & 6.32 \\
\hline TM14 & UTt & RE & 662 & 300 & 36 & 10.58 \\
\hline TM15 & UTt & RE & 388 & 301 & 35 & 11.70 \\
\hline TM16 & UTt & RE & 223 & 297 & 32 & 9.12 \\
\hline TM19 & UTt & $\mathrm{RE}$ & 400 & 295 & 34 & 7.39 \\
\hline TM20 & UTt & RE & 275 & 293 & 41 & 10.51 \\
\hline TM21 & UTt & RE & 604 & 289 & 38 & 7.62 \\
\hline TM22 & UTt & RE & 321 & 326 & 40 & 12.38 \\
\hline TM23 & UTt & $\mathrm{RE}$ & 501 & 288 & 40 & 10.39 \\
\hline WA01 & UWn & RA & 69 & 321 & 34 & 6.23 \\
\hline WAO2 & UWn & RA & 193 & 282 & 29 & 8.51 \\
\hline WAO3 & UWn & RA & 147 & 321 & 34 & 7.92 \\
\hline WA07 & UWn & RA & 129 & 279 & 33 & 7.34 \\
\hline WA 10 & LWn & $\mathrm{RB}$ & 23 & 167 & 22 & 4.17 \\
\hline WA 13 & Wm & RB & 202 & 296 & 35 & 8.45 \\
\hline WA15 & Wm & $\mathrm{RB}$ & 141 & 303 & 37 & 8.21 \\
\hline WA16 & Wm & RB & 97 & 290 & 31 & 6.01 \\
\hline WA 17 & $\mathrm{Wm}$ & RB & 131 & 297 & 31 & 8.26 \\
\hline WA 19 & Wm & RB & 144 & 294 & 33 & 6.76 \\
\hline WA23 & Wop & RB & 102 & 289 & 29 & 7.28 \\
\hline WA26 & Wop & RB & 142 & 295 & 24 & 4.33 \\
\hline WHO3 & UWn & RA & 22 & 287 & 26 & 6.83 \\
\hline WHOG & UWn & $R B$ & 23 & 289 & 23 & 7.85 \\
\hline WTO3 & UTt & $\mathrm{RE}$ & 65 & 289 & 28 & 5.33 \\
\hline WT05 & UTt & RF & 392 & 295 & 38 & 9.15 \\
\hline
\end{tabular}




\section{MEANS OF NG, N, AND Q GROUPED BY RADIOLARIAN ZONE}

Lamprocyclas gamphonycha Zone Code : RA

samples $=6$ mean $\mathrm{NG}=95 \quad$ mean $\mathrm{N}=29.5 \quad$ mean $\mathrm{Q}=6.98$

Lamprocyrtis heteroporos Zone Code : RB

samples $=9$ mean $\mathrm{NG}=112 \quad$ mean $\mathrm{N}=29.4 \quad$ mean $\mathrm{Q}=6.81$

Lamprocyrtis hannai Subzone Code : RC

samples $=2$

mean $N G=262 \quad$ mean $N=29.0$

mean $Q=8.77$

Lychnocanium sp. aff. grande Subzone Code : RD

samples $=6$

mean NG $=155 \quad$ mean $\mathrm{N}=27.3$

mean $Q=5.90$

Didymacyrtis sp. A Zone Code : RE

samples $=31$

mean NG $=435$

mean $\mathrm{N}=34.9$

mean $\mathrm{Q}=9.59$

Anthocyrtidium ehrenbergi pliocenica Subzone Code : RF

samples $=15$

mean NG $=289$

mean $\mathrm{N}=32.7$

mean $Q=9.10$

Heliodiscus asteriscus forma large pores Subzone Code : RG

samples $=12$

mean NG $=308$

mean $\mathrm{N}=35.7$

mean $\mathrm{Q}=8.82$

Didymocyrtis laticonus Subzone Code : RH

samples $=12$

mean NG $=422$

mean $\mathrm{N}=32.7$

mean $Q=9.02$

Heliodiscus umbonatum Subzone Code : RI

samples $=1$

mean NG $=1187$

mean $\mathrm{N}=36.0$

mean $Q=9.30$ 


\section{E.4 REDUCED DATA SET}

This section tabulates the reduced data set used in the thesis. This data set includes all the original counting groups and some combined groups which generally represent over $2 \%$ of the fauna. After these major elements of the fauna were chosen (13 groups) their percentages were recalculated to $100 \%$ and it is the recalculated percentages that are tabulated here. The samples are again arranged in alphabetical order of thesis number. The variables listed are indexed on the facing page.

On page A154 the samples are grouped by radiolarian biozone and the means of the 13 groups presented. 
SAM : thesis sample number

AGE : New Zealand Stage

ZN : Radiolarian zone

R1 : Actinomma spp.

R2 : Hexacontium spp.

R3 : Thecosphaera spp.

R4 : Cenosphaera spp.

R5 : Prunulum spp.

R6 : Stylosphaerids 
- A150 -

\begin{tabular}{|c|c|c|c|c|c|c|c|c|}
\hline SAM & AGE & $\mathrm{ZN}$ & R1 & $\mathbf{R} 2$ & R3 & R4 & R5 & R6 \\
\hline CRO3 & LWn & RA & 5.1 & 3.2 & 3.8 & 1.9 & 8.2 & 5.1 \\
\hline ECO2 & LWo & $\mathrm{RD}$ & 2.6 & 3.1 & 6.6 & 4.0 & 7.9 & 1.8 \\
\hline ECO4 & LTk & $\mathrm{RE}$ & 2.9 & 3.8 & 6.7 & 2.1 & 10.9 & 1.7 \\
\hline HRO2 & UTt & RF & 2.8 & 3.7 & 4.6 & 1.9 & 6.0 & 6.0 \\
\hline HRO4 & UTt & RG & 1.3 & 2.2 & 7.8 & 0.4 & 8.2 & 2.2 \\
\hline HR05 & UTt & $R G$ & 1.8 & 3.2 & 2.3 & 0.0 & 7.8 & 4.6 \\
\hline HRO6 & UTt & $\mathrm{RH}$ & 2.9 & 1.7 & 2.9 & 0.8 & 11.2 & 5.4 \\
\hline KB01 & LTt & $\mathrm{RH}$ & 2.7 & 10.3 & 2.7 & 4.0 & 11.7 & 1.8 \\
\hline LT01 & LWo & $\mathrm{RC}$ & 4.1 & 3.2 & 2.7 & 0.0 & 5.5 & 3.2 \\
\hline LT05 & LTt & $\mathrm{RH}$ & 1.9 & 12.0 & 8.3 & 1.4 & 11.1 & 4.6 \\
\hline LT06 & LTt & $\mathrm{RH}$ & 0.4 & 6.1 & 8.3 & 4.8 & 13.9 & 6.5 \\
\hline LT08 & LTt & $\mathrm{RH}$ & 3.2 & 6.4 & 5.2 & 6.4 & 8.8 & 6.0 \\
\hline LT09 & LTt & $\mathrm{RI}$ & 3.4 & 6.5 & 5.3 & 5.3 & 11.5 & 7.3 \\
\hline MOO2 & UTt & $\mathrm{RE}$ & 10.7 & 4.0 & 4.9 & 1.8 & 11.2 & 4.0 \\
\hline MOO3 & UTt & $\mathrm{RE}$ & 5.3 & 5.0 & 2.3 & 3.4 & 16.0 & 8.4 \\
\hline MOO5 & UTt & RE & 4.3 & 1.9 & 3.3 & 2.4 & 10.5 & 2.9 \\
\hline MO06 & UTt & $\mathrm{RE}$ & 3.7 & 2.3 & 2.8 & 2.3 & 14.0 & 5.1 \\
\hline MOO7 & UTt & $\mathrm{RE}$ & 4.6 & 5.0 & 3.7 & 0.0 & 6.4 & 5.5 \\
\hline M010 & UTt & RE & 4.9 & 2.5 & 3.0 & 1.5 & 8.9 & 3.9 \\
\hline M011 & UTt & $\mathrm{RE}$ & 4.8 & 4.8 & 5.2 & 0.8 & 5.2 & 4.8 \\
\hline MO13 & UTt & RE & 4.9 & 7.3 & 4.4 & 1.5 & 5.9 & 4.4 \\
\hline MO14 & UTt & RE & 4.7 & 0.5 & 2.6 & 1.0 & 5.2 & 10.4 \\
\hline MSO3 & UTt & $\mathrm{RE}$ & 3.8 & 1.9 & 2.9 & 2.4 & 9.1 & 3.8 \\
\hline MSO4 & UTt & $\mathrm{RE}$ & 5.7 & 11.4 & 3.8 & 0.5 & 4.3 & 6.2 \\
\hline MSO5 & UTt & RE & 2.8 & 3.3 & 2.8 & 3.3 & 12.8 & 7.1 \\
\hline MSO6 & UTt & $\mathrm{RE}$ & 1.3 & 5.7 & 4.3 & 2.2 & 8.7 & 11.3 \\
\hline MSO7 & UTt & RE & 3.3 & 10.0 & 3.3 & 4.3 & 9.0 & 5.2 \\
\hline MSO8 & UTt & RF & 4.0 & 8.9 & 2.2 & 1.8 & 4.9 & 5.4 \\
\hline MS09 & UTt & RF & 3.1 & 3.1 & 4.9 & 2.2 & 8.9 & 3.1 \\
\hline MS10 & UTt & RF & 8.3 & 7.3 & 8.3 & 11.5 & 12.5 & 15.6 \\
\hline MS11 & UTt & RF & 3.4 & 5.8 & 8.3 & 2.9 & 15.0 & 10.7 \\
\hline MS12 & UTt & RG & 6.0 & 10.6 & 6.0 & 0.9 & 10.6 & 6.9 \\
\hline MS13 & UTt & $R G$ & 17.1 & 8.1 & 4.5 & 1.8 & 8.6 & 6.3 \\
\hline MS14 & UTt & RG & 4.4 & 4.9 & 3.9 & 1.0 & 9.3 & 6.3 \\
\hline MS15 & UTt & RG & 4.5 & 9.0 & 5.0 & 2.3 & 8.6 & 5.0 \\
\hline MS16 & UTt & RG & 4.6 & 10.0 & 12.1 & 3.8 & 8.4 & 12.1 \\
\hline MS18 & UTt & RH & 1.6 & 4.8 & 9.7 & 3.2 & 15.1 & 3.2 \\
\hline MS19 & LTt & $\mathrm{RH}$ & 2.3 & 4.2 & 3.7 & 0.9 & 7.0 & 4.2 \\
\hline MT04 & UTt & $\mathrm{RE}$ & 3.5 & 2.2 & 6.6 & 1.8 & 6.6 & 2.6 \\
\hline MT07 & UTt & $\mathrm{RE}$ & 2.6 & 4.3 & 7.3 & 0.4 & 6.0 & 2.6 \\
\hline MT08 & UTt & RG & 2.2 & 2.2 & 2.6 & 1.7 & 9.1 & 5.2 \\
\hline МТ09 & UTt & RG & 2.0 & 4.0 & 4.4 & 3.2 & 7.7 & 3.2 \\
\hline MT10 & UTt & $R G$ & 2.1 & 2.7 & 5.9 & 0.0 & 17.0 & 2.1 \\
\hline PBO2 & UTt & RE & 4.9 & 4.2 & 8.5 & 3.5 & 15.5 & 10.6 \\
\hline PBO4 & UTt & $\mathrm{RF}$ & 10.7 & 5.1 & 5.1 & 6.0 & 8.8 & 10.2 \\
\hline PB05 & UTt & RF & 3.7 & 5.3 & 2.9 & 0.0 & 11.8 & 6.1 \\
\hline PB06 & UTt & RF & 5.4 & 5.4 & 2.2 & 2.7 & 9.9 & 5.8 \\
\hline PB09 & UTt & $\mathrm{RF}$ & 2.2 & 6.7 & 3.1 & 0.9 & 10.7 & 1.8 \\
\hline PB11 & UTt & $\mathrm{RF}$ & 4.2 & 7.0 & 1.9 & 4.2 & 14.6 & 4.7 \\
\hline
\end{tabular}


SAM : thesis sample number

AGE : New Zealand Stage

ZN : Radiolarian zone

R1 : Actinomma spp.

R2 : Hexacontium spp.

R3 : Thecosphaera spp.

R4 : Cenosphaera spp.

R5 : Prunulum spp.

R6 : Stylosphaerids 


\begin{tabular}{|c|c|c|c|c|c|c|c|c|}
\hline SAM & AGE & $\mathrm{ZN}$ & R1 & R2 & R3 & R4 & R5 & R6 \\
\hline RKO2 & UTt & $\mathrm{RH}$ & 4.6 & 4.6 & 1.9 & 2.3 & 13.4 & 2.8 \\
\hline RK03 & UTt & $\mathrm{RH}$ & 0.0 & 5.1 & 4.2 & 3.0 & 6.8 & 2.1 \\
\hline RK04 & LTt & $\mathrm{RH}$ & 2.9 & 3.3 & 4.1 & 1.2 & 9.5 & 3.7 \\
\hline RMO3 & UTt & RE & 7.9 & 7.9 & 2.1 & 12.1 & 15.0 & 13.6 \\
\hline RM04 & UTt & RE & 3.7 & 2.8 & 0.9 & 1.9 & 6.5 & 6.0 \\
\hline RM05 & UTt & RF & 4.4 & 1.9 & 7.3 & 1.0 & 9.7 & 2.9 \\
\hline RM06 & UTt & RF & 2.9 & 2.9 & 3.4 & 1.4 & 10.1 & 5.3 \\
\hline RM07 & UTt & $\mathrm{RF}$ & 6.6 & 7.7 & 3.3 & 0.5 & 7.7 & 10.9 \\
\hline SCV1 & UTt & RG & 1.8 & 1.4 & 5.0 & 1.4 & 5.0 & 4.5 \\
\hline SMA1 & UTt & $\mathrm{RE}$ & 3.5 & 5.3 & 6.1 & 0.9 & 9.2 & 2.2 \\
\hline SMA3 & UTt & RE & 3.8 & 5.1 & 4.7 & 1.7 & 7.3 & 12.4 \\
\hline SMA4 & UTt & RF & 1.8 & 4.1 & 4.6 & 2.7 & 7.8 & 7.8 \\
\hline SMA5 & UTt & $\mathrm{RG}$ & 9.0 & 8.6 & 4.7 & 1.2 & 7.5 & 5.5 \\
\hline SMA6 & UTt & $?$ & 3.1 & 4.8 & 7.0 & 1.8 & 10.1 & 4.0 \\
\hline SMH1 & UTt & RE & 3.7 & 0.0 & 8.2 & 3.2 & 13.2 & 4.6 \\
\hline SMR1 & LWo & $\mathrm{RD}$ & 8.1 & 4.7 & 5.6 & 0.4 & 6.0 & 5.1 \\
\hline SPA1 & LTt & $\mathrm{RH}$ & 4.0 & 2.2 & 4.0 & 2.2 & 10.6 & 6.6 \\
\hline SWM1 & LWo & $\mathrm{RC}$ & 1.1 & 2.2 & 1.8 & 4.8 & 15.8 & 5.9 \\
\hline SWR1 & LWo & $\mathrm{RD}$ & 5.0 & 4.6 & 2.5 & 2.1 & 9.2 & 11.3 \\
\hline SWR2 & LWo & $\mathrm{RD}$ & 6.3 & 2.7 & 3.6 & 1.8 & 7.6 & 5.8 \\
\hline SWR3 & LWo & $R D$ & 4.3 & 3.0 & 6.0 & 4.7 & 18.4 & 3.4 \\
\hline SWR4 & LTt & $\mathrm{RH}$ & 4.3 & 11.3 & 9.1 & 3.0 & 11.3 & 6.9 \\
\hline TK05 & Wop & $?$ & 2.7 & 2.7 & 5.4 & 8.1 & 5.4 & 2.7 \\
\hline TM06 & Wop & RD & 2.7 & 0.5 & 3.2 & 3.2 & 5.9 & 0.5 \\
\hline TM14 & UTt & RE & 3.5 & 6.1 & 4.8 & 3.1 & 4.4 & 6.6 \\
\hline TM15 & UTt & RE & 4.0 & 5.8 & 2.7 & 3.6 & 12.4 & 5.8 \\
\hline TM16 & UTt & RE & 5.6 & 9.8 & 3.8 & 1.7 & 5.6 & 6.0 \\
\hline TM19 & UTt & RE & 3.1 & 2.7 & 2.7 & 0.9 & 13.5 & 4.5 \\
\hline TM20 & UTt & RE & 5.5 & 2.2 & 3.3 & 2.8 & 9.4 & 2.2 \\
\hline TM21 & UTt & RE & 3.2 & 8.5 & 5.3 & 3.7 & 6.9 & 0.0 \\
\hline TM22 & UTt & RE & 2.1 & 4.7 & 1.7 & 0.9 & 6.0 & 8.1 \\
\hline TM23 & UTt & RE & 2.6 & 4.2 & 2.1 & 2.6 & 4.7 & 5.8 \\
\hline WA01 & UWn & RA & 8.2 & 9.8 & 3.7 & 6.5 & 9.8 & 7.8 \\
\hline WAO2 & UWn & RA & 9.0 & 5.4 & 5.4 & 4.1 & 4.1 & 19.0 \\
\hline WAO3 & UWn & RA & 12.3 & 2.1 & 2.9 & 2.5 & 4.1 & 33.7 \\
\hline WA07 & UWn & RA & 11.2 & 16.5 & 1.0 & 4.9 & 6.8 & 24.8 \\
\hline WA 10 & LWn & RB & 19.9 & 8.5 & 13.5 & 6.4 & 9.2 & 16.3 \\
\hline WA 13 & Wm & RB & 3.6 & 4.0 & 6.2 & 1.3 & 6.2 & 8.4 \\
\hline WA 15 & Wm & RB & 12.8 & 7.2 & 3.1 & 2.6 & 9.2 & 10.8 \\
\hline WA 16 & Wm & RB & 9.5 & 4.8 & 3.8 & 1.9 & 15.7 & 6.7 \\
\hline WA17 & Wm & RB & 11.7 & 9.7 & 2.0 & 5.1 & 10.2 & 0.0 \\
\hline WA19 & $\mathrm{Wm}$ & RB & 10.4 & 4.0 & 4.0 & 1.0 & 8.0 & 12.9 \\
\hline WA23 & Wop & RB & 1.8 & 3.6 & 7.2 & 0.9 & 5.0 & 5.0 \\
\hline WA26 & WOP & $\mathrm{RB}$ & 3.4 & 1.3 & 7.8 & 2.2 & 5.2 & 3.0 \\
\hline WHO3 & UWn & RA & 6.9 & 0.4 & 7.8 & 4.3 & 13.4 & 2.6 \\
\hline WHOG & UWn & RB & 10.2 & 5.8 & 5.8 & 2.2 & 7.6 & 3.1 \\
\hline WT03 & UTt & RE & 2.4 & 6.7 & 19.0 & 16.2 & 11.0 & 11.0 \\
\hline WT05 & UTt & $\mathrm{RF}$ & 3.7 & 2.8 & 2.3 & 0.9 & 7.4 & 8.3 \\
\hline
\end{tabular}


SAM : thesis sample number

R7 : Dictyocoryne and Hymeniastrum spp.

R8 : Stylodictya spp.

R9 : Porodiscus spp.

R10 : Spongotrochus glacialis

R11 : Carpocaniidae

R12 : Cyrtocapsella and Stichocorys spp.

R13 : Artostrobiidae 


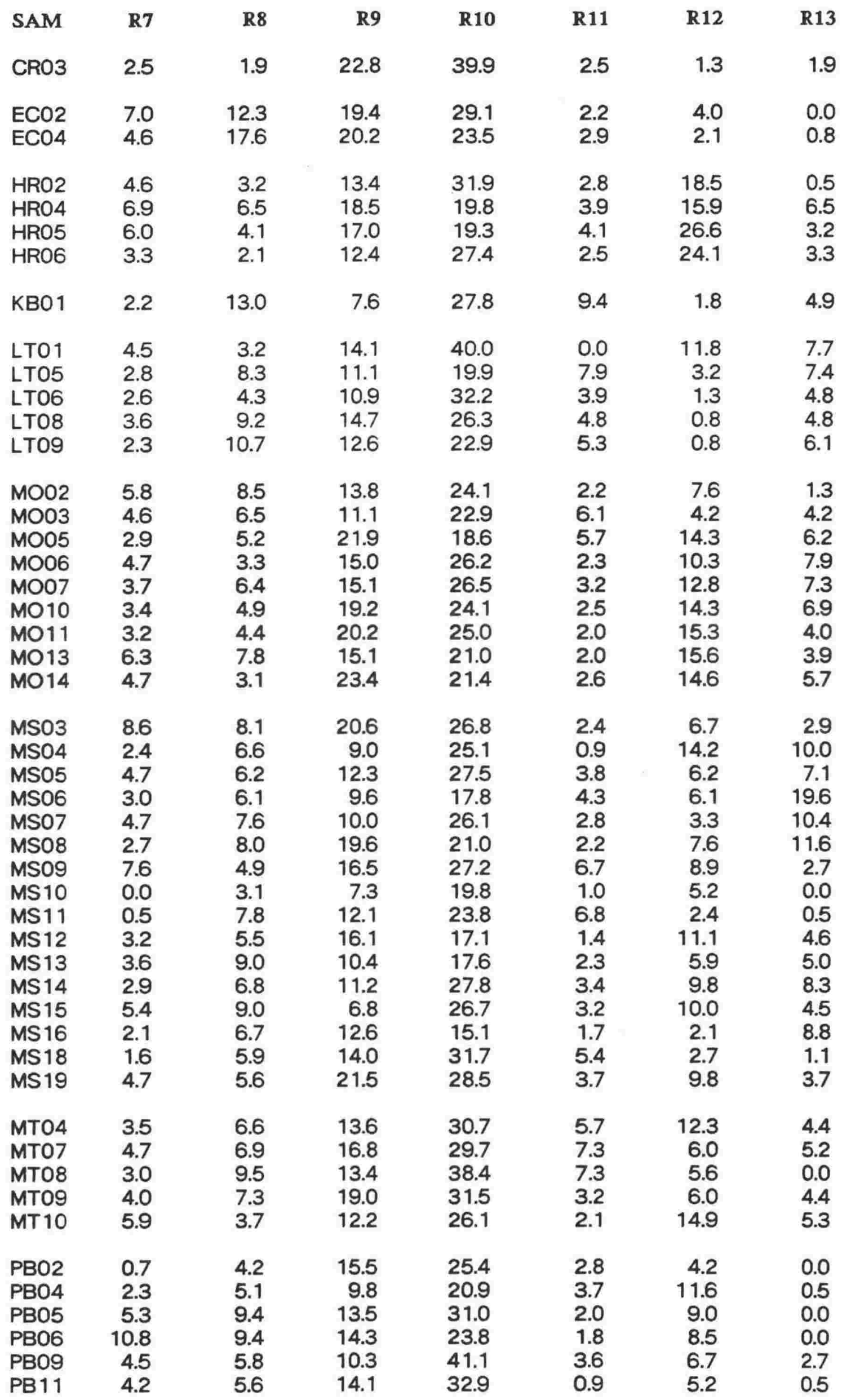


SAM : thesis sample number

R7 : Dictyocoryne and Hymeniastrum spp.

R8 : Stylodictya spp.

R9 : Porodiscus spp.

R10 : Spongotrochus glacialis

R11 : Carpocaniidae

R12 : Cyrtocapsella and Stichocorys spp.

R13 : Artostrobiidae 


\begin{tabular}{|c|c|c|c|c|c|c|c|}
\hline SAM & R7 & R8 & R9 & R10 & R11 & $\mathbf{R} 12$ & R13 \\
\hline RKO2 & 5.1 & 4.2 & 21.8 & 16.7 & 3.7 & 15.3 & 3.7 \\
\hline RKO3 & 9.3 & 9.7 & 17.4 & 30.9 & 3.4 & 6.8 & 13 \\
\hline RKO4 & 5.4 & 8.3 & 14.0 & 35.1 & 0.8 & 9.9 & 1. \\
\hline RMO3 & 1.4 & 1.4 & 2.1 & 10.0 & 8.6 & 12.1 & \\
\hline RMO4 & 6.0 & 6.5 & 19.1 & 21.4 & 3.7 & 12.6 & \\
\hline RMO5 & 4.9 & 4.4 & 13.1 & 28.2 & 3.9 & 12.1 & \\
\hline RMO6 & 3.8 & 3.8 & 21.6 & 21.6 & 1.9 & 12.5 & \\
\hline RM07 & 3.3 & 5.5 & 20.2 & 22.4 & 2.2 & 7.1 & \\
\hline SCV1 & 6.3 & 7.2 & 16.7 & 30.2 & 1.8 & 16.2 & 2. \\
\hline SMA1 & 5.3 & 7.5 & 16.7 & 32.9 & 2.6 & 6.1 & \\
\hline SMA3 & 4.7 & 7.7 & 13.2 & 28.6 & 3.0 & 6.4 & \\
\hline SMA4 & 1.4 & 5.9 & 21.5 & 34.2 & 2.7 & 5.0 & \\
\hline SMA5 & 3.9 & 5.9 & 13.7 & 25.5 & 3.1 & 3.5 & \\
\hline SMAG & 4.8 & 10.1 & 13.7 & 30.8 & 3.1 & 4.4 & 2.2 \\
\hline SMH1 & 8.7 & 5.9 & 23.7 & 22.4 & 0.5 & 5.5 & 0.5 \\
\hline SMR1 & 8.5 & 9.8 & 8.1 & 40.6 & 0.4 & 0.4 & \\
\hline SPA 1 & 1.8 & 7.5 & 18.1 & 33.2 & 4.4 & 3.5 & \\
\hline SWM1 & 8.1 & 18.4 & 16.5 & 23.2 & 0.0 & 1.5 & 0. \\
\hline SWR1 & 8.4 & 10.5 & 5.5 & 35.7 & 1.3 & 2.9 & 0.8 \\
\hline SWR2 & 9.4 & 6.7 & 15.2 & 19.7 & 2.2 & 17.0 & \\
\hline SWR3 & 3.0 & 4.7 & 7.3 & 39.7 & 0.4 & 4.7 & \\
\hline SWR4 & 1.7 & 7.4 & 7.8 & 26.8 & 6.9 & 2.2 & \\
\hline TK05 & 8.1 & 0.0 & 24.3 & 35.1 & 0.0 & 5.4 & 0.0 \\
\hline TM06 & 10.5 & 10.5 & 15.5 & 45.2 & 0.5 & 0.5 & \\
\hline TM14 & 7.0 & 7.4 & 8.7 & 21.4 & 3.1 & 21.8 & \\
\hline TM15 & 3.6 & 6.2 & 19.1 & 21.8 & 2.2 & 12.0 & \\
\hline TM16 & 4.3 & 9.0 & 14.5 & 20.9 & 5.1 & 12.8 & \\
\hline TM19 & 10.8 & 6.7 & 20.6 & 16.1 & 4.5 & 13.5 & \\
\hline TM20 & 3.9 & 5.0 & 23.8 & 25.4 & 2.2 & 12.7 & 1. \\
\hline TM21 & 8.5 & 7.9 & 18.0 & 15.9 & 6.3 & 12.2 & 3. \\
\hline TM22 & 5.1 & 9.8 & 19.6 & 16.2 & 4.3 & 16.2 & 5. \\
\hline TM23 & 6.3 & 11.1 & 18.4 & 13.7 & 4.7 & 17.4 & 6. \\
\hline WA01 & 3.7 & 6.5 & 13.1 & 28.6 & 1.2 & 0.4 & 0.8 \\
\hline WAO2 & 5.9 & 3.2 & 5.9 & 32.1 & 0.0 & 0.0 & \\
\hline WAO3 & 1.6 & 3.3 & 9.1 & 25.1 & 0.0 & 0.4 & \\
\hline WA07 & 2.9 & 6.3 & 3.9 & 16.5 & 1.0 & 0.5 & \\
\hline WA10 & 0.7 & 0.0 & 7.8 & 14.9 & 1.4 & 0.7 & 0. \\
\hline WA 13 & 9.3 & 3.6 & 12.9 & 35.1 & 1.8 & 1.8 & 5. \\
\hline WA 15 & 8.7 & 5.1 & 9.2 & 27.7 & 1.0 & 0.5 & 2 \\
\hline WA16 & 8.6 & 7.6 & 14.3 & 21.4 & 1.4 & 1.0 & 3. \\
\hline WA 17 & 6.6 & 3.1 & 10.2 & 28.1 & 1.0 & 0.5 & 11.7 \\
\hline WA 19 & 9.0 & 7.5 & 10.9 & 26.4 & 2.0 & 0.5 & 3. \\
\hline WA23 & 13.1 & 8.6 & 14.9 & 32.4 & 0.9 & 2.3 & 4.5 \\
\hline WA26 & 8.2 & 7.3 & 26.7 & 27.2 & 0.9 & 0.9 & 6.0 \\
\hline WHO3 & 9.5 & 3.9 & 13.8 & 32.8 & 0.9 & 2.6 & 1. \\
\hline WHOG & 4.4 & 5.8 & 10.7 & 37.8 & 2.2 & 0.0 & \\
\hline WT03 & 1.4 & 2.4 & 6.7 & 14.8 & 6.7 & 1.9 & \\
\hline WT05 & 3.7 & 9.7 & 16.6 & 23.0 & 5.5 & 12.0 & \\
\hline
\end{tabular}


ZN : Radiolarian zone

R1 : Actinomma spp.

R2 : Hexacontium spp.

R3 : Thecosphaera spp.

R4 : Cenosphaera spp.

R5 : Prunulum spp.

R6 : Stylosphaerids

R7 : Dictyocoryne and Hymeniastrum spp.

R8 : Stylodictya spp.

R9 : Porodiscus spp.

R10 : Spongotrochus glacialis

R11 : Carpocaniidae

R12 : Cyrtocapsella and Stichocorys spp.

R13 : Artostrobiidae 
MEANS OF R1 - R13 GROUPED BY RADIOLARIAN ZONE

$\begin{array}{lrrrrrr}\text { ZN } & \text { R1 } & \text { R2 } & \text { R3 } & \text { R4 } & \text { R5 } & \text { R6 } \\ & & & & & & \\ \text { RA } & 8.8 & 6.2 & 4.1 & 4.0 & 7.7 & 15.5 \\ \text { RB } & 9.3 & 5.4 & 5.9 & 2.6 & 8.5 & 7.4 \\ \text { RC } & 2.6 & 2.7 & 2.3 & 2.4 & 10.6 & 4.5 \\ \text { RD } & 4.9 & 3.1 & 4.6 & 2.7 & 9.2 & 4.7 \\ \text { RE } & 4.2 & 4.7 & 4.6 & 2.9 & 9.2 & 5.7 \\ \text { RF } & 4.5 & 5.2 & 4.3 & 2.7 & 9.7 & 7.0 \\ \text { RG } & 4.7 & 5.6 & 5.3 & 1.5 & 9.0 & 5.3 \\ \text { RH } & 2.6 & 6.0 & 5.3 & 2.8 & 10.9 & 4.5 \\ \text { RI } & 3.4 & 6.5 & 5.3 & 5.3 & 11.5 & 7.3\end{array}$

$\begin{array}{lrrrrrrr}\text { ZN } & \text { R7 } & \text { R8 } & \text { R9 } & \text { R10 } & \text { R11 } & \text { R12 } & \text { R13 } \\ \text { RA } & 4.4 & 4.2 & 11.4 & 29.2 & 0.9 & 0.9 & 2.8 \\ \text { RB } & 7.6 & 5.4 & 13.1 & 27.9 & 1.4 & 0.9 & 4.7 \\ \text { RC } & 6.3 & 10.8 & 15.3 & 31.6 & 0.0 & 6.6 & 4.2 \\ \text { RD } & 7.8 & 9.1 & 11.8 & 35.0 & 1.2 & 4.9 & 1.1 \\ \text { RE } & 4.8 & 6.7 & 15.9 & 22.4 & 3.7 & 10.5 & 4.7 \\ \text { RF } & 4.0 & 6.1 & 14.9 & 26.9 & 3.2 & 8.8 & 2.7 \\ \text { RG } & 4.4 & 6.8 & 14.0 & 24.6 & 3.1 & 10.6 & 5.1 \\ \text { RH } & 3.7 & 7.1 & 14.3 & 28.0 & 4.7 & 6.8 & 3.3 \\ \text { RI } & 2.3 & 10.7 & 12.6 & 22.9 & 5.3 & 0.8 & 6.1\end{array}$




\section{E.5 PALLISER BAY TUFF SAMPLES}

This section tabulates the number per gram of sediment of various components of the fraction $>54 \mu$ for samples above and below the tuff in the Palliser Bay Section. The following abbreviations are used:

SAM : sample number.

POS : stratigraphic distance from the base of the tuff $(\mathrm{cm})$.

BEN : number of benthic forams per gram of sediment.

PLK : number of planktic forams per gram of sediment.

SPC : number of sponge spicules per gram of sediment.

RAD : number of radiolarians per gram of sediment.

SHR : number of glass shards per gram of sediment. 


$\begin{array}{lrrrrrr}\text { SAM } & \text { POS } & \text { BEN } & \text { PLK } & \text { SPC } & \text { RAD } & \text { SHR } \\ \text { PTY } & 320 & 702 & 121 & 477 & 1179 & 442 \\ \text { PTX } & 270 & 1355 & 240 & 156 & 1139 & 720 \\ \text { PTW } & 210 & 597 & 157 & 162 & 754 & 722 \\ \text { PTV } & 170 & 505 & 312 & 187 & 601 & 550 \\ \text { PTU } & 130 & 1505 & 226 & 336 & 1376 & 614 \\ \text { PTT } & 110 & 1734 & 371 & 159 & 781 & 2091 \\ \text { PTS } & 80 & 1064 & 294 & 509 & 633 & 4850 \\ \text { PTR } & 60 & 1209 & 212 & 233 & 594 & 15591 \\ \text { PTQ } & 40 & 779 & 269 & 150 & 479 & 28806 \\ \text { PTG } & -20 & 971 & 158 & 172 & 475 & 730 \\ \text { PTH } & -40 & 827 & 73 & 345 & 827 & 1466 \\ \text { PTI } & -60 & 467 & 16 & 561 & 751 & 419 \\ \text { PTJ } & -80 & 475 & 67 & 218 & 615 & 380 \\ \text { PTK } & -100 & 444 & 39 & 283 & 1088 & 509 \\ \text { PTL } & -120 & 877 & 115 & 108 & 793 & 531 \\ \text { PTM } & -140 & 925 & 182 & 288 & 735 & 273 \\ \text { PTN } & -160 & 298 & 69 & 346 & 941 & 1059 \\ \text { PTO } & -180 & 338 & 93 & 344 & 1045 & 423 \\ \text { PTP } & -200 & 490 & 16 & 253 & 371 & 498\end{array}$


Plates of Radiolaria 


\section{PLATE 1 (opposite)}

1. ? Oropelex sp. : $\times 90:$ RM02 : AA4/2

2. Collosphaera sp. A : $\times 360:$ MO09 : AA4/6

3. Collosphaera sp. aff. huxleyi Muller : x250 : PB11 : 167/7

4. Collosphaera sp. aff. huxleyi Muller : x290 : TM14 : AA2/7

5. Acrosphaera spinosa echinoides (Haeckel) : x350 : SMR1 : AA4/8

6. Acrosphaera spinosa spinosa (Haecke1) : $\times 320$ : SCV1 : AA4/10

7. Actinomma antarcticum (Haeckel) : $\times 170$ : TM23 : AA1/1

8. Actinomma antarcticum (Haecke1) : $\times 410:$ LT03 : AA7/4 medullary only

9. Actinomma antarcticum (Haeckel) : x130 : TM23 : AA1/1 double cortical shell

10. Actinomma antarcticum (Haeckel) : x140 : MO05 : AA4/7

11. Actinomma cf. medianum Nigrini : $\times 220$ : MS15 : AA3/6

12. Actinomma leptodermum (Jorgensen) : $\times 310:$ WA02 : AA8/3

13. Actinomma leptodermum (Jorgensen) : $\times 250:$ WA02 : AA8/3 

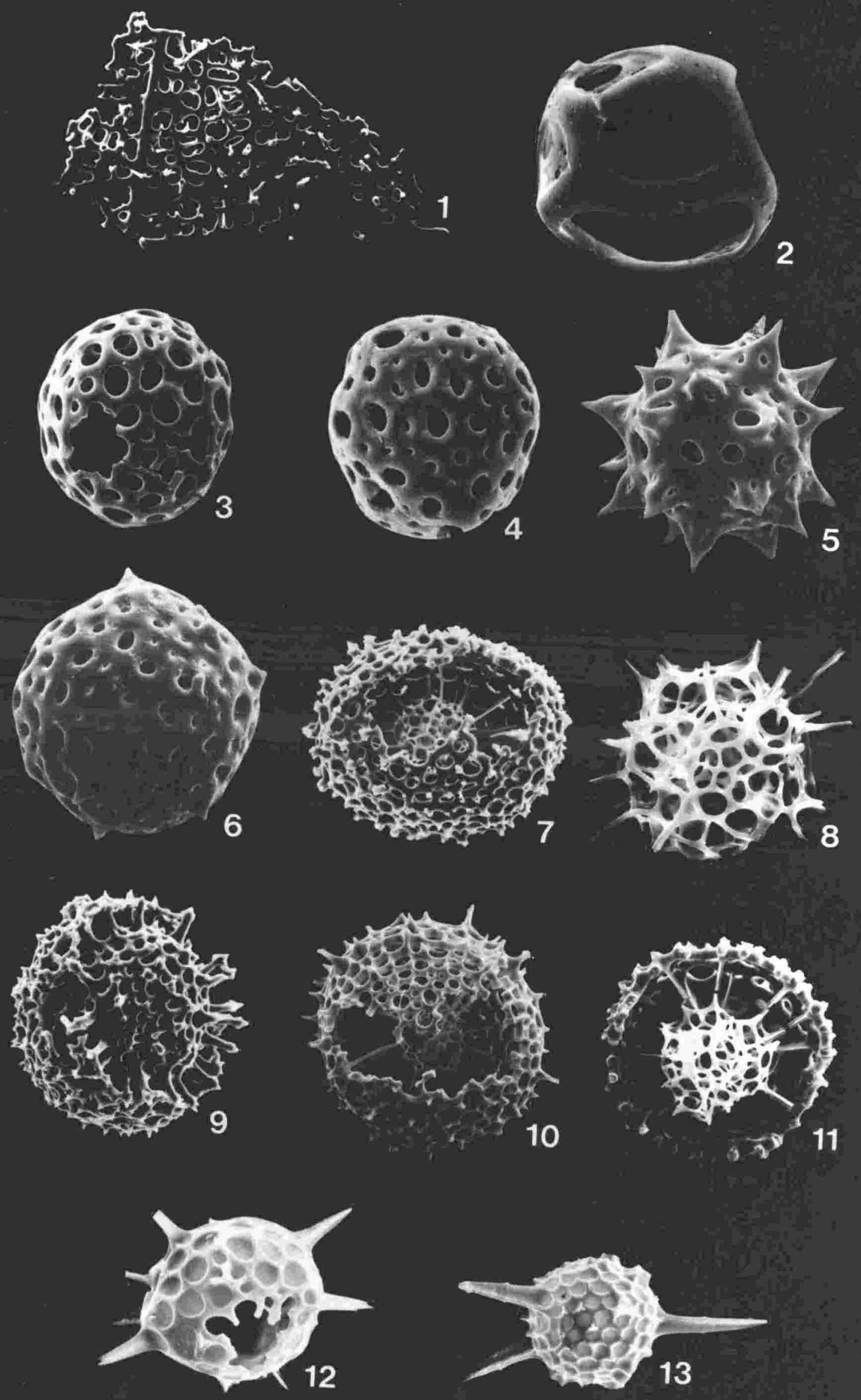


\section{PLATE 2 (opposite)}

1. Collosphaera cf. polygona Haeckel : x123 : RM05: M38/4

2. Siphonosphaera polysiphonia Haeckel : x403: WA16: L37/4

A. focused on circumference

B. focused on surface of same specimen

3. Acrosphaera spinosa echinoides (Haeckel) : ×413 : WA01 : L28/3

A. focused on surface

B. focused on circumference of same specimen

4. Otosphaera polymorpha Haeckel : ×397: M013:013/2

5. Collosphaera sp. aff. huxleyi Muller : x401 : SMA3 : P27/1

6. Actinomma antarcticum (Haeckel) : x306 : MO02 : U38/3 medullary only

7. Actinomma cf. medianum Nigrini : $\times 250:$ MO11 : K24/4

8. Actinomma polycanthum (Muller) group : $\$ 412$ : TM20 : RIO
A. focused on internals
B. focused on surface of same specimen 

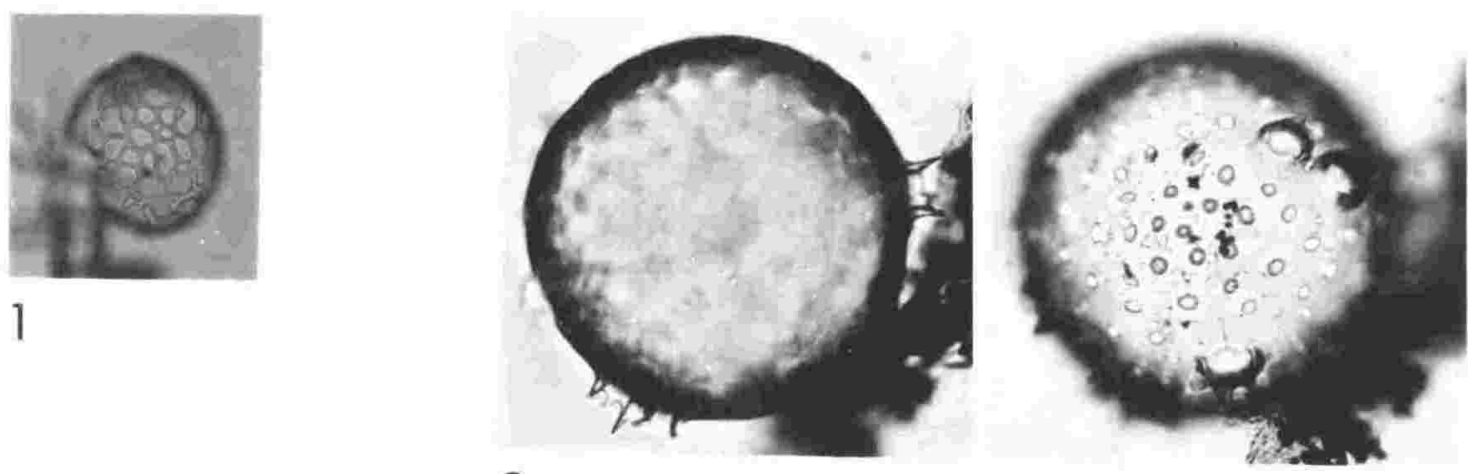

$2 \mathrm{~A}$

B
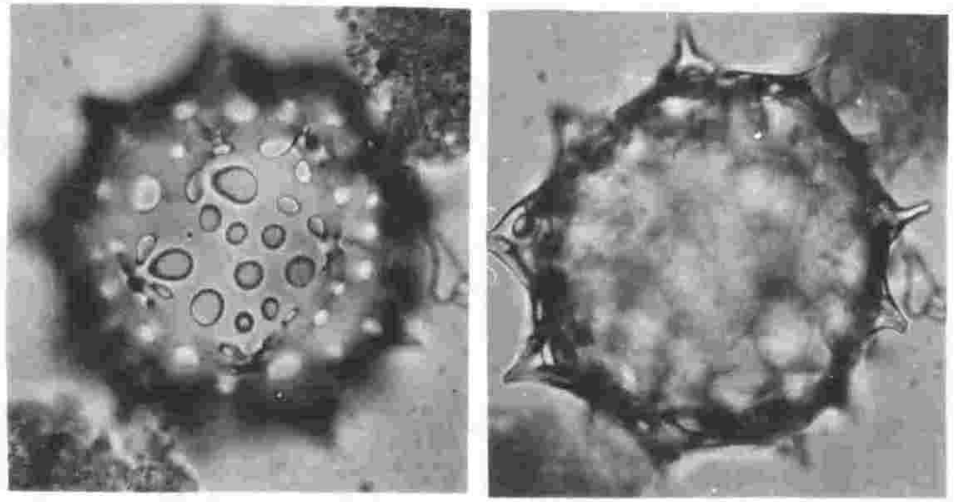

$3 \mathrm{~A}$

B

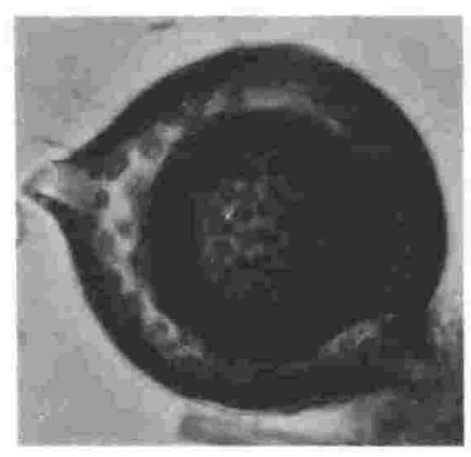

4

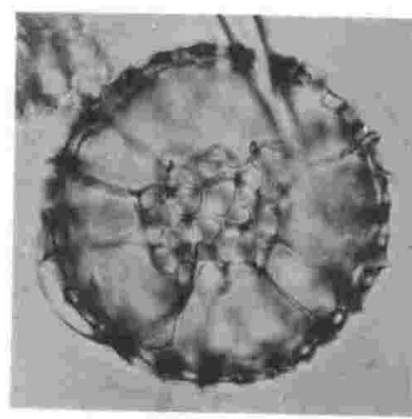

7
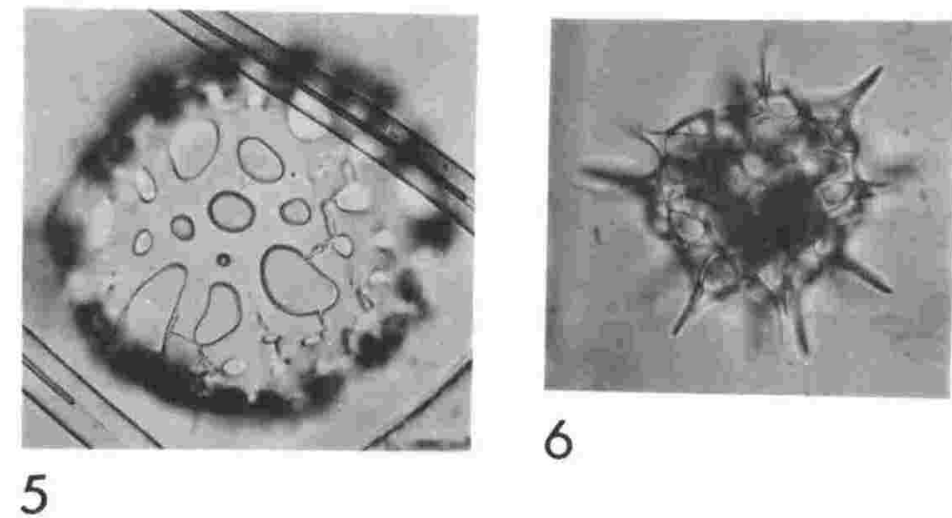

6

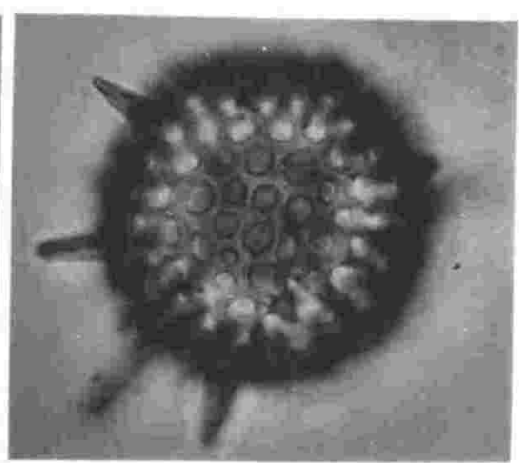

B 
PLATE 3 (opposite)

1. Actinomma polycanthum (Muller) group : ×220 : RM05: AA5/5 approximately 16 spines

2. Actinomma polycanthum (Muller) group : ×330: MS03 : AA2/10 "oval" form

3. Actinomma polycanthum (Muller) group : ×210 : RM04: MISC/5 approximately 10 spines

4. ? Actinomma polycanthum (Muller) group ? : $\mathbf{4} 410$ : SWR4 : AA4/12 medullary shell

5. Actinomma polycanthum (Muller) group : x320 : RM05: AA5/5 broken specimen showing medullary shells

6. Cladococcus dentata (Mast) : $\mathrm{x} 140$ : TM20 : AA1/10

7. Cladococcus stalactites Haeckel : $\times 130$ : RM03 : AA4/1

8. Cenosphaera cristata Haeckel : $\times 250$ : MO04 : AA4/4

9. Cenosphaera sp. C : $\times 270:$ RM01 : AA4/2

10. Cenosphaera sp. A : $\times 330:$ TM16 : AA6/1 transmitted light photos of same specimen : Plate 4, figures 1a,b

11. Acanthosphaera sp. A : $\times 360:$ M009 : AA4/6 "many-spined" form

12. Acanthosphaera sp. A : $\times 220: \mathrm{MO} 13: \mathrm{AA} 4 / 7$ "intermediate" form

13. ? Acanthosphaera sp. B ? : x180:WA02 : AA8/2 

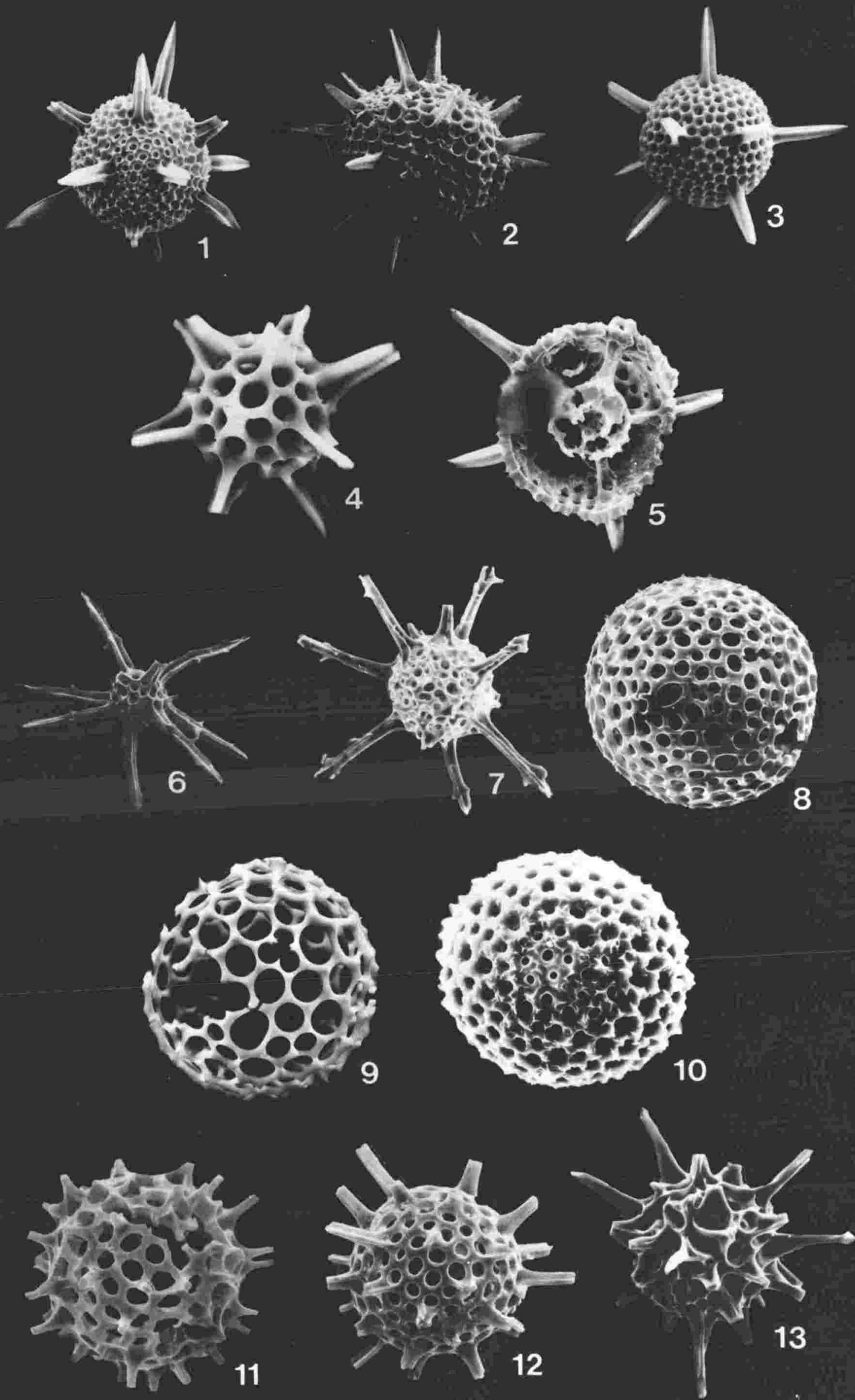


\section{PLATE 4 (opposite)}

1. Cenosphaera sp. A : $\mathrm{x} 407$ : TM16 : RIO

SEM photo of same specimen : Plate 3, figure 10
A. focused on surface
B. focused on circumference of same specimen

2. Cenosphaera sp. B : x380 : PB02 : L39/1
A. focused on surface
B. focused on circumference of same specimen

3. Cenosphaera sp. D : $\mathrm{x} 284: \mathrm{PB} 11: \mathrm{F} 33 / 1$

A. focused on surface

B. focused on circumference of same specimen

4. Acanthosphaera dodecastyla Mast : x435 : LT09 : K16/3

5. Acanthosphaera sp. A : $\times 422$ : HRO4d : R28/1

"few-spined" form

6. Acanthosphaera sp. B : ×294 : TM20 : RIO

7. Hexacontium enthacanthum Jorgensen : $\times 264$ : WA10 : W19/1
A. focused on surface
B. focused on internals of same specimen 

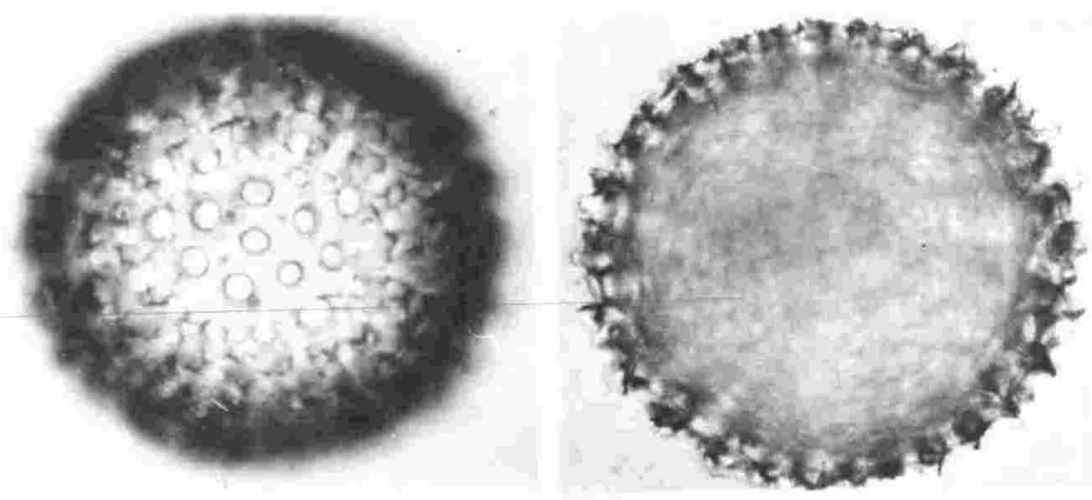

lA

B
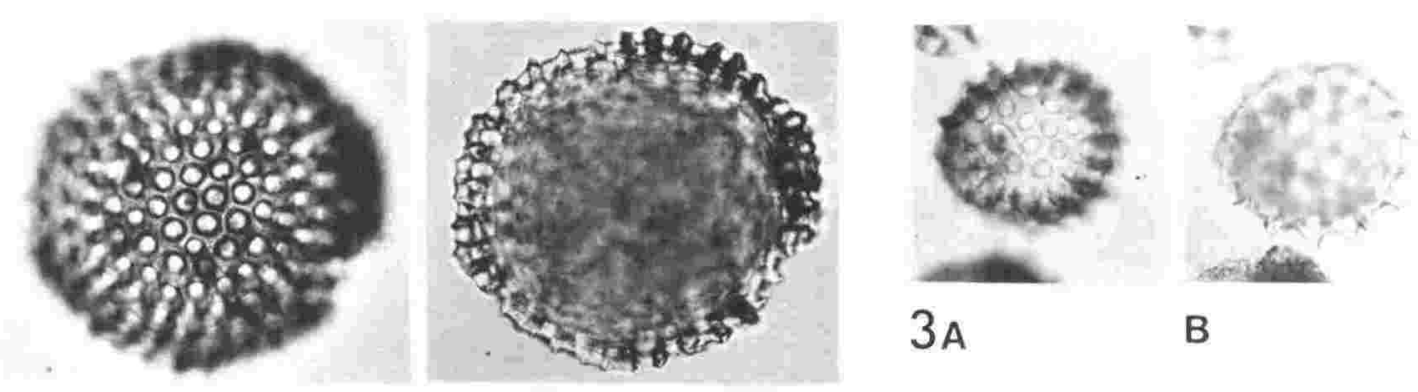

$2 \mathrm{~A}$

B
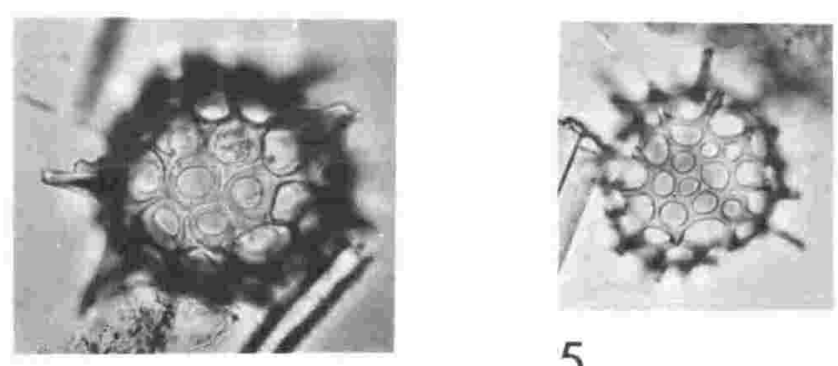

5

4

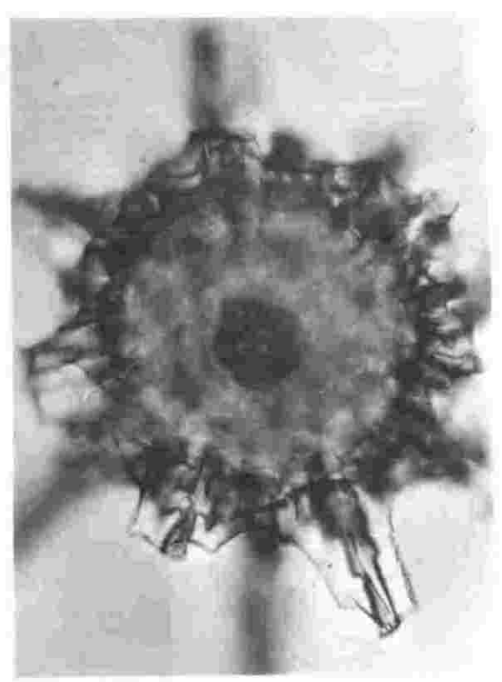

6
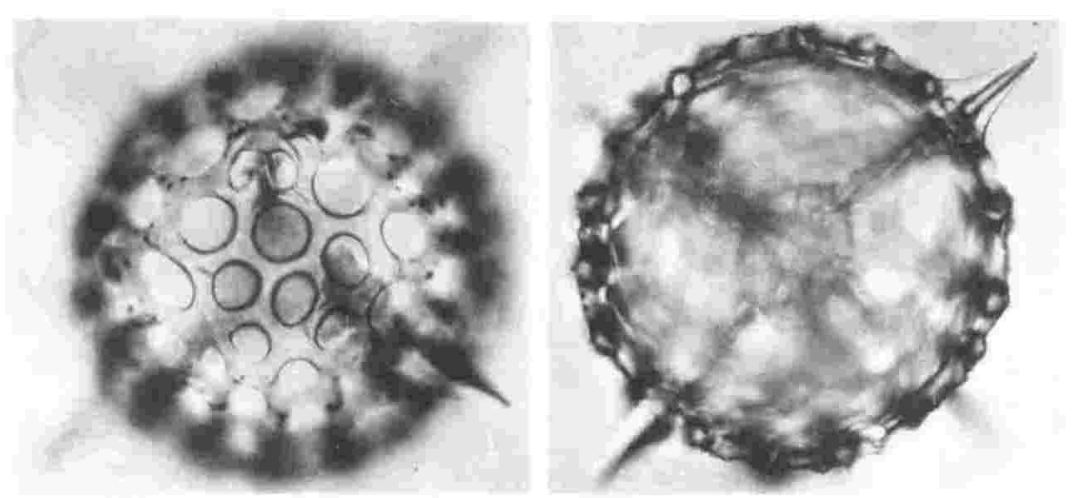

$7 A$

B 


\section{PLATE 5 (opposite)}

1. Hexacontium laevigatum Haeckel : x210 : PB04 : $158 / 6$

"long spined" form

2. Hexacontium enthacanthum Jorgensen : x220 : MO04 : AA4/4

3. Hexacontium enthacanthum Jorgensen : x180 : RM06: AA5/4

"quadrate" form

4. Hexacontium enthacanthum Jorgensen : $\mathrm{x} 270: \mathrm{RM} 01: \mathrm{AA} 4 / 2$

5. Hexacontium laevigatum Haeckel : x180 : RM02 : AA4/2

6. Hexacontium enthacanthum Jorgensen : x220:TM20 : AA6/4 "oval" form

7. Hexacontium laevigatum Haeckel : $\times 240:$ TM14 : AA2/7 "oval" form

8. Hexacontium laevigatum Haeckel : x270 : PB11 : 167/8

form transitional to $\boldsymbol{H}$. enthacanthum

9. Thecosphaera cf. akitaensis Nakaseko : $\times 450$ : SMA5 : AA4/12

10. ? Thecosphaera grecoi Vinassa de Regny group ? : ×310 : PB02 : 156/2

11. Prunulum sp. : $\mathrm{x} 380$ : TM20 : AA6/6

transmitted light photo of same specimen : Plate 6, figure 2

12. Styptosphaera stupacea Haeckel : x180 : RM05 : AA5/5

13. Styptosphaera spumacea Haeckel : x270 : RM02 : AA4/1 

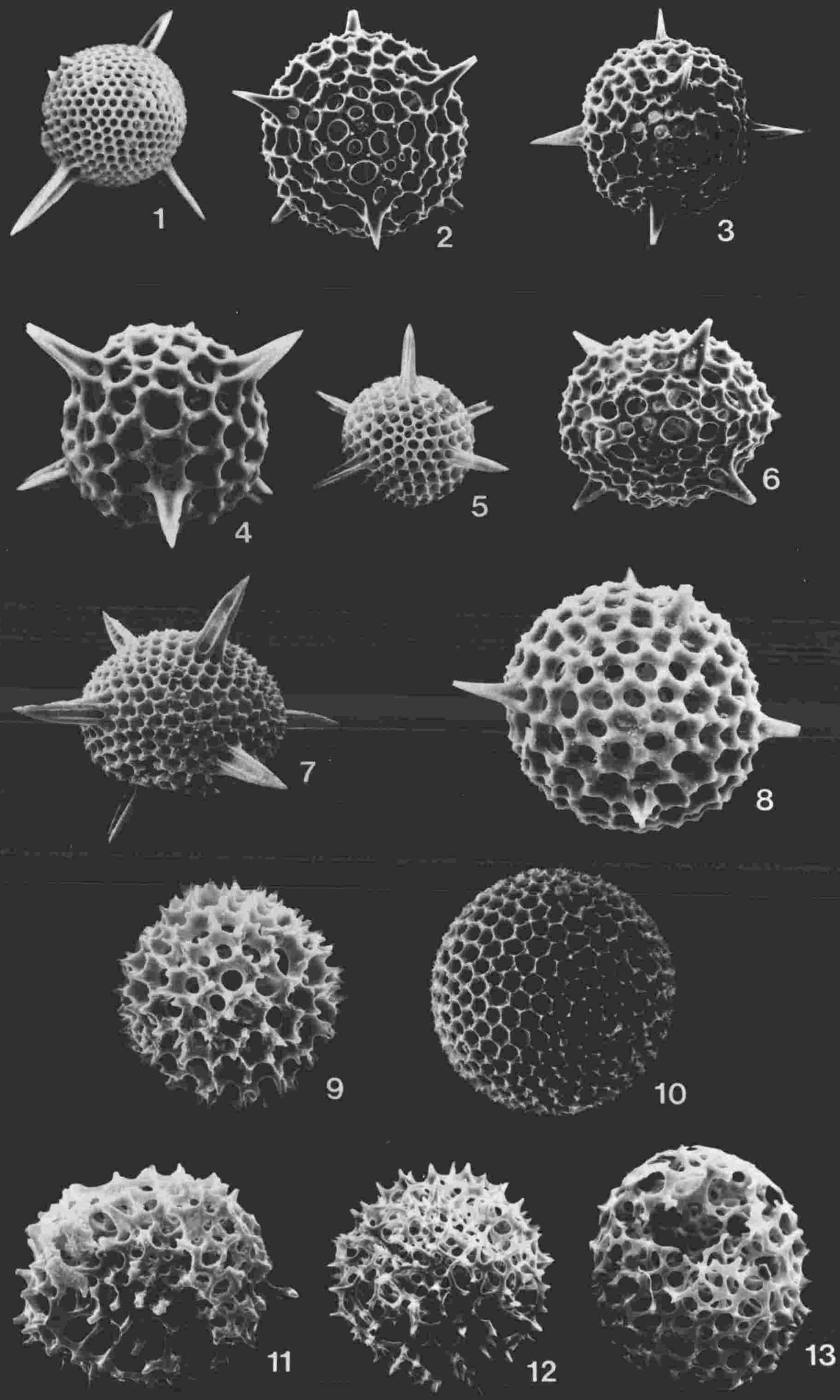


\section{PLATE 6 (opposite)}

1. Thecosphaera grecoi Vinassa de Regny group : $\mathrm{x} 411$ : WH03 : W23/1

A. focused on surface

B. focused on internals of same specimen

2. Prunulum sp. : $\mathrm{x} 294:$ TM20 : RIO

SEM photo of same specimen : Plate 5, figure 11

3. Prunulum sp. : $\mathrm{x} 407$ : SMA5 : M41/2

4. Prunulum sp. : $\mathrm{x} 292$ : MS06 : G26/1

A. focused on surface

B. focused on internals of same specimen

5. “Xiphatractus" sp. A : х289 : PB06

form transitional to "Stylatractus" universus

A. focused on surface

B. focused on internals of same specimen

6. "Stylatractus" neptunus Haeckel forma large pores : х263 : PB06 : R26/4 cortical shell missing

7. "Xiphatractus" sp. A : $\times 246:$ MO11 : K36/2

8. "Sphaerostylus" sp. aff. timmsi Campbell and Clark : x293 : WA03: 028/2 teratological specimen

9. "Stylatractus" universus Hays : x257 : RM06 : L21/4

A. focused on surface

B. focused on internals of same specimen

10. "Sphaerostylus" sp. aff. timmsi Campbell and Clark : x287 : PB11 : M44/3 


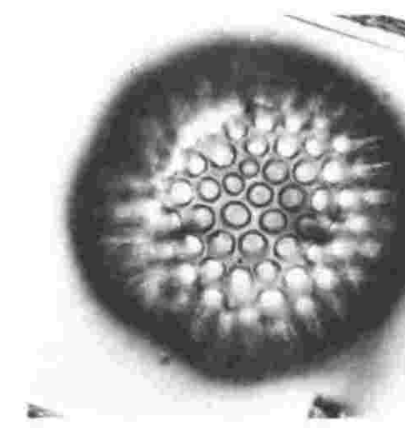

la

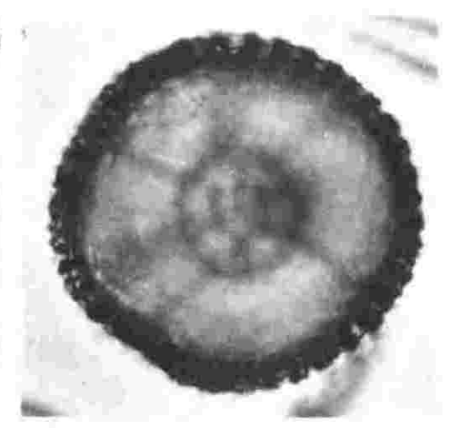

B

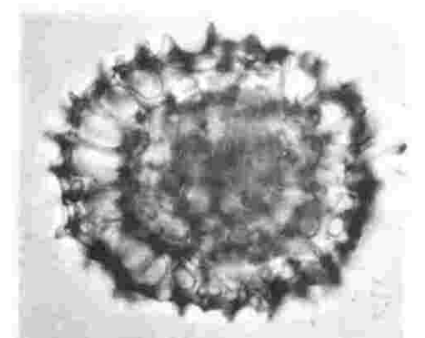

2

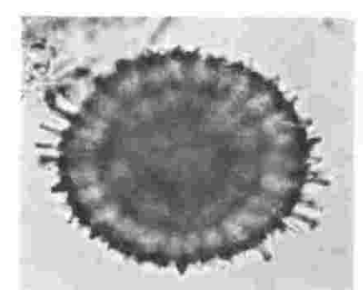

3

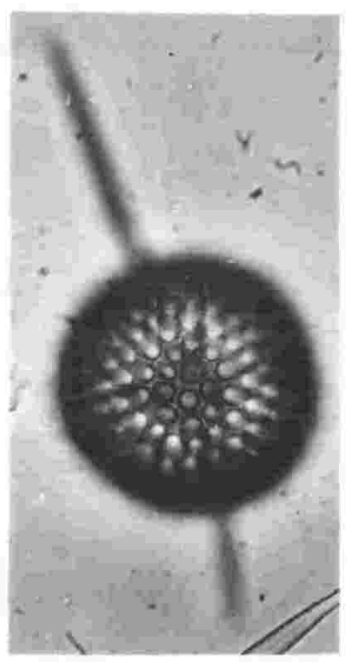

$5 \mathrm{~A}$

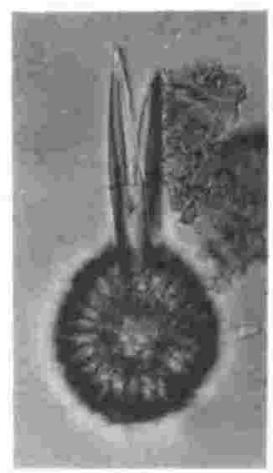

8

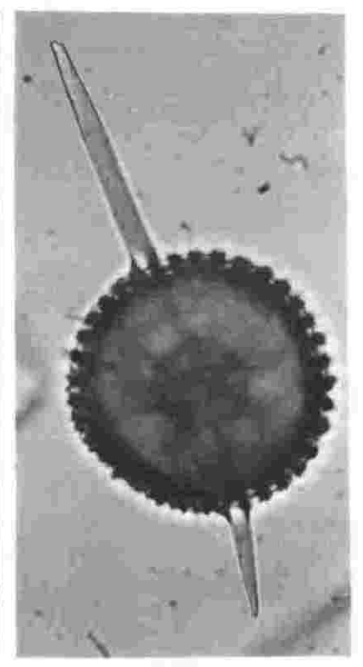

B

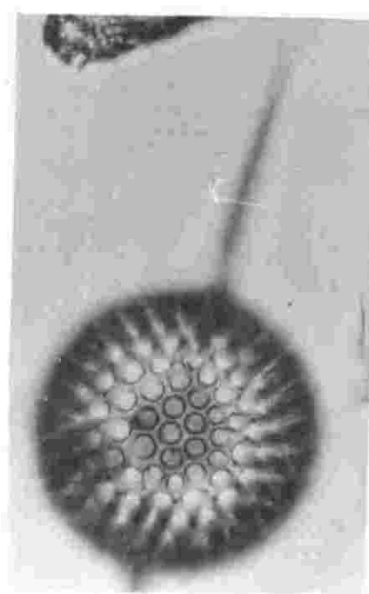

$9 \mathrm{~A}$

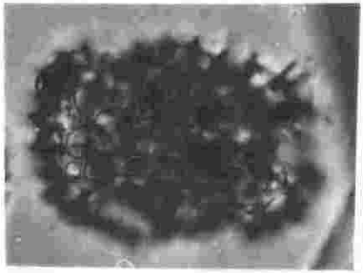

$4 \mathrm{~A}$

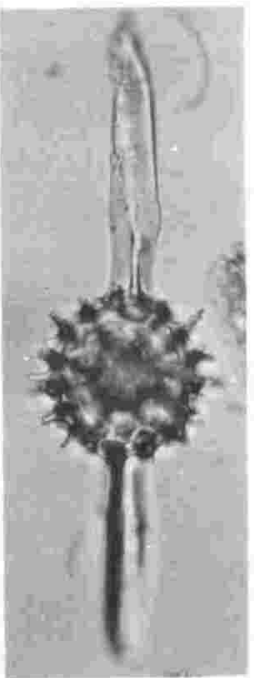

6

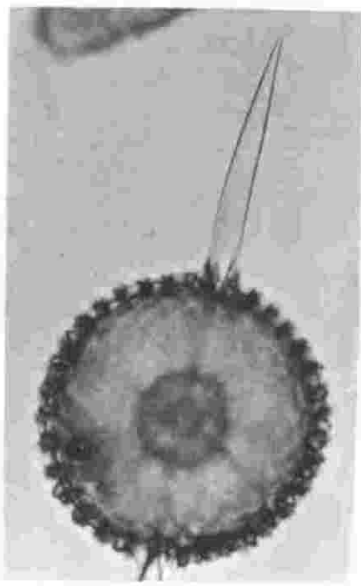

B

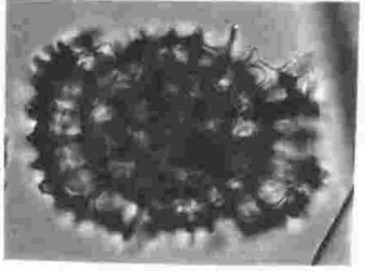

B
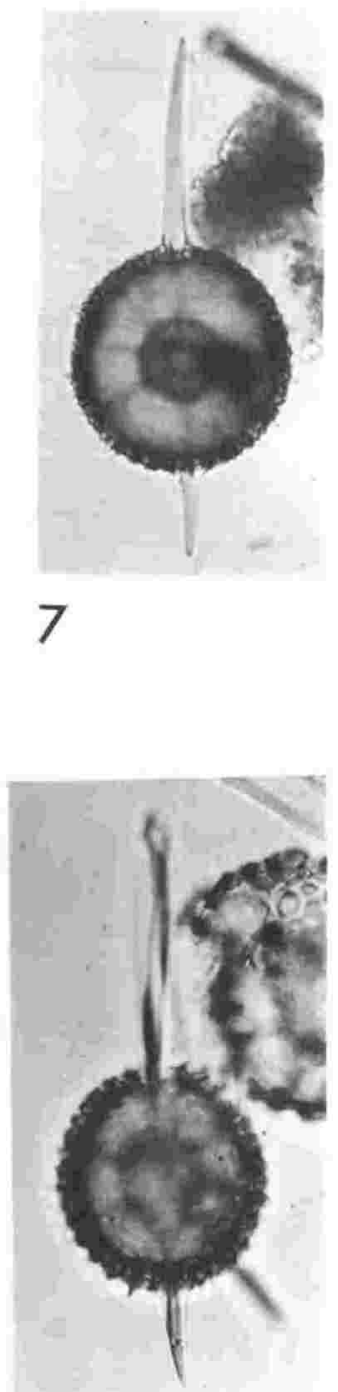

10 


\section{PLATE 7 (opposite)}

1. "Stylatractus" neptunus Haeckel forma large pores : x210: MO02 : AA4/3

2. "Stylatractus" neptunus Haeckel forma large pores : x210 : TM14: AA2/7 teratological specimen

3. "Stylatractus" neptunus Haeckel forma large pores : $\mathrm{x} 240$ : WA16 : AA9/2 cortical shell missing

4. "Stylatractus" neptunus Haeckel forma large pores : x400: MS03 : AA2/10 poorly preserved specimen

5. "Stylatractus" universus Hays : $х 220$ : RM01 : AA4/2

"large pored" form

6. "Stylatractus" universus Hays : x210 : M007 : AA4/5

"small pored" form

7. “Xiphatractus" sp. A : $\times 200:$ PB07 : $161 / 5$

8. "Sphaerostylus" sp. aff. timmsi Campbell and Clark : $\times 300:$ MO08 : AA4/5

9. "Sphaerostylus" sp. aff. timmsi Campbell and Clark : x310 : RM07 : AA5/3

10. "Sphaerostylus" sp. aff. timmsi Campbell and Clark : x270 : RM06 : AA5/4 form with thicker by-spines

11. Prunopyle sp. A : $\mathrm{x} 280: \mathrm{KB} 01: \mathrm{AA} 10 / 4$

12. Actinommid gen. et sp. indet. : $x 320$ : RM07 : AA5/3

13. Actinommid gen. et sp. indet. : $x 320$ : MO04 : AA4/4

14. Prunopyle sp. A : $\times 400:$ PB07 : $161 / 6$

could be a member of the genus Sphaeropyle 

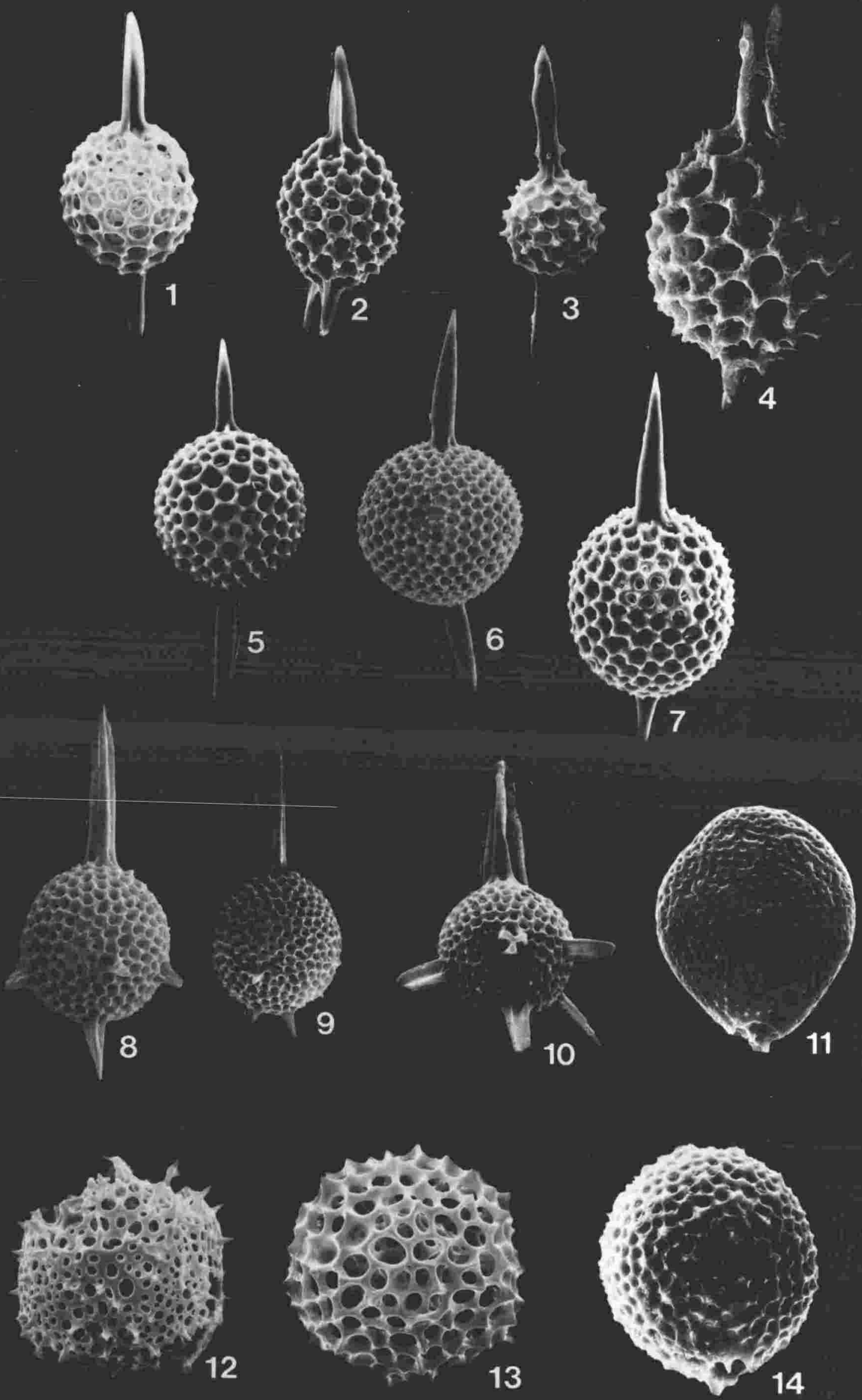


\section{PLATE 8 (opposite)}

1. Spongurus sp. A : $\times 297:$ TM19 : RIO
A. focused on surface
B. focused on internals of same specimen

2. Spongurus sp. A : $\times 288:$ TM19 : RIO

SEM photo of same specimen : Plate 9, figure 1
A. focused on surface
B. focused on internals of same specimen

3. Prunopyle sp. A : x407 : MO14 : U36/1

4. Prunopyle sp. A : $\times 408:$ MS13 : N17/4

5. Spongocore puella Haeckel : x407 : MS08 : S33/2

lattice-mantle present

6. Spongocore puella Haeckel : x292 : PB06 : X47/1

lattice-mantle absent

7. Heliodiscus asteriscus Haeckel : $x 257: \mathrm{ECO} 2: \mathrm{N} 13 / 2$ "long-spined" form

8. Didymocyrtis virgineum (Haeckel) : ×293 : TM16 : RIO

A. focused on circumference

B. focused on surface of same specimen

9. Heliodiscus asteriscus Haeckel : $\mathrm{x} 296$ : MO14 : Q17/4 side view : focused on medullary skeleton 

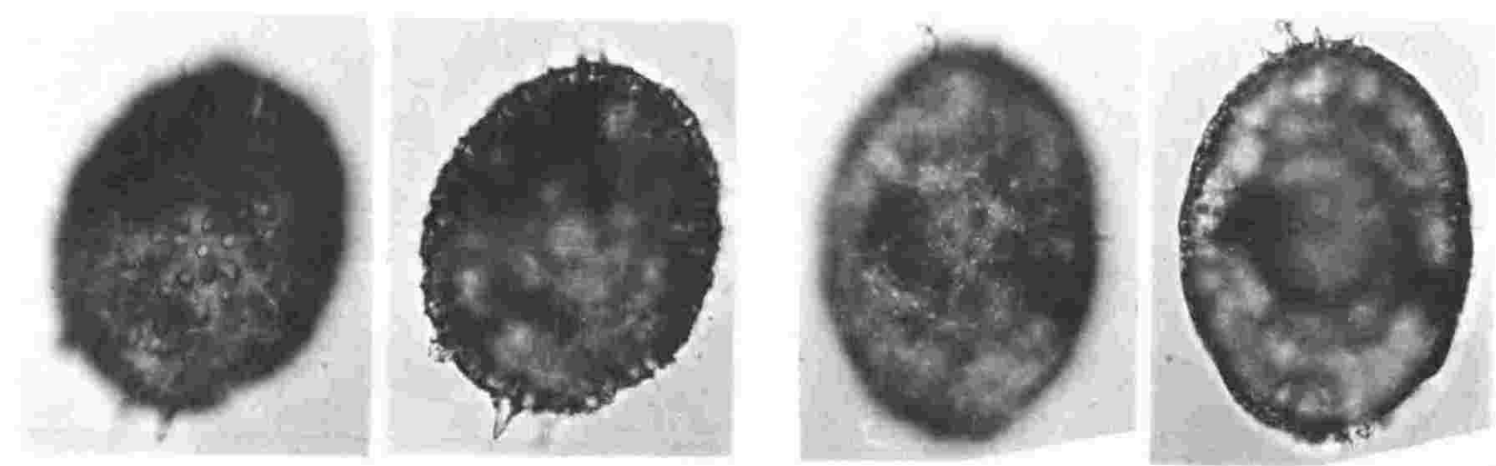

la

B

2A

B
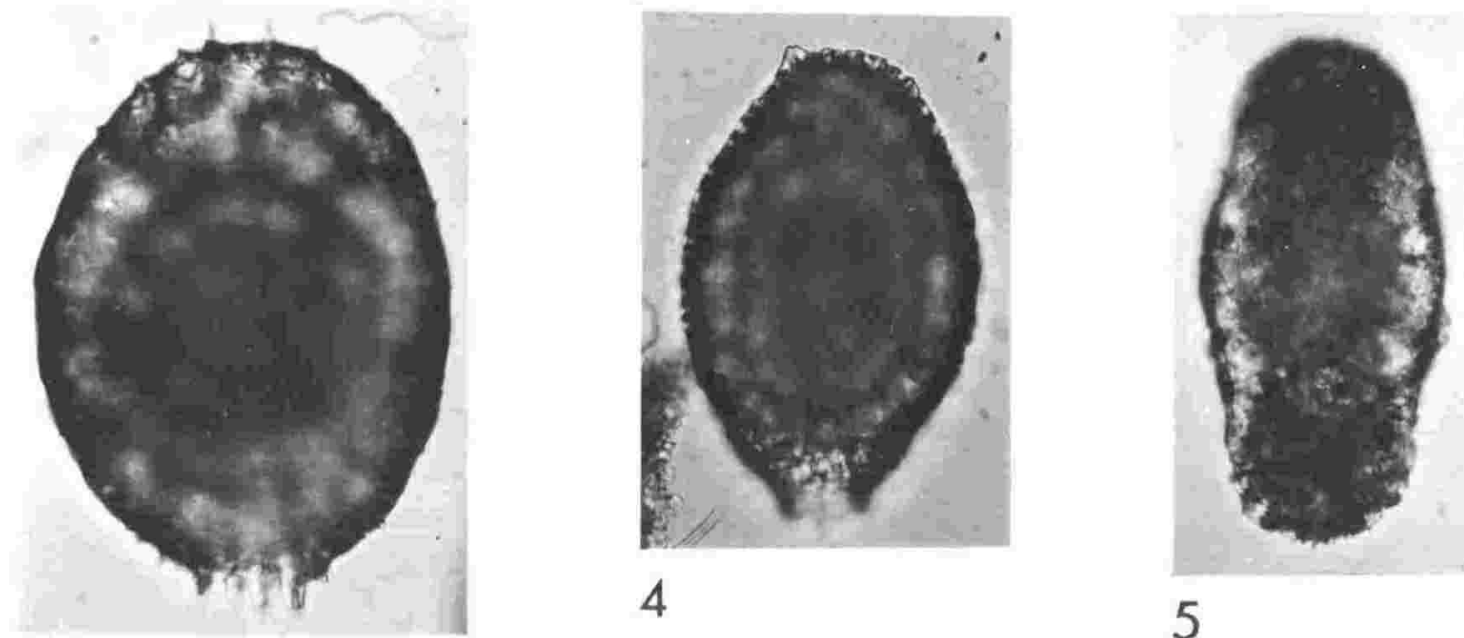

4

5

3

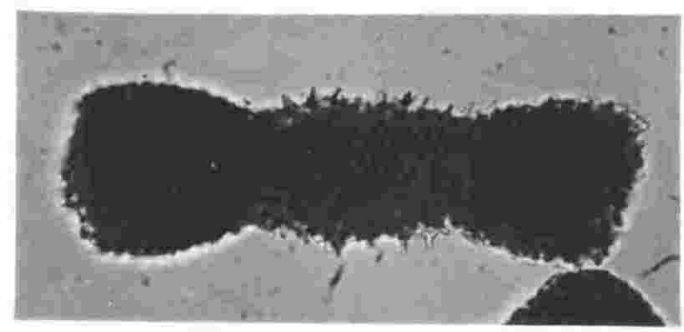

6

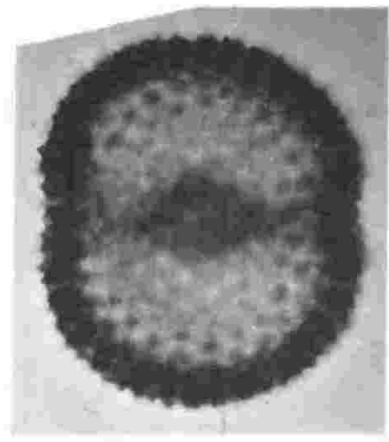

$8 A$

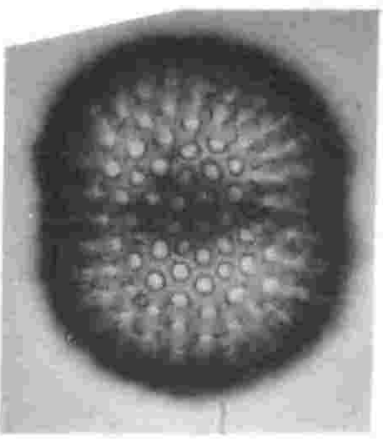

B

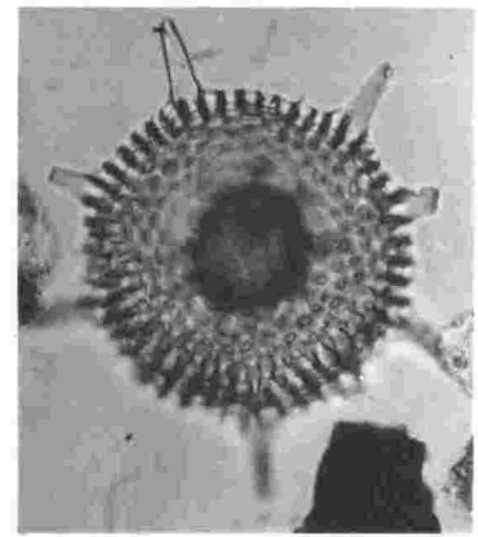

7

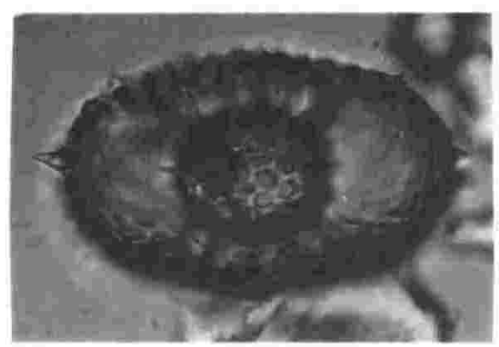

9 


\section{PLATE 9 (opposite)}

1. Spongurus sp. A : $\times 210:$ TM19: AA6/3

transmitted light photos of same specimen : Plate 8 , figures 2a,b

2. Spongurus pylomaticus Riedel : $\times 340:$ LT06 : AA7/2

3. Spongurus sp. A : $\times 310:$ PB11 : 167/7

transitional with Prunopyle antarctica and Spongurus pylomaticus

4. ? Prunopyle antarctica Dreyer : $\times 250$ : WA07 : AA8/6

5. ? Spongurus pylomaticus Riedel : x350 : SMA4 : AA4/11

inner spongy core ?

6. Spongocore puella Haeckel : ×390: PB08 : 164/4 abnormal bent specimen

7. Spongocore puella Haeckel : x310 : WA02 : AA8/2 lattice-mantle present

8. Spongocore puella Haeckel : $\times 310:$ MSO2 : AA2/9

9. Spongocore sp. A : x190 : LT05 : AA7/2

10. ? Prunopyle antarctica Dreyer : $\times 270:$ LT01 : AA7/4

11. Heliodiscus asteriscus Haeckel : $\mathrm{x} 420$ : $\mathrm{PB} 08$ : 164/6

broken specimen showing medullary skeleton

12. Heliodiscus asteriscus Haeckel : $\mathrm{x} 180$ : $\mathrm{PB} 02$ : 156/7

"small pored" form

13. Heliodiscus asteriscus Haeckel : $\mathrm{x} 200$ : TM15 : AA2/6

"large pored" form

14. Heliodiscus of. echiniscus Haeckel : $x 190$ : MS15 : AA3/7

15. Heliodiscus umbonatum (Ehrenberg) : x150 : KB04 : AA8/1

16. Diartus hughesi (Campbell and Clark) group : ×280 : KB01 : AA10/3

17. Diartus hughesi (Campbell and Clark) group : $\times 220:$ MS12 : $\quad$ AA3/6 form more related to Amphymenium 

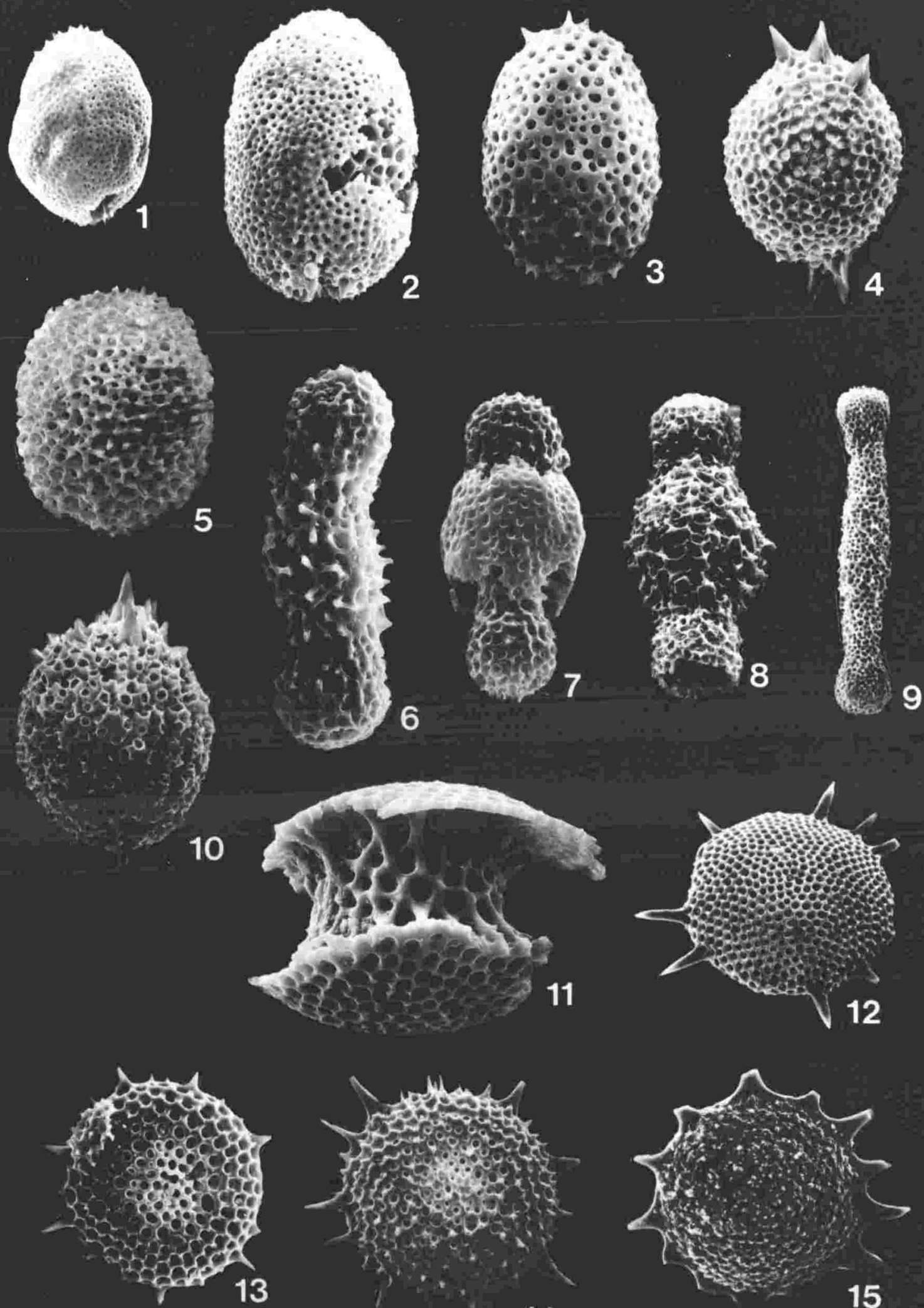

14
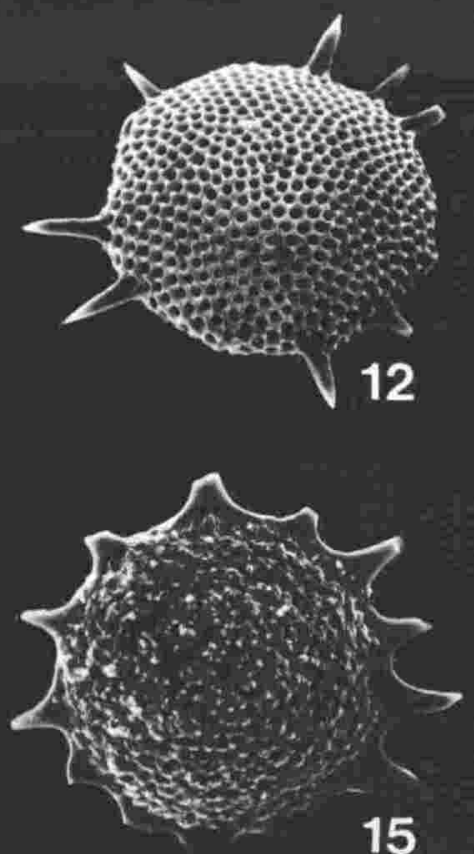

15
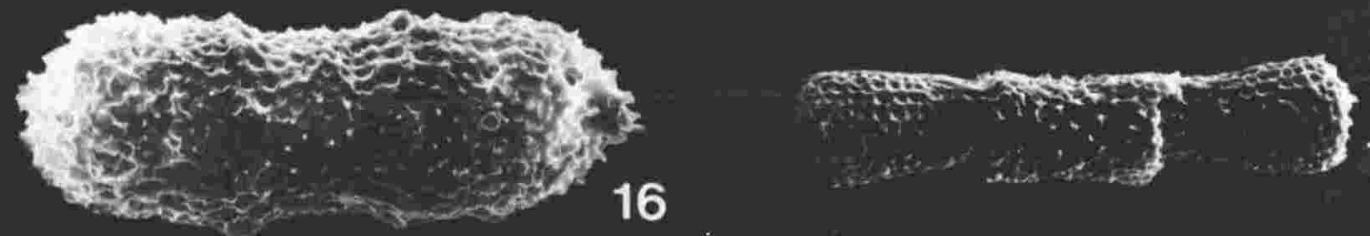
PLATE 10 (opposite)

1. Didymocyrtis laticonus (Riedel) : $\times 257:$ MS12 : 032/2

2. Didymocyrtis sp. A : $\times 302:$ TM16 : RIO

A. focused on surface

B. focused on internals of same specimen

3. Diartus hughesi (Campbell and Clark) group : $\times 374:$ MS14 : 039/2 form more related to Amphymenium

4. Didymocyrtis sp. A : $\times 288$ : TM19 : RIO

SEM photo of same specimen : Plate 11, figure 8

5. Didymocyrtis antepenultima (Riedel and Sanfilippo) : x419: SWR4 : K18/2 form close to $D$. laticonus

6. Didymocyrtis tetrathalmus tetrathalmus (Haeckel) : $x 413:$ WA07 : 040/4

A. focused on cortical surface

B. focused on polar cap

7. Didymocyrtis tetrathalmus tetrathalmus (Haeckel) : $\times 430:$ WA07 : P39/2 form without polar cap preserved 


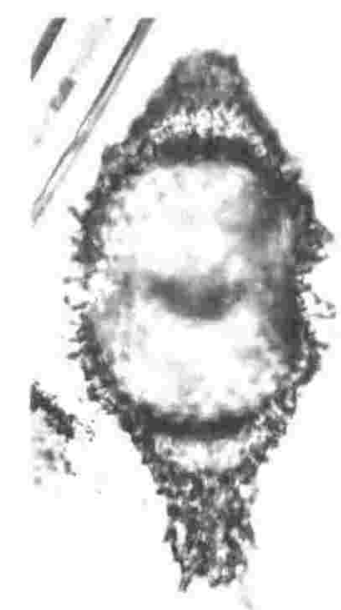

1

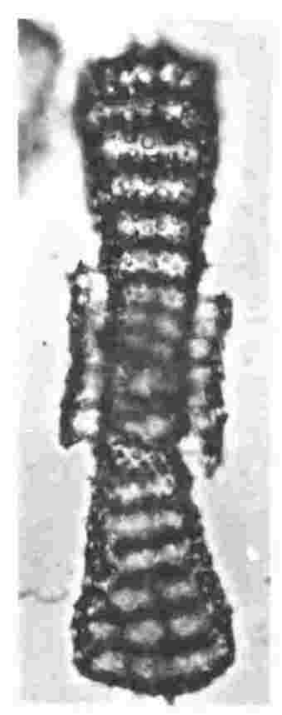

3
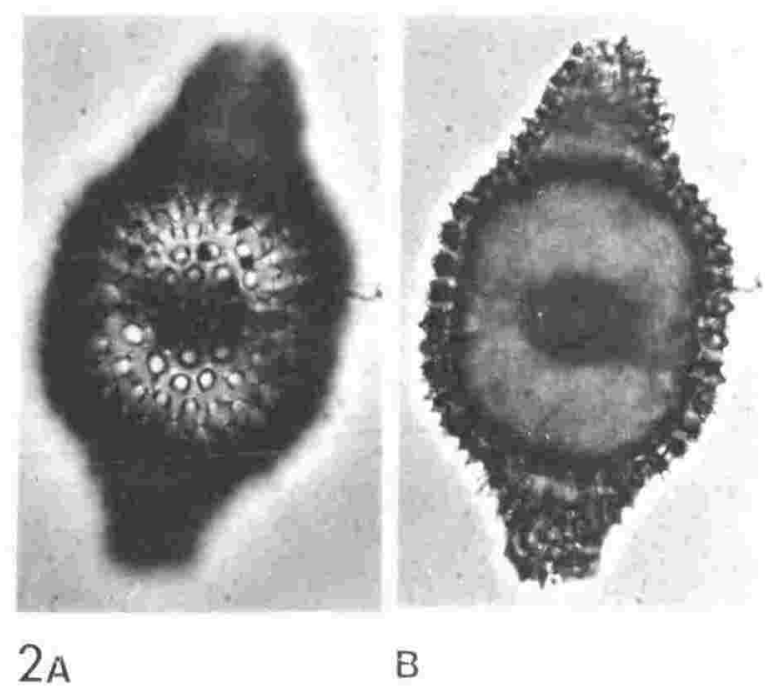

B
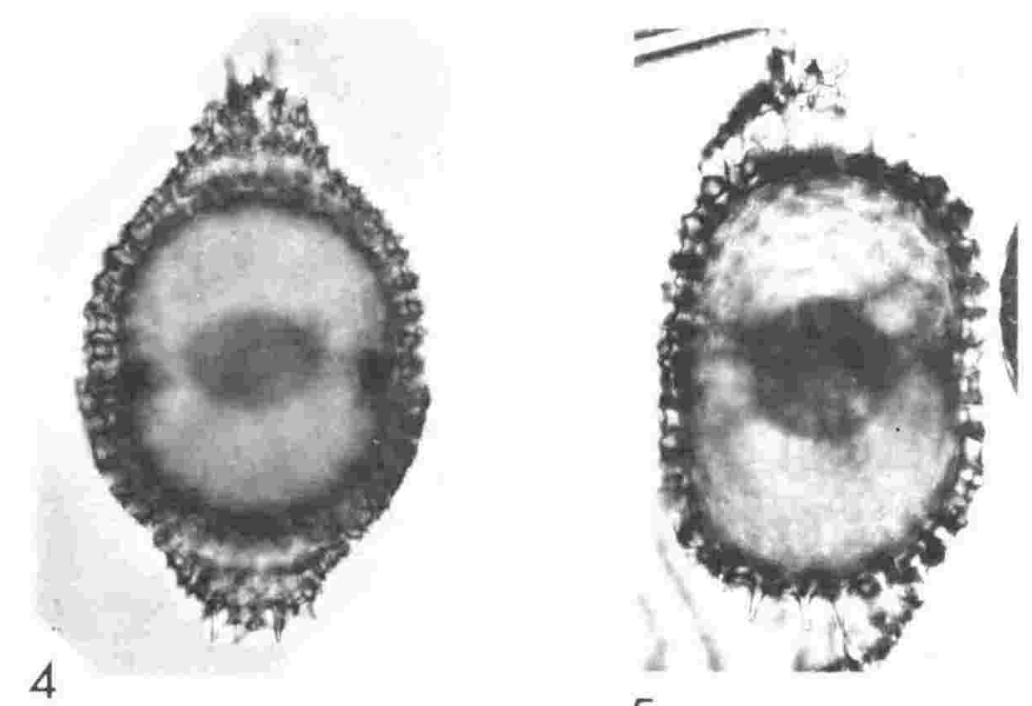

5
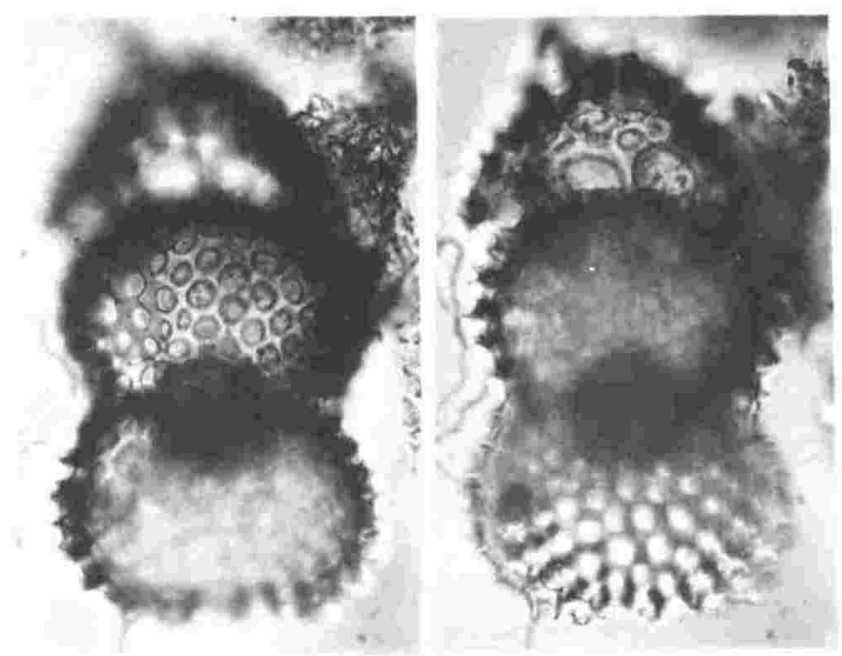

6A

B

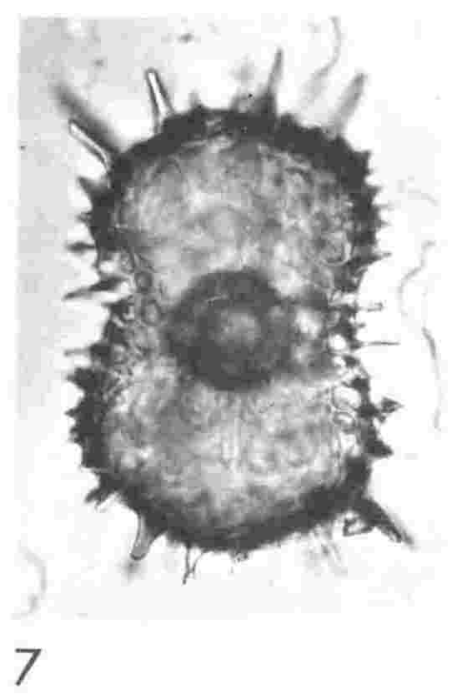




\section{PLATE 11 (opposite)}

1. Didymacyrtis laticonus (Riedel) : $\times 250:$ LT07 : AA7/1

2. Didymocyrtis sp. A : $\mathrm{x} 270: \mathrm{TM} 07: \mathrm{AA} 2 / 8$ poorly preserved specimen

3. Didymocyrtis sp. A : $\times 220$ : MT11 : AA7/5 "spherical" form

4. Didymocyrtis sp. A : $\mathrm{x} 250$ : TM23 : AA1/2 lattice-mantle present

5. Didymocyrtis sp. A : $\mathrm{x} 270: \mathrm{MS} 05: \mathrm{MISC} / 6$ "non-constricted" form

6. Didymacyrtis sp. A : x310 : LT07 : AA7/1 "constricted" form

7. Didymacyrtis sp. A : $\times 260:$ LT05 : AA7/2

8. Didymocyrtis sp. A : $\times 270$ : TM19 : AA6/2 transmitted light photo of same specimen : Plate 10, figure 4

9. Didymocyrtis sp. A : $\mathrm{x} 200: \mathrm{MS} 15: \mathrm{AA} 3 / 7$ "narrow" form

10. Didymocyrtis virgineum (Haeckel) : $\mathrm{x} 340$ : $\mathrm{PB} 07: 161 / 9$ "constricted" form

11. Didymacyrtis virgineum (Haeckel) : $\mathrm{x} 280: \mathrm{RM} 05: \mathrm{AA} 4 / 1$ "non-constricted" form

12. Didymocyrtis tetrathalmus tetrathalmus (Haecke1) : $\mathrm{x} 410$ : WA11 : AA8/7 no polar caps

13. ? Didymocyrtis virgineum (Haecke1) : $\mathrm{x} 250$ : WA07 : AA8/6 could be Prunulum sp.

14. ? Didymocyrtis virgineum (Haeckel) : $\mathrm{x} 310:$ PB08 : 164/5 could be Prunulum sp. 

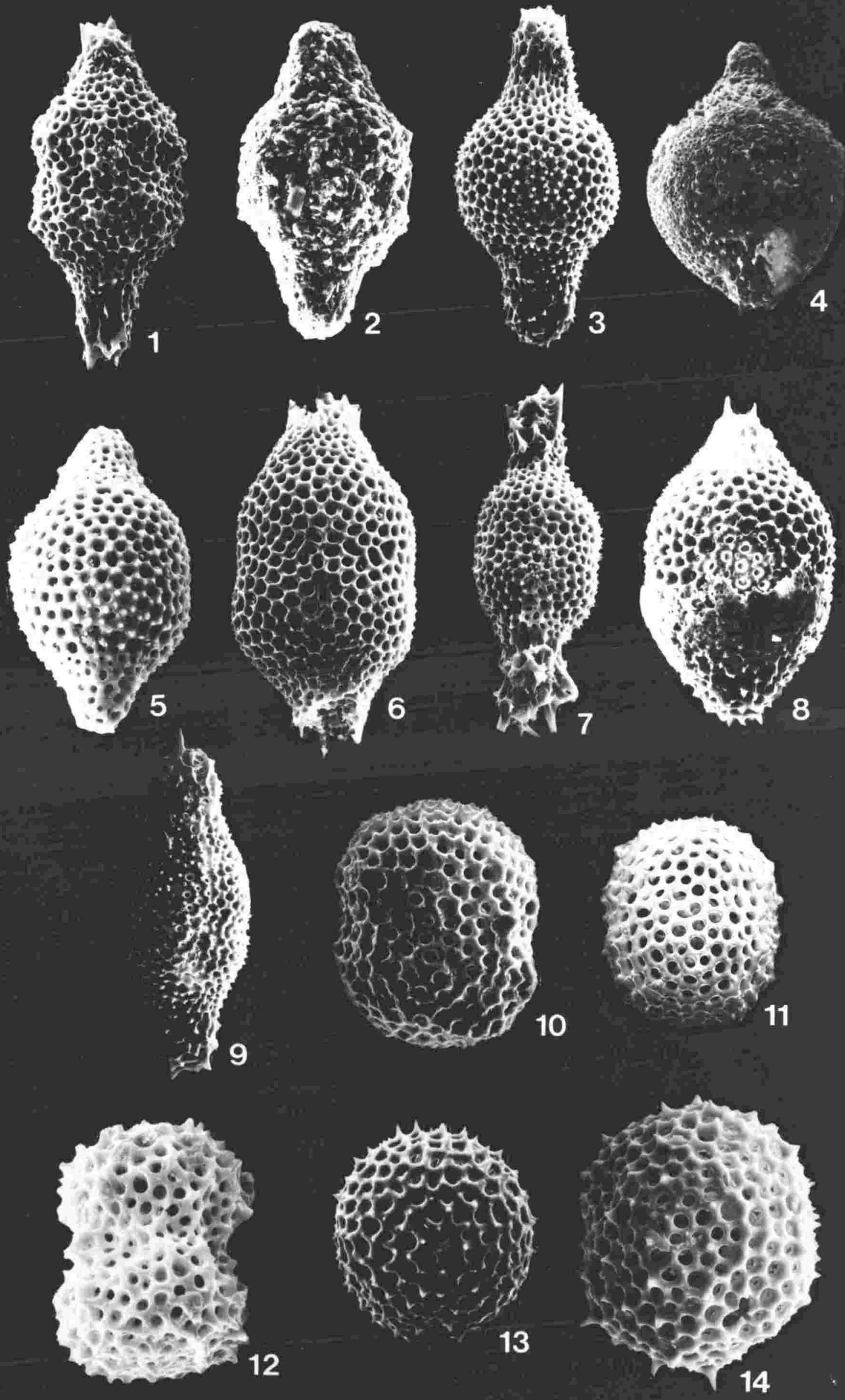


\section{PLATE 12 (opposite)}

1. Dictyocoryne profunda Ehrenberg : $\times 212$ : LT05 : Q30/3 patagium present

2. Dictyocoryne profunda Ehrenberg : x129 : PB05 : W32/1 patagium absent

3. Hymeniastrum cf. euclidis Haeckel : x261 : WA19 : L26/3

4. Hymeniastrum euclidis Haeckel : x262 : MT10 : S27/2

5. Amphirhopalum cf. ypsilon Haeckel : x258: WHO6 : E21/2 one side of forked-arm broken

6. Stylodictya validispina Jorgensen : x333 : HR02 : G33/4 "quadrate" form

7. Stylodictya cornuspira Campbell and Clark : x411 : SPA1 : R47/4

8. Stylodictya validispina Jorgensen : $\times 406:$ RM06 : N16/3 "heavily spined" form

9. Stylodictya validispina Jorgensen : $\mathrm{x} 287$ : PB06 : P46/4 

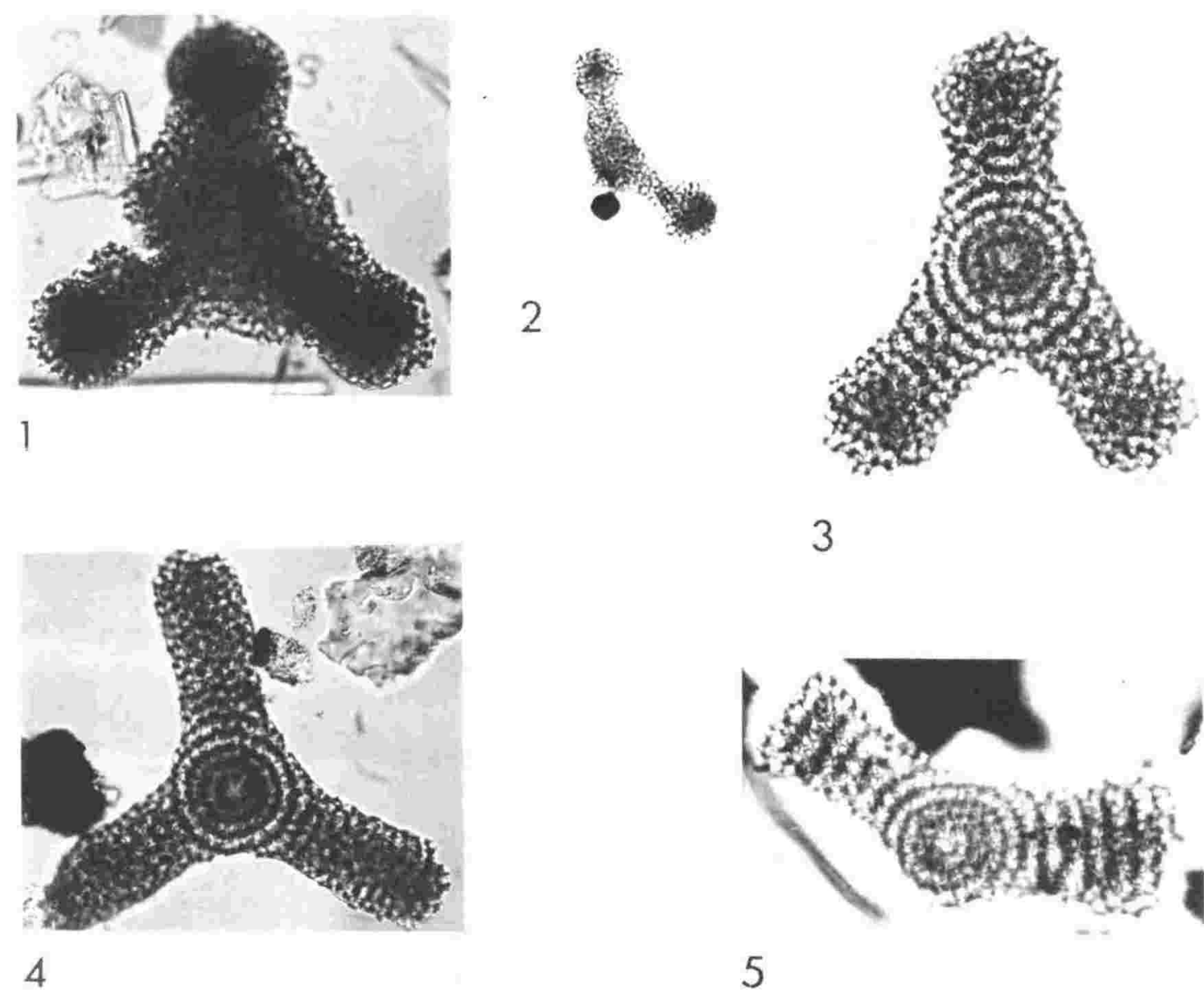

3

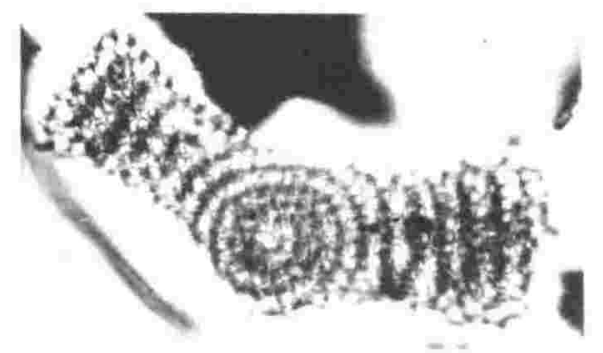

5

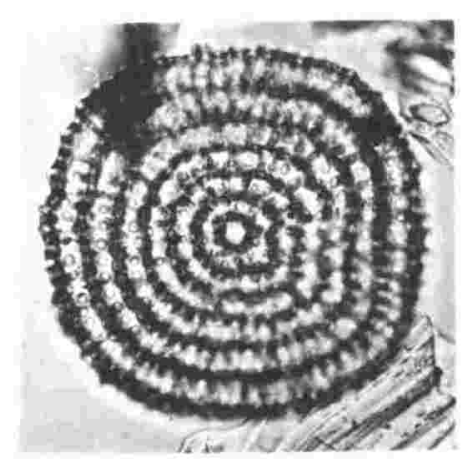

6

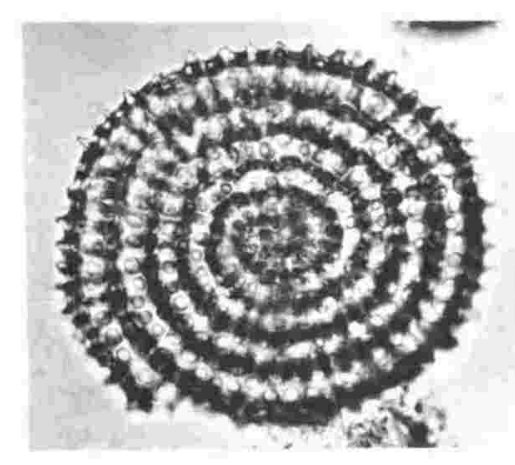

7
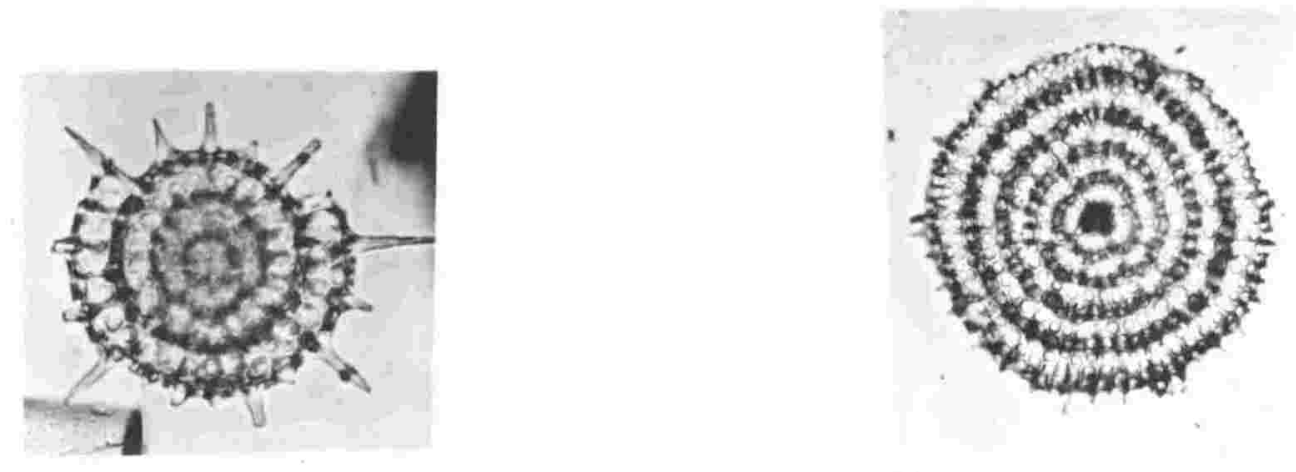
PLATE 13 (opposite)

1. Dictyocoryne profunda Ehrenberg : $\mathrm{x} 180$ : LT06 : AA7/2

patagium present

2. Dictyocoryne profunda Ehrenberg : $\times 160$ : TM23 : AA1/2 partial patagium present

3. Dictyocoryne profunda Ehrenberg : x170 : PB10 : 166/2 patagium absent

4. Dictyocoryne profunda Ehrenberg : $\times 200$ : WA17 : AA9/3 partial patagium present

5. ? Hymeniastrum euclidis Haeckel : x210 : PB06 : 160/3

6. Spongaster pentas Riedel and Sanfilippo : x180 : HR01 : AA9/4

7. Larnacilla typus Haeckel : x240 : LT06 : AA7/2

8. Cubotholus rhombicus Haeckel : $\times 330$ : WA11 : AA8/7

9. Tetrapyle octacantha Muller group : $\times 410$ : SMR1 : AA4/8

10. Tetrapyle octacantha Muller group : $\times 350:$ MO09 : AA4/6 cortical skeleton poorly developed

11. Tetrapyle octacantha Muller group : $\times 310:$ RM02 : AA4/1 "spinose" form

12. Tetrapyle octacantha Muller group : $\mathrm{x} 400: \mathrm{MO} 9$ : AA4/6

13. Tetrapyle octacantha Muller group : x380 : MO09: AA4/6 cortical skeleton poorly developed

14. ? Lithelius minor Jorgensen : $\mathrm{x} 470$ : SMR1 : AA4/9

15. ? Lithelius minor Jorgensen : $\mathrm{x} 470$ : SMR1 : AA4/9 

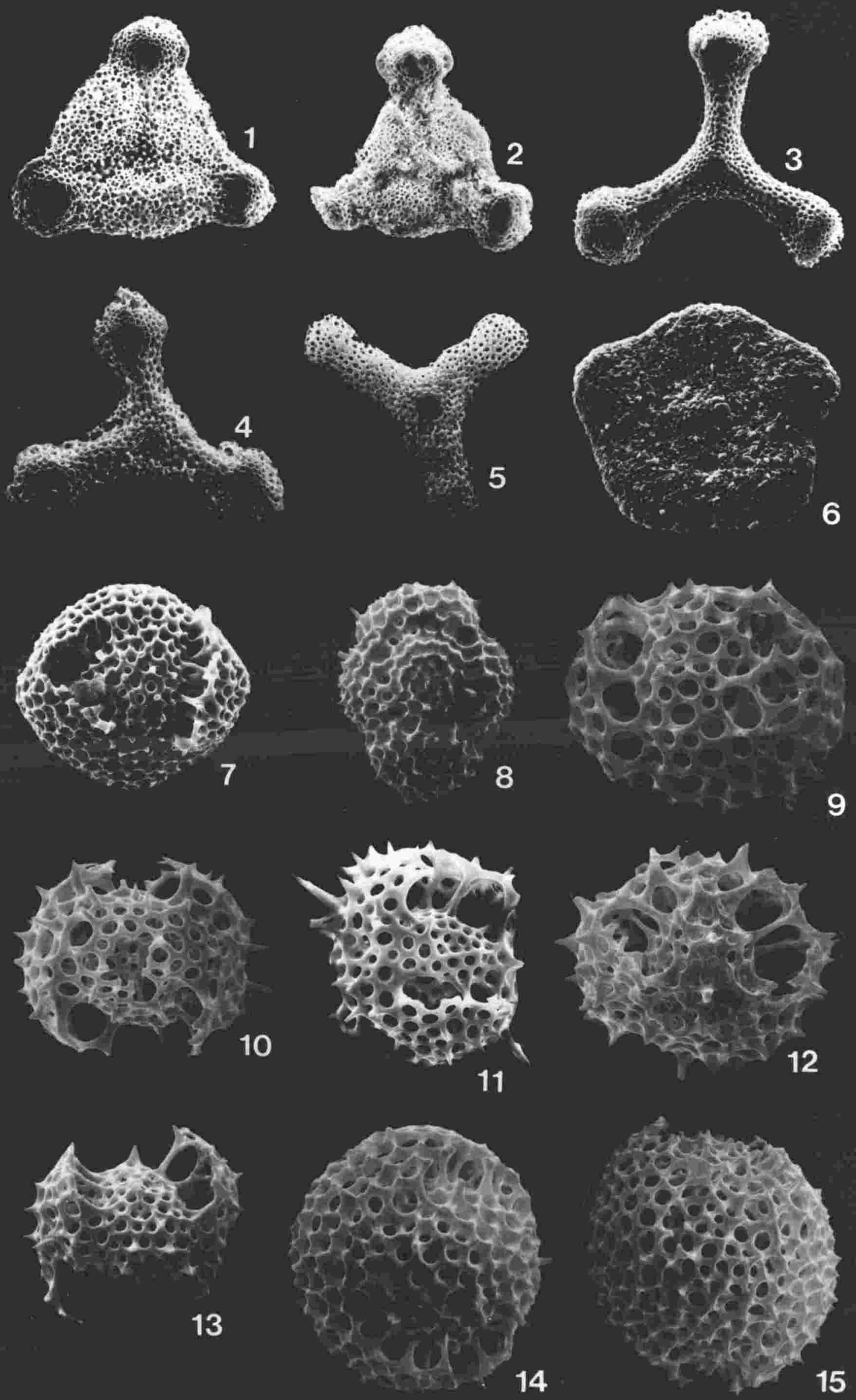


\section{PLATE 14 (opposite)}

1. Porodiscus sp. A : $\mathrm{x} 296$ : TM20 : RIO

SEM photo of same specimen : Plate 15, figure 3

2. Porodiscus sp. A : ×279 : TM20 : RIO

3. Porodiscus sp. B : x116 : TM19 : RIO

4. Porodiscus sp. B : x120 : TM19 : RIO

SEM photo of same specimen : Plate 15, figure 6

5. Stylochlamydium asteriscus Haeckel : $\times 334:$ MO11d : N15/3

6. Spongotrochus glacialis Popofsky : x118 : TM20 : RIO

7. Spongotrochus glacialis Popofsky : x119 : TM19 : RIO

8. Spongotrochus glacialis Popofsky : x284: TM19 : RIO spines present

9. Spongotrochus glacialis Popofsky : x115: TM19 : RIO

SEM photo of same specimen : Plate 15, figure 7 lattice-mantle present

10. Tetrapyle octacantha Muller group : $\times 305: M 010: T 43 / 2$

11. Hexapyle cf. dodecantha Haeckel : x421 : MO11 : M43/4

12. Tetrapyle octacantha Muller group : ×252 : WA01 : U33/1 third girdle present
A. focused on surface
B. focused on internals of same specimen 

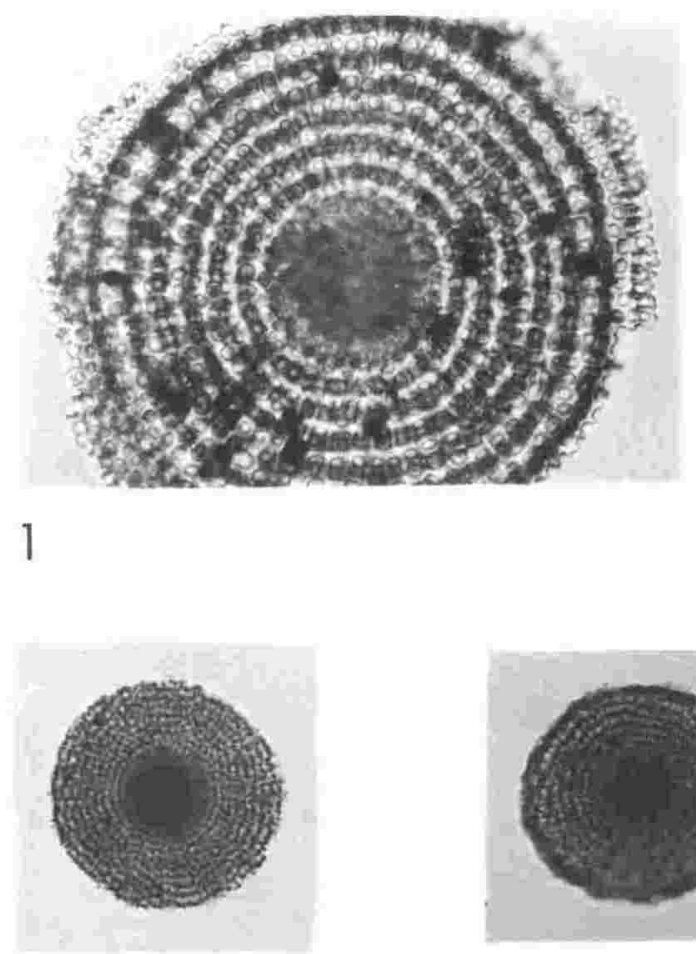

3

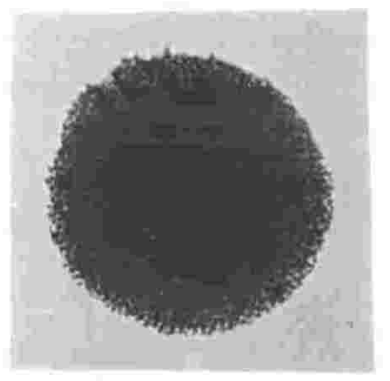

6

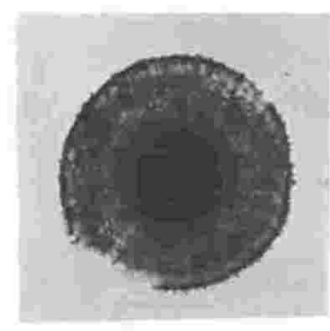

9

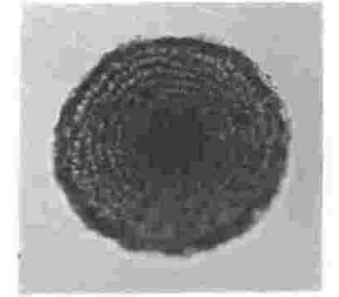

4

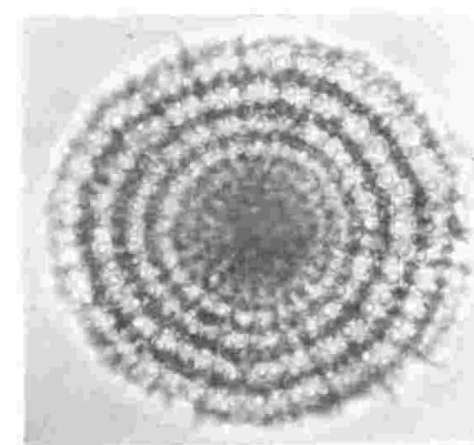

2

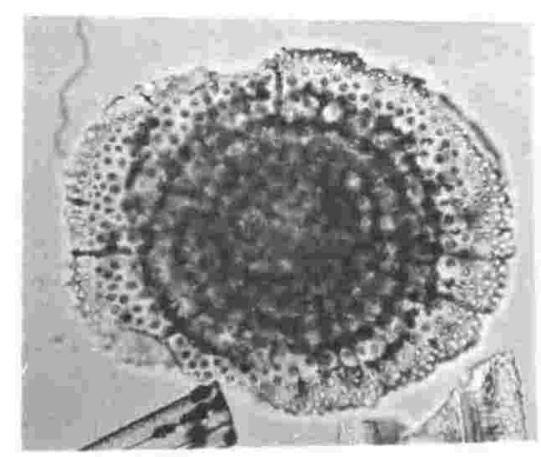

5

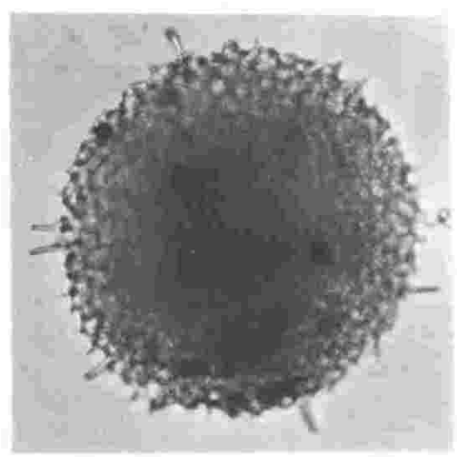

8

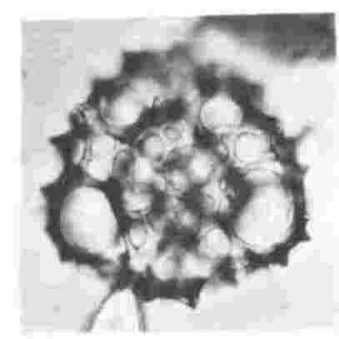

11

$12 \mathrm{~A}$

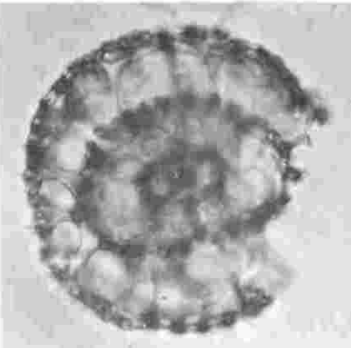

B 


\section{PLATE 15 (opposite)}

1. Stylodictya validispina Jorgensen : x310 : PB07 : 161/3

2. Porodiscus sp. A : x370 : PB11 : 167/9

3. Porodiscus sp. A : x190: TM20 : AA6/6

transmitted light photo of same specimen : Plate 14, figure 1

4. Porodiscus sp. B : $\times 170$ : SMA4 : AA4/11

5. ? Porodiscus sp. B ? : x240 : PB02 : 156/4

poorly preserved specimen

6. Porodiscus sp. B : $\mathrm{x} 190$ : TM20 : AA6/4

transmitted light photo of same specimen : Plate 14, figure 4 lattice-mantle ? present

7. Spongotrochus glacialis Popofsky : $\mathrm{x} 180:$ TM19 : AA6/2

transmitted light photo of same specimen : Plate 14, figure 9 lattice-mantle present

8. Spongotrochus glacialis Popofsky : x180 : RM04 : AA5/6 spines present

9. Spongotrochus glacialis Popofsky : $\mathrm{x} 260$ : PB11 : 167/8

partial spines present

10. Spongotrochus glacialis Popofsky : $\mathrm{x} 150: \mathrm{LT} 05: \mathrm{AA} 7 / 2$

11. Spongotrochus glacialis Popofsky : x170 : SMA4 : AA4/11 poorly preserved specimen

12. Desmospyris sp. aff. rhodospyroides Petrushevskaya : $\mathrm{x} 350$ : LT05 : AA7/2

13. ? Gorgospyris sp. aff. perizostra Sanfilippo and Riedel : $\mathrm{x} 350$ : LT06 : AA7/2

14. Desmospyris rhodospyroides Petrushevskaya : $\mathrm{x} 410$ : RM05 : AA5/5 

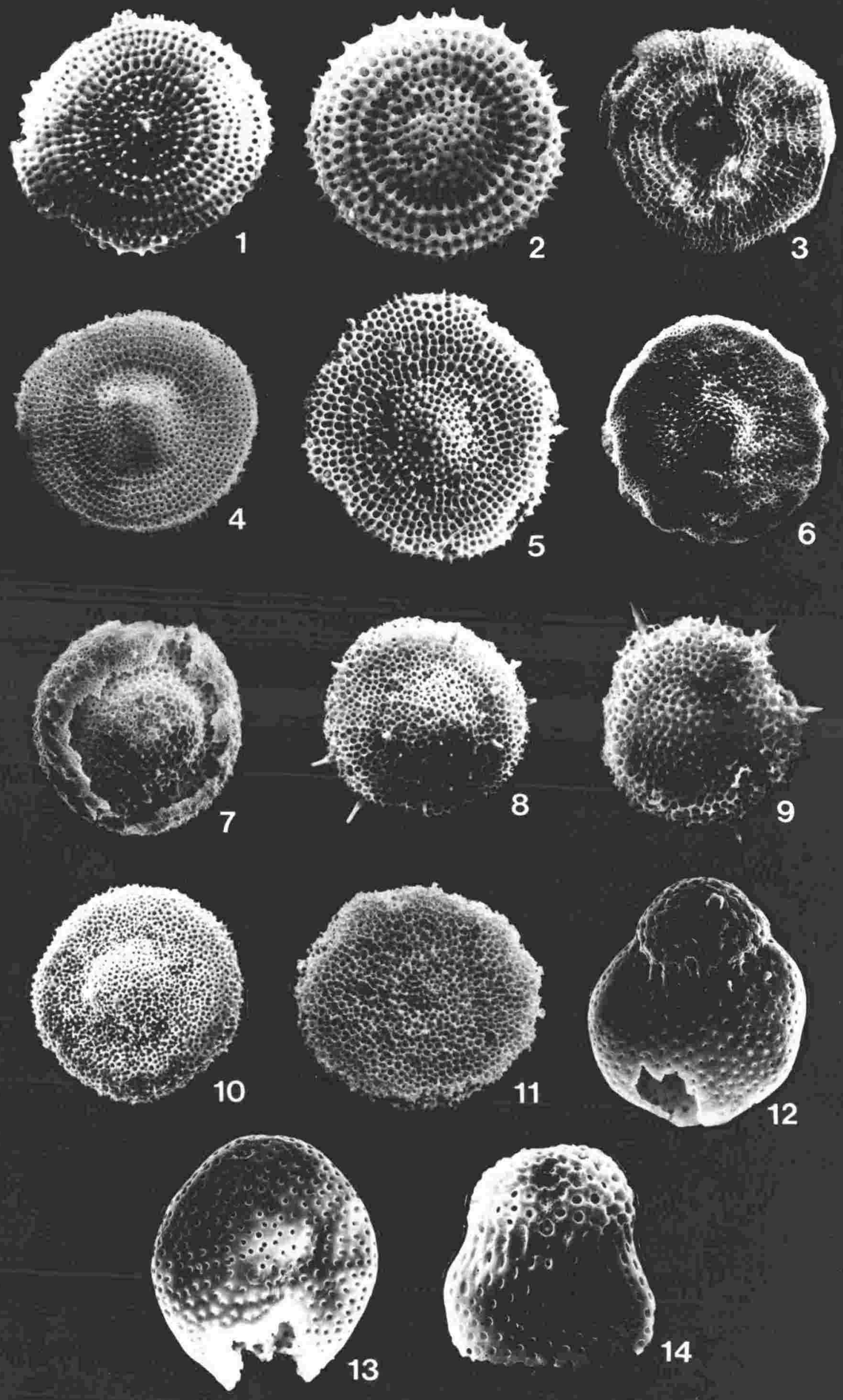


\section{PLATE 16 (opposite)}

1. Lithelius nautiloides Popofsky : х282 : PB04 : S39/1

A. focused on surface

B. focused on internals of same specimen

2. Pylospira octopyle Haecke1 : x283 : PB06 : S45/4

A. focused on surface

B. focused on internals of same specimen

3. Lithelius sp. A : $\mathrm{x} 275: \mathrm{PB} 11: \mathrm{M} 44 / 3$

"Larcospira" type

4. Lithelius sp. B : ×288 : TM20 : RIO

5. Lithelius minor Jorgensen : ×288 : PB06 : ?????

double spiral visible

6. Lithelius nautiloides Popofsky : x384 : SPA1 : R24/2

double spiral visible

7. Antarctissa antedenticulata Chen : $\times 383$ : WA03 : Q37/4

8. Antarctissa conradae Chen : $\times 413$ : MO11 : $\mathrm{S} 28 / 2$

9. Antarctissa antedenticulata Chen : $\mathrm{x} 416$ : WA02 : V42/2

transitional with $A$. longa

10. Antarctissa longa (Popofsky) : $\mathrm{x} 415: \mathrm{WA} 02: \mathrm{S} 31 / 2$

11. Antarctissa antedenticulata Chen : $\mathrm{x} 406:$ WH06 : T16/3

A. focused on surface

B. focused on circumference of same specimen

12. Lophophaena cf. macrencephala Clark and Campbell : x301 : MO13:025/3 


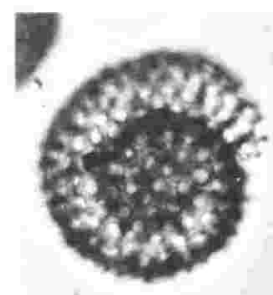

lA

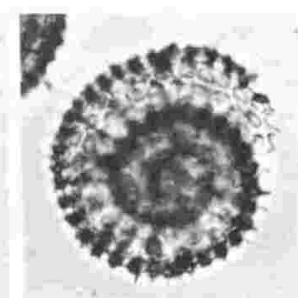

B

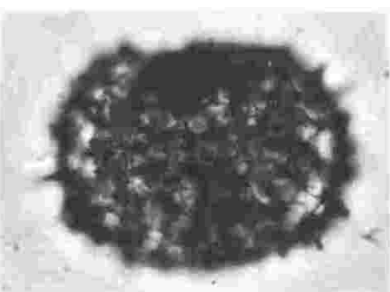

$2 \mathrm{~A}$

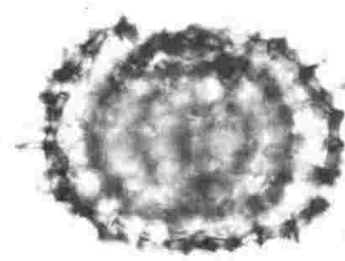

B

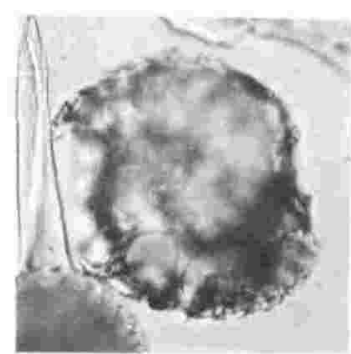

3

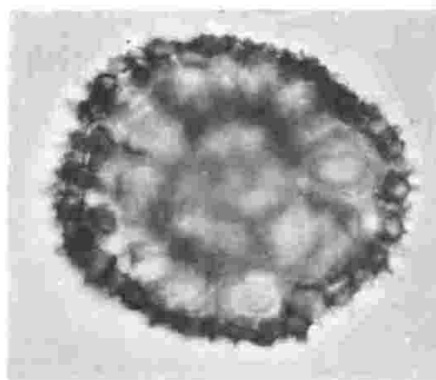

4

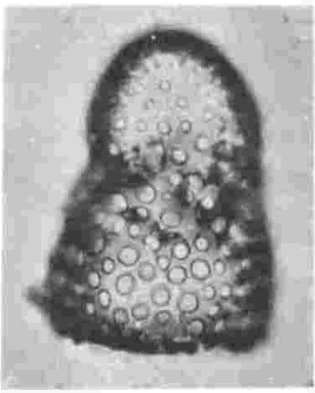

7

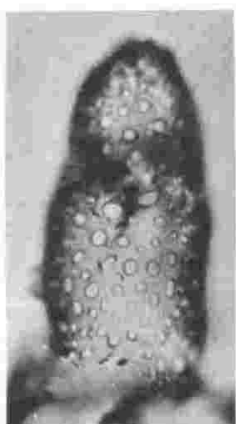

8

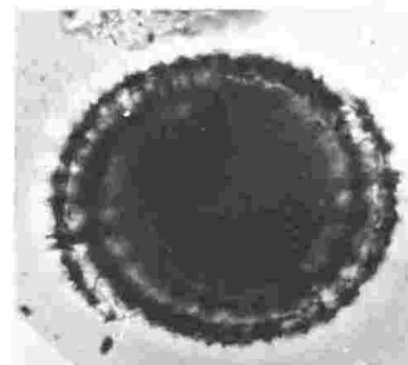

5

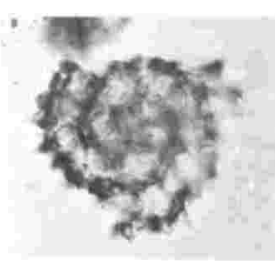

6

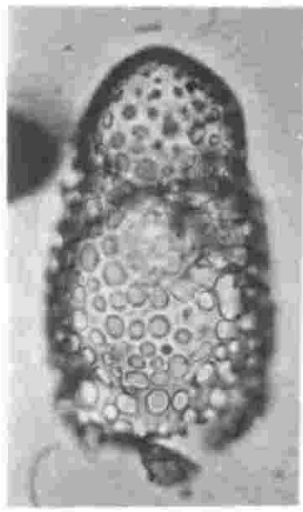

10

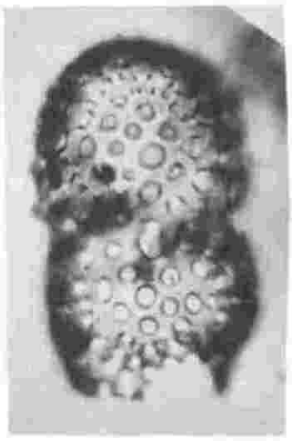

$11_{A}$

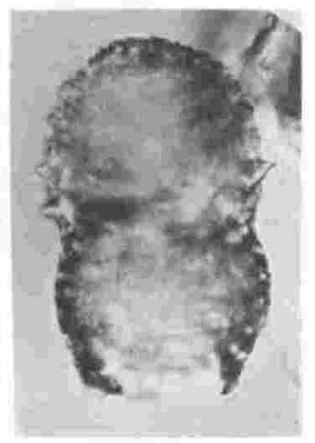

B

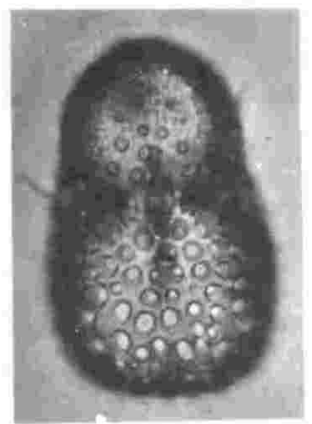

9

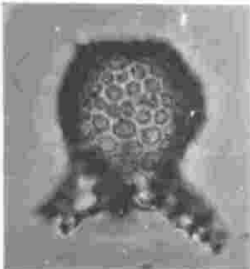

12 


\section{PLATE 17 (opposite)}

1. Phormospyris stabilis (Goll) antarctica (Haecker) group : $\mathrm{x} 490: \mathrm{LT} 05: \mathrm{AA} 7 / 3$ front view

2. Phormospyris stabilis (Goll) antarctica (Haecker) group : x640:TM23: AA1/4 back view

3. Carpocanistrum sp. A : $\mathrm{x} 470$ : $\mathrm{PB} 02: 156 / 8$

form with larger mouth

4. Cystophormis sp. B : $\mathrm{x} 430: \mathrm{TM} 19: \mathrm{AA} 2 / 2$

5. Carpocanistrum sp. A : $\times 450$ : SMA4 : AA4/11

form with very constricted mouth

6. Cystophormis sp. A : $\mathrm{x} 430: \mathrm{PB} 07: 161 / 9$

7. Cystophormis sp. A : $\times 400: \mathrm{PB} 07: 161 / 8$

form with relatively wide mouth

8. Carpocanistrum sp. A : $\times 400:$ LT05 : AA7/2

transitional with Cystophormis sp. A

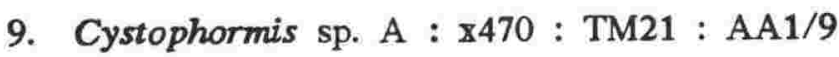

form with prominent terminal teeth

10. Cornutella profunda Ehrenberg : $\times 330$ : MSO3 : AA2/11

"three-pored" form

11. Cornutella profunda Ehrenberg : $\times 380$ : WA17 : AA9/3

"six-pored" form

12. Plectopyramis dodecomma Haeckel : x180 : RM05: AA5/5

"flared" form

13. Plectopyramis dodecomma Haeckel : $\mathrm{x} 250$ : PB07 : 161/5

"tapering" form 

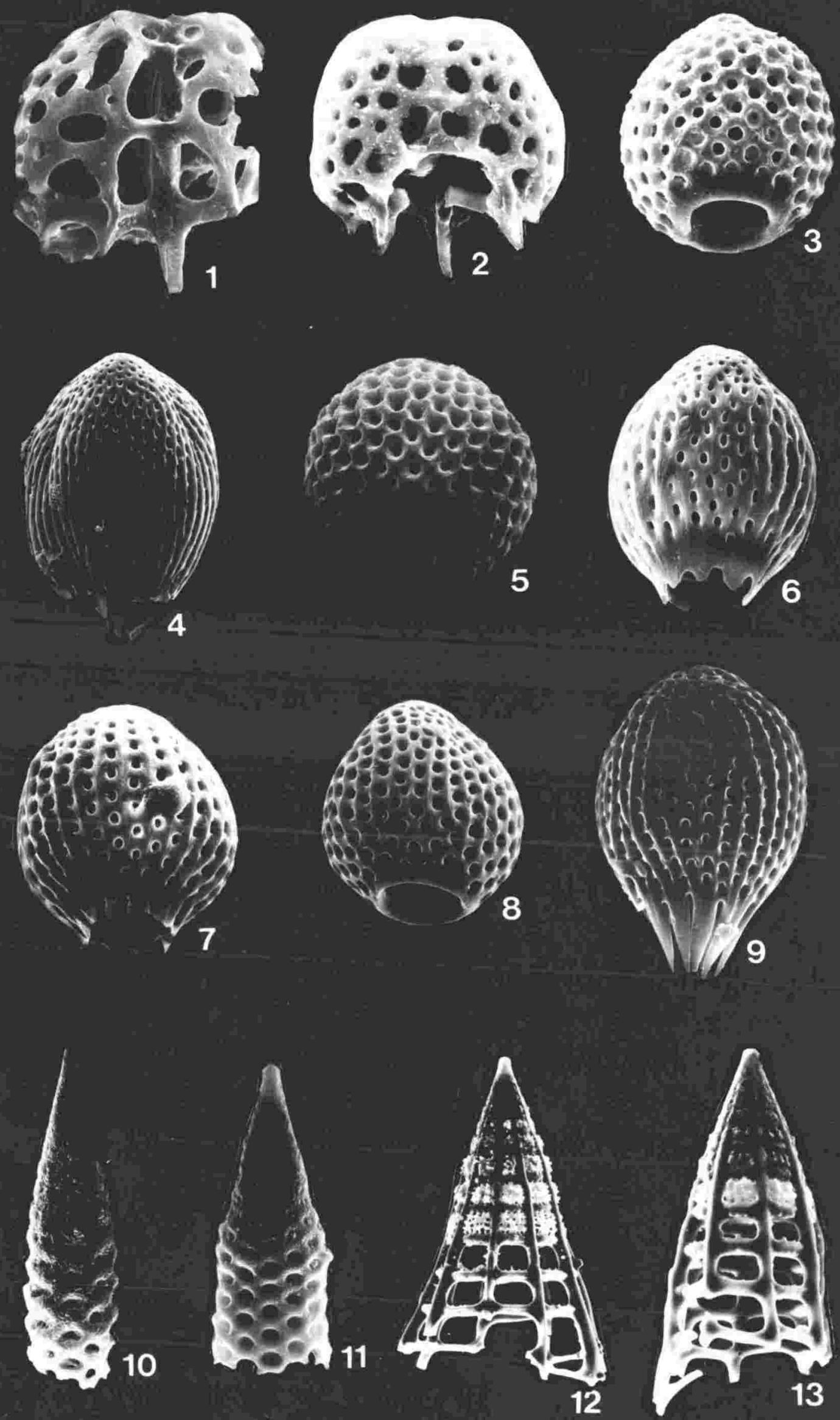


\section{PLATE 18 (opposite)}

1. ? Lithomelissa setosa Jorgensen : $\mathrm{x} 416$ : RM07 : L12/3 transitional with Antarctissa strelkovi
A. focused on surface
B. focused on circumference of same specimen

2. ? Lithomelissa setosa Jorgensen : x429 : MS15 : N13/2 form with feet developed

3. ? Lithomelissa setosa Jorgensen : x407: HR04: J36/4 form with feet developed

4. Desmospyris rhodospyroides Petrushevskaya : x298 : TM22 : U15/3

5. Desmospyris rhodospyroides Petrushevskaya : x310 : MO06 : H30/1

6. Gorgospyris sp. aff. perizostra Sanfilippo and Riedel : ×402 : M011:020/3

A. focused on circumference

B. focused on surface of same specimen

7. Desmospyris (?) sp. A : $\times 433$ : SCV1 : V $30 / 3$

8. Desmospyris (?) sp. A : $\times 293$ : TM23 : F31/1

9. Phormospyris stabilis (Goll) antarctica (Haecker) group : ×297 : RM05 : P29/2

A. and B. Two focus levels on the same specimen

10. Phormospyris stabilis (Goll) scaphipes (Haeckel) group : $\mathrm{x} 412$ : WA23 : N44/4

11. Phormospyris stabilis (Goll) antarctica (Haecker) group : $\mathrm{x} 421:$ WA17 : J47/4
A. focused on back surface
B. focused on front surface of same specimen

12. Phormospyris stabilis (Goll) scaphipes (Haeckel) group : x433 : LT05 : L27/1 transitional with $P$. stabilis antarctica
A. focused on front surface
B. focused on back surface of same specimen

13. Spyrid gen. et sp. indet. : $\mathrm{x} 416$ : MS06 : S32/1 


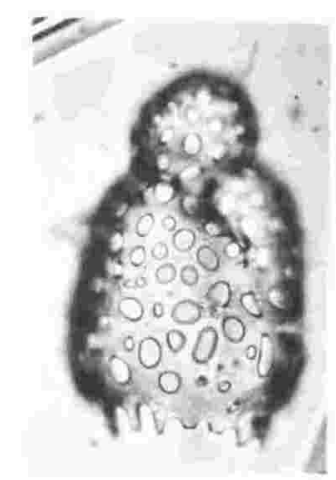

IA

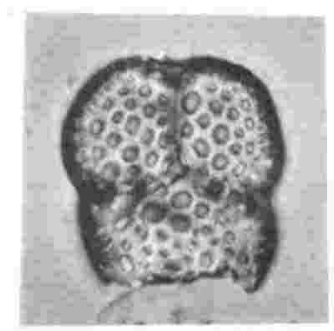

4

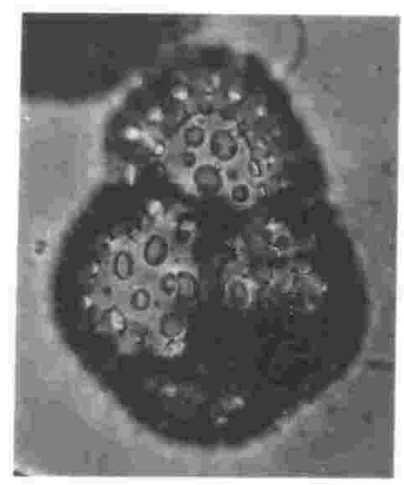

7

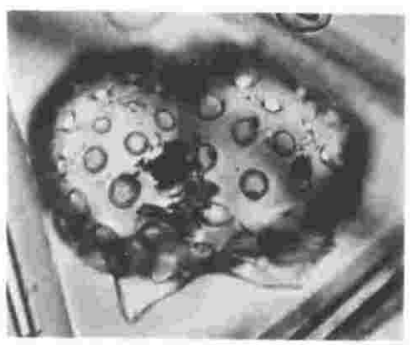

10

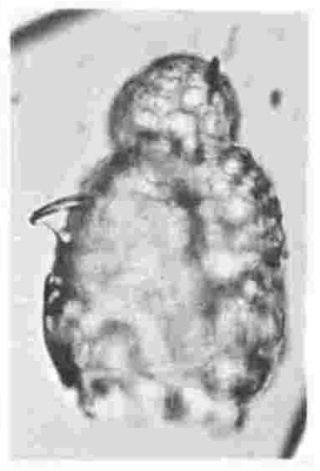

B
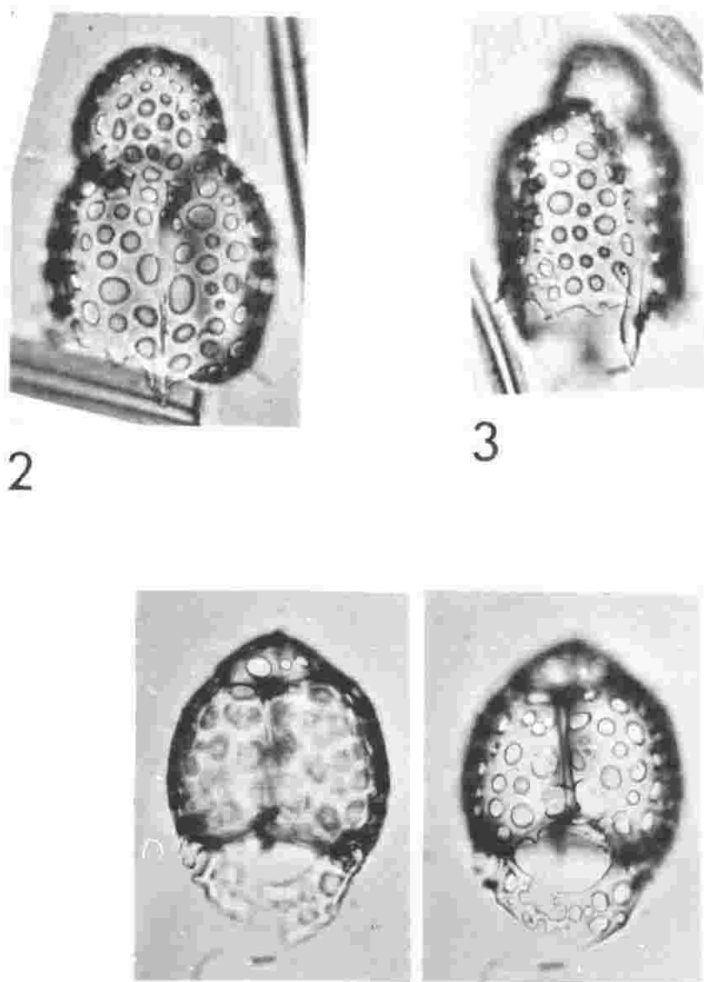

6A

B
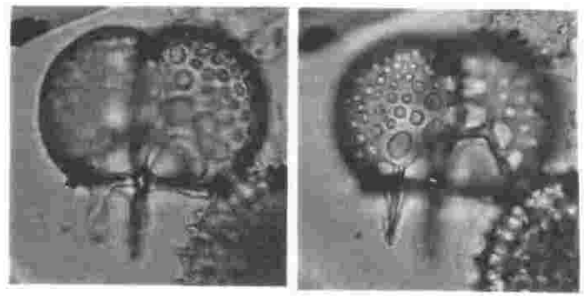

$9 A$

B

8
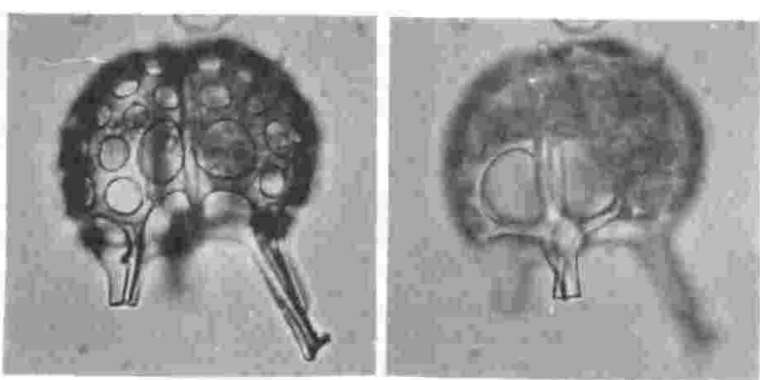

$11 \mathrm{~A}$

B

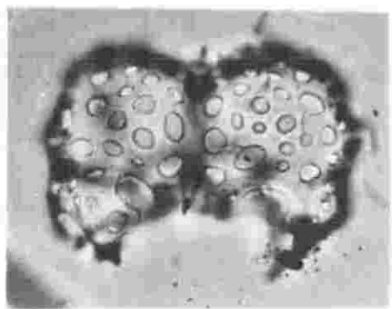

13 


\section{PLATE 19 (opposite)}

1. Dictyophimus hirundo (Haeckel) group : x260: M004: AA4/4

2. Dictyophimus hirundo (Haecke1) group : x280 : LT07 : AA7/1

3. Lychnocanium sp. aff. grande (Campbell and Clark) : x210: MO04:AA4/4

4. Lychnocanium sp. aff. grande (Campbell and Clark) : ×210 : M007 : AA4/5

5. Lychnocanium sp. aff. grande (Campbell and Clark) : $\times 310$ : SMA2 : AA4/9

6. Lychnocanella conicum (Clark and Campbell) : ×340 : LT05: AA7/3

7. Lampromitra tiara Dumitrica : x260 : RM04 : AA5/6

"flaring" form

8. Theocalyptra davisiana davisiana (Ehrenberg) : x270: MS03 : AA2/10

9. ? Theocampe cf. mongolfieri (Ehrenberg) : x290:MS05: MISC/6

10. Cyrtocapsella tetrapera (Haecke1) : x350 : PB06 : 160/11 "constricted" form

11. Stichophormis cornutella Haeckel : $\times 220: \mathrm{LT} 03: \mathrm{AA} 7 / 4$

12. Cyrtocapsella japonica (Nakaseko) : $\times 500$ : PB10 : 166/4 conical fourth segment

13. Cyrtocapsella tetrapera (Haeckel) : х460 : PB03 : 157/3 inverted fifth segment 

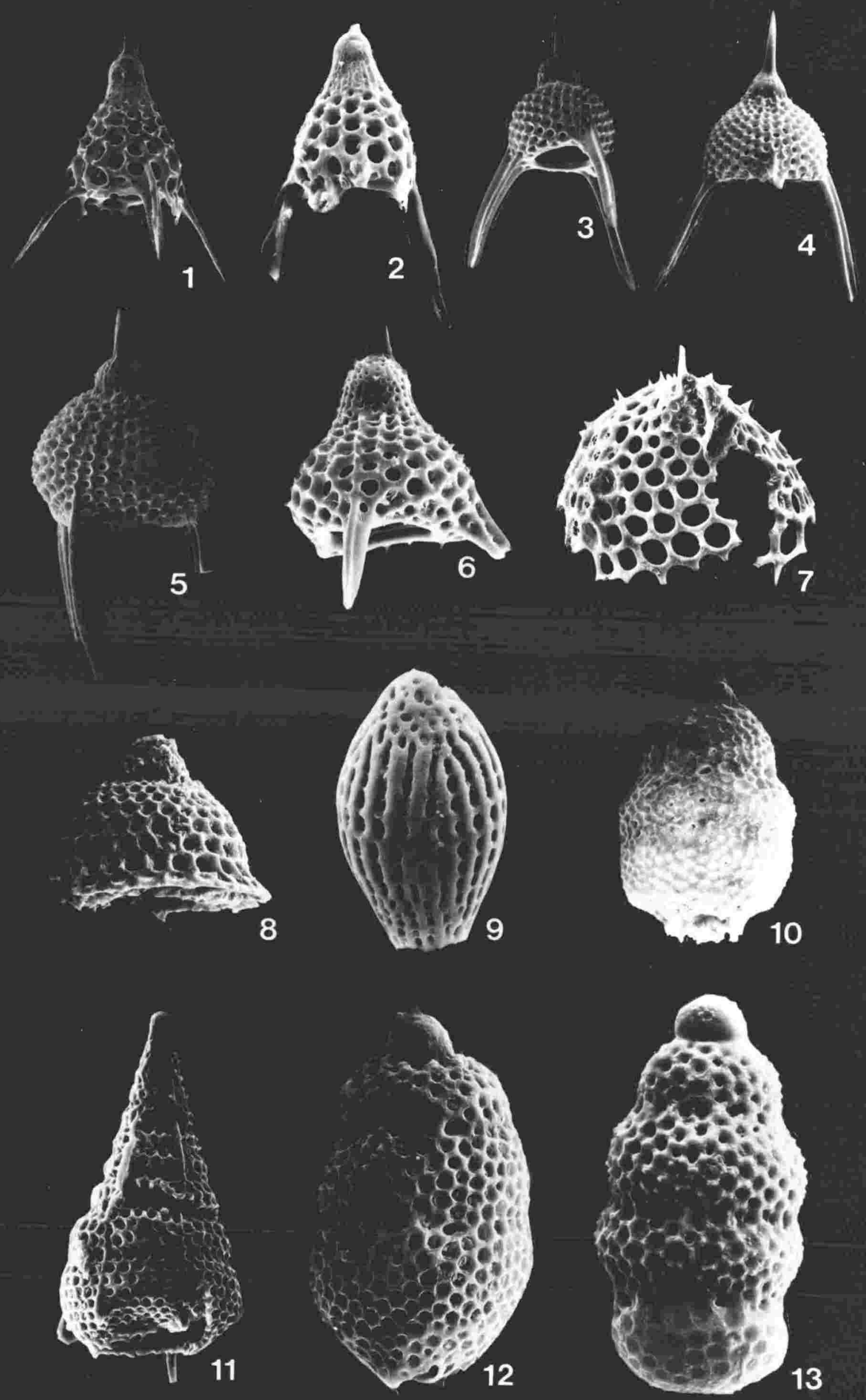


\section{PLATE 20 (opposite)}

1. Carpocanarium papillosum (Ehrenberg) : x306 : MO06 : F33/1

2. Carpocanarium papillosum (Ehrenberg) : x288 : TM22 : M29/2

3. Carpocanarium sp. A : $\times 403:$ MS11 : L18/1

A. focused on surface

B. focused on circumference of same specimen

4. Cystophormis sp. A : $\mathrm{x} 296: \mathrm{HR} 05: \mathrm{L} 27 / 4$

A. focused on surface

B. focused on circumference of same specimen

5. Carpocanistrum sp. A : $\mathrm{x} 223$ : $\mathrm{PB} 05: \mathrm{Q} 43 / 1$

form transitional with Cystophormis sp. A

A. focused on surface

B. focused on circumference of same specimen

6. Cornutella profunda Ehrenberg : ×291 : PB11 : K45/1

7. Plectopyramis dodecomma Haeckel : x285 : PB11 : F13/1

8. Plectopyramis dodecomma Haeckel : x406 : MO11d : Q16/1 secondary meshwork visible

9. Lampromitra tiara Dumitrica : $\mathrm{x} 403$ : WA19 : J30/4

10. Dictyophimus hirundo (Haeckel) group : $\mathrm{x} 411$ : RM06 : Q28/4

11. Dictyophimus hirundo (Haecke1) group : ×289 : MSO4 : N36/1

? small portion of abdomen preserved

12. Dictyophimus hirundo (Haeckel) group : x113 : RM06 : O35/2 abnormally long apical horn 

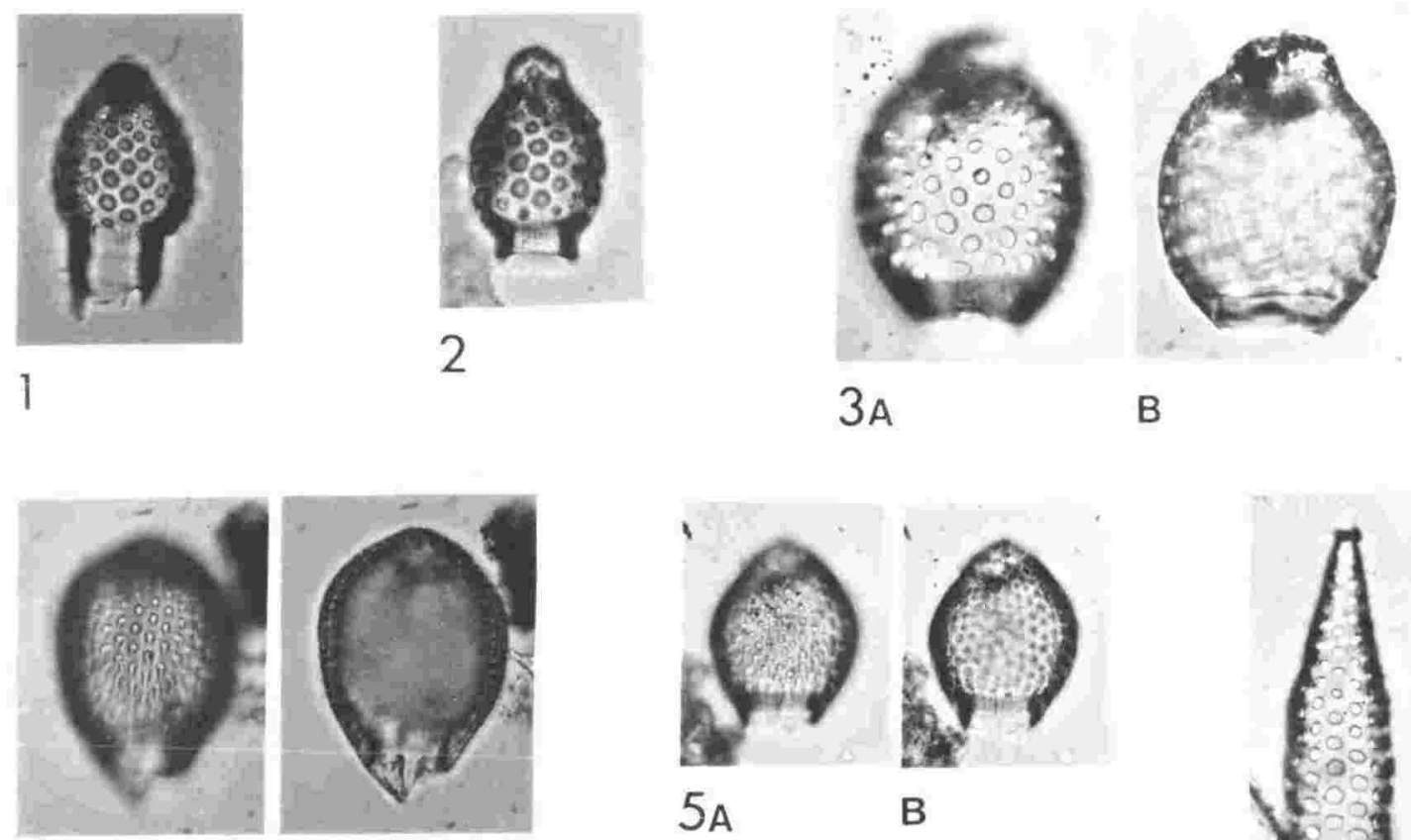

$4 \mathrm{~A}$

B
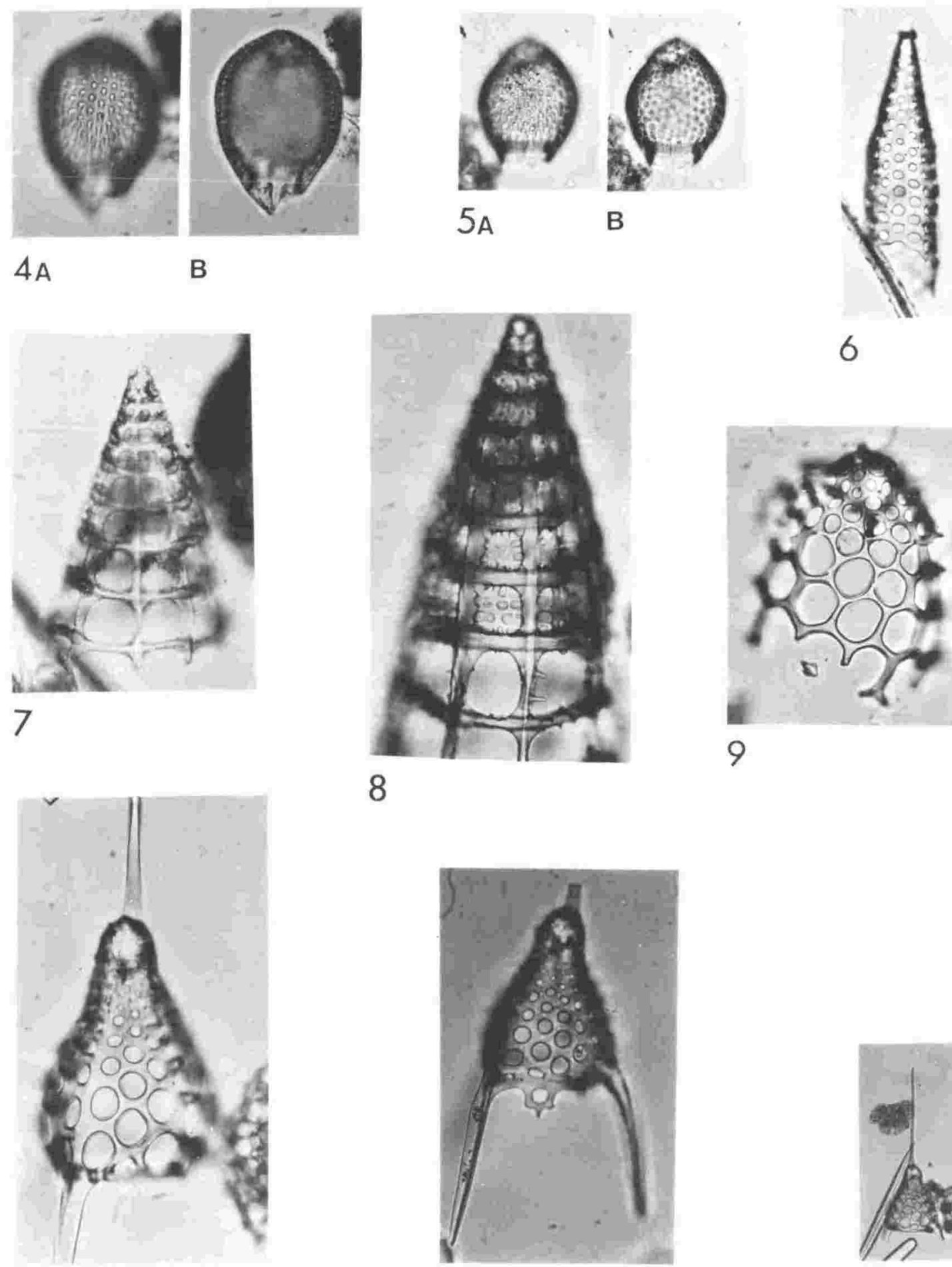

10
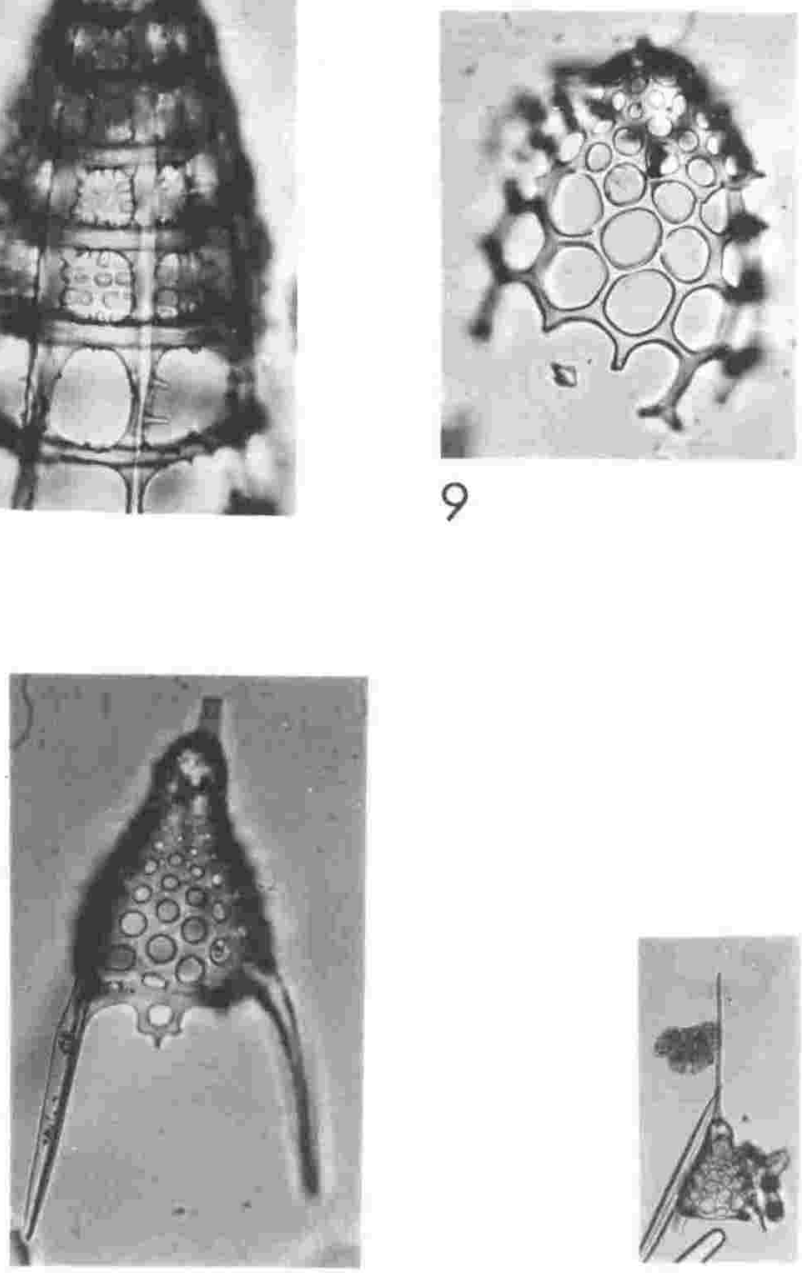
PLATE 21 (opposite)

1. Pseudodictyophimus gracilipes (Bailey) : $\times 384:$ TM19 : S17/2
A. focused on surface of cephalis and thorax
B. focused on circumference of lattice mantle

2. Archipilium macropus (Haeckel) : x404: WT05: J40/3

3. Lychnocanium sp. aff. grande (Campbell and Clark) : ×212 : MO11d : K40/1

4. Lychnocanium sp. aff. grande (Campbell and Clark) : ×285 : PB11 : L42/4
A. focused on surface
B. focused on circumference of same specimen

5. Lychnocanella conicum (Clark and Campbell) : x394: TM20 : T14/4
A. focused on surface
B. focused on circumference of same specimen

6. Cyrtocapsella japonica (Nakaseko) : x402: MO11: K34/3

conical fourth segment

7. Cyrtocapsella tetrapera (Haecke1) : $\times 287:$ HR05:T40/2

8. Cyrtocapsella japonica (Nakaseko) : x371 : MO11d : J36/3
A. focused on surface
B. focused on circumference of same specimen

9. Cyrtocapsella tetrapera (Haecke1) : ×292 : PB11 : L36/1

conical fifth segment
A. focused on surface
B. focused on circumference of same specimen 


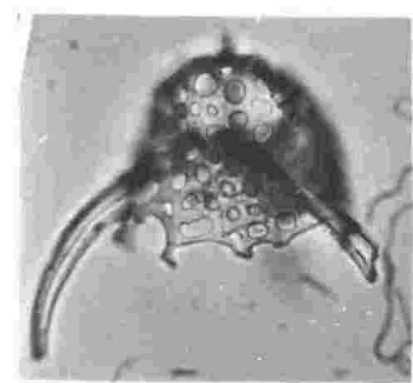

la

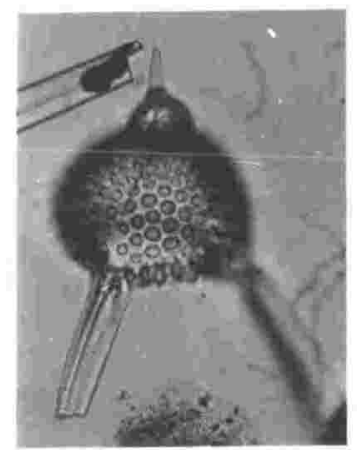

3

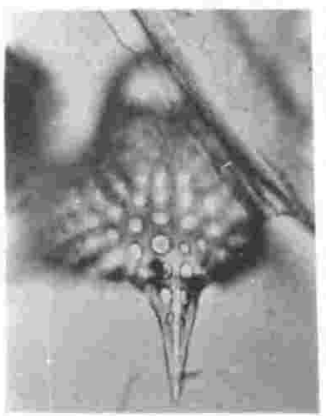

$5 A$

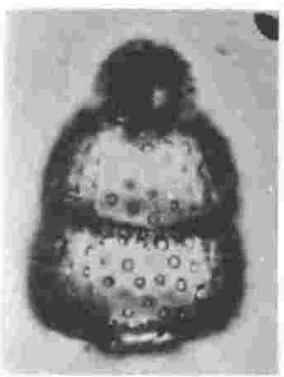

$8 \mathrm{~A}$

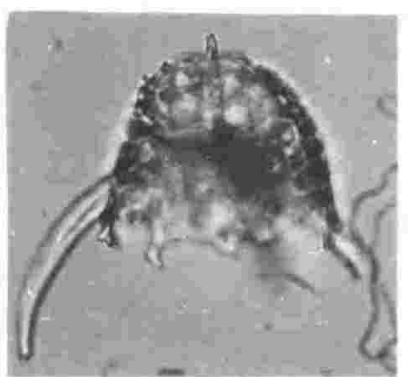

B

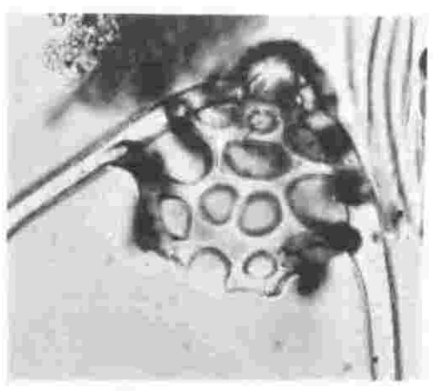

2

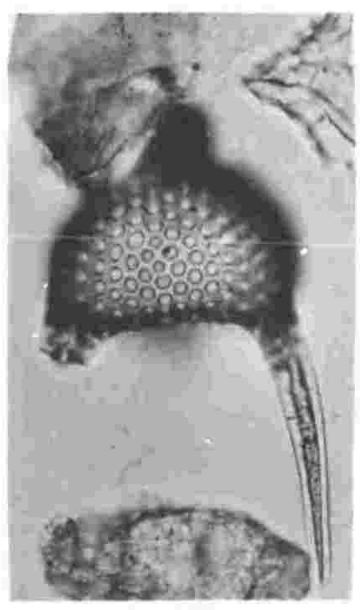

$4 \mathrm{~A}$

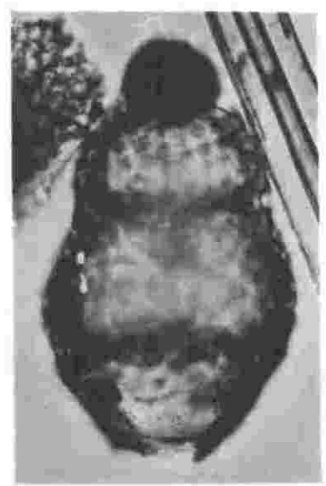

6

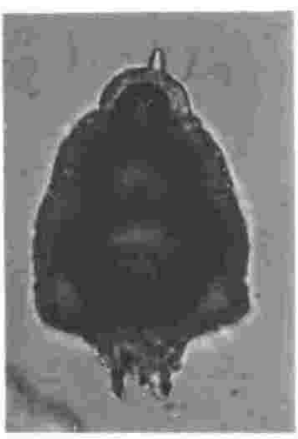

7

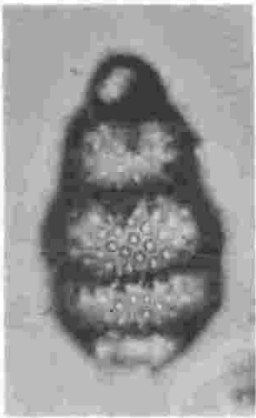

$9 A$

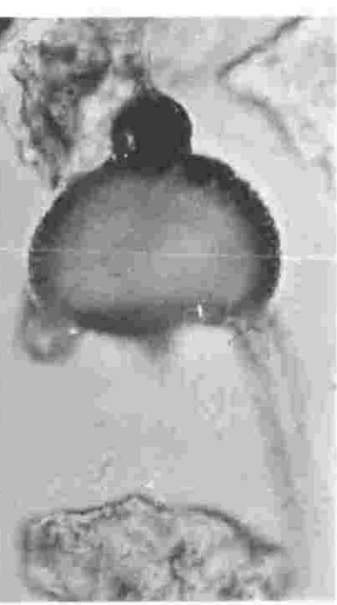

B

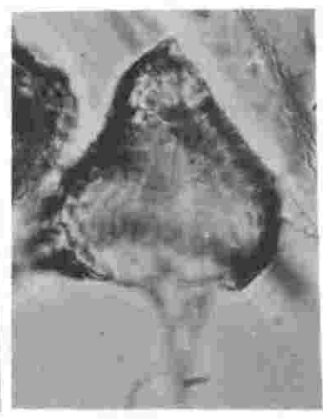

B

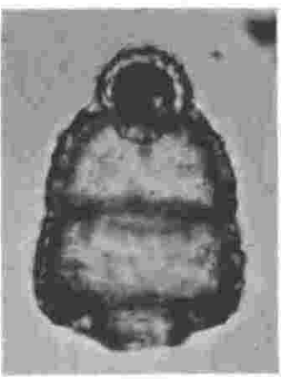

B

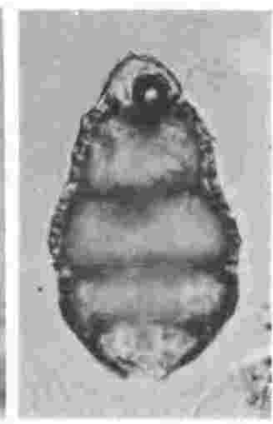

B 


\section{PLATE 22 (opposite)}

1. Cyrtolagena laguncula Haeckel : ×410 : RM07 : L27/3

"spiralling" form

2. Lampromitra erosa Cleve : $\mathrm{x} 410$ : MS14 : 014/2

3. Lampromitra butschlii (Haeckel) : x417 : WA03 : H36/2

4. Theocalyptra bicornis (Popofsky) : x296 : MO13 : N26/2

5. Theocalyptra davisiana davisiana (Ehrenberg) : ×294: WA03 : J22/1

6. Theocalyptra davisiana davisiana (Ehrenberg) : x403: WA07: 028/4

7. Eucyrtidium sp. A : x402 : WA01: T32/3

A. focused on surface

B. focused on circumference of same specimen

8. Eucyrtidium vincentense (Campbell and Clark) : x404 : MS14 : 019/4

9. Eucyrtidium cf. montiparum Ehrenberg : х415 : TM15: 030/3

10. Eucyrtidium calvertense Martin : $\times 413$ : PB11 : D22/3

form transitional with $E$. inflatum

A. focused on surface

B. focused on circumference of same specimen

11. Eucyrtidium inflatum Kling : $\times 343: \mathrm{PB} 05: \mathrm{Y} 13 / 2$ 

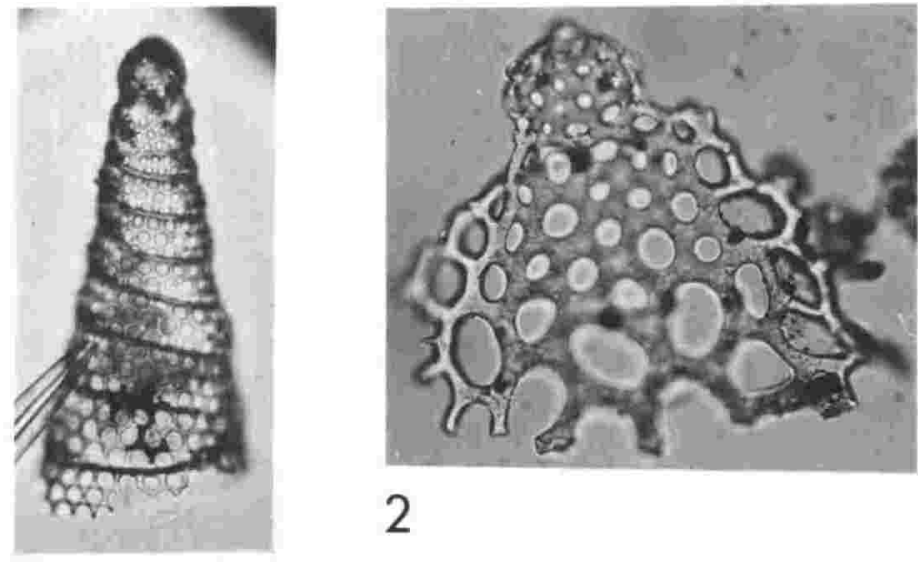

2

1

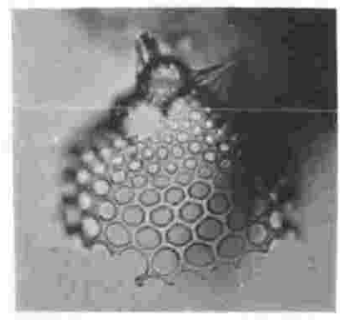

4

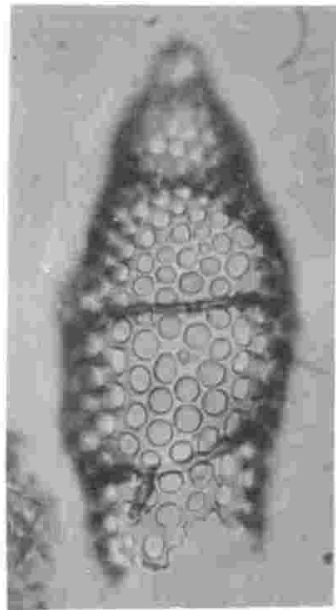

$7 \mathrm{~A}$

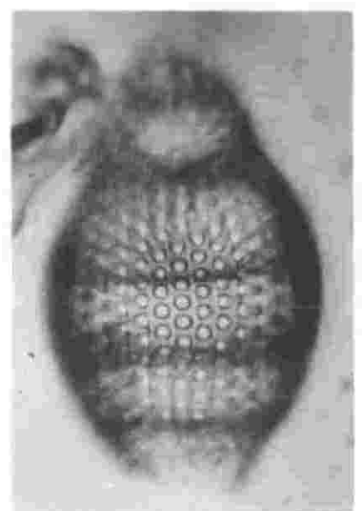

10A

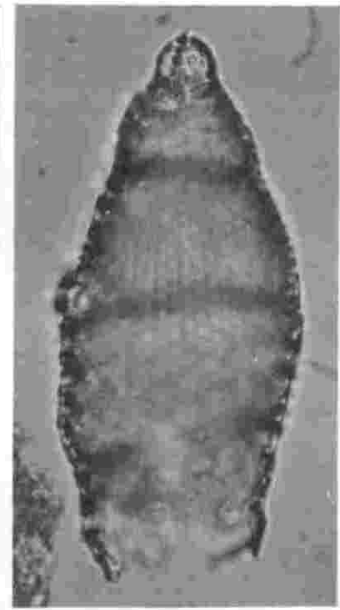

B

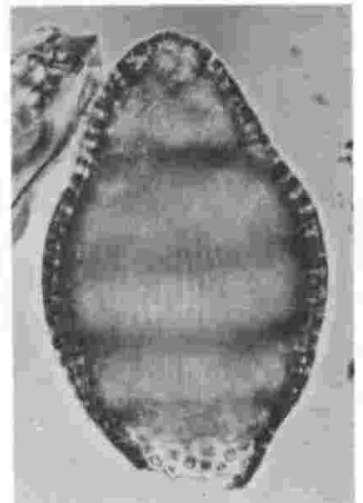

B

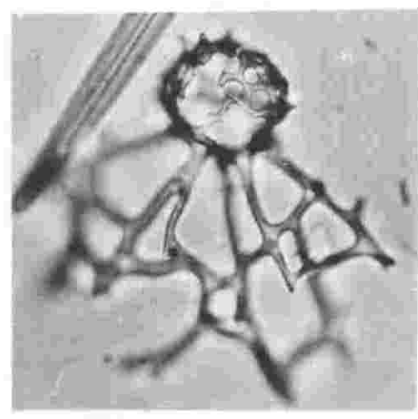

3

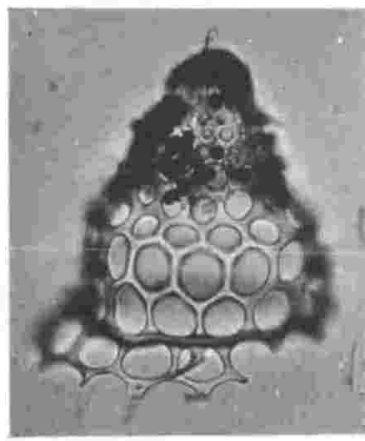

6

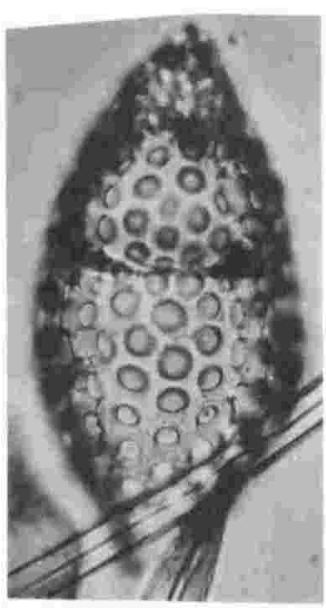

8

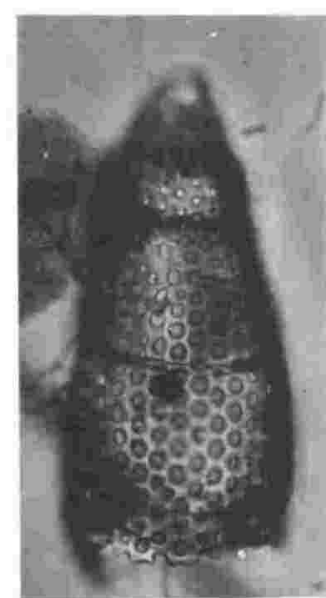

9

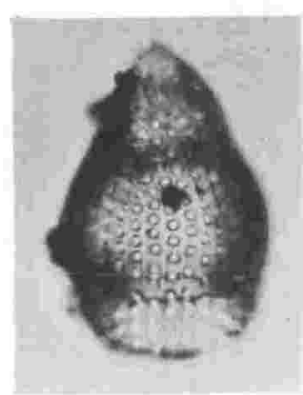

11 


\section{PLATE 23 (opposite)}

1. ? Eucyrtidium calvertense Martin : $\mathrm{x} 440$ : $\mathrm{PB} 08: 164 / 6$

2. Eucyrtidium calvertense Martin : $\times 280$ : WA02 : AA8/3

3. Eucyrtidium acuminatum (Ehrenberg) : x410 : LT08 : AA7/1

4. Eucyrtidium cienkowskii Haeckel group : ×360 : KB01 : AA10/3

5. Eucyrtidium cienkowskii Haeckel group : $\times 410:$ PB07 : 161/4

6. Eucyrtidium cienkowskii Haeckel group : x350 : KB01 : AA10/3

7. Eucyrtidium acuminatum (Ehrenberg) : $\mathrm{x} 310: \mathrm{JAA} 420: \mathrm{MISC} / 3$ 1ateral wing highlighted

8. Eucyrtidium inflatum Kling : x320 : PB07 : 161/8

9. Eucyrtidium acuminatum (Ehrenberg) : x280: TM23: AA1/3

10. Eucyrtidium hexagonatum Haeckel : $\times 330:$ TM14 : AA2/8

11. Eucyrtidium punctatum (Ehrenberg) group : $\times 350:$ WA07 : AA8/6 form transitional with $E$. cienkowskii

12. Eucyrtidium cienkowskii Haeckel group : ×320 : LT01 : AA7/4

13. Eucyrtidium punctatum (Ehrenberg) group : $\times 370:$ TM19: AA2/2

14. Eucyrtidium punctatum (Ehrenberg) group : $\times 380:$ RM07 : AA5/3 

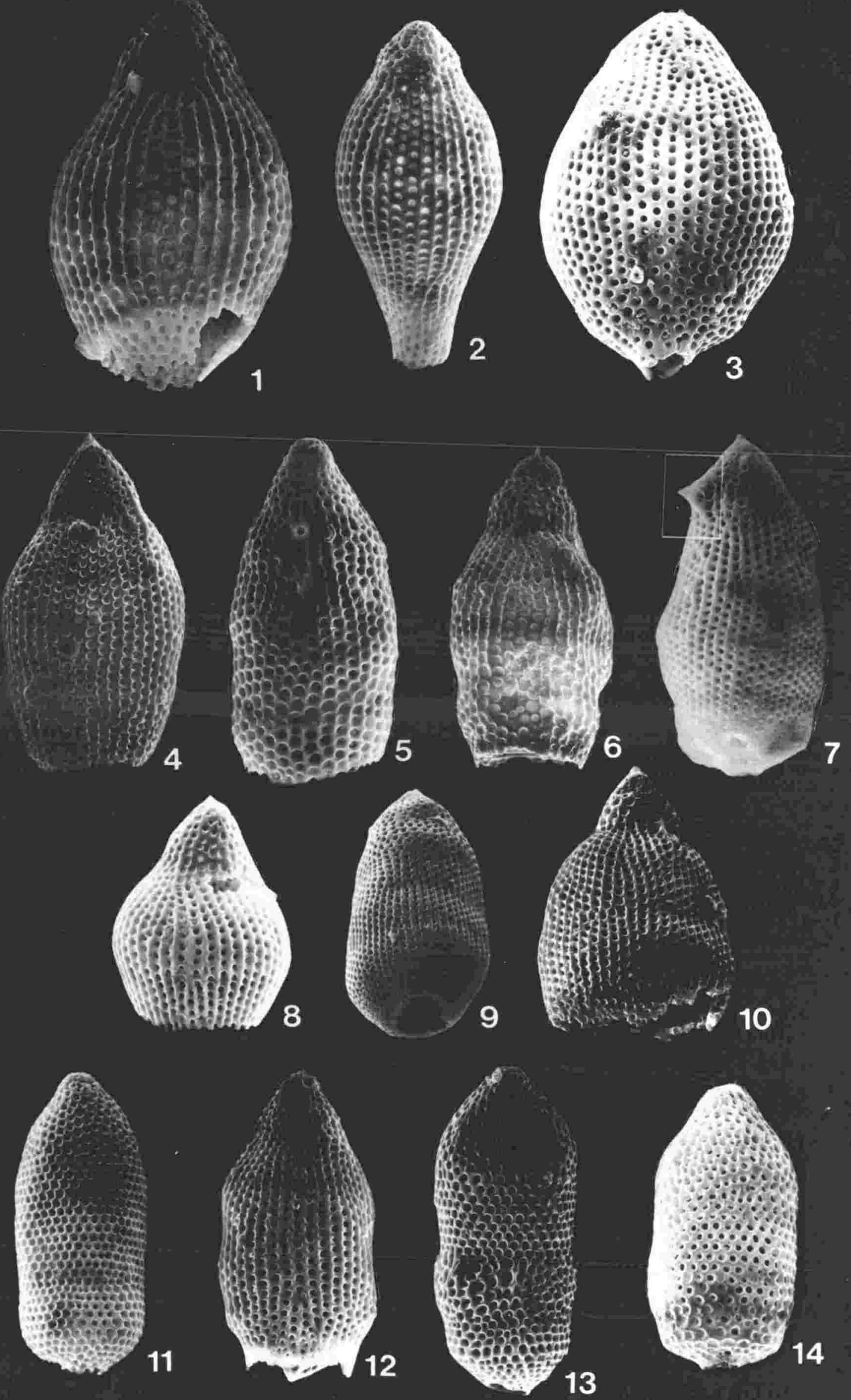
PLATE 24 (opposite)

1. Eucyrtidium calvertense Martin : $\mathrm{x} 339$ : SWR1 : U15/4

form transitional with $E$. inflatum

A. focused on surface

B. focused on circumference of same specimen

2. Eucyrtidium punctatum (Ehrenberg) group : x404 : RM06 : Q18/3

form transitional with $E$. cienkowskii

A. focused on surface

B. focused on circumference of same specimen

3. Eucyrtidium punctatum (Ehrenberg) group : $\times 413:$ HR06 : P31/3

A. focused on surface

B. focused on circumference of same specimen

4. Eucyrtidium punclatum (Ehrenberg) group : x415 : WH06 : R34/1

A. focused on surface

B. focused on circumference of same specimen

5. Eucyrtidium cienkowskii Haeckel group : ×403: HR05:012/2

A. focused on surface

B. focused on circumference of same specimen

6. Eucyrtidium cienkowskii Haeckel group : x257 : SMA4 : M27/2
A. focused on surface
B. focused on circumference of same specimen 

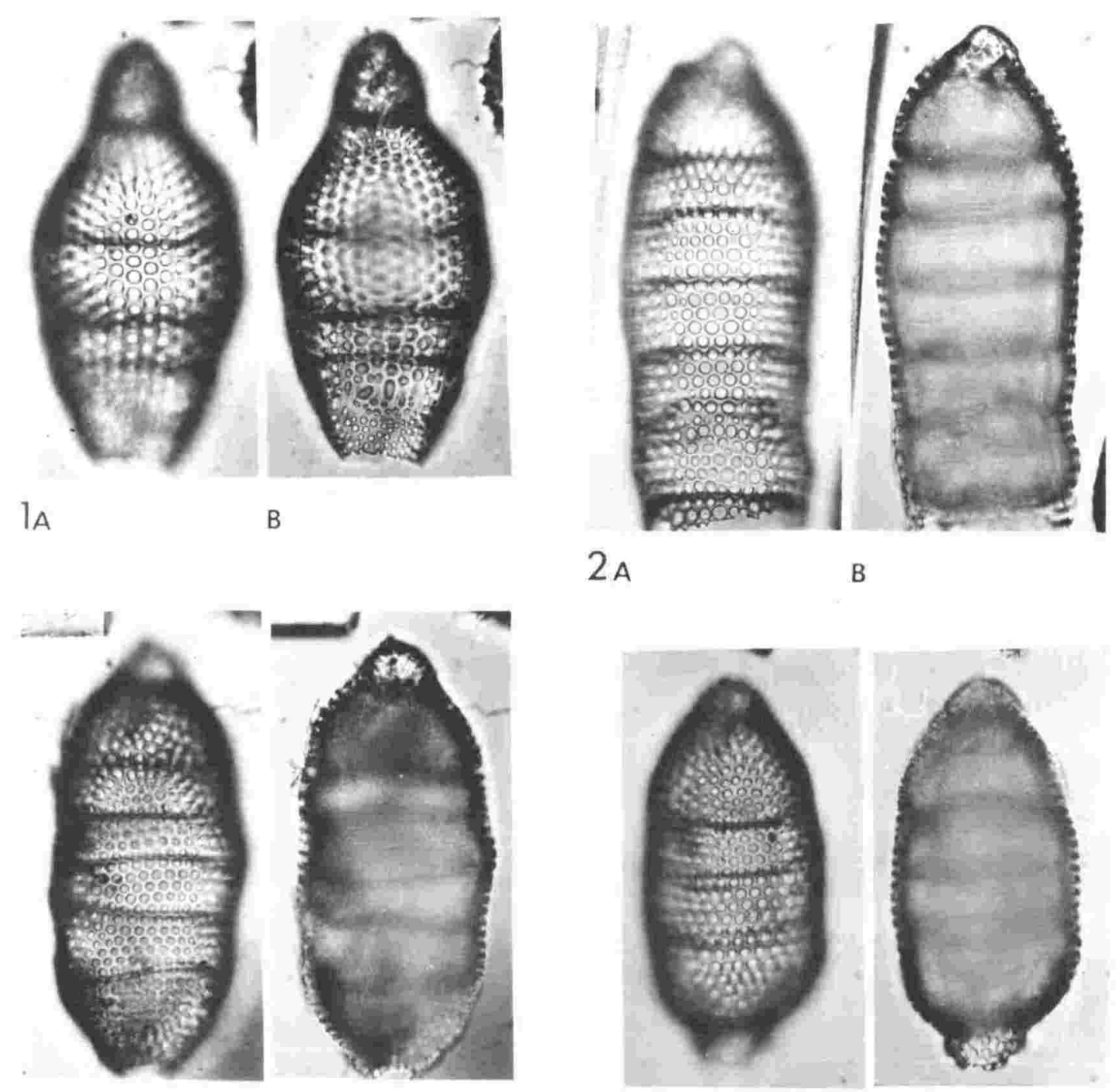

$3 \mathrm{~A}$

B
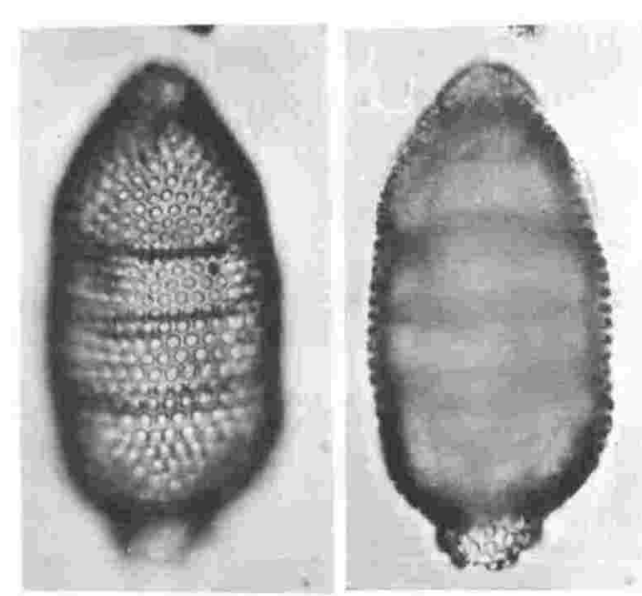

$4 \mathrm{~A}$

B
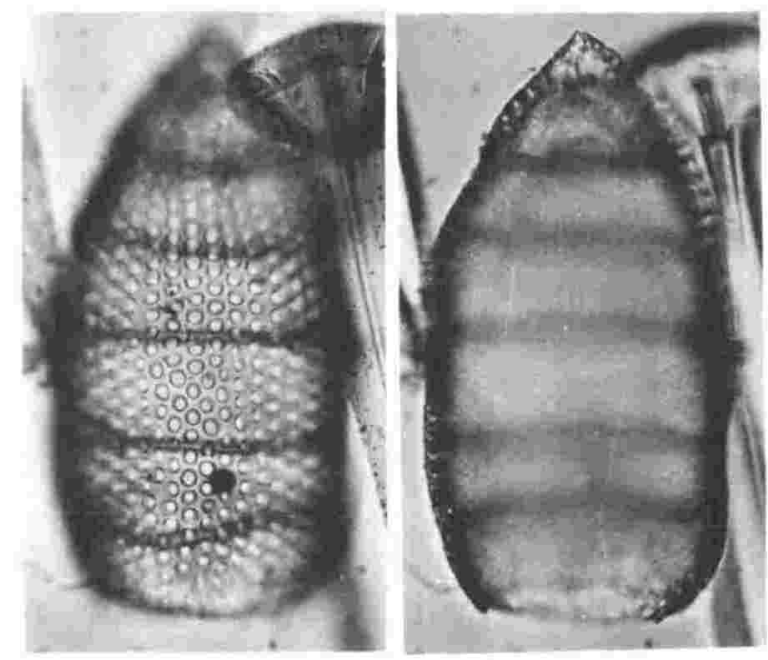

$5 \mathrm{~A}$

B
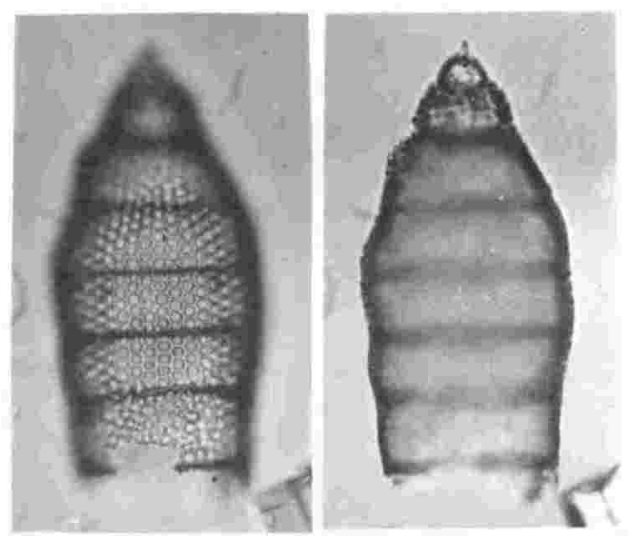

$6 A$
B 


\section{PLATE 25 (opposite)}

1. Stichocorys delmontensis (Campbell and Clark) : $x 360: P B 03: 157 / 4$

2. Stichocorys peregrina (Riedel) : x320 : PB11 : 167/8

3. Stichocorys peregrina (Riedel) : $\times 300:$ PB10 : 166/8

4. Stichocorys peregrina (Riede1) : $\times 260:$ MS08 : AA3/5

5. Stichocorys peregrina (Riede1) : $\mathrm{x} 380:$ MT05 : AA7/5

6. Stichocorys delmontensis (Campbell and Clark) : x400 : PB04 : 158/8

7. Stichocorys peregrina (Riede1) : $\times 350$ : SMA4 : AA4/11

8. Stichocorys delmontensis (Campbell and Clark) : x310 : TM16 : AA2/5 form transitional with $S$. peregrina

9. Eucyrtidium cf. vincentense (Campbell and Clark) : x330 : TM23 : AA1/3

10. Anthocyrtidium (?) sp. A : $\times 320:$ MO04 : AA4/4

11. Anthocyrtidium (?) sp. A : $\times 350:$ LT05: AA7/3 form transitional with $A$. ehrenbergi pliocenica

12. Anthocyrtidium ehrenbergi (Stohr) pliocenica (Seguenza) : x320: RMO6 : AA5/4

13. Anthocyrtidium zanguebaricum (Ehrenberg) : $\mathrm{x} 320: \mathrm{PB} 08: 164 / 1$

14. Anthocyrtidium zanguebaricum (Ehrenberg) : $\mathrm{x} 320:$ TM16 : AA2/5

15. Eucyrtidium sp. A : $\times 310$ : WA03 : AA8/4 


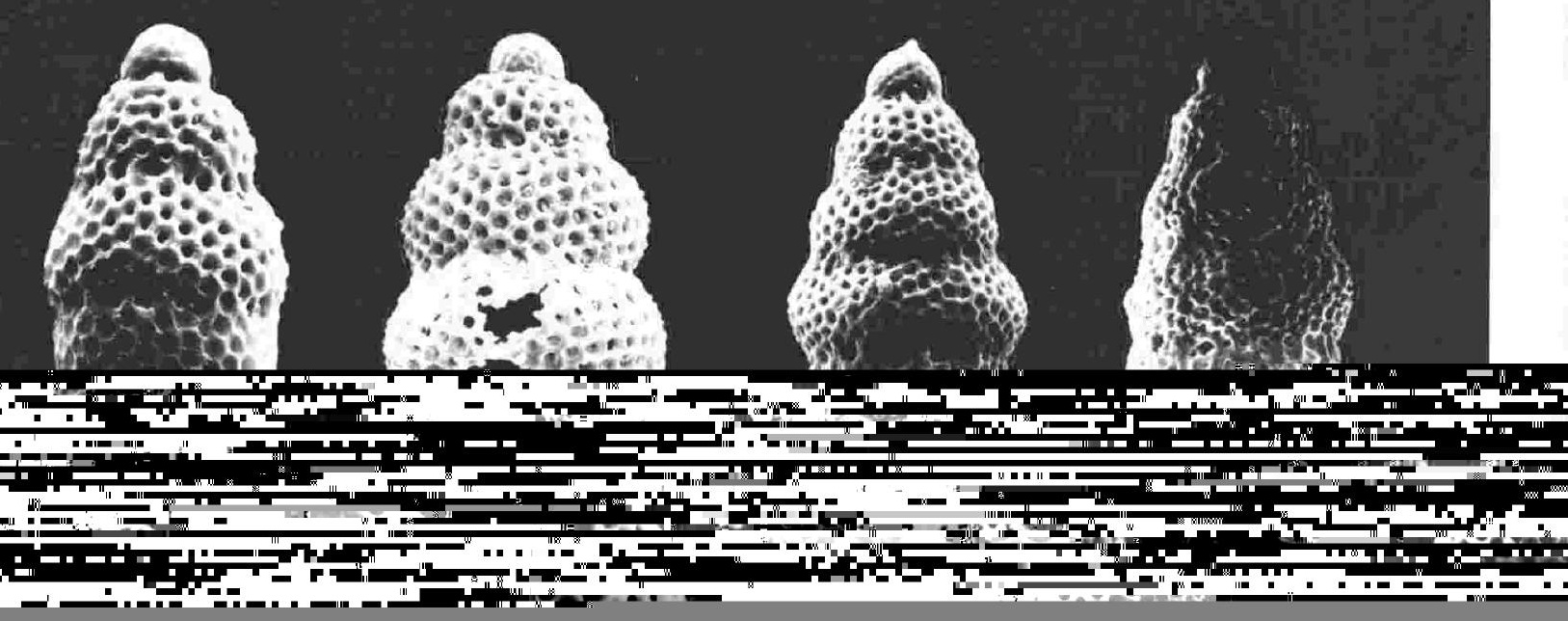

2.

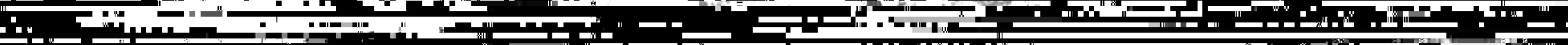

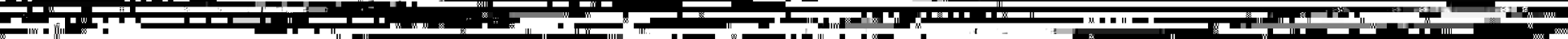
ifl :"

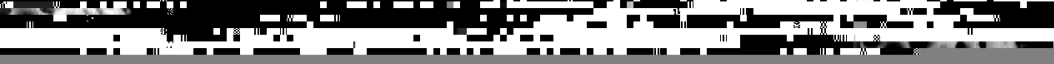




\section{PLATE 26 (opposite)}

1. Eucyrtidium acuminatum (Ehrenberg) : x226: TM22 : P36/3

2. Eucyrtidium cf. montiparum Ehrenberg : x413 : RM06 : Q18/4

3. Eucyrtidium hexagonatum Haeckel : x413 : RM06 : Q18/3 form with lateral wing

4. Stichocorys peregrina (Riede1) : x270 : SWR1 : N30/2

5. Stichocorys delmontensis (Campbell and Clark) : $x 406:$ HR04d : T24/4

A. focused on surface

B. focused on circumference of same specimen

6. Stichacorys peregrina (Riede1) : x289 : PB11 : V35/2

7. Stichocorys sp. A : x257 : RK04: W21/2

8. Stichocorys peregrina (Riedel) : x159: RM05 : P29/3

9. Gondwanaria dogeli (Petrushevskaya) group : ×398: MO11 : K17/3

10. Anthocyrtidium ehrenbergi (Stohr) pliocenica (Seguenza) : x408 : M011 : P45/1

11. Anthocyrtidium (?) sp. A : $\mathrm{x} 305: \mathrm{PB} 06: \mathrm{X} 42 / 1$ 

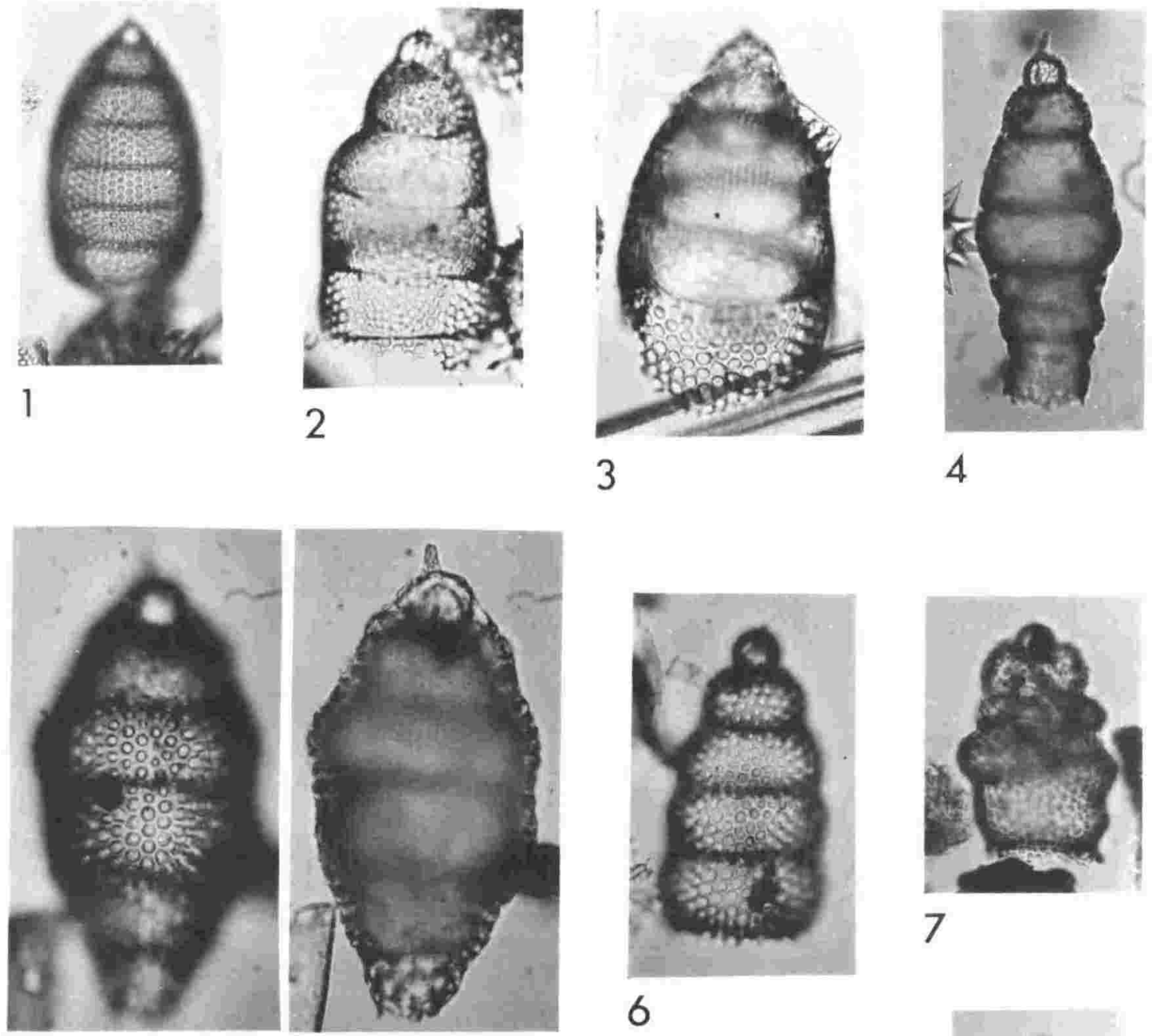

$5 \mathrm{~A}$

B
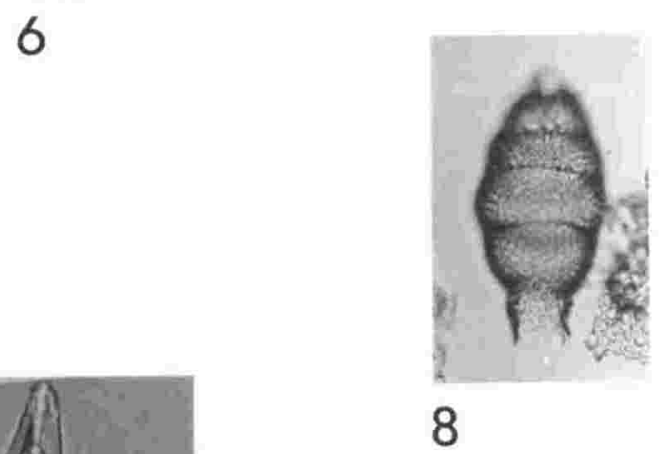

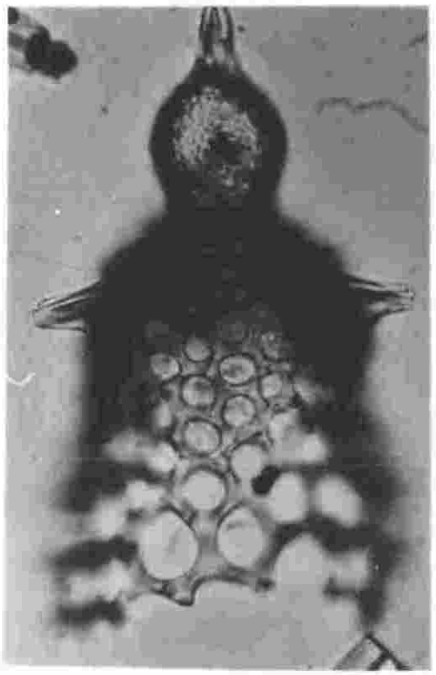

9

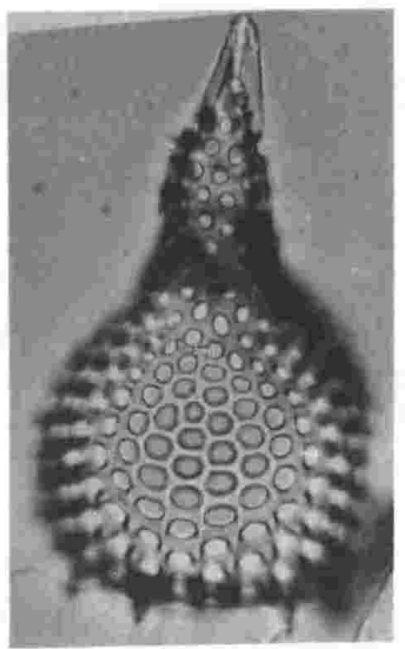

10

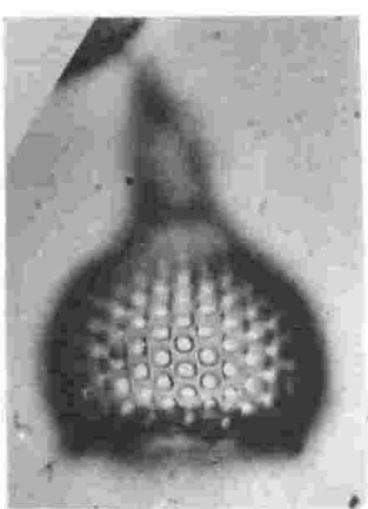

11 


\section{PLATE 27 (opposite)}

1. Lamprocyclas gamphonycha (Jorgensen) : $\mathrm{x} 250$ : WA03 : AA8/4 form transitional with Lamprocyrtis heteroporos

2. Lamprocyclas of. maritalis Haeckel : $\mathrm{x} 220$ : CR03 : AA7/4

3. Lamprocyclas maritalis Haeckel : $\times 240:$ WA17 : AA9/3

4. Lamprocyclas (?) sp. A : $\times 280:$ MO10 : AA4/7

5. Lamprocyclas sp. B : x330 : PB11 : 167/5

6. Lamprocyclas sp. B : x220 : PB11 : 167/5

7. Lamprocyclas sp. E : $\times 250$ : SWR 4 : AA4/12

8. Lamprocyclas (?) sp. A : $\times 270$ : SMA4 : AA4/11 abnormal irregular pored form

9. Lamprocyrtis (?) junonis (Haeckel) : $\times 320:$ MO09 : AA4/7

10. Lamprocyrtis hannai (Campbell and Clark) : $\times 250: \mathrm{RM} 07: \mathrm{AA} 5 / 3$

11. Lamprocyrtis (?) apollinis (Haeckel) : $\times 220:$ WT05 : AA4/8

12. Lamprocyclas sp. D : $\mathrm{x} 400: \mathrm{PB} 08: 164 / 4$

13. Lamprocyrtis cf. junonis (Haeckel) : $\mathrm{x} 300: \mathrm{MO} 09$ : AA4/6

14. Lamprocyclas sp. D : $\mathrm{x} 310: \mathrm{PB} 08: 164 / 1$ 

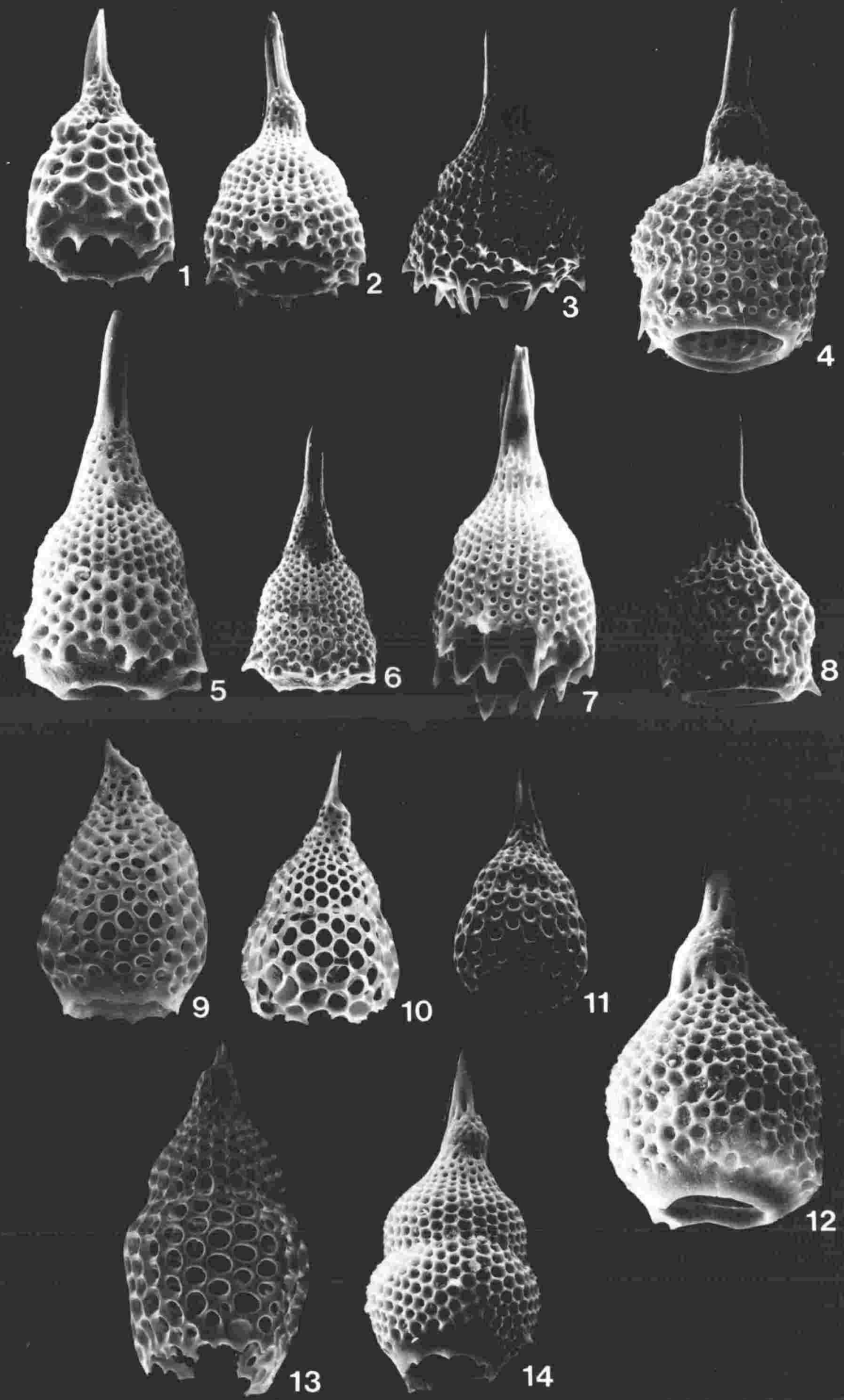
PLATE 28 (opposite)

1. Lamprocyclas sp. C : x240 : RM02 : AA4/1

2. Lamprocyclas sp. C : $\mathrm{x} 300: \mathrm{PB} 02: 156 / 4$

3. Lamprocyclas sp. C : $\mathrm{x} 310$ : $\mathrm{PB} 02: 156 / 5$ thoracic wing present

4. Lamprocyclas sp. C : $\mathrm{x} 290$ : $\mathrm{PB} 02: 156 / 2$ thoracic wing present

5. Lamprocyclas sp. C : x330 : $\mathrm{PB} 02: 156 / 5$ broken specimen showing internal septal ring

6. Lamprocyclas sp. C : $\times 210:$ PB08 : 164/3

7. Lamprocyclas sp. C : $\mathrm{x} 300:$ PB08 : 164/6 abnormal specimen with poor subterminal teeth form transitional with Lamprocyclas sp. D

8. Siphocampe nodosaria (Haecke1) : x440 : PB11 : 167/8

9. Siphocampe lineata (Ehrenberg) group : x430 : LT05: AA7/3

10. Siphocampe lineata (Ehrenberg) group : $\$ 410:$ RM04 : AA5/6 form with distinct lumbar stricture

11. Siphocampe lineata (Ehrenberg) group : $\times 400:$ TM23 : AA1/4 form with distinct lumbar stricture

12. Siphocampe arachnea (Ehrenberg) group : x510: KB01 : AA10/3 

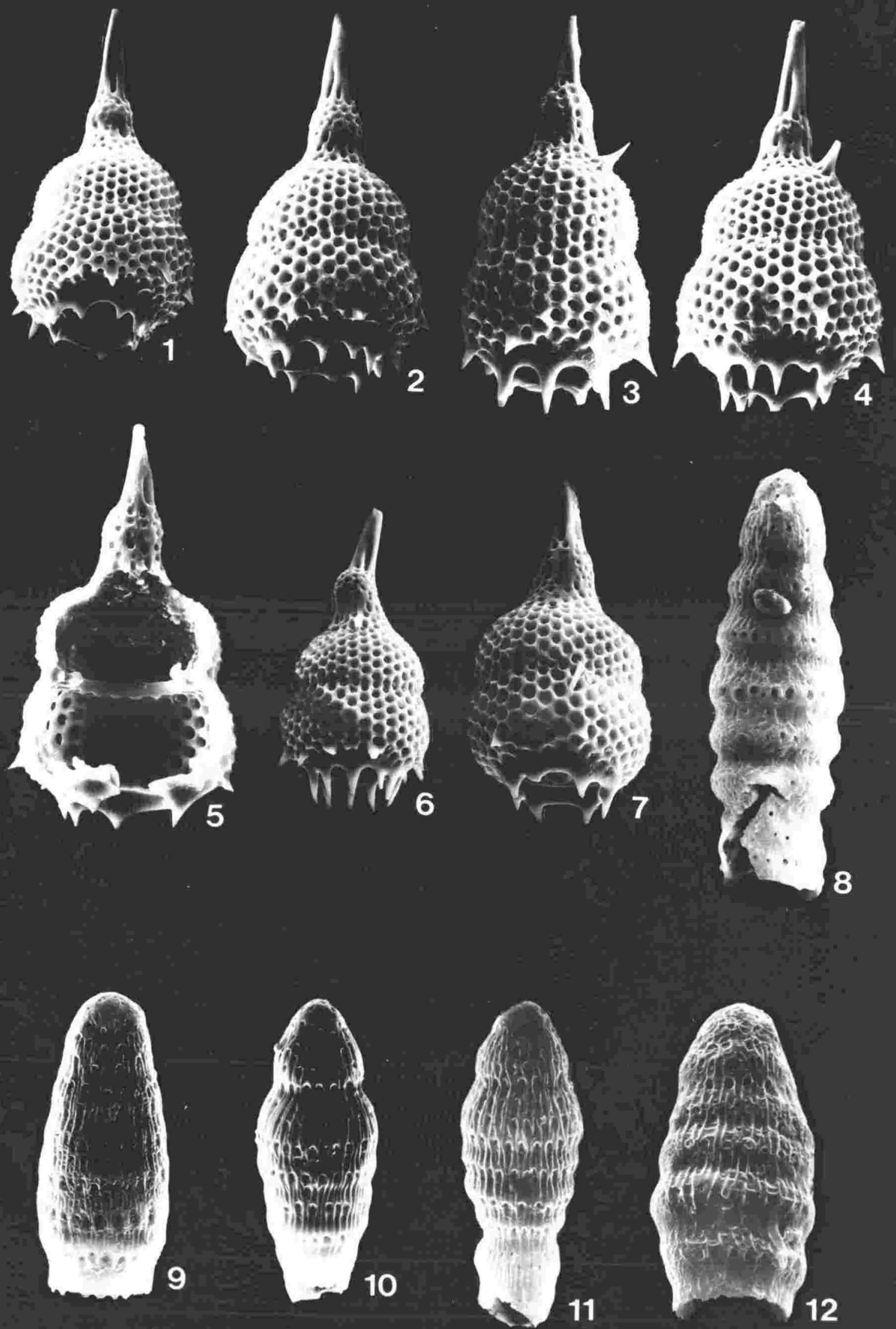


\section{PLATE 29 (opposite)}

1. Phormostichoartus sp. A : $\times 580: \mathrm{MO} 4: \mathrm{AA} 4 / 3$

2. Phormostichoartus sp. A : $\times 470:$ MO04:AA4/3

3. Botryostrobus aquilonaris (Bailey) : x520 : RM04 : MISC/5

4. Phormostichoartus fistula Nigrini : x510 : TM20 : AA1/10

5. Siphostichartus corona (Haeckel) : $\mathrm{x} 360: \mathrm{TM} 23: \mathrm{AA} 1 / 3$

6. Botryostrobus bramlettei (Campbell and Clark) : x450 : RM07 : AA5/3

7. Spirocyrtis subscalaris Nigrini : $\mathrm{x} 400: \mathrm{MO} 9$ : AA4/6

8. Spirocyrtis subscalaris Nigrini : $\mathrm{x} 400$ : WA17 : AA9/3 etched specimen

9. Botryostrobus auritus-australis (Ehrenberg) group : $\times 360$ : TM15 : AA2/6 

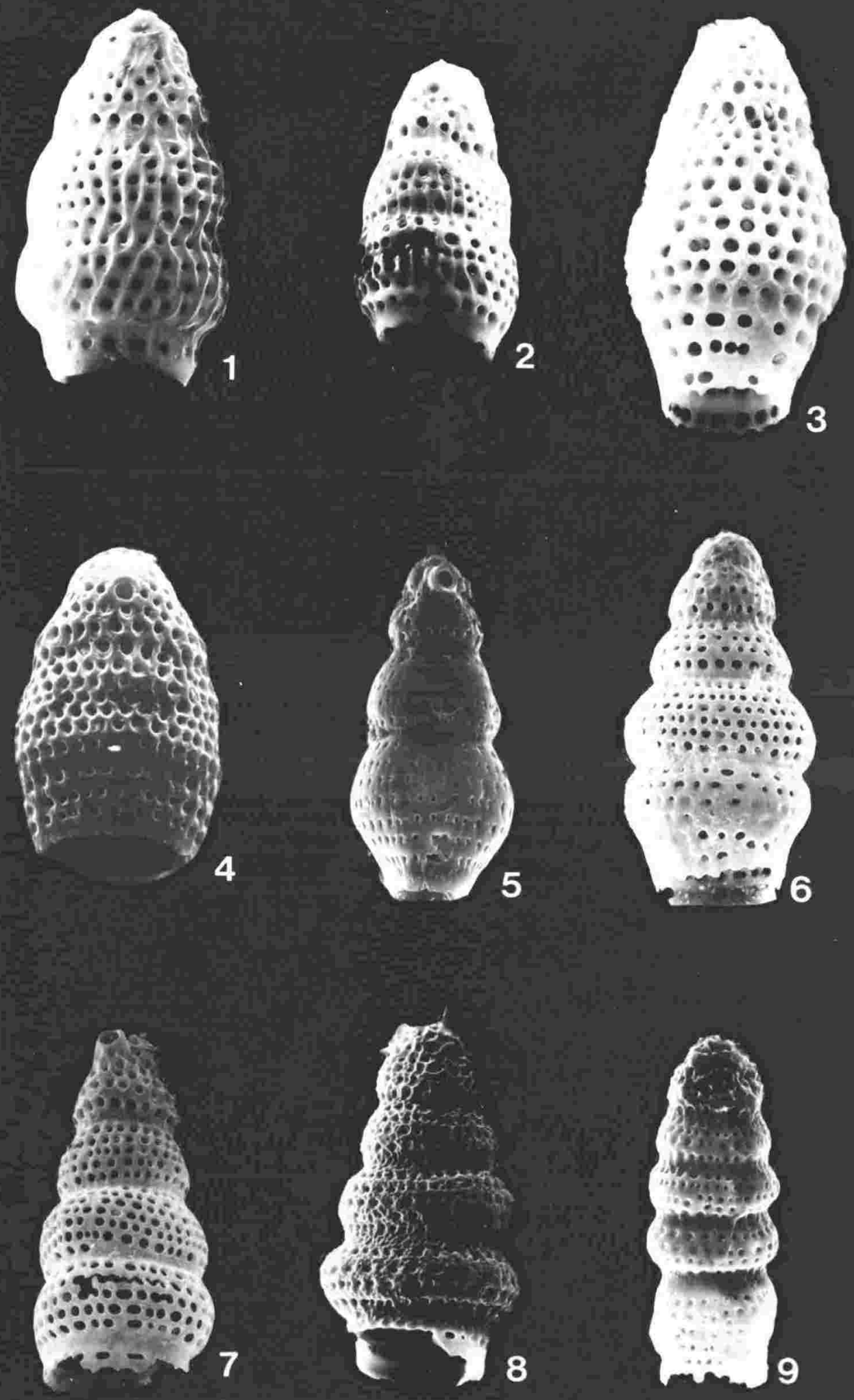


\section{PLATE 30 (opposite)}

1. Lamprocyclas sp. E : x119 : PB06 : E47/1

2. Lamprocyclas sp. C : x114 : PB06 : X45/4 transitional with Lamprocyclas sp. D

3. Botryostrobus bramlettei (Campbell and Clark) : ×289 : PB06 : U37/3

4. Botryostrobus auritus-australis (Ehrenberg) group : х419: WA02 : V42/2

5. Botryostrobus bramlettei (Campbell and Clark) : x283 : WA07 : J40/2 "long skirted" form

6. Siphostichartus corona (Haecke1) : ×287 : TM22 : Q42/3

A. focused on surface

B. focused on circumference of same specimen

7. Phormostichoartus sp. A : x411 : PB09: V22/3

A. focused on surface

B. focused on circumference of same specimen

8. Siphocampe nodosaria (Haecke1) : x406: TM22 : N35/3

A. focused on surface

B. focused on circumference of same specimen

9. Siphocampe arachnea (Ehrenberg) group : x392 : HR04: Q47/4

10. Siphocampe lineata (Ehrenberg) group : $\mathrm{x} 296: \mathrm{MO} 2: \mathrm{P} 40 / 3$

form with distinct lumbar stricture
A. focused on surface
B. focused on circumference of same specimen

11. Spirocyrtis subscalaris Nigrini : $\mathrm{x} 293$ : TM20 : J46/4

12. Botryopyle dictyocephalus Haeckel group : x419 : SMA3 : M43/1

form with a large eucephalic lobe

13. Botryopyle dictyocephalus Haeckel group : x288 : HR04 : R44/3

14. Botryopyle dictyocephalus Haeckel group : x311 : MO13 : O26/2 form with a large eucephalic lobe

15. "Artostrobus" pretabulatus Petrushevskaya : x410 : WT05 : L42/3 

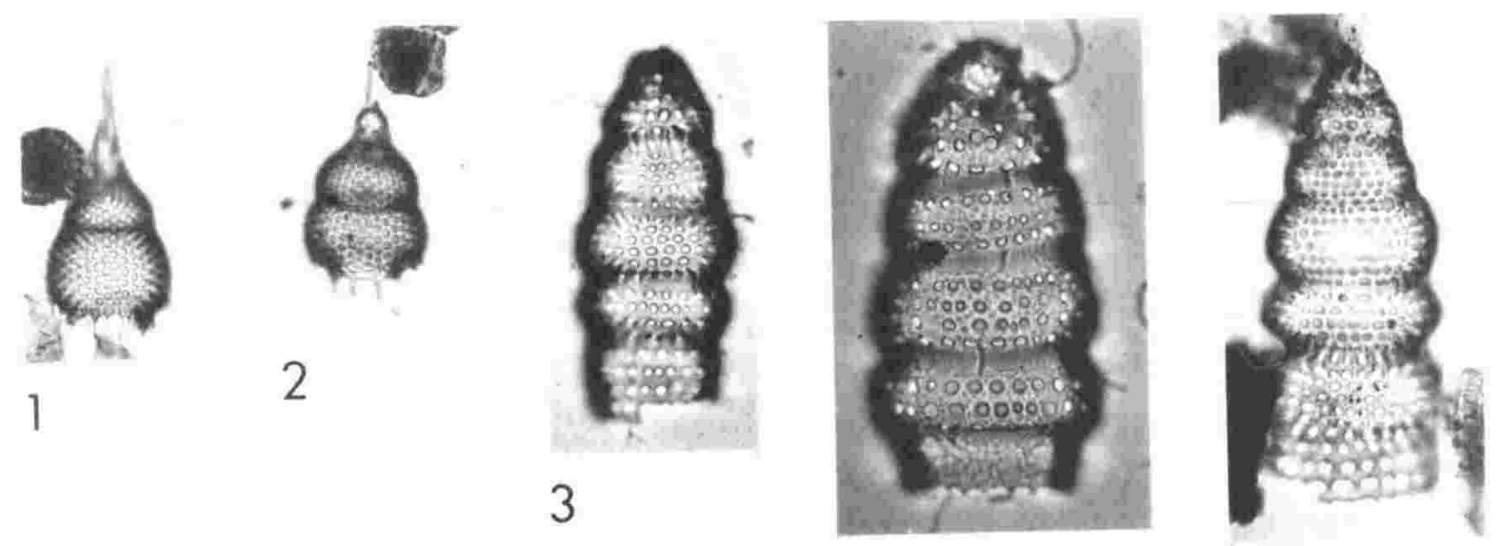
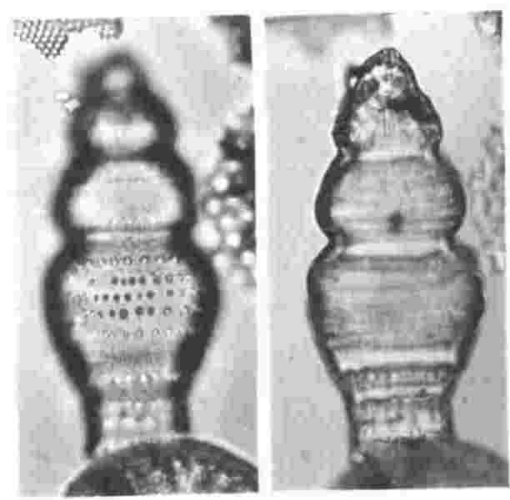

$6 A$

B

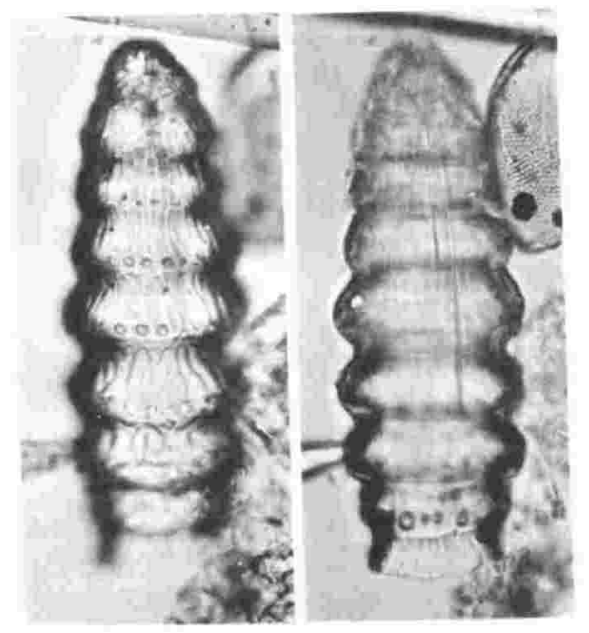

$8 A$

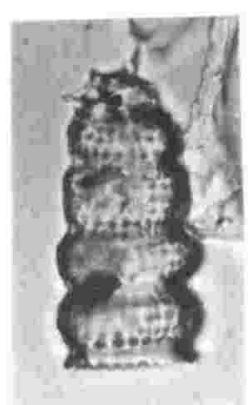

11

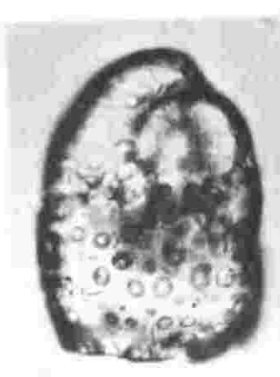

12
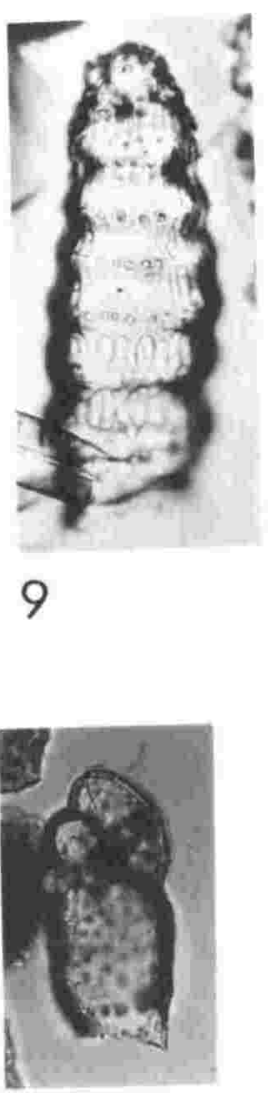

13
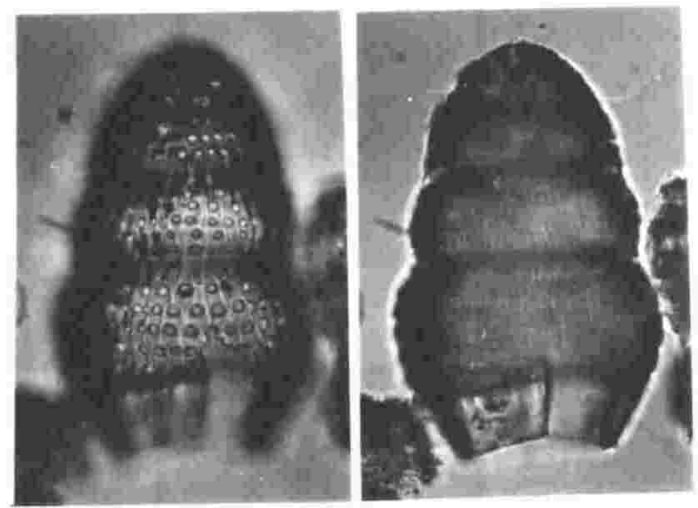

7A

B

5
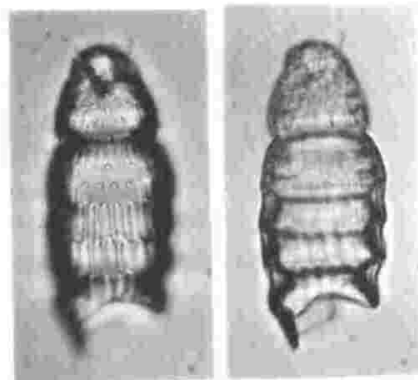

$10 \mathrm{~A}$

B

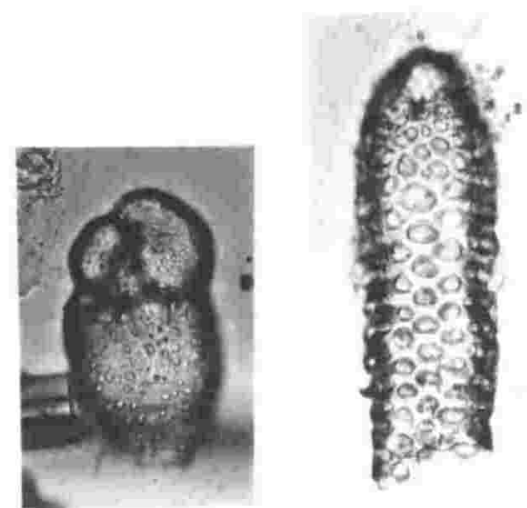

15 